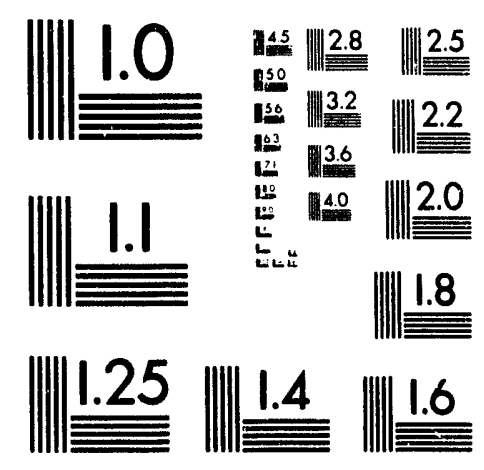



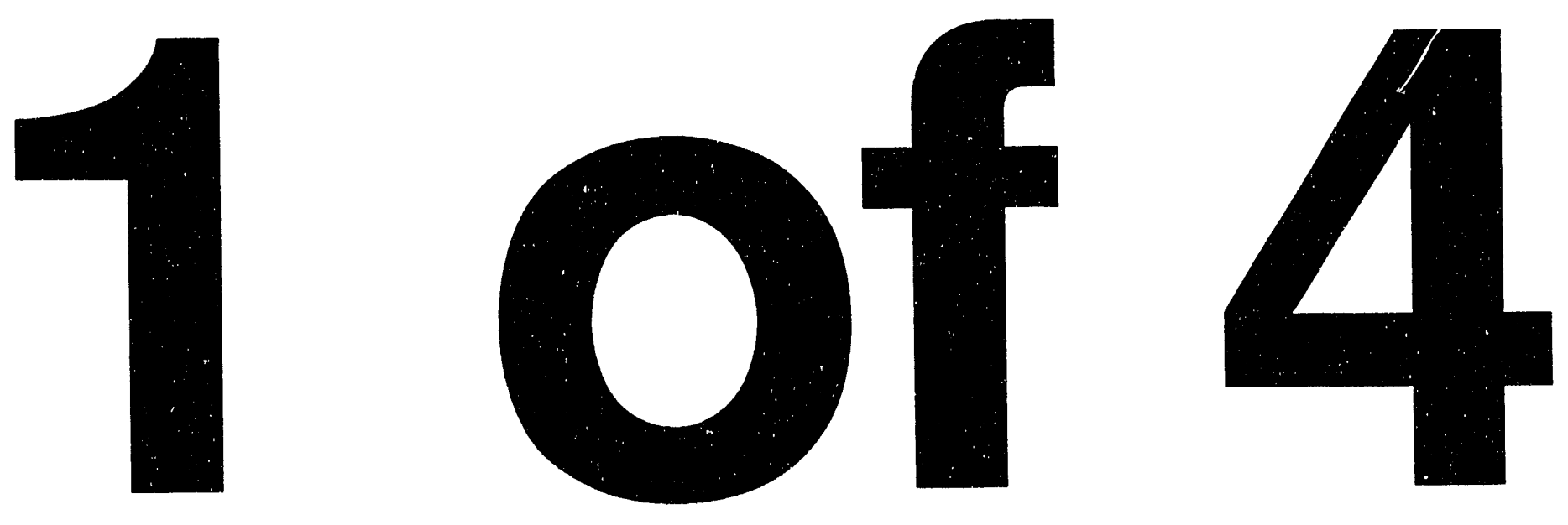
NUREG/CR-6065

ORNL/TM-12396

R1

\section{Systems Analysis of the CANDU 3 Reactor}

Manuscript Completed: June 1993

Date Published: July 1993

Prepared by

J. R. Wolfgong, M. A. Linn, A. L. Wright,

M. Olszewski, M. H. Fontana

Oak Ridge Natinal Laboratory

Operated by Martin Marietta Energy Systems, Inc.

Oak Ridge National Laboratory

Oak Ridge, TN 37831-6285

Prepared for

Division of Systems Research

Office of Nuclear Regulatory Research

U.S. Nuclear Regulatory Commission

Washington, DC 20555-0001

NRC FIN L2015

Under Contract No. DE-ACO5-840R21400

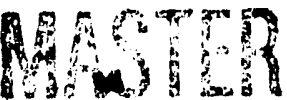




\begin{abstract}
This report presents the results of a systems failure analysis study of the CANDU 3 reactor design; the study was performed for the U.S. Nuclear Regulatory Commission. As part of the study a review of the CANDU 3 design documentation was performed, a plant assessment methodology was developed, representative plant initiating

events were identified for detailed analysis, and a plant assessment was performed. The results of the plant assessment included classification of the CANDU 3 event sequences that were analyzed, determination of CANDU 3 systems that are "significant to safety," and identification of key operator actions for the analyzed events.
\end{abstract}




\section{Contents}

Abstract
List of Figures
List of Tables
Acknowledgments
1. Introduction
1.1 Background and Purpose
1.3 Methodology and Abbreviations
1.4 Limitations
References

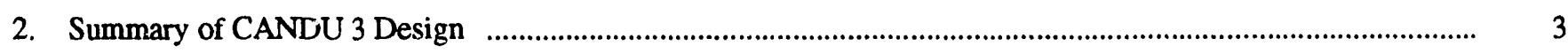

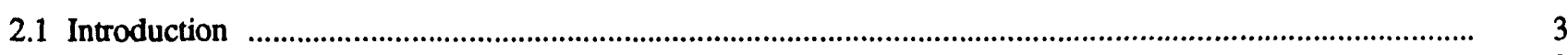

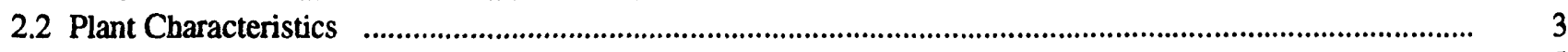

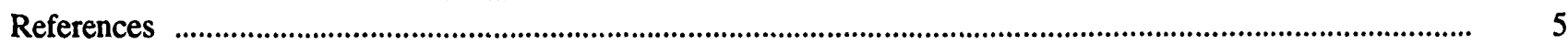

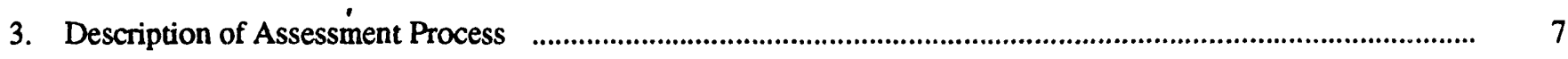

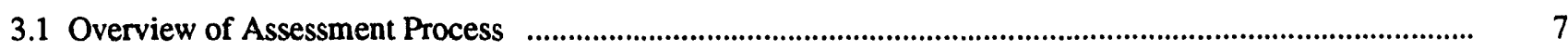

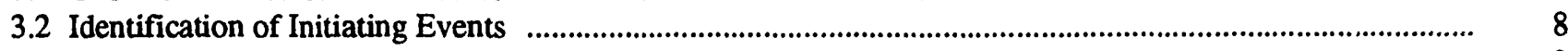

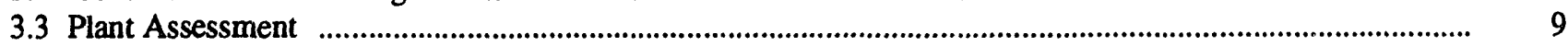

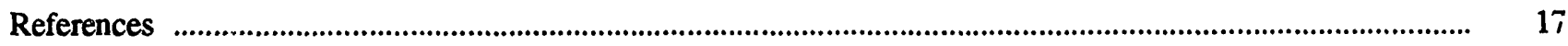

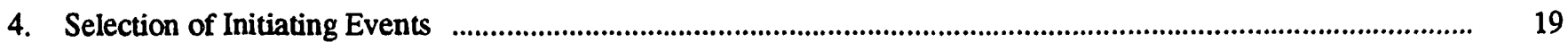

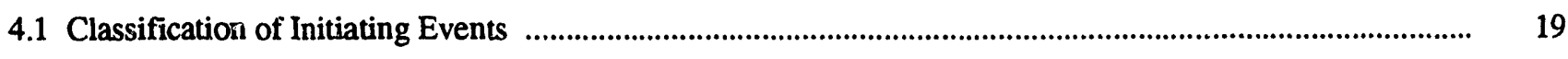

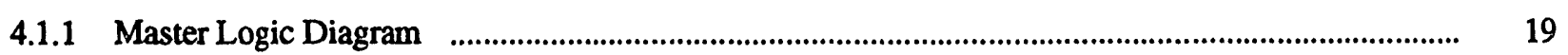

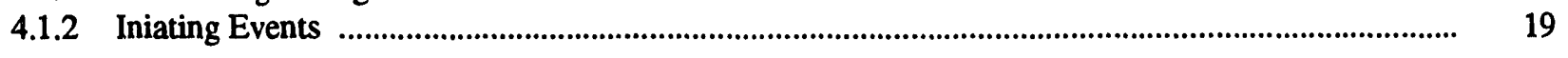

4.2 Selection of Representative Initiating Events ............................................................................................ 20

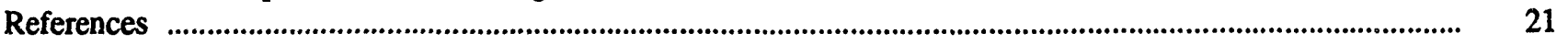

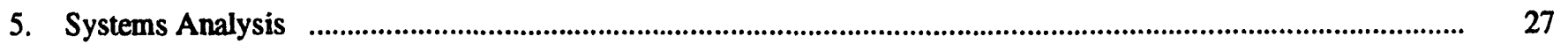

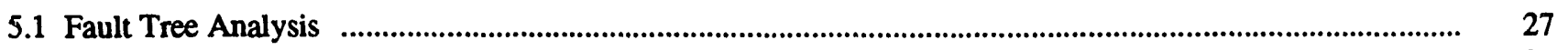

5.2 Systems Description .................................................................................................................................. 27

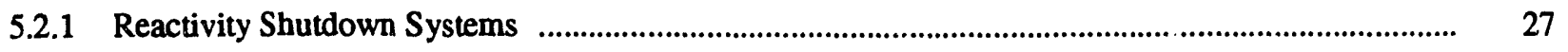

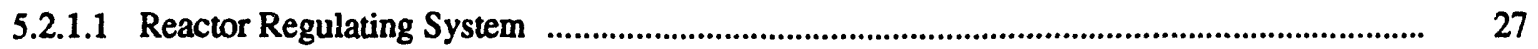

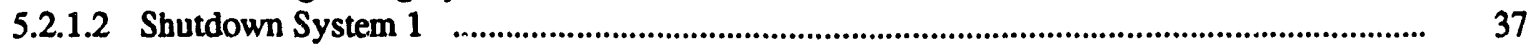

5.2.1.3 Shutdown System 2 .......................................................................................................... 39

5.2.2 Moderator Liquid Poison System .................................................................................................. 39

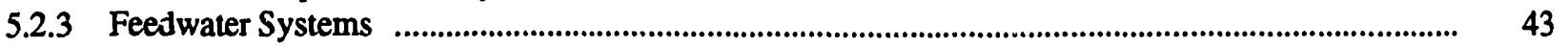

5.2.3.1 Group 1 Feedwater System .......................................................................................... 43

5.2.3.2 Group 2. Feedwater System ….......................................................................................... 43

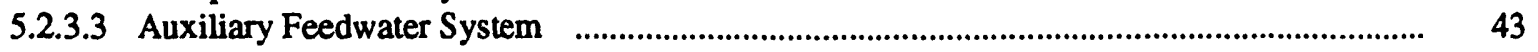




\section{Contents (cont.)}

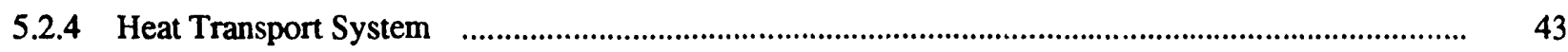

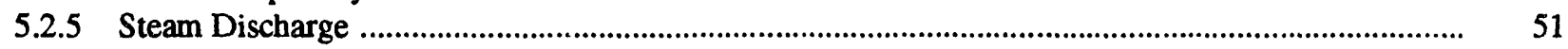

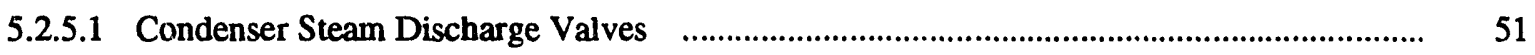

5.2.5.2 Atmospheric Steam Discharge Valves ….......................................................................... 54

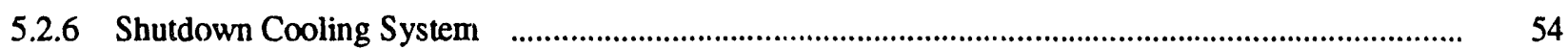

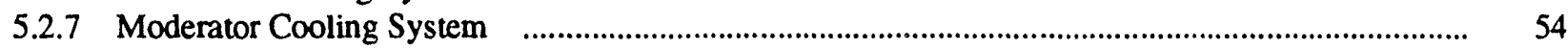

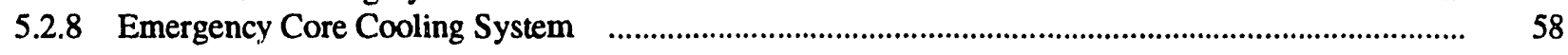

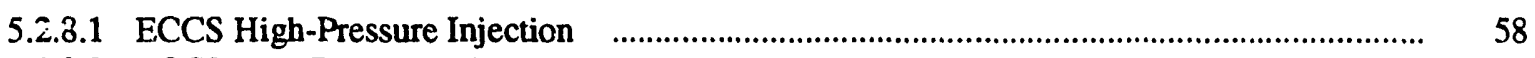

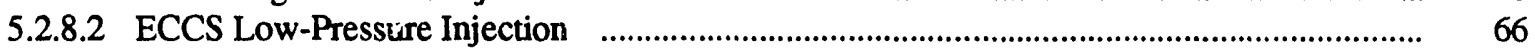

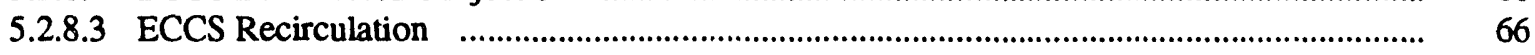

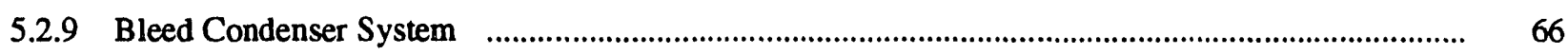

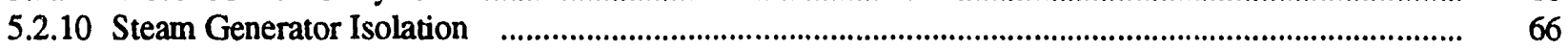

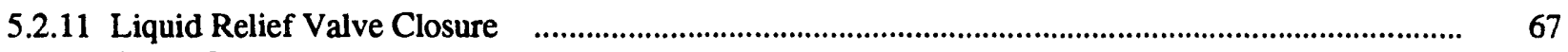

5.2 .12 Crash Cooling ................................................................................................................................. 67

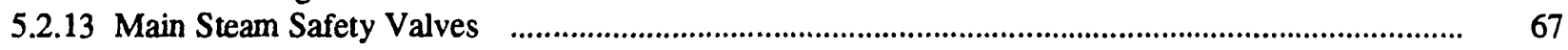

5.2.14 Emergency Generators ................................................................................................................... 67

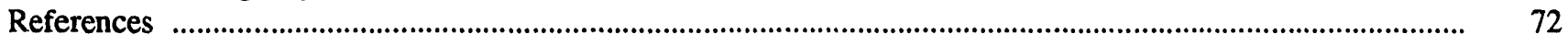

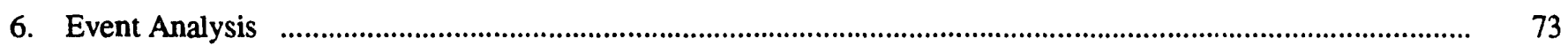

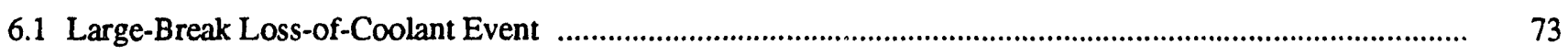

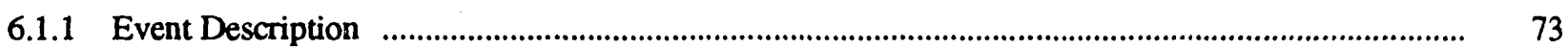

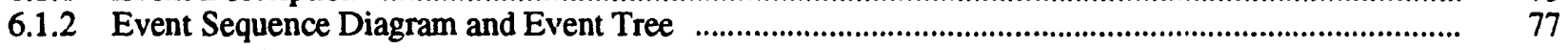

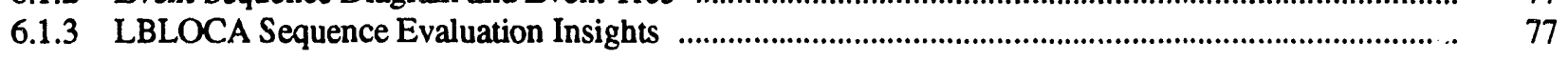

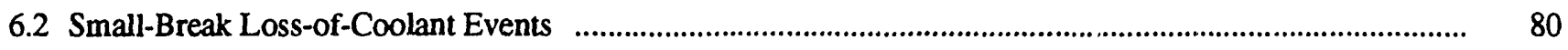

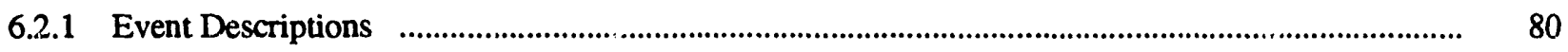

6.2.2 Event Sequence Diagram and Event Tree ....................................................................................... 82

6.2.3 Sequence Evaluation Insights ........................................................................................................ 82

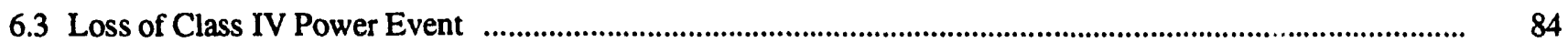

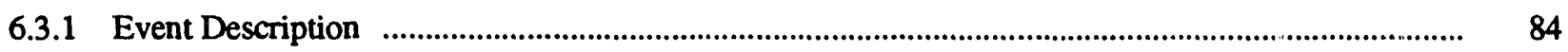

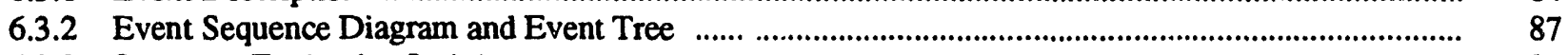

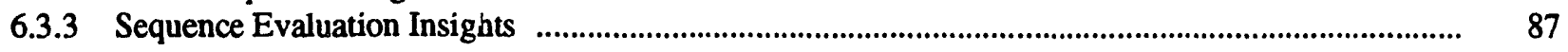

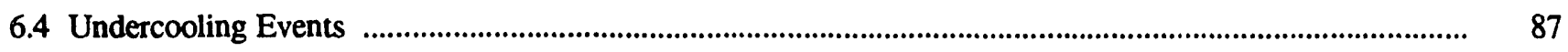

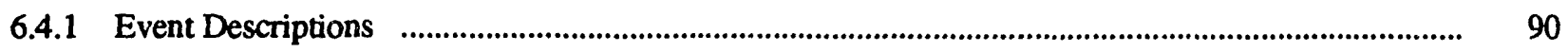

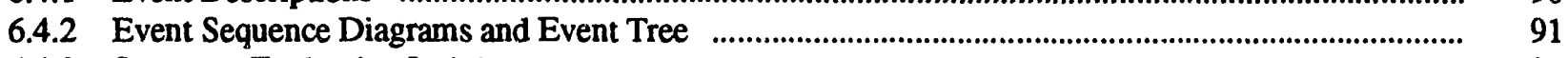

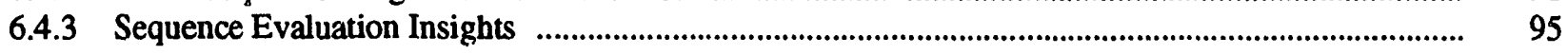

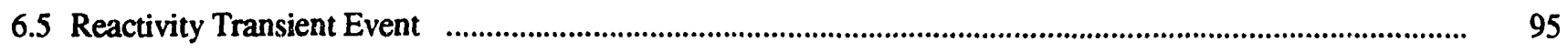

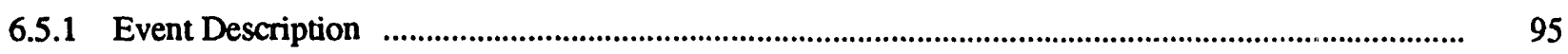

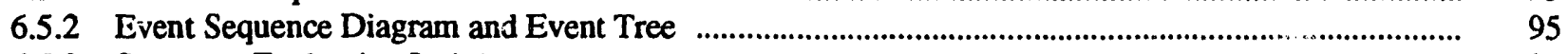

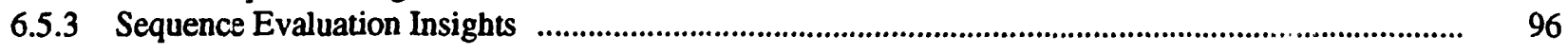

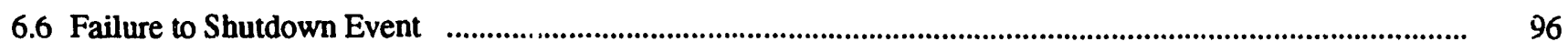

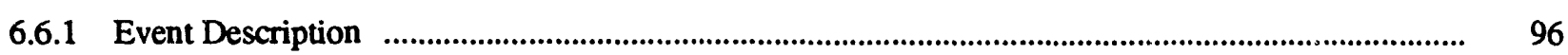

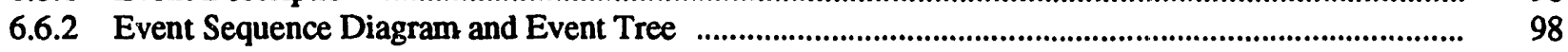

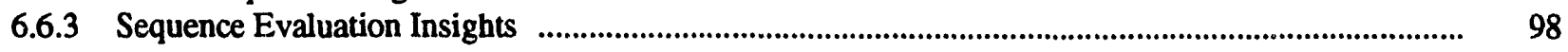

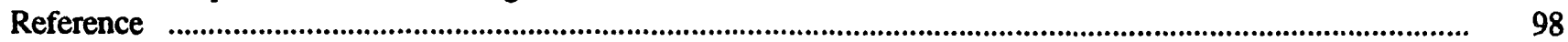




\section{Contents (cont.)}

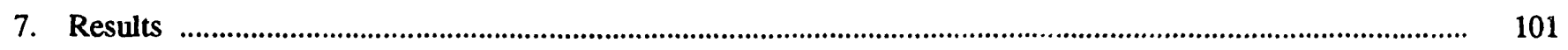

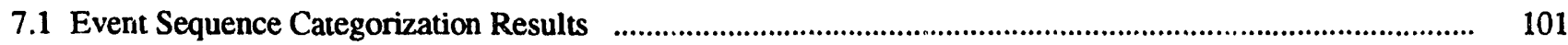

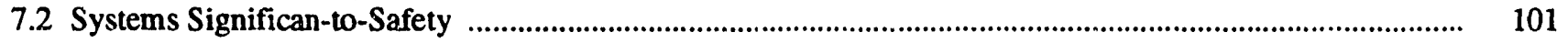

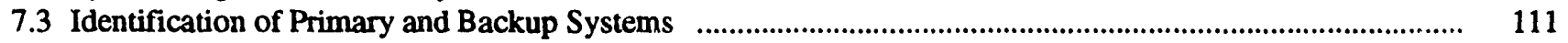

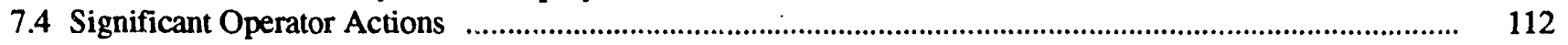

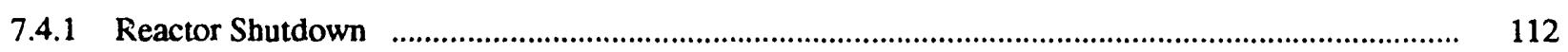

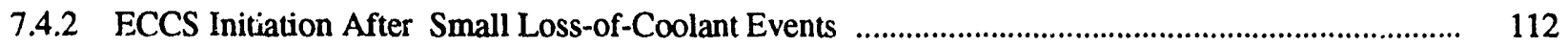

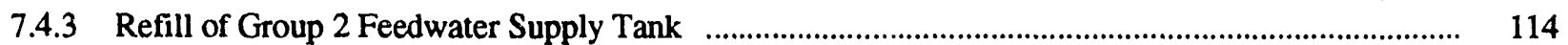

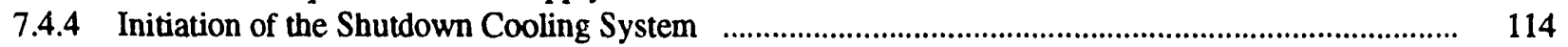

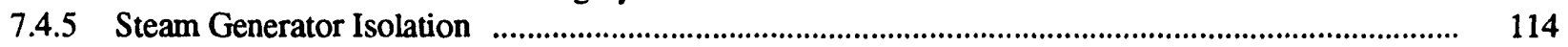

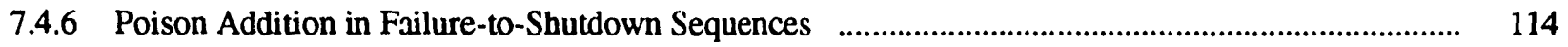

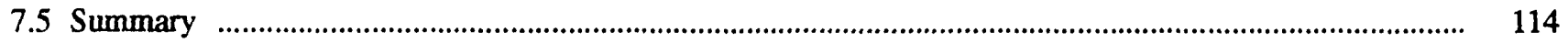

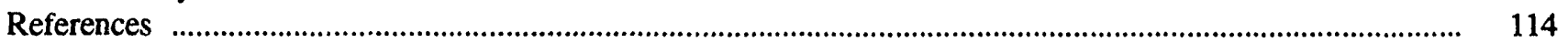

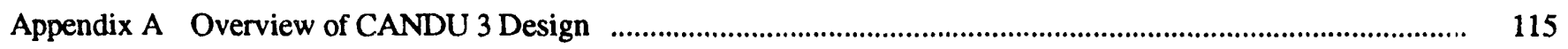

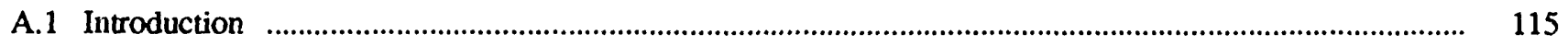

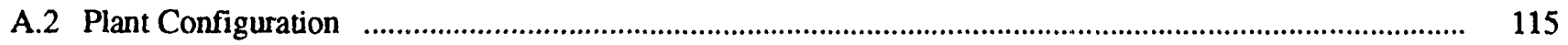

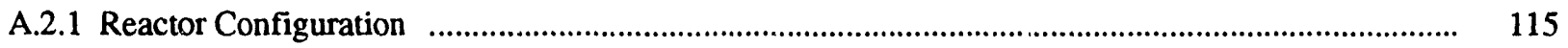

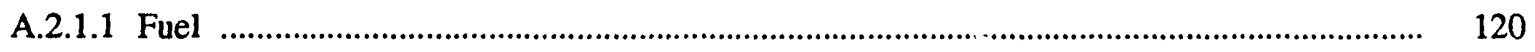

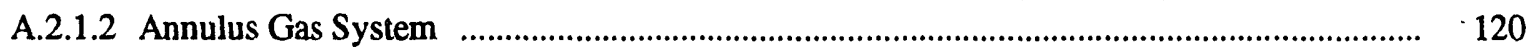

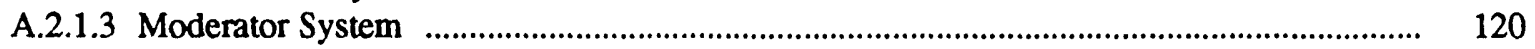

A.2.1.4 Shield Cooling System ...................................................................................................... 120

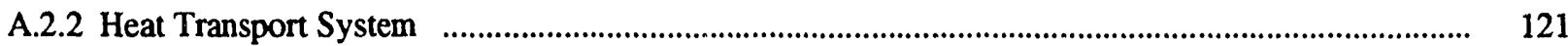

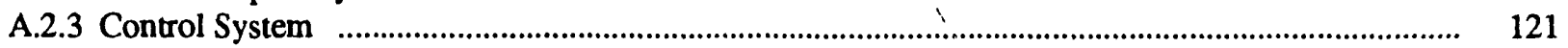

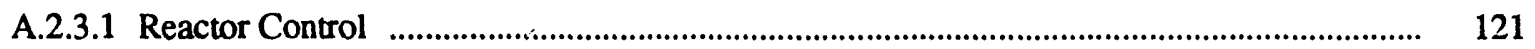

A.2.3.2 Distributed Control System .......................................................................................... 121

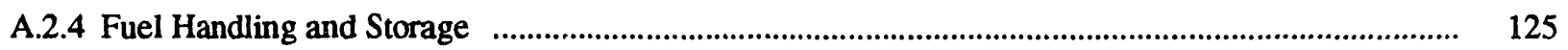

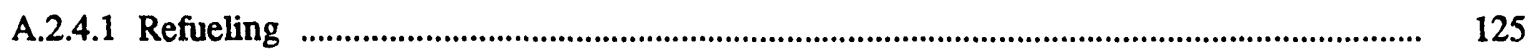

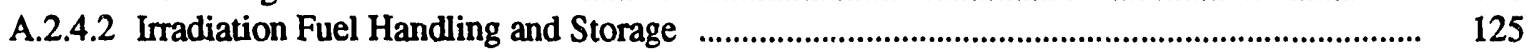

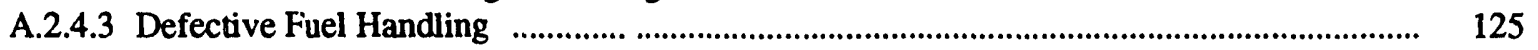

A.2.4.4 Irradiation Fuel Storage Bay ............................................................................................... 128

A.2.4.5 Fuel Handling Control System ......................................................................................... 128

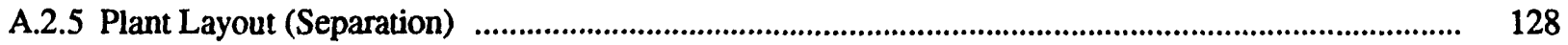

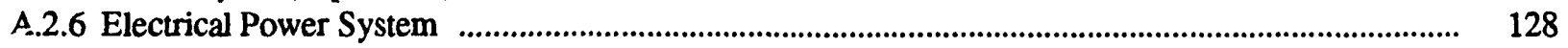

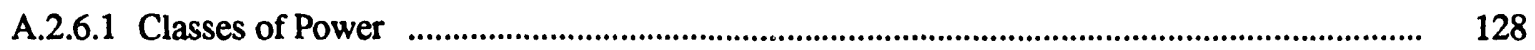

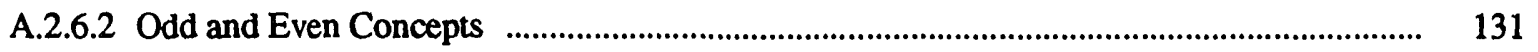

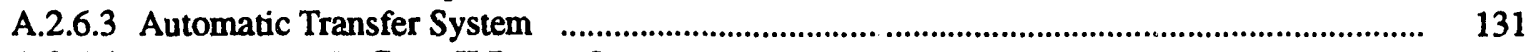

A.2.6.4 Uninterruptible Class II Power Supplies .......................................................................... 131

A.2.6.5 Uninterruptible Class I dc Power Supplies ........................................................................... 131

A.2.6.6 Group 2 Power Supply System ........................................................................................... 132

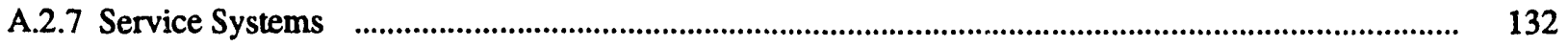

A.2.7.1 Group 1 Recirculated Cooling Water System ....................................................................... 132

A.2.7.2 Group 1 Raw Service Water System …...................................................................... 133

A.2.7.3 Compressed Air System ..................................................................................................... 133

A.2.7.4 Reactor Building Ventilation System ................................................................................. 133

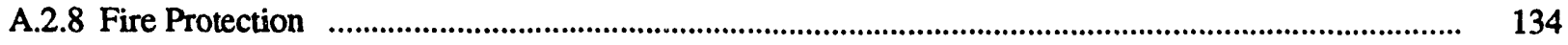




\section{Contents (cont.)}

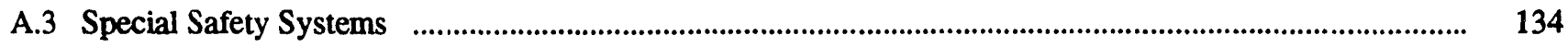

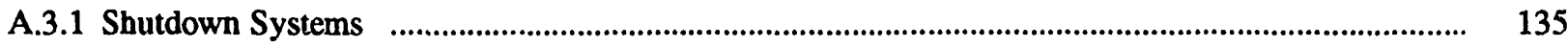

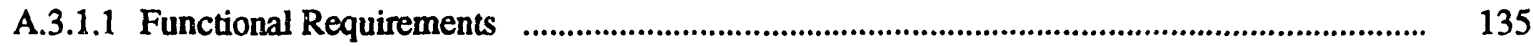

A.3.1.2 Systen Description ..................................................................................................... 135

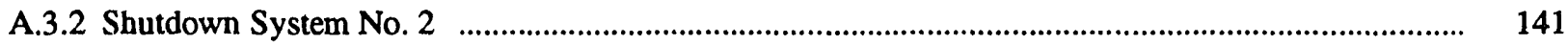

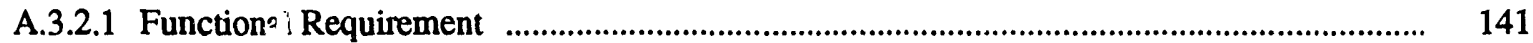

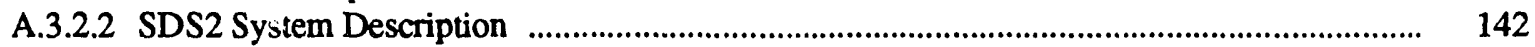

A.3.2.3 Equipment Layout .............................................................................................................. 143

A.3.2.4 Reactor and Process Measurements ….......................................................................... 143

A.3.2.5 Logic Processing ................................................................................................................... 143

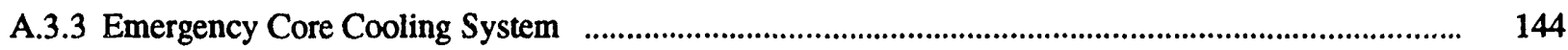

A.3.3.1 System Functional Requirements ........................................................................................ 144

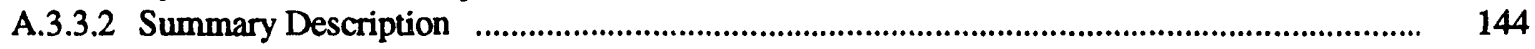

A.3.3.3 System Operation ............................................................................................................ 145

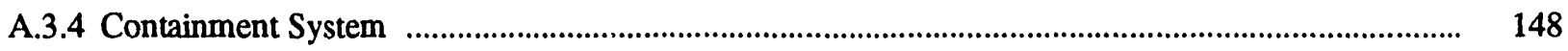

A.3.4.1 System Functional Requirements ..................................................................................... 148

A.3.4.2 Design Basis .................................................................................................................. 148

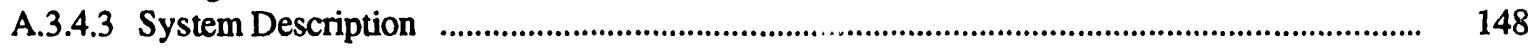

A.3.4.4 Operating Modes ................................................................................................................... 149

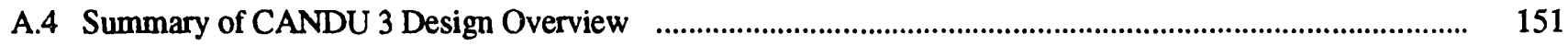

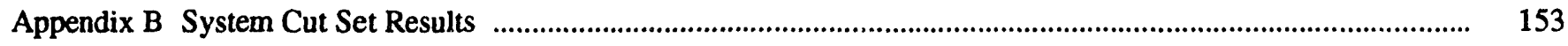

B.1 Presentation of System Cut Set Results .................................................................................................... 153

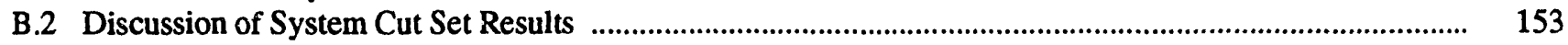

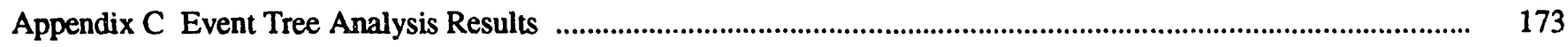

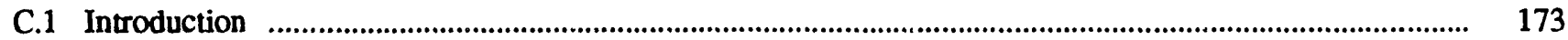

C.2 Large-Break Loss-of-Coolant Event Analysis Results ............................................................................ 173

C.3 Small-Break Loss-of-Coolant Accident Event Analysis Results .............................................................. 173

C.4 Loss of Class IV Power Event Analysis Results ................................................................................ 173

C.5 Undercooling Event Analysis Results ...................................................................................................... 173

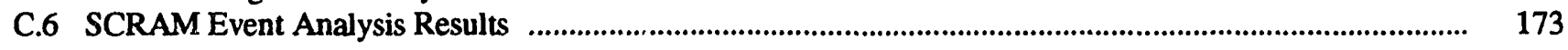

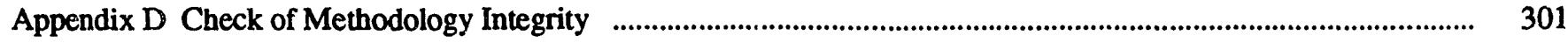

Appendix E Comparison to AECL Analyzed Events ..................................................................................... 


\section{List of Figures}

Figure

Page

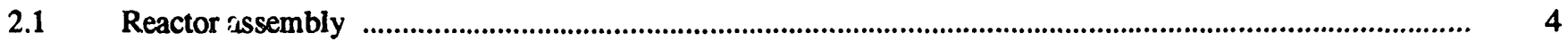

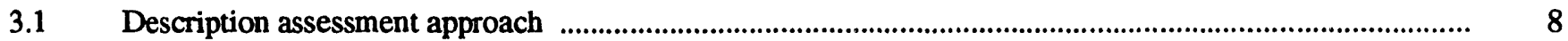

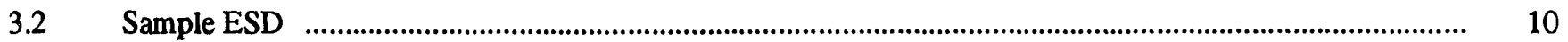

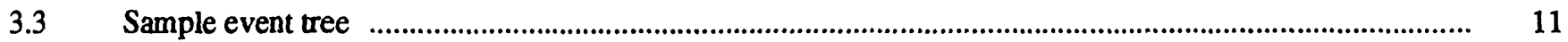

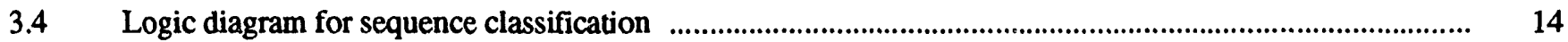

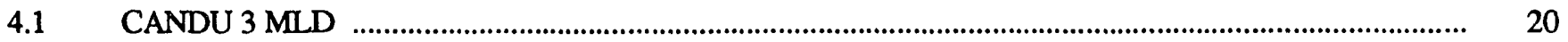

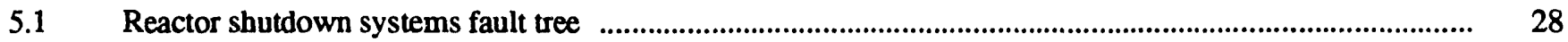

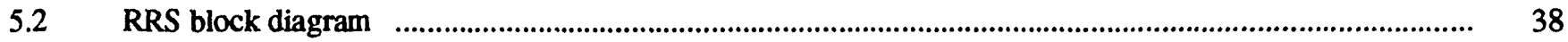

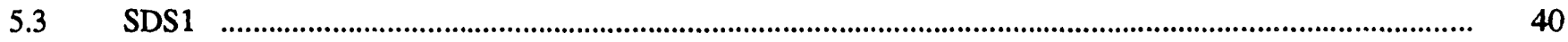

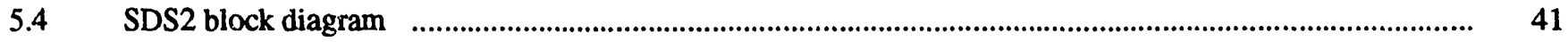

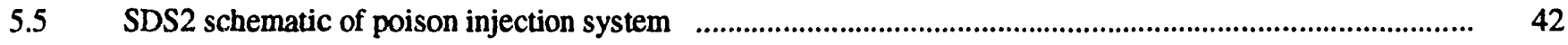

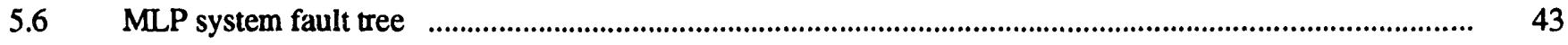

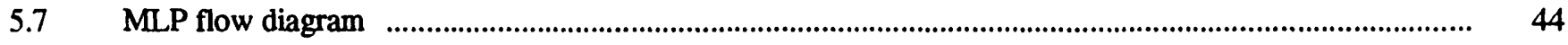

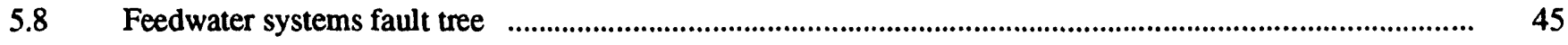

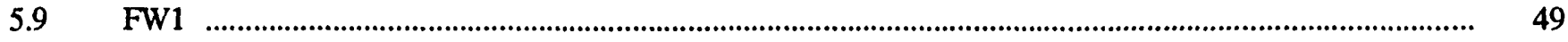

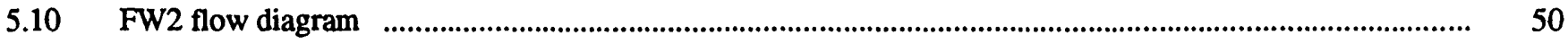

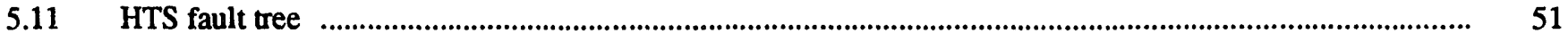

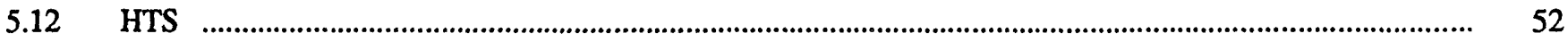

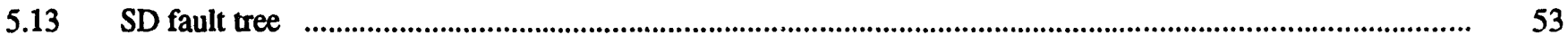

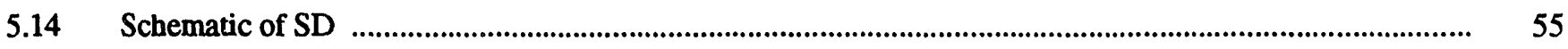

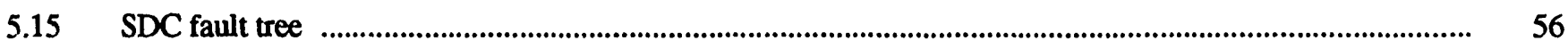

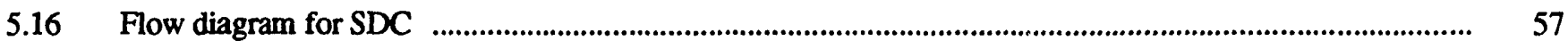

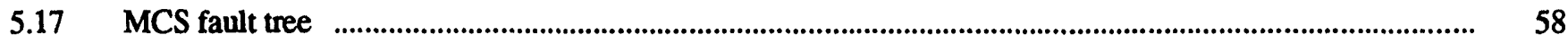

5.18 MCS flow diagram ............................................................................................................................... 59

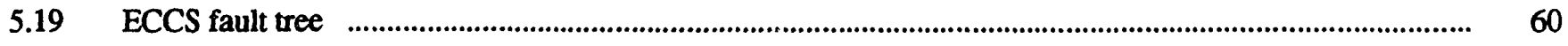

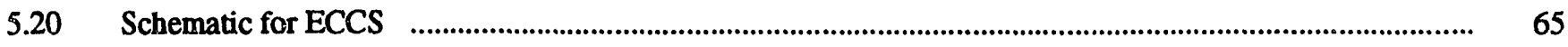

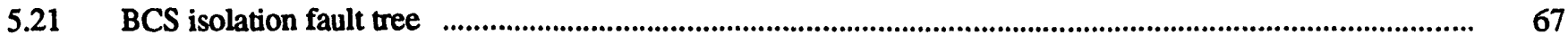

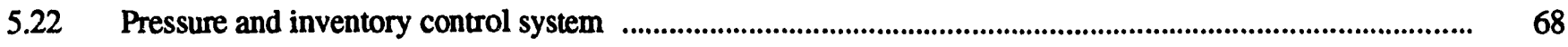

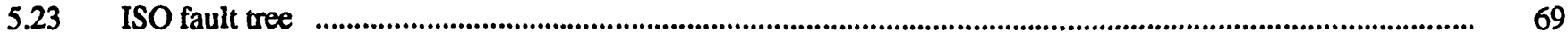

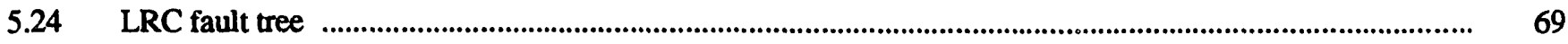

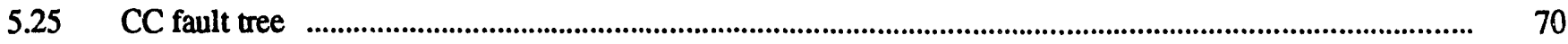

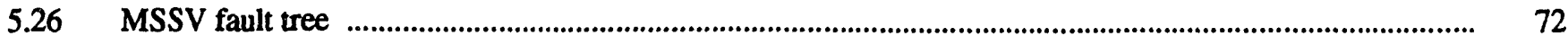

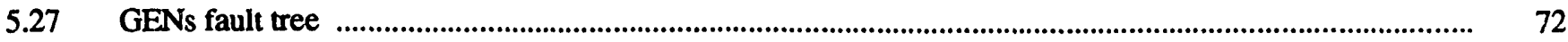




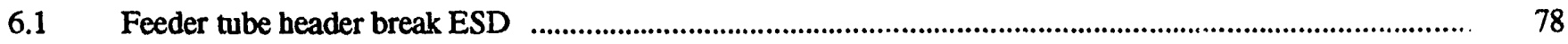

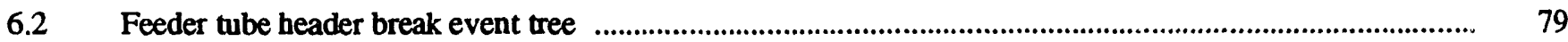

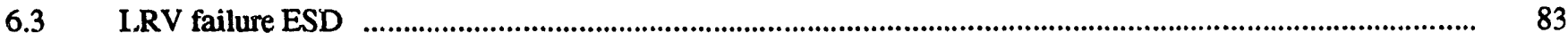

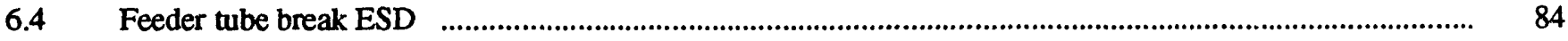

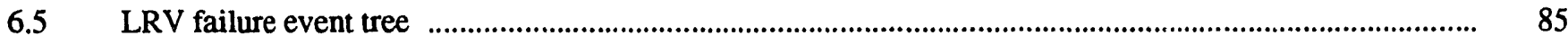

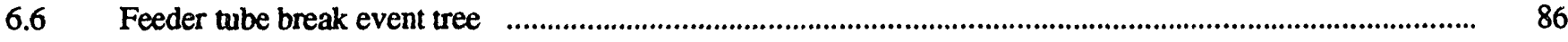

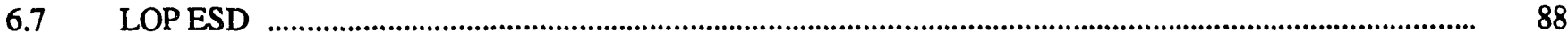

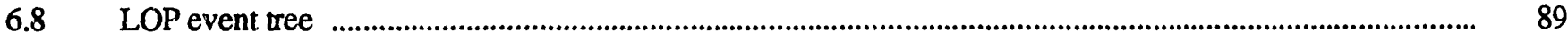

$6.9 \quad$ Feedwater piping break in reactor building ESD ........................................................................................... 91

$6.10 \quad$ Feedwater piping break in turbine building ESD ...................................................................................... 92

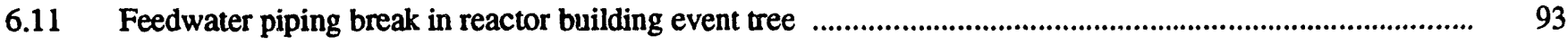

6.12 Feedwater piping break in turbine building event tree .................................................................................. 94

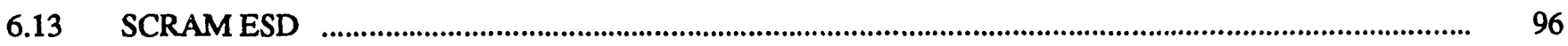

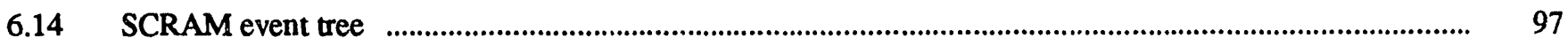

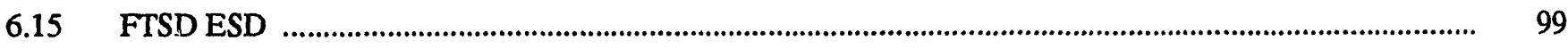

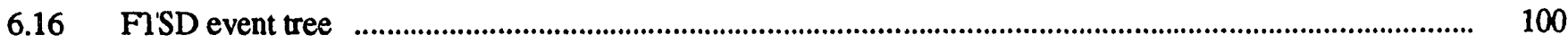

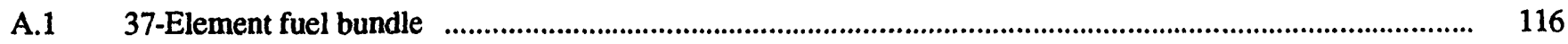

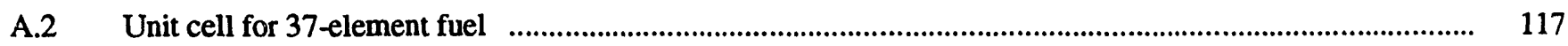

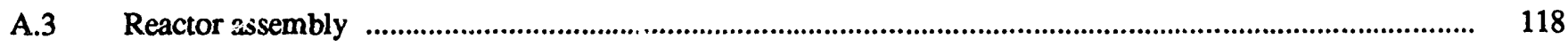

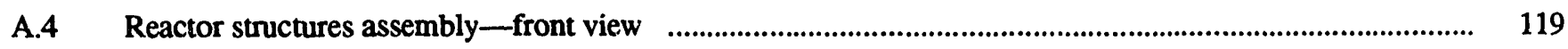

A.5 HTS simplified composite flow diagram ........................................................................................ 122

A.6 Reactor building-section ................................................................................................................... 123

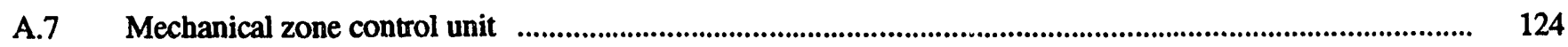

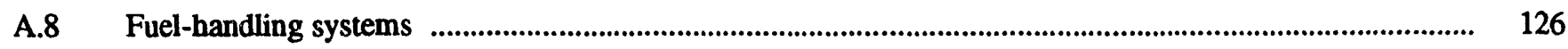

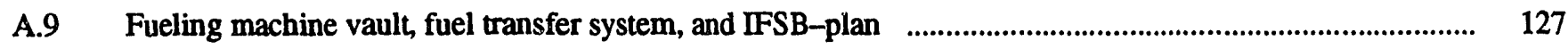

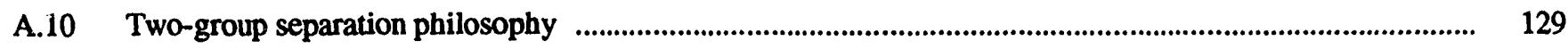

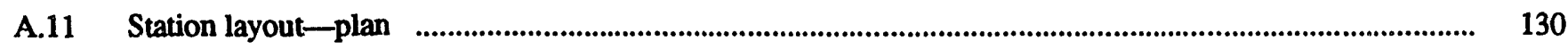

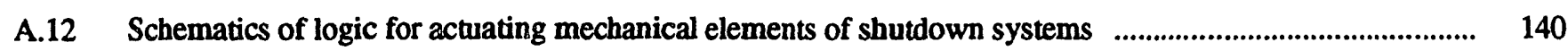

A.13 Schematic diagram of liquid injection system used for SDS2 .............................................................. 142

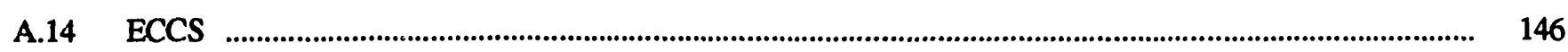

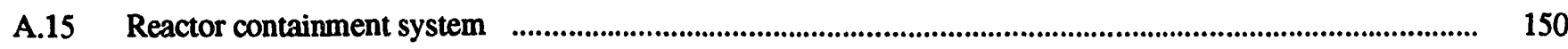




\section{List of Tables}

$2.1 \quad$ CANDU 3 unit data

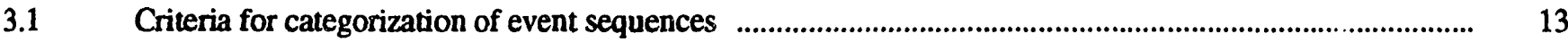

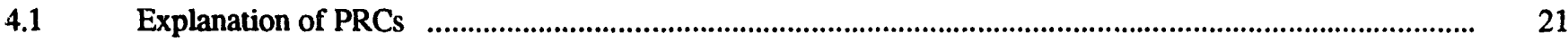

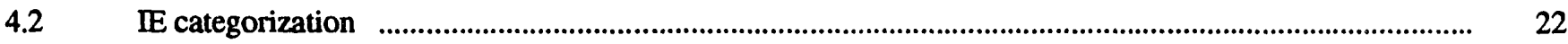

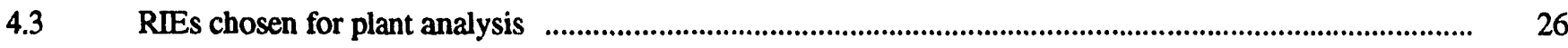

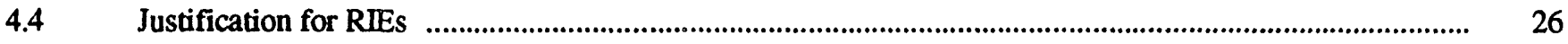

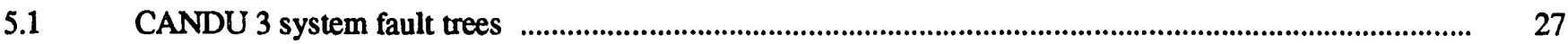

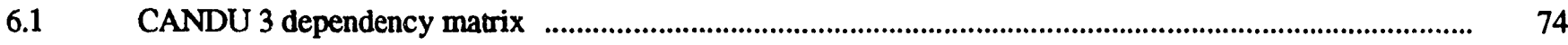

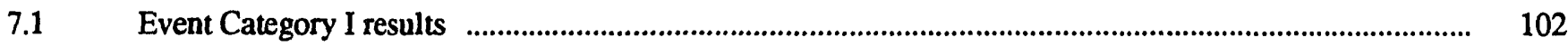

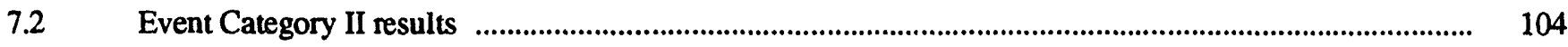

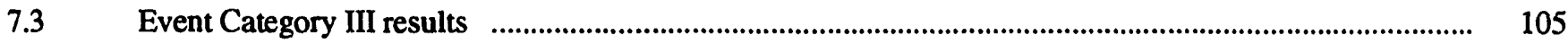

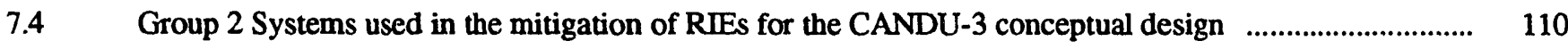

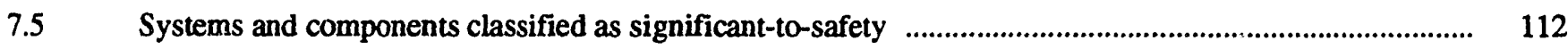

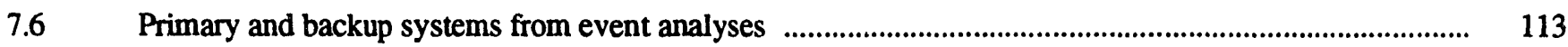

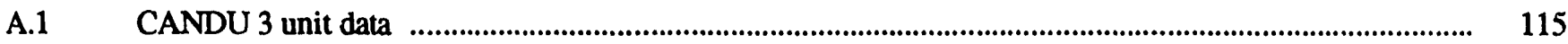

A.2 Coverage of process failures by SDS1 and independently by SDS2 ….................................................. 136

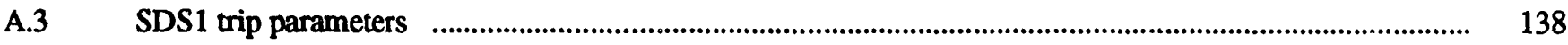

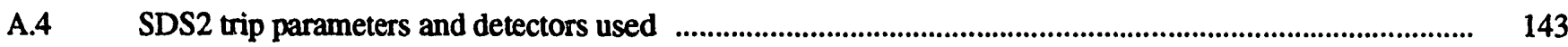

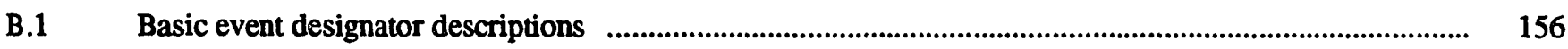

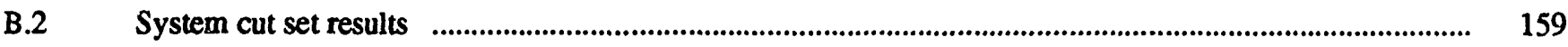

C.1 Feeder tube header break sequence cut sets _.................................................................................. 174

C.2 LBLOCA events sequence categorization: representative initiating event-feeder tube

C.3 Liquid relief valve failure sequence cut sets f.................................................................................. 207

C.4 Small-break loss-of-coolant events sequence categorization: representative initiating

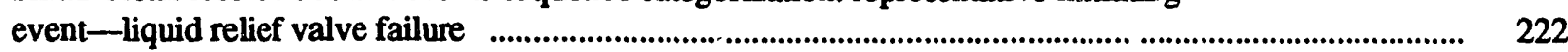

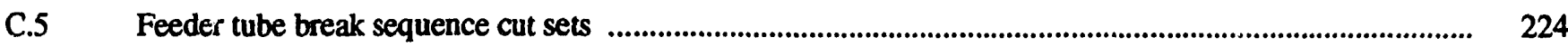

C.6 Small-break loss-of-coolant events sequence categorization: representative initiating event-feeder tube break $\quad$.............................................................................................................................. 246

C.7 Loss of Class IV power sequence cut sets ................................................................................... 248

C.8 Loss of essential power supply events sequence categorization: representative initiating event-loss of Class IV power ............................................................................................................. 262

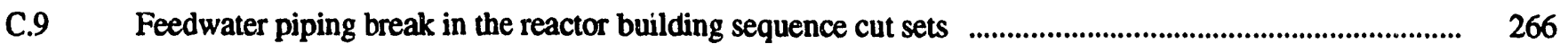

C.10 Undercooling events sequence categorization: representative initiating event-feedwater piping 284

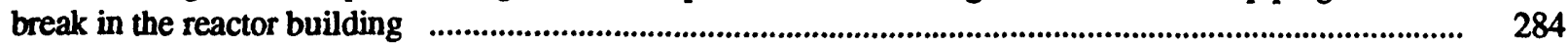

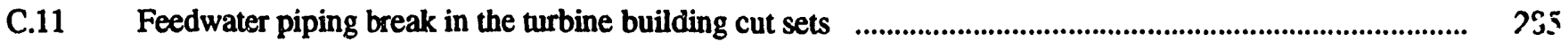


C.12 Undercooling events sequence categorization: representative initiating event-feedwater piping break in the turbine building ........................................................................................................... 289

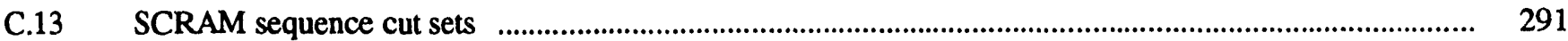

C.14 Reactivity transient events sequence categorization: representative initiating event - SCRAM $\ldots . . . . . . . . . . . .294$

D.1 Feeder tube header break sequence comparisons ................................................................................... 302

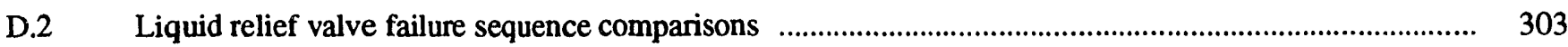

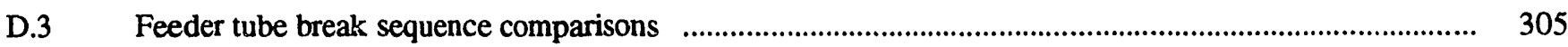

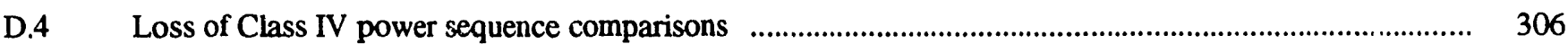

D.5 Feedwater piping break in the reactor building sequence comparisons …............................................... 308

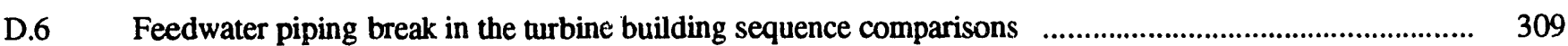

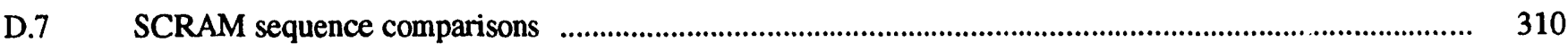

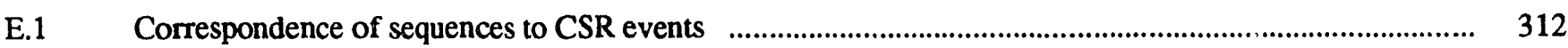




\section{Acknowledgments}

The authors acknowledge the efforts of Andrew Szukiewicz, Ralph Meyer, and Zoltan Rosztoczy of the U.S. Nuclear Regulatory Commission staff, who were responsible for directing and monitoring the CANDU Systems Research Program efforts and who provided insightful comments that greatly enhanced the technical content of this report. We also wish to thank Louis Rib and Bob Curtis of the AECL Technologies staff, who provided the copies of the CANDU 3 illustrations that are used in this report. In addition, we appreciate the contributions that
S. J. Ball, W. P. Bartiold, J. J. Carbajo, N. Clapp, G. J. Dyer, M. Johnson, S. C. Neison, W. A. McAfee, D. G. Morris, G. A. Murphy, R. T. Primm, G. C. Robinson, R. P. Wichner, and V.K. Wilkinson made to the overall CANDU Systems project. Finally, we appreciate the assistance provided by members of the Oak Ridge National Laboratory Engineering Technology/Fusion Energy Division Publications Office, who effectively prepared the final version of this report. 


\section{Acronyms and Abbreviations}

AECL
AFW
ANS
ASD
BCS
CC
CSD
CSR
DOE
EAB
ECCS, ECC
ECI
ESD
FMECA
FTSD
FW
FW1
FW2
GEN
HPI
HTS
IE
ISO
LBLOCA
LOCA
LOCS
LOFWRB
LOFWTB
LOP
LPI
LRC
LRFV
LRV
LWR
MCS
MLD
MLP
MSV, MSSV
NRC
NRR
ORNL
PRA
PRC
PSA
REC
RIE
RRS
SAR
SBLOCA
SBLFB
SD

Atomic Energy of Canada, Limited

Auxiliary Feedwater System

Advanced Neutron Source

Atmospheric Steam Discharge Valve

Bleed Condenser System

Crash Cooling System

Condenser Steam Discharge Valve

Conceptual Safety Report

Departunent of Energy

Exclusion Area Boundary

Emergency Core Cooling System

Emergency Coolant Injection

Event Sequence Diagram

Failure Modes, Effects and Consequences Analyses

Failure To Shutdown

Feedwater System

Group 1 Feedwater System

Group 2 Feedwater System

Emergency Generators

High-Pressure Injection

Heat Transport System

Initiating Event

Steam Generator Isolation

Large-Break Loss-of-Coolant Accident

Loss-of-Coolant Accident

Loss-of-Coolant Signal

Loss of Feedwater in the Reactor Building

Loss of Feedwater in the Turbine Building

Loss of Class IV Power

Low-Pressure Injection

Liquid Relief Valve Closure

Liquid Pelief Valve Failure to Reclose

Liquid Relief Valve

Light-Water Reactor

Moderator Coolirg System

Master Logic Diagram

Moderator Liquid Poison System

Main Steam Safety Valve

U.S. Nuclear Regulatory Commission

Nuclear Reactor Regulation

Oak Ridge National Laboratory

Probabilistic Risk Assessment

Plant Response Category

Probabilistic Safety Assessment

ECC Recirculation

Rerresentative Initiating Event

Reactor Regulating System

Safety Analysis Report

Small-Break Loss-of-Coolant

Small-Break LOCA Feeder Tube Break

Steam Discharge 
SDC

SDS1, SD1

SDS2, SD2
Snutdown Cooling System

Shutdown System 1

Shutdown System 2 


\section{Introduction}

\subsection{Background and Purpose}

The U.S. Nuclear Regulatory Commission (NRC) is performing a preapplication review of the Canadian CANDU 3 reactor design in preparation for possible standard design certification at a future date. Because the CANDU 3 design is significantly different from that of any licensed U.S. reactor, certain features of the safety review for CANDU 3 will be new to the NRC. To support that review, Oak Ridge National Laboratory (ORNL) was asked to perform a systems failure analysis of the CANDU 3 systems that are used during normal reactor operation and postulated accidents to provide the NRC with an understanding of the dynamic behavior of the plant.

In performing a safety review, the NRC isually classifies event sequences as Anticipated Operatioridl Occurrences, Design-Basis Accidents, and Severe Accidents. Events in each classification are then held to different requirements. Important safety systems and operator actions also enter into the review. Thercfore, the ORNL study includes a classification of important event sequences and an identification of "systems significant to safety" and key operator actions.

\subsection{Scope}

The expected results from this study included

- a list of categorized CANDU 3 event sequences,

- a list of CANDU 3 systems designated as significant-tosafety, and

- a list of key operator actions.

This report provides the following:

- A brief description of the CANDU 3 design, which focuses on the major characteristics of the plant, particularly those that differ from U.S. light-water reactors (LWRs).

- A description of the assessment methodology, which is an adaptation of Probabilistic Risk Assessment (PRA) analysis techniques using fault trees and event trees.

- Results of the fault tree analysis. These trees identify, for each system, those conditions that could cause failure of the system to perform its mitigation function in response to plant transients.

- A listing of initiating events and results of the event tree analysis for representative initiating events.
- The event tree results that are used to classify event sequences and identify systems that play an important role in the safety of the plant when responding to offnormal events.

- The results of the study as indicated previously.

\subsection{Methodology}

Because the CANDU 3 design is not fully developed, detailed design information that would be needed for a licensing review or for a PRA analysis is not available. Therefore, the CANDU Systems Research Program adapted assessment methodologies such that a meaningful assessment could be made on the basis of the information available.

The process by which the program arrived at its results is briefly described in the following paragraphs. The plant assessment methodology is described in detail in Chap. 3 .

CANDU design characteristics were obtained from Atomic Energy of Canada, Limited (AECL) information sources provided to ORNL by the NRC; these sources are given as Refs. 1-7, or as footnotes. ${ }^{*-* * * *}$ Information from a CANDU-600 Probabilistic Safety Assessment (PSA) was also made available for on-site inspection at AECL

"Atomic Energy of Canada, Limited, "The CANDU 3 Technical Description," 74-01371-TED-001, Rev. 3/89-09-15.

${ }^{\dagger}$ Atomic Ent:rgy Control Board, Regulatory Document R7, "Requirerr.ents for Containment Systems for CANDU Nuclear Power Plants," 1987.

¥Atomic Energy Control Board, Regulatory Document R8, "Requirements for Shutdown Systems in CANDU Nuclear Plants," 1987.

** Atomic Energy Control Board, Regulatory Document R9, "Requirements for Emergency Core Cooling System in CANDU Nuclear Plants," 1987.

i† Atomic Energy Control Board, Regulatory Document R10, "The Use of Two Shutdown Systems in Reactors," 1977.

\$Atomic Energy Control Board, Regulatory Document R77. "Overpressure Protection Requirements for Primary Heat Transpor Systems in CANDU Power Reactors Fitted with Two Shutdown Systems," 1987.

*** Atomic Energy Control Board, Regulatory Document R90, "Policy on Decommissioning of Nuclear Facilities," 1988.

$f^{+} t_{\mathrm{H}}$. Tamm et al., Overview of the Technical Basis for the Safety of CANDU Reactors, Paper presented at the Intemational Symposium on Nuclear Safety, Tokyc, Dec. 8-10, 1987.

$\ddagger \ddagger$ D. G. Hurst and F. C. Boyd, Reactor Licensing and Safety Requirements, Paper presented at the 12th Annual Conference of the Canadian Nuclear Association, Ottawa, June 11, 1972.

**** P. J. Allen et al., Atomic Energy of Canada, Limited, "Extemal Analysis Repor-Conceptual Probabilistic Safety Assessment," Rev. 0/89-02-28, 1989. 
Rockville, Maryland, offices. Also, two meetings were held with AECL to clarify questions that arose as the ORNL staff became more knowledgeable about the plant. ${ }^{*} \ddagger^{* *}$

Initiating events were identified and used in the plant assessment process. The plant assessment process used adaptations of PRA techniques that included the use of fault trees and event trees and was supplemented with a System Dependency Matrix. Fault tree evaluations identified failure modes for the systems assessed.

On the basis of the plant assessment, plant events were classified into groups as EC-Is, EC-IIs, EC-IIIs, and EC-IVs (Chap. 3 defines these categories). Plant events are comprised of an initiating event (also referred to as an initiator) and the plant response (referred to as the event sequence in the report). Thus, multiple plant events result from each initiating event, depending on the possible combinations of component/system failures. The plant assessment process also identified systems sigrificant-tosafety and key operator actions.

\subsection{Limitations}

Several limitations exist that preclude the performance of a complete and comprehensive independent analysis of the safety-related issues regarding the CANDU 3 reactor. Because the CANDU 3 design is currently incomplete, sufficient design detail does not exist to perform in-depth failure analyses. For instance, certain aspects such as operator actions and maintenance effects cannot be examin`d in detail because the procedures on which these analyses would be based are not yet available.

The focus of this effort was on systems behavior during power operations. Other plant conditions such as low or zero power operations were not examined. In addition, earthquakes, fires, floods, and common-mode failures associated with such events were not considered in this analysis.

\footnotetext{
" "Point Lepreau Nuclear Generating Station - Unit 1 - Safety Report," Parts 1 and 2, 1990.

† Atomic Energy of Canada, Limited Technologies, Rockville, Maryland, personal communication to Oak Ridge National Laboratory Staff, March 10, 1992.

$\ddagger_{\text {Atomic Energy of Canada, Limited, Presentation of Information at }}$ NRC/AECL Review Meeting on the CANDU 3 Systems Research Sudy, February 10, 1993.

** Letter from AECL Technologies to the U.S. NRC, "Responses to February 10, 1993 NRC/ORNL Reques, for Information," February 22. 1993.
}

The main focus of the report is on events that affect the fuel in the reactor core; it is thought that these have the greatest potential to lead to significant radionuclide releases. Event tree and fault tree analyses were not performed for the containment, refueling, and waste storage systems because available information on these systems in the Canadian documentation was sparse.

The initiating events were obtained from a review of a comprehensive set of sources, including U.S. LWRs and research reactors and Canadian CANDU operating experience. The representative initiating events against which the plant response is gaged are comprehensive, but further analysis and experience could indicate different or additional events that should be analyzed.

\section{References}

1. Atomic Energy of Canada, Limited, "CANDU 3 Conceptual Safety Report," Vols. 1 and 2, 1989."

2. Atomic Energy of Canada, Limited, "The CANDU 3 Technical Outline," Rev. 11, June 1992. ${ }^{\dagger}$

3. P. H. Wigfull, "Reactor Licensing in Canada," Nuclear Safet'j' 24(4) (1983). ${ }^{\dagger}$

4. R. K. Nakagawa, Atomic Energy of Canada, Limited, "The Technology of CANDU On-Power Refueling," TTR-305, 1991."

5. D. Pendergast et al., Atomic Energy of Canada, Limited, "The Technology of CANDU Loss of Coolant Analysis," TTR-276, Rev 0, 1991.*

6. A. R. Khan and P. Archer, Atomic Energy of Canada, Limiter." "The Technology of CANDU Shutdown Systems," TTR-306, Rev 0, 1991."

7. E. G. Price et. al., The Technology of CANDU Fuel Channels, TTR-291, Rev 0, Atomic Energy of Canada, Limited, 1991.*

\footnotetext{
* Available in NRC PDR for inspection and copying for a fee.

t Available in public technical libraries.
} 


\section{Summary of CANDU 3 Design}

\subsection{Introduction}

This section provides a very brief summary of CANDU 3 characteristics that affect safety considerations. Appendix A, which is derived from ext:snsive condensation of the CANDU 3 Conceptual Safety Report (CSR), ${ }^{1}$ the CANDU 3 Technical Outline, ${ }^{2}$ and the CANDU 3 Technical Description, ${ }^{*}$ serves as a convenient source of plant design information.

\subsection{Plant Characteristics}

The CANDU 3 design is a derivation of the CANDU reactors that have been in operation for almost 30 years.

Twenty-three CANDU-type reactors have been built and operated to date. The CANDU 3 is a sinailer power version of the CANDU concept that builds on an extensive data and information base, but at present it is in a conceptual design stage. Therefore, many details, needed for extensive safety assessment and for PRAs, are not available. The plant unit data are given in Table 2.1. A sketch of the reactor assembly is shown in Fig. 2.1.

The reactor is cooled and moderated by heavy water and is fueled by natural enrichment uranium. The fuel is in the form of uranium dioxide pellets, in zirconium alloy tubes $495 \mathrm{~mm}$ long. The fuel assemblies are bundles containing 37 rods and are stacked horizontally in zirconium pressure tubes, 12 to a tube. The 232 pressure tubes are arranged so that each is fed by a coolant feeder tube from 4 inlet headers. ${ }^{2}$ The heated coolant exits from the core to individual tubes that feed to two outlet headers that supply the primary coolant side of two steam generators. The pressure tubes, feeder tubes, headers, pumps, pressurizer, fuel loading machine, and associated supply systems form the main pressure boundary.

The pressure tubes are contained inside zirconium alloy calandria tubes; these penetrate the calandria vessel, which contains a heavy water moderator at low pressure. The moderator system includes a moderator level control system, a pressure relief system employing rupture disks, a moderator cover gas control system that controls moderator pressure as well as recombines radiolytic deuterium to prevent buildup of combustible concentrations in the cover gas, and a moderator neutron poison system. The calandria vessel is contained within a shield tank that contains light water.

\footnotetext{
*Atomic Energy of Canada, Limited, "The CANDU 3 Technical Description," 74-01371-TED-001, Rev. 3/89-09-15, 1989.
}

Table 2.1 CANDU 3 unit data

\begin{tabular}{|c|c|}
\hline \multicolumn{2}{|l|}{ Reactor } \\
\hline Type & Horizontal pressure tube \\
\hline Coolant & Pressurized heavy water \\
\hline Moderator & Heavy water \\
\hline Number of fuel channels & 232 \\
\hline \multicolumn{2}{|l|}{ Fuel } \\
\hline Fuel & $\begin{array}{l}\text { Compacted and sintered } \\
\text { natural } \mathrm{UO}_{2} \text { pellets, } \\
12.15-\mathrm{mm} \text { diam., clad in } \\
13.08-\mathrm{mm}-\mathrm{OD}, 0.42- \\
\text { mm-thick Zircaloy-4 } \\
\text { sheath }\end{array}$ \\
\hline Form & $\begin{array}{l}\text { Fuel bundle assembly of } 37 \\
\text { elements }\end{array}$ \\
\hline Length of bundle & $495.3 \mathrm{~mm}$ \\
\hline Outside diameter & $102.4 \mathrm{~mm}$ \\
\hline Bundle weight & $\begin{array}{l}23.5 \mathrm{~kg} \text { (includes } \\
19.1 \mathrm{~kg} \mathrm{U})\end{array}$ \\
\hline Bundles per fuel channel & 12 \\
\hline \multicolumn{2}{|l|}{ Heat transport system } \\
\hline $\begin{array}{l}\text { Number of steam } \\
\text { generators }\end{array}$ & 2 \\
\hline Steam generator type & $\begin{array}{l}\text { Vertical U-tube with inte- } \\
\text { gral steam drum and } \\
\text { preheater }\end{array}$ \\
\hline $\begin{array}{l}\text { Number of heat transport } \\
\text { pumps }\end{array}$ & 4 \\
\hline Heat transport pump type & $\begin{array}{l}\text { Vertical, centrifugal, single } \\
\text { suction, double discharge }\end{array}$ \\
\hline $\begin{array}{l}\text { Reactor outlet header } \\
\text { pressure (gage) }\end{array}$ & $9.9 \mathrm{MPa}$ \\
\hline $\begin{array}{l}\text { Reactor outlet tempera- } \\
\text { ture }\end{array}$ & $310^{\circ} \mathrm{C}$ \\
\hline Reactor coolant flow & $5.3 \mathrm{Mg} / \mathrm{s}$ \\
\hline $\begin{array}{l}\text { Steam temperature } \\
\text { (nominal) }\end{array}$ & $260^{\circ} \mathrm{C}$ \\
\hline $\begin{array}{r}\text { Steam quality } \\
\text { (minimum) }\end{array}$ & $99.75 \%$ \\
\hline Steam pressure (gage) & 4.6 $\mathrm{MPa}$ \\
\hline Total fission heat & $1440.3 \mathrm{MW}(\mathrm{th})$ \\
\hline $\begin{array}{l}\text { Net electrical output } \\
\text { (nominal) }\end{array}$ & $450 \mathrm{MW}(\mathrm{e})^{a}$ \\
\hline
\end{tabular}

Refueling is performed continuously while at power. This is necessary because of the low excess reactivity due to the use of natural enrichment uranium. On-line refueling 


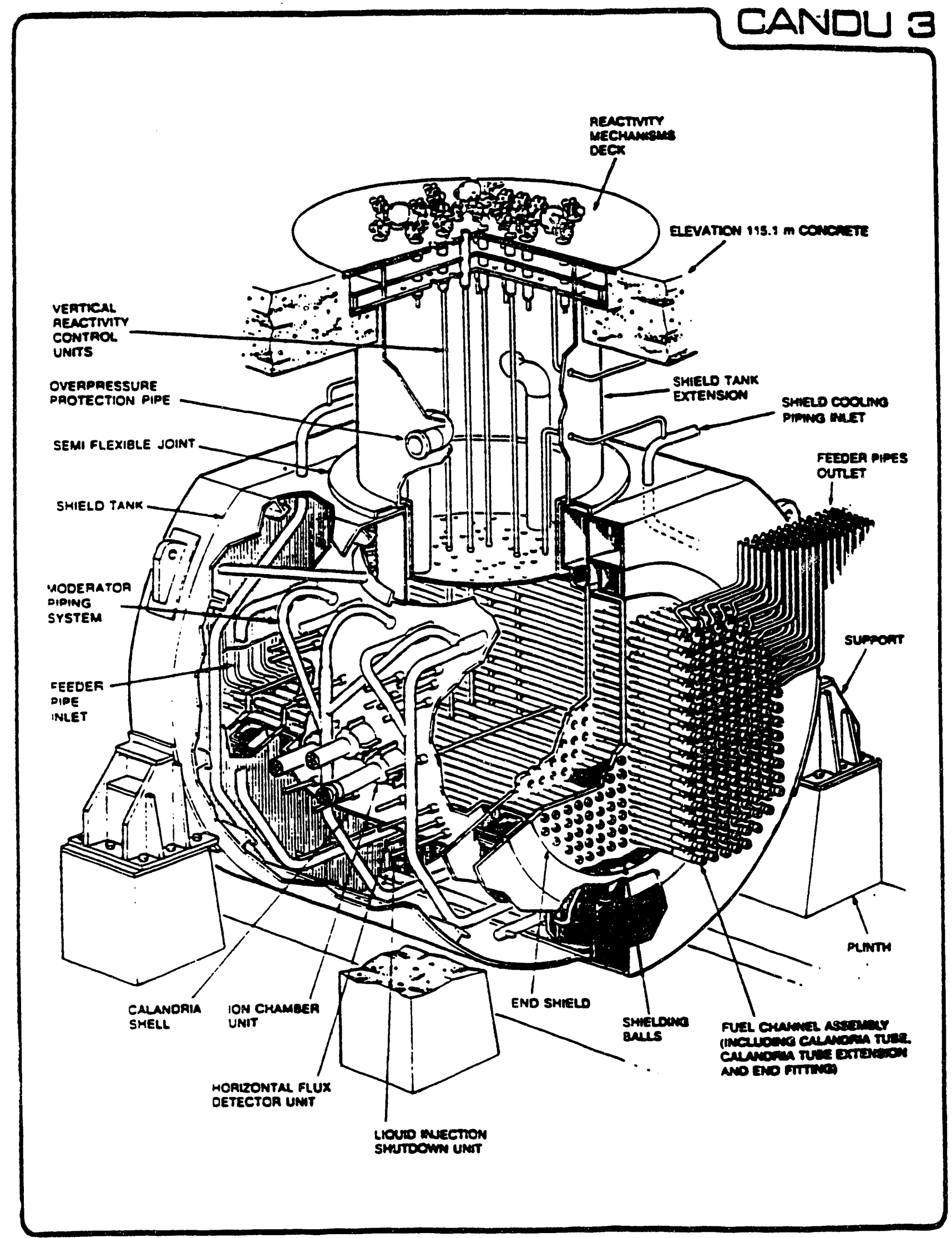

Figure 2.1 Reactor assembly 
contributes to the historically very high capacity factors achieved by the CANDU class reactors. Refueling for the CANDU 3 differs from previous CANDUs in that all fueling is performed from one face of the reactor, whereas in prior designs, fuel was inserted from one face and removed from the opposite face. For fuel removal, coolant flow pressure forces are relied upon to propel the fuel string into the refueling machine. The refueling is automatically controlled by computer and can be observed remotely by the operators in the control room.

The reactor is controlled by a distributed digital control system. One reason for this is that the core is sufficiently large in physical size to be potentially subject to spatial variations in neutron flux, which must be locally monitored and controlled; manual control is not feasible.

Normal reactor control is accomplished by mechanical regulating rods, which enter the core from the top. Also, reactivity is controlled by the refueling scheme, which shuffles new and irradiated fuel, and by a boron or gadolinium liquid poison system in the moderator.

The reactor has a positive coolant void reactivity coefficient and could theoretically experience a positive power transient in the event of voids from, for example, large loss-oif-coolant accidents (LOCAs). Under this circumstance, the normal regulating system is not capable of shutting down the reactor. Therefore, there are two independent safety shutdown systems, SDS1 and SDS2. SDS1 uses mechanical spring-injected rods that enter the core from the top. SDS2 uses a helium-pressure-driven gadolinium nitrate poison solution injection, with the injectors entering the moderator vessel from the side (at right angles to the fuel and calandria tubes).

An emergency core cooling system (ECCS) employs a gasdriven high-pressure injection (HPI) system and a lowpressure injection (LPI) system, with long-term residual heat removal using pump-driven cooling water.
The containment system utilizes a steel-lined reinforced concrete building that hass space coolers, but does not have a spray or deluge system. The system is designed to withstand a large-break LOCA, but a break in the main steam system internal to containment could exceed the design basis although it would not exceed the ultimate capability of the containment. The containment has heavy water vapor recovery systems and a hydrogen igniter system.

The plant is designed to provide physical separation between Group 1 systems and Group 2 systems. Generally, Group 1 systems provide for normal operation of the plant. and Group 2 systems provide safety backup. Group 2 systems are environmentally qualified, including seismic qualification. Electrical power supplies are arranged in four classes, I, II, III, and IV, depending on interruptability and reliability requirements.

The concept of dual failures is different than that of the U.S. systems. For CANDU, failure of the normal process system counts as the first failure, while failure of the backup safety system counts as the second failure.

As mentioned previously, Appendix A is a convenient source of design information. It is recommended that those needing familiarization with the CANDU 3 design read Appendix A before proceeding. More detail is provided in Refs. 1 and 2.

\section{References}

1. Atomic Energy of Canada, Limited, "CANDU 3 Conceptual Safety Report," Vols. 1 and 2, 1989."

2. Atomic Energy of Canada, Limited, "The CANDU 3 Technical Outline," Rev. 11, June 1992."

\footnotetext{
* Available in NRC PDR for inspection and copying for a fee.
} 


\section{Description of Assessment Process}

\subsection{Overview of Assessment Process}

The project products were developed by performing a systematic assessment of the CANDU 3 plant conceptual design. The major steps in the assessment process are indicated in Fig. 3.1. The design information sources detailed in Chap. 1 were reviewed* by a team of technical experts to become familiar with the plant design. This team consisted of experts in the following technical areas:

1. instrumentation and control;

2. reactor operations and human factors;

3. fuel performance, radiological waste, and fission products;

4. severe accident phenomena;

5. neutronics;

6. materials, structures, and mechanical systems; and

7. reactor safety.

The team of technical experts then provided technical guidance in the application of the assessment methodology and reviewed the fault and event trees for completeness and accuracy.

Several plant assessment methodologies were considered for use including HAZOP, FMECA, and standard fault tree and event tree techniques. Three criteria were used when selecting the assessment methodologies to be used in the study. One was related to the products required from the project. Because they are typical of products from a PRA of a plant, techniques normally used in PRAs (event trees and fault trees) were favored.

The amount of detail required to implement the methodology effectively was the second criterion to be considered when selecting the approach to be used in this study. And finally, there is the need to provide the NRC with the information in a deterministic format to allow a more consistent review with respect to NRC regulatory criteria. As described in Chap. 2 and Appendix A, the CANDU 3 plant is a highly complex design that depends upon multiple layers of active engineered systems to provide for safe operation. From the project's inception it was clear that the project scope would not support utilization of an approach that required formal processing of a high level of detail. In addition, difficulties would

\footnotetext{
"In the context of this program "review" is interpreted as meaning familiarization rather than assessment of acceptability, which is an NRC formal review function.
}

have existed with such an approach because the level of detail available at the present stage of the CANDU 3 design would not support application of such an approach. Fortunately, a substantial data base exists from previous CANDU experience. A large number of individual components and subsystems are of a standard nature (pumps, heat exchangers, etc.), and the vulnerabilities of these systems are understood by experts knowledgeable in such systems in other nuclear plants. Methodologies utilizing such expertise (with additional attention devoted to significant, unique systems to ensure that their designs and potential weaknesses were understood) would, therefore, provide the results required. Thus, the methodology chosen needed to be flexible so that it could be tailored to take advantage of expert judgment and devote additional attention to specific areas of interest when warranted, while providing the logical framework needed to complete the systematic assessment of the plant and provide PRA-type information. An assessment methodology using a combination of event trees and fault trees was chosen because it best fit the requirements of the program.

A comprehensive list of initiating events (IEs) was developed (this is described in Sect. 3.2) utilizing experience with U.S. LWRs, U.S. research reactors, and currently operating CANDU power reactors. The goal of this activity was to develop a short list of iepresentative initiating events (RIEs) for which event trees would be completed. The IEs selected for this short list are to be representative of the spectrum of CANDU 3 plant responses (i.e., systems that respond to mitigate the IE).

The plant assessment used the RIEs and the CANDU plant design information to produce the project products specified in Chap. 1. Systematic assessment began with a description of the event sequence and preparation of an event sequence diagram (ESD) for each RIE. The ESD shows the normal and alternative paths for successful termination of an event and, thus, provides a pictorial representation of the progression of a plant sequence from the IE to the termination of the sequence. It was used to identify those systems called upon to respond to a given IE. An event tree was prepared for the IE using the ESD. Fault trees were prepared for each system identified in the event tree. The fault trees were used to gain insight into the vulnerabilities of each system. A system dependency matrix was developed to determine the relationship between fronuline (e.g., the shutdiwn systems that are directly engaged in mitigating $a_{1}$ IE) and support systems (e.g., the electrical power supply system that provides a support function to the frontline systems). The event tree and fault tree models were solved to (1) classify the event 


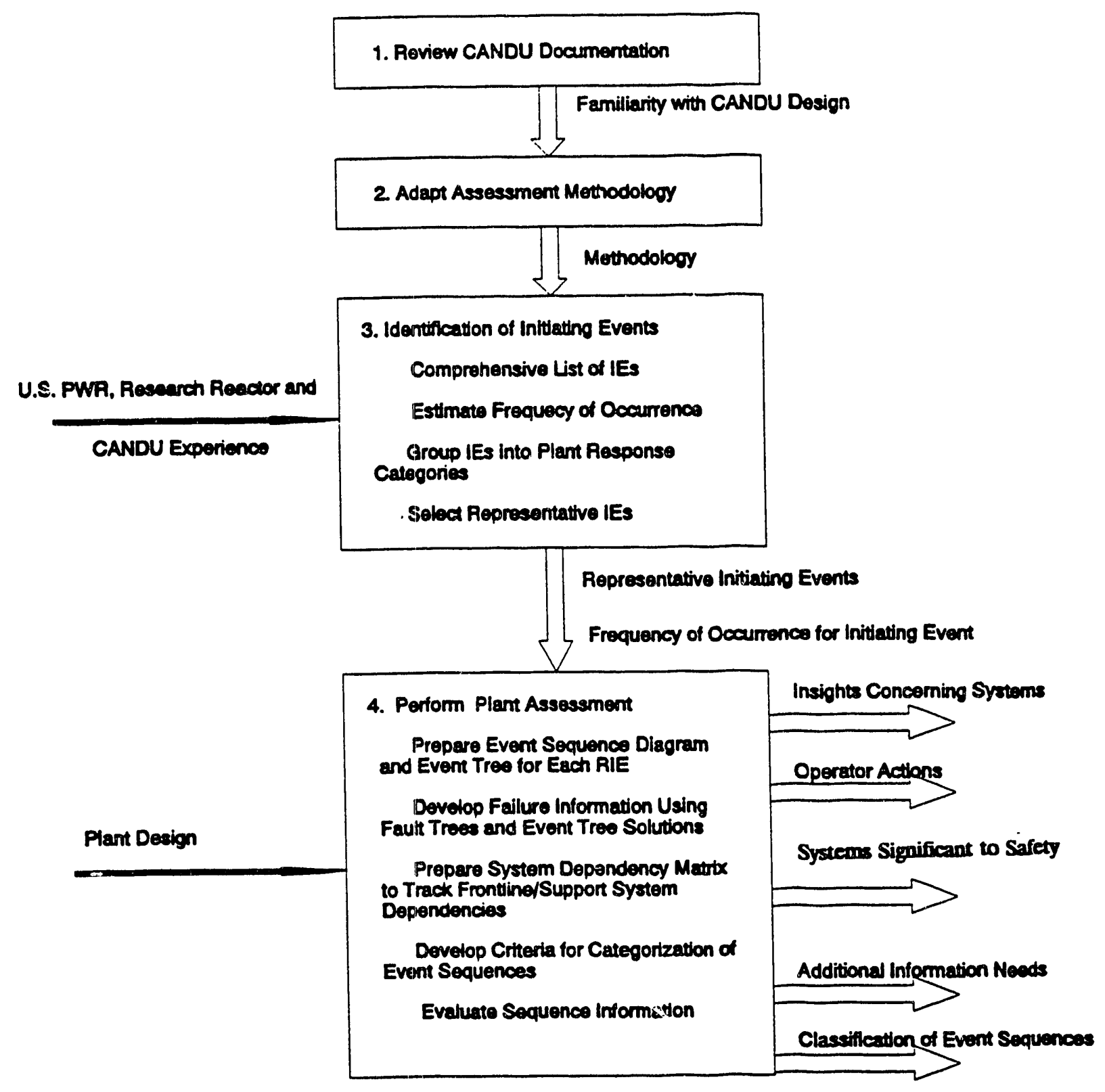

Figure 3.1 Description of assessment approach

sequences, (2) identify key operator actions, (3) provide insights concerning potential failure modes, and (4) identify systems significant-to-safety.

\subsection{Identification of Initiating Events}

The objectives of this effort were to (1) produce a comprehensive list of IEs and their estimated frequency of occurrence, (2) group the initiators into plant response categories, and (3) select RIEs that would be analyzed using the plant assessment methodology. As a starting point, data regarding IEs for various types of reactors were collected. The following experience was reviewed for applicability:

- operating experience for commercial U.S. LWRs and research reactors,

- the regulatory data base for commercial U. S. LWRs, and

- Canadian operating experience for CANDU designs.

In addition, information concerning potential IEs unique to the CANDU 3 design was obtained from the review performed by the team of technical experts. The listing of all IEs (drawn from the sources described previously) was 
reviewed to help identify any overlap in plant response to the various postulated IEs. Because the plant responds to several IEs in the same manner (i.e., there are many more IEs than there are unique plant responses), IEs that invoke similar plant responses were grouped together into a single plant resporise category (PRC). The PRC could then be evaluated rether than requiring a separate analysis for each individual event.

PRCs for the CANDU 3 were determined using a Master Logic Diagram (MLD). The MLD, a common tool now used in PRAs, presents the logical process of identifying the mechanisms that could lead to an undesired event such as a release of radioactivity from the reactor plant. Essentially, the MLD functioned as a top-level fault tree and served to identify the PRCs.

Each CANDU 3 IE was assigned to a PRC. In addition, a frequency of occurrence was estimated for each $\mathrm{E}$. This frequency is an order-of-magnitude estimate based on available data and engineering judgment. An IE table was prepared to summarize this information. This table contains a comprehensive listing of initiating events and their estimated frequency of occurrence (see Chap. 4).

The next step was to review the PRCs to determine whether any were similar enough to warrant further combination. The guideline for this review was to reduce the level of effort required while maintaining sufficient analysis detail. This reduction step resulted in the selection of seven RIEs that would be evaluated using the fault tree and event tree methodology. Selection of the RIEs is based on PRA experience and operational information for the CANDU 3 plant. Consequently, an RIE represents or is typical of the type of response that the plant would have to a set of specific initiators. Although it could exist, it is not necessary to have a one-to-one relationship between PRCs and RIEs. For illustration purposes, assume event $X$ is similar to a loss of essential power supplies. This event and all other IEs that invoke a similar plant response would be placed in the PRC "Loss of Essential Power Supplies." Now, assume that event $Y$ is similar to a loss of primary heat transport event. This event and all other IEs that invoke a similar plant response would be placed in the PRC "Loss of Heat Transport." However, the CANDU 3 plant response to both the "Loss of Essential Power Supplies" PRC and the "Loss of Heat Transport" PRC is expected to be generally the same, and that response can be adequately modeled by the IE "Loss of Class IV Power." Thus, "Loss of Class IV Power" is designated an RIE and it is used to represent all initiators under the "Loss of Heat
Transport" PRC and the "Loss of Essential Power Supplies" PRC.

\subsection{Plant Assessment}

Systematic assessment of the plant was performed by applying the event tree and fault tree methodology to each RIE. Description of each step in the methodology is provided below.

Prepare ESD and Event Trees. For each RIE, narrative text and an ESD were developed. An ESD is a graphical representation of the plant response to a particular IE. It shows, as a minimum, the normal and alternative (given postulate failures) plant system requirements for responding to a particular event. The objective is to produce a complete pictorial representation of the plant's operation. In addition, the ESDs were used to identify primary and backup systems and systems significant-tosafety in the CANDU 3 design. Systems required in the primary success path are designated primary systems. These systems are simply those systems and components that would be expected to respond to a given IE (i.e., no failures). Any system that is called upon in the ESD to prevent core damage outside the primary success path is designated a backup system.

A simplistic example of an ESD is found in Fig. 3.2. This ESD shows the primary path (designated as the farthest left-hand side path of the ESD) after an IE to be the successful operation of system $A$ and system $C$. If system A fails, then system B must function as a backup to system A. System $C$ must still work in order to mitigate the event. If either system A or system B succeeds and system C succeeds, the IE is successfully mitigated.

Based on the plant response information contained in the ESDs, an event tree was prepared for each RIE. Figure 3.3 contains an example event tree that corresponds to the example ESD contained in Fig. 3.2. The event tree branch points represent success (upward) or failure (downward) of systems designed to mitigate the IE. Each path through the event tree results in some "end state" that defines a specific condition of the plant. This condition would be a function of the particular series of system success or failures defined by that event tree sequence. While there could be any number of end states up to the number of unique sequences in the event tree, the number of end states actually defined is usually much less than this maximum number. This is because many "unique" sequences result in the same plant 


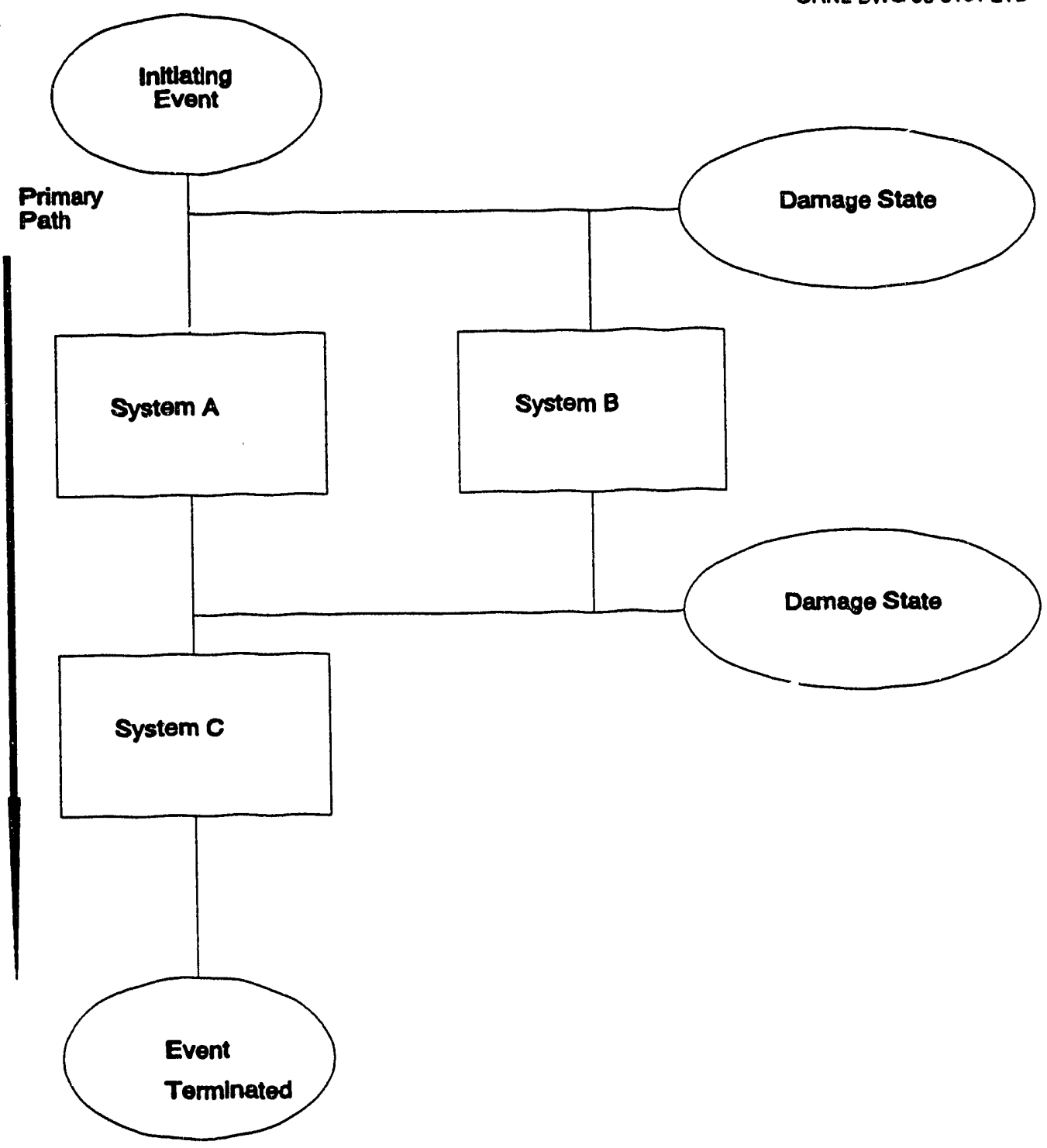

Figure 3.2 Sample ESD

condition. For the example event tree in Fig. 3.3, only two end states are defined, success or failure in termination of the event.

Three plant end states have been defined for use in this study. Event tree designations of end states are based largely on engineering judgment, because no significant consequence analyses have been performed. The defined plant end states follow:

- CC-1-No significant fuel cladding damage and no fission product release from the fuel.

- CC-2-Moderate fuel cladding damage with release of some volatile fission products from the fuel (the fuel rod gap inventory), but coolable geometry of fuel bundles is maintained.
- CC-3-Extensive core damage with large release of fission products from the fuel and potential relocation of core debris.

As described in the next section, fault trees were used to model the systems and understand how failure of the systems could occur. Only the frontline systems (including both primary and backup) were incorporated in the event trees. Frontline systems are those systems that act directly to respond to or mitigate an event. Support systems are those systems that provide a support function to the frontline system (electric power is the most common one). Because of the lack of design details at this stage, the impact of support systems and components cannot be evaluated completely through the use of only event and fault trees. Consequently, additional tools were developed (such as a system dependency matrix, discussed later) to separately track and evaluate these support functions. 
Description

ORNL-DWG 93-3182 ETD

Initating Event System A System B Syotem C End Stato

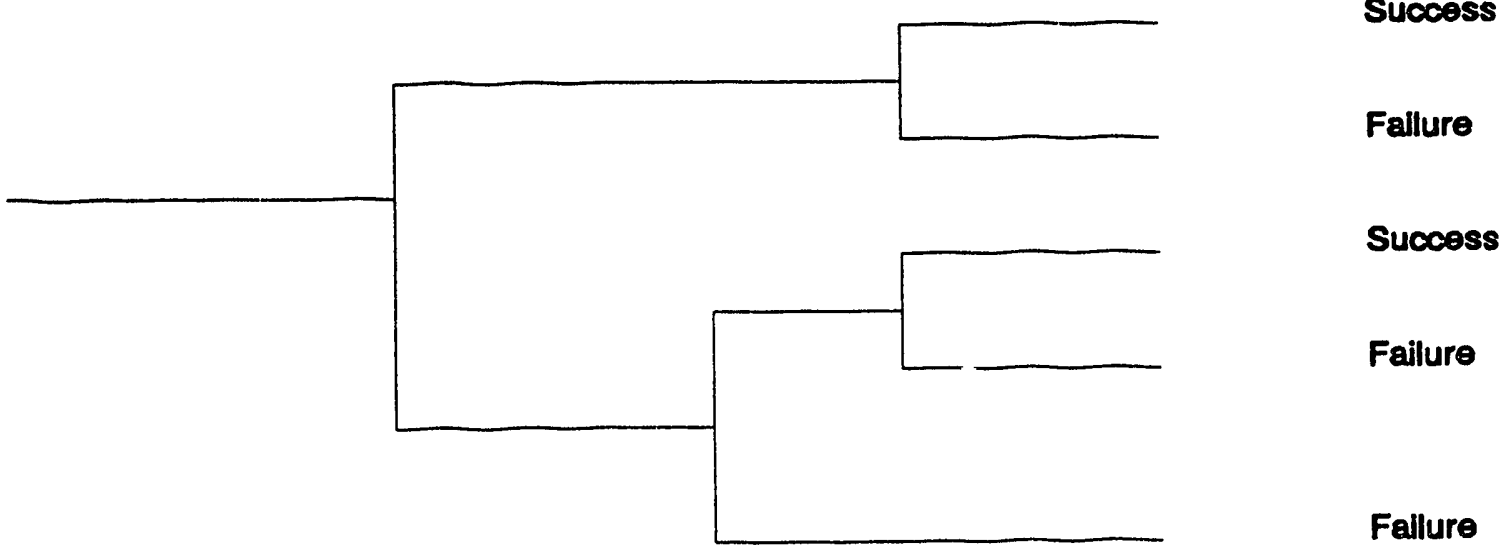

Figure 3.3 Sample event tree

Development of Failure Information. For each system identified in the event tree, a fault tree was developed to determine the system vulnerabilities. The fauit trees were developed to differing levels of detail depending on whether failures were being developed for a frontline or support system. The design infor.sation generally allowed fault trees to be developed to the component level for the frontline systems but only to the system (essential cooling water) or subsystem level (train A of the essential cooling water) for support systems. Thus, the fault trees include the following: (1) active component failures of frontline systems; (2) passive component failures of frontline systems; (3) operator error of frontline systems (operations and maintenance); and (4) system level failures of support functions. This level of analysis was acceptable because at this point in the conceptual design, primary interest is in the identification of potential common-mode and dependent failure mechanisms within the support systems. These were identified through the combined use of the fault trees and the system dependency matrix.

The fault trees for each system were solved to determine the 1,2 , and 3 failure combinations (cut sets) associated with that system function. Cut sets are those combinations of failures that result in failure of the system function; for a given system, this means the failure of the system to perform its mitigation function. One-event cut sets identify those instances where a single active component failure or operator action failure can fail the system function. Twoand three-event cut sets, likewise, identify dual and triple independent failures that result in system function failure. This was accomplished using the Integrated Reliability and Risk Analysis System (IRRAS) code. ${ }^{1}$ This cut set information was then used for identification of design issues associated with each system. For example, the CANDU 3 special safety systems SDS1, SDS2, and the ECCS are required to be tolerant of a single operator failure or the failure of a single active component. Thus, any one-event cut sets for these systems identify areas where additional information or further attention is warranted. (If quantitative failure data are available, the cut sets also identify the failures that are most probable, and this also can highlight areas that may merit further attention.)

The event trees were then solved using the fault tree solutions, and sequence level failure combinations were generated. This information identified the system failure combinations that could contribute to a particular failure sequence in the event tree. This information along with the IE frequency was used to classify the event sequences.

Development of Support Data and Evaluation of Common-Mode Effects. To track the dependencies between frontline and support systems and between support systems themselves, a system dependency matrix was developed. The system dependency matrix (see Chap. 6) was developed to identify support systems whose failure could affect the operation of a frontline system and to identify any dependencies among the support systems themselves. Normally, this matrix is developed to the detail necessary to identify very specific information regarding the many dependencies within the plant. However, the design detail available at the conceptual stage is not sufficient to fully develop such a high level of dependency 


\section{Description}

information. Consequently, the results reflect the available level of detail. Because the design is conceptual and will likely undergo change, data base tools were developed to assist the NRC in tracking these changes and aid in the identification of their impacts on the plant. ${ }^{2}$

Evaluation of Sequence Information. The sequence information resulting from solution of the event trees was evaluated to (1) classify each sequence, (2) identify the systems significant-to-safety, and (3) identify key operator actions. Each sequence in the event tree was evaluated to determine its event category as a function of its IE (from the $\mathrm{IE}$ table) and the type and number of failures in the sequence (from the event tree solution). The four possible event categories are designated as EC-I, EC-II, EC-III, and EC-IV. These event categories were defined by NRC to help identify scenarios to be analyzed by the applicant for design certification:

- The EC-I category was defined to include scenarios that might occur at least once in the lifetime of a given plant. Scenarios similar to those in this category might be selected by NRC as Anticipated Operational Occurrences for analysis by the applicant.

- The EC-II category was defined to include lowfrequency initiators and single component or operator failures. These scenarios might occur once in the lifetime of a class of plants. Some of these scenarios might later be selected as Design-Basis Accidents for analysis by the applicant.

- The EC-III category was defined to include very-lowprobability scenarios, some with multiple failures, which would be typical of "Severe Accidents." Such scenarios might be analyzed in PRAs to determine licensing source terms and to assess containment capabilities.

- The EC-IV category was defined to include scenarios with such low probabilities that detailed analysis would probably not be worthwhile. These are sometimes referred to as Residual Risk scenarios.

The criteria for categorizing a particular sequence is provided in Table 3.1. A logic diagram for the categorization process is shown in Fig. 3.4(a-c). As indicated in Fig. 3.4, each categorization bin is individually identified. This classification method is used in Appendix $C$ when classifying the event tree sequences.

Although this methodology produces qualitative results, it has a basis in quantitative analysis. This method is discussed further in Appendix D where some limited quantification is done to confirm these qualitative results.
Systems significant-to-safety were identified using the ESDs and the System Dependency Matrix. As used in this report "systems significunt-to-safety" identifies those systems that can have a significant impact on the successful response of the plant to an IE. Thus the term is related to, but does not mean, "safety related" as defined in the Canadian design (i.e., a Group 2 system) or "safetygrade" as applied in U. S. designs. Commercial U.S. operating experience demonstrates that nonsafety-related equipment is sometimes required to successfully mitigate an IE. Thus, in the context of this definition of significantto-safety, safety-related equipment is a subset of systems significant-to-safety.

The CANDU 3 design has two general categorizations of systems with respect to their safety functions. "Group 1" systems are those process systems and components required for the production of electrical power while the plant is in its normal operating mode. "Group 2" systems and components are required in the event of serious process system failures. As such, Group 2 systems must ensure that all safety functions required to mitigate a serious process system failure are accomplished. However, it is recognized that Group 1 systems have been qualified to perform one or more "safety-related" functions, where safety-related has a particular meaning within the Canadian design philosophy. ${ }^{3}$ These safety-related functions are usually defined for very specific conditions or accidents. This report is not intended to provide an evaluation of the CANDU 3 design vs U.S. criteria for safety-related functions. Consequently, systems and components will be designated as either Group 1 or Group 2.

These are the criteria used in this report for judging whether a system is classified as significant-to-safety:

\section{Candidate Systems Criteria:}

1. Only those systems or components that contribute to successful termination (primary and backup paths) of an $\mathrm{IE}$ are considered candidates for being designated significant-to-safety. Successful termination is defined as resulting in plant end states $\mathrm{CC}-1$ and CC-2. Systems on pathways leading to plant end state CC-3 are not considered as being significant-to-safety, although such systems could be considered candidates for severe accident management actions.

2. All Group 1 systems or components on paths terminating in plant end states $\mathrm{CC}-1$ and $\mathrm{CC}-2$ are considered candidates for being designated significantto-safety. This included frontline systems and their support systems. 
Table 3.1 Criteria for categorization of event sequences

\begin{tabular}{|c|c|}
\hline Event category & Criteria \\
\hline EC-I & $\begin{array}{c}\text { IE frequency } \mathrm{P}_{\mathrm{IE}} \geq 10^{-2} \\
\text { Plus no failures (Bin A) } \\
\text { or } \\
1 \text { single active component failure (Bin B) } \\
\text { or } \\
1 \text { operator error (Bin B) }\end{array}$ \\
\hline EC-II & $\begin{array}{c}\text { IE frequency } 10^{-2}>P_{\mathrm{IE}} \geq 10^{-4} \\
\text { Plus no failures (Bin E) } \\
\text { or } \\
1 \text { single active component failure (Bin F) } \\
\text { or } \\
1 \text { operator error }(\operatorname{Bin} F)\end{array}$ \\
\hline EC-III & $\begin{array}{l}\text { IE frequency } P_{\mathrm{IE}} \geq 10^{-4} \\
\text { Plus } 1 \text { system failure }(\mathrm{Bin} C, \mathrm{G})^{a} \\
\text { or } \\
2 \text { single active component failures }(\mathrm{Bin} C, \mathrm{G})^{a} \\
\text { or } \\
2 \text { operator errors }(\mathrm{Bin} \mathrm{C}, \mathrm{G})^{a} \\
\text { or } \\
2 \text { combination failures }(\mathrm{Bin} C, \mathrm{G})^{a} \\
\text { or } \\
1 \text { common-mode failure }(\mathrm{Bin} \mathrm{C}, \mathrm{G})^{a}\end{array}$ \\
\hline & $\begin{array}{c}\text { OR } \\
\text { IE frequency } 10^{-4}>\mathrm{P}_{\mathrm{IE}} \geq 10^{-7} \\
\text { Plus no failures (Bin } \mathrm{I}) \\
\text { or } \\
1 \text { single active component failure (Bin } \mathrm{J}) \\
\text { or } \\
1 \text { operator error }(\operatorname{Bin} \mathrm{J})\end{array}$ \\
\hline EC-IV & $\begin{array}{l}\text { All other sequences } \\
\text { (Bins } \mathrm{D}, \mathrm{H}, \mathrm{K}, \mathrm{L}, \mathrm{M} \text { ) }\end{array}$ \\
\hline
\end{tabular}

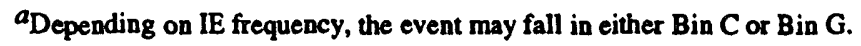

3. All Group 2 systems on paths terminating in plant end states CC-1 and CC-2 are designated as significant-tosafety.

\section{Criteria for Systems Significant to Safety:}

1. Any Group 1 candidate system or component whose function is not backed up will be designated as being significant-to-safety. For the purposes of selecting systems significant-to-safety, the term backup here will be restricted to its use only where the backup system leads to the equivalent plant end state as the original system.
2. If any Group 1 candidate system or component has only Group 1 backup, the candidate system or component will be designated as significant-to-safety. The backup will not.

3. If a Group 2 candidate system is backed up by a Group 1 system, the Group 1 backup will not be designated as significant-to-safety.

4. Any Group 1 candidate system or component with at least one Group 2 backup will not be designated as significant-to-safety. 


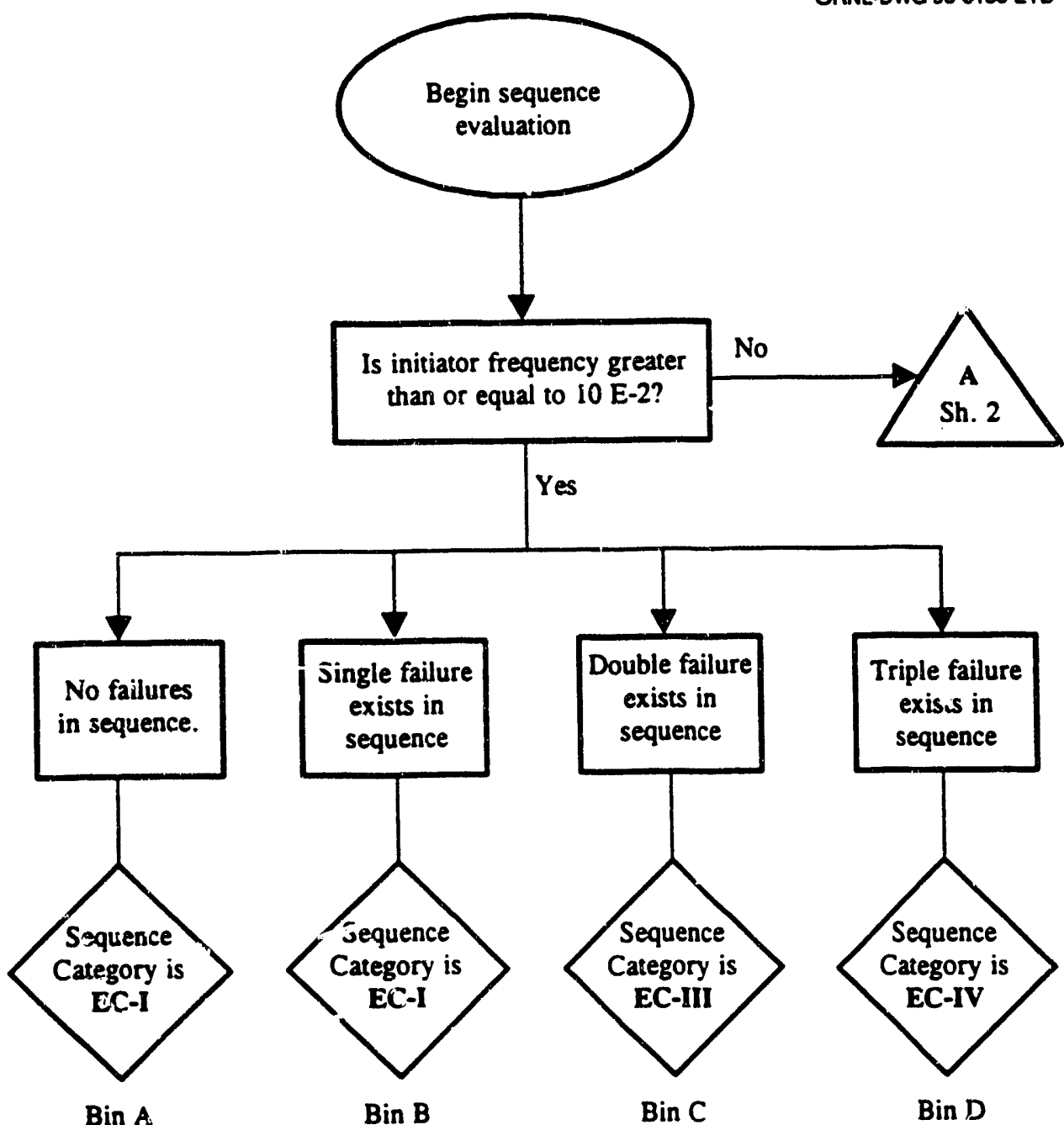

NOTES:

Single failure denotes 1 singie uctive component failure or 1 operator failure.

Double failure denotes 1 system failure or 2 component failures or 2 operator failures or combisaticn cumponent/operator failures or 1 comunon mode failure.

(a) Triple failure finotes multiple failures which excesd the criteria for Double Failure.

Figure 3.4 Logic diagram for sequence classification 


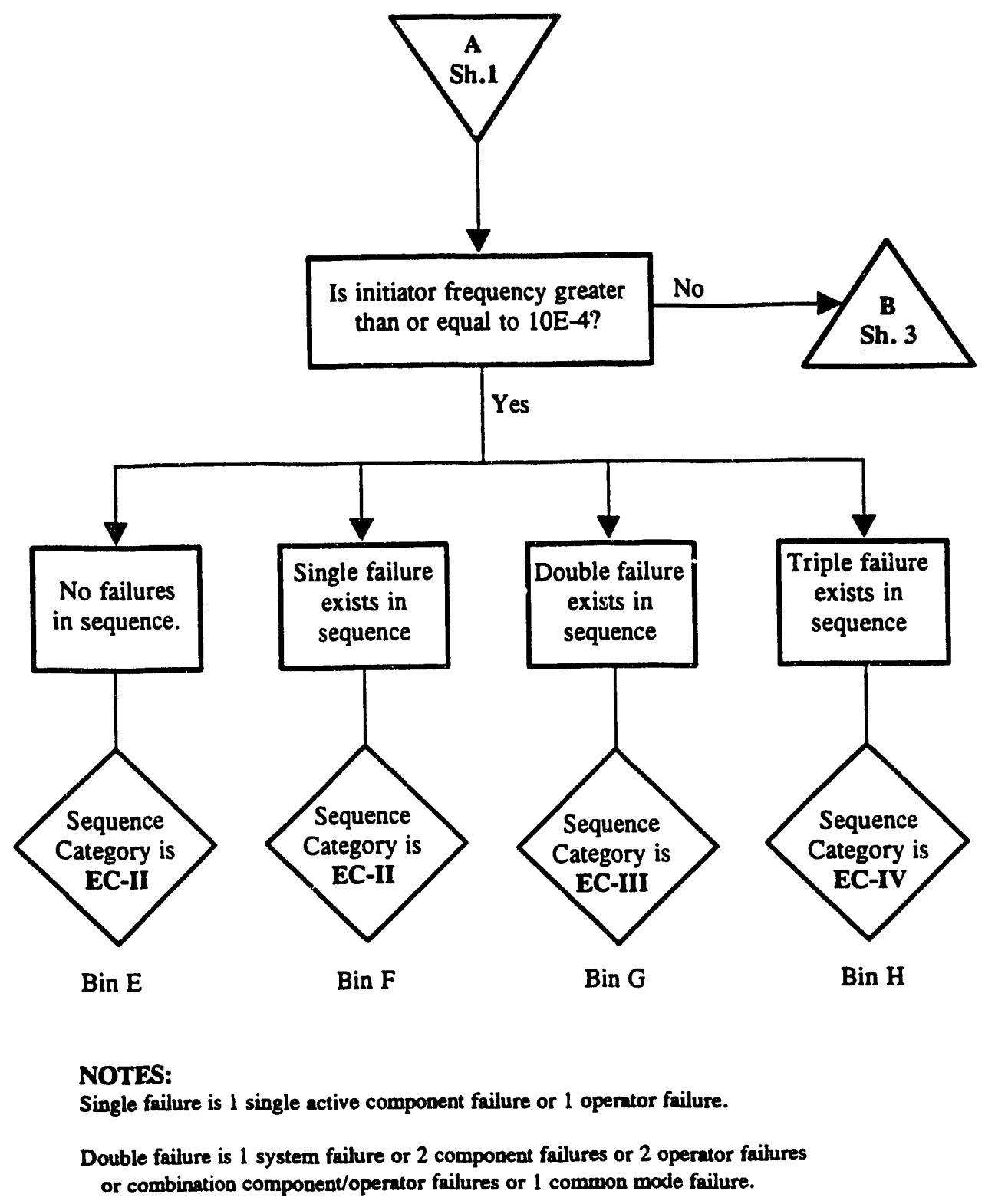

(b) Triple failure is multiple failures which exceed the criteria for Double Failure.

Figure 3.4 (continued) 


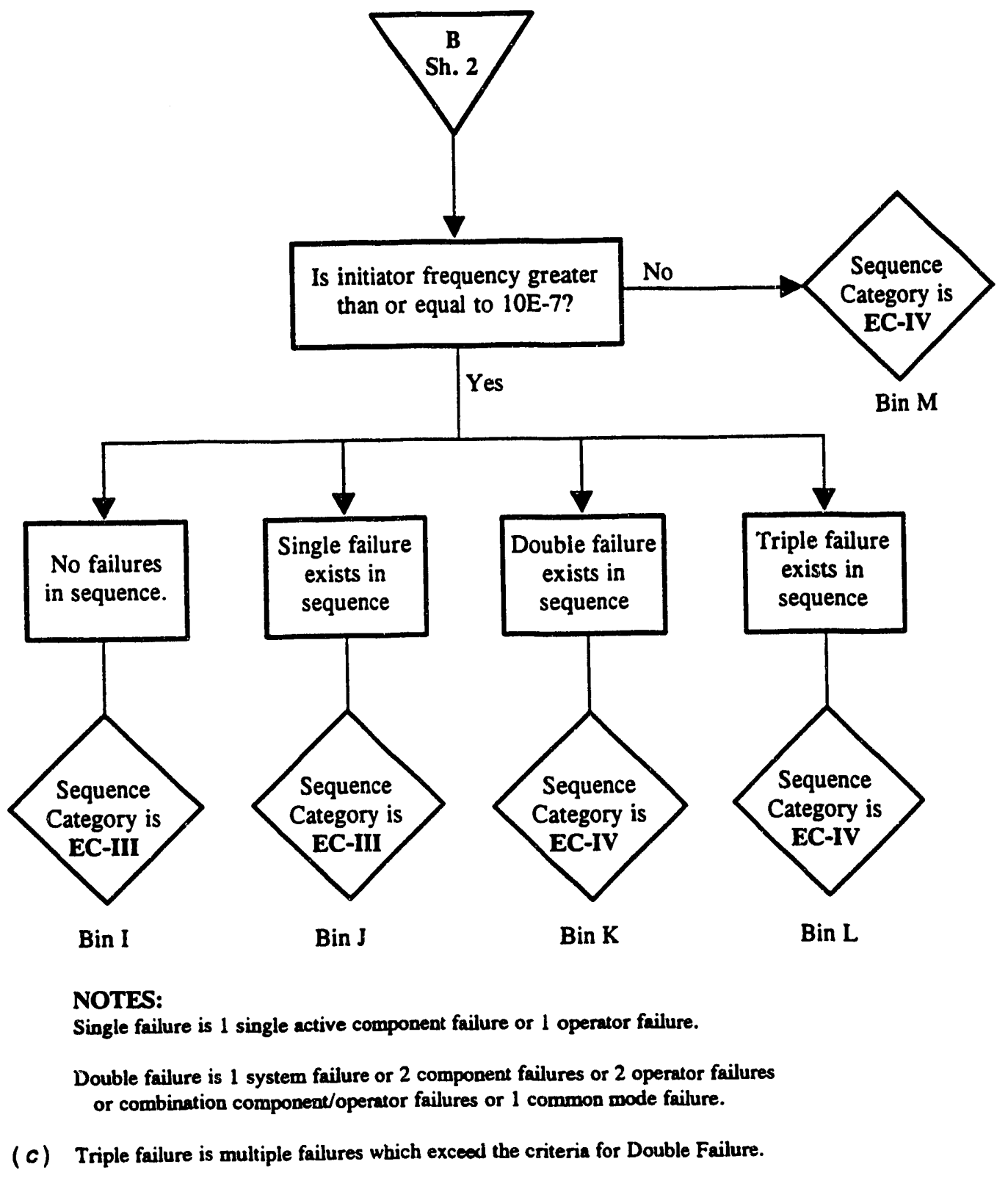

Figure 3.4 (continued) 


\section{References}

1. K. D. Russell et al., Idaho National Engineering Laboratory, "Integrated Reliability and Risk Analysis System," USNRC Report NUREG/CR-5813, ID-83415, January 1992."

2. M. E. Chandler, Martin Marietta Energy Systems, Inc., Oak Ridge Natl. Lab., "Guide to Reading and
Updating the Electrical Dependency Database Generated for the CANDU 3 Nuclear Reactor," ORNL/TM-12178, August 1992.

3. Atomic Energy of Canada, Limited, "CANDU 3 Conceptual Safety Report," Vol. 1, Appendix D1 1989..$^{\dagger}$

Available for purchase from the National Technical Information Service, Springfield, VA 22161.

$t_{\text {Available in NRC PDR for inspection and copying for a fee. }}$ 


\section{Selection of Initiating Events}

\subsection{Classification of Initiating Events}

For this work IEs were developed primarily using existing U.S. LWR PRA and Safety Analysis Report (SAR) experience and CANDU safety analyses along with engineering judgment based on the available conceptual design information for the CANDU 3 design. A rigorous analysis identifying potential initiators for this design had been provided in the CANDU documentation. The CANDU information was used extensively to identify IEs for this project. The approach used here was sufficient to obtain a broad-based understanding of potential IEs applicable to the CANDU 3 plant.

\subsubsection{Master Logic Diagram}

An MLD was developed to show the conditions necessary for off-site releases to occur. The MLD presented in Fig. 4.1 shows that the undesired event (off-site release) can result either from a release from a subsystem outside containment (e.g., fuel handling operations) or as a result of core damage concurrent with containment failure or excessive leakage. The ten conditions shown in the MLD as having the potential for leading to core damage are the PRCs identified for CANDU 3. Table 4.1 provides an explanation of each PRC.

\subsubsection{Initiating Events}

Several sources were considered to develop a comprehensive list of IEs for this analysis. These sources include analyses of commercial LWR and research reactor experience, ${ }^{*}$ NRC standards, ${ }^{1}$ NRC Safety Review Plans, ${ }^{2}$ and existing CANDU reactor analyses. ${ }^{\dagger}, \ddagger$ In addition, a limited operating history of CANDU plants and other AECLdesigned plants was reviewed for initiators that have occurred or events that may be precursors to possible IEs. The list was also supplemented with engineering judgment of ORNL personnel familiar with the CANDU 3 design. This was to help identify initiators not identified from other sources and to give credence to those taken from other sources, particularly those not specifically related to CANDU reactors.

\footnotetext{
"D. H. Johnson et al., Martin Marietta Energy Systems, lnc., Oak Ridge Natl. Lab., "High Flux Isotope Reactor Probabilistic Risk Assessment," ORNL/RRD/NT-36/R1/N1, August 1991.

†P. J. Allen et al., Atomic Energy of Canada Limited, “CANDU 3 External Analysis Report, Conceptual Probabilistic Safety Assessment," 74-03660-AR-001, Rev. 0, February 28, 1989.

$\ddagger_{R}$. K. Jaitly et al., Atomic Energy of Canada Limited, "CANDU 3 Systematic Review of the Plant Design for Identification of Initiating Events," 74-00580-ASD-001, Rev. 2. April 10, 1992.
}

Each potential initiator was evaluated to determine the plant response to that initiator. Events for which the plant response is similar (i.e., the same systems respond to mitigate the event) were grouped into the same PRC. Some of the events reviewed were not applicable to the CANDU 3 design and, therefore, were not included. Grouping of the events into PRCs was done so that events could be evaluated concurrently as a group rather than repeating the evaluation for every IE separately. The initiators within each PRC were assumed to occur with the reactor operating at full power. A frequency for each initiator was assigned based on available data and engineering judgment. If frequency information was available and the sources of that information were judged to be applicable to the CANDU 3, the frequency value was used. If frequency information was not readily available, a frequency was derived using conservative screening values for the initiating failures. The following screening values were used:
- mechanical active failure
$10^{-2}$
- mechanical passive failure
$10^{-3}$
- system failure (group 2 system)
$10^{-3}$
- system failure (nongroup 2 system)
$10^{-2}$
- human error (nonroutine)
$10^{-1}$
- human error (routine)
$10^{-2}$

The frequencies assigned were order-of-magnitude values because of the preliminary nature of the plant design. This IE is presented in Table 4.2 along with the reference sources for each event and its frequency.

The CANDU 3 plant has many design features that are similar to light-water PWRs (LWPWRs). For this reason, it was prudent to use existing PWR information as a source for identifying IEs for CANDU 3 . The categorization of IEs for PWR risk assessments was used as a starting guideline for grouping the CANDU IEs into PRCs. However, some additional categories were also identified because of the design differences between the CANDU 3 and LWPWRs, or events were moved between categories because of differences in the plant response between the PWR design and the CANDU 3. In some cases, there are additional aspects to consider regarding the consequences of some initiators within a category. For example, a steamline break initiator can cause overcooling of the reactor core; however, in the CANDU 3 design, a break within containment may have greater significance as a challenge to the containment. In such cases, the event was placed into the category that was judged to best represent the event. 


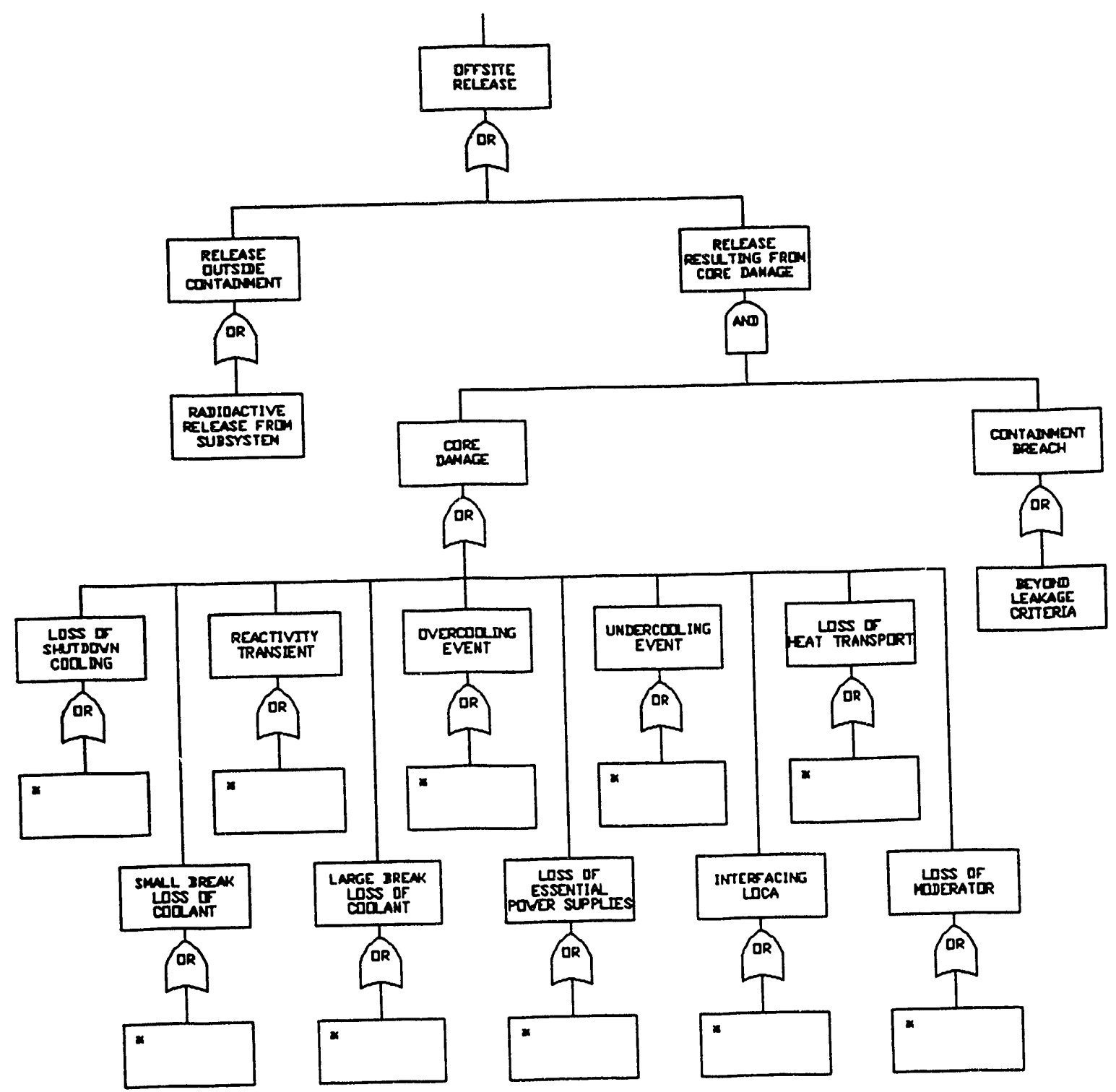

"REPER TO INTTATING EVENTS LIST DN TABLE 4.2

Figure 4.1 CANDU 3 MLD

\subsection{Selection of Representative Initiating Events}

Two of the major goals of this study were the classification of accident sequences and the identification of systems, structures, and components significant to safety. Because there is a limited number of unique plant responses (i.e., components and systems available to respond to an event), not all of the PRCs need be evaluated to achieve these goals. The PRCs chosen are expected to (1) exhibit similar plant responses as other categories and (2) show the safety significance of the respective systems, structures, and components.

The PRCs chosen for further analysis included: (1) LargeBreak Loss-of-Coolant (LBLOCA), (2) Small-Break Lossof-Coolant (SBLOCA), (3) Loss of Essential Power Supplies, (4) Undercooling Event, and (5) Reactivity Transient. The remaining PRCs represent plant responses 
Table 4.1 Explanation of PRCs

\begin{tabular}{|c|c|}
\hline PRC & Explanation \\
\hline Loss of Shutdown Cooling & $\begin{array}{l}\text { Shutdown cooling system fails to remove the decay heat following successful } \\
\text { shutdown of the reactor }\end{array}$ \\
\hline Reactivity Transient & Events associated with the reactor core that adversely affect reactor power \\
\hline Overcooling Event & Events that result in an increase in heat removal by the secondary system \\
\hline Undercooling Event & $\begin{array}{l}\text { Events that result in a decrease or loss of heat removal by the secondary } \\
\text { system }\end{array}$ \\
\hline Loss of Heat Transport & Events that result in a decrease or loss of heat removal by the primary system \\
\hline $\begin{array}{l}\text { Small-Break Loss-of-Coolant } \\
\text { Accident }\end{array}$ & $\begin{array}{l}\text { Pipe breaks in heat transport system lines of diameter }<10 \mathrm{~cm} \text { or events that } \\
\text { result in an equivalent loss of inventory }\end{array}$ \\
\hline $\begin{array}{l}\text { Large-Break Loss-of-Coolent } \\
\text { Accident }\end{array}$ & $\begin{array}{l}\text { Pipe breaks in heat transport system lines of diameter }>10 \mathrm{~cm} \text { or events that } \\
\text { result in an equivalent loss of inventory }\end{array}$ \\
\hline Loss of Essential Power Supplies & Events that result in loss of power to plant equipment \\
\hline Interfacing LOCA & Boundary between the primary and secondary systems is breached \\
\hline Loss of Moderator Event & Events that result in a reactor transient due to a moderator anomaly \\
\hline
\end{tabular}

that are not expected to be unique from the five selected categories or that impose less demands on the plant systems. Consequently, they were considered to be adequately represented by the five selected categories and not further analyzed.

For each of the five selected categories, one or more RIEs were chosen for further analysis. The initiators were chosen based on an engineering judgement that the events would be the most demanding on the system functions. These representative events were selected based upon PRA experience and operational information of the CANDU plant and were judged to adequately address the remaining initiators. The seven RIEs selected for the chosen categories are presented in Table 4.3. Detailed plant analysis was conducted for these IEs. The representative event for each of the PRCs is given in the RIE column of Table 4.2. Table 4.4 presents the justification for the RIEs selected for each PRC.

\section{References}

1. R. A. Bari et al., Brookhaven National Laboratory, "Probabilistic Safety Analysis Procedures Guide," USNRC Report NUREG/CR-2815, Rev. 1, August 1985.

2. U. S. Nuclear Regulatory Commission, "Standard Review Plan," USNRC Report NUREG-0800, Rev. 2, July $1981{ }^{*}$

\footnotetext{
* Available for purchase from the National Technical Information Service, Springfield, VA 22161.
} 


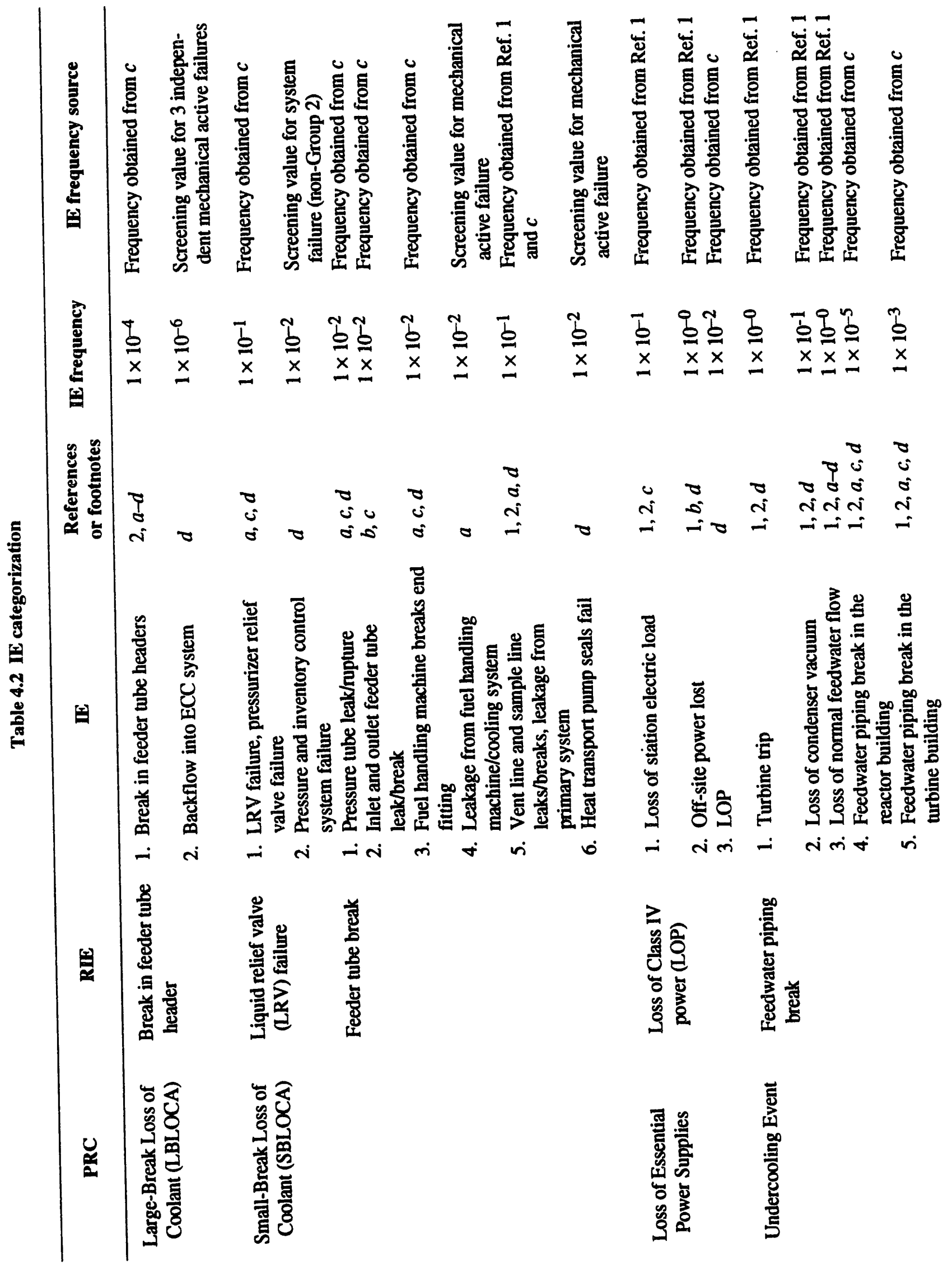




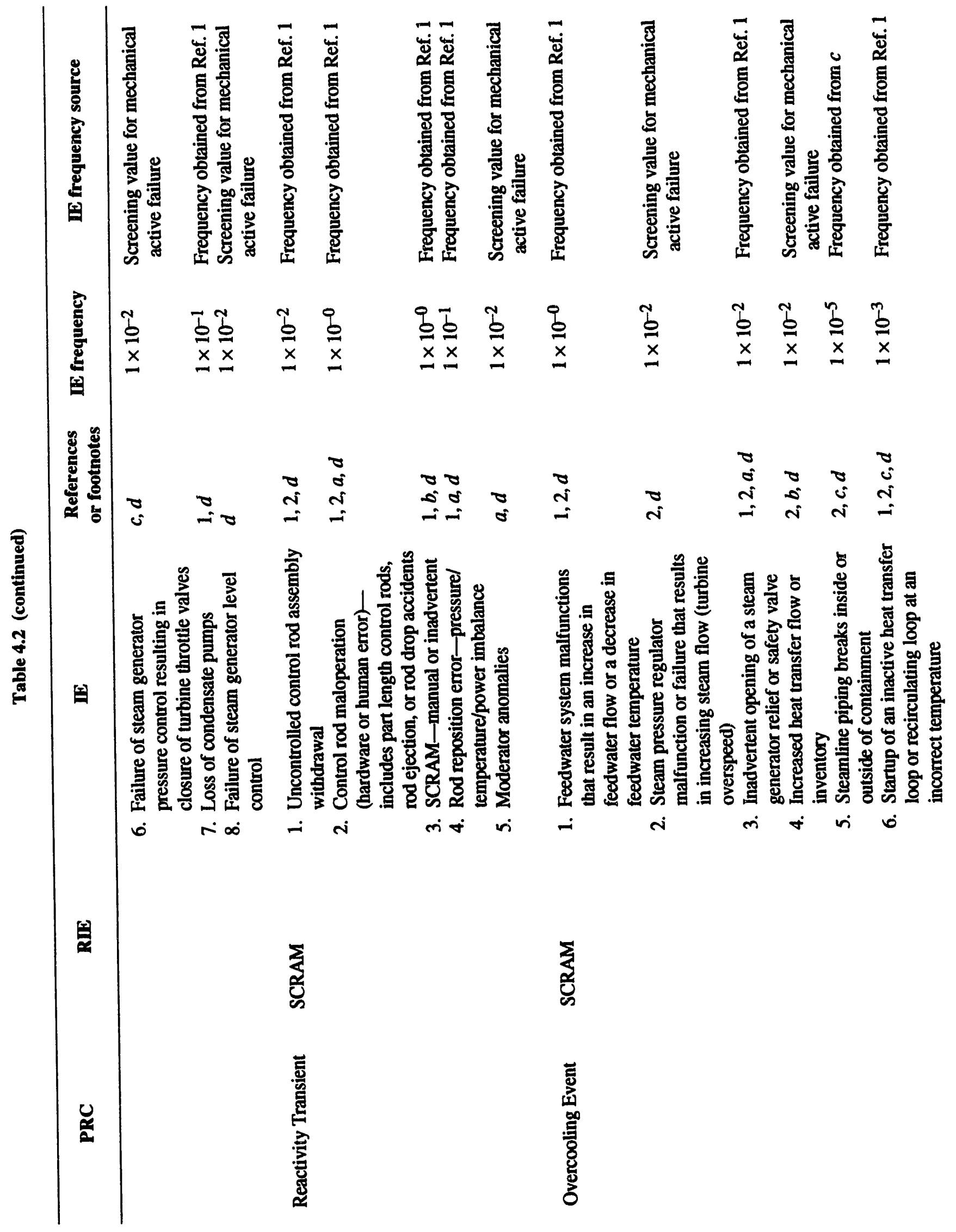




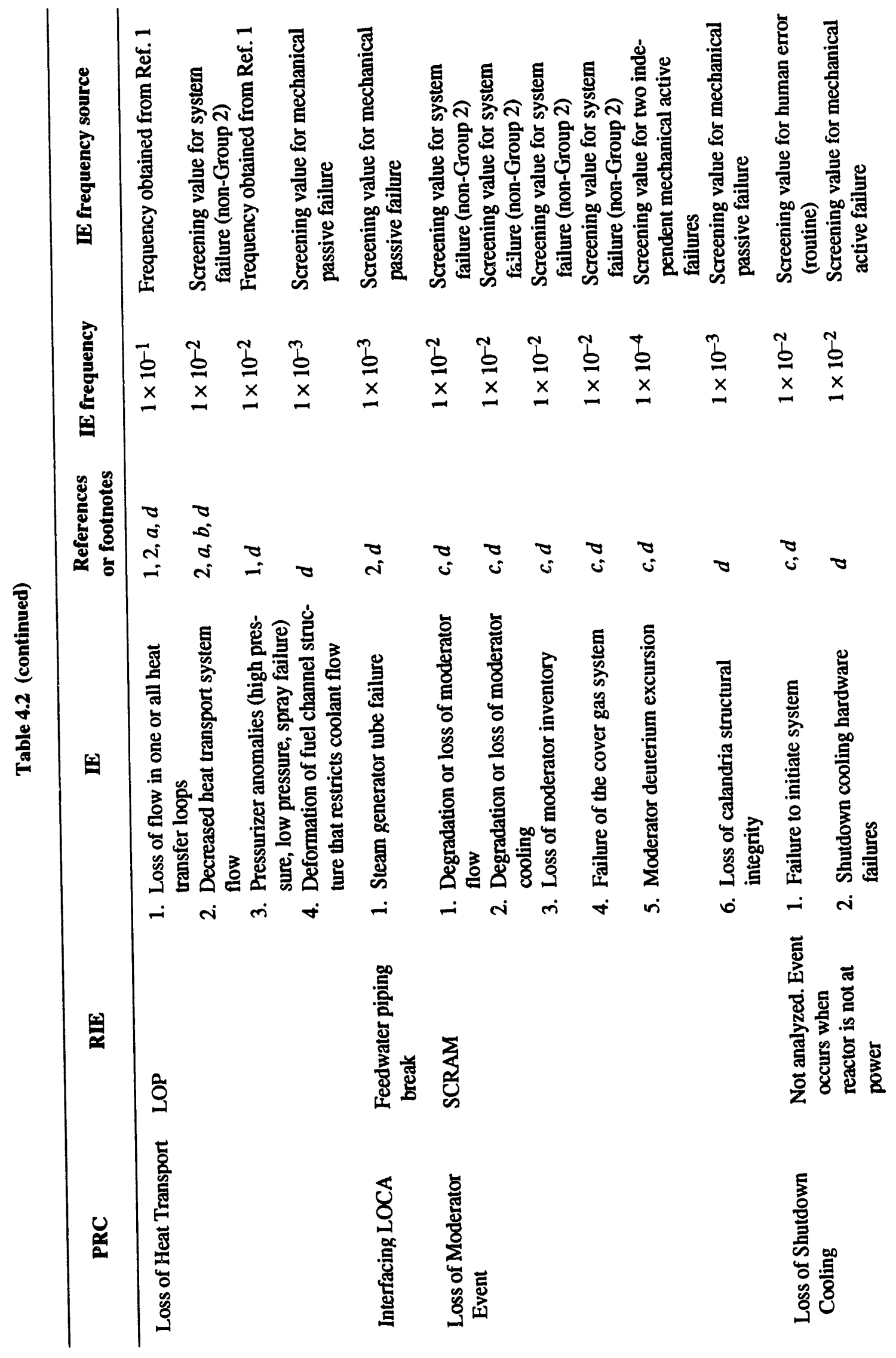


Selection

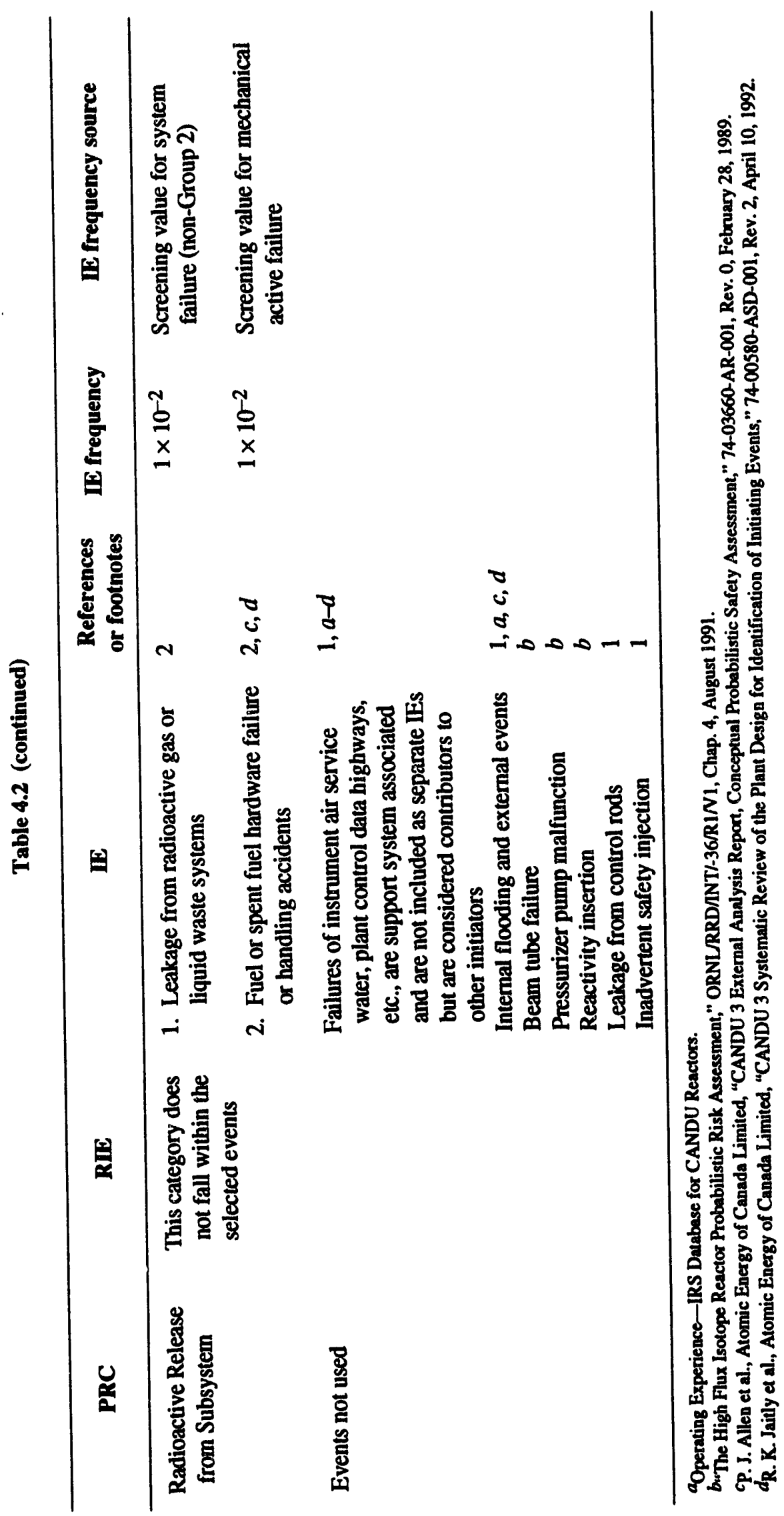


Table 4.3 RIEs chosen for plant analysis

\begin{tabular}{|c|c|}
\hline PRC & RIES \\
\hline LBLOCA & Break in feeder tube header \\
\hline SBLOCA & $\begin{array}{l}\text { Liquid relief valve failure } \\
\text { Pressure and inventory control } \\
\text { system failure }\end{array}$ \\
\hline $\begin{array}{l}\text { Loss of Essential Power } \\
\text { Supplies }\end{array}$ & $\begin{array}{l}\text { Loss of Class IV Power } \\
\text { (LOP) }\end{array}$ \\
\hline Undercooling Event & $\begin{array}{l}\text { Feedwater piping break in } \\
\text { reactor building } \\
\text { Feedwater piping break in } \\
\text { turbine building }\end{array}$ \\
\hline Reactivity Transient & SCRAM \\
\hline
\end{tabular}

Table 4.4 Justification for RIEs

\begin{tabular}{|c|c|c|}
\hline PRC & RIE & Justification \\
\hline LBLOCA & Break in feeder tube header & $\begin{array}{l}\text { Large volume of coolant inventory loss } \\
\text { Requires immediate ECCS response }\end{array}$ \\
\hline \multirow[t]{2}{*}{ SBLOCA } & Liquid relief valve failure & $\begin{array}{l}\text { Requires elements of other SBLOCAs such as crash cooling } \\
\text { Requires isolation of the bleed condenser } \\
\text { Reactor regulating system not credited for reactor shutdown }\end{array}$ \\
\hline & Feeder tube break & $\begin{array}{l}\text { Demonstrates plant response to a small loss of coolant that cannot } \\
\text { be isolated }\end{array}$ \\
\hline $\begin{array}{l}\text { Loss of Essential } \\
\text { Power Supplies }\end{array}$ & LOP & $\begin{array}{l}\text { Designed plant to feed power to itself upon loss of off-site power } \\
\text { or station load } \\
\text { Requires operation of diesel generators }\end{array}$ \\
\hline \multirow[t]{2}{*}{ Undercooling Event } & $\begin{array}{l}\text { Feedwater piping break in } \\
\text { reactor building }\end{array}$ & $\begin{array}{l}\text { Loss of coolant supply to the steam generators } \\
\text { Poses potential challenge to the containment } \\
\text { Poses a direct challenge to the Group } 2 \text { feedwater system }\end{array}$ \\
\hline & $\begin{array}{l}\text { Feedwater piping break in } \\
\text { turbine building }\end{array}$ & $\begin{array}{l}\text { Does not require the operator to isolate a draining boiler } \\
\text { Initiating frequency is estimated to be } 2 \text { orders of magnitude } \\
\text { greater than feedwater piping breaks in the reactor building }\end{array}$ \\
\hline Reactivity Transient & SCRAM & $\begin{array}{l}\text { Requires the reactor to be shut down } \\
\text { Other reactivity initiators result in a SCRAM-type event }\end{array}$ \\
\hline Overcooling Event & SCRAM & $\begin{array}{l}\text { Overcooling of the core not a direct concern except that it forces } \\
\text { the reactor to be shut down, which then closely follows a } \\
\text { SCRAM sequence }\end{array}$ \\
\hline Loss of Heat Transport & LOP & $\begin{array}{l}\text { The heat transport pumps trip on a LOP, resulting in loss of forced } \\
\text { flow through the core, which looks like a LOP event except that } \\
\text { loss of power implies that other equipment also is unavailable. } \\
\text { Simply stated, classifying this event as a LOP makes the analysis } \\
\text { of the event more conservative. }\end{array}$ \\
\hline Interfacing LOCA & Feedwater piping break & $\begin{array}{l}\text { Shutdown cooling system would initiate to bypass the steam } \\
\text { generators such as in a feedwater piping break }\end{array}$ \\
\hline $\begin{array}{l}\text { Loss of Moderator } \\
\text { Event }\end{array}$ & SCRAM & $\begin{array}{l}\text { Moderator anomaly would result in a reactivity transient, which } \\
\text { will result in reactor shutdown }\end{array}$ \\
\hline
\end{tabular}




\section{Systems Analysis}

\subsection{Fault Tree Analysis}

The RIEs selected for analysis (Table 4.3) were analyzed using event trees as discussed in Chap. 3. The event tree branch points represent success or failure of systems designed to mitigate the initiator. Fault trees were used to model these systems to demonstrate how failure of the systems could occur. Many of the same systems would be used to mitigate different IEs and, therefore, are present in more than one event tree. For this reason, the fault trees are treated separately in this chapter. In addition, fault trees allow system evaluations to help identify potential system vulnerabilities (see Appendix B). The plant analyses that utilize the fault trees will be presented in Chap. 6 .

Fourteen fault trees are presented and described in this chapter. (Information contained in the system descriptions was obtained from Ref. 1 unless indicated otherwise.) The fault trees will reflect failure of general mitigating functions intended to be performed by the systems. In some cases, the fault trees contain more than one system that could satisfy that function. For example, the feedwater system (FW) fault tree contains fault trees for the Group 1 feedwater system (FW1), Group 2 feedwater system (FW2), and the auxiliary feedwater system (AFW). In some accident scenarios any one of these three systems could satisfy the requirements for the FW needs, and therefore the FW fault tree would be employed at the event tree branch point calling for the FW function. In those cases where a specific system is needed, only the appropriate portion(s) of the fault tree would be called upon in the event. Table 5.1 summarizes the fault trees developed for each mitigating function. Multiple systems contained by a single fault tree are shown in this table.

\subsection{Systems Descriptions}

\subsubsection{Reactivity Shutdown Systems}

The three methods of reactor shutdown are the reactor regulating system (RRS), SDS1, and SDS2.

Figure 5.1 $(a)-(q)$ presents the fault tree for failure to shut down the reactor.

\subsubsection{Reactor Regulating System}

The RRS is an integrated system comprising reactor flux and thermal power measurements, reactivity control devices, and a set of distributed control system programs; all are coordinated to perform three main functions:

(1) monitor and control total reactor flux and power to satisfy the station load demands, (2) monitor and control

Table 5.1 CANDU 3 system fault trees

\begin{tabular}{lll}
\hline \multicolumn{1}{c}{ Mitigating function } & \multicolumn{1}{c}{ Fault tree } & \multicolumn{1}{c}{ Systems within fault tree } \\
\hline Reactivity Shutdown & Reactor Regulating System & $\begin{array}{l}\text { Reactor Regulating System } \\
\text { Shutdown System 1 } \\
\text { Shutdown System 2 }\end{array}$ \\
Heat Removal & Moderator Liquid Poison & $\begin{array}{l}\text { Group 1 Feedwater } \\
\text { Group 2 Feedwater } \\
\text { Auxiliary Feedwater }\end{array}$ \\
& Feedwater & Condenser Steam Discharge Valves \\
& Heat Transport System & Atmospheric Steam Discharge Valves \\
& Steam Discharge & \\
& Shutdown Cooling System & High-Pressure Injection \\
Inventory Control & Eoderator Cooling System & Low-Pressure Injection \\
& Bleed Condenser System & \\
& Isolate Steam Generator & \\
Liquid Relief Valve Closure & \\
Pressure Control & Crash Cooling & \\
On-site Power & Main Steam Safety Valves & \\
\hline
\end{tabular}




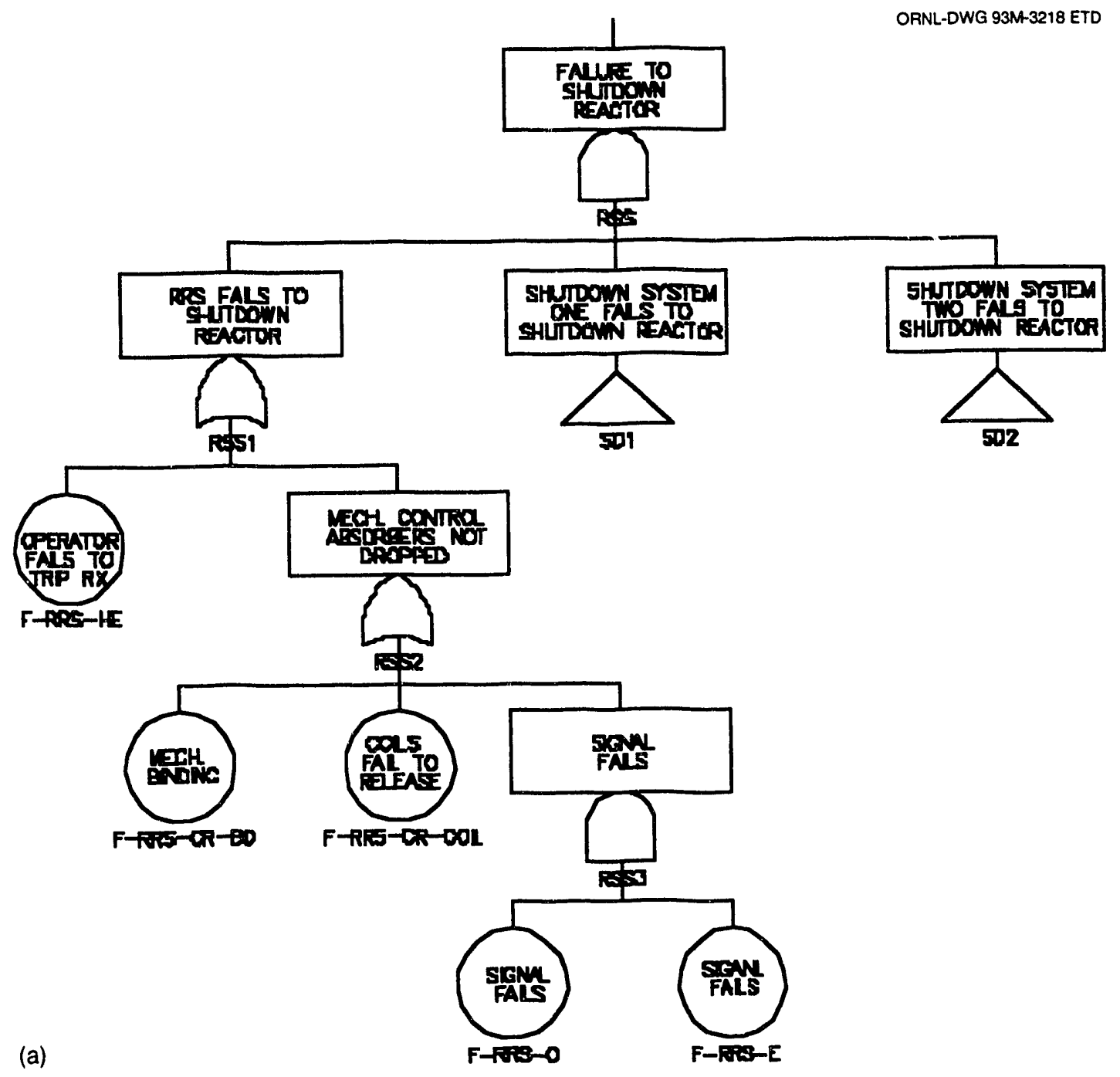

Figure 5.1 Reactor shutdown systems fault tree 


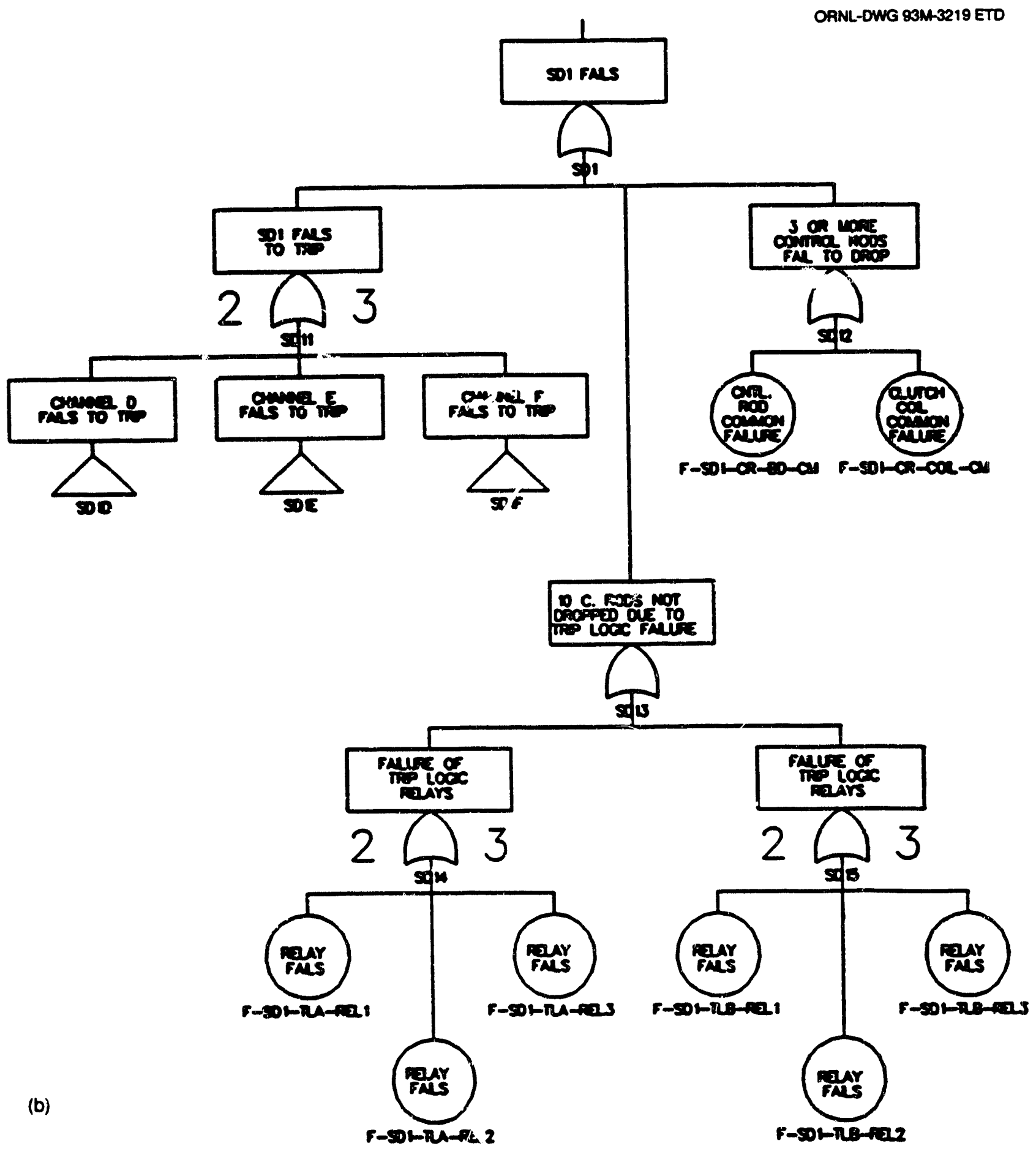

Figure 5.1 (continued) 

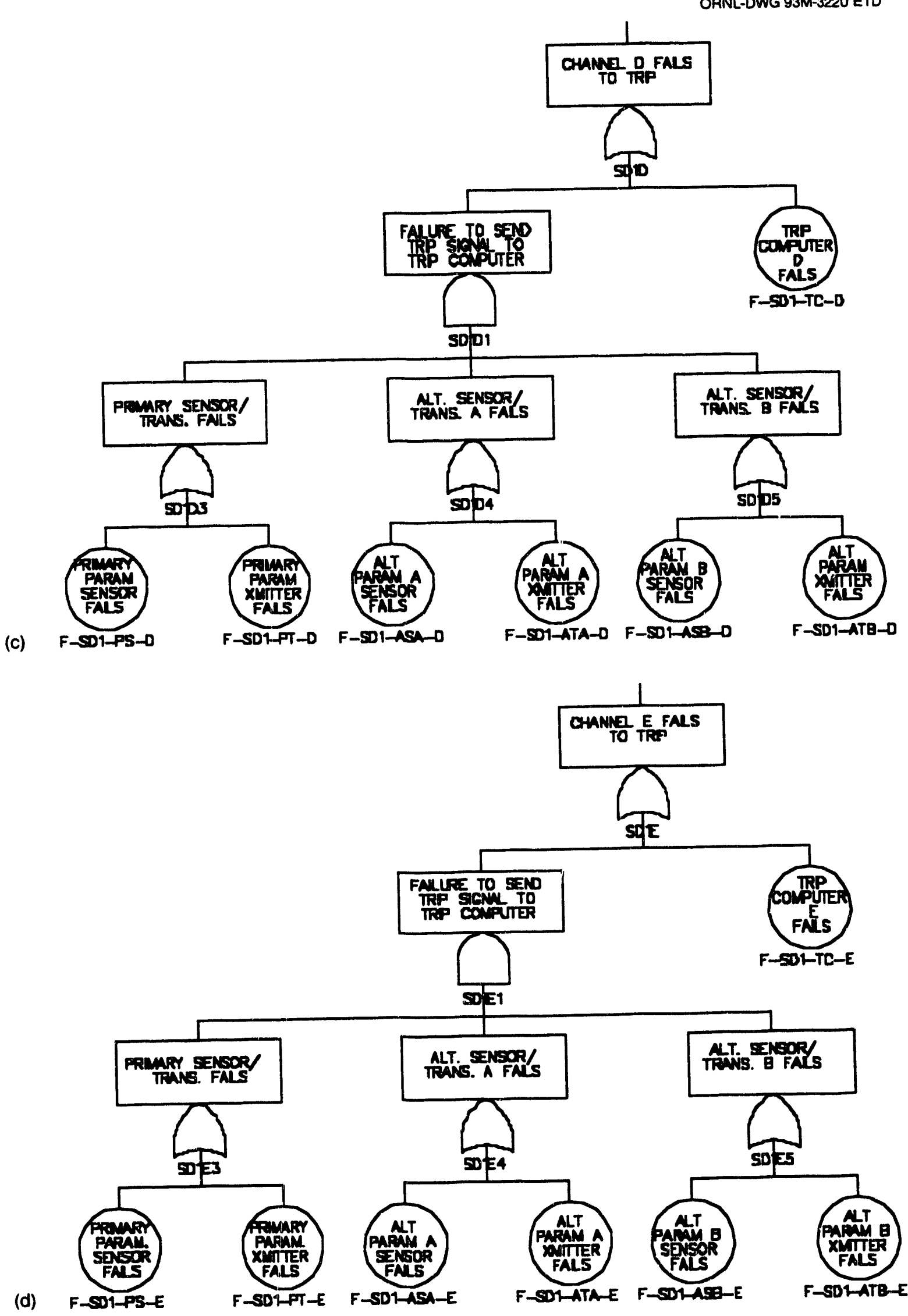

Figure 5.1 (continwed) 


\section{CHANIE F FALS}

TO TRP
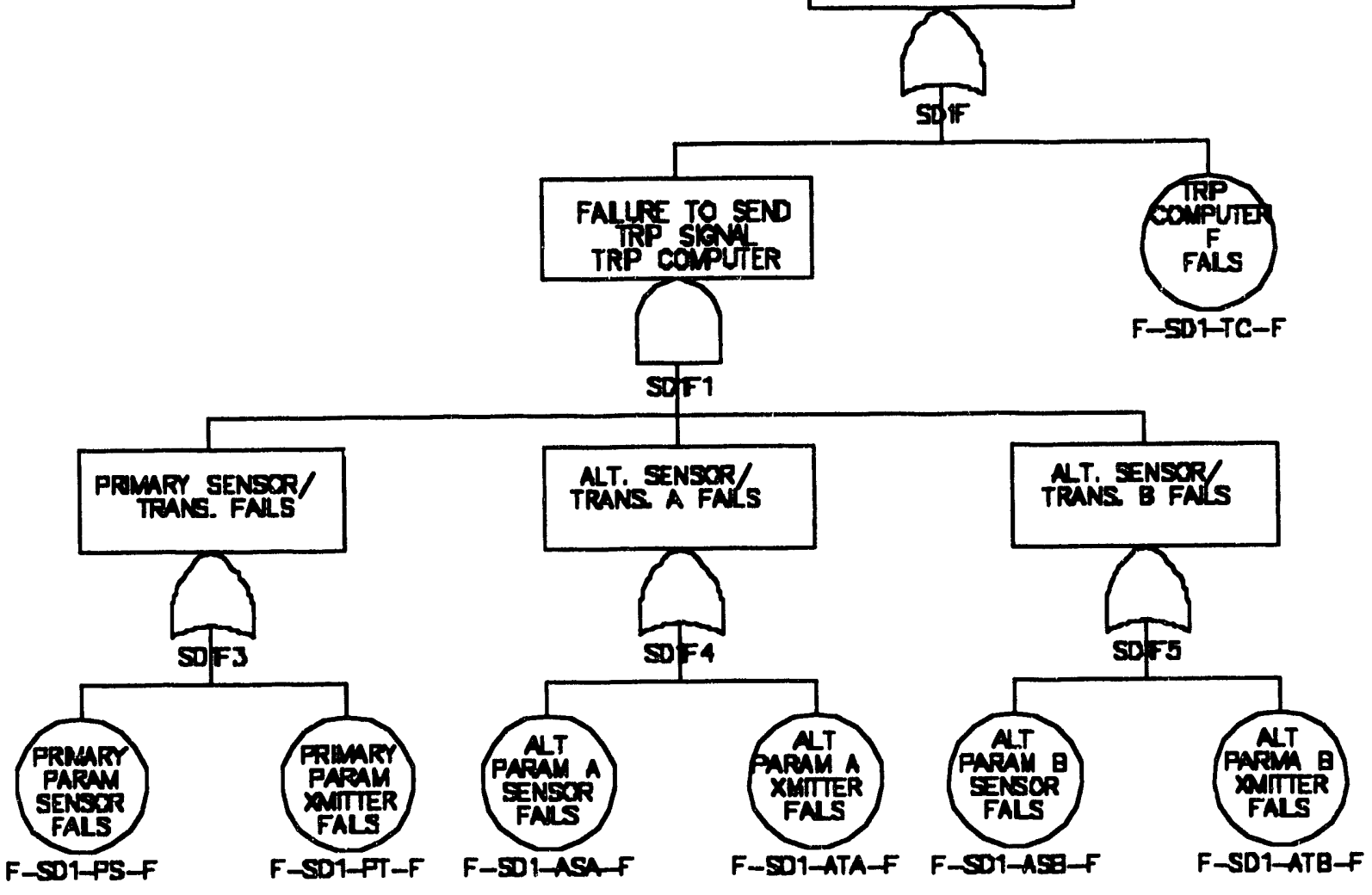

(e) F-SO1-PS-F

F-S01-TT-F F-501-ASA-F

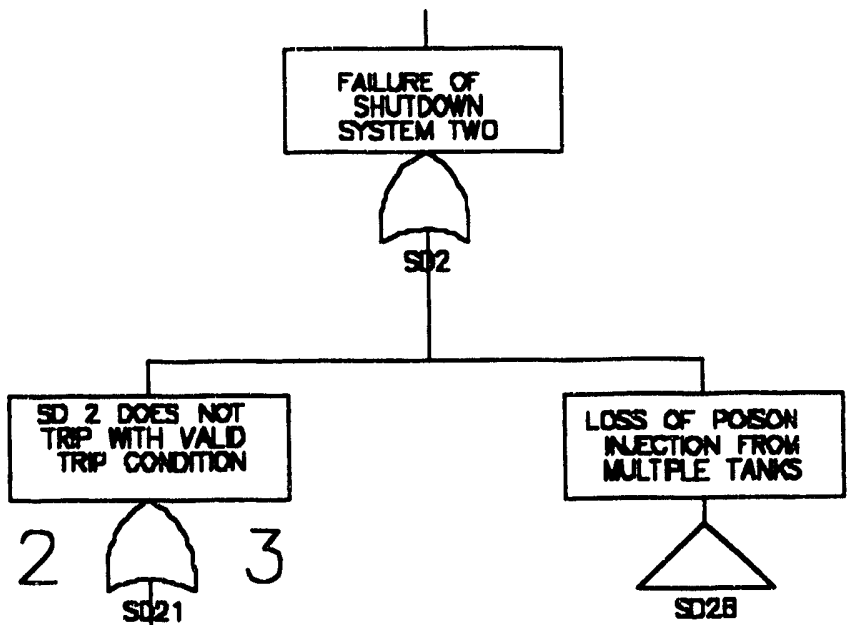

(f)
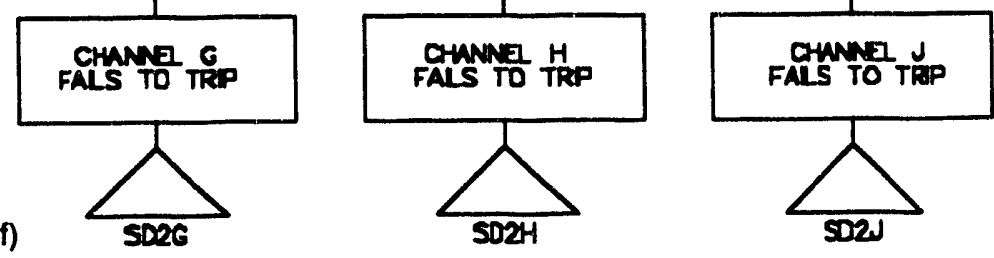

Figure 5.1 (continued) 

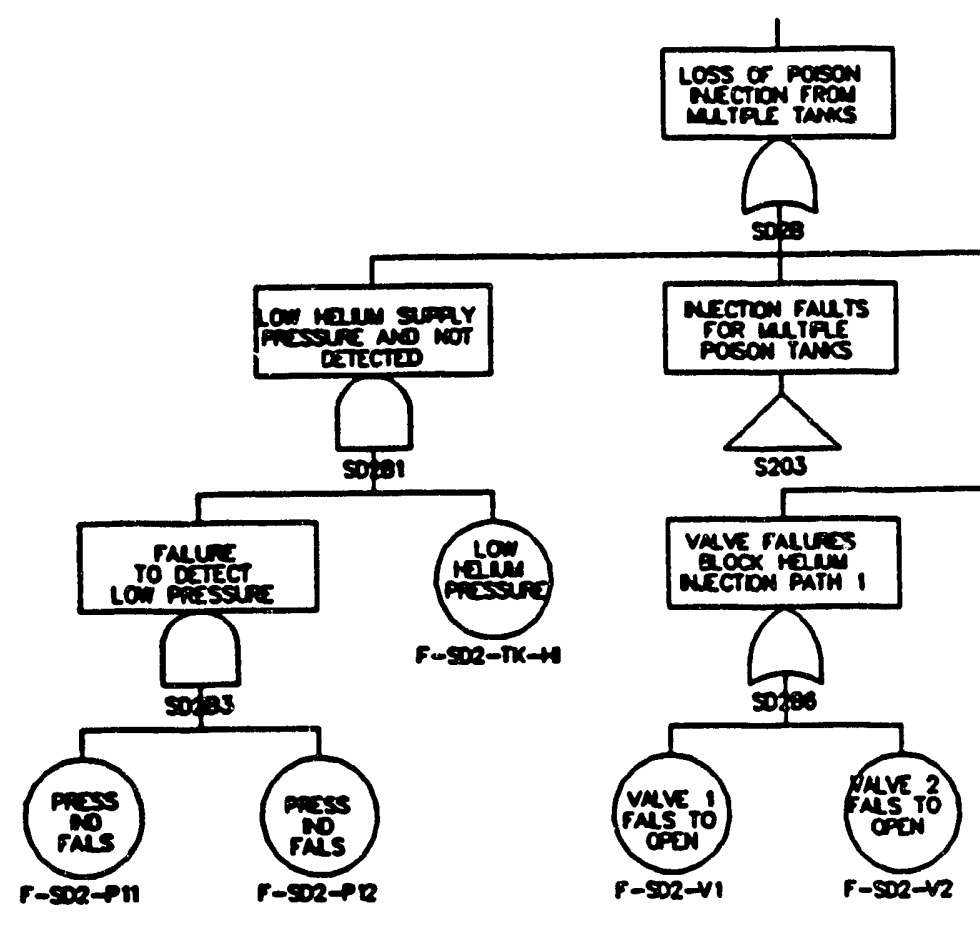

ORNL-DWG 93M-3222 ETD

(g)

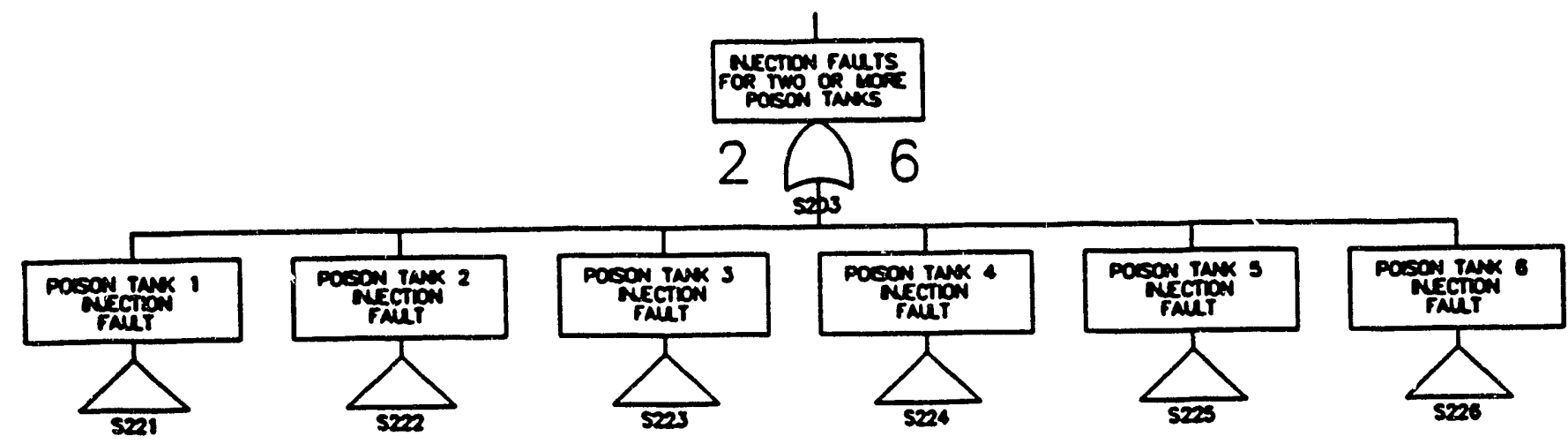

(h)

Figure 5.1 (continued) 

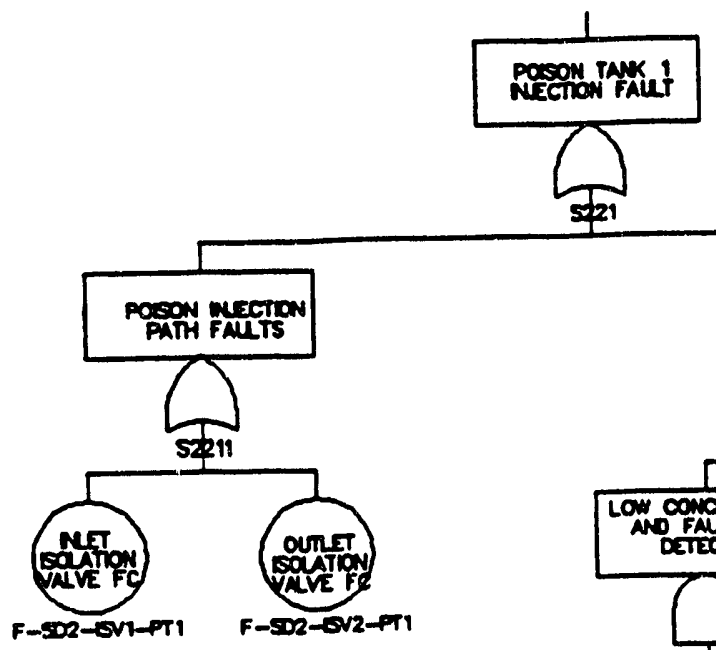

(i)
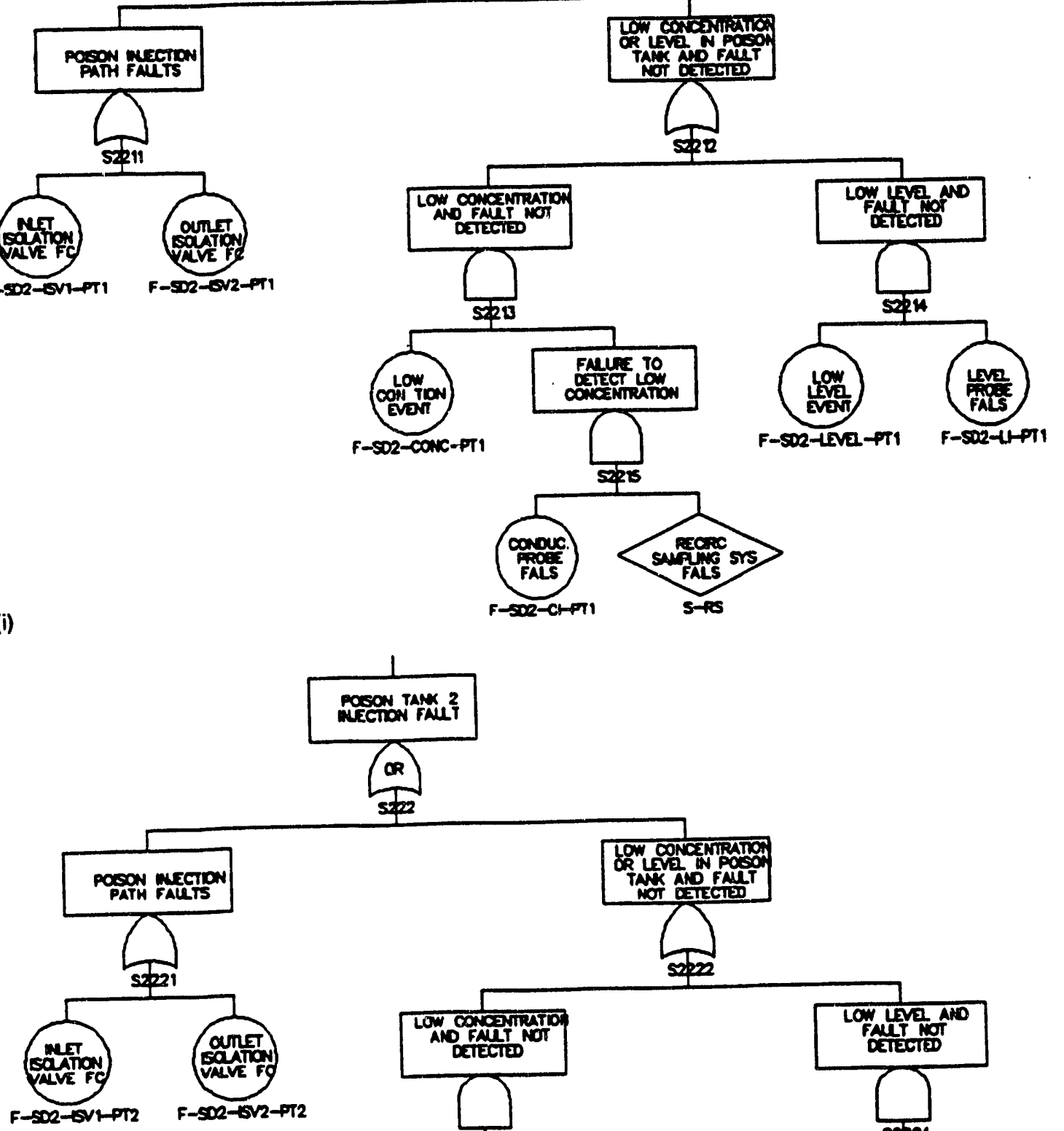

(j)
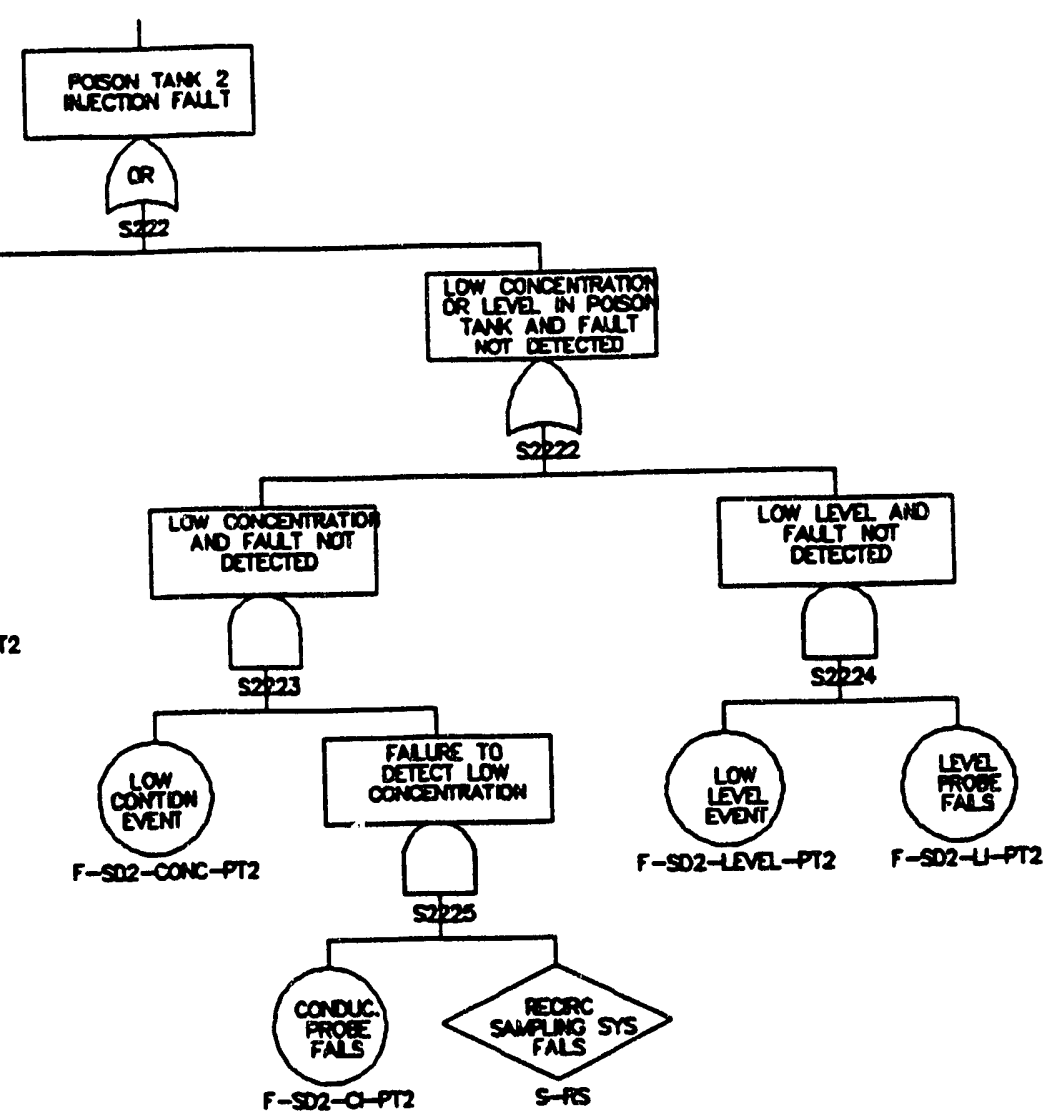

Figure 5.1 (continued) 

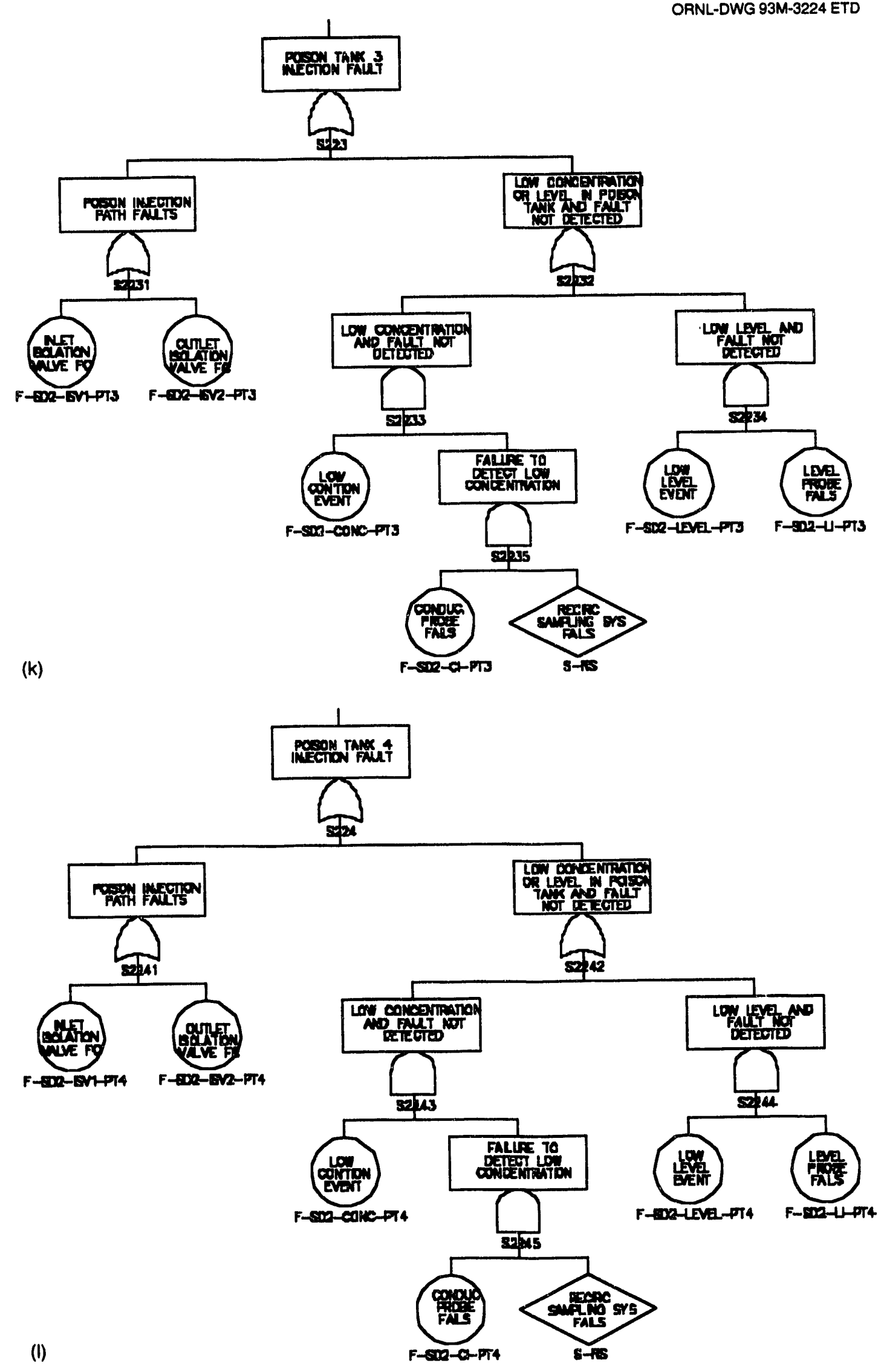

Figure 5.1 (continued) 


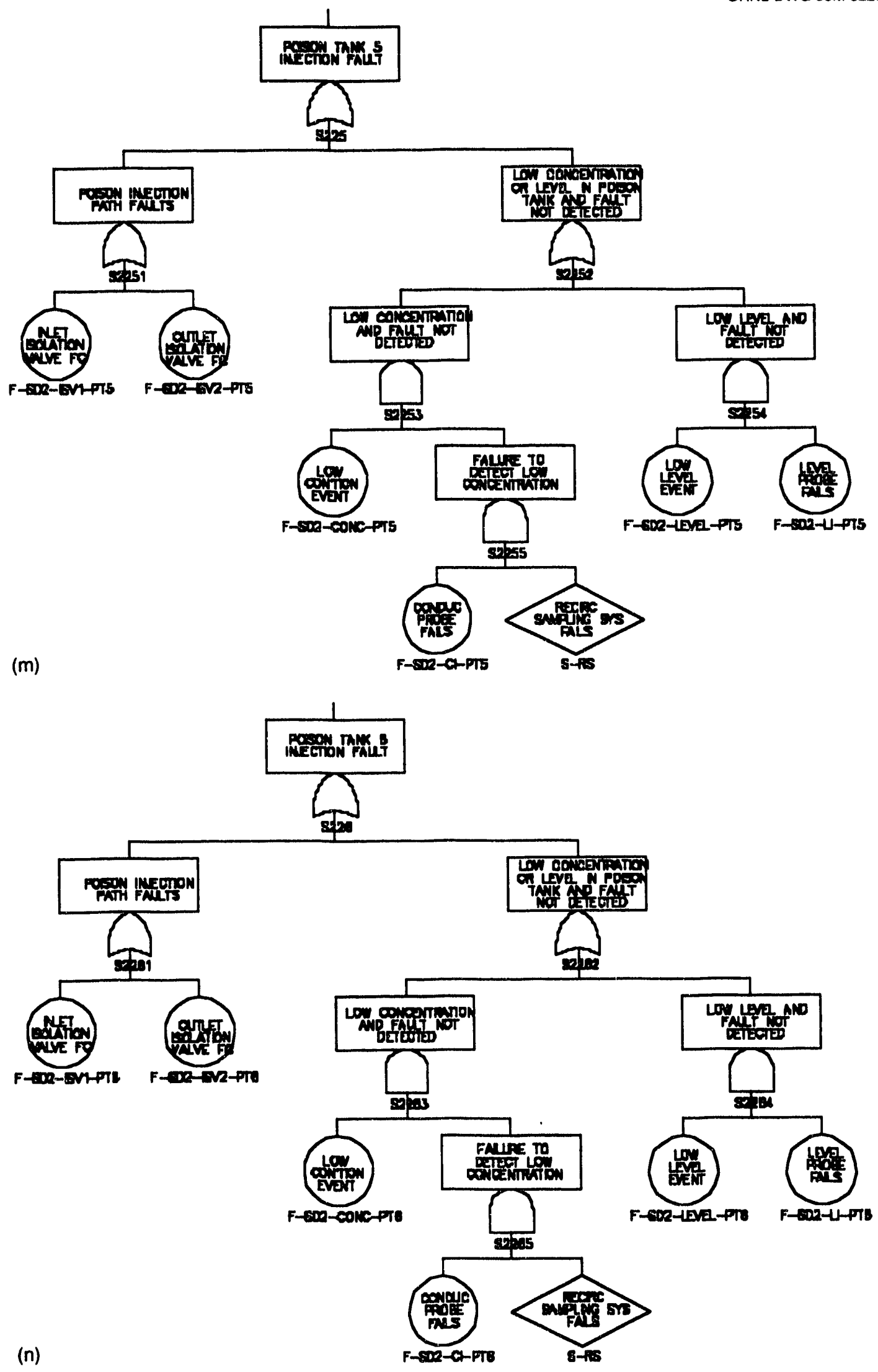

Figure 5.1 (continued) 

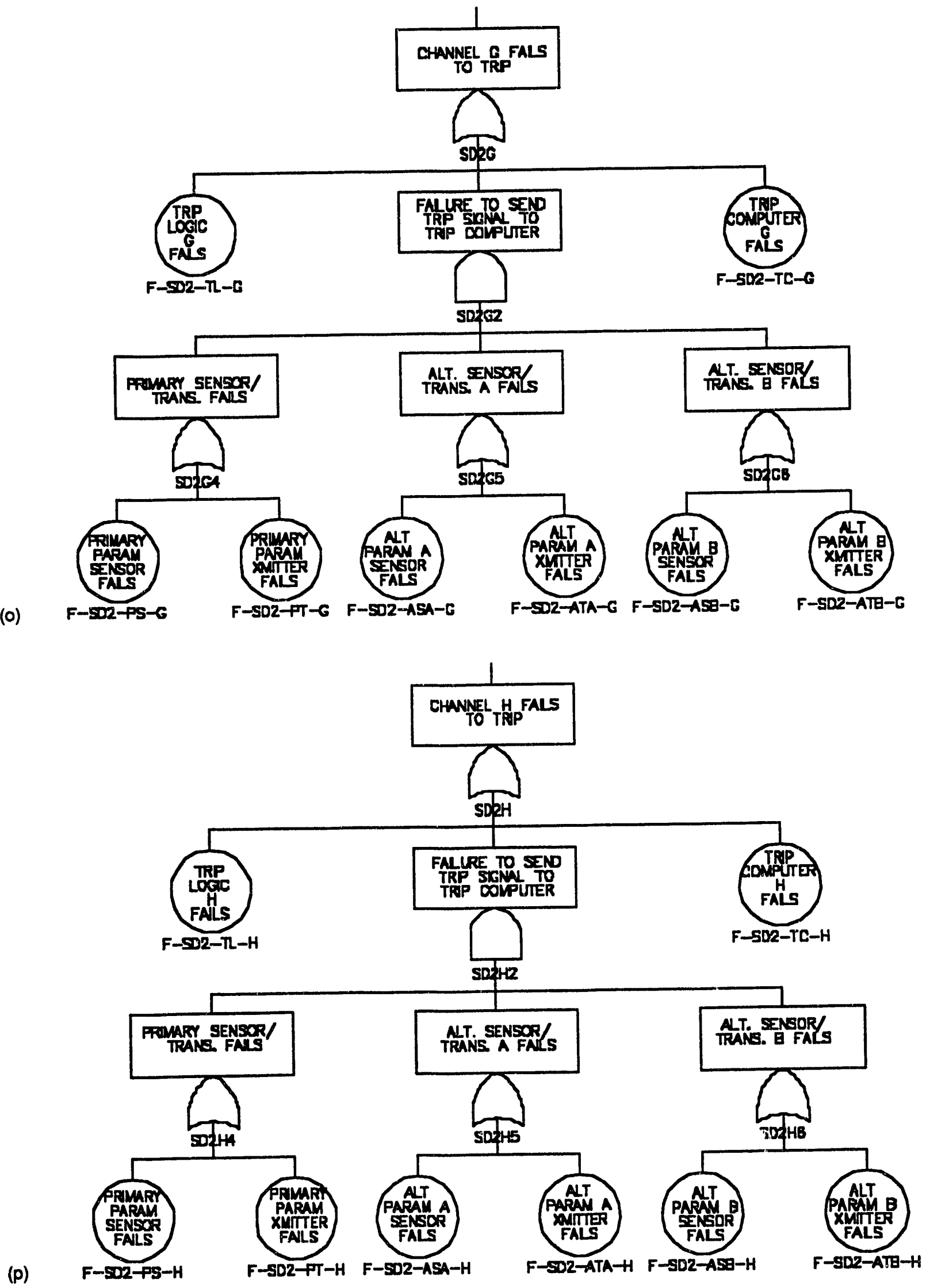

Figure 5.1 (continued) 


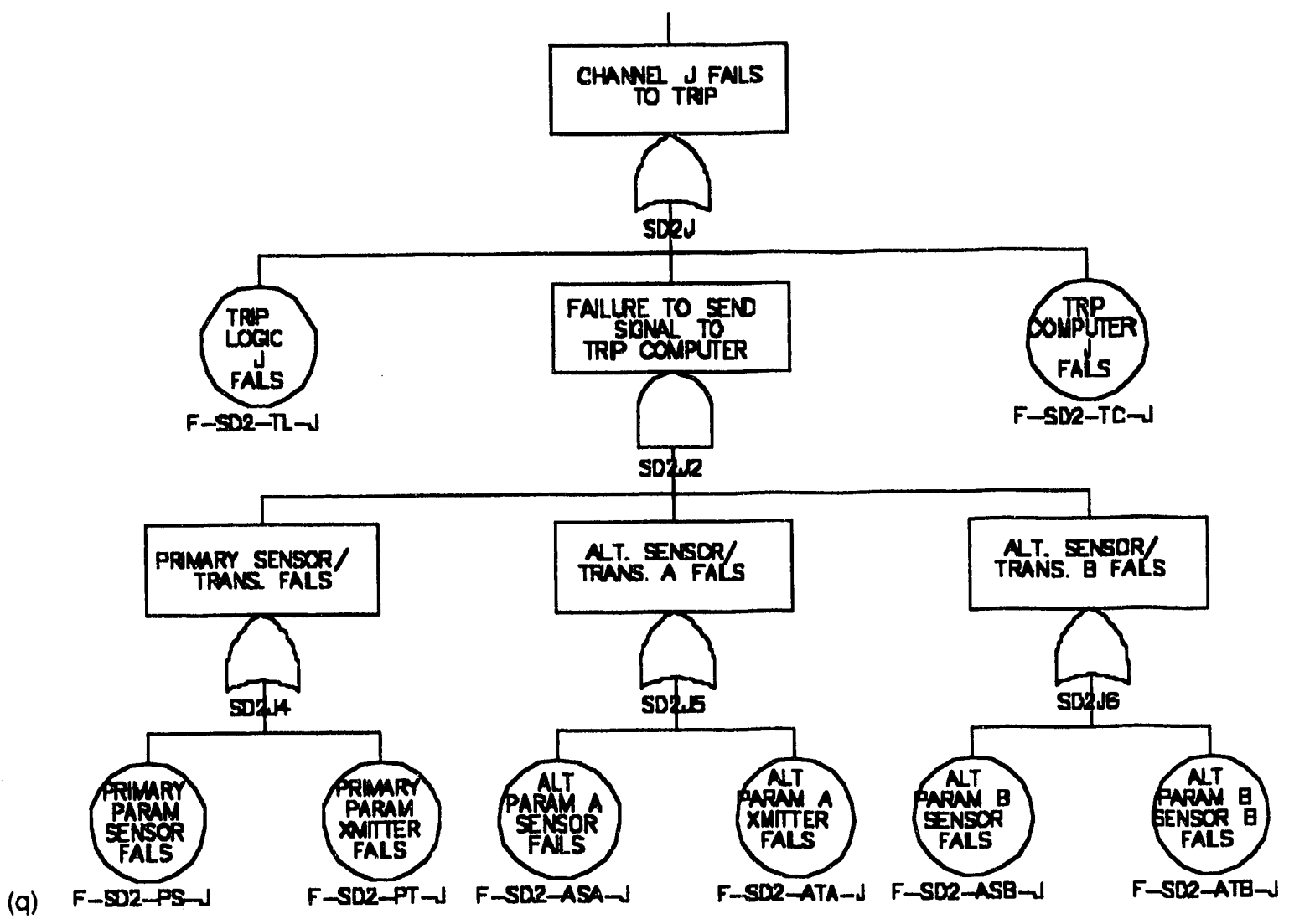

Figure 5.1 (continued)

reactor flux shape, and (3) monitor important plant parameters and reduce reactor power at an appropriate rate if any parameter is out of limits.

Two control absorbers, similar to shutoff rods, are controlled by the RRS. The control absorbers can also be inserted by operator action. Mechanical control absorbers are normally parked out of the core and are driven in to supplement the negative reactivity of the zone control elements or dropped to cause a fast reactor power reduction. Mechanical zone control units are moved into the core or withdrawn out of the core to maintain the appropriate power level in each zone of the core. Mechanical zone control units can act in unison for bulk reactivity control or differentially for spatial (flux tilt) control. The control absorbers can be used for reactor shutdown in cases where a quick shutdown is not required. Both absorbers must be inserted to shut down the reactor. Figure 5.2 is a block diagram representing the $R R S$.

\subsubsection{Shutdown System 1}

SDS1 is the primary method of quickly terminating reactor operation when certain parameters enter an unacceptable range. SDS1 releases 24 spring-assisted gravity-drop absorber elements or shutoff rods to terminate the fission process. SDS1 is required to have sufficient speed and negative reactivity to immediately reduce the reactor power to decay heat level with the two most effective shutoff rods assumed immobile.

Two banks of shutdown rods ( 12 rods each) are tripped by an associated logic circuit. Each logic circuit is designed to trip upon receiving signals from any two of the three trip computers, designated as channels " $D$," "E," and "F." Tripping a logic circuit will cause the shutdown rod clutch coils in that bank to be deenergized, allowing the rods to be inserted. SDS1 uses "general coincidence logic," which means that if any two of the nine signals feeding a trip computer exceed their trip limits, that channel will trip. This is somewhat less restrictive than the "local coincidence logic" used in SDS2 (see Sect. 5.2.1.3). To not satisfy the two-of-three logic and fail to activate SDS1, two of the three channels must fail to detect the need for a reactor trip or fail to respond to the trip signal.

SDS1 receives power from Group 2, Class I and II power supplies. The logic is arranged so that a channel trips upon loss of power to that channel. Loss of power to the neutron 
Systems

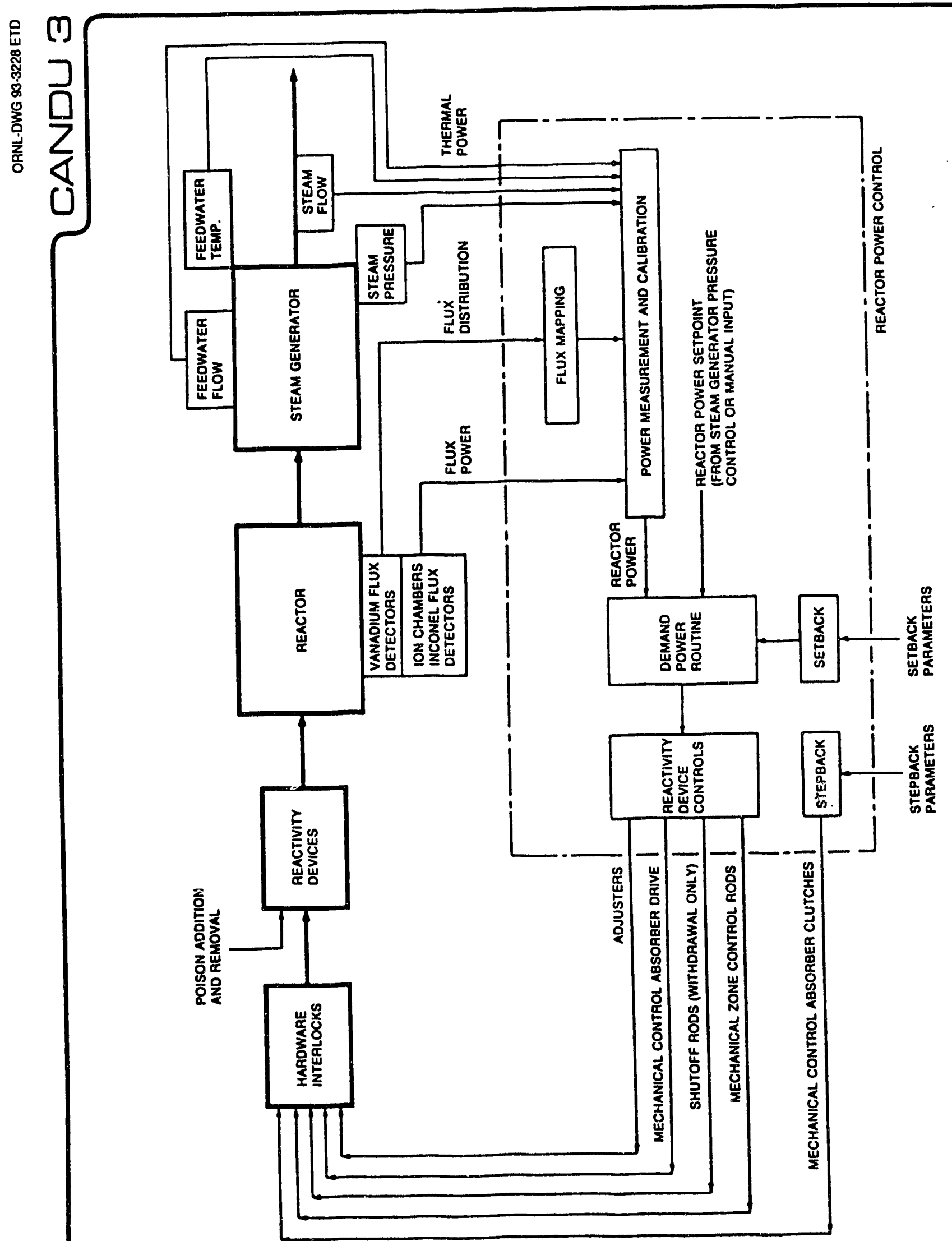


instivi:-entation or the process transmitters results in a channel trip. A power loss that results in an irrational signal to the trip computer results in a channel trip. A second channel must be then tripped to activate SDS1. Loss of power to the clutch coils results in the shutoff rods being dropped. Figure 5.3 is a block diagram for SDS1.

\subsubsection{Shutdown System 2}

SDS2 provides an independent, alternate method of quickly terminating the fission process. SDS2 operis quickacting valves to release high-pressure helium that forces concentrated gadolinium nitrate solution (i.e., poison) from six poison tanks into the moderator. SDS2 has sufficient speed and negative reactivity to reduce the reactor power to levels consistent with available cooling for all SDS2 trip parameters with the most effective nozzle assumed out of service. SDS2 incorporates design features to prevent unnecessary injections when SDS1 has shut down the reactor.

Eight of the nine trip variables used in SDS1 are used in SDS2 (moderator level is eliminated from the SDS2 trip parameters); sensor channels for the SDS2 system variables are kept independent of those for SDS1. Three solenoid valves are used to actuate the quick-opening helium supply valves that are signaled by three independent trip computer channels designated "G," "H," and "J." Each solenoid valve is used to control one pair of quickopening valves. Unlike the "general coincidence logic" used in SDS1, the "local coincidence logic" used for SDS2 requires at least two shutdown signals from two trip computers be actuated by a common variable. Some communication between trip computers is needed to determine coincident trips on a common variable. To have SDS1 trip preferentially (an SDS2 trip would require extensive cleanup of the moderator $\mathrm{D}_{2} \mathrm{O}$ to remove the poisons), the SDS2 flux signals are delayed (low-pass filtered) with respect to the SDS1 signals.

Group 2, Class I and Class II power supplies are connected to each channel. The logic and instrumentation are designed so that a channel trips on loss of power. Loss of power to individual transmitters is annunciated and causes a parameter trip due to the faulted signal. The outputs from each sensor after amplification are fed to a trip computer, and the trip computer sends a trip signal to the trip logic circuits. SDS2 has three trip logic circuits, one for each pair of the quick-opening helium supply valves. The quickopening valves are arranged in three parallel pairs. Two of the three channels must fail to detect the need for a reactor trip or fail to respond to the trip signal to prevent poison injection.
A vessel containing high-pressure helium supplies the source of energy for rapid injection. Measurements of the helium makeup supply pressure are performed by two different methods. The tank is connected to a helium header (i.e., three parallel paths with two quick-opening valves in each path) that supplies the injection force for the six poison tanks. The level in each poison tank is also monitored, and the operator is wamed by alarm if more than one poison tank is valved off.

The quick-opening valves are air-to-close, spring-to-open, so they fail open on loss of air supply or loss of electrical power. Air is supplied to the quick-opening valves by the plant compressed air system. Special logic prevents the testing of two different valve pairs within $10 \mathrm{~min}$ of each other. This ensures that the interspace between the quickopening valves is depressurized and, thus, prevents spurious partial injections. Vent lines are provided to vent the helium from the interspace to the reactor building atmosphere. The vent valves are normally closed and fail open on loss of air or power.

A pressure balance line exists between the SDS2 piping and the upper region of the calandria tank. The purpose of this line is assumed to keep pressure on both ends of the poison tanks at the same pressure to avoid partial poison injections because there is no isolation between the poison tanks and the moderator. This line was assumed to be small in comparison to the belium supply lines and was, therefore, not considered as a potential failure in the analysis of this system. Figure 5.4 is a block diagram for SDS2, and Fig. 5.5 is a schematic of the SDS2 poison injection system.

\subsubsection{Moderator Liquid Poison System}

The moderator liquid poison system (MLP) is used during normal operations as part of the reactor power control scheme. The system may also provide an alternate means to poison the reactor when other means of reactor shutdown have failed. Note that the system is not designed for this purpose; however, it is assumed for this analysis that the system contains sufficient negative reactivity to effectively shut down the reactor for some sequences. This method of reactor shutdown is slower than the normal shutdown systems and, therefore, would be less effective in mitigating some accidents. The poison is delivered from the boron poison tank by way of gravity through a flow control valve and an isolation valve. The MLP is used during normal operation, and a tank level alarm is provided to notify the operator when more poison must be added and mixed in the tank. Figure 5.6 presents the fault tree for this system. A system diagram is presented in Fig. 5.7. 
Systems

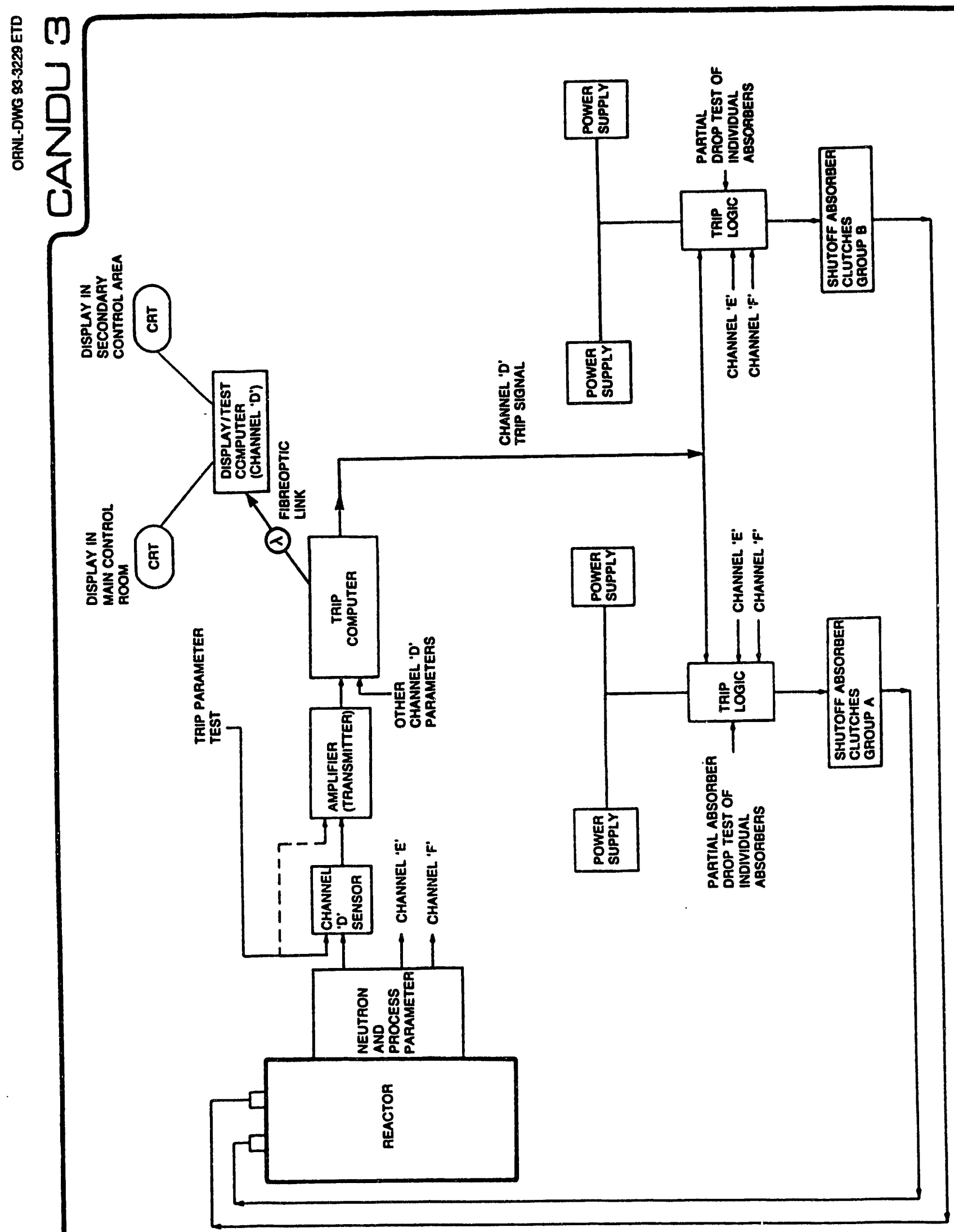




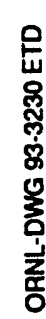

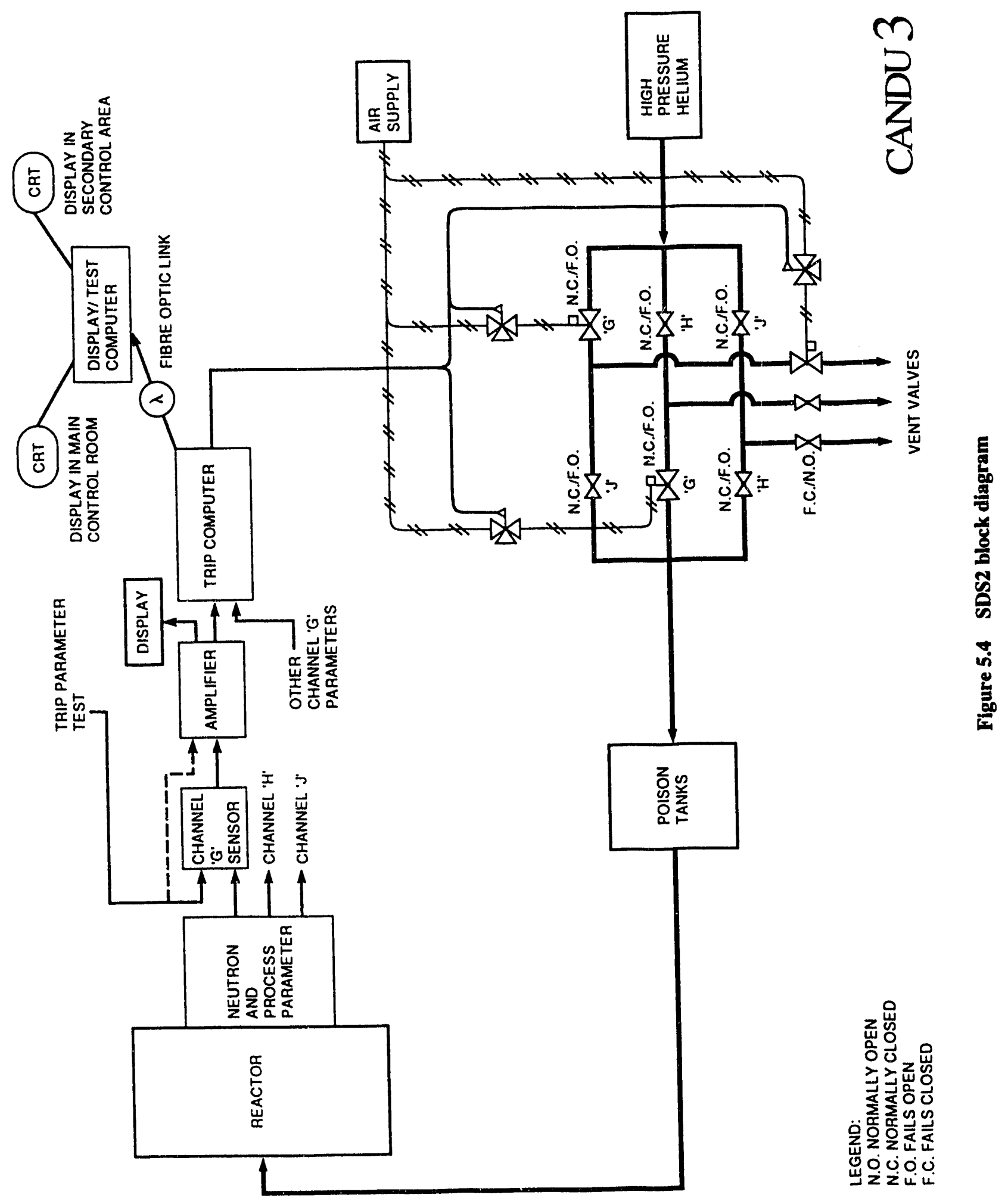


Systems

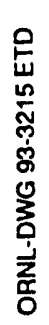

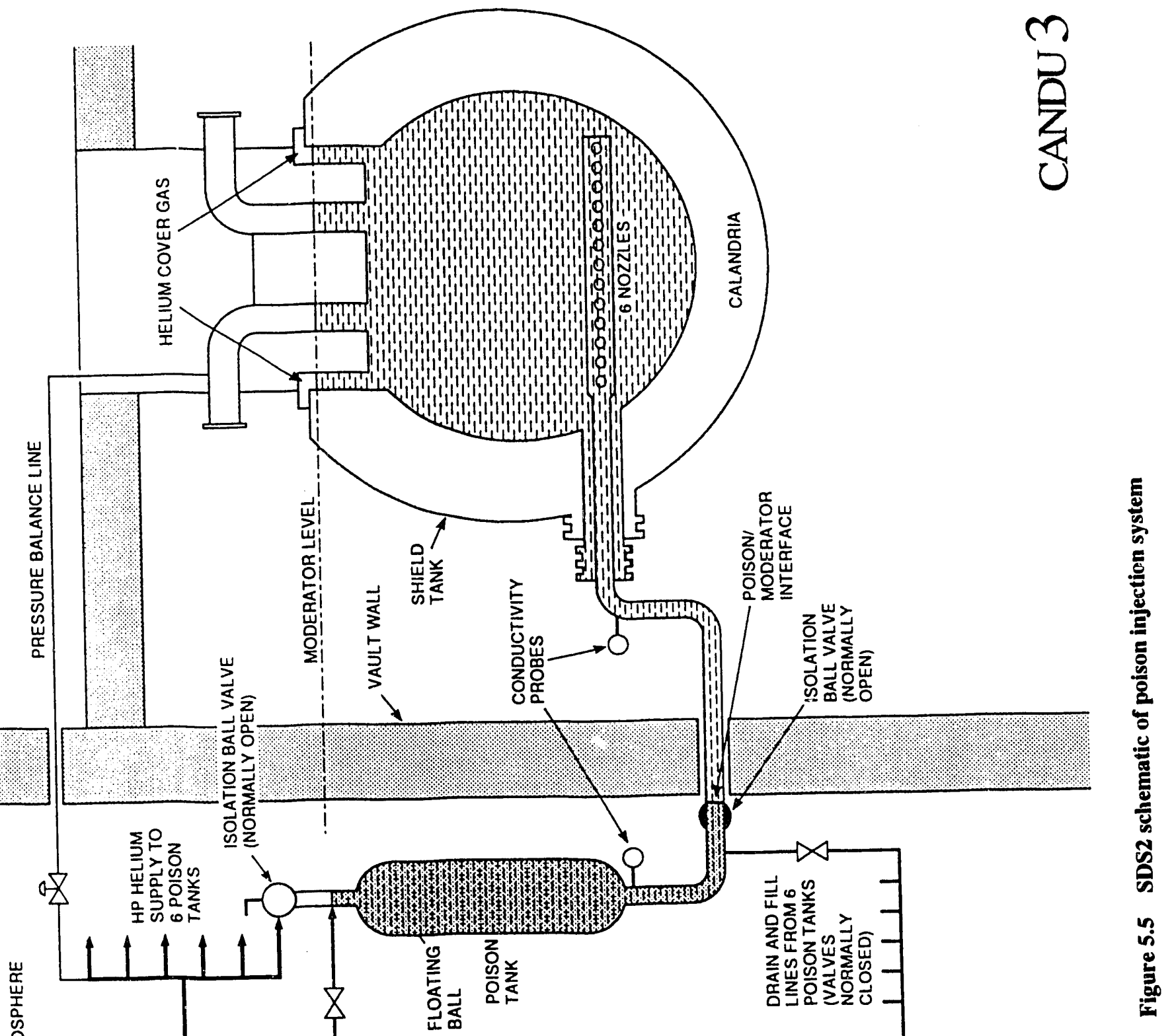




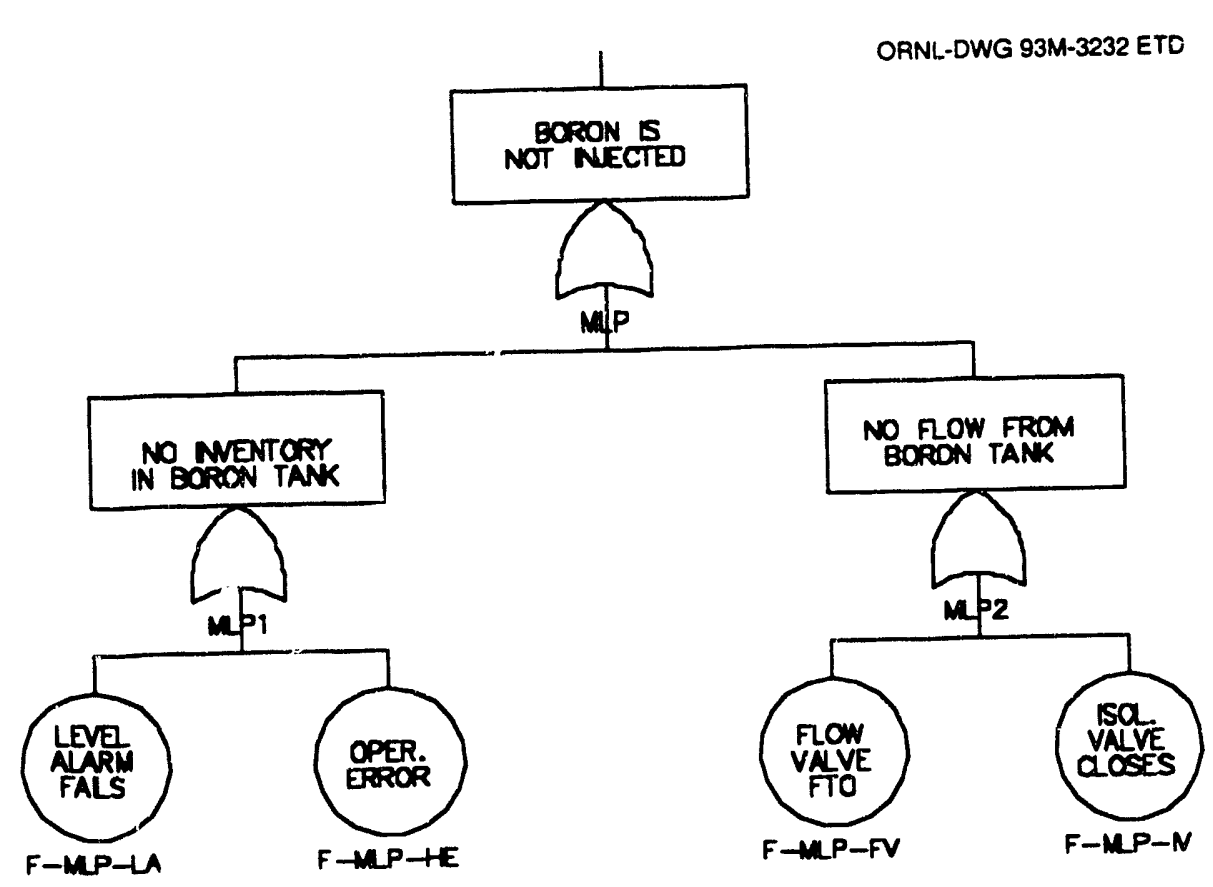

Figure 5.6 MLP system fault tree

\subsubsection{Feedwater Systems}

The purpose of the FW in mitigating accidents is to remove heat from the reactor via the steam gererators. Three systems can satisfy the feedwater requirements, and these are modeled together as FW; these three systeins are designated FW1, FW2, and AFW. Figure 5.8(a)-(i) shows the FW fault tree model.

\subsubsection{Group 1 Feed water System}

The FW1 supplies controlled feedwater flow to maintain required steam generator levels. FW1 includes three 50\% main feedwater pumips that operate on Class IV power. The feedwater is stored in a deaerator storage tank, and flow is regulated by three $50 \%$ capacity regulating valves (boiler level control vaives). In addition, two trim valves are installed at each steam generator. The main FW pump motors and lube oil coolers are cooled by the recirculated cooling water system, and backup croling is provided by the firewater system. If plant air is lost and not restored within $1.5 \mathrm{~h}$, the three main level control valves will fail closed. It was assumed that the valves receive power from the Class II Group 1 buses. Figure 5.9 shows the FW1 configuration.

\subsubsection{Group 2 Feedwater System}

The FW2 provides an inciependent supply of high-pressure feedwater to the steam generators following a total loss of FW1 supply. The FW2 system is housed in the Group 2 pumphouse and includes two (100\% capacity) pumps and a supply tank separate from FW1. The tank contains a ló-h supply and requires operator action to refill the tank when empty. Following a loss of normal feedwater, the FW2 pumps start automatically on low steam generator level or low feedwater supply pressure. The major fault categories are loss-of-conlant fault, coolant flow path fault, and loss of pumping function. Each steam generator has two valves (in parallel) that isolate the FW2 from the steam generator. It is assumed that there is sufficient flow to the steam generator if one of the two, isolation valves are open. It was also assumed that the isolation valves receive power from Class II Group 2 buses. A flow diagram for FW2 is presented in Fig. 5.10.

\subsubsection{Auxiliary Feedwater System}

The AFW pump can discharge $4 \%$ of normal feedwater flow into the two stean generators. The pump is diesel driven and is started within $30 \mathrm{~s}$ of loss of feedwater flow. AFW supply is taken from the FW1 supply, and flow is pumped through the FW1 piping. The discharge valve for the AFW pump must also open. Figure 5.9 shows how the AFW pump is connected to the FW1 piping.

\subsubsection{Heat Transport System}

The beat transport system (HTS) circulates pressurized heavy water through the reactor fuel channels to remove heat produced by fission of niaural uranium fuel. The heat is carried by the reactor coolant to the steam generators where it is transferred to light water to produce steam, 


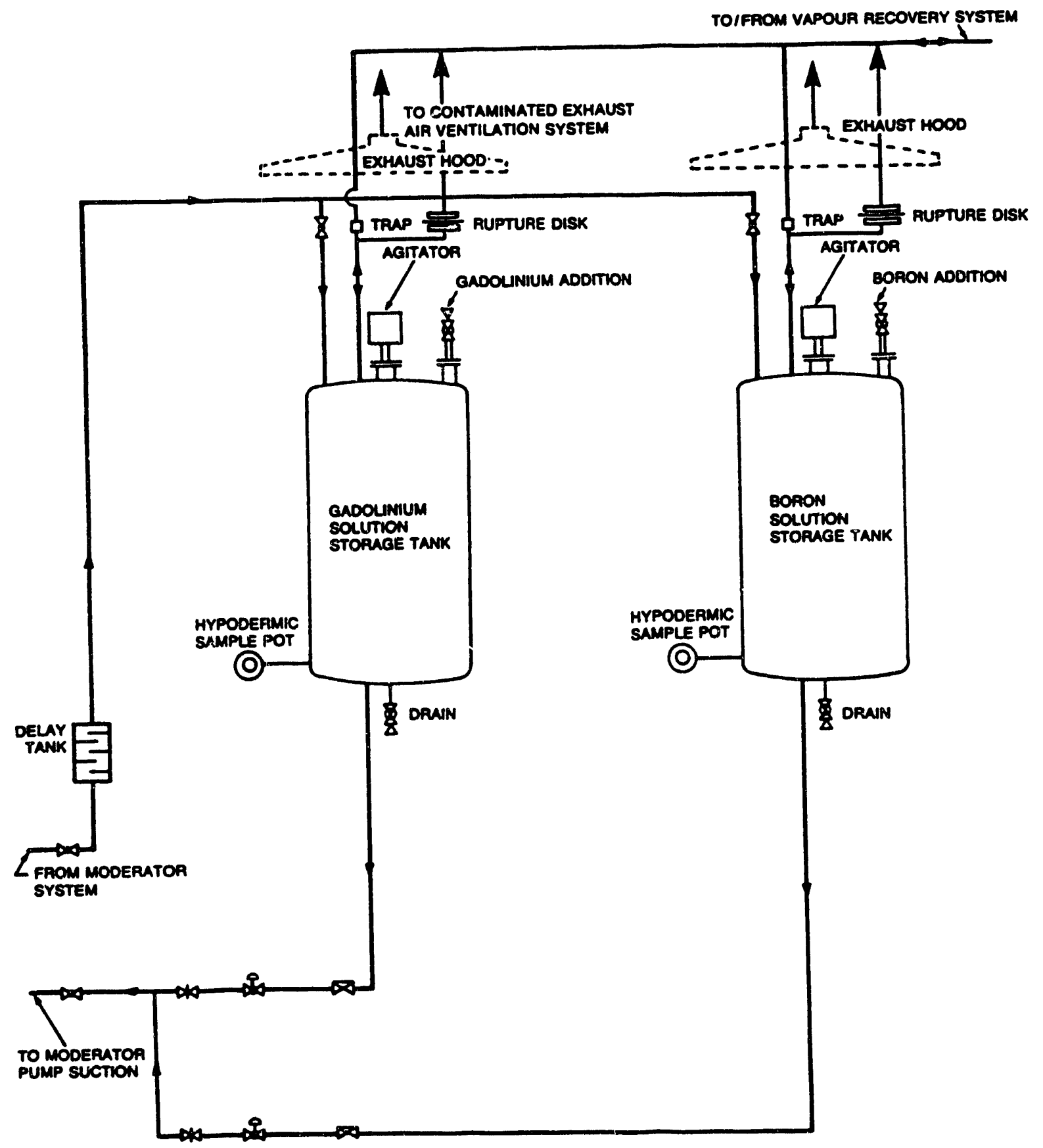

Figure 5.7 MLP flow diagram 
(a)

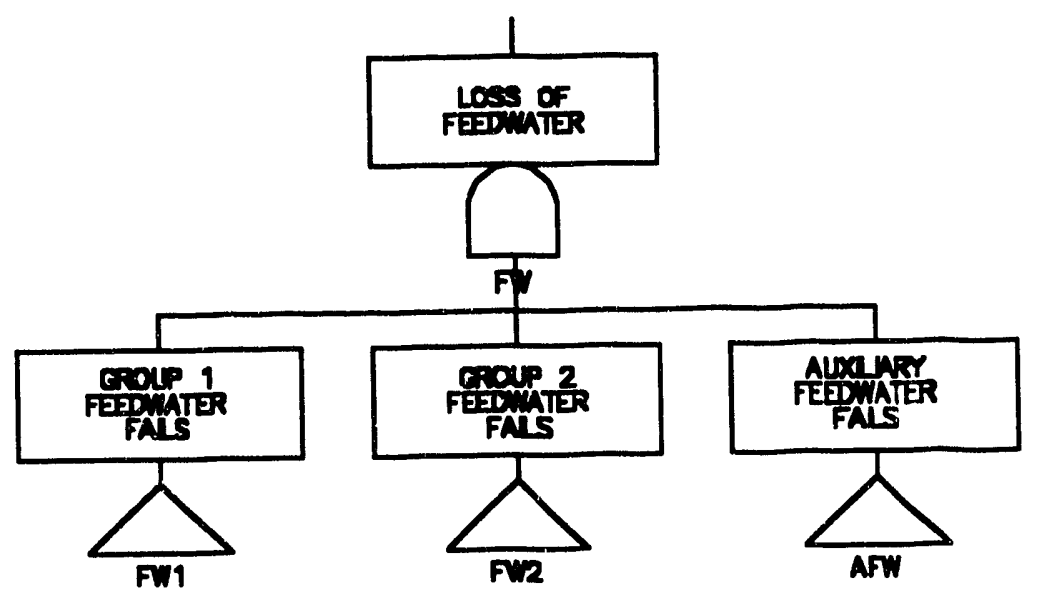

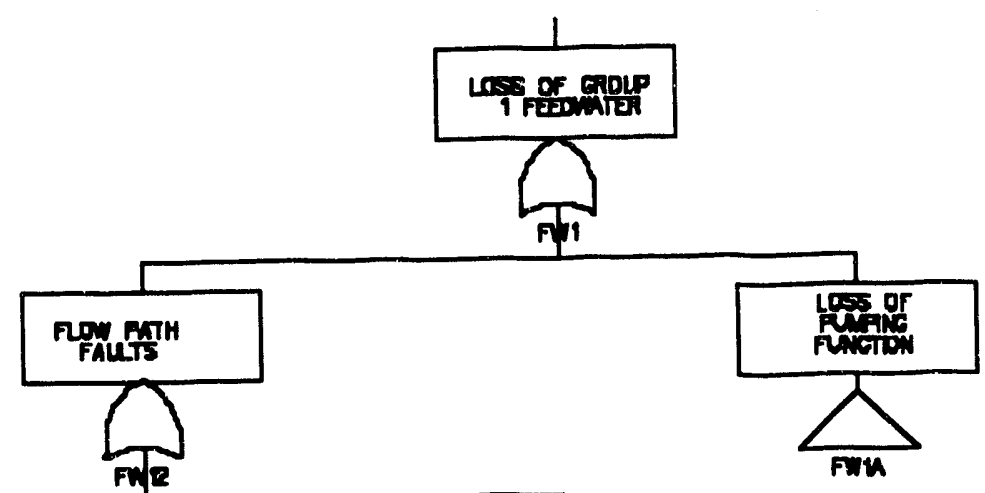

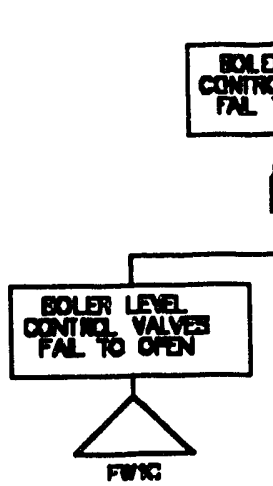

(b)
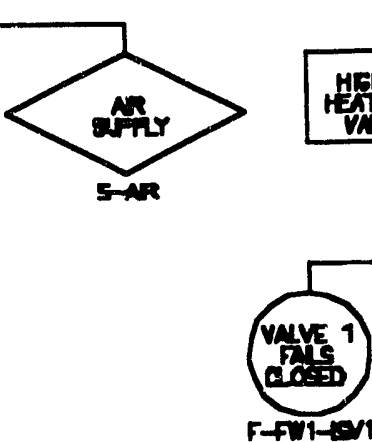

Figure 5.8 Feedwater systems fault tree 


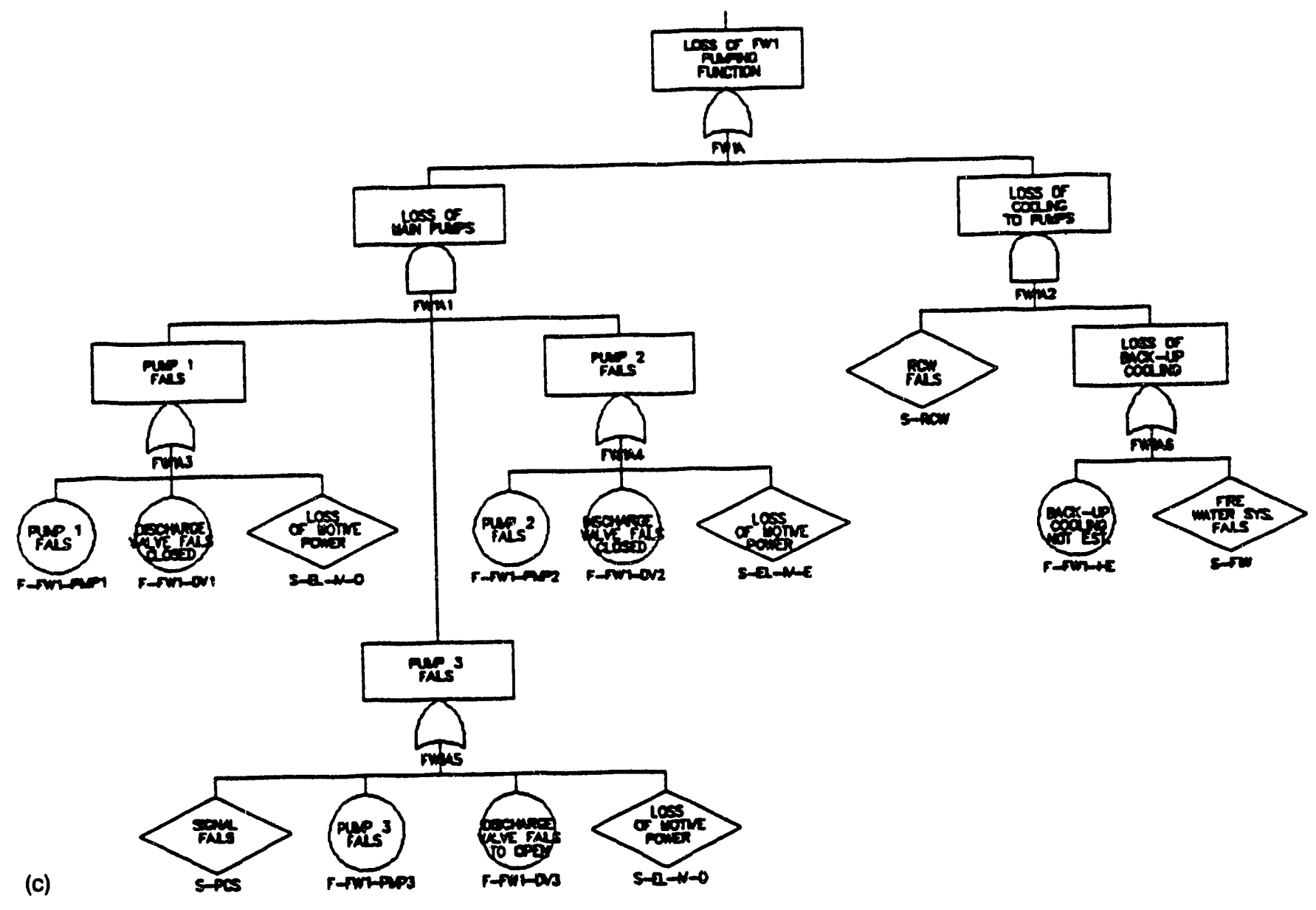

(c)

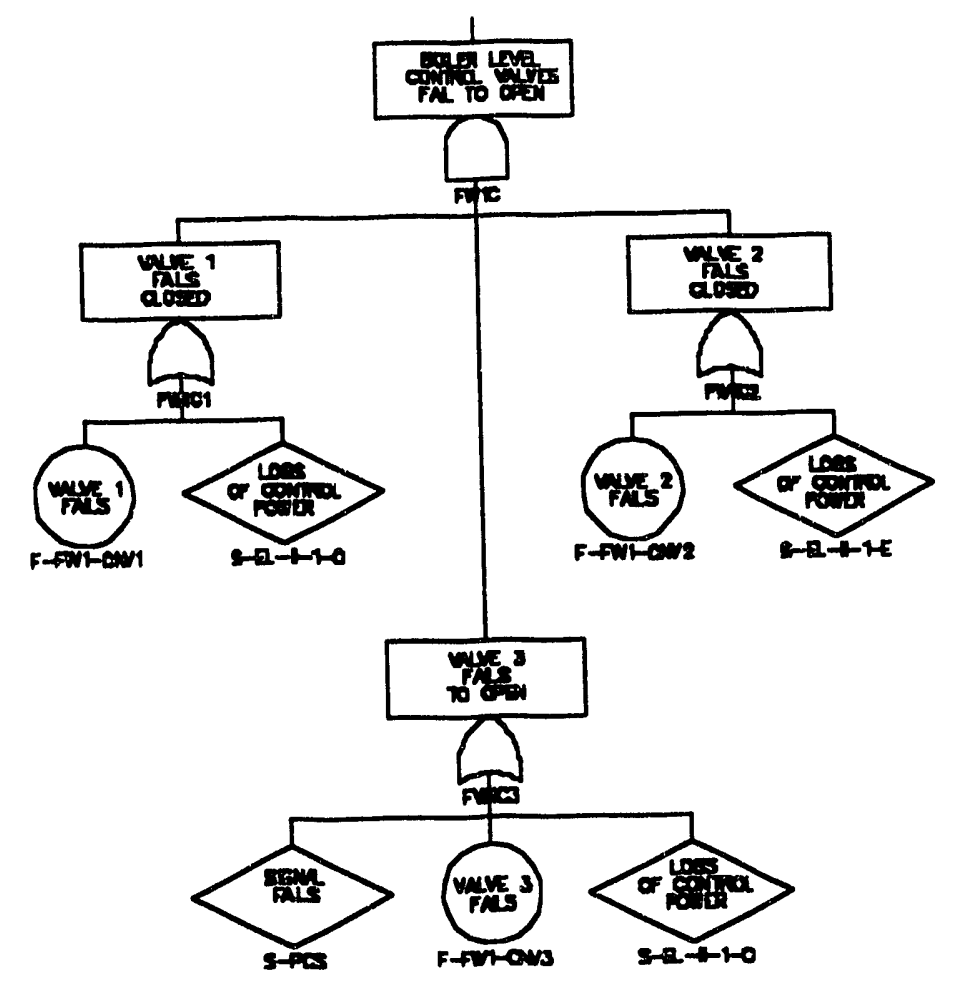

Figure 5.8 (continued) 


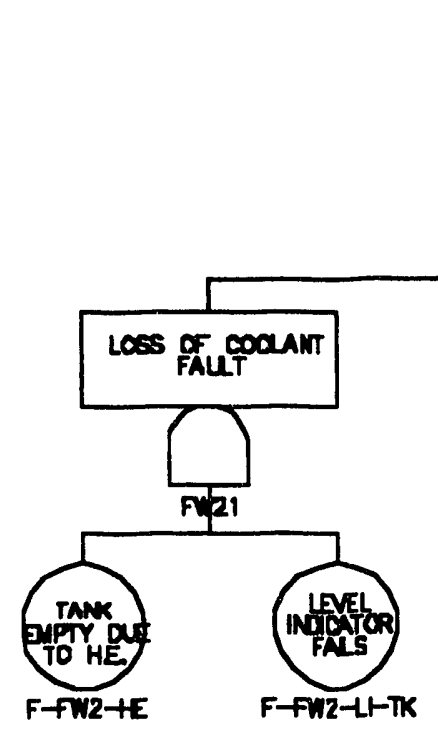

(e)

(f)

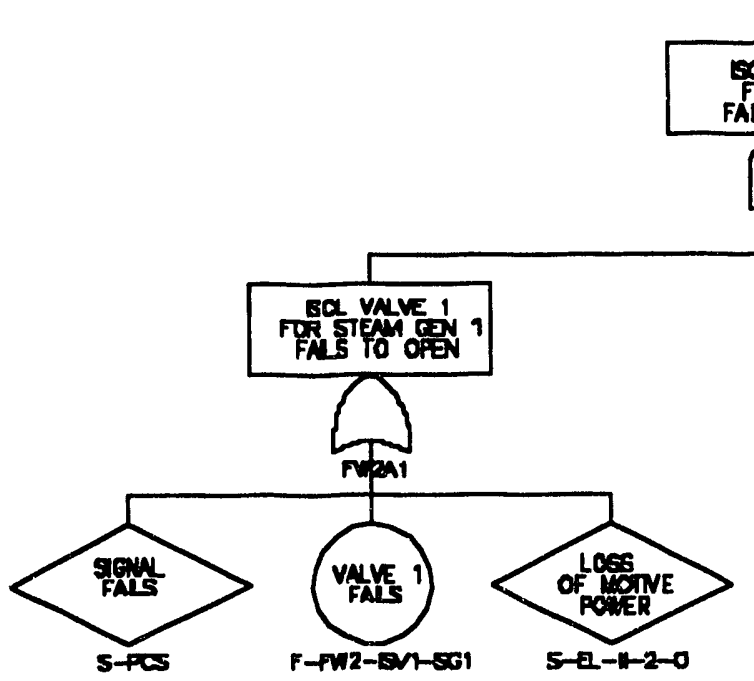

geoup 2

PUDOMATER FALT

$C$

Fe
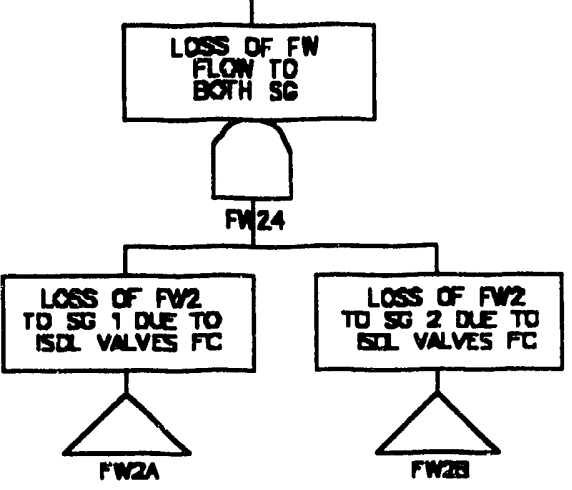

aves

ALL TO of

Fin
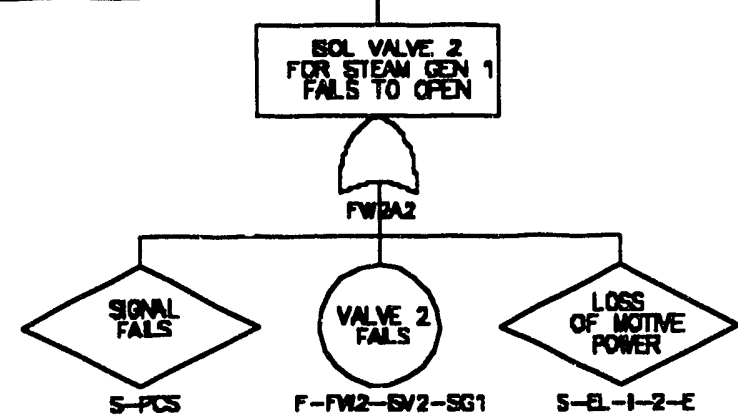

(g)

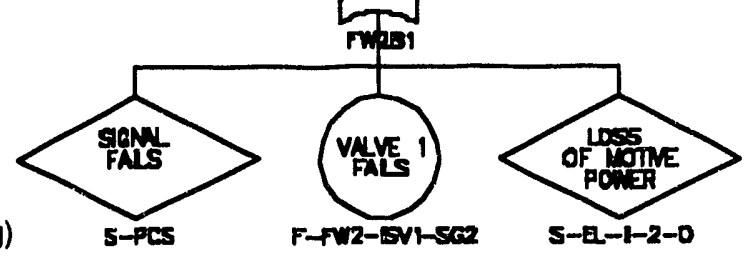

Figure 5.8 (continued) 


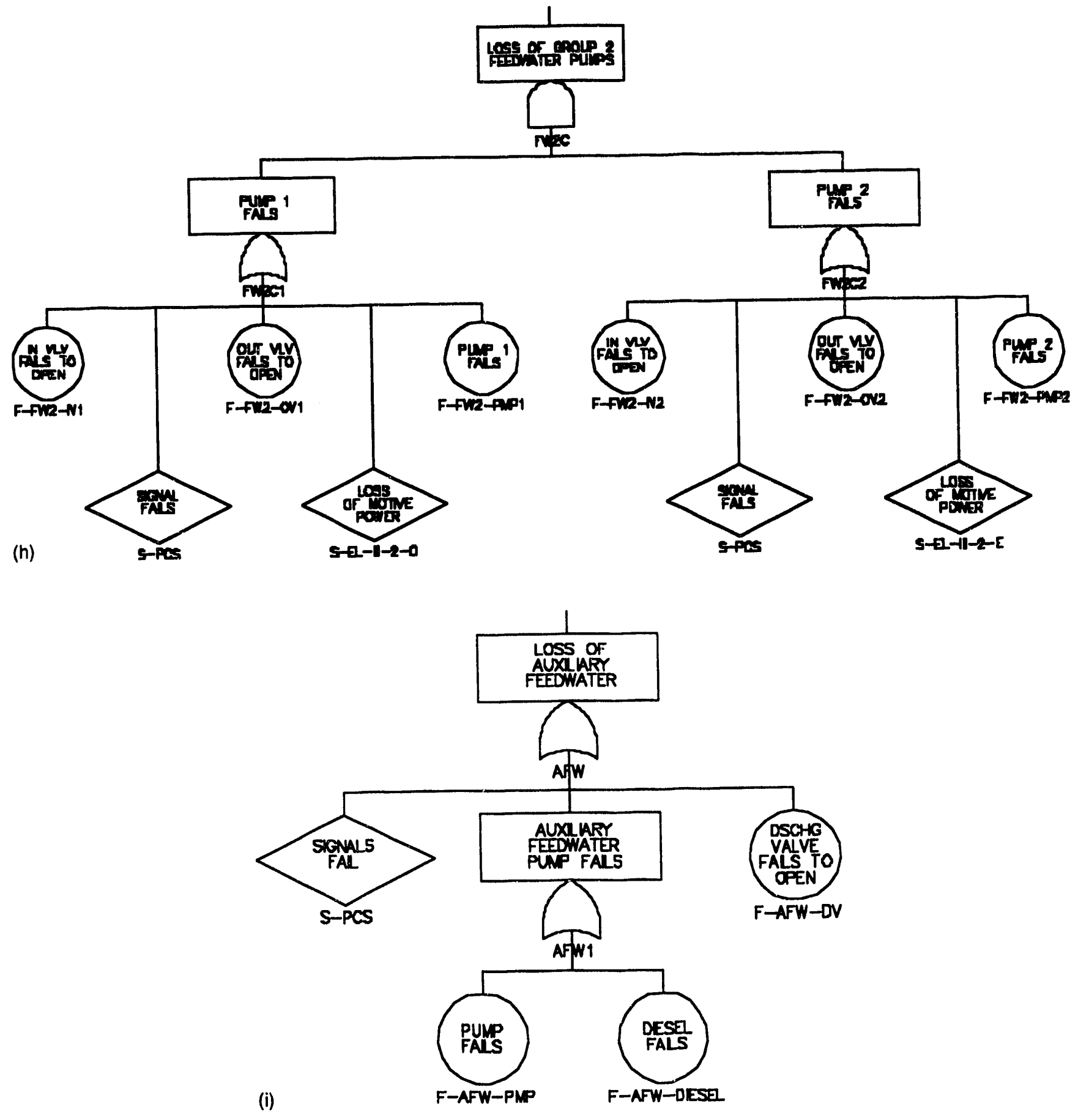

Figure 5.8 (continued) 
Systems

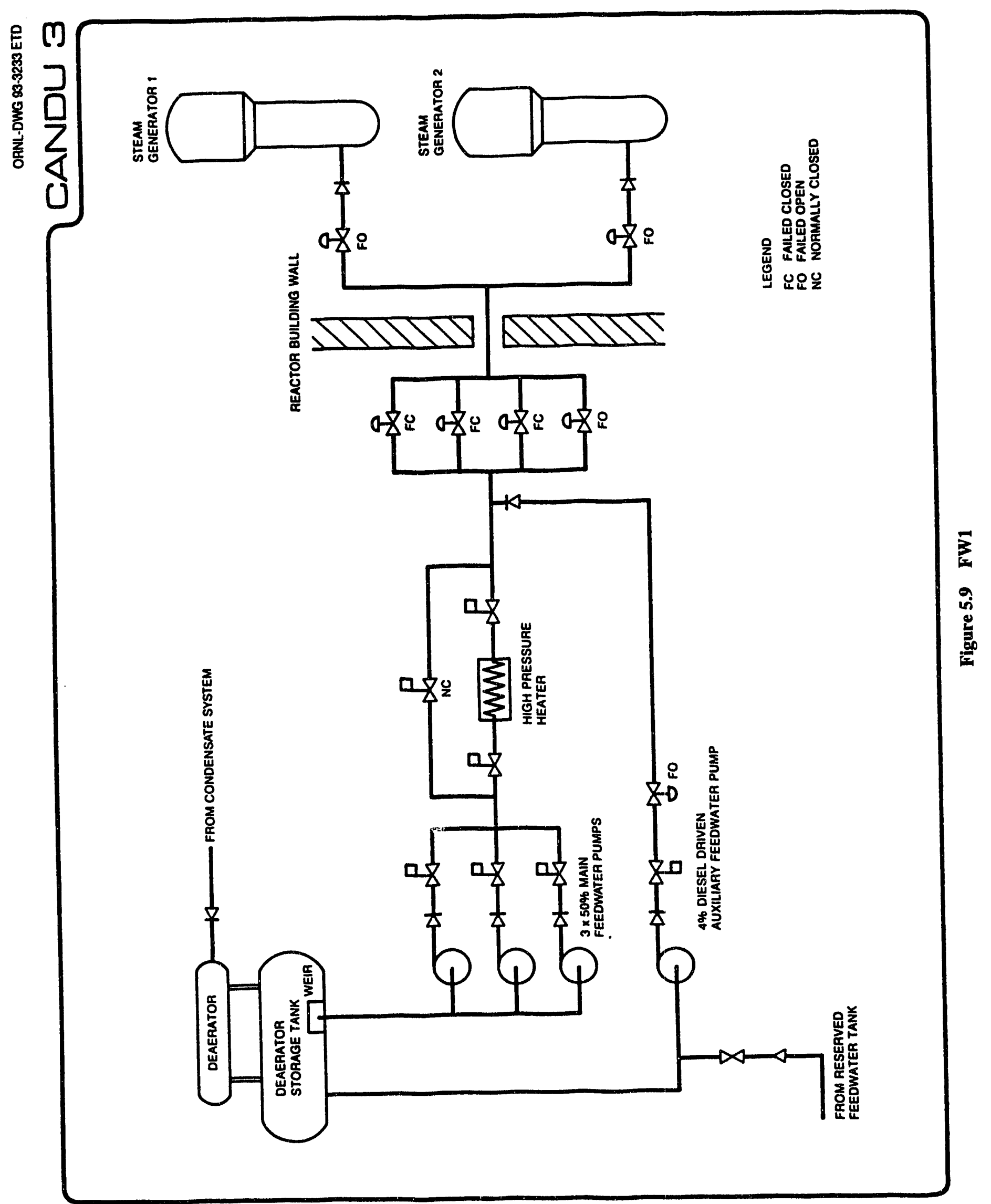



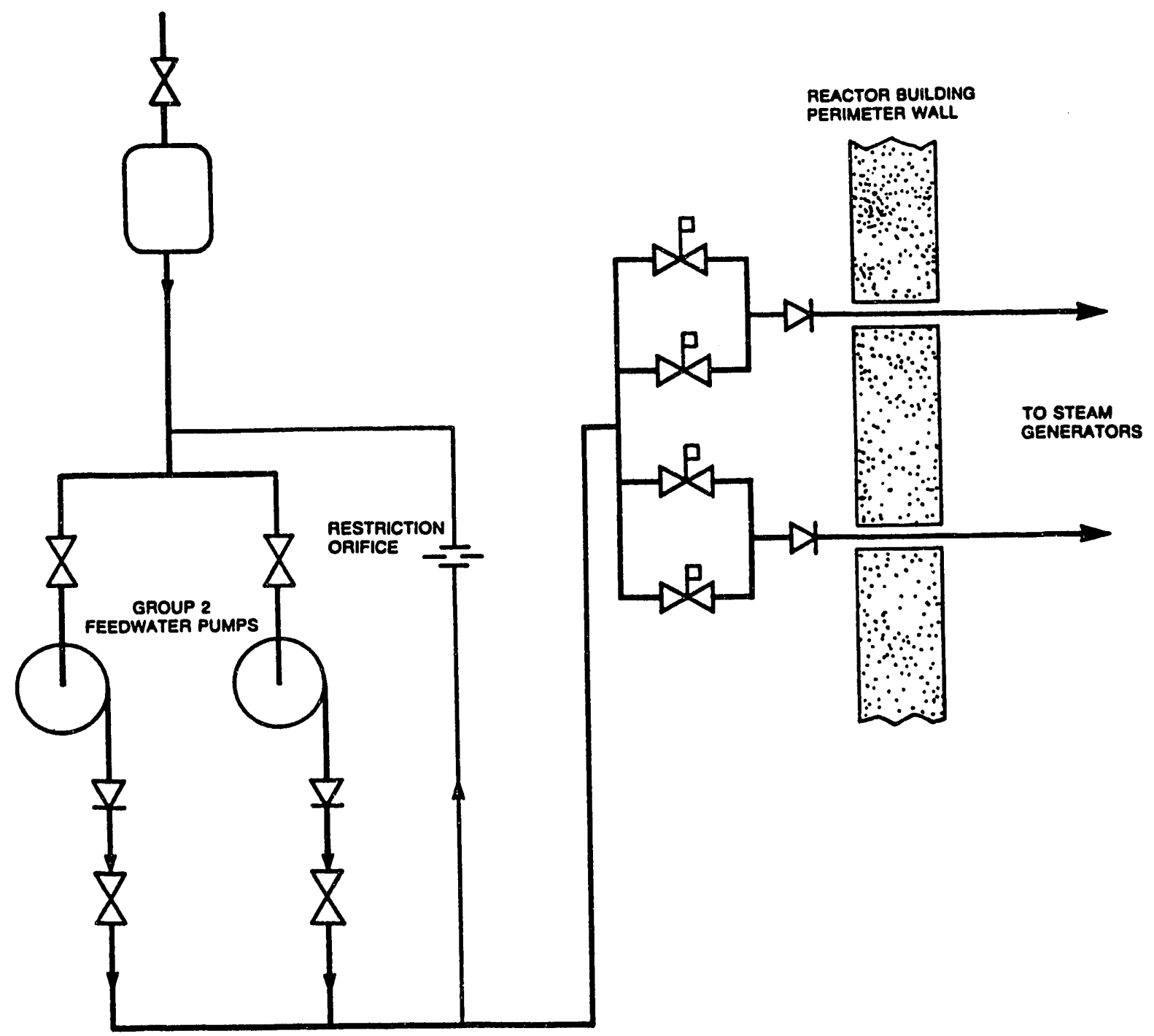

Figure 5.10 FW2 flow diagram 
which subsequently drives the turbine-generator. The major components of the HTS are the 232 reactor fuel channels, two vertical steam generators, four motor-driven heat transport pumps, four reactor inlet headers, two reactor outlet headers, and interconnecting pipes. ${ }^{2}$ The failure mode addressed by the fault tree in Fig. 5.11 is loss of flow in the HTS due to pump failure. The pumps require Class IV electrical power. The HTS is shown in Fig. 5.12.

\subsubsection{Steam Discharge}

The systems included in the steam discharge (SD) function are the condenser steam discharge valves (CSD) and the atmospheric steam discharge valves (ASD). The purpose of the SD function is to remove the heat transferred to the main steam system in the steam generators. Each of these is described in further detail in the following paragraphs.
Figure 5.13(a)-(c) presents the fault tree for the SD heat removal function. Figure 5.14 shows the schematic for these systems.

\subsubsection{Condenser Steam Discharge Valves}

The primary function of CSDs is to discharge live steam to the condenser and maintain temperature in the HTS so that the reactor power remains at the designated level. The CSDs are also used to discharge steam on a loss of load or turbine trip, so the main steam safety valves (MSSVs) do not lift. There are four CSDs for each steam generator. These valves have pneumatic actuators and fail closed on loss of air. ${ }^{2}$ The CSD fault tree uses an earlier CANDU 3 design ${ }^{1}$ of two CSDs per steam line because the success criteria for the new configuration were not specified. This results in a conservative model for CSD unless all four valves are required for success in the new configuration.

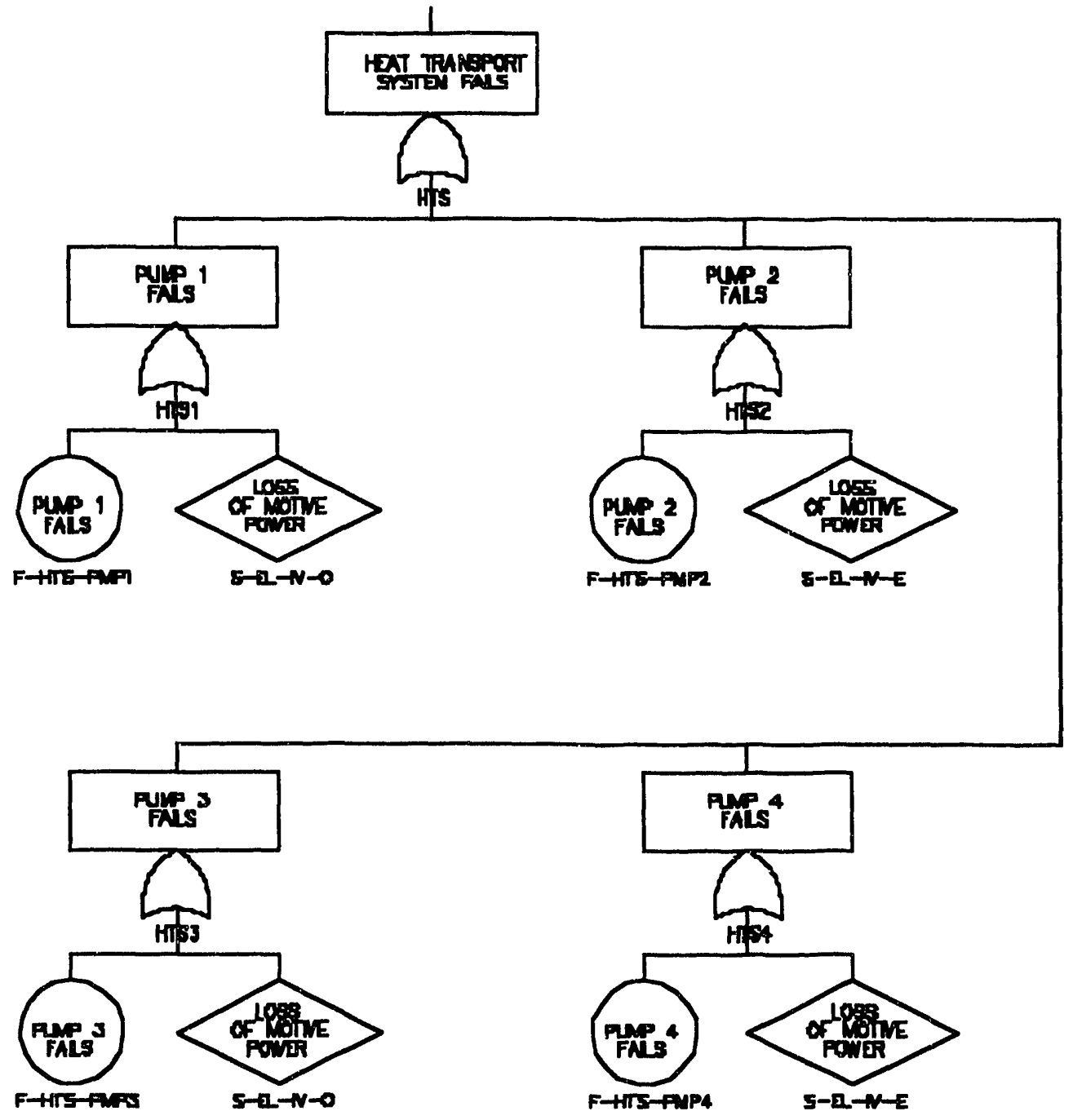

Figure 5.11 HTS fault tree 


\section{Systems}

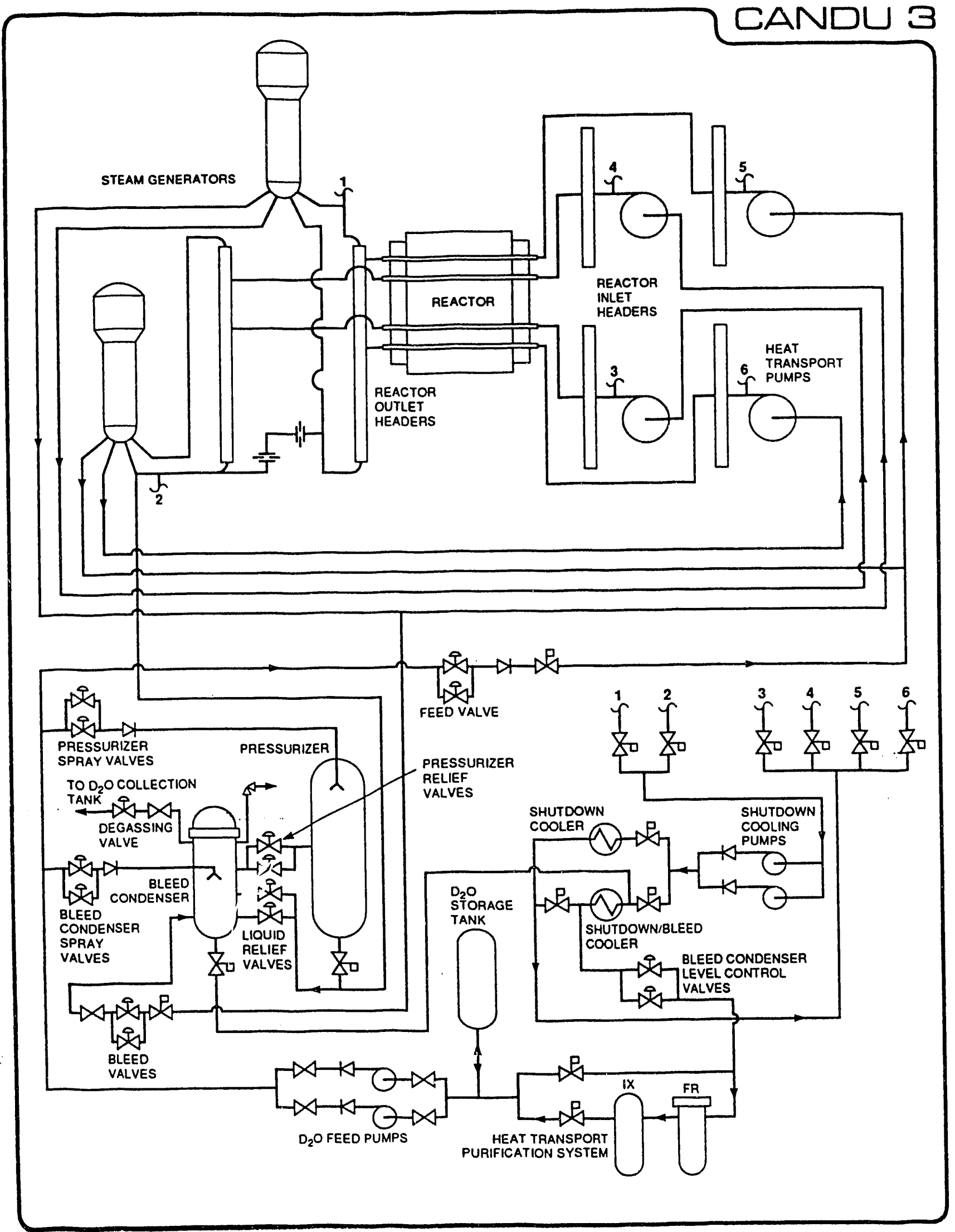

Figure 5.12 HTS 
(a)

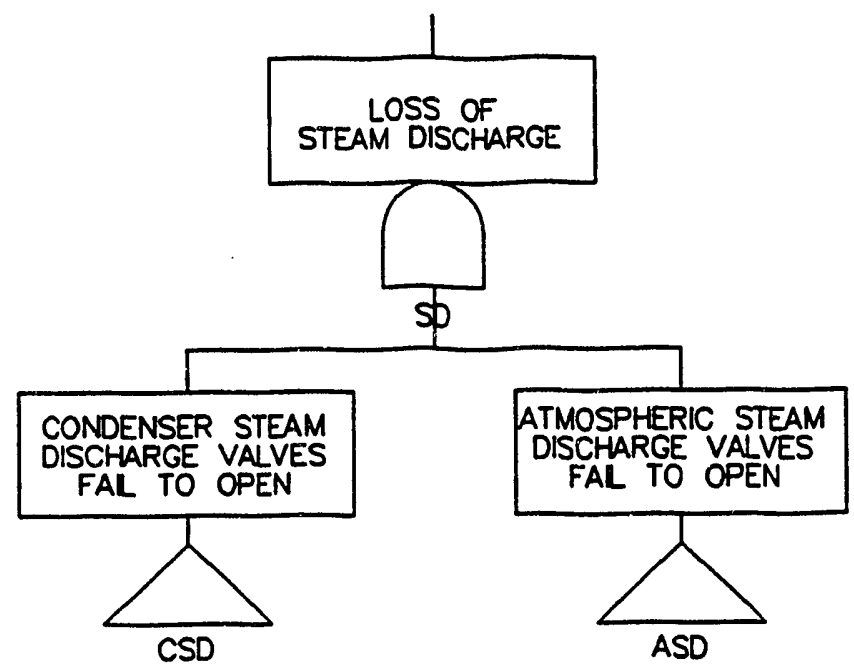

(b)
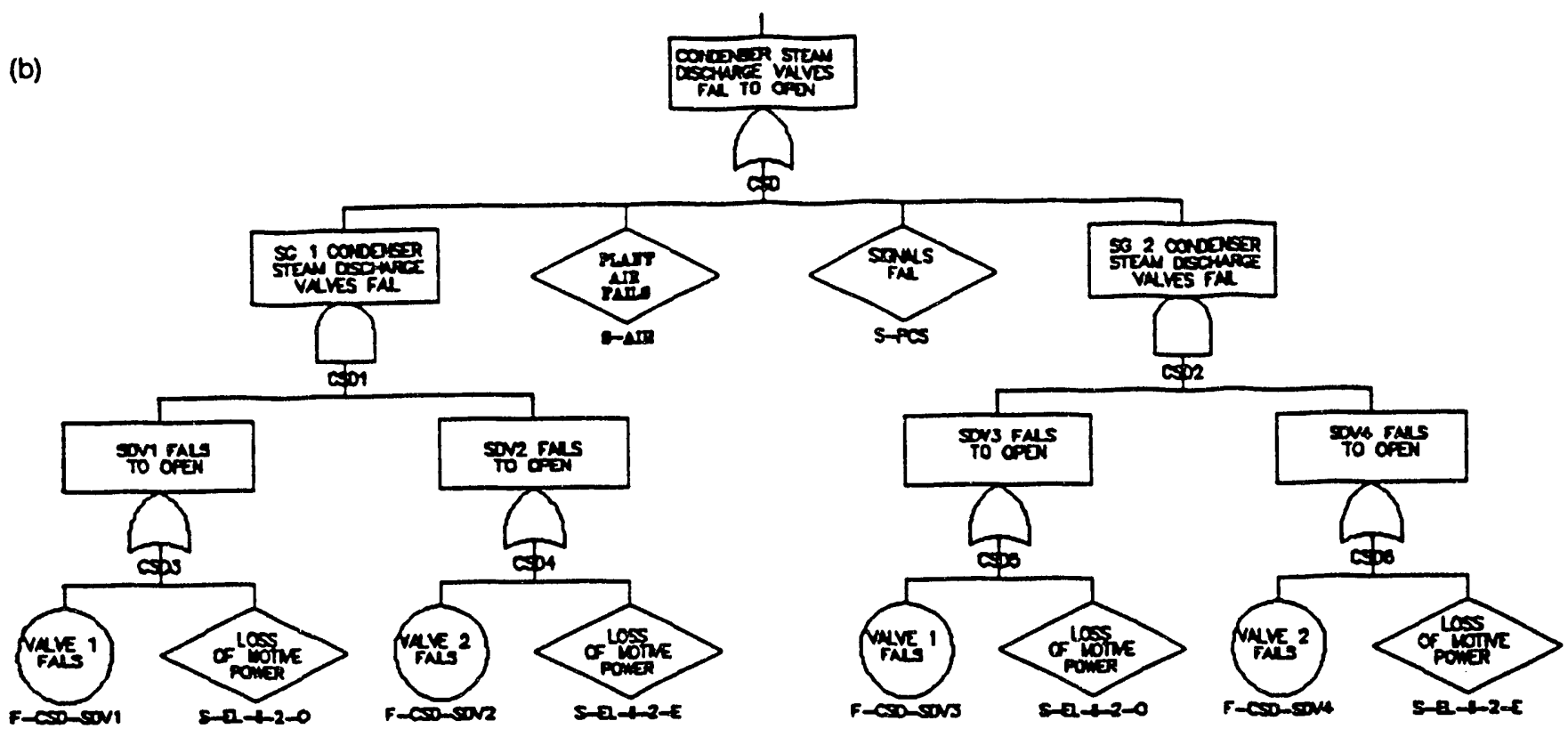

Figure 5.13 SD fault tree 
(c)
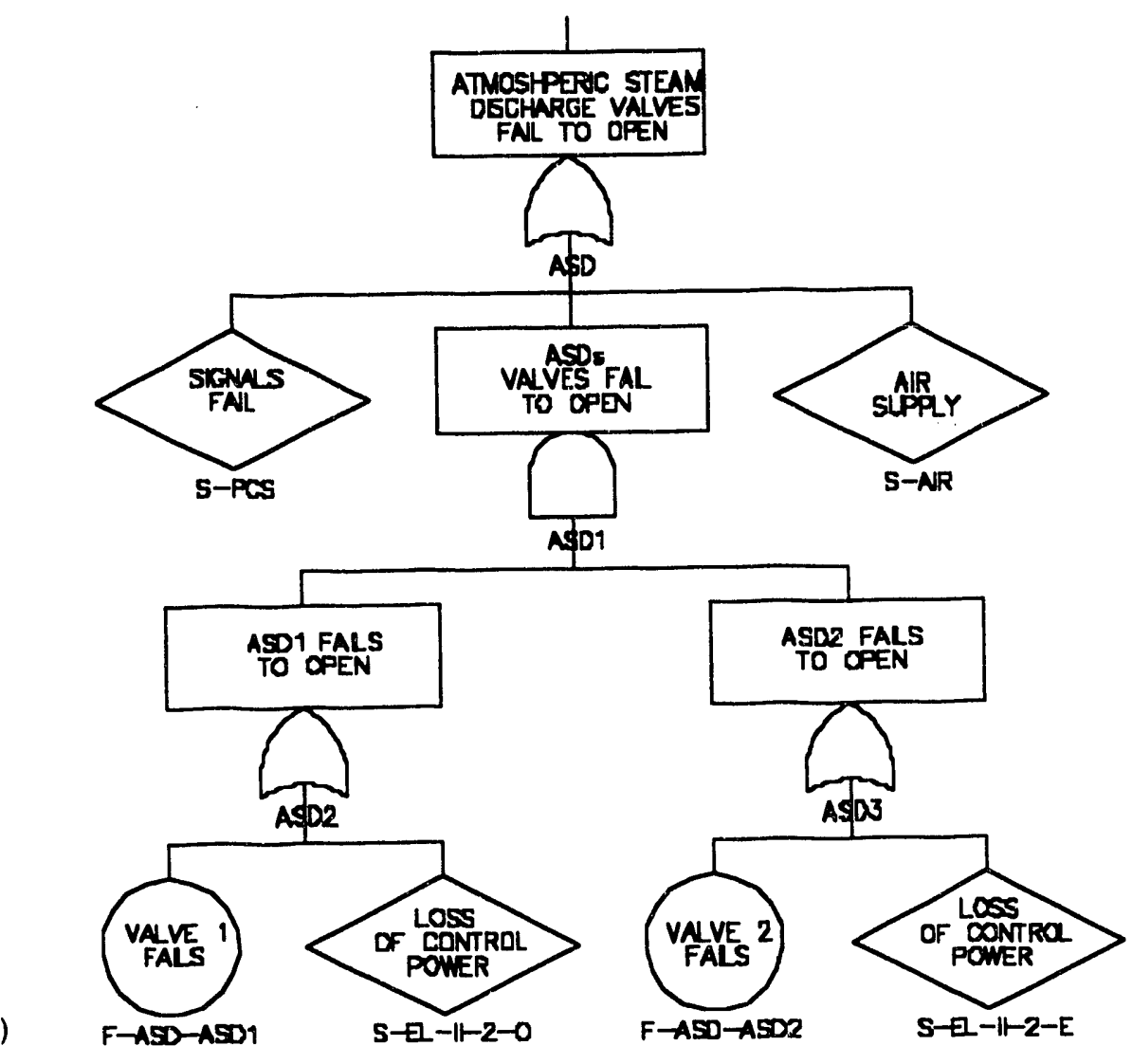

Figure 5.13 (continued)

\subsubsection{Atmospheric Steam Discharge Valves}

The ASDs are used to control steam generator pressure. The ASDs are opened in proportion to steam generator pressure error, normally with an offset in the steam pressure set point. These valves may also be used to provide a heat sink during shutdown for decay heat removal when the main condenser is unavailable. There is one ASD per steam generator.

\subsubsection{Shutdown Cooling System}

The shutdown cooling system (SDC) removes decay heat following reactor shutdown and cools the HTS to a temperature suitable for maintenance of the heat transport components. It is capable of cooling the HTS from full system pressure and temperature and of maintaining it at a low temperature for an indefinite period of time. The SDC consists of two pumps (50\% capacity), two heat exchangers (50\% capacity), and associated valves and piping. The pumps take coolant from the reactor outlet headers and return it via the heat exchanger to the reactor inlet headers. The SDC is normally cold and depressurized and isolated from the HTS. The SDC must be started manually. The fault tree for loss of shutdown cooling is shown in Fig. 5.15(a) and (b). The failure modes modeled in the fault tree are failure to initiate sysiem operation, loss of flow, and loss of heat removal from the heat exchangers. Figure 5.16 shows the flow diagram for the SDC.

\subsubsection{Moderator Cooling System}

The moderator cooling system (MCS) is independent from the HTS. It includes two pumps (50\% capacity) and two $50 \%$ heat exchangers. The calandria extension maintains the moderator level in the calandria within the required range by accommodating moderator swell and shrinkage resulting from temperature fluctuations. The moderator functions as a heat sink when other heat removal systems have failed. For the MCS to remove heat from the HTS, the pressure tubes must deform and come in contact with the calandria tube because very limited heat transfer will occur across the $\mathrm{CO}_{2}$-filled space. Figure 5.17 shows the fault tree for loss of moderator cooling, and Fig. 5.18 is a flow diagram for the moderator system. 
Systems

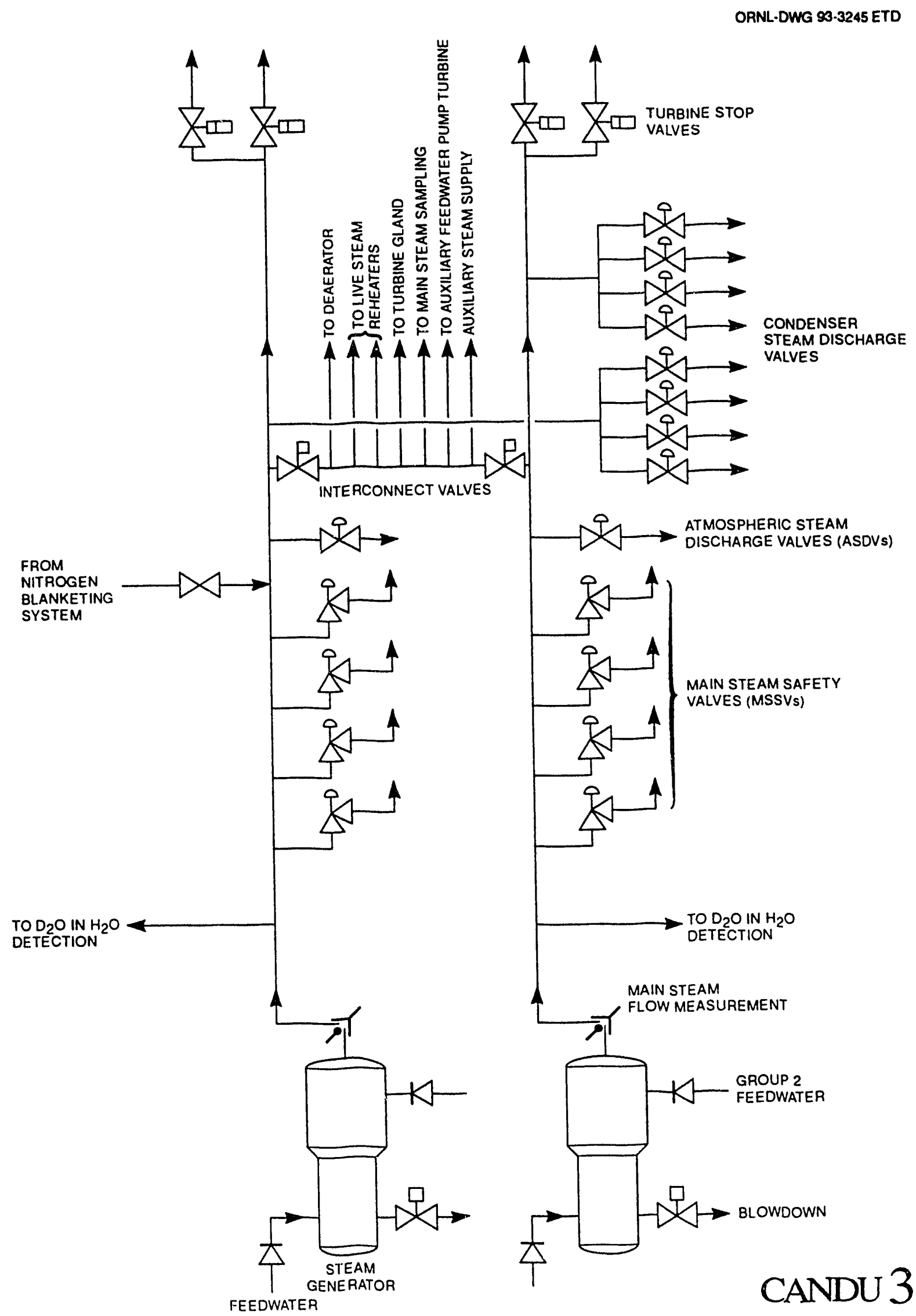

Figure 5.14 Schematic of SD 
(a)
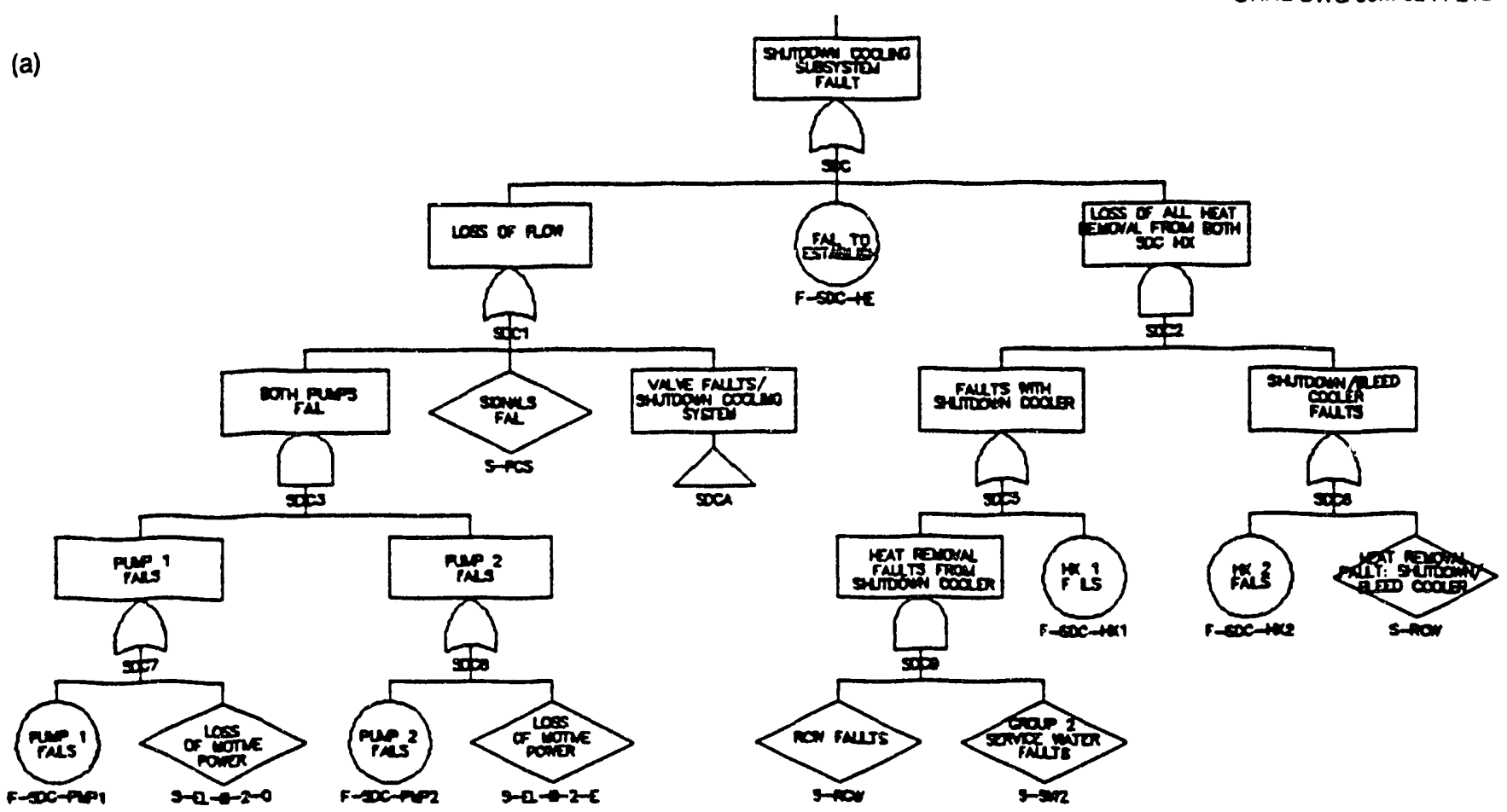

(b)
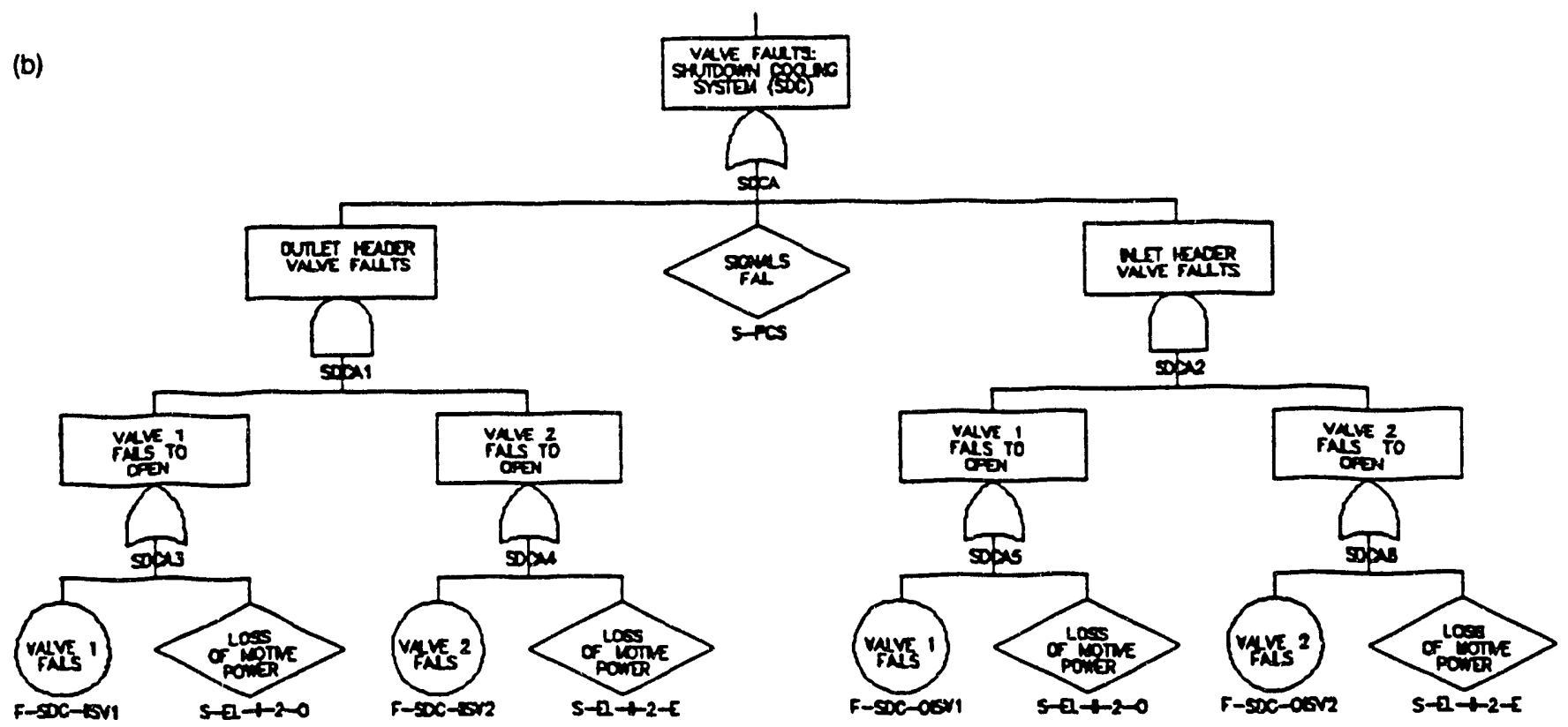

Figure 5.15 SDC fault tree 

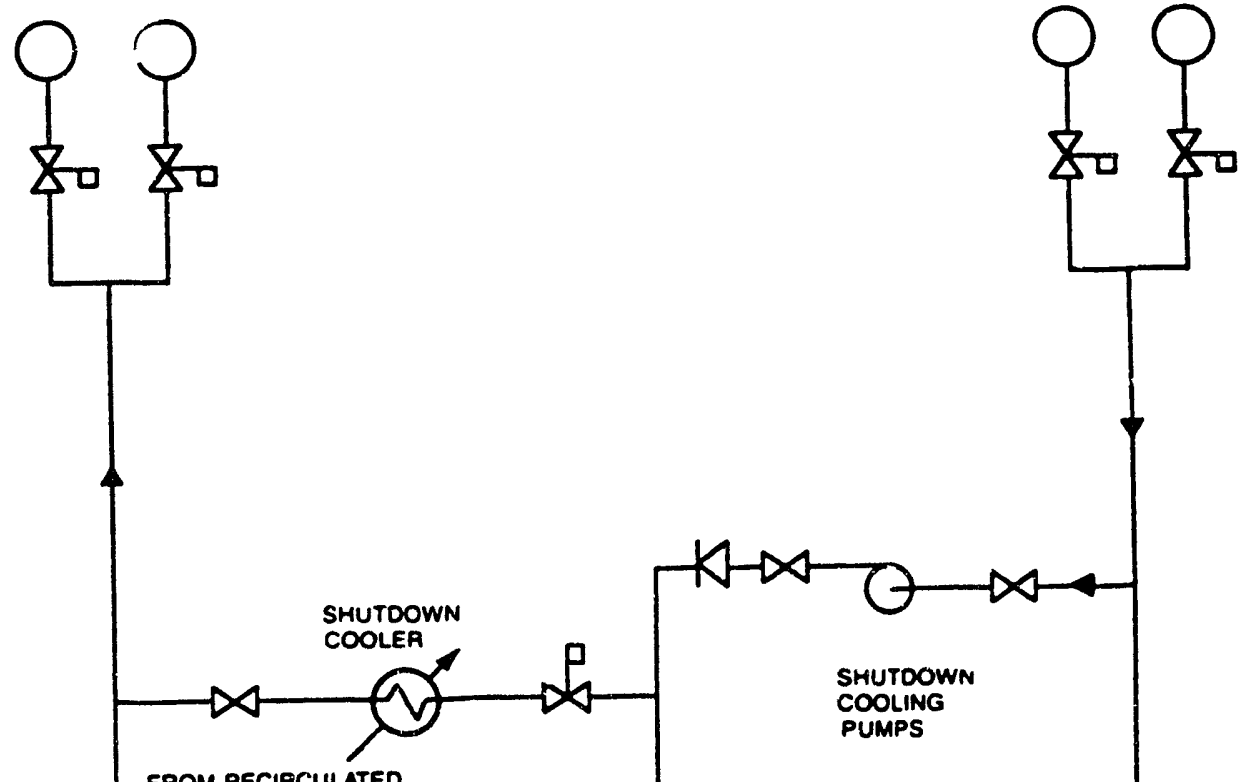

FROM RECIACULATED

COOLIMS WATEA

SYSTEMGMOUP 2

RAW SERN'SE WATER
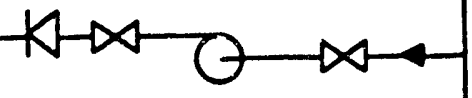

SHUTOOWN

COOLING

PUMPS

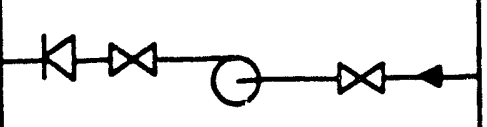

FROM BL EED
T J MEAT

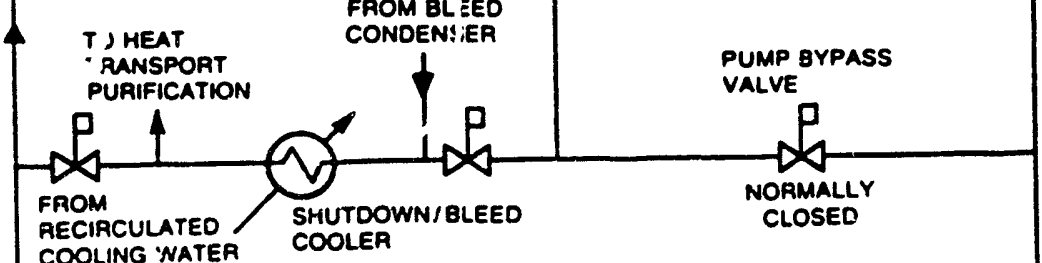

COOLNG NNATER COOLEP

SYSTEM

$\left.\right|_{1} ^{1}$<smiles>[AlH2]C1CC1</smiles>

hEAT EXCHANGER

BYPASS VALVE

Figure 5.16 Flow diagram for SDC 


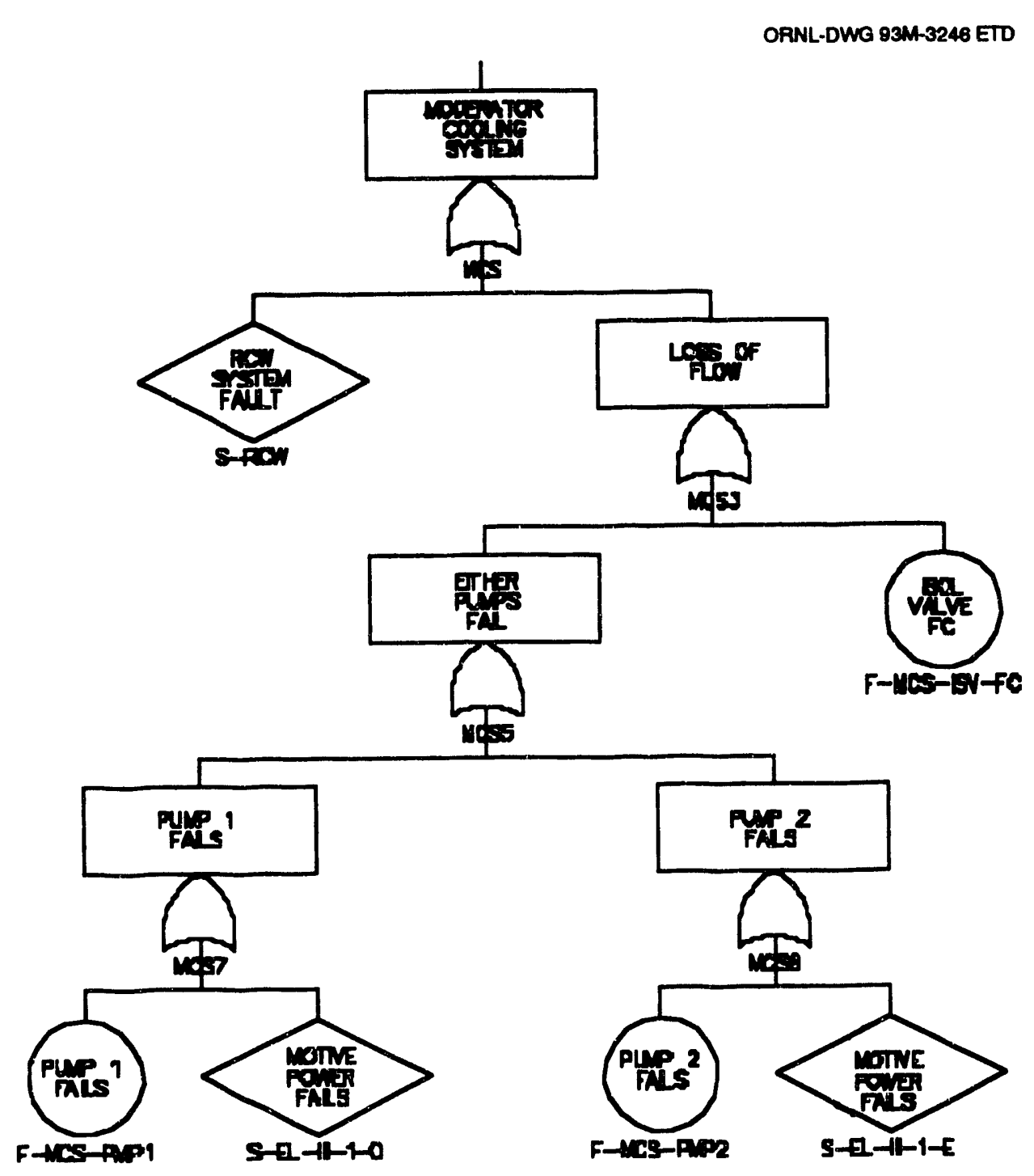

Figure 5.17 MCS fault tree

\subsubsection{Emergency Core Cooling System}

The ECCS supplies emergency coolant to the reactor headers in the event of a loss-of-coolant type accident. The system operation is divided into two parts, short-term injection and long-term recirculation. The short-term injection consists of two stages: HPI and LPI. The fault tree in Fig. 5.19(a)-(i) demonstrates how the ECCS can fail to replenish lost HTS inventory. Figure 5.20 shows a schematic for the ECCS. The ECCS design analyzed in this report is that documented in the CSR. ${ }^{1}$

\subsubsection{ECCS High-Pressure Injection}

The HPI mode of the ECCS is initiated by the loss-ofcoolant signal (LOCS) when there is a loss-of-coolant event and subseguently the need to refill the core. The ECCS (i.e., HPI, LPI, and recirculation) is controlled by dedicated computers that perform the initiation, monitor- ing, display, and testing function. Each signal essential for the system operation is triplicated so that a single component or power supply failure does not incapacitate or spuriously invoke system operation.

A LOCS is generated when the HTS pressure falls to a predetermined value and one of the emergency core cooling conditioning signals (high reactor building pressure or low pressurizer level) is activated. The logic used with the three channels is such that any two channels alarming due to low heat transport pressure in conjunction with any two of the three conditioning signals will generate the LOCS.

The system logic performs the following functions:

1. opens gas isolation values, the HPI valves, and the $\mathrm{D}_{2} \mathrm{O}$ isolation valves, 


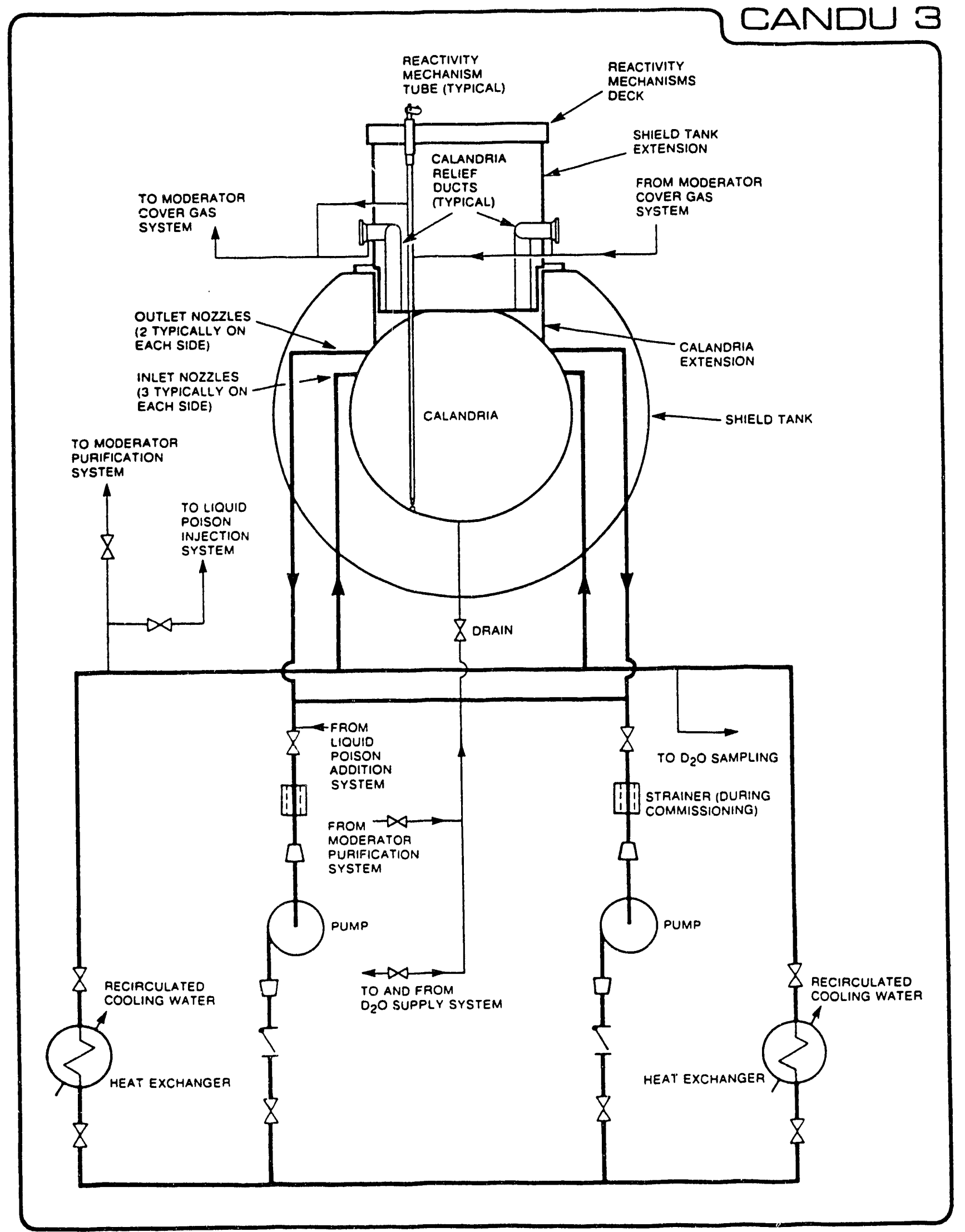

Figure 5.18 MCS tlow diagram 
(a)
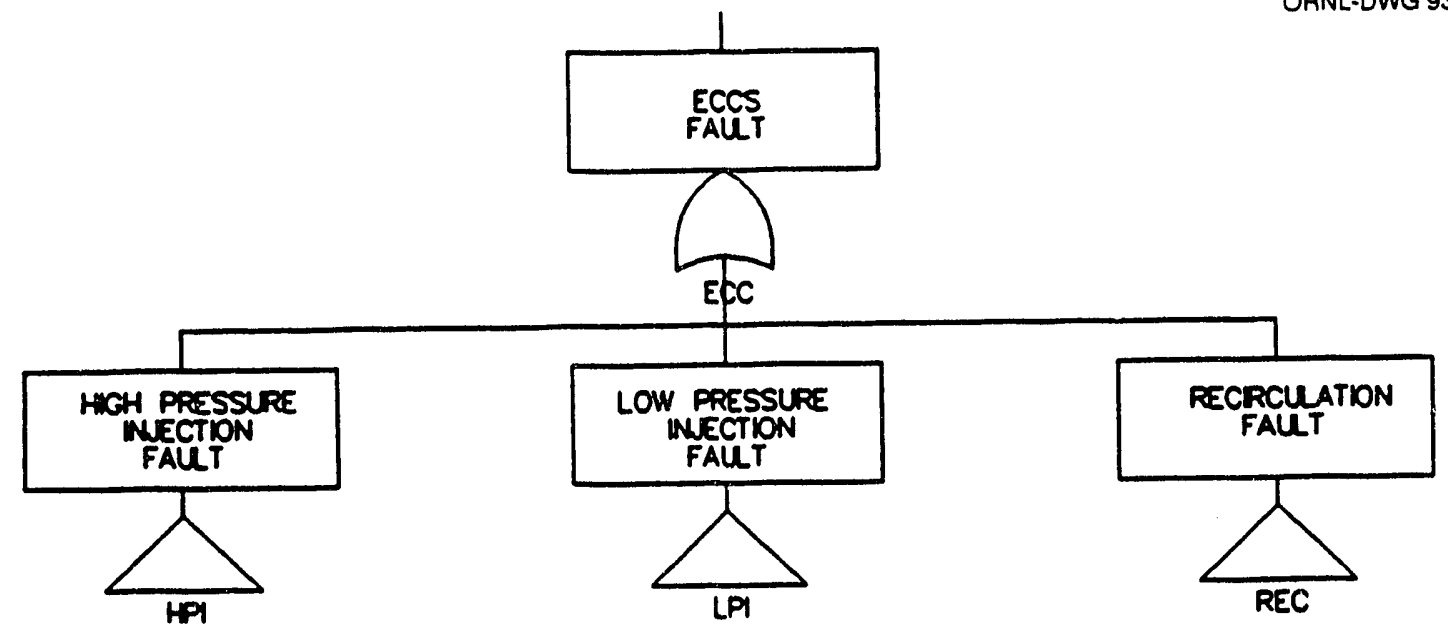

(b)
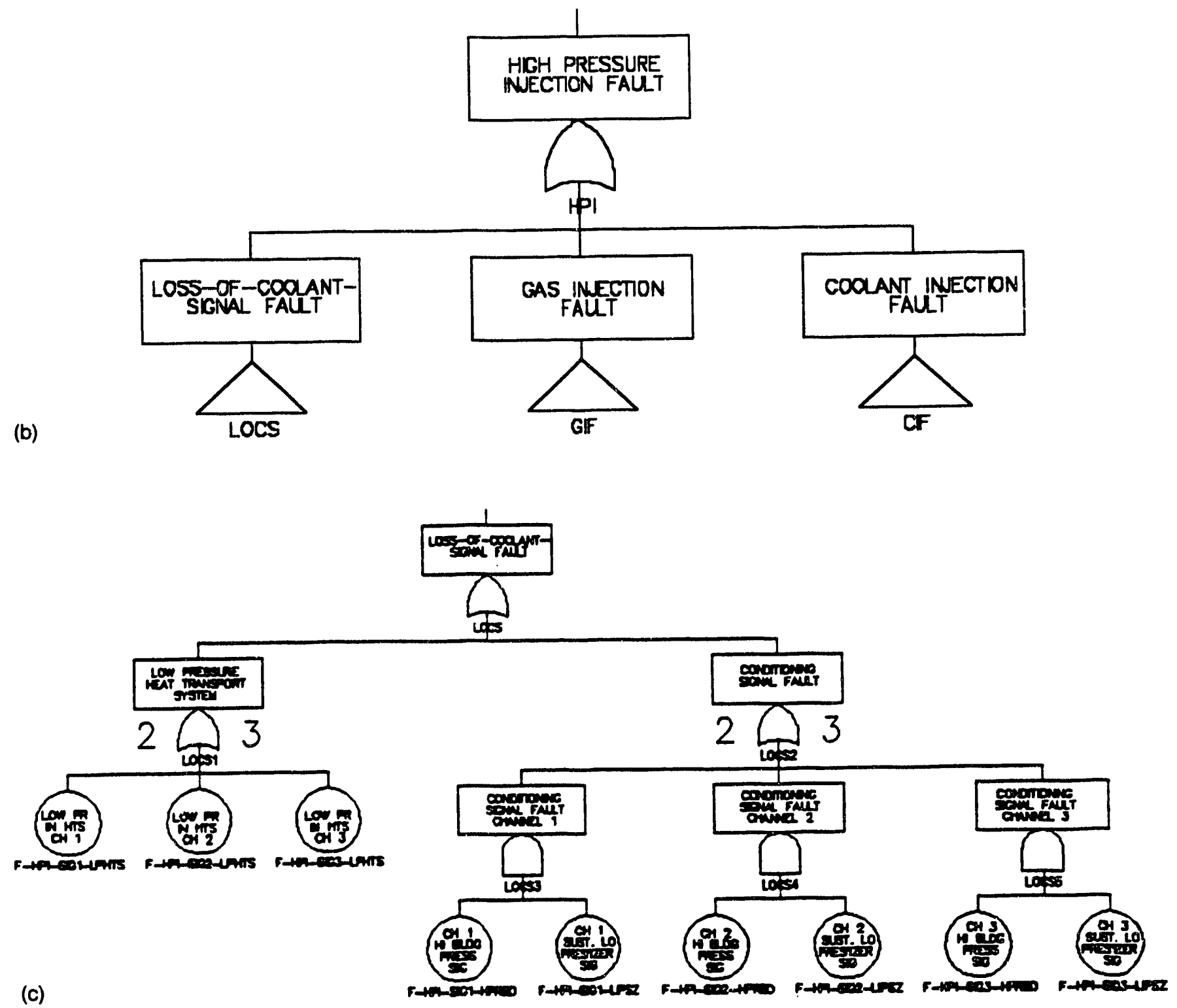

Figure 5.15 ECCS fault tree 

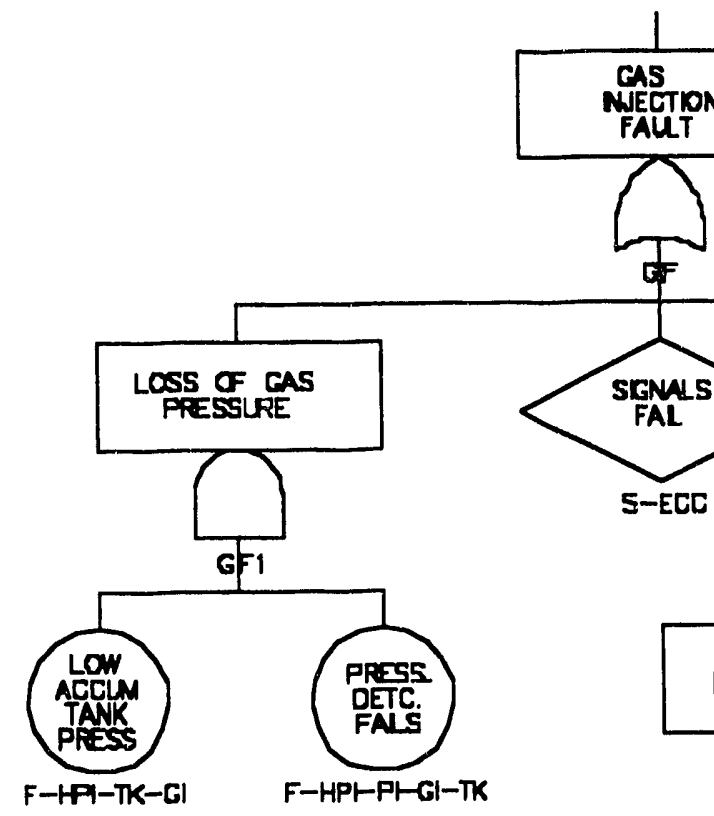

(d)
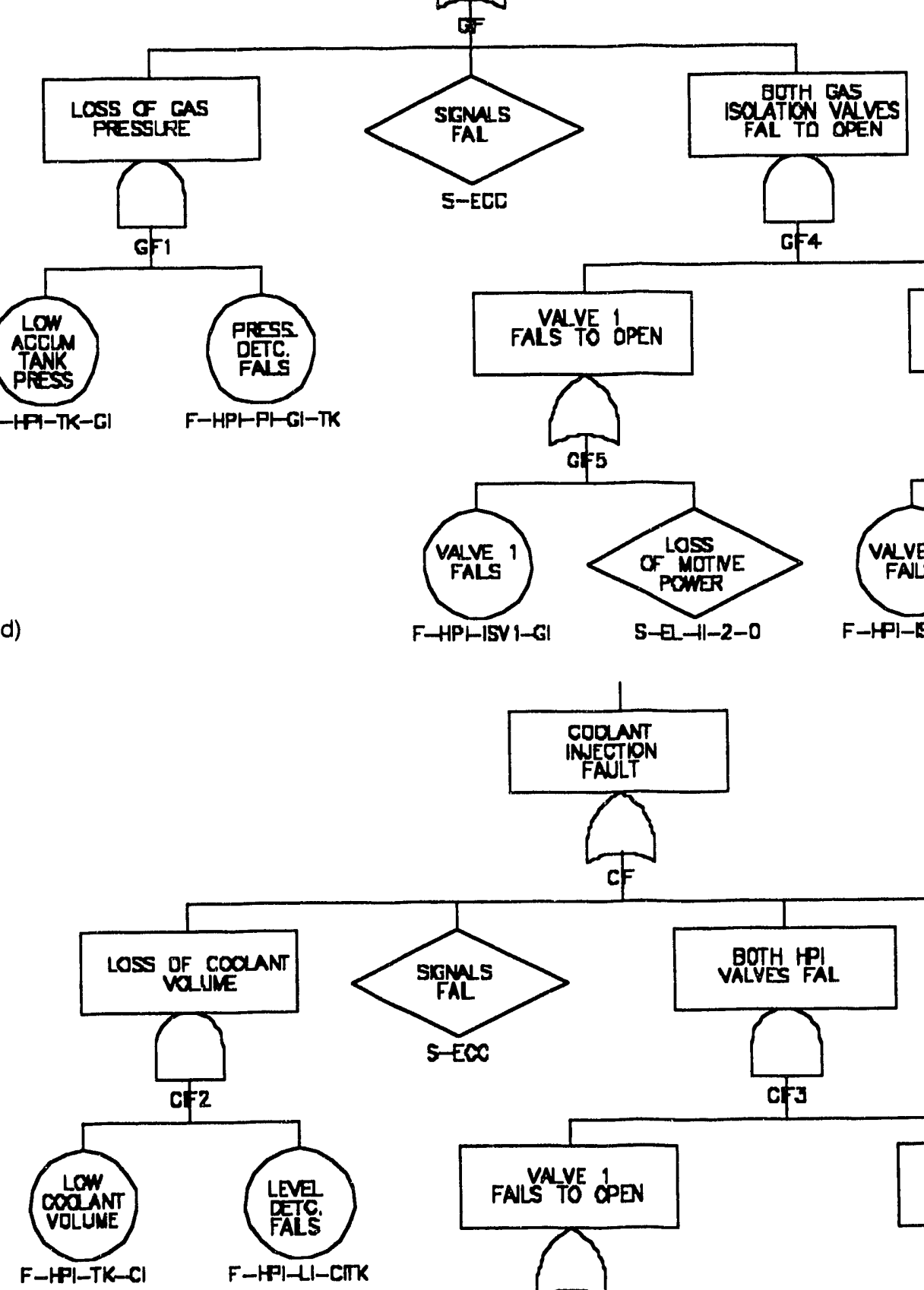

(e)
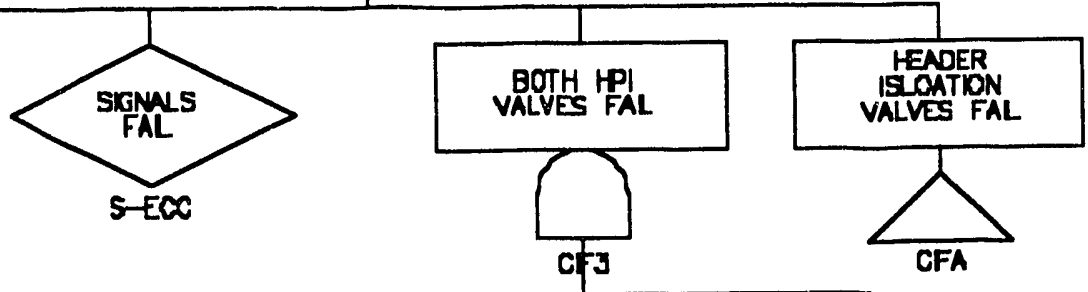

FALS TO OPEN
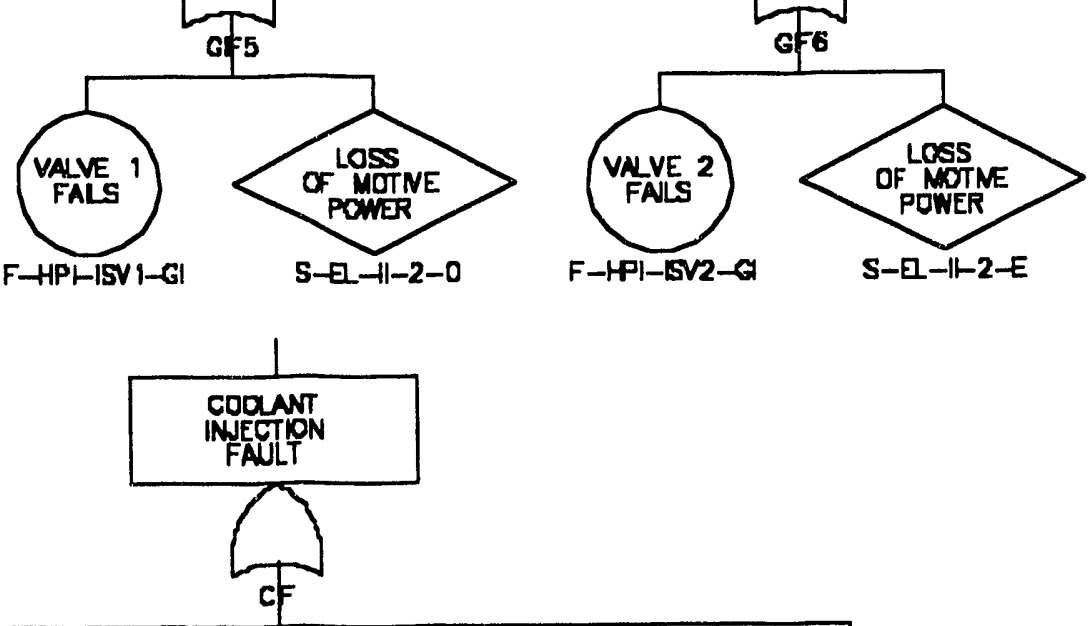

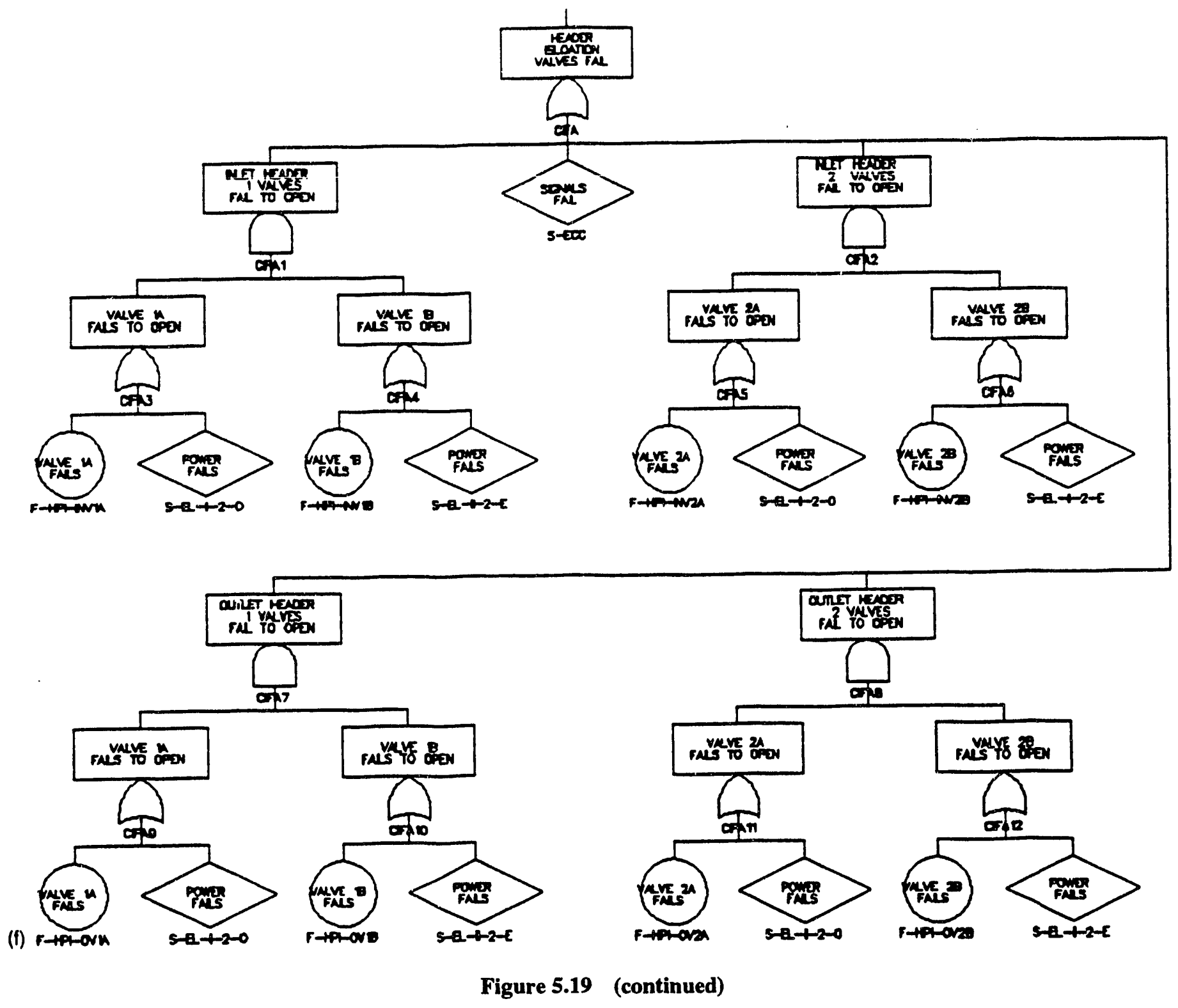

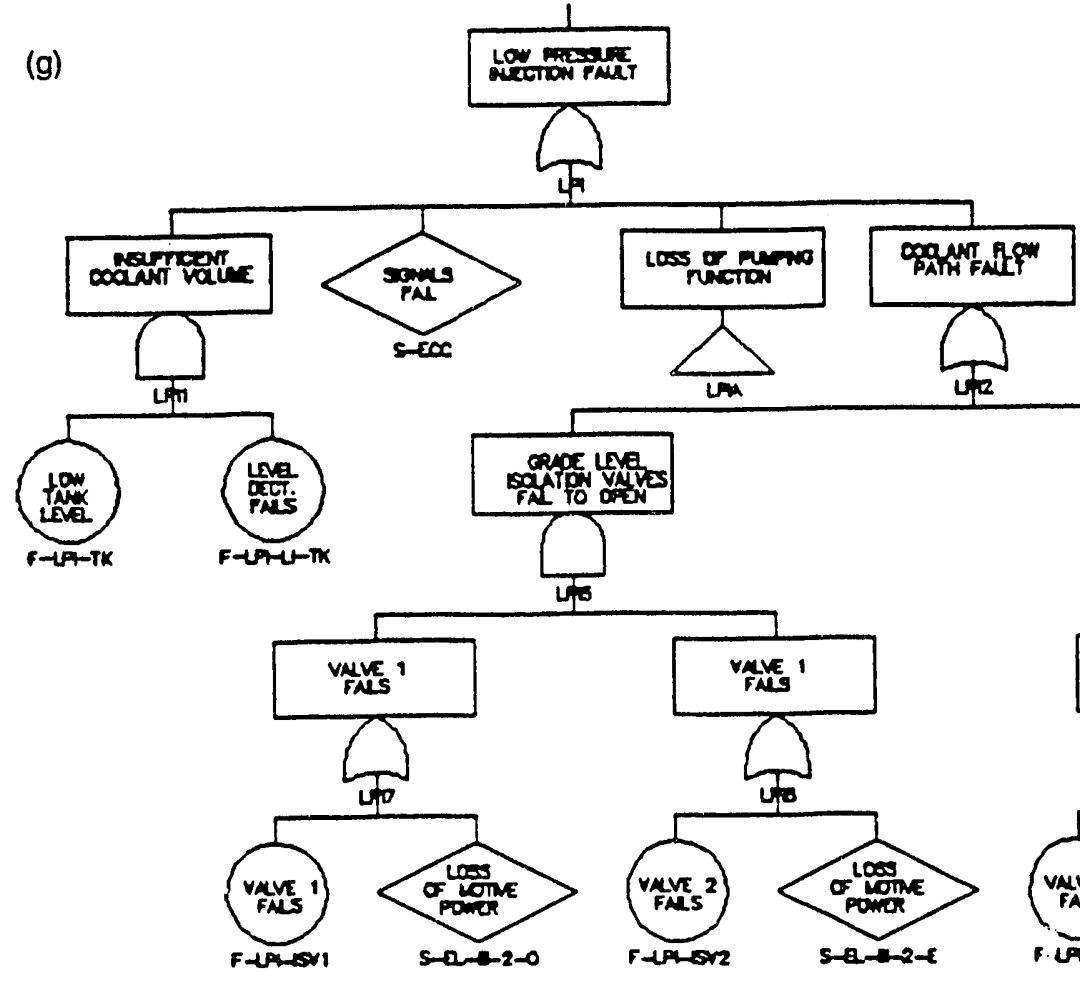

(h)
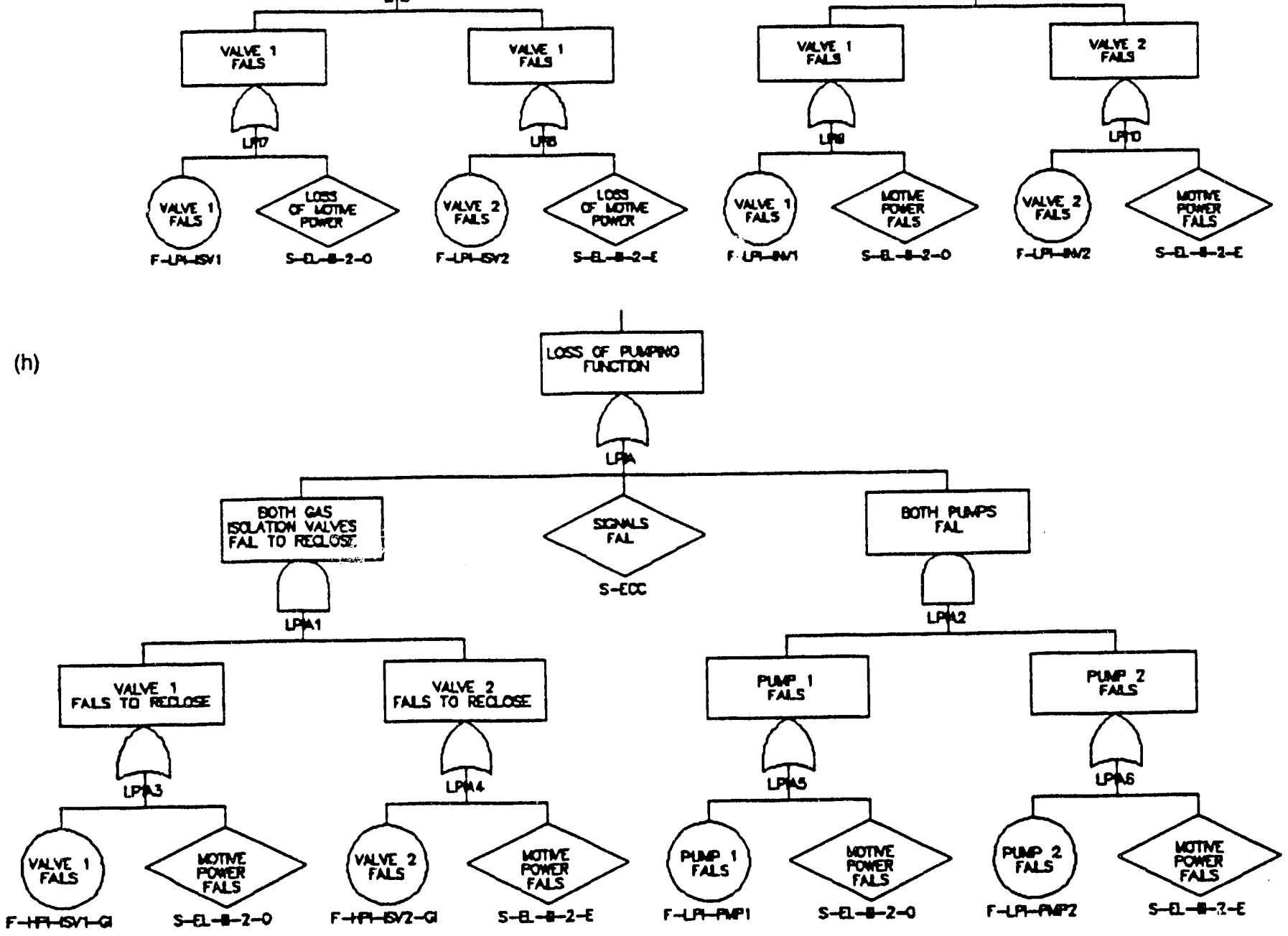

Figure 5.19 (continued) 


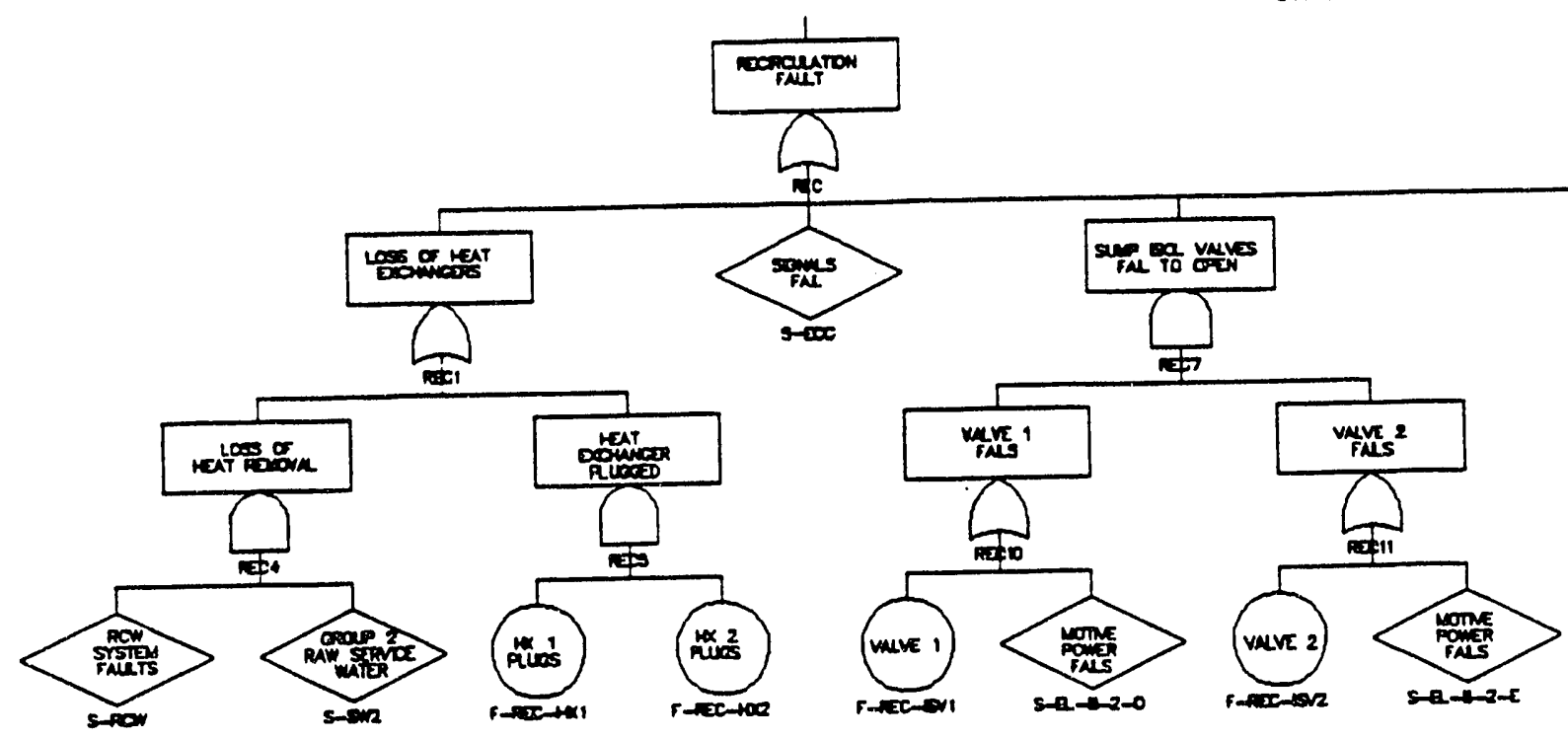

(i)

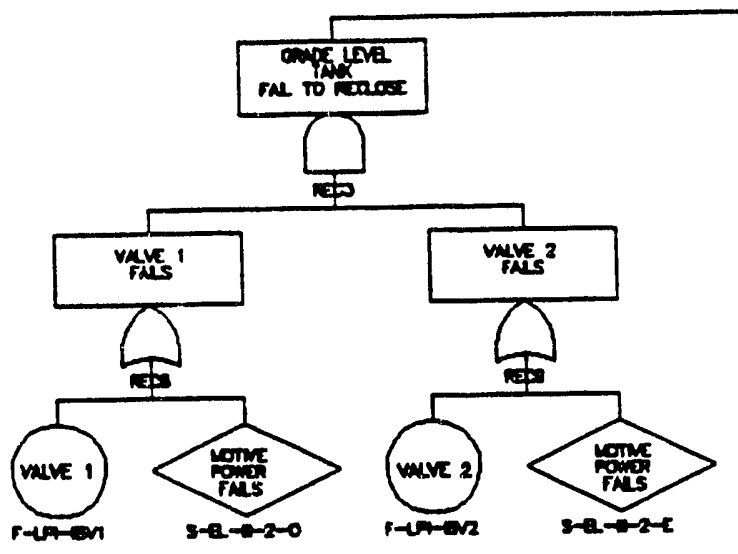

Figure 5.19 (continued)

2. starts one of the emergency core cooling pumps,

3. opens the grade-level tank isolation valves,

4. starts the Group 2 Class III diesel generators,

5. opens the MSSVs, and

6. trips the heat transport pumps.

Note that only the first three of these functions are required for successful ECCS operation. These other functions are to help alleviate complications that may accompany a LOCA.

The rupture disks in the ECCS burst when the gas isolation and HPI valves open. Opening these valves along with the $\mathrm{D}_{2} \mathrm{O}$ isolation valves allows the pressurized gas (stored in the accumulator gas tank) to inject the water from the coolant tank into the HTS when the HTS pressure falls

NUREG/CR-6065 below the HPI (accumulator gas) pressure. A low-level signal in the water accumulator tank results in the HPI valves being closed to prevent air from being forced into the HTS.

An air compressor backed up by a compressed nitrogen supply maintains the gas tank pressure. The electrical valves for HPI are supplied from Group 2, Class II power. The controls and power supplies for parallel valves are separated and independent. Parallel valves are on "odd" and "even" feeds. The valves fail "as is" on loss of power. The pressure in the gas accumulator tank and the level in the water tank are monitored.

The conditions that can result in failure of HPI can be categorized as follows: (1) conditions that cause LOCS faulis, (2) conditions that prevent gas injection (i.e., loss of 

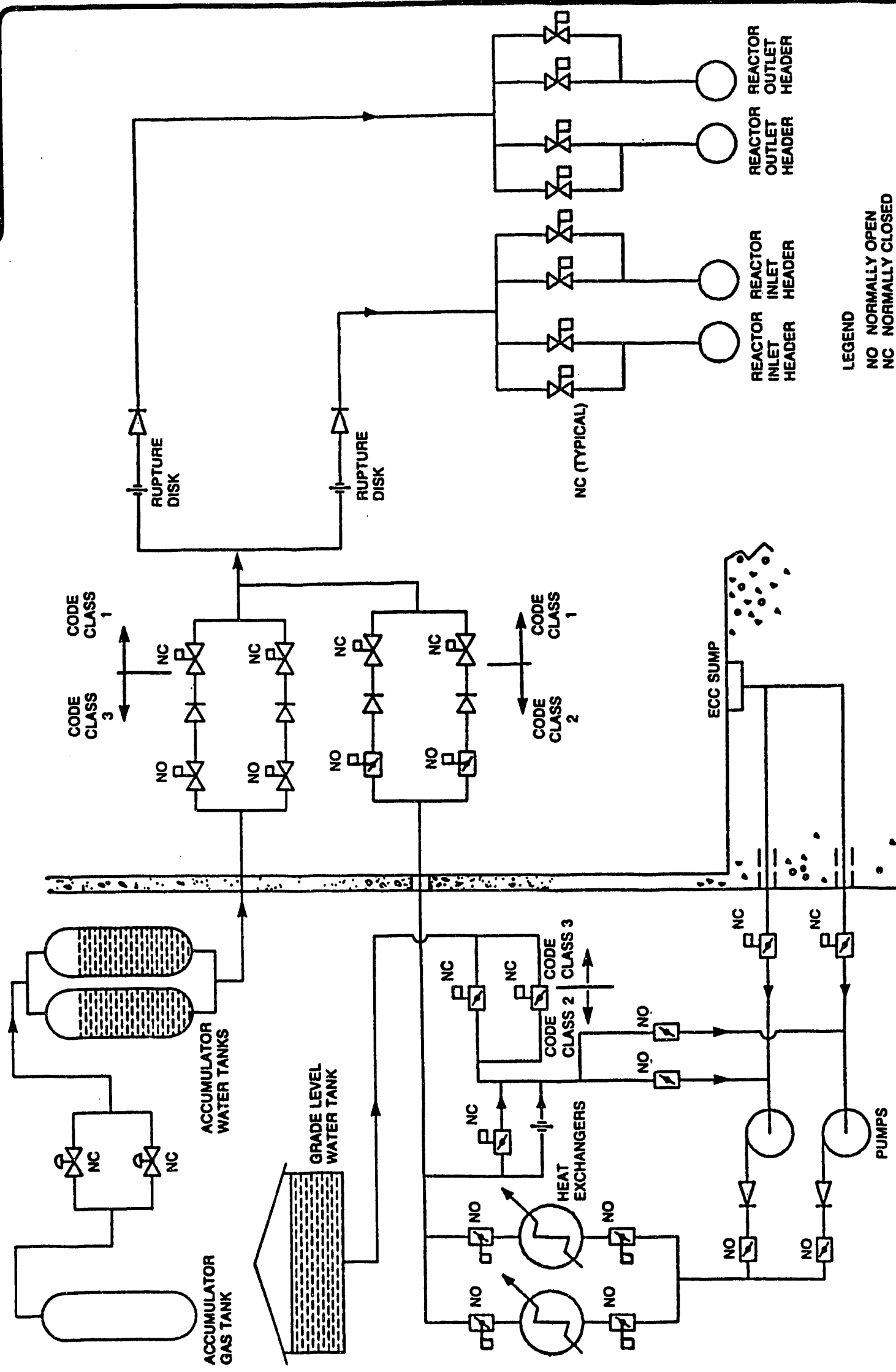
pressure and flow path faults), and (3) conditions that prevent coolant injection (i.e., loss of coolant and coolant flow path faults).

\subsubsection{ECCS Low-Pressure Injection}

During the HPI mode, the grade-level isolation valves are opened, and one of the two pumps is started by the LOCS, which initiated HPI. The operating pump recirculates water via a bypass loop during HPI.

Following the HPI mode of ECCS, the LPI mode of the ECCS is initiated automatically. The HPI valves are closed, and the LPI valves are opened. Water from the grade-level tank is injected into the HTS via the pumps. A low-level signal in the grade-level tank closes the valves in the pump suction line from the tank and terminates the LPI mode of ECCS. These operations are required for successful system operation.

The pumps are energized from Group 2, Class III buses and are $100 \%$ capacity. The valves used during LPI are powered by Group 2, Class III power and fail "as is." The controls and power supplies to each valve of a pair are separated and independent. The pair of valves are fed from "odd" and "even" circuits. The water level in the gradelevel tank is monitored.

The three main failure categories for LPI are loss of coolant, coolant flow path fault, and loss of pumping function. Flow path faults include isolation valves for the water tank and LPI injection valves.

\subsubsection{ECCS Recirculation}

Recirculation of the ECCS (REC) is the long-term mode of cooling the reactor core following a loss-of-coolant event. Recirculation is initiated following LPI mode of operation of ECCS, which terminates when the low-level signal in the grade-level tank closes the valves in the pump suction line from the tank.

The REC mode starts when cooling water flow is initiated to the recirculation heat exchangers and the recovery line isolation valves are opened to the reactor building sump. The mixture of the heat transport coolant and water from the HPI and LPI tanks that collected on the floor and sump of the reactor building is then returned to the HTS by the pumps. For large breaks, decay heat is removed from the core via the coolant discharged from the break, and this heat is transferred to the recirculated cooling water (or the Group 2 service water as a backup) via the ECCS heat exchangers. There are two $100 \%$ capacity heat exchangers in this system. The valves used during REC mode are powered by Group 2, Class III power and fail "as is." The controls and power supplies to each valve of a pair are separated and independent. The valve pairs are powered from "odd" and "even" circuits.

The major failure categories are loss of the heat exchangers and coolant flow path faults. The pumps are modeled as part of the LPI stage of ECCS.

For small breaks, decay heat is transferred to the steam generators and rejected via the MSSVs. These valves have a total capacity of over $100 \%$ steam flow at normal steam generator pressure.

\subsubsection{Bleed Condenser System}

The bleed flow from the HTS is discharged into the bleed condenser system (BCS) as two-phase steam and liquid. The steam is condensed by cooling spray supplied by the heavy water feed pumps. The bleed flow is further cooled by the shutdown/bleed cooler. The shutdown/bleed cooler also operates as shutdown cooler for decay heat removal during reactor shutdown. The BCS is equipped with spring-loaded safety relief valves that are designed in conjunction with the heat transport relief valves to ensure that HTS overpressure protection requirements are met.

The liquid relief valves (LRVs) are designed to open to avoid overpressurization of the HTS. These valves are designed to fail open on loss of power or air. Failure of these valves to reclose will result in loss of HTS inventory through the $\mathrm{BCS}$ to the $\mathrm{D}_{2} \mathrm{O}$ storage tank and into the reactor building. Failure to isolate the BCS in this situation would result in an event like a SBLOCA. The BCS and makeup system level control valves can isolate the BCS. The fault tree for the failure to isolate the BCS is shown in Fig. 5.21. It was assumed that the valves receive power from the Class II Group 1 buses and the BCS level control valves require plant air. Figure 5.22 shows the HTS pressure and inventory control system.

\subsubsection{Steam Generator Isolation}

The feedwater piping breaks between a steam generator and its check valve require the operator to isolate flow away from that steam generator to minimize water loss. ${ }^{*}$ The valve used to accomplish this is air-operated and fails open on loss of air or power. It was assumed that the valve

\footnotetext{
*Atomic Energy of Canada, Limited, Presentation of Information at NRC/AECL Review Meeting on the CANDU 3 Systems Research Study, February 10, 1993.
} 


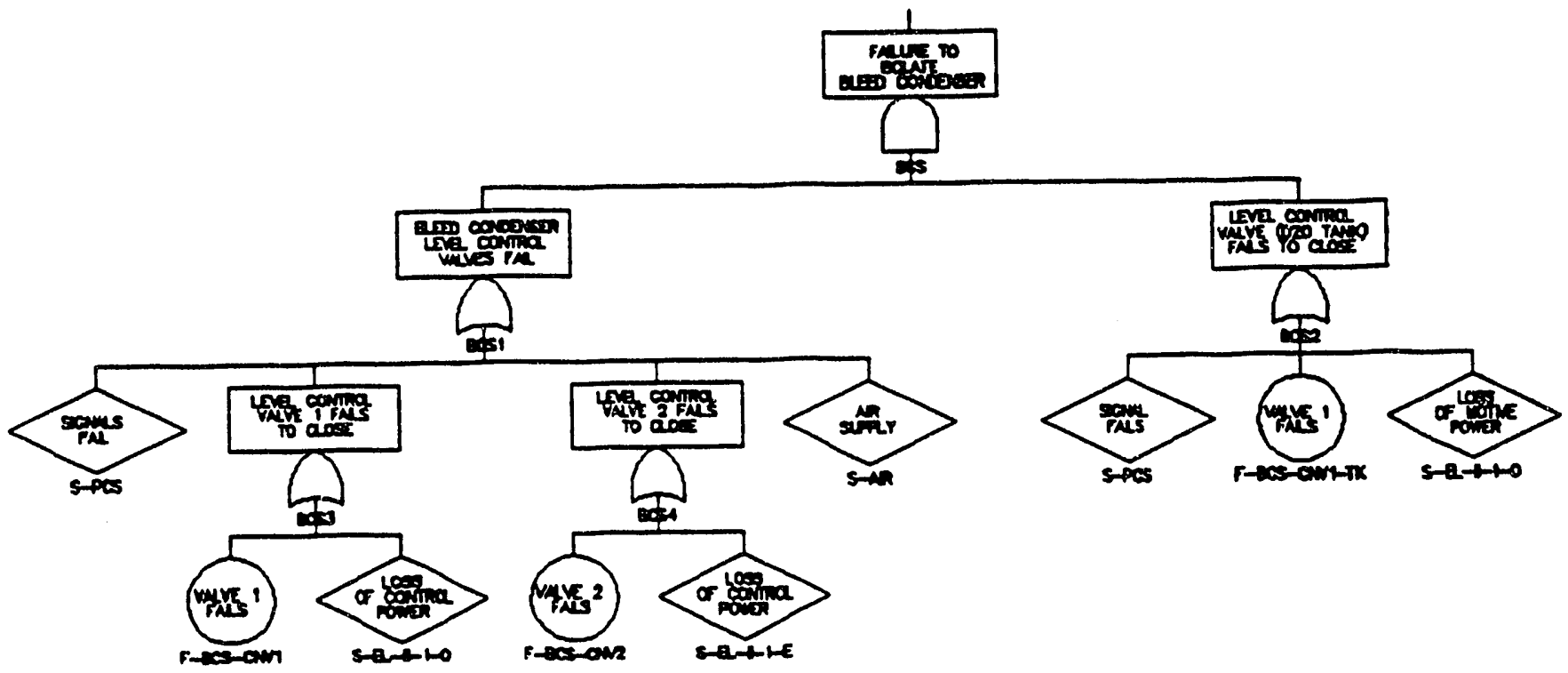

Figure 5.21 BCS isolation fault tree

receives its control power from Group 1 Class II power. Figure 5.9 shows the valves that would be used to accomplish ISO. The fault tree for ISO failure is shown in

Fig. 5.23.

\subsubsection{Liquid Relief Valve Closure}

It is necessary for the LRVs to open and relieve HTS inventory into the BCS to control HTS pressure during normal plant operation and during mitigation of some IEs. It is important for the LRVs to reclose so that sufficient HTS inventory is maintained. The fault tree in Fig. 5.24 shows the failure mechanisms for the LRVs failing to close. The LRVs are part of the pressure and inventory control system and are shown in Fig. 5.22.

\subsubsection{Crash Cooling}

The crash cooling (CC) of the steam generators is performed to quickly remove heat from the reactor core, allowing the pressure in the HTS to drop so that ECCS injection can be achieved. CC is accomplished by opening the MSSVs to release steam. The MSSVs are signaled by the ECCS control system to open upon receipt of a LOCS. In addition, half of the MSSVs are signaled to open when SDS2 is initiated. ${ }^{*}$ The MSSVs require instrument air to

\footnotetext{
"Letter from AECL Technologies to the U.S. NRC, "Responses to February 10,1993 NRC/ORNL Request for Information," February 22, 1993.
}

open and are assumed to receive control power from the Group 2 Class II buses. The CC fault tree is presented in Fig. 5.25(a)-(c).

\subsubsection{Main Steam Safety Valves}

Four MSSVs are provided for each of the two steam mains (i.e., steam generators). The MSSVs protect the steam system and steam generators from overpressure. The failure mode of concern in Fig. 5.26 is failure of the MSSVs to open to discharge the steam. The MSSVs for both steam generators are required to open to discharge steam. It is assumed that if three MSSVs open, then flow is suficient to discharge the steam from that steam generator. It is also assumed that the MSSVs self-actuate for the steam removal function. Figure 5.14 shows the MSSVs.

\subsubsection{Emergency Generators}

The emergency generators (GENs) are required to supply power to equipment necessary to safely shut down the plant on LOP. Little information was provided regarding the GEN system; therefore, a single event fault tree was drawn for restoration of Class III power. The restoration of Class III power includes either off-site power being recovered or operation of the diesel generators. The fault tree for the GEN system is presented in Fig. 5.27. Partial restorations of power were not analyzed due to the amount of available resources. 


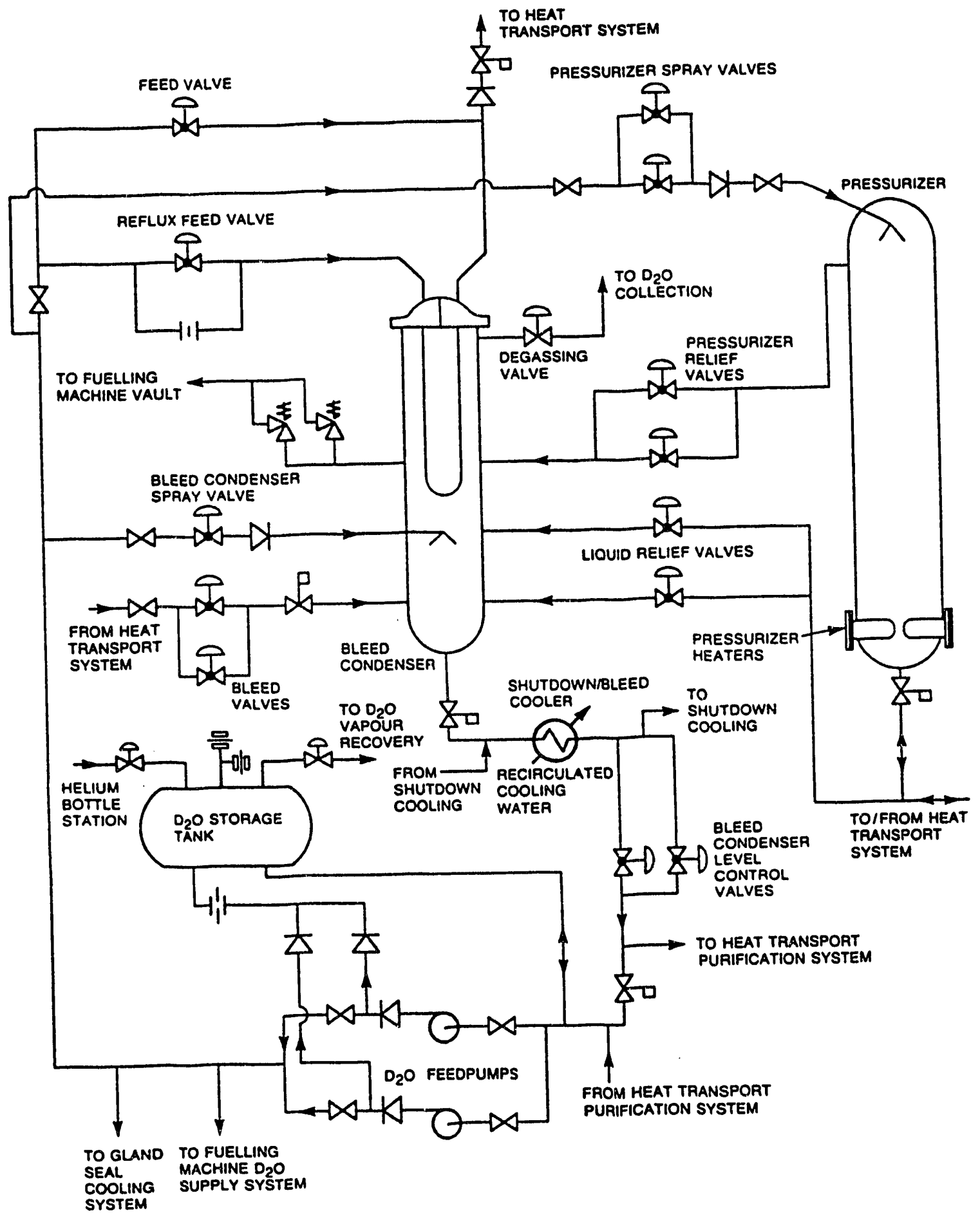

Figure 5.22 Pressure and inventory control system 


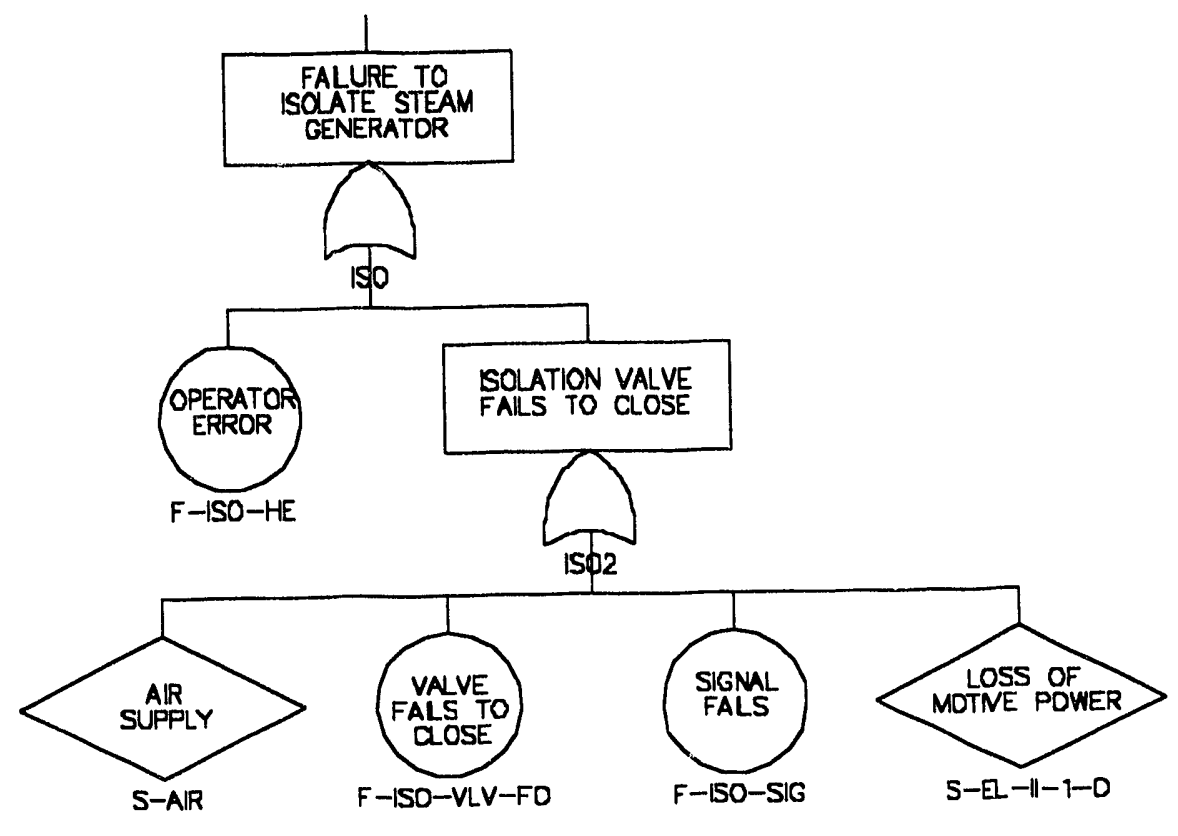

Figure 5.23 ISO fault tree

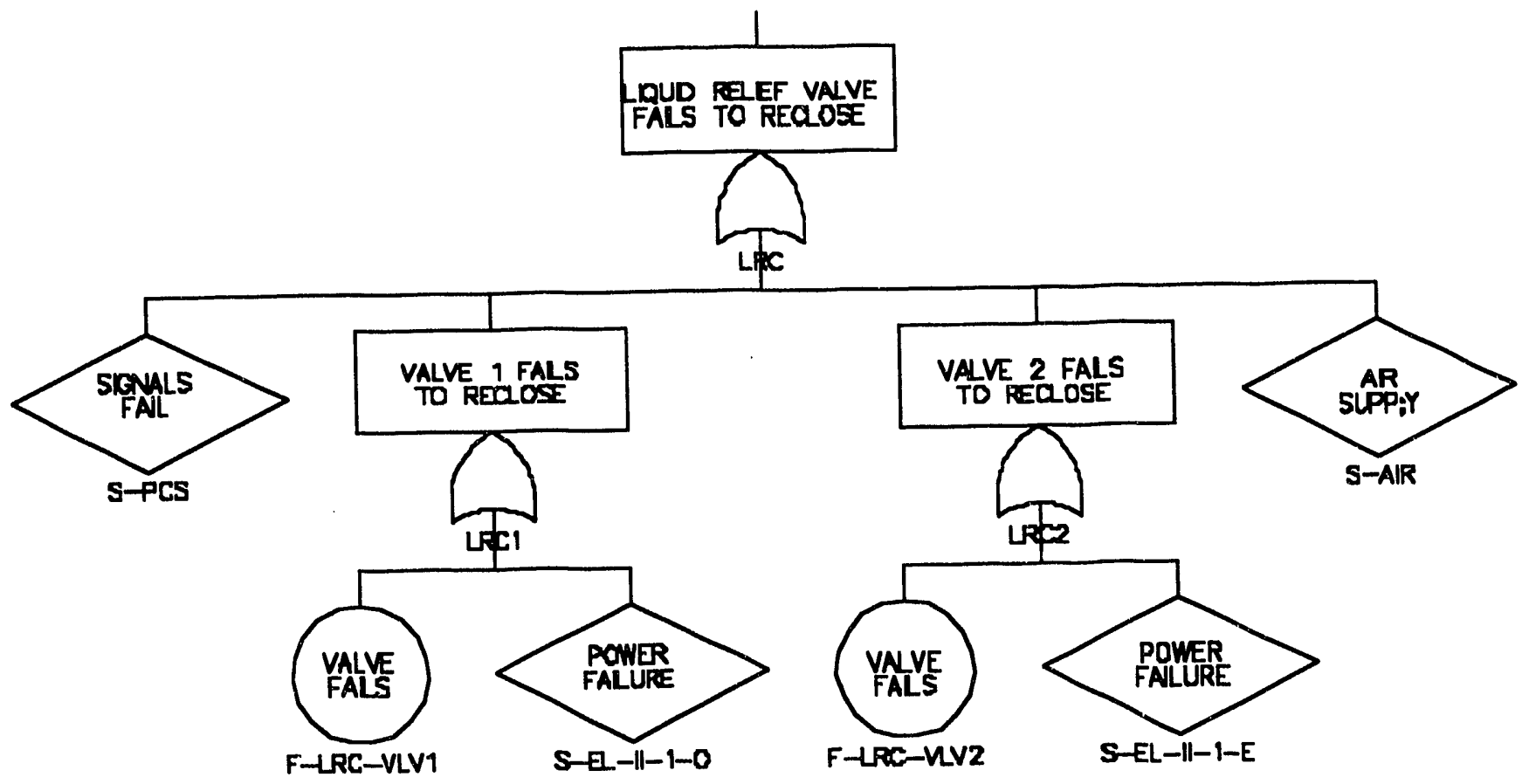

Figure 5.24 LRC fault tree 
(a)
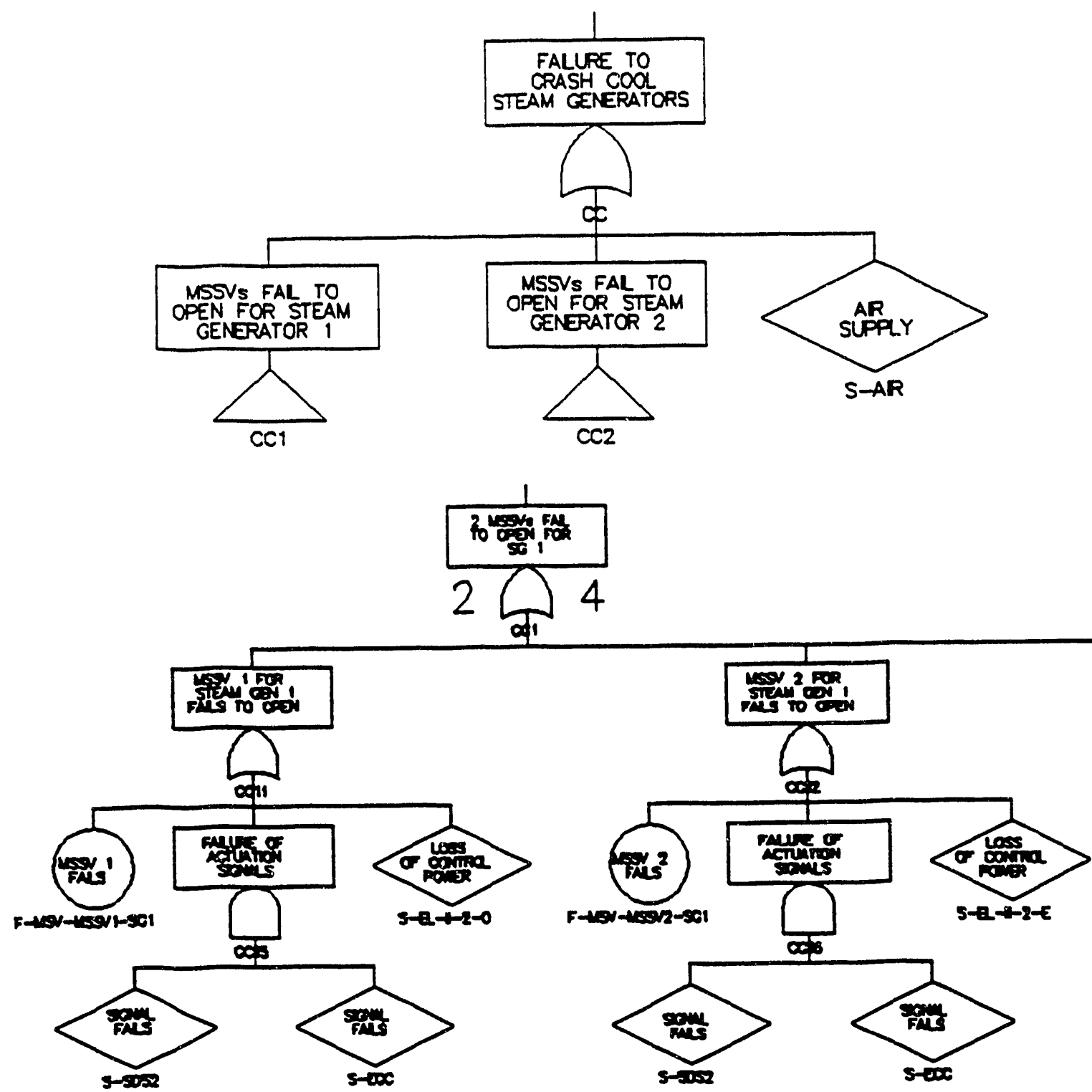

(b)
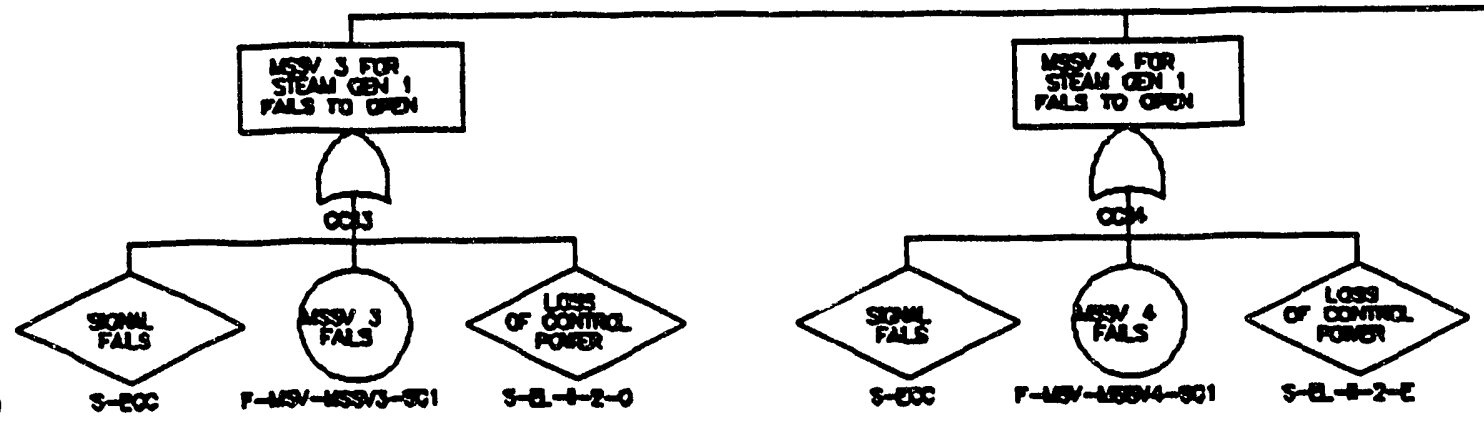

Figure 5.25 CC fault tree 

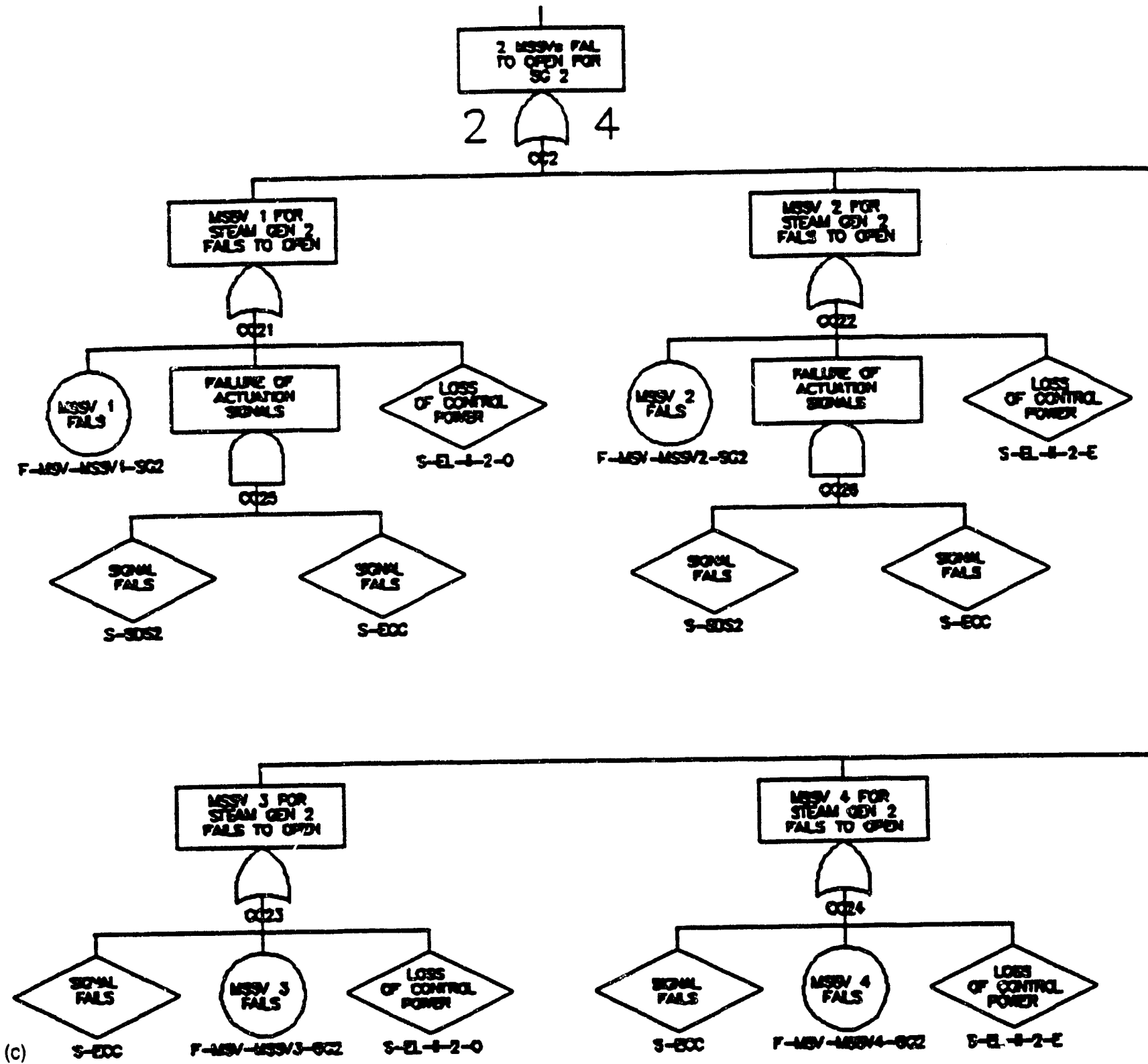

Figure 5.25 (continued) 


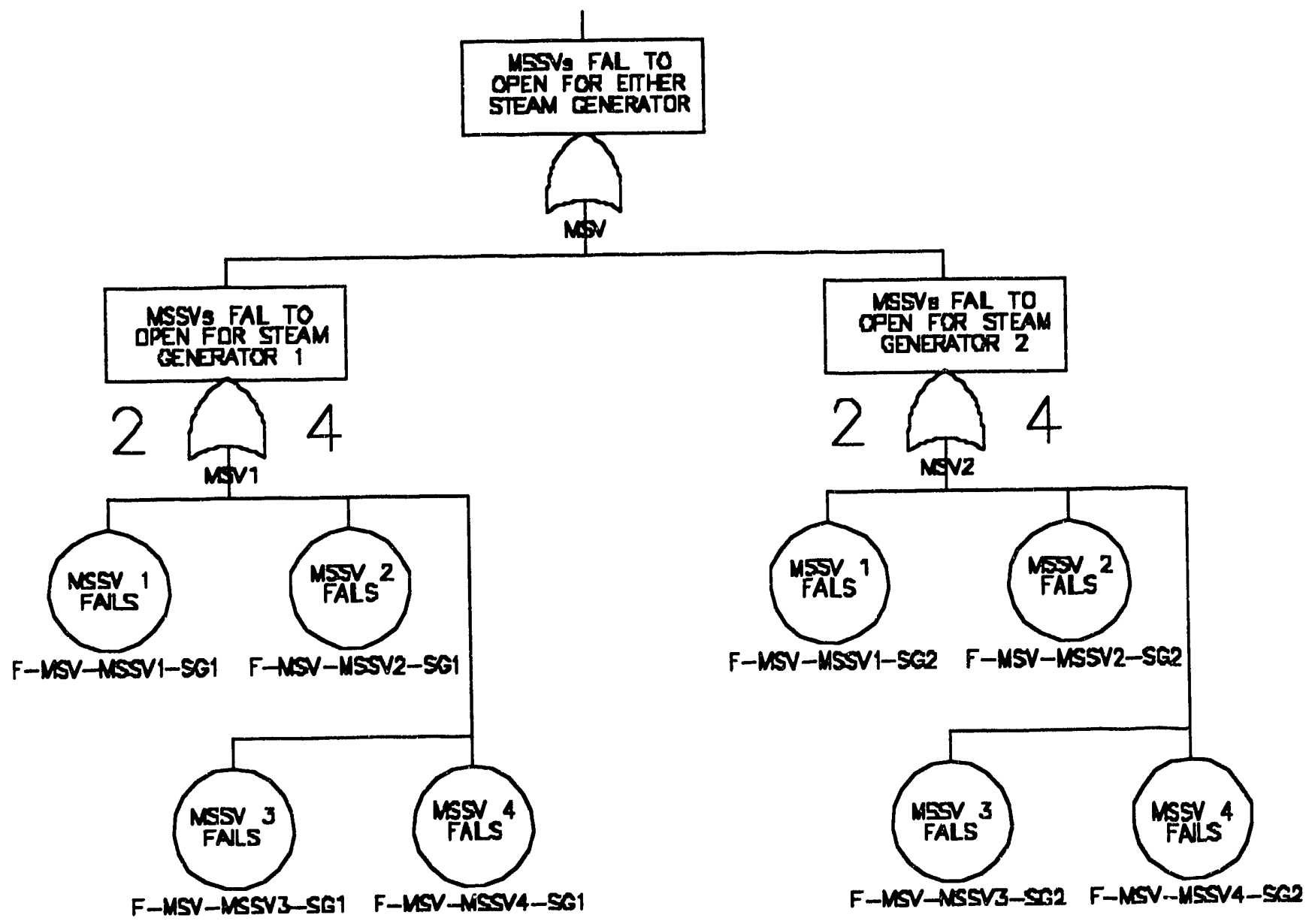

Figure 5.26 MSSV fault tree

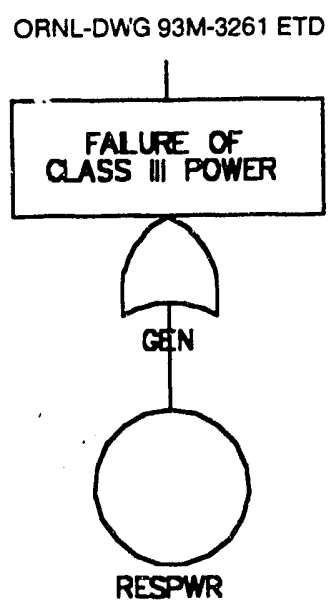

\section{References}

1. Atomic Fnergy of Canada, Limited, CANDU 3 Conceptual Safety Report, Vols. 1 and 2, 1989. ${ }^{\dagger}$

2. Atomic Energy of Canada, Limited, CANDU 3 Technical Outline, Rev. 11, June 1992. ${ }^{\dagger}$

\footnotetext{
${ }^{\dagger}$ Available in NRC PDR for inspecting and copying for a fee.
}

Figure 5.27 GENs fault tree 


\section{Event Analysis}

The IEs identified in Chap. 4 were classified according to the general plant response to each one. It was then judged that the plant responses (event sequences) for all identified initiators could be evaluated based on the analysis of five plant response categories:

\section{LBLOCA,}

2. SBLOCA,

3. Loss of Essential Power Supplies,

4. Undercooling Event, and

5. Reactivity Transient.

Seven specific IEs were judged to adequately address the plant response for these categories and to be representative of the remaining initiators. The seven events analyzed are

1. Feeder Tube Header Break,

2. LRV Failure,

3. Feeder Tube Break,

4. LOP,

5. Feedwater Piping Break in the Reactor Building,

6. Feedwater Piping Break in the Turbine Building, and

7. SCRAM.

In arkalyzing plant response to each of these IEs, failure to shutdown (FTSD) was included, not withstanding the fact that CANDU 3 has two indejendent shutdown systems. For most of these cases, FTSD led to additional event sequences that could be described by a separate event tree referred to as the FTSD transfer sequence (see Sect. 6.6). It can be noted that LBLOCA with failure to scram leads directly to major core damage and does not involve the FTSD transfer sequence.

Sections 6.1 through 6.6 contain event descriptions, ESDs, and event trees for the seven RIEs and the FTSD sequences.

To track dependencies between systems, a system dependency maurix was developed. Plant systems are listed in the first column, and supporting systems are placed across the top of the matrix. The numbers represent the intersection of a system and its support system. This information is used during various stages of the analysis to help identify system supports and common dependencies between systems and components. The dependency matrix is presented in Table 6.1.

\subsection{Large-Break Loss-of-Coolant Event}

\subsubsection{Event Description}

An LBLOCA is defined in this study as a break in largediameter $(>10-\mathrm{cm})$ piping of the primary HTS (primary loop). Such failures can occur in the reactor inlet header or reactor outlet header. Consequently, the LBLOCA event analyzed is a break in a feeder tube header. These failures are expected to occur with probabilities in the range of $10^{-4}$; a value of $5.9 \times 10^{-5}$ for an inlet header break has been cited in Canadian safety studies."

During the period of low flow, the fuel temperature rises, and fuel cladding failures may occur. These challenges must be met:

1. timely shutdown of the fission process (reactivity control),

2. rapid injection of emergency coolant (primary heat removal), and

3. maintenance of a coolable geometry.

The LBLOCA scenario will be followed through the following four time intervals:

1. before reactor trip 0-2s

2. after trip but before ECCS signal 2-10 s

3. after ECCS signal $10 \mathrm{~s}-15 \mathrm{~min}$

4. long term >15 min

\section{Before Reactor Trip}

An LBLOCA leads to a discharge of coolant in the 1000-kg/s range (for Point Lepreau Unit 1, a CANDU-6 type, the SAR ${ }^{\dagger}$ cites a value of $\left.10,000 \mathrm{~kg} / \mathrm{s}\right)$. This leads to a rapid depressurization of the primary system and a rapid increase in containment pressure. Conditioning of the ECCS logic is provided by either bigh containment pressure or sustained low pressurizer level; also containment isolation would be initiated. The loss of coolant would also

\footnotetext{
"P. J. Allen et al., Atomic Energy of Canada, Limited, Extemal Analysis Reporn-Conceptual Probabilistic Safery Assessment, Rev. 0/89-02-28, ig89.

tupoint Lepreau Nuciear Generating Stution Unit 1 Safety Analysis Report," Parts 1 and 2, 1990.
} 


\section{Event}

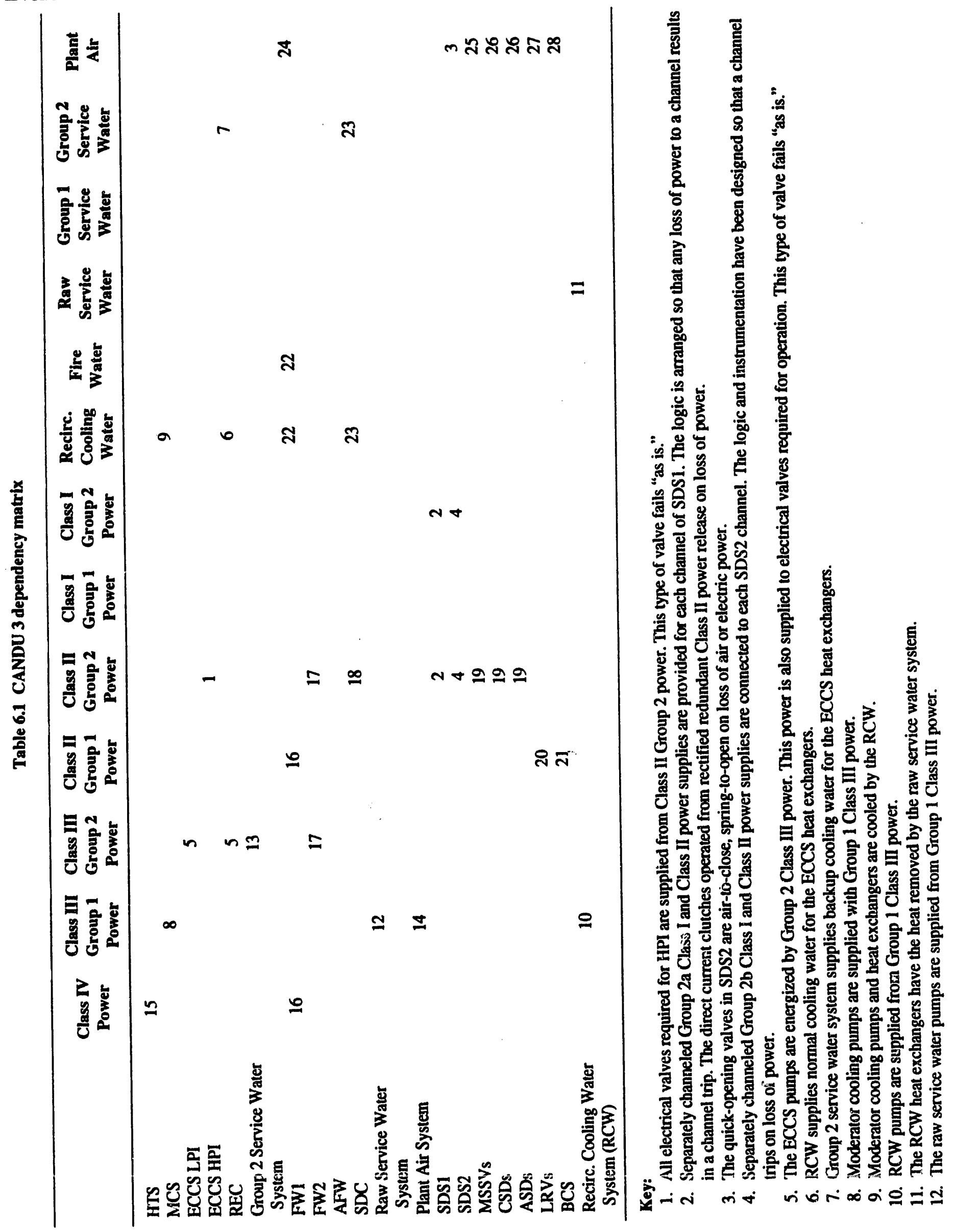


Event

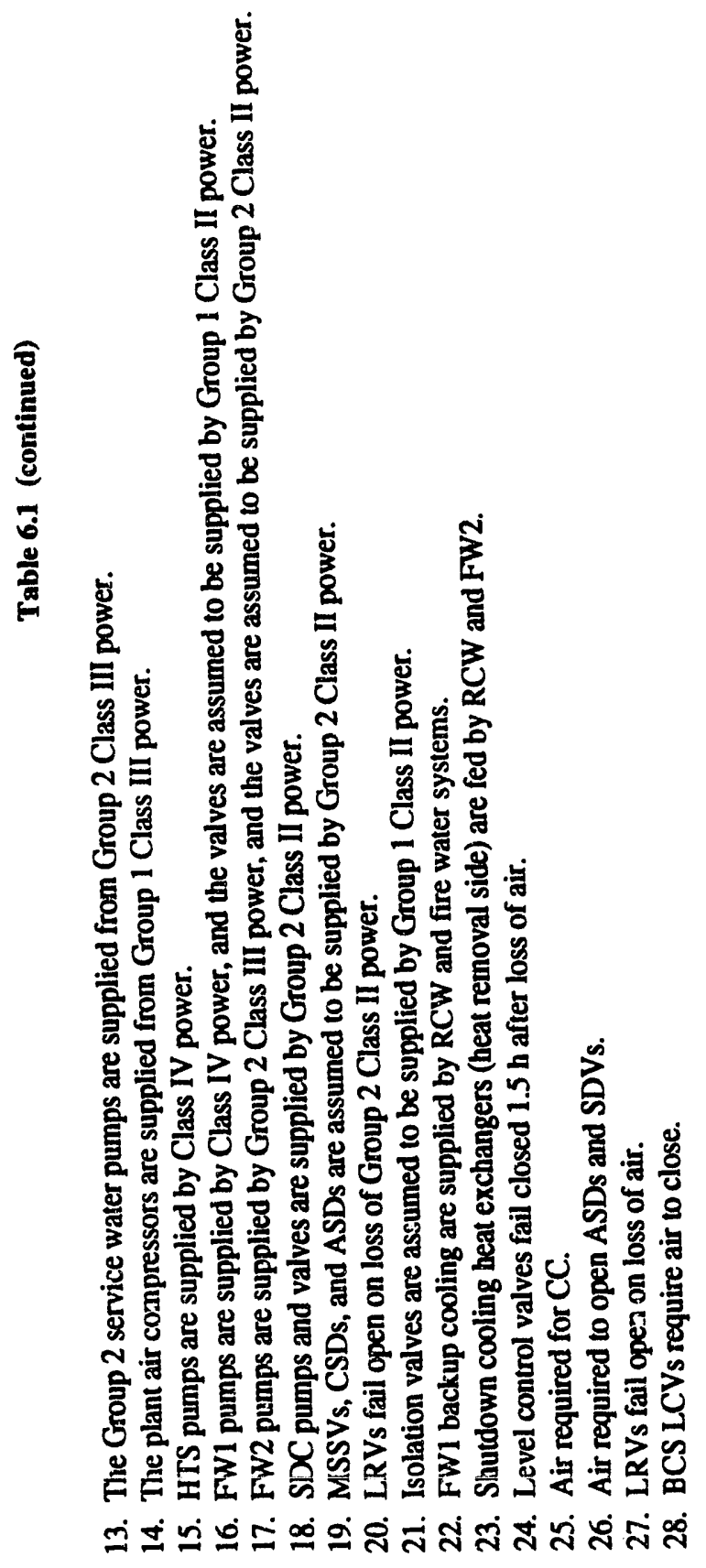


lend to void formation with the power to flow mismatch ca using additional voiding. Because of the positive coolant vı id reactivity, the reactor power rises quickly. Within 1 to 2 ; after the break, the reactor is shut down following detection of high flux, high rate of flux increase, or high containment pressure. Reactivity control is established by inserting shutoff rods (SDS1) or injecting liquid poison into the moderator (SDS2). Failure to trip the reactor will lead to a core damage state.

\section{After Trip but Before ECCS Signal}

Following the reactor trip, the reactor fission process is stopped, and reactor power decreases to $10 \%$ of full power within $2 \mathrm{~s}$. The decay power level continues to decrease rapidly, but, in the absence of cooling, primary system temperatures continue to rise, and the potential exists for zirconium-steam reactions that produce hydrogen.

\section{After ECCS Signal}

When the primary system pressure drops below the initiation set point (5.5 MPa for Point Lepreau*), the LOCS is given. This causes the following actions:

- initiation of emergency coolant injection (ECI) beginning with the high-pressure system, followed by the LPI system, and

- closure of valves to the pressurizer, feed system, and purification circuit.

Thus, the coolant inventory of the primary heat transport loop is no longer replenished from the pressurizer and inventory control system.

The ECI sequence is then initiated. The high-pressure isolation valves open to allow flow of gas from the highpressure gas tank to pressurize the water tanks containing the emergency coolant. The high-pressure gas vent valves close to prevent the :uss of : $:$-pressure gas through the relief valves. The HPI valves open, blowing the two ECCS rupture disks, and allow cooi water to flow from the emergency coolant water tanks toward the $\mathrm{D}_{2} \mathrm{O}$ isolation valves, which are signaled to open. The injection of emergency coolant into the HTS via the shutdown ccolant connections to each header occurs when the pressure drops sufficiently (4.14 MPa for Point Lepreau ${ }^{\dagger}$ ).

The two standby Class III diesel generators are also started and provide power for the LPI and recirculation modes in the event that Class IV power is not available.

\footnotetext{
* "Poirt Lepreau Nuclear Generating Station Unit 1 Safety Analysis Repor," Parts 1 and 2, 1990.
}

The MSSVs open $30 \mathrm{~s}$ after the LOCS is received and cause the steam generators (and, hence, the entire steam and FW systems) to be crash-cooled. In addition to the LOCA signal, which opens all the MSSVs, a signal generated by the SDS2 instrumentation opens half of the MSSVs. ${ }^{\dagger}$ The steam generators are crash-cooled to reduce the transfer of heat from the steam generator secondary side to the primary coolant. Crash cooldown is not considered in this analysis of an LBLOCA because it is not initiated until at least $30 \mathrm{~s}$ into the transient and therefore acts too late to effectively charge the sequence in an LBLOCA.

\section{Long Term}

The ECCS pumps are started on the LOCS. As the accumulator pressure decreases, more of the injection flow comes from the pumps. Upon receipt of a low accumulator tank level, the running ECCS pump and grade-level tank are aligned for LPI to the primary system. At this time the HPI path is valved closed. Injection occurs when the primary system pressure is low enough. The REC mode is automatically initiated by the receipt of a low-grade level tank level or high building sump level signal.

If additional failures occur during the sequence, alternative paths are possible for the LBLOCA. Potential complicating factors include the following:

1. LOP

2. ECCS impairment

- failure of crash cooldown

- failure of injection and steam generator crash cooldown

- failure of injection

3. ECCS and moderator heat sink impairment

4. degraded ECCS.

\section{Loss of Class IV Power}

This accident is used in the design of the ECCS to ensure that no fuel channel damage occurs. ${ }^{1}$ LOP is assumed to occur due to turbine unloading when the pressure in the main steam interconnect drops below $95 \%$ of normal. The most important effect is the rundown of the heat transport pumps. Although the ECCS control logic includes trip of the heat transport pumps, the early LOP is more limiting because the pump trip occurs sooner.

\footnotetext{
tLetter from AECL Technologies to the U.S. NRC, "Responses to February 10,1993, NRC/ORivL Requesi for Infomation," Febriany 22, 1993.
} 
Event

A difference in temperature-pressure history during the event is expected only during the short period when the pumps begin to coast down until the emergency coolant is injected. Because the HPI requires only Class II or I power, it is not affected by the LOP. The LPI and recirculation modes require Class III power that, in case of a LOP, would be supplied by the diesel generators.

\section{Failure of Crash Cooldown}

In an LBLOCA, crash cooldown of the boiler does not have a major effect on system behavior. Thus, failure of crash cooldown has no significant effect on the progression of the sequence.

\section{Failure of Injection and Boiler Crash Cooldown}

This sequence follows that described previously until the time period following ECCS signal receipt. In this sequence the MCS becomes the heat sink for the fuel. The process allowing this to occur involves plastic deformation of the pressure tube due to continued heating. If the pressure is high enough, the pressure tube expands into the calandria tube. If the pressure is low, the pressure tube will sag into contact with the calandria tube. This direct contact between the pressure tube and the calandria tube provides a conduction path for heat to be transferred from the fuel to the moderator.

The system temperature continues to rise with about half (under certain conditions) of the beat generation within the fuel channel coming from the reaction of steam with the Zircaloy cladding. Eventually, the steam flow is very low, and the temperature transient is controlled by (1) the rate of steam flow and (2) the oxidation reaction of the Zircaloy. Significant amounts of hydrogen are produced, and significant fuel damage is expected to occur.

As the power generation witiin the fuel continues to decay and the unreacted hot Zircaloy is depleted, the temperature begins to decrease. A quasi-steady state would be reached when the decay heat can be removed by radial heat transfer through the pressure tube/calandria interface tube into the moderator.

\section{Failure of Injection}

Crash cooldown is assumed to function, and this cools the primary system during the short term of the event. However, the pressure tube behavior would not be modified because the radial strain to contact the calandria tube would occur before crash cooldown becomes effective.

\section{ECCS and Moderator Sink Impairment}

The MCS provides the only means for removing decay and reaction heat in the event the ECCS fails to function. An early loss of the MCS would lead to extensive core damage.

\subsubsection{Event Sequence Diagram and Event Tree}

The ESD for an LBLOCA is shown in Fig. 6.1. The ESD is a pictorial representation of the logical sequence of operations necessary to mitigate an LBLOCA. The ESD was used as an aid in the development of the event tree (Fig. 6.2). The event tree resulted in 29 sequences designated as LB-A through LB-AC. The event tree displays the end state and the classification category for the RIE sequences.

The events listed along the top of the event tree page refer to the system fault trees from Chap. 5 that are called by the LBLOCA event tree. The fault trees are

1. SD1-shutdown system one,

2. SD2-shutdown system two,

3. HTS-heat transport system,

4. HPI-high-pressure injection mode of ECCS,

5. LPI-low-pressure injection mode of ECCS,

6. REC-recirculation mode of ECCS, and

7. MCS-moderator cooling system.

\subsubsection{LBLOCA Sequence Evaluation Insights}

The two important aspects of the LBLOCA sequences are quick and immediate shutdown of the reactor and prompt refill of the primary coolant system. This demonstrates the necessity for reliability of SDS1, SDS2, and ECCS although the MCS does provide a backup to the ECCS.

The HTS reduces the extent of fuel damage by maintaining forced flow through the reactor core. Failure of the HTS will result in localized fuel damage but not to the extent of an uncoolable geometry as long as the ECCS or MCS is operable.

Crash cooling of the steam generators during an LBLOCA seems to have little effect in the progression of the 
Event

ORNL-DWG 93-3187 ETD
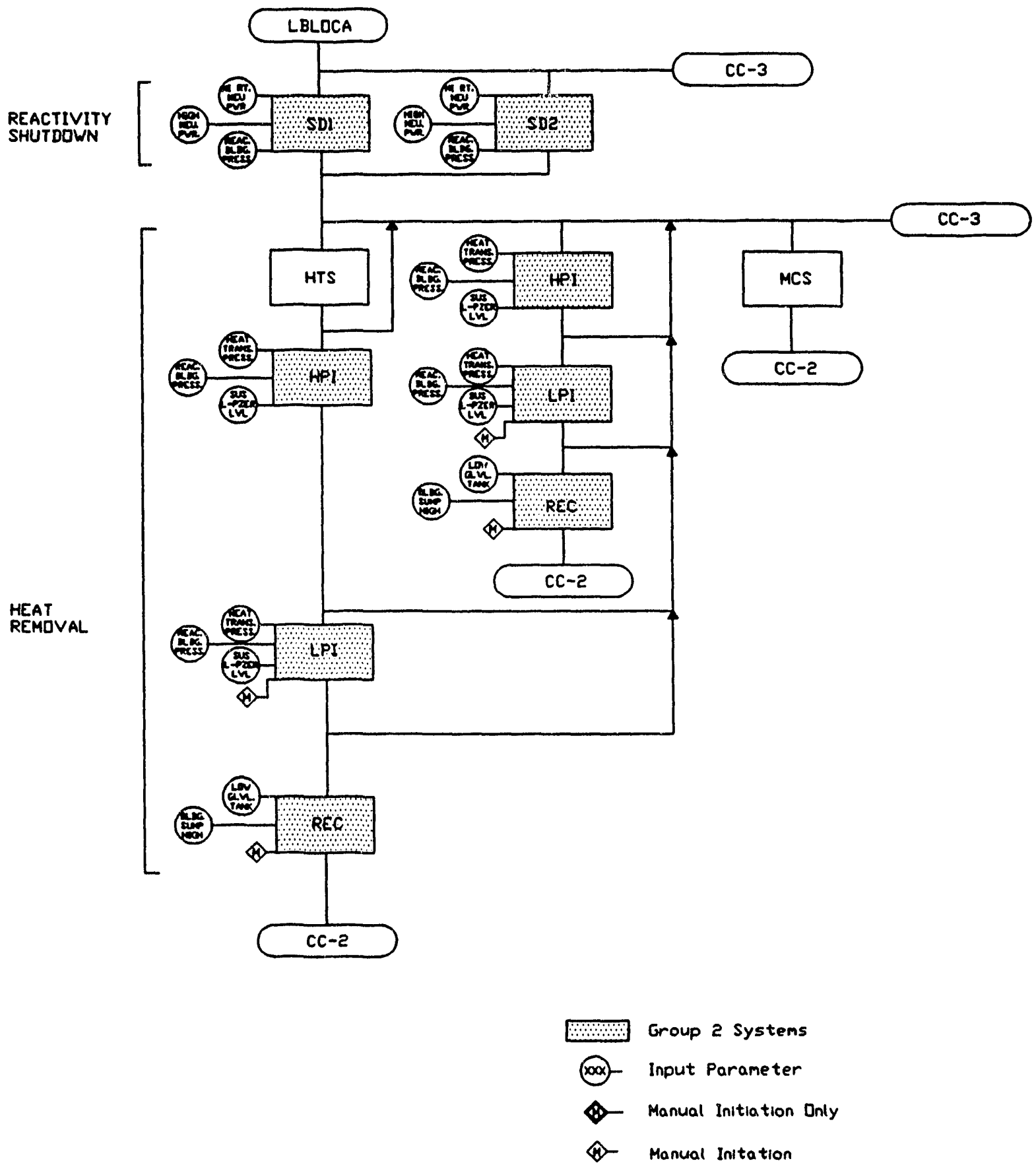

Figure 6.1 Feeder tube header break ESD 
Event

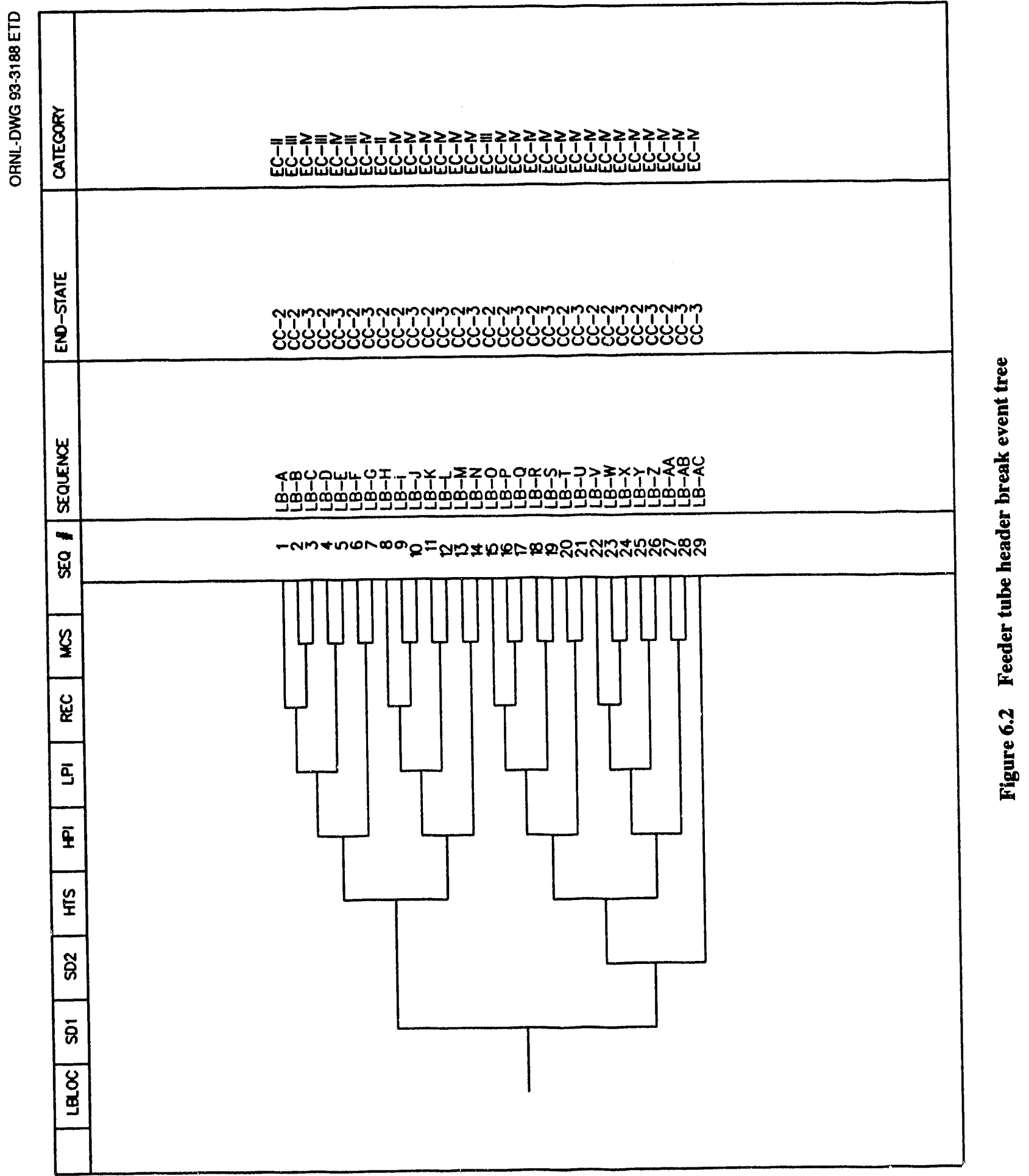


Event

sequences. It appears to have greater significance with regard to SBLOCAs.

\subsection{Small-Break Loss-of-Coolant Events}

An SBLOCA is defined in this study as a break in smalldiameter $(<10-\mathrm{cm})$ piping and spurious openings of primary system relief valves. Such failure can occur in smalldiameter pipes and liquid relief or pressurizer relief valves. Two events were selected for analysis to represent these types of SBLOCA events: failure of an LRV to reclose and a feeder tube break.

When compared to LBLOCAs, there are significant differences in system responses to mitigate the consequences of such accidents:

1. The steam generator is the major heat sink for the SBLOCA and is often the only heat sink required to cool down the primary system until the SDC is established. (The steam generator is far less importani as a heat sink for LBLOCA events.)

2. A LOCS is not generated for some SBLOCAs and emergency core cooling must be operator-initiated.

3. Steam generator crash cooling is more important to some SBLOCAs, so that rapid cooldown of the primary system may be accomplished.

4. Manual shutdown of the reactor is sufficient to mitigate some SBLOCA events.

5. In an SBLOCA, heat transport to the steam generator is facilitated by natural convection flow.

6. Rewetting is not a concern for the SBLOCA before the introduction of emergency core cooling.

Note that the ECCS signal automatically triggers the ECI and the sequence leading to steam generator crash cooling. In addition, the SDS2 instrumentation signals half of the MSSVs to open should the ECCS fail to initiate crash cooling. In the case of an SBLOCA, there is sufficient time to manually initiate the ECCS should automatic initiation fail to occur.

The SBLOCA events are also analyzed for failure of the reactor shutdown systems. Failure to shut down the reactor sequences are discussed in Sect. 6.6.

\subsubsection{Event Descriptions}

\subsubsection{Liquid Relief Valve Failure to Reclose}

The LRVs serve as overpressure protection for the HTS. As the HTS pressure increases, liquid may be relieved and sent to a BCS. Failure to reclose after opening results in loss of coolant inventory through the BCS. The estimated frequency of occurrence of this event is $1 \times 10^{-1}$ /year.

The following scenarios will be discussed for LRV failure:

1. BCS isolation and ECCS available,

2. no BCS isolation,

3. no crash cooldown, and

4. ECCS impaired.

\section{Bleed Condenser Isolation and ECCS Available}

Following an opening of an LRV, coolant leaves the primary cooling system and enters the BCS. Pressurizer and heavy-water feed pumps provide make-up water. Local boiling should be expected but could be handled by the reactivity regulating system. The pressurizer level decreases, and reactor shutdown will come from either SDS1 or SDS2.

The steam generator is the main heat sink. When the BCS is isolated, no more leakage occurs from the primary system, and the lost coolant can be fed back via feed pumps. Fuel cooling is ensured by either feedwater to the steam generator or shutdown cooling. When Class IV power is available, the main heat transport pumps ensure forced flow; the ECCS is not called upon. No fuel damage is expected in this event.

\section{No Bleed Condenser Isolation}

If the BCS cannot be isolated, coolant will leave the primary system through the $\mathrm{D}_{2} \mathrm{O}$ storage tank into the containment building. The LOCS will be given, and emergency core cooling and steam generator crash cooling will start. The operator must isolate the leak, ensure feedwater flow through the steam generators, and later start the SDC.

In SBLOCAs, the piping fills in the forward direction with flow assisted by the main heat transport pumps. The pump head keeps the inlet header pressure higher than the outlet

\footnotetext{
*P. J. Allen et al., Atomic Energy of Canada, Limited, External Analysis Report-Conceptual Probabilistic Safety Assessment, Rev. 0/89-02-28, 1989.
} 
header pressure; because of this, most if not all of the emergency coolant enters the primary system via the outlet headers. Instead of entering the fuel channels through the outlet headers, this coolant must then flow through the steam generator and heat transport pumps before reaching the fuel channels.

To enhance the effectiveness of the emergency coolant, steam generator crash cooling is relied upon. Steam generator crash cooling has a mission time of $30 \mathrm{~min}$, after which it is no longer needed. It cools down the steam generator to avoid a coolant heatup in the steam generator and, at the same time, helps to reduce the primary system pressure to ensure early ECI.

Because the loss of coolant through the $\mathrm{D}_{2} \mathrm{O}$ storage tank leads to a significant reduction in primary system pressure and a low pressurizer level, some boiling should be expected. However, because the reactor is already in the shutdown state, the associated reactivity increase has no effect on the power level. Because the core is filled with coolant, the fuel is continually cooled, and at worst case, only minimal cladding damage could be expected. With the injection of emergency coolant, the reduction in fuel and cladding temperatures should stop any further cladding damage if it had occurred.

\section{No Crash Cooldown}

Without steam generator crash cooldown, temperatures and pressures remain high, and ECI is delayed. Because of the higher primary system temperatures resulting from the large net input from the steam generator, some fuel damage is expected before emergency coolant is injected. Heat removal would be accomplished with the MCS due to the deformation of the pressure tubes, coming in contact with the calandria tubes, allowing the transfer of heat from the primary coolant into the moderator.

\section{ECCS Impaired}

In the case of coolant injection failure but with steam generator crash cooling working, an increase in early fuel failures can be expected. The lowering of the primary system pressure increases the strain rate for the cladding due to the large pressure difference between the fuel rod and the coolant. Failure of the ECCS will resuit in heat being removed by the MCS as discussed previously.

\subsubsection{Feeder Tube Break}

This event is defined as a break in any of the feeder tube piping. This event results in discharge of the primary coolant directly from the HTS into the reactor building but at a rate much less than that of an $L B L O C A$. The frequency of this event is estimated to be $1 \times 10^{-2}$. $^{*}$

The following scenarios will be discussed for a feeder tube break:

1. crash cooldown and ECCS available,

2. no crash cooldown, and

3. ECCS impaired.

\section{Crash Cooldown and ECCS Available}

Following a feeder tube break, coolant is discharged from the HTS. Pressurizer and heavy water feed pumps provide make-up water. The pressurizer level decreases and reactor shutdown will come from either SDS1 or SDS2. Because coolant leaves the primary system through the break into the containment building, the LOCS will be given and emergency core cooling and steam generator crash cooling will start.

In SBLOCAs, the piping fills in the forward direction with flow assisted by the main beat transport pumps. The pump head keeps the inlet header pressure higher than the outlet header pressure; because of this, most if not all of the emergency coolant enters the primary system via the outlet headers. Instead of entering the fuel channels through the outlet headers, this coolant must then flow through the steam generator and heat transport pumps before reaching the fuel channels.

To enhance the effectiveness of the emergency coolant, steam generator crash cooling is relied upon. Steam generator crash cooling has a mission time of $30 \mathrm{~min}$, after which it is no longer needed. It cools down the steam generator to avoid a coolant heatup in the steam generator and at the same time helps to reduce the primary system pressure to ensure early ECI.

Because the loss of coolant leads to a significant reduction in primary system pressure and a low pressurizer level, some boiling should be expected. However, because the reactor is already in the shutdown state, the associated reactivity increase has no effect on the power level. Because the core is filled with coolant, the fuel is continu. ally cooled, and at worst case, only minimal cladding damage could be expected. With the injection of emergency

\footnotetext{
*P. J. Allen et al., Atomic Energy of Canada, Limited, Extermal Analysis Report-Conceptual Probabilistic Safety Assessment, Rev. 0/89-02-28, i989.
} 
Event

coolant, the reduction in fuel and cladding temperatures should stop any further cladding damage if it had occurred.

\section{No Crash Cooldown}

Without steam generator crash cooldown, temperatures and pressures remain high and ECI is delayed. Because of the higher primary system temperatures resulting from the large net input from the steam generator, some fuel damage is expected before emergency coolant is injected. Heat removal would be accomplished with the MCS due to the deformation of the pressure tubes coming in contact with the calandria tubes, allowing the transfer of heat from the primary coolant into the moderator.

\section{ECCS Impaired}

In the case of coolant injection failure but with steam generator crash cooling working, an increase in early fuel failures can be expected. The lowering of the primary system pressure increases the strain rate for the cladding due to the large pressure difference between the fuel rod and the coolant. Failure of the ECCS will result in heat being removed by the MCS, as previously discussed.

\subsubsection{Event Sequence Diagrams and Event Trees}

The ESDs for LRV failure and feeder tube break are shown in Figs. 6.3 and 6.4. The ESDs are pictorial representations of the logical sequences of operations necessary to mitigate these SBLOCA events. The ESDs were used in the development of the event trees presented in Figs. 6.5 and 6.6.

The LRV failure event tree resulted in 34 sequences designated as LRVF-A through LRVF-AH plus 14 failure to shutdown (FTSD) sequences designated as LRVF-FTSD-A through LRVF-FTSD-N (the FTSD transfer event tree is presented in Sect. 6.6). The events listed along the top of the event tree refer to the system fault trees from Chap. 5 that are called by the LRV failure event tree. The fault trees are

1. SD1-shutdown system 1

2. SD2-shutdown system 2

3. BCS-isolate BCS

4. CC-crash cooling

5. FW-Group 1 and 2 feedwater systems and auxiliary feedwater

6. HPI-high-pressure injection mode of ECCS

7. LPI-low-pressure injection mode of ECCS
8. SD-steam removal systems-CSDs, ASDs

9. MSV-main steam safety valve

10. SDC-shutdown cooling system

11. MCS-moderator cooling system.

The feeder tube break event tree resulted in 18 sequences designated as SBLFB-A through SBLFB-Q plus 14 FTSD sequences designated as SBLFB-FTSD-A through SBLFBFTSD-N (the FTSD transfer event tree is presented in Sect. 6.6). The events listed along the top of the event tree refer to the system fault trees from Chap. 5 that are called by the feeder tube break event tree. The fault trees are

1. SD1-shutdown system 1

2. SD2-shutdown system 2

3. CC-crash cooling

4. FW-Group 1 and 2 feedwater systems and auxiliary feedwater

5. HPI-high-pressure injection mode of ECCS

6. LPI-low-pressure injection mode of ECCS

7. MCS-moderator cooling system.

\subsubsection{Sequence Evaluation Insights}

The SBLOCA events are analyzed assuming Class IV power is available. The unavailability of Class IV power means that forced flow through the HTS would not occur. Decay heat is then transferred via thermal convection to the steam generators where it is removed by the feedwater. Primary system and fuel temperatures are expected to be higher than when Class IV power is available, and some damage to the fuel sheath could be expected. The FW1 would also be unavailable due to LOP, placing greater emphasis on the FW2 and AFW. The CSDs would also not be an option for steam removal because the condensate piüips would trip and result in loss of condenser vacuum. This leaves the ASDs and the MSSVs as the two options for steam removal.

In the event of loss of the plant air systems, the steam removal function relies on the spring actuation of the MSSVs when their air reservoirs are depleted. This is because the CSDs, ASDs, and the MSSVs all require air to open, although the MSSVs are also spring-actuated."

\footnotetext{
*Atomic Energy of Canada, Limited, Presentation of Information at NRC/AECL Review Meeting on the CANDU 3 Systems Research Study, February 10, 1993.
} 

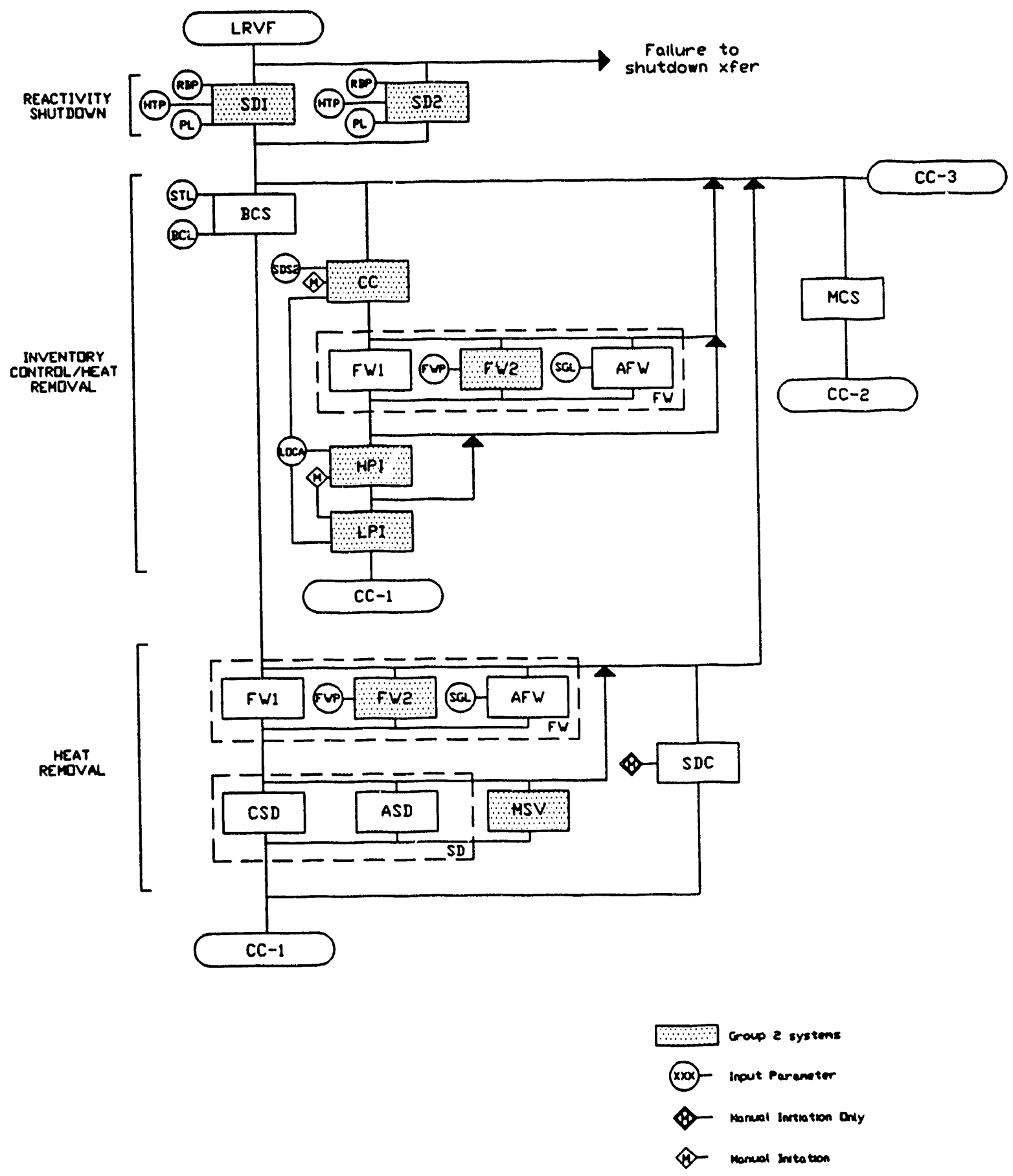

Figure 6.3 LRV failure ESD 

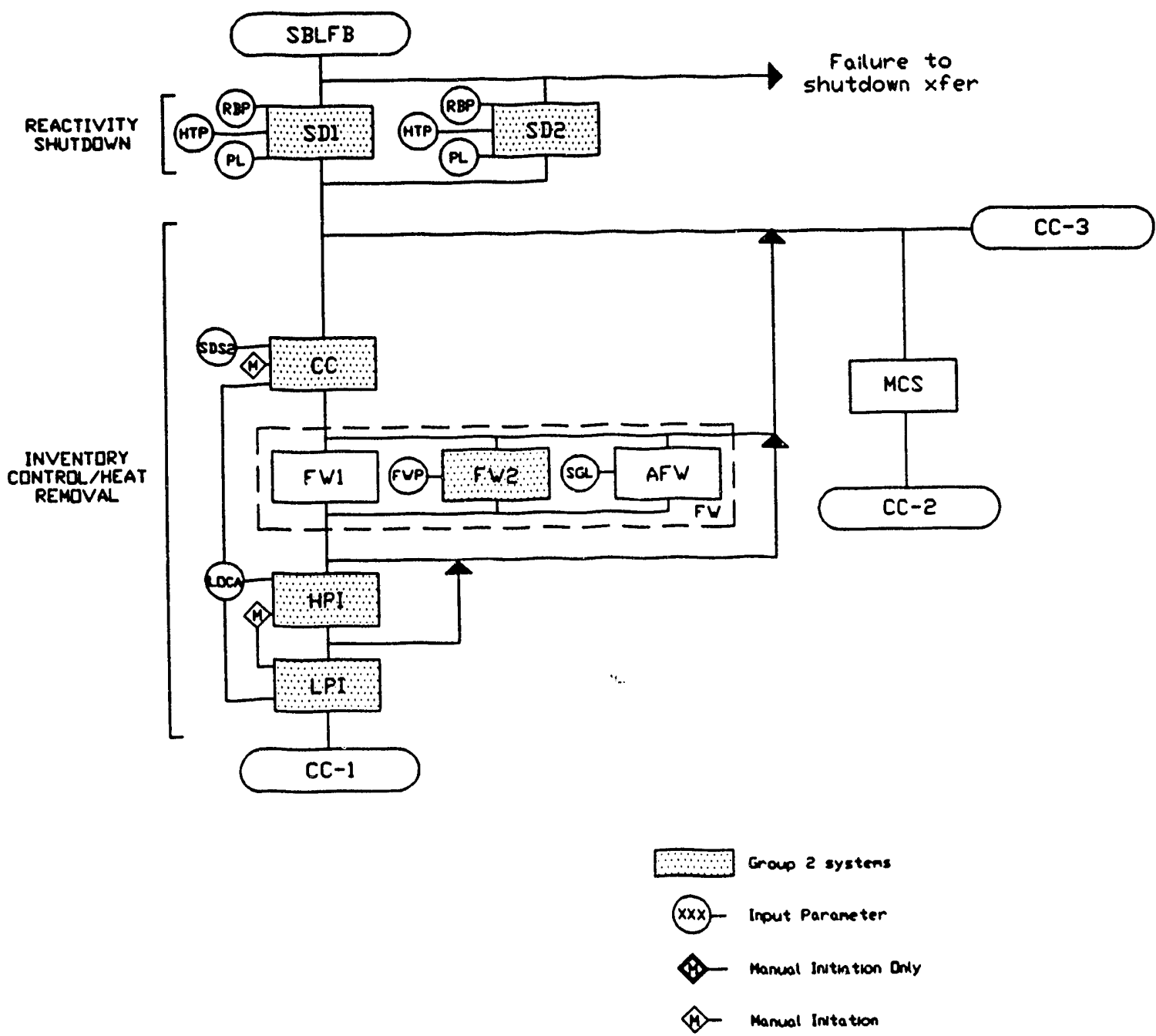

Figure 6.4 Feeder tube break ESD

\subsection{Loss of Class IV Power Event}

\subsubsection{Event Description}

An LOP is defined in this study as the simultaneous loss of power to two $13.8-\mathrm{kV}$ buses. Such failures can occur because of total station disconnection coincident with a turbine trip or a loss of station-generated power, because of a turbine or reactor trip, causing perturbations to the grid. They are expected to occur with probabilities in the range of $10^{-2}$. $^{*}$

\footnotetext{
* P. J. Allen et al., Atomic Energy of Canada, Limited, External Aralysis Report-Conceptual Probabilistic Safety Assessment, Rev. 0/89-02-28, 1989.
}

NUREG/CR-6065
For this assessment no distinction is made between a shortterm loss of power and a long-term loss of power. Shortterm losses are typically the result of fluctuations in the grid frequency and/or voltage. Long-term losses usually result from external events such as tornadoes and earthquakes. The former are more frequent and are usually recovered from within a few hours. The latter are less frcquent, with recovery sometimes taking days.

The sudden LOP would cause the turbine to trip immediately. This causes an increase in steam generator pressure because of the reduction in steam flow to the turbine. The LOP would also cause the main sieam generator feedwater pumps to stop. A diesel-driven auxiliary feedwater pump can supply feedwater at a reduced rate. After a turbine trip, 


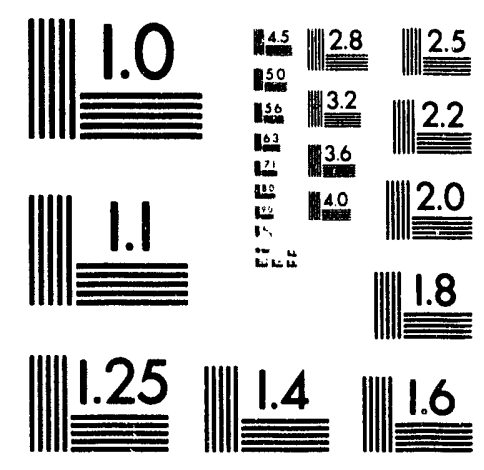



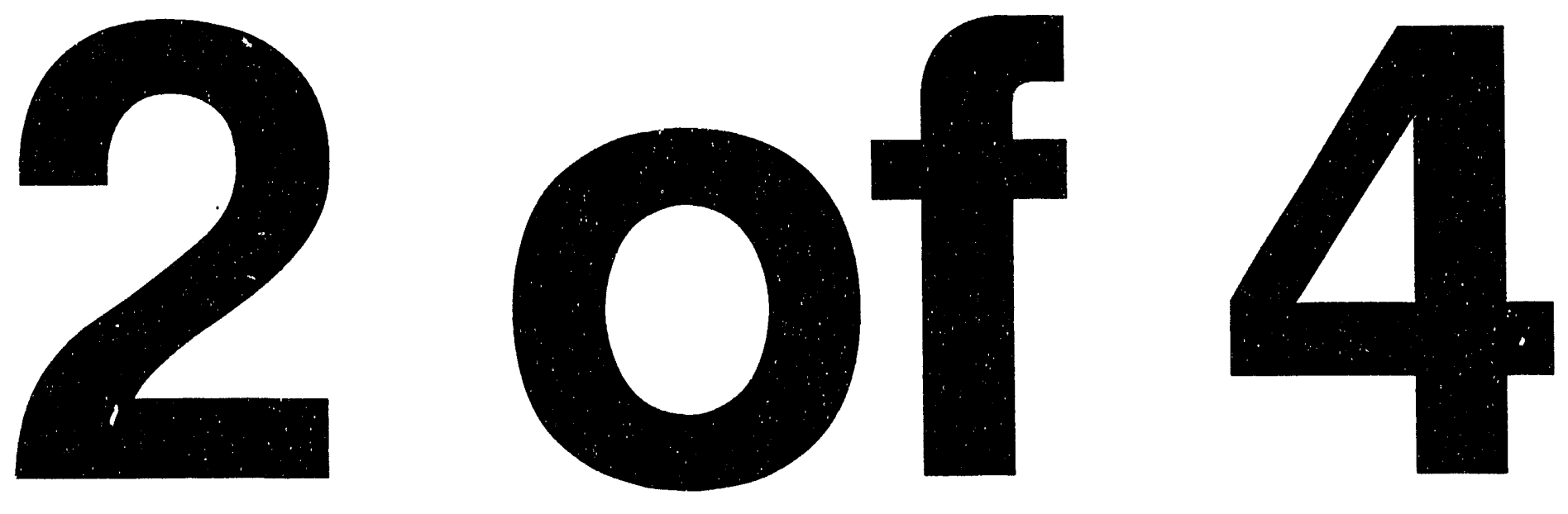
Event

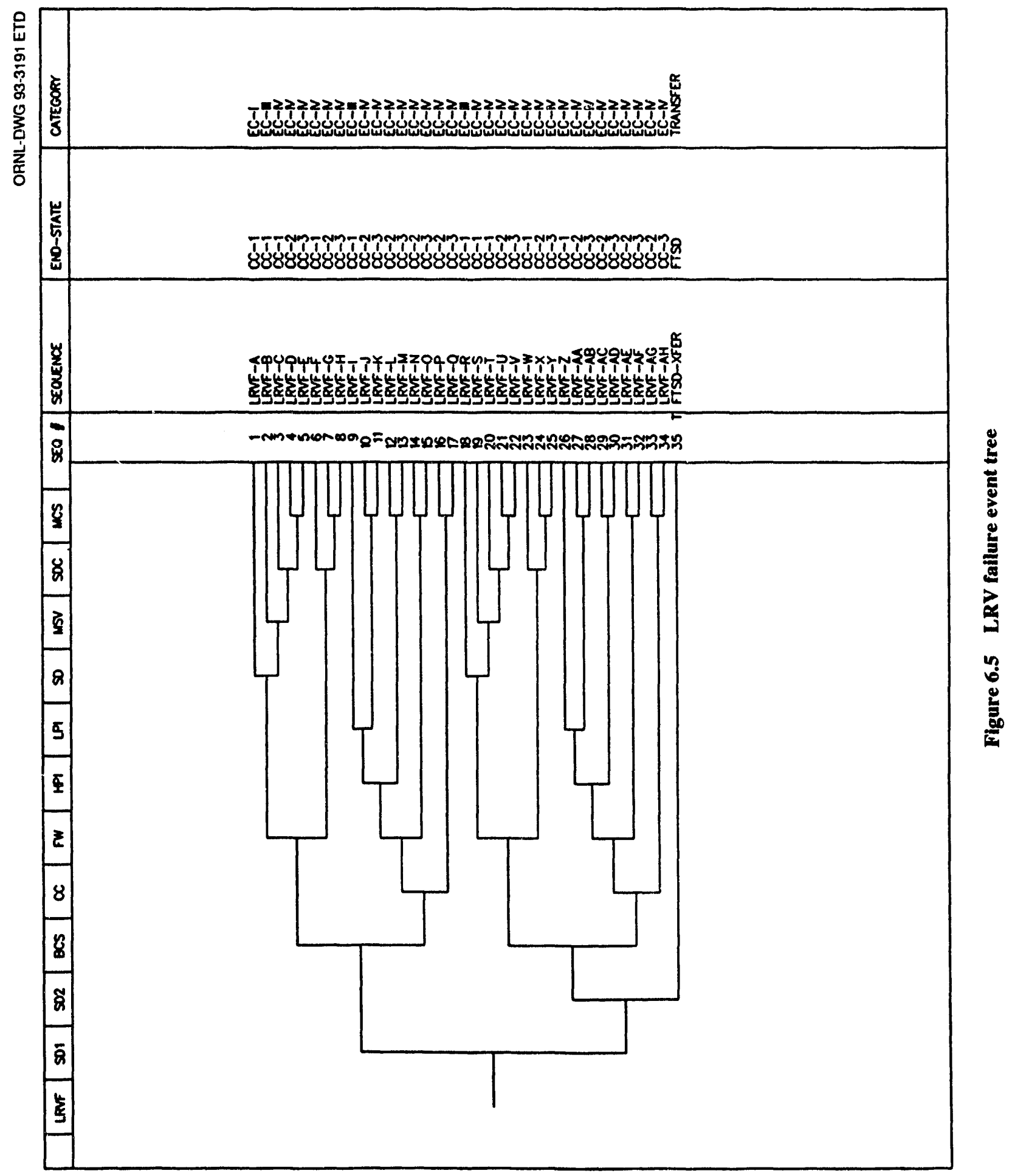




\section{Event}

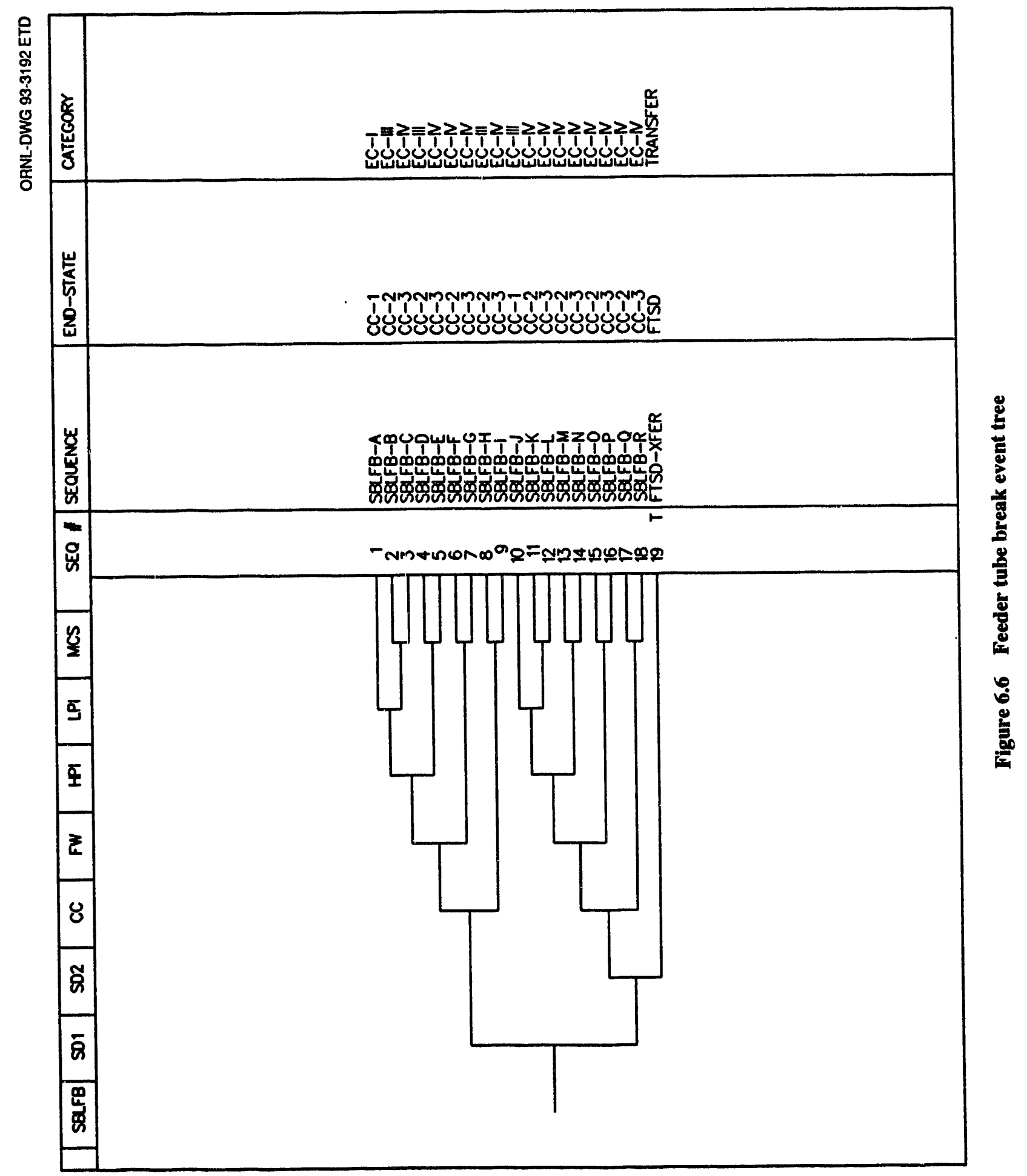


a signal would normally be applied immediately to fully open the CSDs, which would discharge steam from the main steam header to the condenser. With the LOP the condenser circulating water puups become unavailable, disabling the steam condenser and preventing the CSDs from opening. The result would be that the boiler pressure rises and the ASDs open. However, the pressure in the steam generators may be too large to be handled by the ASDs alone which, for the Point Lepreau plant, have a total capacity of $10 \%$ of rated steam flow. ${ }^{*}$ As a result, the main steam valves would open to limit the pressure rise.

Coolant in:-entory is normally provided by the feed pumps and the feed and bleed valves that are connected to the primary circuit via the purification lines. The feed pumps are temporarily lost, but the bleed valves would remain available.

The pressure, flow, and power signals are powered by uninterruptible Class I/II power supplies.

The LOP will initiate an automatic startup of the diesel generators to energize Class III buses within $60 \mathrm{~s}$. In the analysis it was assumed that Class III power is restored to all or none of the Class III buses. In other words, partial restorations of power were not analyzed.

Following restoration of Class III power, the LRVs must reclose to prevent continued loss of primary coolant inventory. Failure of either of these valves to reclose results in sequences similar to an SBLOCA. Closure of the LRVs allows the SDC to be activated because it uses Class III power.

FTSD sequences are analyzed for LOP when Class III power has been restored. These sequences are discussed in Sect. 6.6.

\subsubsection{Event Sequence Diagram and Event Tree}

The ESD for LOP is shown in Fig. 6.7. The ESD is a pictorial representation of the logical sequence of operations necessary to mitigate the LOP condition. The ESD was used in the development of the event tree presented in Fig. 6.8. The LOP event tree resulted in 45 sequences designated as LOP-A through LOP-AS and 14

\footnotetext{
* "Point Lepreau Nuclear Generating Station Unit 1 Safety Analysis Report," Parts 1 and 2, 1990.
}

FTSD sequences designated as LOP-FTSD-A through LOP-FTSD-N (the FTSD transfer event tree is presented in Sect. 6.6).

The events listed along the top of the event tree page refer to the system fault trees from Chap. 5 that are called by the LOP event tree. The fault trees are

1. RSS--reactivity shutdown system

2. GEN-Ciass III diesel generator

3. LRC-liquid relief valve closure

4. BCS-isolate bleed condenser

5. CC-crash cooling

6. FW2-Troup 2 feedwater system

7. AFW-auxiliary feedwater system

8. HPI-high-pressure injection mode of ECCS

9. LPI-low-pressure injection mode of ECCS

10. ASD-atmospheric steam discharge valve

11. MSV_-main steam safety valve

12. SDC-shutdown cooling systemi

13. MCS-moderator cooling system.

\subsubsection{Sequence Evaluation Insights}

Failure to restore Class III power requires that the power supplies needed for isolation of the BCS be battery backed; otherwise, continued loss of primary coolant inventory will result because the LRVs fail open on loss of power.

Failure of the LRVs to reclose following restoration of Class III power results in sequences very much like the LRVF SBLOCA sequences except that FW1 and the CSDs are not available due to the unavailability of Class IV power.

The FTSD sequences show the FW1 and the CSDs, which would not be available when LOP occurs. These sequences would all result in the EC-IV category because at least three failures are required tefore a FTSD sequence is reached.

\subsection{Undercooling Events}

The undercooling PRC is represented by two IEs. One of these involves a feedwater line break inside the reactor 
Event

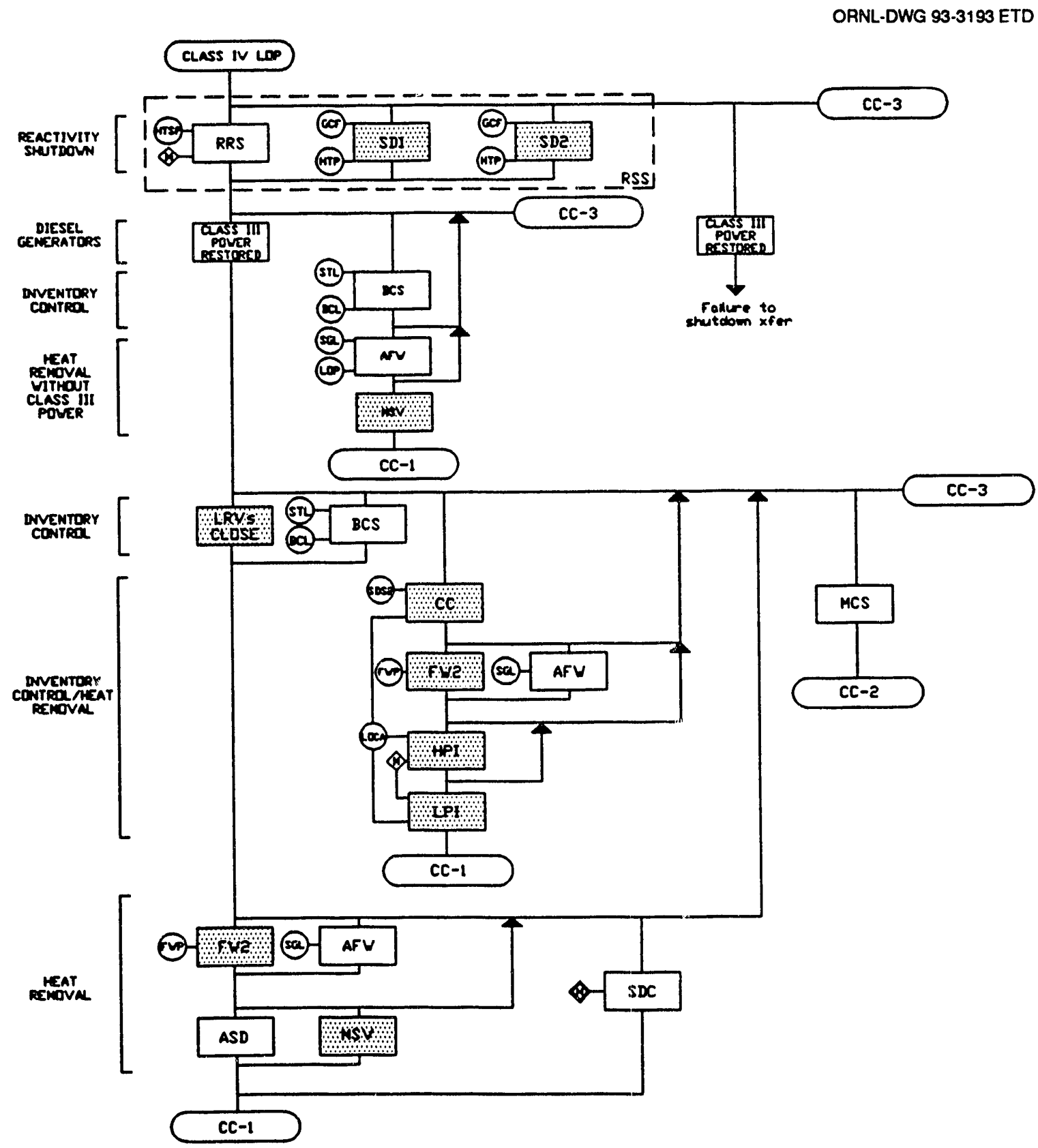

Group 2 systems
Input Parameter
Manual Initiation Only

Figure 6.7 LOP ESD 
Event

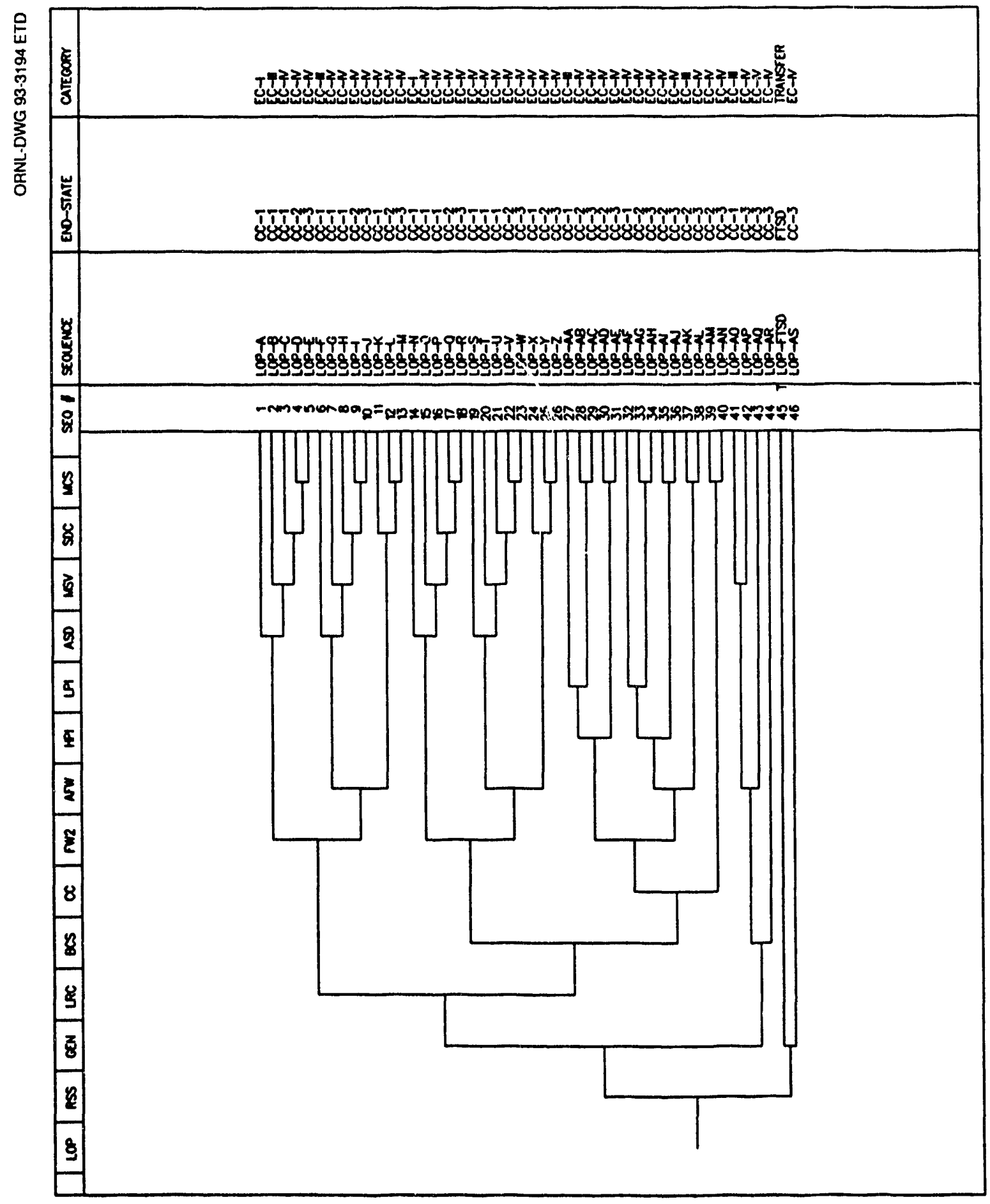

ב⿱艹 
building upstream of one of the steam generators, and the other is a feedwater line break that occurs inside the turbine building. These were analyzed separately because the plant responses are different. These initiators are designated as LOFWRB and LOFWTB, respectively. ESDs and event trees were constructed for each of these initiators.

\subsubsection{Event Descriptions}

\subsubsection{Feedwater Piping Break in the Reactor Building}

The LOFWRB initiator involves a break in the FW1 piping between a steam generator check valve and the steam generator. A frequency of $1 \times 10^{-5} /$ year was used for this initiator. "The rationale supporting this frequency was judged to be appropriate for this analysis based on the current level of information.

The two basic functions that must be met to mitigate this initiator are reactor shutdown and heat removal from the reactor core. SDS1 and SDS2 can shut down the reactor on high heat transport pressure, low steam generator level, or low feedwater line pressure. RRS shutdown is assumed to be unavailable for this initiator because the steam generator level measurements are not qualified for the steam environment that would be created by the released feedwater. If SDS1 and SDS2 should fail to shut down the reactor, the event is analyzed for FTSD sequences. These sequences are discussed later in Sect. 6.6.

Short-term heat removal is accomplished by thermosyphoning through the steam generators. The heat transport pumps are designed to trip on "sustained low HTS pressure" and therefore would not provide forced flow. The Group 2 feedwater is available for automatic initiation on loss of Group 1 feedwater. The Group 2 feedwater sprays on the top of each tube bundle but will not accumulate in the steam generator where the break occurred. For this reason, the operator must isolate flow away from the draining steam generator to avoid excessive loss of feedwater inventory. The SDC has enough capacity to cool the reactor from $100 \%$ heat and pressure. The analysis assumes the steam generator contains sufficient inventory to allow time for the SDC to be initiated even if the FW2 does not start automatically. This would, however, require quick response from the operator because the SDC requires manual initiation.

\footnotetext{
*P. J. Allen et al., Atomic Energy of Canada, Limited, External Analysis Report-Conceptual Probabilistic Safety Assessment, Rev. 0/89-02-28, 1989.
}

Heat removal via the steam generator using the FW2 may cause some damage to the fuel cladding because the heat removal capability of one of the steam generators would be lost since it is isolated from the system. Operation of either the ASD or the MSSVs will be required for steam removal in conjunction with the Group 2 feedwater. The CSDs are not demanded for these sequences due to unavailability of the condenser. Condenser vacuum is assumed to be lost subsequent to any turbine trip. The condenser would therefore be unavailable for these sequences because the turbine is designed to trip on loss of feedwater.

The MCS is the last line of defense against severe core damage when the other heat removal methods have failed. The pressure tube deformation required for heat transfer to the moderator is the extent of the expected core damage for this sequence. Using the MCS to remove the decay heat implies that other heat removal methods have failed. Failure of the MCS would then result in extensive core damage.

\subsubsection{Feedwater Piping Break in the Turbine Building}

The LOFWTB event includes piping failures occurring inside the turbine building that would result in a total loss of FW1 and auxiliary feedwater. These piping failures could occur in the FW piping, in the deaerator storage tank piping, or in the condensate system. The frequency assigned for this initiator was $1 \times 10^{-3} /$ year because piping is a passive component. This is also the same frequency used in the "CANDU 3 Conceptual Probabilistic Safety Assessment."*

Again, the required functions for mitigating this initiator are reactor shutdown and reactor core heat removal. The reactor can be shut down by RRS on high HTS pressure or low steam generator level. SDS1 and SDS2 can also shut down the reactor on high HTS pressure, low steam generator level, or low feedwater line pressure. Failure to shut down the reactor using any one of these systems will result in a FTSD sequence. These sequences are discussed in Sect. 6.6.

The FW2 will be initiated automatically on low feedwater line pressure. The Group 2 feed water is sufficient to remove the heat transferred to the steam generators. The heat will be transferred via thermosyphoning because the heat transport pumps are assumed to be unavailable. The Class IV power supply to the heat transport pumps is not qualified for the steam environment in the turbine building resulting from the feedwater line break. For this reason, the heat transport pumps are not credited for these sequences. The steam from the steam generators would be released 
either from the ASDs or the MSSVs. Again, as for the LOFWRB, the CSDs are not available for use because condenser vacuum is lost following a turbine trip.

An alternate means for heat removal is the SDC. The steam generators contain sufficient volume to give the operator time to initiate SDC. Successful initiation and operation of the SDC will terminate the sequence with no core damage.

The MCS is the last means of heat removal. The core damage expected would be that required for pressure tube deformation to allow heat transfer to the moderator. Failure to remove the decay heat by some means will result in extensive core damage.

\subsubsection{Event Sequence Diagrams and Event Trees}

The ESDs for a LOFWRB and LOFWTB are shown in Figs. 6.9. and 6.10. The ESDs are pictorial representations of the logical sequences of operations necessary tc - iitigate feedwater piping breaks. The ESDs are used in the development of the event trees, which are presented in Figs. 6.11 and 6.12 .

The LOFWRB event tree resulted in 22 sequences designated as LOFWRB-A through LOFWRB-U and 14 FTSD sequences designated as LOFWRB-FTSD-A through LOFWRB-FTSD-N (the FTSD transfer event tree is presented in Sect. 6.6). The LOFWTB event tree resulted

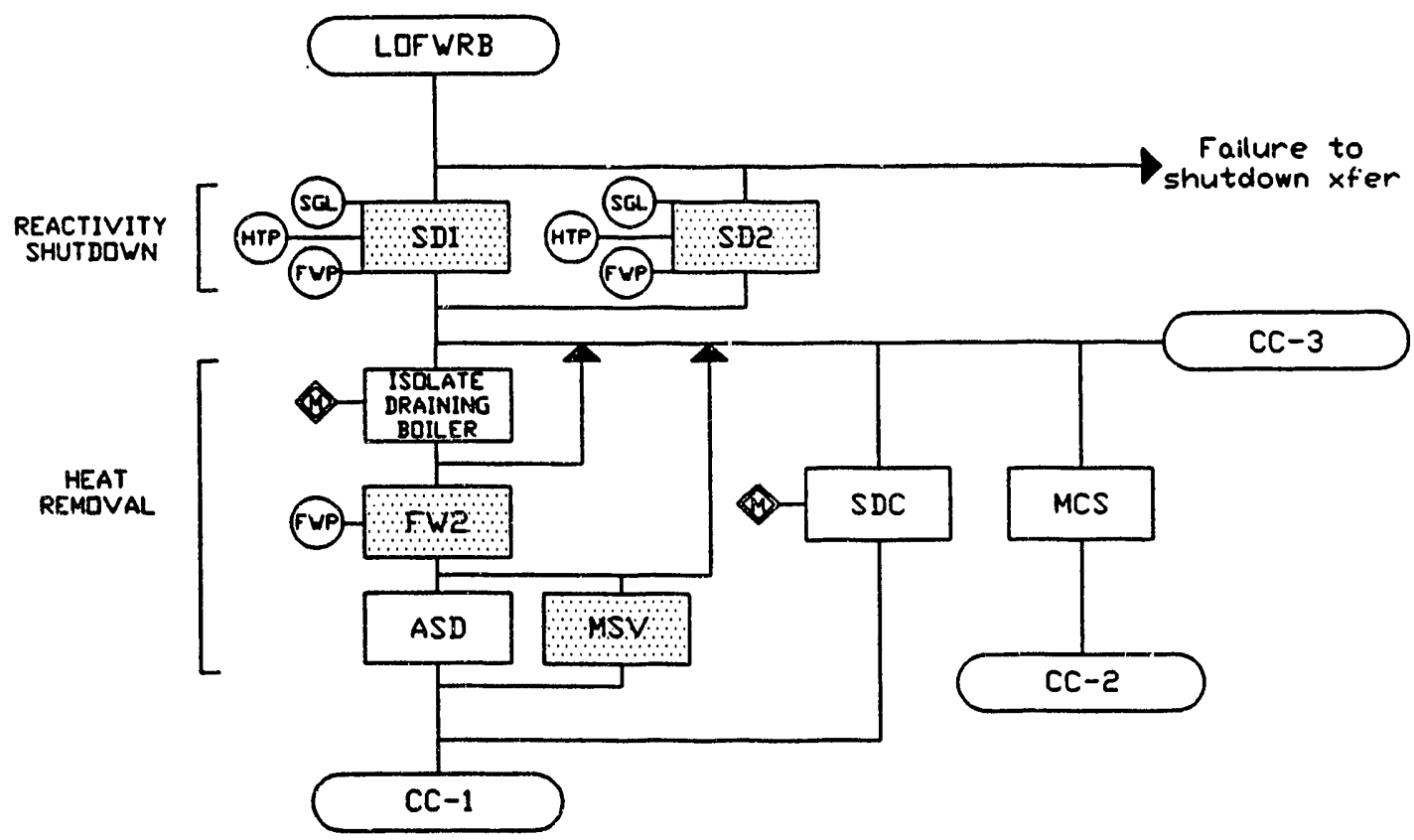

$$
\begin{aligned}
& \text { Group } 2 \text { systems } \\
& \text { Input Parameter } \\
& \Delta \text { - Manual Initiation Only } \\
& \Delta \text { - Manual Initation }
\end{aligned}
$$

Figure 6.9 Feed water piping break in reactor building ESD 


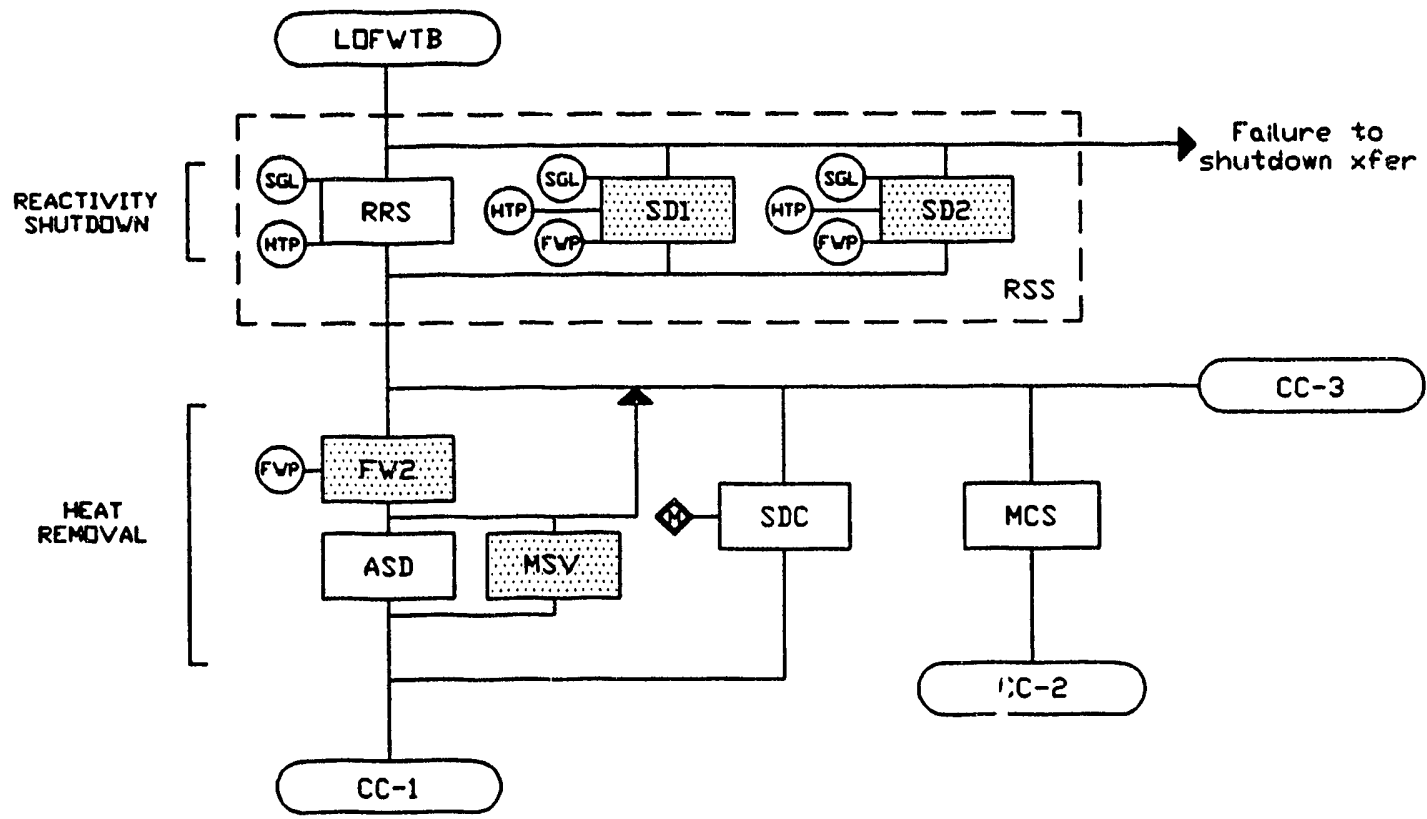

$$
\begin{aligned}
& \text { Group } 2 \text { systems } \\
& \text { Input Parameter } \\
& \text { Manual Initiation Dnly } \\
& \text { Manual Initation }
\end{aligned}
$$

Figure 6.10 Feedwater piping break in turbine building ESD

in 8 sequences designated as LOFWTB-A through LOFWTB-H plus 14 FTSD sequences designated as LOFWTB-FTSD-A through LOFWTB-FTSD-N (the FTSD transfer event tree is presented in Sect. 6.6).

The events listed along the top of the event tree page refer to the system fault trees from Chap. 5 that are called by the feedwater piping break event trees. The fault trees for LOFWRB are

1. SD1-shutdown system 1

2. SD2-shutdown system 2

3. ISO-isolate steam generator

4. FW2-Group 2 feedwater system

5. ASD_atmospheric steam discharge valve
6. MSV-main steam safety valve

7. SDC-shutdown cooling system

8. MCS-moderator cooling system.

The fault trees for LOFWTB are

1. RSS-reactor shutdown systems

2. FW2-Group 2 feedwater system

3. ASD-atmospheric steam discharge valve

4. MSV - main steam safety valve

5. SDC-shutdown cooling system

6. MCS-moderator cooling system. 
Event

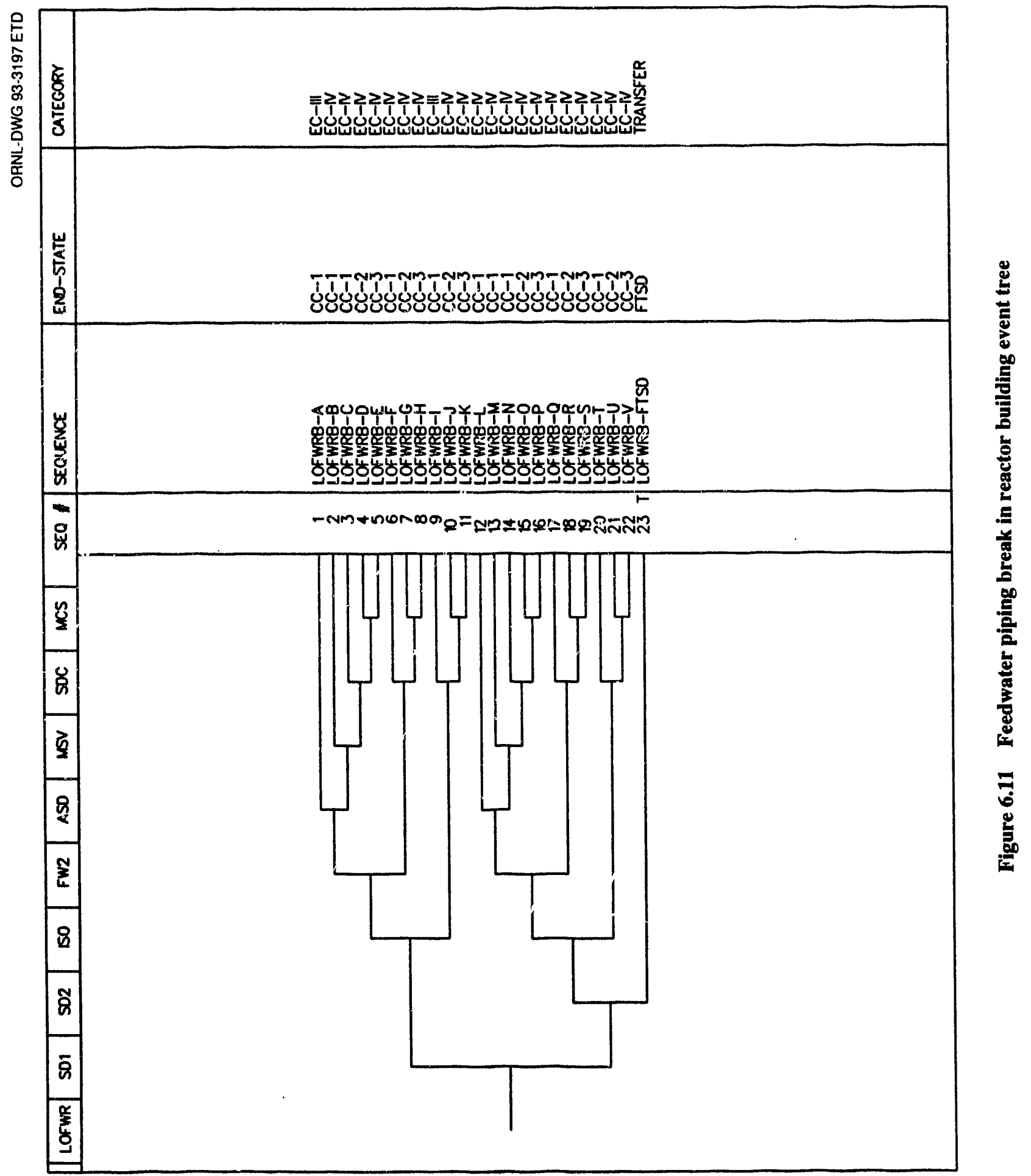


Event

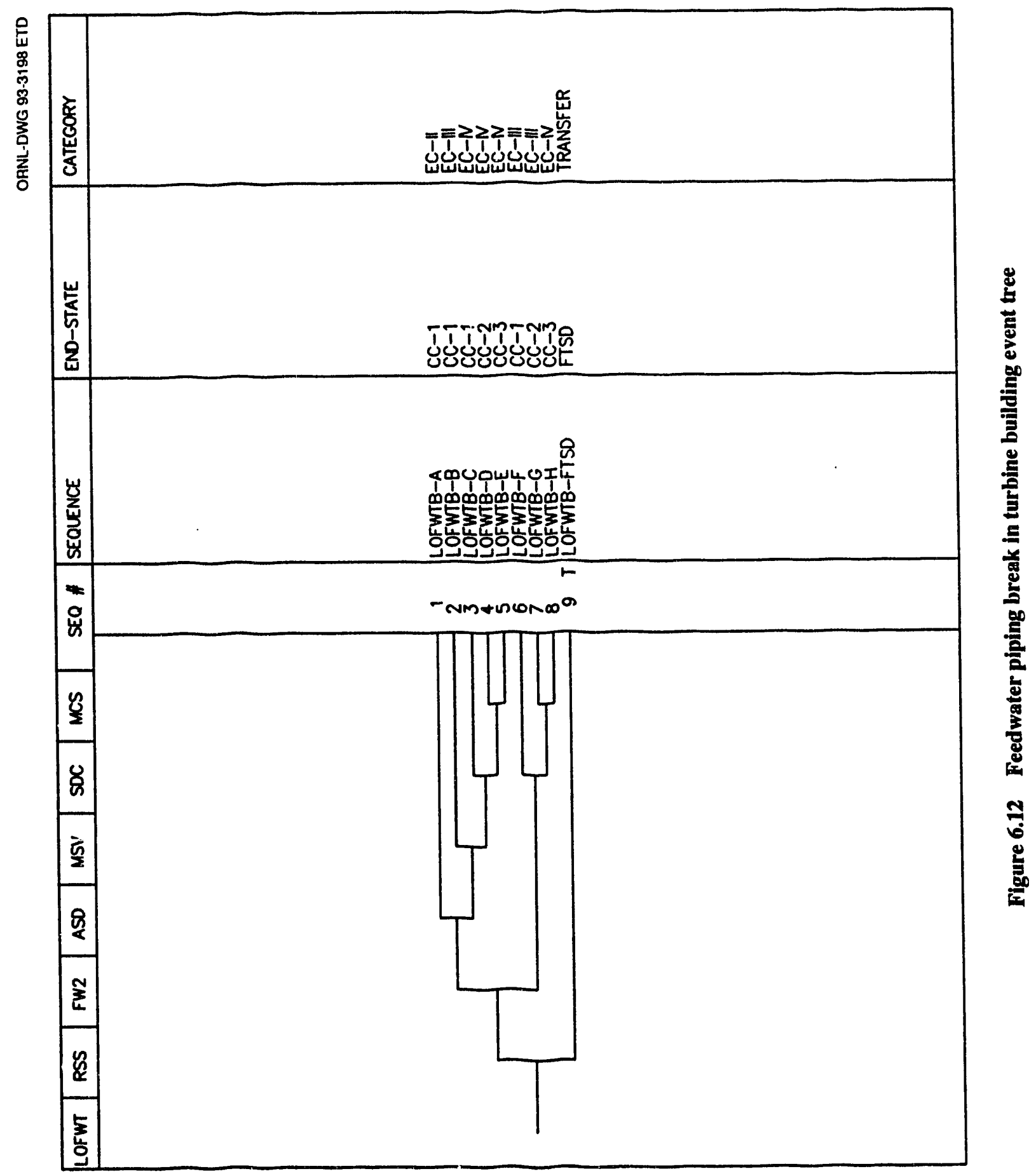




\subsubsection{Sequence Evaluation Insights}

Operator action is required to isolate the draining steam generator for LOFWRB. Initiation of shutdown cooling also requires operator action. Therefore, any sequence resulting in end state $\mathrm{CC}-1$ requires some type of operator action for feedwater piping breaks in the reactor building. Special attention should be given to the ASDs for feedwater piping breaks in the turbine building. The ASDs require plant air to open, but the plant air compressors are not qualified for the steam environment that would be present in the turbine building. ${ }^{*}$

\subsection{Reactivity Transient Event}

\subsubsection{Event Description}

The SCRAM initiator was analyzed to represent events when reactor shutdown is initiated by operator action. This initiator is intended to show how the plant will respond to transients that are anticipated to be more likely than some other initiators included in the analysis. SCRAM scenarios may include failure of the reactor to shut down automatically on designated trip parameters, anticipated transients, or response to alarms by the operators.

The functions needed to SCRAM the reactor and bring it to safe shutdown are reactivity shutdown and heat removal. Reactivity shutdown is the insertion of absorber or shutoff rods and/or liquid poison to stop the fission reaction in the reactor core. Heat removal is necessary to take the decay heat away from the reactor core. Inventory control is maintained by the pressurizer volume.

Reactivity shutdown is initiated manually and can be accomplished using the RRS. SDS1 and SDS2 provide backup to the RRS if it were to fail to shut down the reactor. RRS and SDS1 are the preferred shutdcwn means because activation of SDS2 would require significant poison cleanup from the moderator before the reactor could be restarted. Failure to shut down the reactor with one of these systems would result in a FTSD sequence, which is described in Sect. 6.6.

\footnotetext{
*P. J. Allen et al., Atomic Energy of Canada, Limited, External Analysis Report-Conceptual Probabilistic Safety Assessment, Rev. 0/89-02-28, 1989.
}

Removal of the decay heat from the reactor is accomplished by transferring the heat to the feedwater in the steam generators. This is the preferred method of heat removal following a SCRAM so that the plant can be ready to return to power after eliminating the problem that required the SCRAM. The heat transport pumps may continue to operate, but this is not essential because thermosyphoning would provide adequate flow through the reactor core. Any one of the three feedwater systems has sufficient capacity to remove the decay heat. The steam produced in the steam generators would be discharged to the condenser through the CSDs. It is assumed that condenser vacuum is maintained so long as the condensate pumps are running. Failure of the steam discharge valves or condenser vacuum would result in the ASD's opening to release the steam pressure. The steam generator MSSVs are provided as a means to relieve pressure in the steam generators if the steam discharge valves or ASDs do not function adequately. (Although initiation of the SDC would probably be performed before allowing the MSSVs to lift repeatedly, they are included as a redundant portion of the steam removal function for the SCRAM sequences.)

The SDC is designed to cool the reactor from $100 \%$ heat and pressure and therefore can be used as an alternate means to cool the reactor following a SCRAM. While the SDC would be required for all long-term reactor shutdowns, this analysis considers only short-term cooling of the reactor while awaiting return to power. The SDC requires manual initiation from the operators.

The MCS can be used to maintain reactor temperature below levels where fuel will melt when other cooling methods have failed. This requires pressure tube deformation to come in contact with the calandria tubes for heat transfer, as discussed earlier with other initiators. This again dictates a certain level of fuel damage but to a lesser degree than that occurring from no core cooling. Failure to remove the decay heat will result in extensive core damage.

\subsubsection{Event Sequence Diagram and Event Tree}

The ESD for a SCRAM, shown in Figure 6.13, is a pictorial representation of the logical sequence of operations necessary to mitigate the SCRAM condition. The ESD was used in the development of the event tree, which is presented in Figure 6.14. The event tree resulted in 8 sequences designated as SCRAM-A through SCRAM-H and 14 FTSD sequences designated as SCRAM-FTSD-A through SCRAM-FTSD-N (the FTSD transfer event tree is presented in Sect. 6.6). 

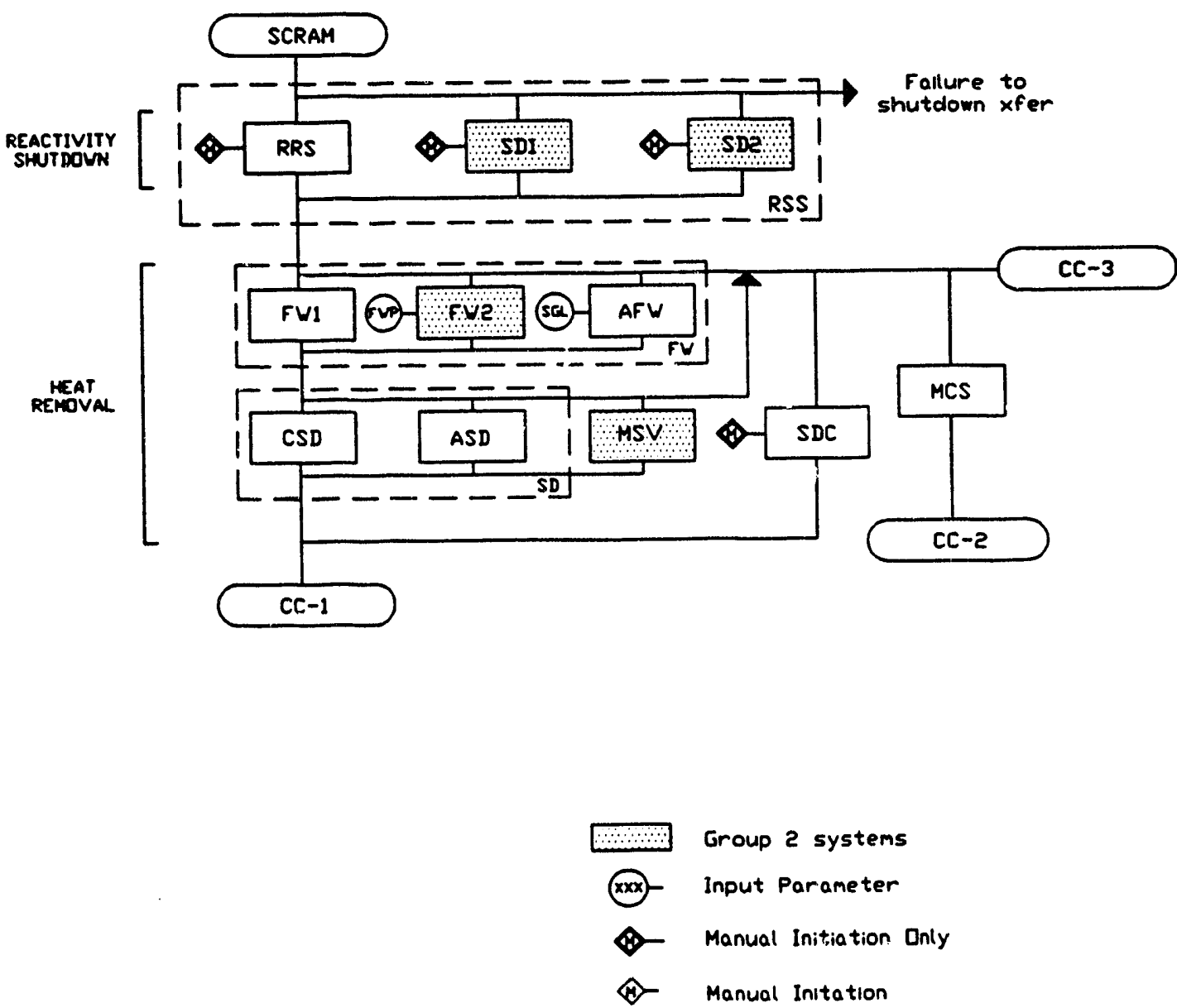

Figure 6.13 SCRAM ESD

The events listed along the top of the event tree page refer to the system fault trees from Chap. 5 that are called by the SCRAM event tree. The fault trees are

1. RRS-reactivity regulating system and shutdown systems 1 and 2

2. FW-Group 1 and 2 feedwater systems and auxiliary feedivater

3. SD-steam discharge (CSD and ASD)

4. MSV-main steam safety valve

5. SDC-shutdown cooling system

6. MCS-moderator cooling system.

\subsubsection{Sequence Evaluation Insights}

The CSDs and the ASDs require air to open. Therefore, failure of the plant ai system to supply instrument air to these valves will require the operator to initiate the SDC, or the repeated lifting of the MSSVs will occur.

NUREG/CR-6065

\subsection{Failure to Shutdown Event}

\subsubsection{Event Description}

The FTSD event is defined in this study as the condition whereby the systems designed for reactor shutdown are not available. In all of the previously analyzed events, SDS1 and SDS2 were designated for reactor shutdown. The RRS was sanctioned for reactivity control in some, but not all, of the events.

FTSD is referred to as a transfer event, as opposed to an IE, because the other events, except for the LBLOCA, "transfer" to it. As such, FTSD is assigned a frequency of occurrence of 1.0. However, this is a conditional event with failures of SDS1 and SDS2 (and in some cases the RRS) having occurred before transferring to the FTSD tree. 


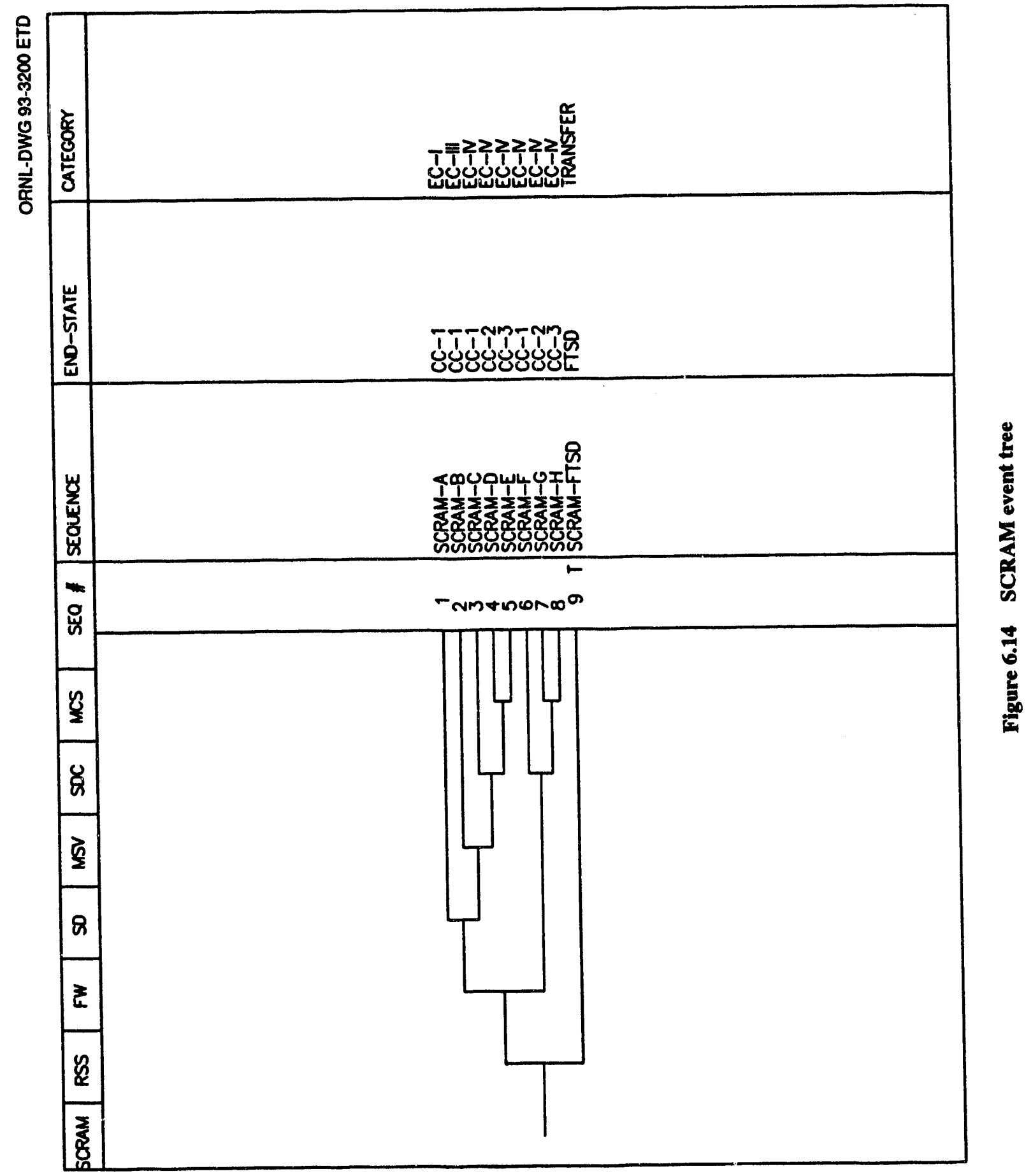


After a failure of the reactivity control systems, the following functions are required to mitigate the FTSD transfer event:

- reactivity control,

- heat removal, and

- inventory control.

The MLP system provides boron poison for reactivity control during normal operation of the reactor and during shutdown. However, in the absence of other means of reactor shutdown, the MLP system is proposed as an alternate means for reactor shutdown. Failure of the MLP system is expected to result in extensive core damage.

Heat removal is accomplished by removing steam and supplying cooling $w$ ter to the secondary side of the steam generator. Steam removal may be accomplished by actuation of the CSDs or the ASDs. Should failure of both the CSDs and ASDs occur, the MSSVs will lift to relieve steam pressure. Assuming the steam generator is available as a heat sink, FW1 or FW2 may be used to remove heat on the secondary side. Unavailability of both these systems will require the AFW. Failure to remove heat is expected to result in core melt.

Finally, water inventory must be made up so that the core is not uncovered. This is accomplished by closing the LRVs. Should this fail, the BCS must be isolated to halt further loss of primary coolant inventory. If this is not possible, the HPI and LPI modes of the ECCS can provide inventory makeup. Failure to control inventory is expeitted to result in core melt.

\subsubsection{Event Sequence Diagram and Event Tree}

The ESD for the FTSD is shown in Fig. 6.15. The ESD is a pictorial representation of the sequence of operation necessary to mitigate the FTSD condition. The ESD was used in the development of the event tree, which is presented in Figure 6.16. The event tree resulted in 14 sequences designated as FTSD-A through FTSD-N.

The events listed along the top of the event tree page refer to the system fault trees from Chap. 5 that are called by the FTSD event tree. The fault trees are

1. MLP-moderator liquid poison system

2. SD-steam discharge systems (CSDs and ASDs)

3. MSV-main steam safety valve

4. FW-Group 1 and 2 feedwater systems and auxiliary feedwater

5. LRC_liquid relief valve closed

6. BCS-isolate bleed condenser

7. HPI-high-pressure injection mode of ECCS

8. LPI-low-pressure injection mode of ECCS

\subsubsection{Sequence Evaluation Insights}

The FTSD sequences presented in the analysis are based exclusively on engineering judgement. Because transfer to a FTSD sequence requires failure of both SDS1 and SDS2 and in some cases RRS, at least three failures must occur before this transfer occurs. Therefore, all resultant FTSD sequences are automatically classified as EC-IV events. Although the FTSD analysis may provide useful information about the systems that might be employed in this type of situation, few insights are to be drawn from analysis of these sequences.

\section{Reference}

1. Atomic Energy of Canada, Limited, "CANDU 3 Conceptual Safety Report," Vols. 1 and 2, 1989."

\footnotetext{
*Available in NRC PDR for inspection and copying for a fee.
} 
ORNL-DWG 93-3201 ETD

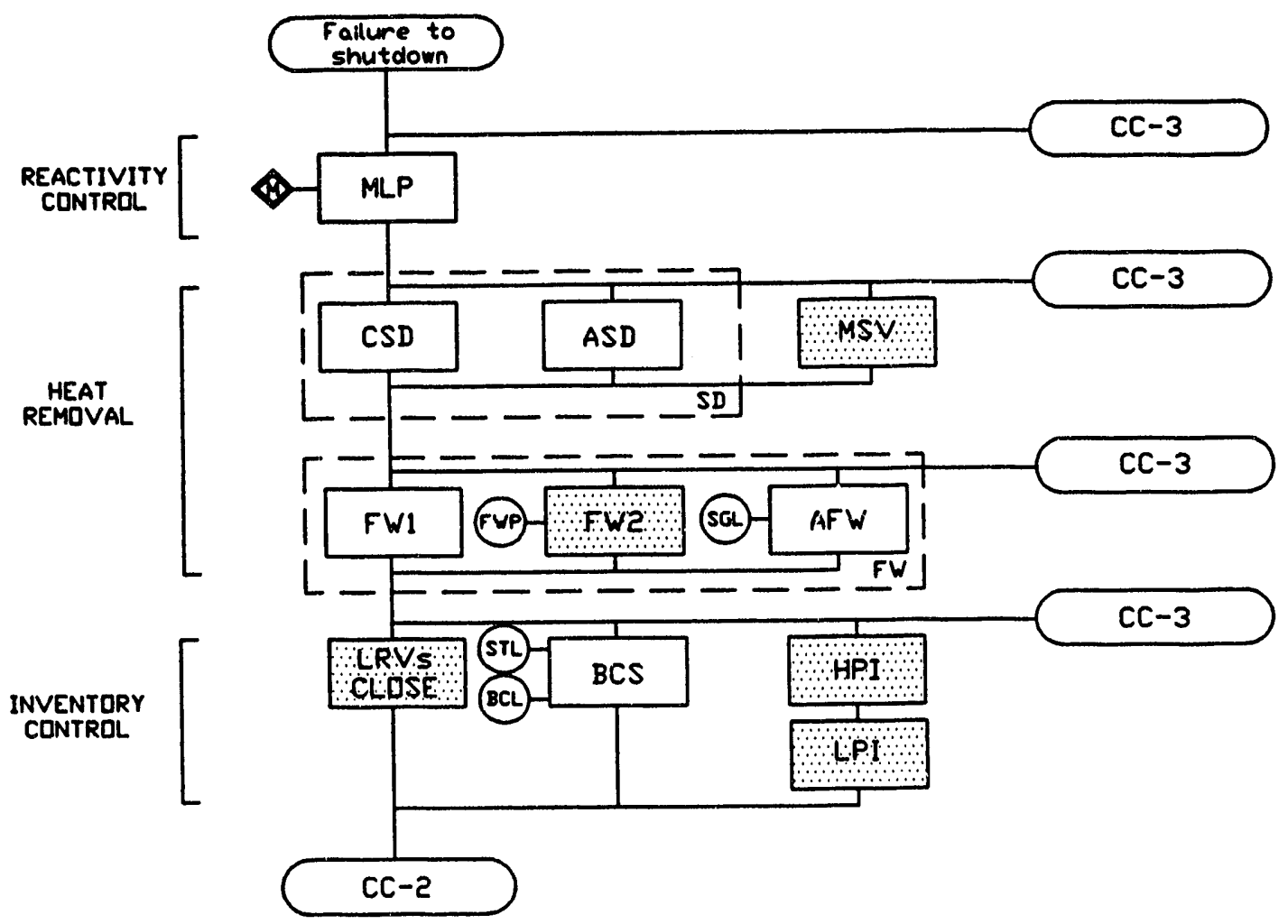

Group 2 systems

(xxx) Input Parameter

0- Manual Initiation Dnly

(1) Manual initation

Figure 6.15 FTSD ESD 
Event

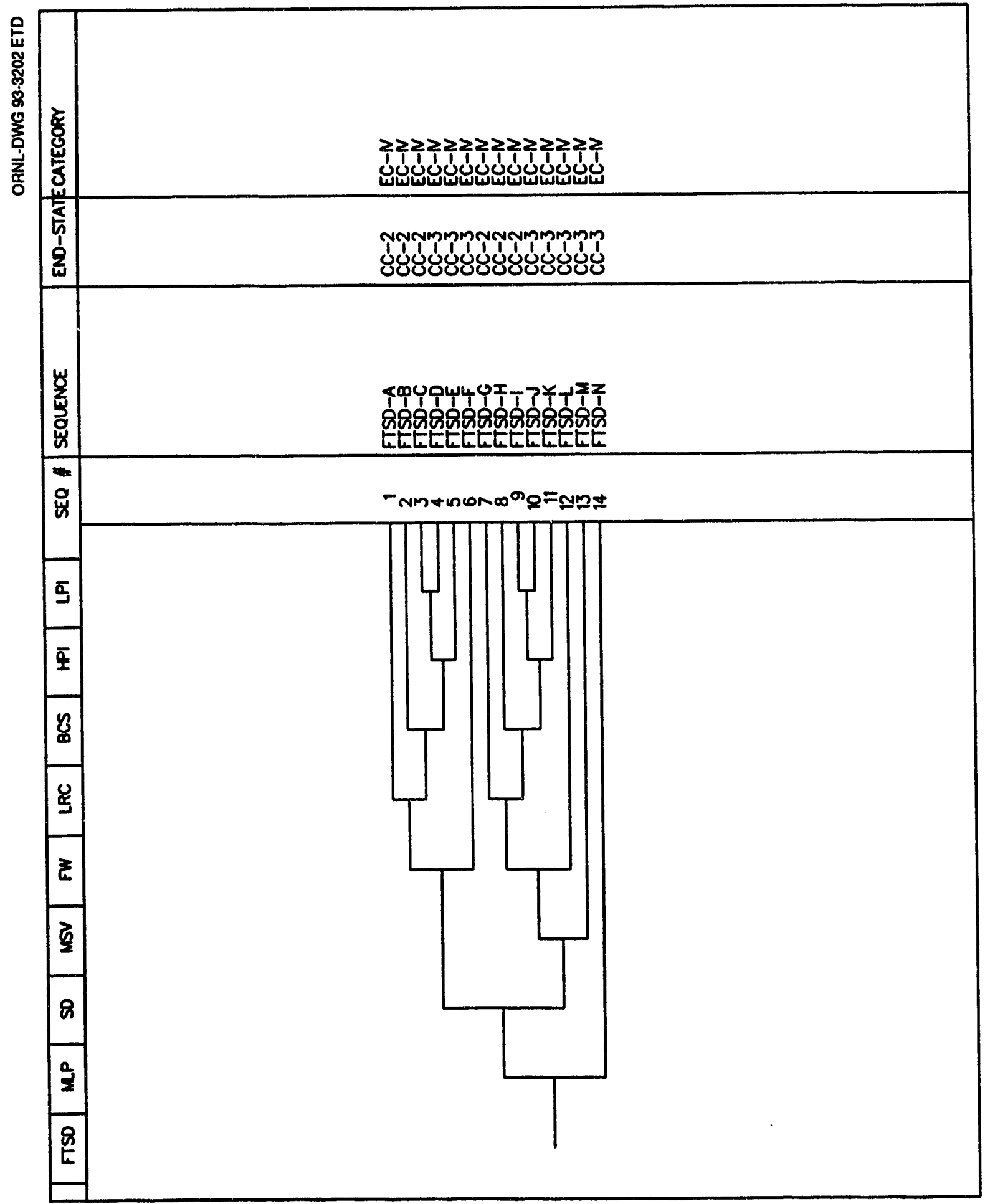

홀 


\section{Results}

This chapter provides a discussion of the insights from the results of the event tree evaluations and the review of the ESDs. Of primary interest are the event sequence categorization results, the identification of systems significant to safety, and identification of key operator actions.

The ESDs and the event trees are presented in Chap. 6. An ESD was prepared for each of the seven RIEs: LBLOCA initiator, two SBLOCA initiators (LRV failure and feeder tube break), LOP initiator, two loss of feedwater initiators (pipe break inside and outside the reactor building), and a general scram initiator. FTSD was not treated as a separate IE in this analysis, but as an extension of possible sequences resulting from other initiators. This is because FTSD sequences potentially serve as the next line of defense should the reactor shutdown systems fail. Consequently, the sequences for mitigation of an FTSD are treated as transfers from the other ESDs. Significant insights from the FTSD transfer event are subject to these conditions.

\subsection{Event Sequence Categorization Results}

Tables 7.1-7.3 present the event categorization results for the EC-I, EC-II, and EC-III classifications, respectively. These categories identify sequences that might later be chosen as Anticipated Operational Occurrences, DesignBasis Accidents, and Severe Accidents, respectively, for analysis at the time of CANDU 3 design certification. These results were determined by combining the systems and event analyses discussed in Chaps. 5 and 6 with the event sequence categorization criteria discussed in Chap. 3 (Table 3.1). The full event sequence cut sets (presented in Appendix $\mathrm{C}$ of this report) were analyzed to develop the data presented in Tables 7.1-7.3 as follows:

1. Each of the seven RIEs had a number of event sequences (e.g., LB-A, LB-B, etc.) associated with it. For each event sequence a determinant failure(s) was identified; this was the sequence cut set(s) that results in the sequence being placed in the most limiting category (EC-I being most limiting, and EC-IV being least limiting). A particular sequence can have more than one determinant failure, because there may be multiple cut sets that would result in the sequence being classified in its most limiting category. Sequences where all cut sets had three or more failures had no determinant cut set (because all would be classified as EC-IV).

2. Based on the determinant failures, each sequence for the analyzed RIEs could then be categorized by the criteria discussed in Chap. 3 (Table 3.1).
3. Finally, the event sequences represented by the RIEs (as noted in Table 4.2) were categorized based on the RIE duterminant failures, the initiating frequencies for these events, and the categorization criteria.

The meaning of the EC-I, EC-II, EC-III, and EC-IV classifications (from Chap. 3) are presented again here:

- The EC-I category was defined to include scenarios that might occur at least once in the lifetime of a given plant. Scenarios similar to those in this category might be selected by NRC as Anticipated Operational Occurrences for analysis by the applicant.

- The EC-II category was defined to include lowfrequency initiators and single component or operator failures. These scenarios might occur once in the lifetime of a class of plants. Some of these scenarios might later be selected as Design-Basis Accidents for analysis by the applicant.

- The EC-III category was defined to include very low probability scenarios, some with multiple failures, which would be typical of so-called Severe Accidents. Such scenarios might be analyzed in PRAs to determine licensing source terms and to assess containment capabilities.

- The EC-IV category was defined to include scenarios with such low probabilities that detailed analysis would probably not be worthwhile. These are sometimes referred to as Residual Risk scenarios.

Finally, note that Tables 7.1-7.3 also present, for each of the categorized event sequences, the plant end state associated with that sequence. The plant end states defined in Chap. 3 are presented again here:

- CC-1-No significant fuel cladding damage and no fission product release from the fuel.

- CC-2-Moderate fuel cladding damage with release of some volatile fission products from the fuel (the fuel rod gap inventory), but coolable geometry of fuel bundles is maintained.

- CC-3-Extensive core damage with large release of fission products from the fuel and potential relocation of core debris.

\subsection{Systems Significant-to-Safety}

CANDU-3 systems are separated in terms of a "two-group separation philosophy." This concept generally divides systems into two groups, each capable of performing the 
Table 7.1 Event Category I results

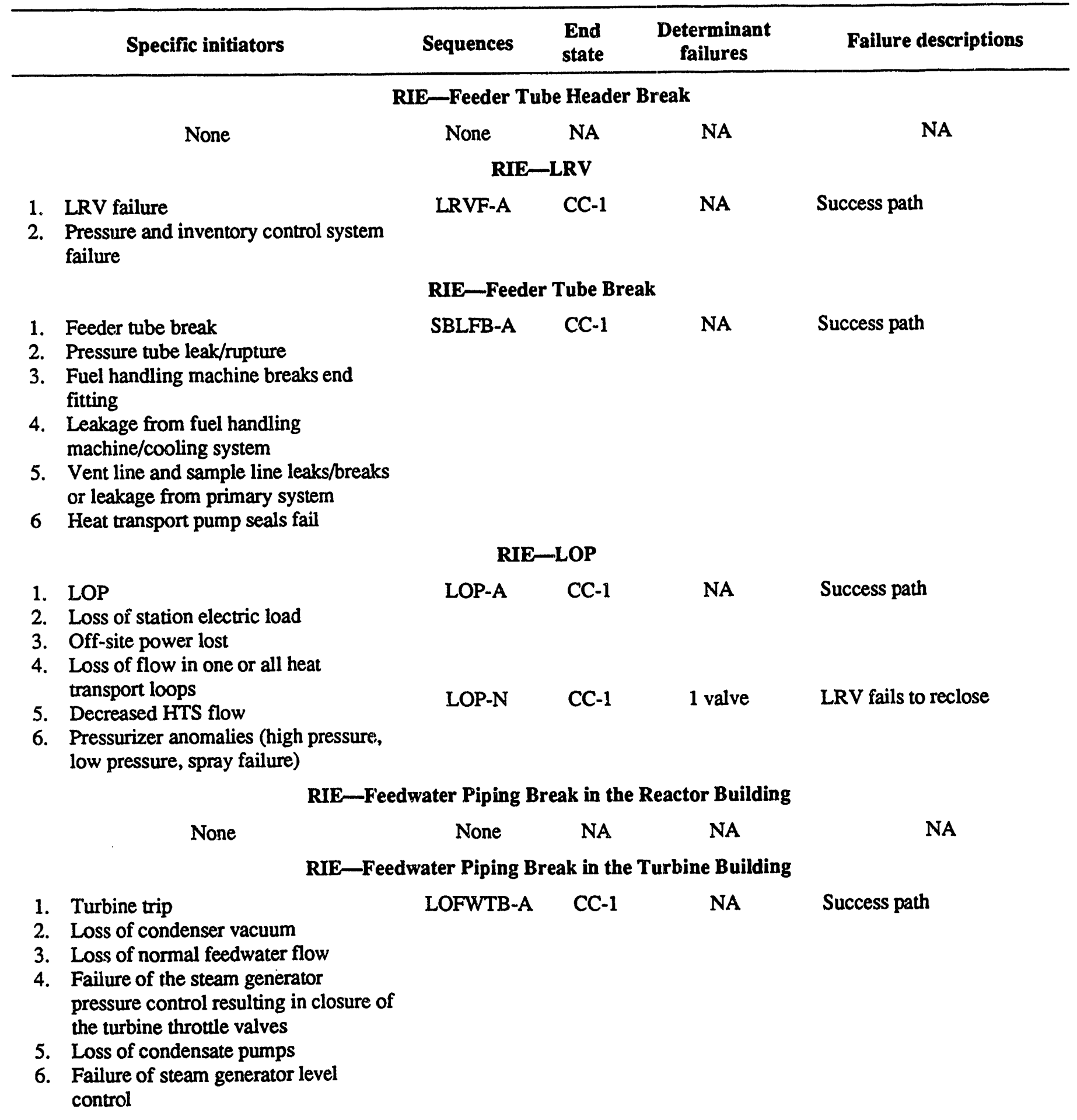


Results

Table 7.1 (continued)

\section{Specific initiators}

1. SCRAM

2. Uncontrolled control rod assembly withdrawal

3. Control rod maloperation (part length control rods, rod ejection, or rod drop)

4. Rod position error (pressure, temperature, power imbalance)

5. Moderator anomalies

6. Feedwater system malfunctions that result in an increase in feedwater flow or a decrease in feedwater temperature

7. Steam pressure regulator malfunction or failure that results in increasing steam flow (uurbine overspeed)

8. Inadvertent opening of a steam generator relief or safety valve

9. Increased heat transfer flow or inventory

10. Degradation or loss of moderator flow

11. Degradation or loss of moderator cooling

12. Loss of moderator inventory

13. Failure of the cover gas system
Sequences

\section{RIE-SCRAM}

Failure descriptions

Determinant
failures Failure descriptions

SCRAM-A CC-1 NA Success path 
Results

Table 7.2 Event Category II results

\begin{tabular}{|c|c|c|c|c|c|}
\hline & Specific initiators & Sequences & End state & $\begin{array}{l}\text { Determinant } \\
\text { failures }\end{array}$ & Failure descriptions \\
\hline \multicolumn{6}{|c|}{ RIE_Feeder Tube Header Break } \\
\hline \multirow[t]{6}{*}{1.} & Feeder tube header & LB-A & $\mathrm{CC}-2$ & NA & Success path \\
\hline & & LB-H & $\mathrm{CC}-2$ & Pump failure & Failure of any one of the four HTS pumps \\
\hline & \multicolumn{5}{|c|}{ RIE-LRV Failure } \\
\hline & None & None & NA & NA & NA \\
\hline & \multicolumn{5}{|c|}{ RIE-Feeder Tube Break } \\
\hline & None & None & NA & NA & NA \\
\hline \multicolumn{6}{|c|}{ RIE-LOP } \\
\hline \multirow[t]{3}{*}{1.} & Deformation of fuel & LOP-A & CC-1 & NA & Success path \\
\hline & 20 & LOP-N & $\mathrm{CC}-1$ & 1 valve & LRV fails to reclose \\
\hline & \multicolumn{5}{|c|}{ RIE_Feedwater Piping Break in the Reactor Building } \\
\hline \multirow[t]{3}{*}{1.} & Steam generator tube & LOFWRB-A & CC-1 & NA & Success path \\
\hline & & LOFWRB-Z & $\mathrm{CC}-1$ & $\begin{array}{l}\text { Signal failure, } \\
\text { valve failure, } \\
\text { human error }\end{array}$ & $\begin{array}{l}\text { The draining steam generator cannot be } \\
\text { isolated due to valve failure, signal fail- } \\
\text { ure, or failure of the operator to close } \\
\text { the valve }\end{array}$ \\
\hline & \multicolumn{5}{|c|}{ RIE-Feedwater Piping Break in the Turbine Building } \\
\hline 1. & $\begin{array}{l}\text { Feedwater piping break } \\
\text { in the turbine building }\end{array}$ & LOFWTB-A & $\mathrm{CC}-1$ & NA & Success path \\
\hline \multicolumn{6}{|c|}{ RIE-SCRAM } \\
\hline 1. & $\begin{array}{l}\text { Steamline piping breaks } \\
\text { inside or outside con- } \\
\text { tainment }\end{array}$ & SCRAM-A & CC-1 & NA & Success path \\
\hline 2. & $\begin{array}{l}\text { Startup of an inactive } \\
\text { heat transfer loop or } \\
\text { recirculating loop at an } \\
\text { incorrect temperature }\end{array}$ & & & & \\
\hline 3. & $\begin{array}{l}\text { Moderator deuterium } \\
\text { excursion }\end{array}$ & & & & \\
\hline 4. & $\begin{array}{l}\text { Loss of calandria struc- } \\
\text { tural integrity }\end{array}$ & & & & \\
\hline
\end{tabular}


Table 7.3 Event Category III results

\begin{tabular}{|c|c|c|c|c|c|}
\hline & Specific initiators & Sequences & $\begin{array}{l}\text { End } \\
\text { state }\end{array}$ & Determinant failures & Failure descriptions \\
\hline \multicolumn{6}{|c|}{ RIE_Feeder Tube Header Break } \\
\hline \multirow[t]{4}{*}{1.} & $\begin{array}{l}\text { Feeder tube header } \\
\text { break }\end{array}$ & LB-B & $\mathrm{CC}-2$ & $\begin{array}{l}2 \text { Valves, } 2 \text { heat } \\
\text { exchangers }\end{array}$ & $\begin{array}{l}\text { ECCS recirculation sump isolation } \\
\text { valves fail to open or the heat exchang- } \\
\text { ers foul }\end{array}$ \\
\hline & & LB-D & $\mathrm{CC}-2$ & $\begin{array}{l}2 \text { Valves, } 2 \text { pumps, } \\
\text { undetected low } \\
\text { coolant tank level }\end{array}$ & $\begin{array}{l}\text { ECCS LPI valves fail to open, grade- } \\
\text { level tank isolation valves fail to open, } \\
\text { or insufficient volume in the grade- } \\
\text { level tank goes undetected }\end{array}$ \\
\hline & i & LB-F & $\mathrm{CC}-2$ & $\begin{array}{l}\text { Support system, } \\
2 \text { signals, } 2 \text { valves, } \\
\text { undetected low gas } \\
\text { tank pressure, unde- } \\
\text { tected low coolant } \\
\text { tank volume }\end{array}$ & $\begin{array}{l}\text { ECCS control signals fail, ECCS initia- } \\
\text { tion signals fail, HPI valves fail to } \\
\text { open, undetected low pressure in } \\
\text { helium accumulator tank, or undetected } \\
\text { low volume in coolant tank }\end{array}$ \\
\hline & & LB-O & $\mathrm{CC}-2$ & $\begin{array}{l}\text { Common mode, } \\
2 \text { relays, } 2 \text { trip } \\
\text { computers }\end{array}$ & $\begin{array}{l}\text { Failure of multiple shutdown rods to } \\
\text { insert, failure of relays in the SDS1 trip } \\
\text { logic, or failure of two SDS1 trip } \\
\text { computers }\end{array}$ \\
\hline \multirow[t]{3}{*}{2.} & Backflow into ECCS & LB-A & $\mathrm{CC}-2$ & NA & Success path \\
\hline & & LB-H & $\mathrm{CC}-2$ & Pump failure & $\begin{array}{l}\text { Failure of any one of the four HTS } \\
\text { pumps }\end{array}$ \\
\hline & \multicolumn{5}{|c|}{ RIE-LRV Failure } \\
\hline \multirow[t]{3}{*}{$\begin{array}{l}1 . \\
2 .\end{array}$} & $\begin{array}{l}\text { LRV failure } \\
\text { Pressure and inven- } \\
\text { tory control system }\end{array}$ & LRVF-B & $\mathrm{CC}-1$ & Support system & $\begin{array}{l}\text { Failure of the instrument air system } \\
\text { causes the ASDs and CSDs to fail to } \\
\text { open }\end{array}$ \\
\hline & & LRVF-I & $\mathrm{CC}-1$ & $\begin{array}{l}\text { Support systems, } \\
2 \text { valves }\end{array}$ & $\begin{array}{l}\text { Failure of the Group } 1 \text { Class II odd } \\
\text { power bus, plant control system, or } \\
\text { failure of } 2 \text { isolation valves may result } \\
\text { in failure to isolate the bleed condenser }\end{array}$ \\
\hline & & LRVF-R & $\mathrm{CC}-1$ & $\begin{array}{l}\text { Common mode, } \\
2 \text { relays, } 2 \text { trip } \\
\text { computers }\end{array}$ & $\begin{array}{l}\text { Failure of multiple SDS1 shutdown rods } \\
\text { to insert either due to binding or multi- } \\
\text { ple coil failures or failure of } 2 \text { trip logic } \\
\text { relays or } 2 \text { trip computers results in } \\
\text { failure of SDS1 }\end{array}$ \\
\hline
\end{tabular}




\begin{tabular}{|c|c|c|c|c|c|}
\hline & Specific initiators & Sequences & $\begin{array}{l}\text { End } \\
\text { state }\end{array}$ & Determinant failures & Failure descriptions \\
\hline \multicolumn{6}{|c|}{ RIE-Feeder Tube Break } \\
\hline $\begin{array}{l}1 . \\
2 . \\
3 .\end{array}$ & $\begin{array}{l}\text { Feeder tube break } \\
\text { Pressure tube leak/ } \\
\text { rupture } \\
\text { Fuel handling }\end{array}$ & SBLFB-B & $\mathrm{CC}-2$ & $\begin{array}{l}2 \text { Valves, } 2 \text { pumps, } \\
\text { undetected low } \\
\text { grade-level tank level }\end{array}$ & $\begin{array}{l}\text { ECCS LPI isolation valves, injection } \\
\text { valves, or pumps fail; or insufficient } \\
\text { volume in the grade-level tank is } \\
\text { undetected }\end{array}$ \\
\hline 4. & $\begin{array}{l}\text { machine breaks end } \\
\text { fitting } \\
\text { Leakage from fuel } \\
\text { handling machine/ } \\
\text { cooling system } \\
\text { Vent line and sample }\end{array}$ & SBLFB-D & $\mathrm{CC}-2$ & $\begin{array}{l}2 \text { Signals, } 2 \text { valves, } \\
\text { undetected low gas } \\
\text { tank pressure, unde- } \\
\text { tected low coolant } \\
\text { tank volume }\end{array}$ & $\begin{array}{l}\text { ECCS initiation signals, isolation } \\
\text { valves, or injection valves fail; or } \\
\text { undetected low pressure in the helium } \\
\text { gas tank; or insufficient volume in the } \\
\text { high-pressure coolant tank goes } \\
\text { undetected }\end{array}$ \\
\hline & $\begin{array}{l}\text { line leaks/breaks or } \\
\text { leakage from primary } \\
\text { system }\end{array}$ & SBLFB-H & CC-2 & $\begin{array}{l}\text { Support systems, } \\
2 \text { MSSVs }\end{array}$ & $\begin{array}{l}\text { Failure of the instrument air system } \\
\text { causing the MSSVs to not open; ECCS } \\
\text { control system fails to open the }\end{array}$ \\
\hline 6. & $\begin{array}{l}\text { Heat transport pump } \\
\text { seals fail }\end{array}$ & & & & $\begin{array}{l}\text { MSSVs; either the even or odd Group } 2 \\
\text { Class II power bus or failure of } 2 \\
\text { MSSVs on the same steam generator }\end{array}$ \\
\hline & & SBLFB-J & CC-1 & $\begin{array}{l}\text { Common-mode fail- } \\
\text { ure, } 2 \text { relays, } 2 \text { trip } \\
\text { computers }\end{array}$ & $\begin{array}{l}\text { Failure of multiple SDS1 shutdown rods } \\
\text { to insert either due to binding or multi- } \\
\text { ple coil failures, failure of } 2 \text { trip logic } \\
\text { relays, or failure of } 2 \text { trip computers }\end{array}$ \\
\hline \multicolumn{6}{|c|}{ RIE-LOP } \\
\hline 1. & LOP & LOP-B & $\mathrm{CC}-1$ & 2 Valves & Failure of ASDs \\
\hline $\begin{array}{l}2 . \\
3 . \\
4 .\end{array}$ & $\begin{array}{l}\text { Loss of station electric } \\
\text { load } \\
\text { Off-site power lost } \\
\text { Loss of flow in one or } \\
\text { all heat transport loops }\end{array}$ & LOP-F & CC-1 & $\begin{array}{l}2 \text { Valves and/or } \\
\text { pumps, human error, } \\
\text { and level indication } \\
\text { failure }\end{array}$ & $\begin{array}{l}\text { FW2 pump or valve failures that disable } \\
\text { the system; failure to replenish the } \\
\text { FW2 supply tank after } 10 \mathrm{~h} \text { either due } \\
\text { to human error or tank level indication } \\
\text { failure }\end{array}$ \\
\hline $\begin{array}{l}5 . \\
6 .\end{array}$ & $\begin{array}{l}\text { Decreased HTS flow } \\
\text { Pressurizer anomalies } \\
\text { (high pressure, low }\end{array}$ & LOP-AA & CC-1 & Support system & $\begin{array}{l}\text { Failure of the Group } 1 \text { Class II power } \\
\text { board may result in failure to isolate } \\
\text { the BCS }\end{array}$ \\
\hline & $\begin{array}{l}\text { pressure, spray } \\
\text { failure) } \\
\text { Deformation of fuel }\end{array}$ & LOP-AK & $\mathrm{CC}-1$ & Support system & $\begin{array}{l}\text { Failure of the plant control sysiem may } \\
\text { cause failure to isolate the BCS and } \\
\text { failure to initiate FW2. }\end{array}$ \\
\hline 7. & $\begin{array}{l}\text { Deformation of fuel } \\
\text { channel that restricts } \\
\text { coolant flow }\end{array}$ & LOP-AO & CC-1 & Support system & $\begin{array}{l}\text { Failure to restore Class II power either } \\
\text { with the diesel generators or by } \\
\text { sestoring Class IV power }\end{array}$ \\
\hline
\end{tabular}


Table 7.3 (continued)

Specific initiators

1. Feedwater piping break in the reactor building

2. Steam generator tube failure

\section{LOFWRB-B CC-1 2 Valves}

LOFWRB-F CC-1 Tank level indicator and human error, 2 pumps and/or valves

LOFWRB-G CC-2 Support system

LOFWRB-J CC-2 Signal or valve and human error or two human errors

LOFWRB-L CC-1 $\begin{aligned} & \text { Common mode, } 2 \text { trip } \\ & \text { logic relays, } 2 \text { trip } \\ & \text { computers }\end{aligned}$

Failure descriptions

\section{RIE-Feedwater Piping Break in the Reactor Building}

LOFWRB-I CC-1 Signal failure, valve failure, human error
Success path

The draining steam generator cannot be isolated either due to valve failure, signal failure, or the operator failing to close the valve

Both ASDs fail to open

Operator fails to refill the Group 2 feedwater tank after $10 \mathrm{~h}$, and the level indicator fails to alarm on low level, or a combination of pumps and valves in the FW2 fails

Plant control system failure to operate valves in the FW2 and the SDC

The draining steam generator cannot be isolated either due to valve failure, signal failure, or the operator failing to close the valve; and the operator fails to initiate the SDC

Failure of SDS1 due to failure of 2 trip logic relays, or failure of 2 trip computers, or common-mode failure of at least 3 shutoff rods binding or clutch coils failing
1. Feedwater piping break in the turbine building

2. Turbine trip

3. Loss of condenser vacuum

4. Loss of normal feedwater flow

5. Failure of the steam generator pressure control resulting in closure of the turbine throttle valves

6. Loss of condensate pumps

7. Failure of steam generator level control

LOFWTB-B $\quad$ CC-1 $\begin{gathered}2 \text { Valves, support } \\ \text { system }\end{gathered}$

LOFWTB-F CC-1 Tank level indicator and human error, 2 pumps and/or valves

LOFWTB-G CC-2 Support system
ASDs fail to open due to failure of the valves or failure of the instrument air system

Operator fails to refill the Group 2 feedwater tank after $10 \mathrm{~h}$, and the level indicator fails to alarm on low level, or a combination of pumps and valves in the FW2 fails

Failure of the plant control system may result in failure to initiate the FW2 and to open valves in the SDC 
Table 7.3 (continued)

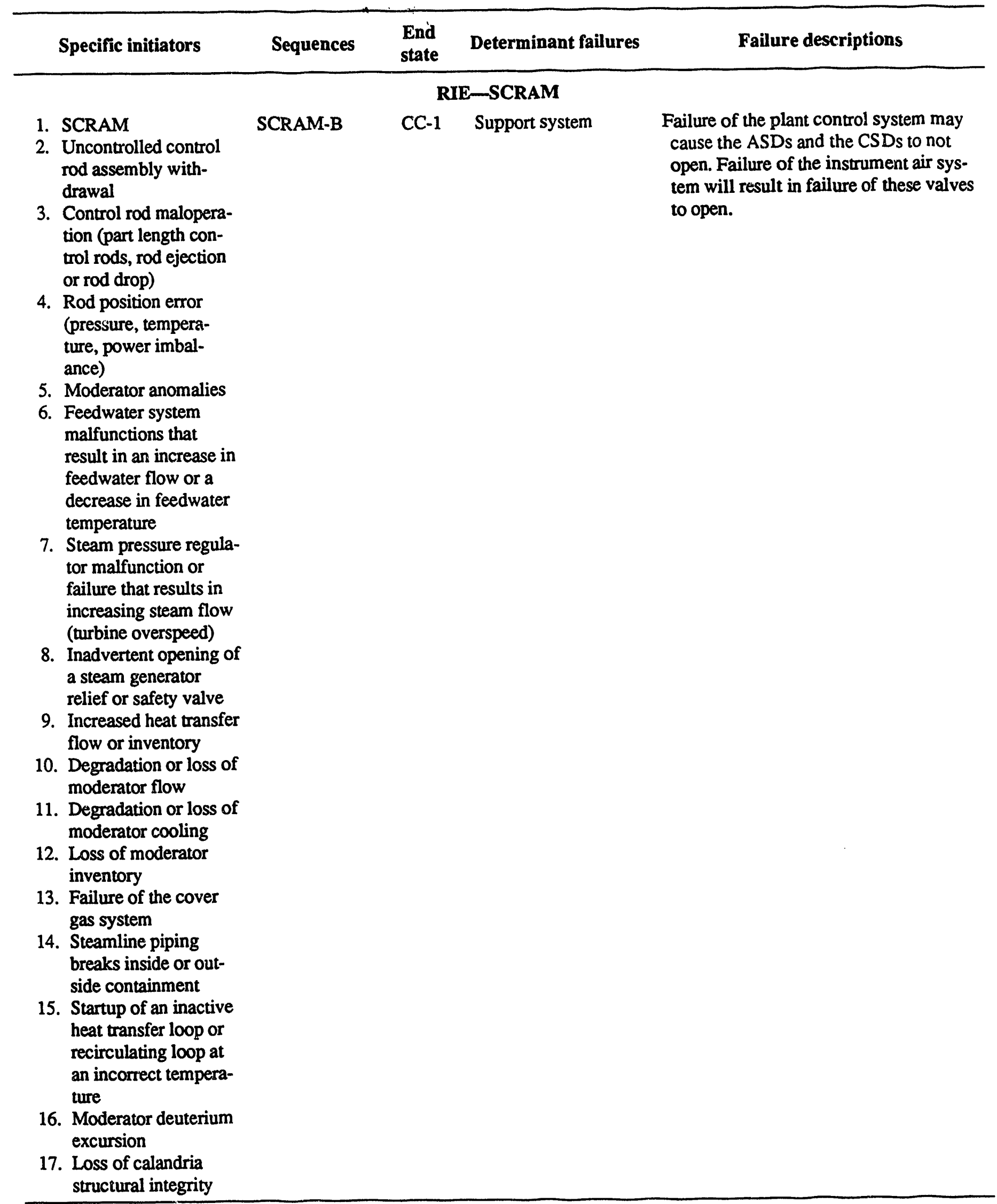


essential functions of reactor shutdown, decay heat removal, and monitoring of the plant parameters. In general, "Group 1" systems contribute to normal power production, while "Group 2" systems have a safety-related function or safety-related support function. Group 1 systems alone can perform an orderly shutdown and cooldown of the reactor. However, Group 2 systems can perform all required safety-related functions in the event of an accident, even one that disables Group 1. It is recognized, however, that many Group 1 systems have been qualified to perform a safety-related function under specific conditions. ${ }^{1}$ This report is not intended to provide an evaluation of the CANDU 3 design vs U.S. criteria for : safety-related functions, and systems will be designated as either Group 1 or Group 2.

The phrase "systems significant-to-safety," as used in this report, identifies those systems and components that could have a significant impact on the successful response of the plant to a given IE. The term does not mean "safetyrelated" as defined previously. U.S. commercial nuclear operating experience has shown that nonsafety-related equipment can exercise significant influence on the path taken to mitigate an event or on the consequences of an event. In the context of this definition of significant-tosafety, safety-related equipment would be considered a subset of equipment significant-to-safety.

The ESDs and the event tree evaluations are used to assist in the identification of such significant impacts on successful plant response. For this analysis, "significant" is defined as any system, component, or operator action that is important for the successful mitigation of an $\mathbb{E E}$. Because the terms "significant" and "important" are judgmental and subject to interpretation, a set of rules was established to permit a rational and consistent means to identify significant-to-safety systems and components and to provide a clear basis for their differentiation from nonsignificant-to-safety systems and components. These criteria are used in selecting systems and components significant to safety:

\section{Candidate Systems Criteria:}

1. Only those systems or components that contribute to successful termination (primary and backup paths) of an IE are considered candidates for being designated significant-to-safety. Successful termination is defined as resulting in plant end states $\mathrm{CC}-1$ and $\mathrm{CC}-2$. Systems on pathways leading to plant end state $\mathrm{CC}-3$ are not considered as being significant-to-safety, although such systems could be considered candidates for severe accident management actions.
2. All Group 1 systems or components on paths terminating in plant end states $\mathrm{CC}-1$ and $\mathrm{CC}-2$ are considered candidates for being designated significant-to-safety. This included frontline systems and their support systems.

3. All Group 2 systems on paths terminating in plant end states CC-1 and CC-2 are designated as significant-tosafety.

\section{Criteria for Systems Significant-to-Safety:}

1. Any Group 1 candidate system or component whose function is not backed up will be designated as being significant-to-safety. For the purposes of selecting systems significant-to-safety, the term "backup" here will be restricted to its use only where the "backup" leads to the equivalent plant end state as the original system.

2. If any Group 1 candidate system or component bas only Group 1 backup, the candidate system or component will be designated as significant-to-safety. The backup will not.

3. If a Group 2 candidate system is backed up by a Group 1 system, the Group 1 backup will not be designated as significant-to-safety.

4. Any Group 1 candidate system or component with at least one Group 2 backup will not be designated as significant-to-safety.

\section{Group 2 Systems Designated as Significant-to-Safety}

A review of the ESDs shows several Group 2 frontline systems that lie on paths leading to safe shutdown of the reactor. A summary of this information is shown in Table 7.4. As a result of the definitions of significant-to-safety presented, these Group 2 systems are defined as significant-tosafety.

Reference to the CANDU-3 dependency matrix in Table 6.1 shows the following Group 2 support systems as providing a support function in the mitigation of transients and accidents:

1. Class V/Group 2 electric power-supports SDS1 and SDS2

2. Class II/Group 2 electric power-supports SDS1, SDS2, FW2, and HPI

3. Class III/Group 2 electric power-supports LPI, REC, and Group 2 service water

4. Group 2 service water-supports REC

These Group 2 support systems are also defined as being significant-to-safety. 
Table 7.4 Group 2 Systems used in the mitigation ${ }^{a}$ of RIEs for the CANDU-3 conceptual design

\begin{tabular}{|c|c|c|c|c|c|c|c|c|c|}
\hline RIE & SDS1 & SDS2 & $\begin{array}{r}\text { ECCS } \\
\text { (HPI) }\end{array}$ & $\begin{array}{l}\text { ECCS } \\
\text { (LPI) }\end{array}$ & $\begin{array}{l}\text { ECCS } \\
\text { (REC) }\end{array}$ & $\mathrm{CC}$ & FW2 & MSV & LRV \\
\hline $\begin{array}{l}\text { Large loss of coolant } \\
\text { Small loss of coolant }\end{array}$ & $r$ & $\mathscr{v}$ & $v_{b}$ & $v_{b}$ & $v_{b}$ & $\checkmark$ & $\checkmark$ & & \\
\hline $\begin{array}{l}\text { Small loss of coolant } \\
\text { (LRV failure) }\end{array}$ & & & & & & & & & \\
\hline $\begin{array}{l}\text { Small loss of coolant } \\
\text { (feeder tube break) }\end{array}$ & $\checkmark$ & $\checkmark$ & $\checkmark$ & $\checkmark$ & $\boldsymbol{V}$ & $\checkmark$ & $\alpha$ & & \\
\hline Loss of Class IV electric power & $\checkmark$ & $\checkmark$ & $c^{b}$ & $\sim^{b}$ & $\checkmark$ & & $\checkmark$ & $\checkmark$ & $\checkmark$ \\
\hline $\begin{array}{l}\text { Loss of feedwater (reactor } \\
\text { building) }\end{array}$ & $\nu$ & 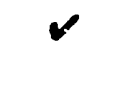 & & & & & $\checkmark$ & $v$ & \\
\hline Loss of feedwater (Turbine & $\checkmark$ & $\checkmark$ & & & & & $v$ & $\checkmark$ & \\
\hline $\begin{array}{l}\text { Building) } \\
\text { Required SCRAM }\end{array}$ & $\boldsymbol{r}$ & $\checkmark$ & & & & & $\checkmark$ & $\checkmark$ & \\
\hline
\end{tabular}

a Mitigation is defined as ending in plant end states CC-1 or CC-2.

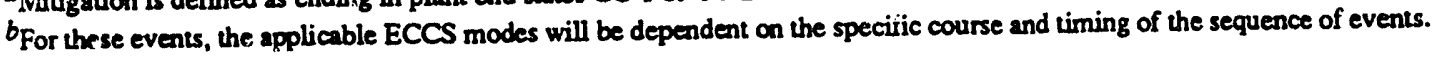

\section{Group 1 Systems Designated as Significant-to-Safety}

Review of the ESDs shows several Group 1 systems in a path for successful termination of the events. The designation of the individual systems as significant-to-safety will depend on the actual function of the Group 1 system, its role as a primary or a backup, and redundancy of the function with respect to available Group 1 and Group 2 systems. A discussion of the Group 1 systems designated as significant-to-safety follows.

Bleed Coridenser System (BCS)-This system performs an overpressure protection functicn for the HTS. The HTS LRVs are desigred to open on loss of power or loss of air. Failure of these valves to reslose will result in loss of the primary inventory through the bleed condenser to the $\mathrm{D}_{2} \mathrm{O}$ storage tank and then ints the reactcr building. Failure of this function will result in an event similar to a small loss of coolant. Also, if the primary LRVs open and fail to reclose, isolation of the BCS will effectively isolate this failure and stop the primary inventory loss. This isolation function is backed up by a Group 2 system except for the case of long-term failure to restore Class III power during a LOP event. In this set of circumstances, the function of isolation of the LRVs that failted open on loss of power is not bached up. Consequently, the BCS is designated as significant-to-safety.

Shutdown Cooling System (SDC)-The SDC provites long-term decay heat removal from the core. It is a Group 1 system that has its primary support provided by Group 1 support systems. However, SDC is provided with backup support from Group 2 support systems. Long-term decay beat removal is a significant function that is necessary to maintain the long-term safety of the reactor. Also, the SDC is sized to remove $100 \%$ of maximum core decay heat, thus allowing its use as a possible shutdown path immediately after reactor trip. The SDC is designated as significant-to-safety.

Auxiliary Feedwater System (AFW)-This diesel-powered system provides a small amount, of \#OW to the steam generators. Supply is taken from the FW1 and is pumped through the FW1 piping. Similar to FW1, the AFW function is backed up by the Group 2 system FW2 with the exception of the loss of Class IV electric power event, when there is long-term failure to recover Class III power. If Class $\pi$ power is not available to provide power to the FW2 pumps and isolation valves, the diesel-driven AFW can be used to provide water to the steam generators with removal of deray beat through the MSSVs. The AFW is designated as significant-to-safety.

Condenser Steam Discharge Valves (CSDs) and Atmospheric Steam Discharge Valves (ASDs)_-These valves are used to release steam from the secondary system to control pressure in the steam generators. The ASDs can also be used as a beat sink for decay beat removal when used in conjunction with a source of water to the steam generators. Although the function of opening for steam relief is redundant between the three sets of valves, the function of reclosing afterward is not. If any of the valves do not reclose, then a situation is created that is similar to a loss of feedwater event. These two systems will be designated as significant-to-safety. 
Moderator Cooling System (MCS)-The MCS is the last line of defense for heat removal from the core. For analyzed events other than the LBLOCA, actuation of the MCS would most likely result in a more severe plant end state than would be expected using the normal and emergency heat removal systems. For the LBLOCA, however, actuation of the MCS as a backup system is expected to lead to an end state similar to that which would occur if it was not employed. Thus, the MCS will be considered to perform a backup function as defined in the significant-tosafety criteria, and it is designated as significant-to-safety.

Isolation of Steam Generator (ISO)-Isolation of a steam generator is required when a feedwater piping break occurs between the steam generator and its check valve to avoid excessive loss of feedwater inventory. This function is backud up by a Group 1 system. Therefore, ISO will be designated as significant-to-safety.

\section{Group 1 Systems Designated as Not Significant-to- Safety}

Based on the criteria defined earlier in this section, the following Group 1 systems were not designated as significant-to-safety.

Reactor Regulating System (RRS)-The RRS is used as the initial means to shut down the reactor after an IE that does not result in large primary or secondary inventory losses. It is backed up by SDS1 and SDS2, both of which are Group 2. Consequently, the RRS will not be designated as significant-to-safety.

Group I Feedwater System (FWI)-This system supplies controlled feedwater to maintain required steam generator levels. For all transients, the FW1 function is backed up by the FW2. Consequently, the FW1 will not be designated as significant-to-safety.

Heat Transport System (HTS)-'This system circulates pressurized heavy water through the core and to the steam generator to remove core heat. It also serves a function of maintaining flow during a large loss-of-coolant event; it is expected, for this situation, that the ECCS will refill the core more quickly if the HTS is available. ${ }^{*}$ However, the HTS is backed by by the Group 2 ECCS in the large lossof-coolant event. Consequently, the HTS is not designated as significant-to-safety.

\footnotetext{
*Atomic Energy of Canada, Limited, Presentation of Information at NRC/AECL Review Meeting on the CANDU 3 Systems Research Sudy, February 10, 1993.
}

Moderator Liquid Poison System (MLP)-The MLP is used during normal operations as part of the reactor power control scheme. The system can also be used to poison the reactor when other means of reactor shutdown have failed. This system only appears in the FTSD ESD. However, for this system to be called upon, the RRS, SDS1, and SDS2 systems must have failed; SDS1 and SDS2 are also Group 2 systems. As such the MLP is performing a backup function to a safety-related system. Consequently, the MLP is not designated as significant-to-safety.

Table 7.5 summarizes all of the Group 1 and 2 frontline and support systems and their designations as significant or not significant-to safety.

\subsection{Identification of Primary and Backup Systems}

Table 7.6 summarizes how the various CANDU 3 systems were determined to be either primary or backup systems (depending on whether they were on primary or backup success paths in the ESDs) for the events analyzed in this study. The table also notes those systems that were identified as "significant-to-safety" in Sect. 7.2 and also those that are Group 2 systems.

A review of the ESDs shows at what points in the analyzed sequences that Group 1 and Group 2 systems play an important role in the mitigation of transients or accidents at the CANDU 3 reactor. The ESD evaluation for the seven RIEs shows the following:

1. For each of the analyzed RIEs, there are several successful shutdown paths (CC-1 or CC-2 end states) that utilize both Group 1 and Group 2 systems.

2. With the exception of extended loss of Class III power in the LOP event and failure to isolate the draining boiler in the Feedwater Piping Break in the Reactor Building event, all of the RIEs have at least one success path to an acceptable end state (CC-1 or CC-2) that includes only Group 2 systems.

3. The LOP, Feedwater Piping Break in the Turbine Building, and SCRAM events each have at least one success path to an acceptable end state (CC-1 or CC-2) that utilizes only Group 1 systems. The other RIEs do not contain any success paths that only utilize Group 1 systems.

A review of the dependency matrix (see Table 6.1) in combination with the event sequence information shows support functions being provided to Group 2 systems from 
Table 7.5 Systems and components classified as significant-to-safety

\begin{tabular}{lll}
\hline CANDU 3 designation & \multicolumn{1}{c}{ Frontline systems } & \multicolumn{1}{c}{ Support systems } \\
\hline $\begin{array}{c}\text { Group 2 systems } \\
\text { designated as significant- } \\
\text { to-safety }\end{array}$ & $\begin{array}{l}\text { Shutdown System 1 } \\
\text { Shutdown System 2 }\end{array}$ & $\begin{array}{l}\text { Group 2 Class I Power } \\
\text { Group 2 Class II Power }\end{array}$ \\
& $\begin{array}{l}\text { ECCS-High Pressure Injection } \\
\text { ECCS-Low Pressure Injection } \\
\text { ECCS-Recirculation }\end{array}$ & $\begin{array}{l}\text { Group 2 Class III Power } \\
\text { Group 2 Service Water } \\
\text { Group 2 Portion of Plant Air }\end{array}$ \\
& $\begin{array}{l}\text { Crash Cooling System } \\
\text { Group 2 Feedwater }\end{array}$ & \\
& Main Steam Safety Valves & \\
& Liquid Relief Valves & Recirculating Cooling Water \\
Group 1 systems & Bleed Condenser System & Group 1 Portion of Plant Air \\
designated as significant- & Shutdown Cooling System & \\
to-safety & Auxiliary Feedwater System & \\
& Condenser Steam Discharge Valves & \\
& Atmospheric Steam Discharge Valves & \\
& Moderator Cooling System & \\
Isolation of Steam Generator & \\
Group 1 systems & Moderator Liquid Poison System & \\
designated as not & Reactor Regulating System & \\
significant-to-safety & Group 1 Feedwater & \\
& Heat Transport System &
\end{tabular}

two Group 1 systems. This presents the potential for failure of a Group 1 system to fail the function of a Group 2 system which, in turn, could compromise the Group 2 mitigation path. The dependency matrix shows that plant air provides support to SDS2 (the SDS2 plant air support is, however, for fail-safe valves and, therefore, is not a true dependency), and Group 2 service water and the recirculated cooling water provide support to the REC mode.

The Group 2 service water provides backup cooling water to the ECCS heat exchangers. The recirculated cooling water, a Group 1 system, is the normal cooling water supply to these heat exchangers.

The plant air system support of SDS2 is to provide the means to hold closed the quick-opening valves on the highpressure helium used to force reactivity poison into the reactor. On loss of air the valves fail open, which is a safe configuration. However, such a design could also result in unanticipated shutdowns if loss of plant air occurred during operations.

The plant air system is also required to open the MSSVs and reclose the LRVs. However, these portions of the air system are classified as Group 2.

\subsection{Significant Operator Actions}

This section summarizes significant operator actions identified through the systems and event analyses discussed in Chaps. 5 and 6.

\subsubsection{Reactor Shutdown}

Manual action is required to shut down the reactor for the SCRAM initiator. The SCRAM initiator is defined as an event in which the operator is required to initiate reactor shutdown for some reason. This could be any abnormal occurrence requiring operator intervention. This requires the operators to be alert to abnormal situations and ready to respond to them properly.

\subsubsection{ECCS Initiation After Small Loss-of- Coolant Events}

A LOCS may not be generated for some of the smaller loss-of-coolant events. Manual activation of the ECCS is therefore required for inventory makeup in these events. The Point Lepreau Safety Report* pointed out that for

\footnotetext{
"“Point Lepreas Unit 1 Safety Report, Part 2 Accident Analysis," Vol. 1, May 1991.
} 
Results

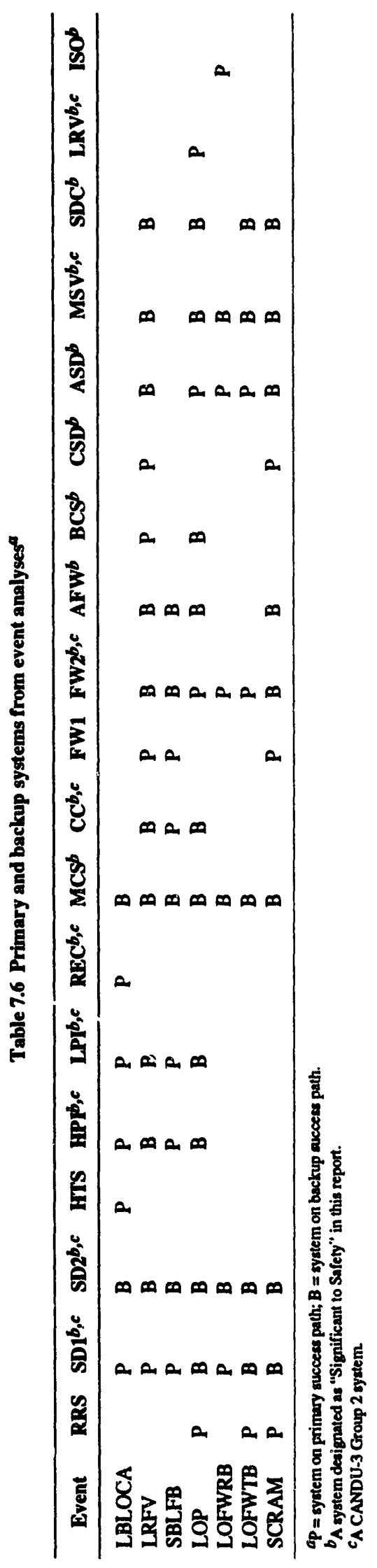




\section{Results}

some Point Lepreau SBLOCAs, the operator would initiate system ECCS actions; however, the specific actions that the operator would take were not called out in the report. As discussed previously for reactor shutdown, the operators must be able to recognize these events to respond properly.

\subsubsection{Refill of the Group 2 Feedwater Supply Tank}

The Group 2 feedwater supply tank has a 10-h capacity. The operator must act to refill this tank when the supply has been depleted. Alarms are provided to notify the operator when the tank is in need of refilling. Failure of the SDC could require extended use of the steam generators to remove the decay heat via the FW2. Removal of the sensible heat from the secondary side after other means of decay heat removal have been established may be required to prevent damage to secondary side equipment. This too may require extended use of the FW2.

\subsubsection{Initiation of the Shutdown Cooling System}

The SDC is used primarily for long-term cooling of the reactor after shutdown. The system is designed for $100 \%$ heat and pressure and therefore can be used as an alternative method to cool the reactor during mitigation of events. The system has no automatic start signals and therefore requires operator action any time it is needed. The SDC is the backup means for heat removal following loss of feedwater events, particularly those downstream of the steam generator check valves. The SDC would also be initiated following a steam generator tube break to limit the release of radioactivity to the secondary side. ${ }^{*}$

\footnotetext{
*Atomic Energy of Canada, Limited, Presentation of Information at NRC/AECL Review Meeting on the CANDU 3 Systems Research Study, February 10, 1993.
}

\subsubsection{Steam Generator Isolation}

Breaks in the feedwater piping between the steam generator and the steam generator check valve require the operator to isolate that steam generator and direct feedwater flow away from it to avoid excessive release of feedwater inventory into the reactor building. Isolation of the steam generator is also needed following a steam generator tube rupture."

\subsubsection{Poison Addition in Failure-to-Shutdown Sequences}

In this analysis, the MLP is assumed to be used for reactor shutdown in FTSD sequences. This system would require the operator to open the flow control valve from the poison tank to allow the poison to be introduced to the moderator. This action would be important because it would become the means of reactor shutdown after the shutdown systems have failed. It is likely that this action would have to be performed in a high-stress situation, considering the events that may have occurred for the event to have progressed to this point.

\subsection{Summary}

In summary, this study has provided an independent examination of event sequences, safety systems, and operator actions that might play a role in any future $\mathrm{NRC}$ review of the CANDU 3 for design certification. The results and observations recorded here will provide the NRC with documented information that can be used in reaching regulatory decisions for the CANDU 3.

\section{Reference}

1. Atomic Energy of Canada, Limited, "CANDU 3 Conceptual Safety Report," Vol. 1, Appendix D1, 1989. ${ }^{\dagger}$

\footnotetext{
${ }^{\dagger}$ Available in NRI: PDR for inspection and copying for a fee.
} 


\section{Appendix A \\ Overview of CANDU 3 Design}

\section{A.1 Introduction}

The purpose of this appendix is to identify succinctly the characteristics of the CANDU 3 design that affect the plant safety characteristics. The material in this chapter is a condensation of descriptions given in the Conceptual Safety Report (CSR) ${ }^{1}$ and the CANDU 3 Technical Outline. ${ }^{2}$ The CANDU 3 plant is in the conceptual design stage, but it is based on considerable experience with plants of this type. The design is described in depth, consistent with its conceptual status, in Refs. 1 and 2.

The functional requirements and capabilities of the plant to accommodate accidents are as described by Atomic Energy of Canada, Limited (AECL). ${ }^{1,2^{*}}$ No implication is made that the U.S. Nuclear Regulatory Commission (NRC) or its contractors agree with these claims at this time.

\section{A.2 Plant Configuration}

General plant parameters are given in Table A.1 (from Ref. 2).

\section{A.2.1 Reactor Configuration}

The reactor is a $\mathrm{D}_{2} \mathrm{O}$-cooled, $\mathrm{D}_{2} \mathrm{O}$-moderated, natural enrichment design in which the $\mathrm{UO}_{2}$ fuel is clad in Zircaloy and arranged in 37-rod clusters as shown in Fig. A.1. The clusters are arranged in 232 zirconium-niobium horizontal pressure tubes, 12 to a tube, which are enclosed in Zircaloy calandria tubes and separated from the calandria tubes by an annulus gas space as shown in Fig. A.2. Coolant to the fuel is provided by feeder tubes connecting the coolant supply header to each pressure tube; the general arrangement is shown in Fig. A.3. The calandria tank contains $\mathrm{D}_{2} \mathrm{O}$, which acts as a moderator and has its own heat removal system. The calandria tank has a helium cover gas control system and, because the tank is not designed for high pressure, a pressure relief system. This system activates in the event of overpressurization and is designed to accommodate one pressure tube failure. The calandria tank is surrounded by the shield tank, which is filled with $\mathrm{H}_{2} \mathrm{O}$ and also has limited heat removal capability. Figure A.4 shows an elevation view of the reactor. Also shown are the reactivity control rods, reactivity control unit (RCUs), the calandria tank overpressure relief pipes, and the liquid poison injection systems, which are described later. All components are replaceable, except for the calandria tank and

\footnotetext{
* Atomic Energy of Canada, Limited, The CANDU 3 Technical Description, 74-01371-TED-001, Rev. 3 /89-09-15, 1989.
}

the shield tank. Refueling is performed continuously while the reactor is operating, as described later.

Table A.1 CANDU 3 unit data

\begin{tabular}{|c|c|}
\hline \multicolumn{2}{|l|}{ Reactor } \\
\hline Type & Horizontal pressure tube \\
\hline Coolant & Pressurized heavy water \\
\hline Moderator & Heavy water \\
\hline Number of fuel channels & 232 \\
\hline \multicolumn{2}{|l|}{ Fuel } \\
\hline Fuel & $\begin{array}{l}\text { Compacted and sintered } \\
\text { natural } \mathrm{UO}_{2} \text { pellets, } \\
12.15-\mathrm{mm} \text { diam, clad in } \\
\text { 13.08-mm-OD, } 0.42-\mathrm{mm} \text { - } \\
\text { thick Zircaloy-4 sheath }\end{array}$ \\
\hline Form & $\begin{array}{l}\text { Fuel bundle assembly of } 37 \\
\text { elements }\end{array}$ \\
\hline Length of bundle & $495.3 \mathrm{~mm}$ \\
\hline Outside diameter & $102.4 \mathrm{~mm}$ \\
\hline Bundle weight & $\begin{array}{l}23.5 \mathrm{~kg} \text { (includes } \\
19.1 \mathrm{~kg} \mathrm{U} \text { ) }\end{array}$ \\
\hline Bundles per fuel channel & 12 \\
\hline \multicolumn{2}{|l|}{ Heat transport system } \\
\hline $\begin{array}{l}\text { Number of steam } \\
\text { generators }\end{array}$ & 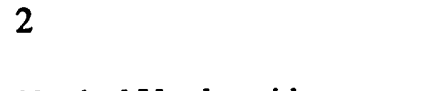 \\
\hline Steam generator type & $\begin{array}{l}\text { Vertical U-tube with } \\
\text { integral steam drum and } \\
\text { preheater }\end{array}$ \\
\hline $\begin{array}{l}\text { Number of heat transport } \\
\text { pumps }\end{array}$ & 4 \\
\hline Heat transport pump type & $\begin{array}{l}\text { Vertical, centrifugal, single } \\
\text { suction, double discharge }\end{array}$ \\
\hline $\begin{array}{l}\text { Reactor outlet beader } \\
\text { pressure (gage) }\end{array}$ & $9.9 \mathrm{MPa}$ \\
\hline Reactor outlet temperature & $310^{\circ} \mathrm{C}$ \\
\hline Reactor coolant flow & $5.3 \mathrm{Mg} / \mathrm{s}$ \\
\hline $\begin{array}{l}\text { Steam temperature } \\
\text { (nominal) }\end{array}$ & $260^{\circ} \mathrm{C}$ \\
\hline Steam quality (minimum) & $99.75 \%$ \\
\hline Steam pressure (gage) & $4.6 \mathrm{MPa}$ \\
\hline Total fission heat & $1440.3 \mathrm{MW}(\mathrm{th})$ \\
\hline $\begin{array}{l}\text { Net electrical output } \\
\text { (nominal) }\end{array}$ & $450 \mathrm{MW}(\mathrm{e})^{a}$ \\
\hline
\end{tabular}

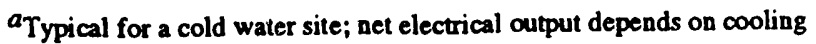
water temperature and turbine generator and condenser design. Source: Adapted from Ref. 2.
} 
Appendix A

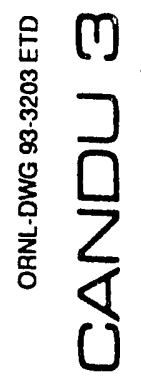
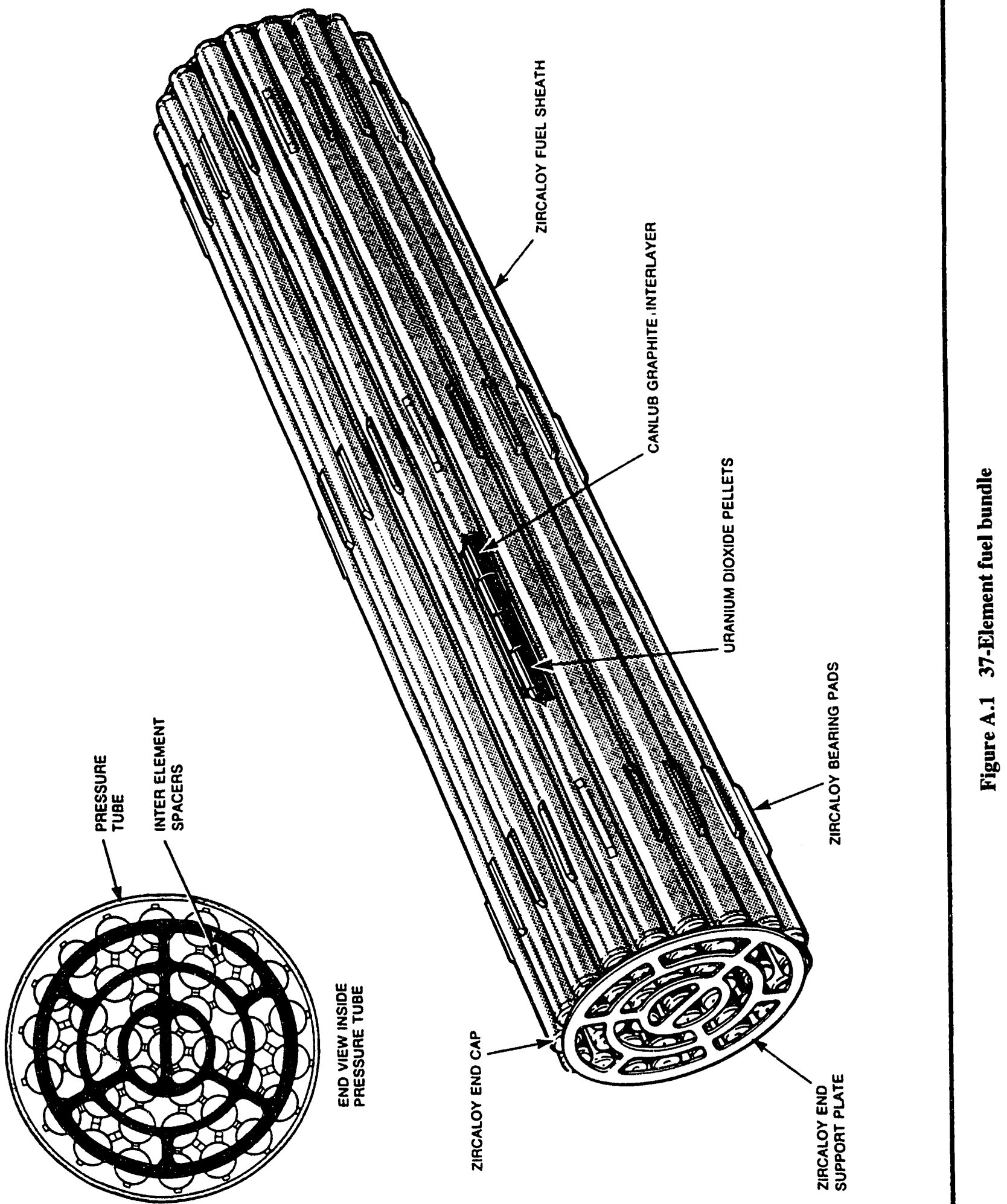
Appendix A ORNL-DWG 93-3204 ETD

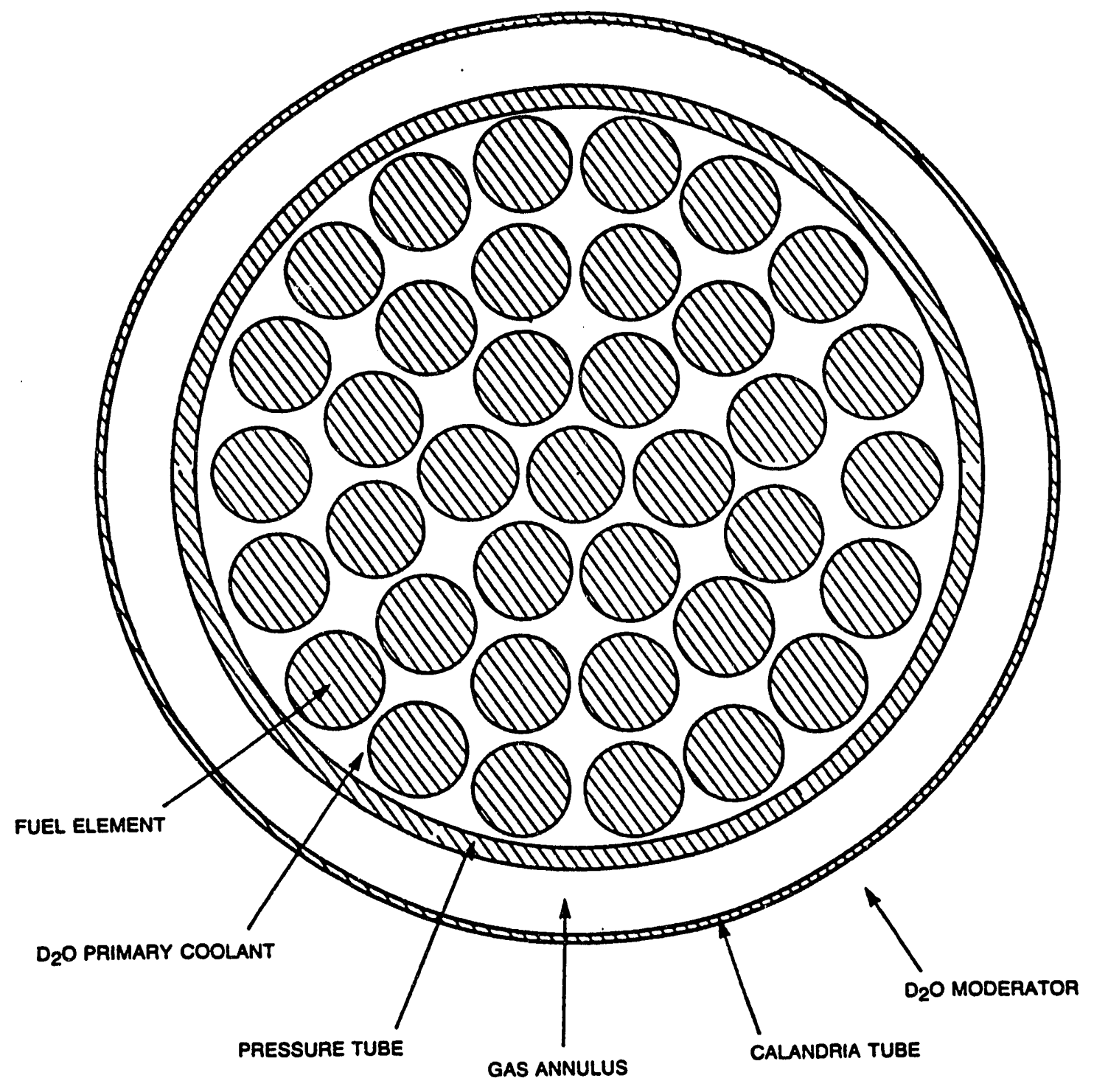

Figure A.2 Unit cell for 37-element fuel 


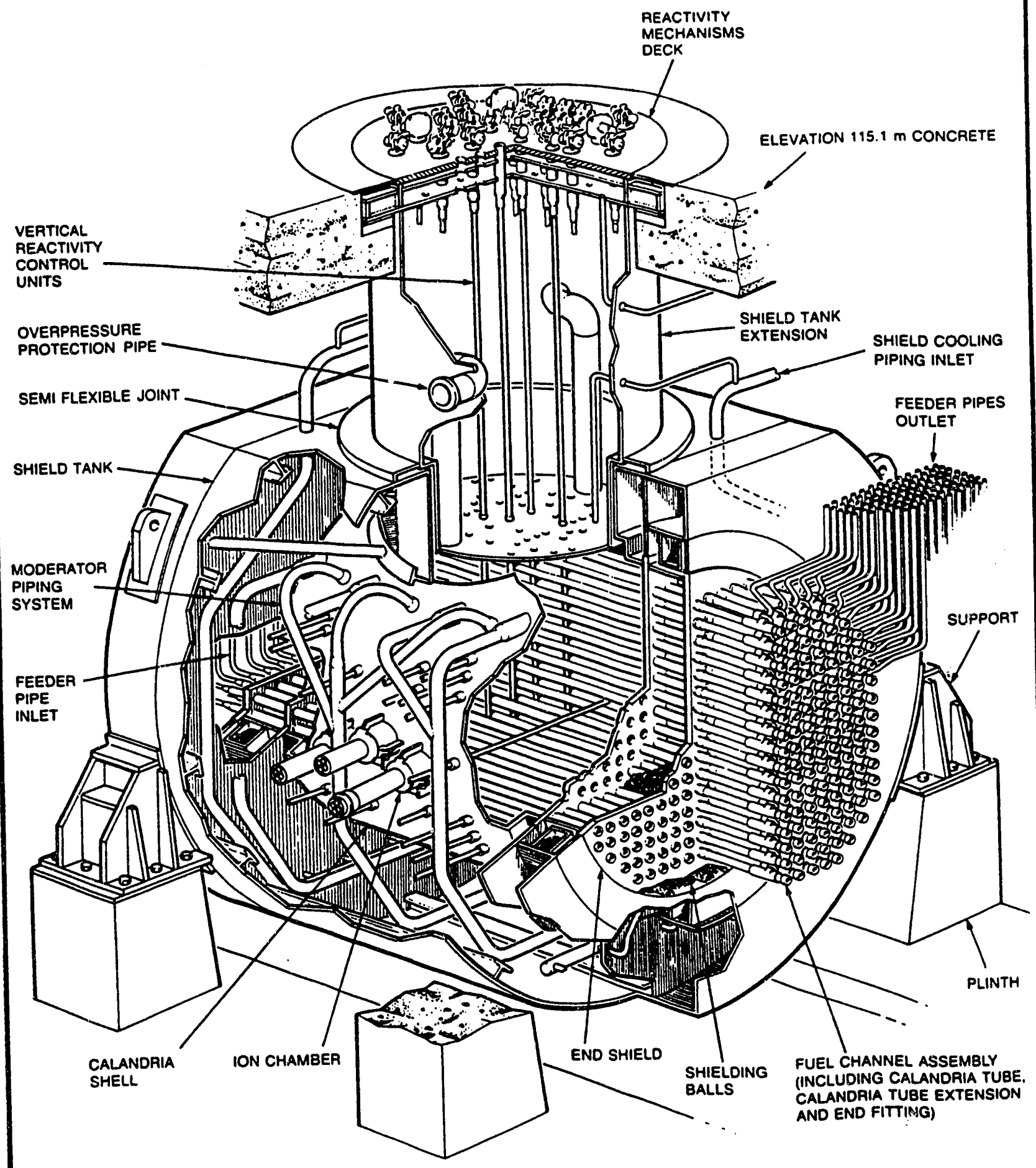

Figure A.3 Reactor assembly 


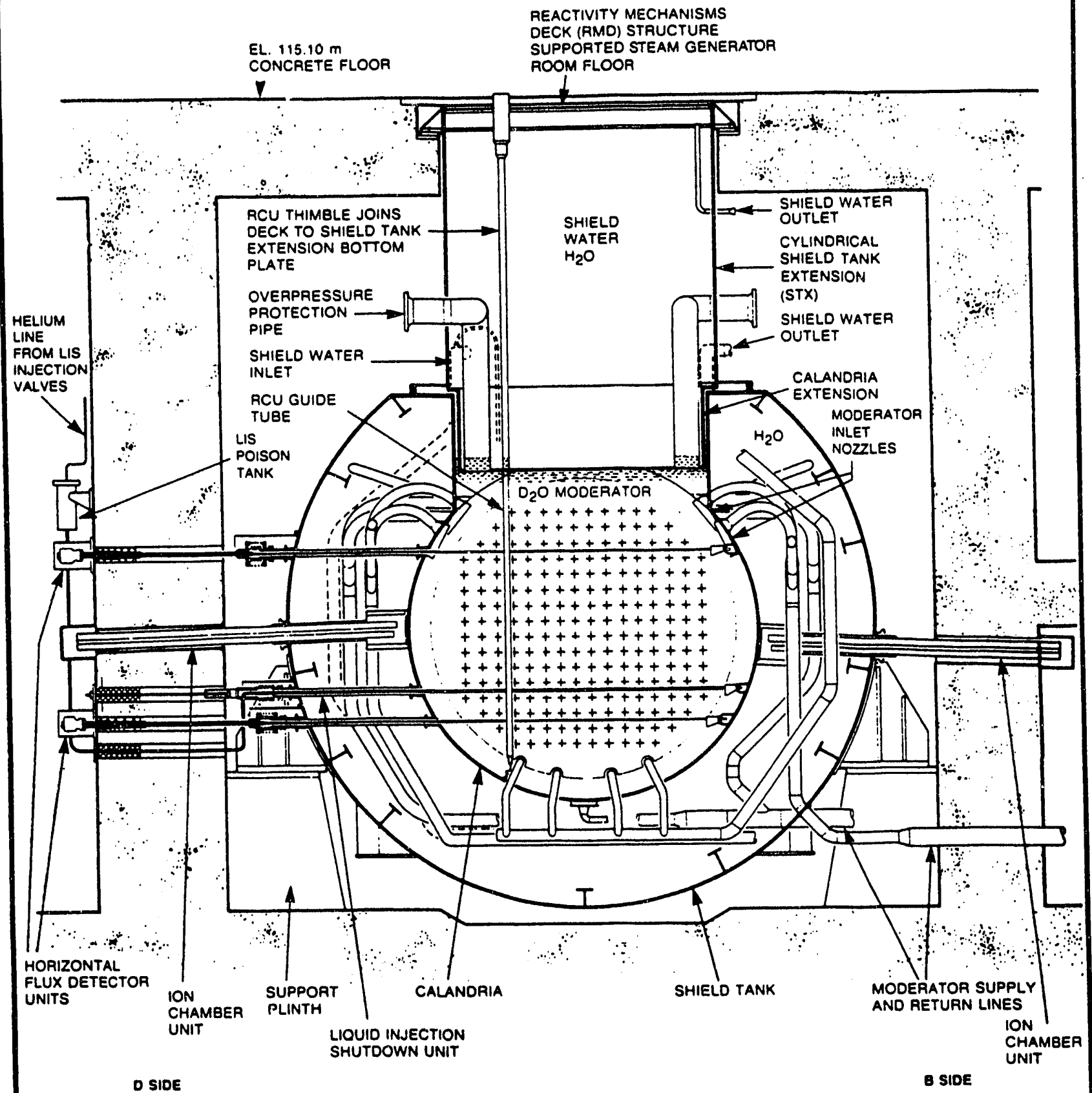

Figure A.4 Reactor structures assembly-front view 


\section{A.2.1.1 Fuel}

The fuel consists of natural enrichment $\mathrm{UO}_{2}$ pellets, $12.15-\mathrm{mm}$ diam, clad in Zircaloy -4 sheaths of $13.08 \mathrm{~mm}$ $O D$ and $0.42 \mathrm{~mm}$ thick. The fuel assemblies are welded into bundles of 37 cylindrical elements in circular array, as shown in Fig. A.1. The fuel assemblies are supported by bearing pads that space them from the inside of the pressure tube. The fuel elements are arranged in circles. The inner circle has 6 elements on a 29.7-mmil diameter, the intermediate circle has 12 elements in a 57.4- $\mathrm{mm}$ diameter, and the outer circle has 18 elements in a 86.5 -mm-diam pitch. The center, of course, has one element. The bundle length is $495.3 \mathrm{~mm}$, and the bundle diameter is $102.4 \mathrm{~mm}$. Each fuel assembly has $21.8 \mathrm{~kg}$ of $\mathrm{UO}_{2}$ and $2.3 \mathrm{~kg}$ of Zircaloy -4 . There are 12 fuel assemblies in each channel and 2784 bundles in the reactor. The average residence time in the reactor is 72 full-power days, and the maximum is 127 full-power days. The nominal peak bundle power (time average) is $740 \mathrm{~kW}$. The nominal element power is $47.1 \mathrm{~kW} / \mathrm{m}$ for the outer ring element, $38.3 \mathrm{~kW} / \mathrm{m}$ for the intermediate ring element, $33.5 \mathrm{~kW} / \mathrm{m}$ for the inner ring element, and $31.7 \mathrm{~kW} / \mathrm{m}$ for the center element.

\section{A.2.1.2 Annulus Gas System}

Commercial "bone-dry" grade carbon dioxide gas is circulated at low pressure through the annuli between the pressure tubes and calandria tubes. The gas-filled annulus restricts heat transfer from the fuel channel pressure tube to the moderator. The dry gas atmosphere prevents corrosion of fuel channel components. Provision is made for sampling the gas in the annulus gas system to measure residual moisture content. A rapid increase in (or high) moisture content is an indication of leakage from the moderator or main heat transport circuit into the annulus. Great emphasis has been placed on such detection of leaks and location of leaks. The annulus gas acts as an insulator during normal operation, but in the event of loss of coolant to the fuel, the pressure tube is expected to deform and expand against the calandria tube, thereby increasing the heat transfer to the moderator.

\section{A.2.1.3 Moderator System}

The moderator system is fully independent from the heat transport system (HTS). It includes two 50\% capacity pumps and two 50\% capacity plate-type heat exchangers. The moderator system is connected to the moderator purification system, the $\mathrm{D}_{2} \mathrm{O}$ sampling system, and the $\mathrm{D}_{2} \mathrm{O}$ supply system to enable moderator $\mathrm{D}_{2} \mathrm{O}$ to be transferred to and from the $\mathrm{D}_{2} \mathrm{O}$ supply system. The calandria extension maintains the moderator level in the calandria within the required range by accommodating moderator swell and shrink resulting from temperature fluctuations.
The heavy water in the calandria functions as a heat sink in the event of a partial loss of primary HTS coolant coincident with failure of the emergency core cooling system (ECCS).

The moderator system is complemented by several auxiliary systems, including the moderator purification, cover gas, liquid poison, and $\mathrm{D}_{2} \mathrm{O}$ collection system. They are designed to maintain operating parameters within an optimum operating range.

The moderator purification system maintains the purity of the heavy water and minimizes corrosion of components and crud activation by controlling the $\mathrm{pD}(\mathrm{pH})$ and by removing impurities present in the $\mathrm{D}_{2} \mathrm{O}$. The moderator purification system is also used to (1) adjust the concentration of the soluble poisons (boron and gadolinium) in response to reactivity demands and (2) remove the soluble poison after initiation of Shutdown System 2 (SDS2). The system consists of a filter and ion exchangers.

The moderator cover gas system controls the concentration of $\mathrm{D}_{2} \mathrm{O}$ by catalytically recombining the deuterium and oxygen gases resulting from the radiolysis of the heavy water moderator to reform heavy water. Helium, which is chemically inert and not activated by neutron irradiation, is used as the cover gas for the moderator system.

The liquid poison system adds negative reactivity to the moderator when required for reactivity adjustments and also provides neutron poison in the moderator to preclude criticality during certain reactor shutdown conditions. The liquid poisons employed are boron, as boric anhydride, and gadolinium, as gadolinium nitrate, dissolved in $\mathrm{D}_{2} \mathrm{O}$.

The moderator $\mathrm{D}_{2} \mathrm{O}$ collection system collects any heavywater leakage from the moderator and associated systems and pumps it into the beavy-water management systems for cleanup and upgrading.

\section{A.2.1.4 Shield Cooling System}

The shield cooling system removes the nuclear heat accumulated within the end shield and shield tank assemblies by circulating demineralized water $\left(\mathrm{H}_{2} \mathrm{O}\right)$ through them. This heat is transferred to the recirculated cooling water system by means of two plate-type heat exchangers. An additional loop is provided, between the heat exchanger outlet and the pump suction line, for system purification. The system also serves as an ultimate heat sink in case of ECCS and moderator heat sink (MHS) failure. Also, in the event of a loss of coolant accident (LOCA), this system is 
ultimately relied upon to remove the heat and allow repair work. (Typically, 6 months after the accident, the switchover from ECCS recirculation to shield cooling is expected.")

The system consists mainly of two $100 \%$ duty circulating pumps, two $50 \%$ duty heat exchangers, one expansion (bead) tank, and an ion exchange purification system with associated piping and valves.

\section{A.2.2 Heat Transport System}

A schematic of the primary HTS is shown in Fig. A.5. The major components of the HTS are the 232 reactor fuel channels, two steam generators, four electrically driven heat transport pumps, four reactor inlet beaders, two reactor outlet headers, a pressurizer, and the interconnected piping. Heavy-water coolant is fed to the fuel channels from the inlet headers and is returned to the outlet headers at the opposite end of the reactor. The arrangement of the HTS equipment within the reactor building is shown in Fig. A.6.

Each steam generator is connected to two heat transport pumps, which are at the opposite end of the reactor. Each heat transport pump provides coolant flow to one-fourth of the CANDU 3 fuel channels. The coolant flow in the CANDU 3 HTS is in a "figure-of-eight" pattern employed in typical CANDU reactors, with the heat transport pumps in series and the coolant making two core passes per cycle. The equipment arrangement, however, with the steam generators and pumps at opposite ends of the reactor, results in unidirectional coolant flow through the core, which is unique to the CANDU 3 design. This facilitates fueling from one end of the reactor with a single fueling machine. The header arrangement results in reactor fuel channels in each vertical half of the core belonging to the same core pass. ${ }^{\dagger}$

The headers, steam generators, and pumps are all located above the reactor. This ensures natural coolant circulation on loss of power to the heat transport pumps. This configuration also allows the pumps and steam generators to be drained for inspection and maintenance while reactor shutdown heat removal is maintained by the shutdown cooling system (SDC).

\footnotetext{
"Atomic Energy of Canada, Limited, Technologies, Rockville, Maryland, peasonal communication to Oak Ridge National Laboratory Staff, March $10,1992$.

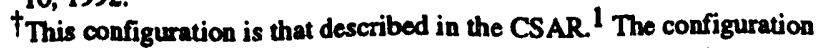
could change to interweaving core passes in subsequent design modifications according to discussions with AECL.
}

\section{A.2.3 Control system}

The CANDU 3 control system is a distributed digital computer system and is described in Ref. 1.

\section{A.2.3.1 Reactor Control}

The core power distribution is radally and axially flattened. Power flattening is achieved through the use of regional differential fuel burnup in combination with a set of absorber devices called adjuster rods. Long-term control of the power distribution is achieved through on-power refueling. The reactor is controlled by the reactor regulating system (RRS), which includes in-core selfpowered flux detectors and zonal flux controllers operated by dedicated dual-redundant control computers. This system provides for global and spatial control of power. In addition, absorber rods provide power maneuvering capabilities for power changes, reactor startup, and reactor shutdown.

The control requirements are dictated by the characteristics of the plant. Both the requirements and the characteristics are quite different from U.S. light-water reactor (LWR) technology. The use of a large $\mathrm{D}_{2} \mathrm{O}$-moderated, natural enrichment core raises problems with spatial instabilities and xenon poisoning, and causes situations where voids in the coolant or moderator could cause reactivity to increase. The RCUs, control rods in U.S. terminology, are telescoping rods that enter from the top of the core, perpendicular to the fuel channels. They are designed so that they move in and out from the top and bottom boundary of the core, although they are driven from the top end only by a cable arrangement. This is shown in Fig. A.7.

\section{A.2.3.2 Distributed Control System}

Most Group 1 (see Sect. A.2.5 for a description of the Group 1 and Group 2 separation philosophy) control functions are implemented by a distributed control system (DCS), which uses data highways for signal transmission and programmable microprocessors for the control logic. The DCS consists of a number of channelized local stations distributed throughout the plant outside the reactor building, linked by channelized dual-redundant co-axial cable data highways. Sensors and actuators are connected to input and output modules in the local stations by relatively short cables.

The DCS replaces the control trunk cabling, control distribution frame, relay logic, analog controllers, and comparators used in previous CANDU control systems, as well as the central computers used for signal multiplexing and digital control. The major control functions (reactor 


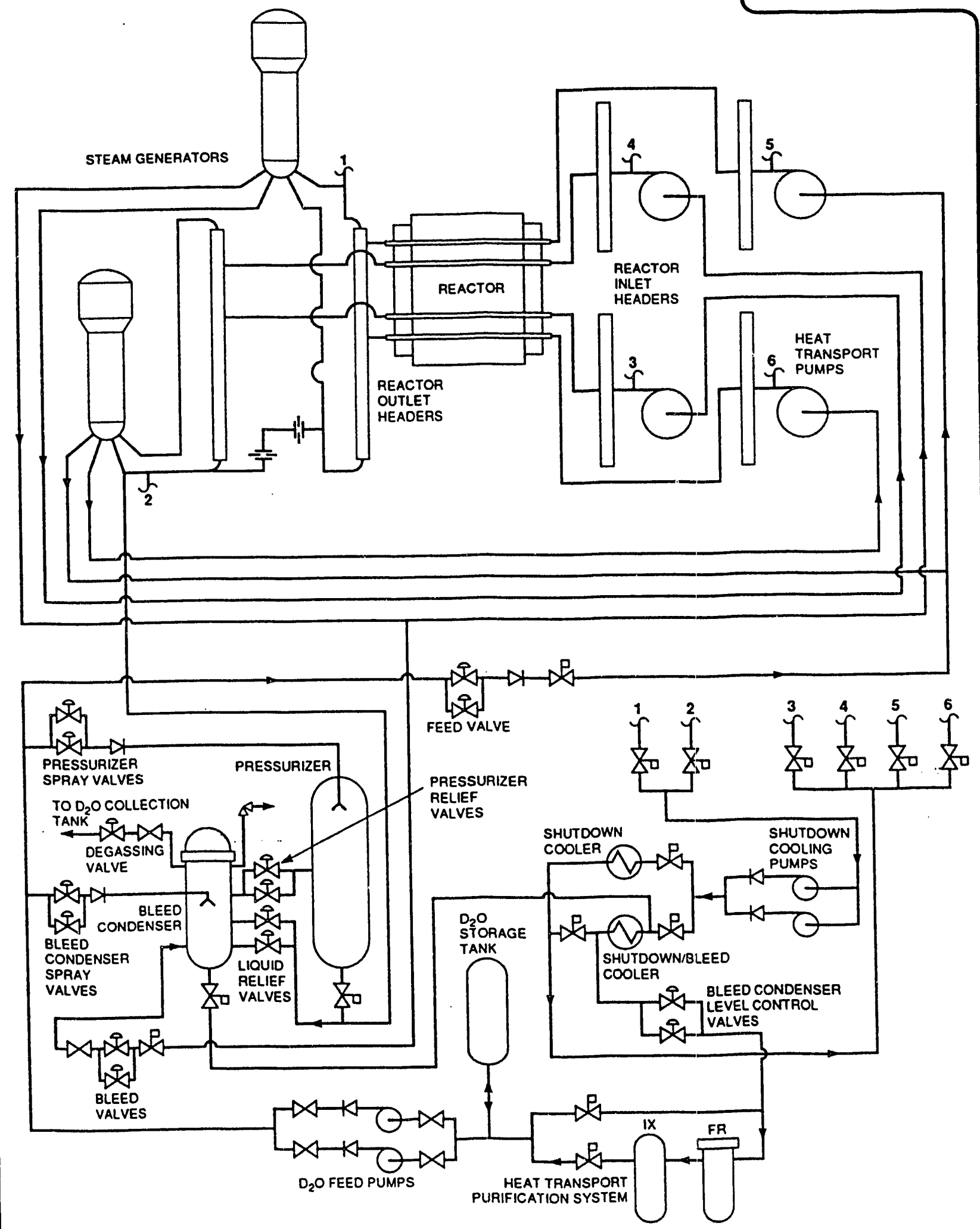

Figure A.5 HTS simplified composite flow diagram 
Appendix A

ORNL-DWG 93.3208 ETD

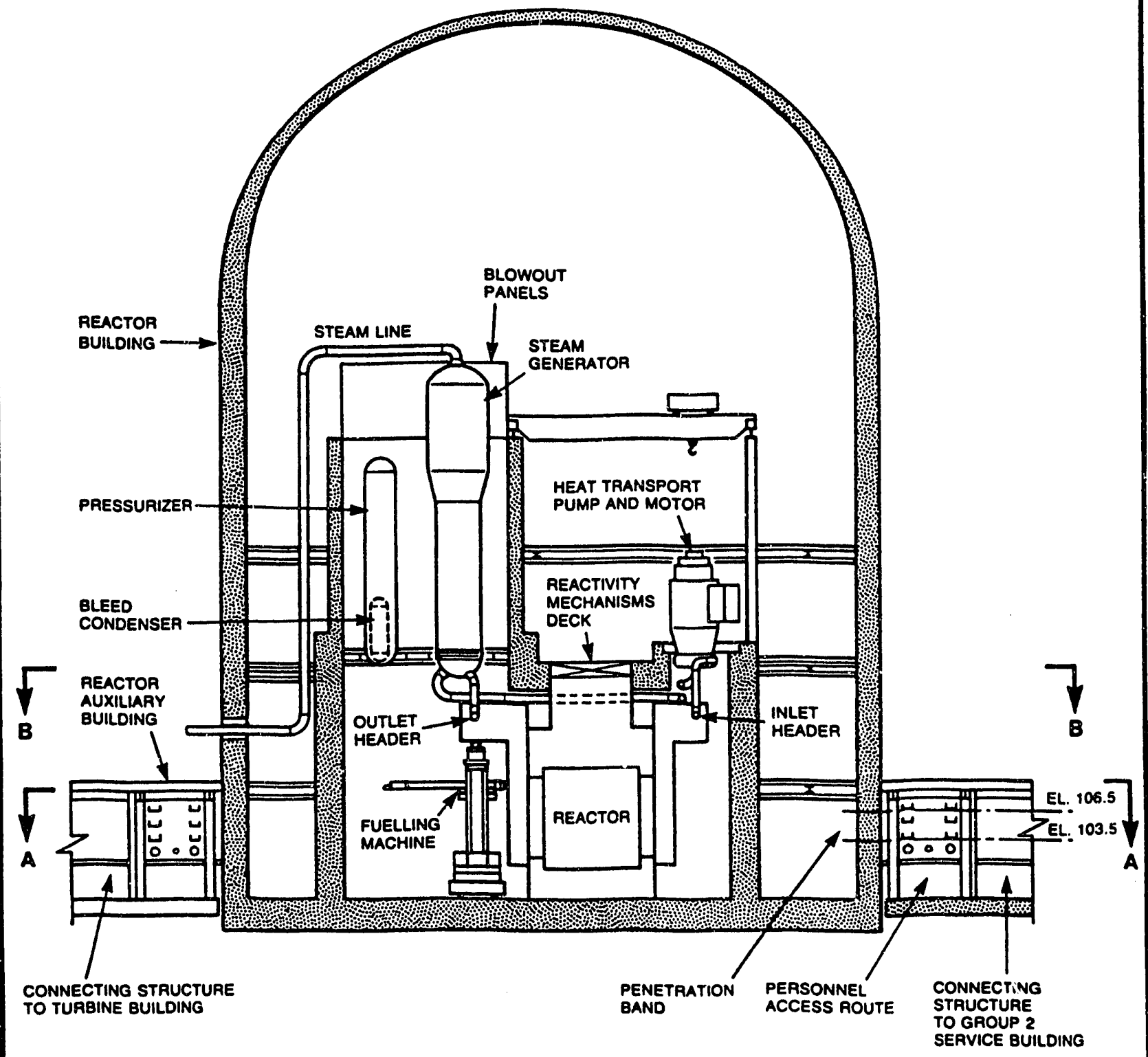

SECTION C.C

Figure A.6 Reactor building - section 


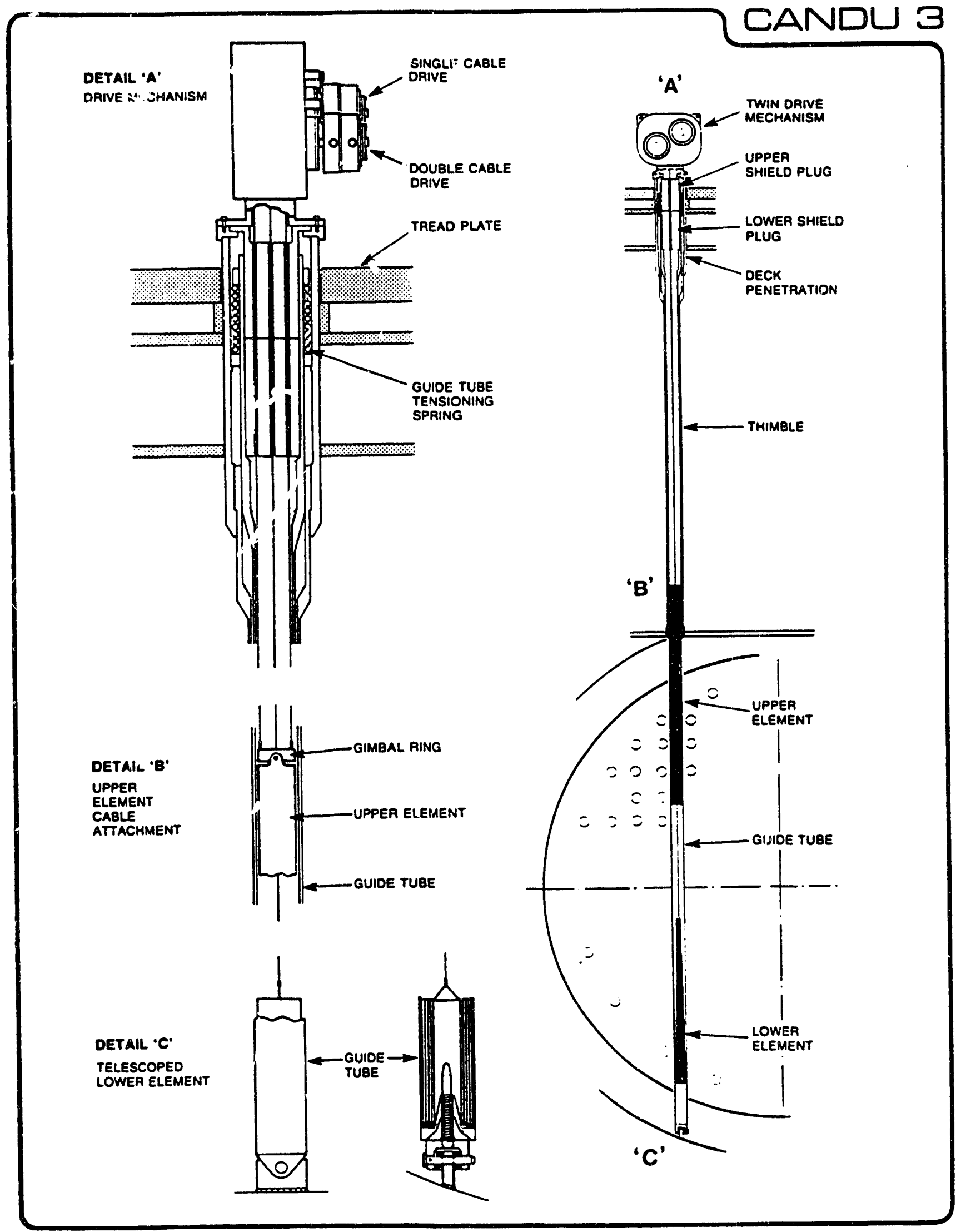

Figure A.7 Mechanical zone control unit 
regulation, heat transport pressure and inventory control, steam generator pressure and level control, etc.) implemented in the central station computers of nrevious CANDU power stations, as well as most of the control loops previously not computerized, are distributed among a number of small, powerful DCS microprocessors. However, the system configuration uses the same dualredundant fault-tolerant concepts used in previous CANDU computerized control systems to ensure a high level of system reliability.

The DCS provides a high rate of data transmission, high system reliability, data security, and comprehensive system fault detection. Automatic failure detection and recovery features protect against cable or device failure. If a module fails, the automatic failure detection features transfer control to the backup module. The system permits replacement of a failed module on-line without affecting the functions performed by the system.

A separate data highway distributed control system is usel for control and monitoring of the fueling machine and related systems.

\section{A.2.4 Fuel Handling and Storage}

\section{A.2.4.1 Refueling}

The CANDU 3 reactor is refueled at power using a single fueling machine located at the outlet end of the reactor. The coolant flow through the reactor in all fuel channels is in the same direction. Fuel pushers, resident in each channel, assist in pushing the fuel from the channel by means of the coolant flow hydraulic impedance.

The fueling machine is operated from the main control room. For refueling, the fueling machine is positioned at the outlet end of the fuel channel and is locked on to the end fitting to obtain a leaktight joint. Figure A.8 shows the fuel handling system. Figure A.9 shows a plan view of the fueling machine vault fuel transfer system and irradiated fuel storage bay (IFSB).

The CANDU 3 fueling machine holds eight pairs of fuel bundles. The machine unloads irradiated fuel bundles through the irradiated fuel port, which leads into the IFSB located outside the reactor building containment wall. The IFSB has a storage capacity for fuel from 6 years of reactor operation, plus a reactor load of fuel. Lifting facilities are provided for the handling and shipping of the irradiated fuel.
The fueling machine, the fuel transfer ports, and irradiated fuel discharge equipment are operated remotely and automatically from the control room. Personnel access to the reactor building is required for in situ maintenance of the fueling machine equipment.

The equilibrium fueling rate for CANDU 3 with 12 reactivity adjuster assemblies is $\sim 85$ fuel bundles per fullpower week of operation.

The fueling machine requires a supply of $\mathrm{D}_{2} \mathrm{O}$ at near ambient temperature and pressures. These vary according to the function being performer.. During on-power fueling, the $\mathrm{D}_{2} \mathrm{O}$ flow direction is alw ys from the fueling machine into the reactor channel. A 5 actor-grade $\mathrm{D}_{2} \mathrm{O}$ supply is therefore provided for the fueling machine head to prevent downgrading of the HTS $\mathrm{D}_{2} \mathrm{O}$ inventory.

A catenary, comprised of high-pressure hoses and control cables, connects the fueling machine to its auxiliary systems (see Fig. A.8). The catenary between the fueling machine carriage and its fixed connections is a double hanging loop that extends and contracts with the travel of the carriage. This catenary also accommodates the rotation of the carriage columns. A catenary overhanging support cart is towed or pushed by the fueling machine carriage. A shorter catenary between the fueling machine head and carriage column catenary connection caters for movement between these two components.

\section{A.2.4.2 Irradiated Fuel Handling and Storage}

The irradiated fuel handling and storage equipment is designed to accommodate operation at the average fueling rate of the reactor. Handling and storage space is also provided under water for irradiated parts of the reactivity control mechanisms, which may be removed from the reactor. The irradiated fuel handling equipment consists of (1) transfer equipment in the irradiated fuel transfer room outside containment and (2) handling equipment in the IFSB. The discharge and transfer operations, including tray loading and conveyance to the storage tray, are controlled remotely. Operations under water in the storage bay are done manually, from the manbridge, using hoists and long tools.

\section{A.2.4.3 Defective Fuel Handling}

Defective irradiated fuel is separated from other irradiated fuel for handling. At the transfer mechanism trough, the defective bundle is unloaded onto a tray. This tray transports the bundle to the bay. It is then lifted manually, under water, into an eight-station covered carousel. This 
Appendix A

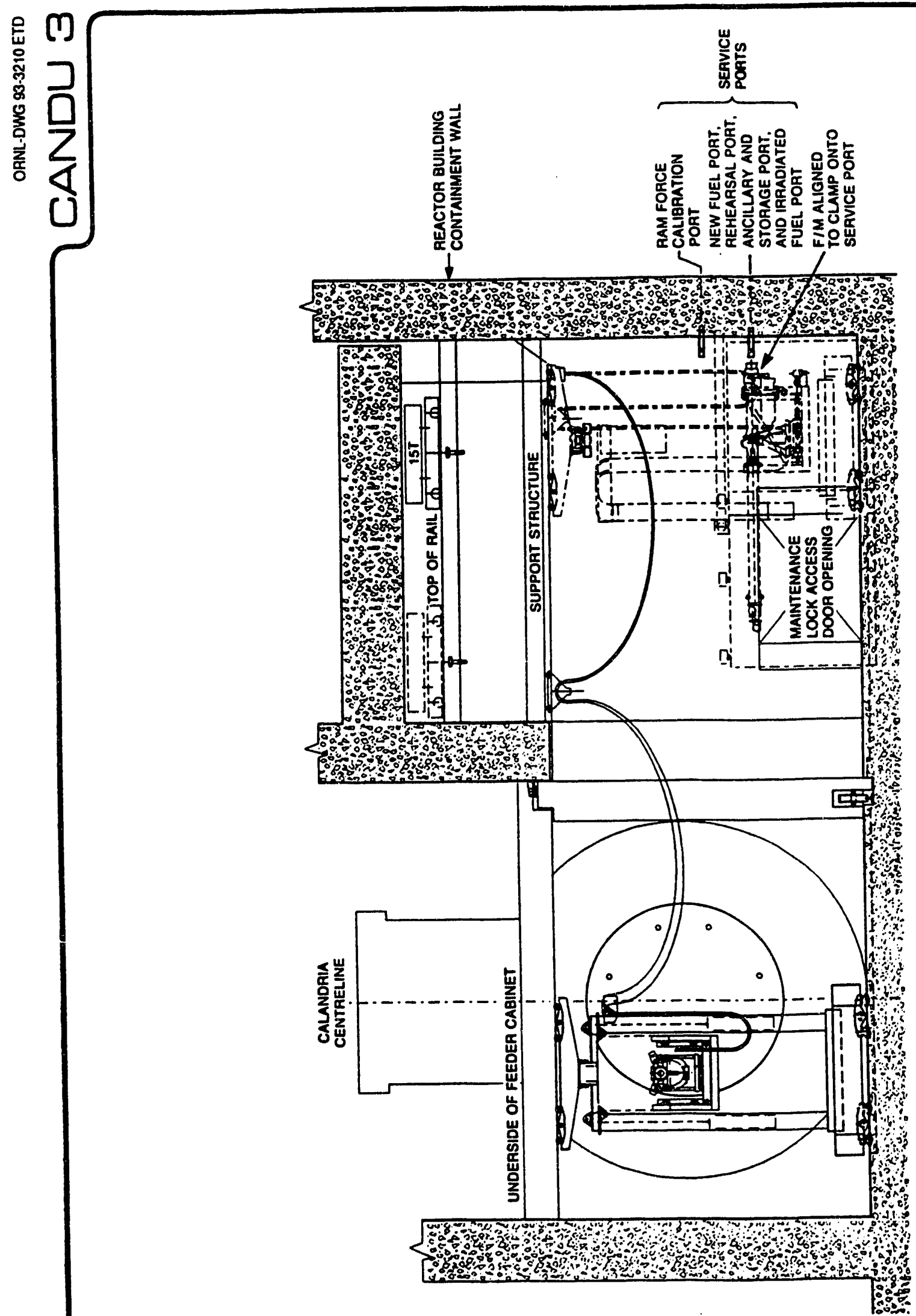




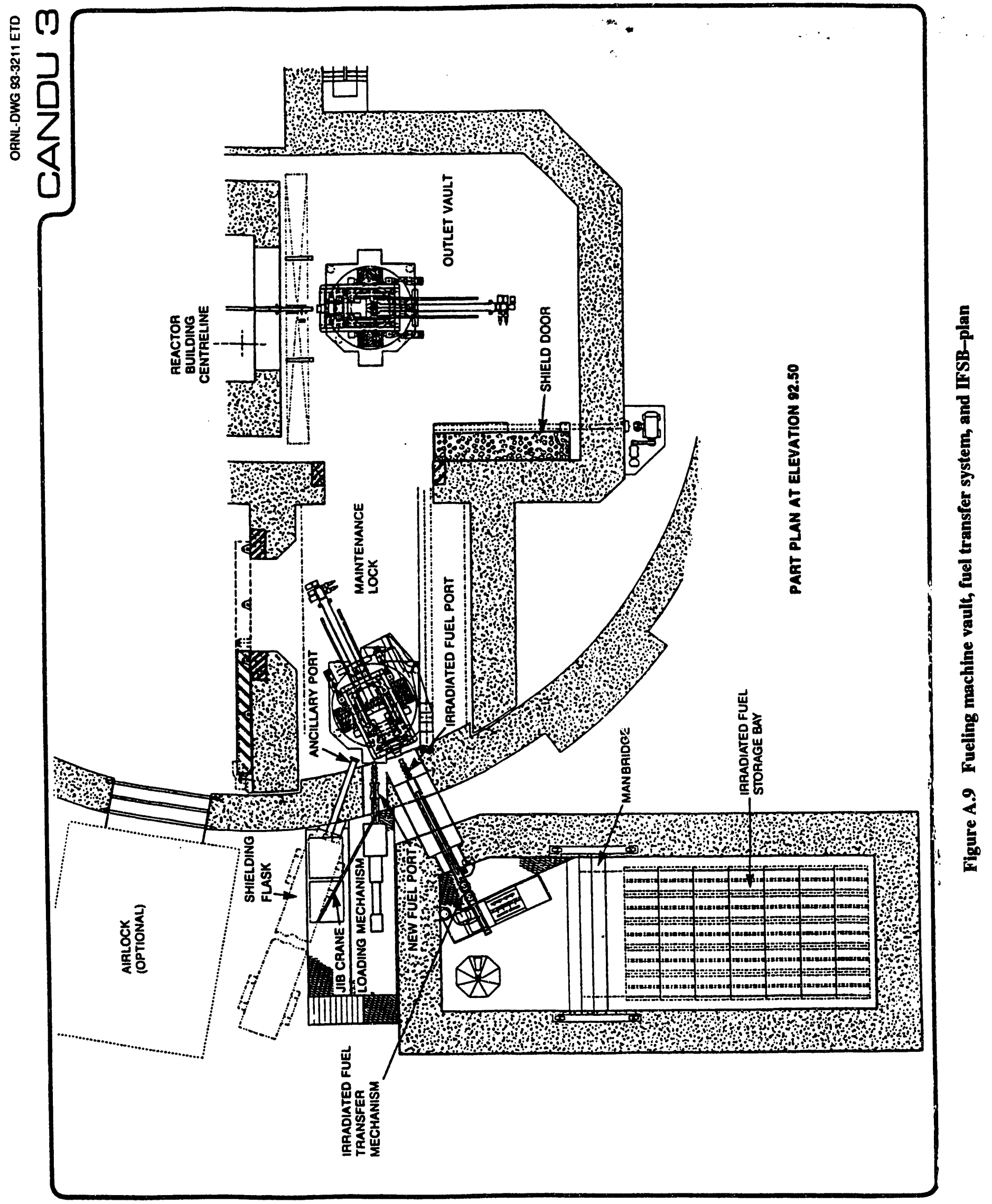


carousel permits control of the "off gassing" from the defective fuel bundle. The bundle is stored in this unit until it is appropriate to store it elsewhere or to can it for permanent control of radioactive releases.

\section{A.2.4.4 Irradiated Fuel Storage Bay}

The IFSB is located in the reactor auxiliary building. It is constructed of concrete and has a welded stainless steel liner.

The IFSB is comprised of two areas:

1. the receiving area where the fuel is inspected, defective fuel is separated and stored, and the remainder of the fuel is shuttled from the transfer port to the storage area; and

2. the storage area where the fuel is stored before being transferred to some longer-term fuel storage facility.

The storage bay has the capacity to store up to 4.5 stationyears of irradiated fuel, plus a reactor core of fuel.

The essential components of the IFSB cooling and purification system are two $100 \%$ duty pumps, two $50 \%$ duty heat exchangers, two filters, and two ion exchangers. Decay heat is removed from the irradiated fuel in the storage bay by recirculating the bay water through the heat exchangers. Recirculating cooling water is supplied to the secondary side of each heat exchanger to remove heat absorbed by the bay water. In addition to cooling, one or two purification loops will operate as required to maintain the desired radioactivity level and remove particulates suspended in the water.

\section{A.2.4.5 Fuel Handling Control System}

The control system utilizes cathode ray tube (CRT)-based color graphics and operator keyboards for a man-machine interface in the main control room. The system configuration is based on a central controller with distributed modules for the connection of process instrumentation and electrical motor controllers. The central controller performs sequential control of fuel handling operations and manages the protective interlock system used for mechanism protection.

The normal overall mode of control for the fuel handling system is automatic with the operator in the main control room observing the sequential operations via the color graphic displays of the plant display system. Capability is also provided to allow the operator, on an interactive basis, to control operations either in a semiautomatic mode, or in a manual mode, using keyboard entries.

\section{A.2.5 Plant Layout (Separation)}

In the CANDU 3 design, systems are separated in terms of the "two-group separation philosophy" shown schematically in Fig. A.10. This concept divides systems into two groups, each capable of performing the essential safety functions of reactor shutdown, decay heat removal, and monitoring. In general, Group 1 systems contribute to normal power production, while Group 2 systems have a safety or safety support function. Group 1 systems alone can perform an orderly shutdown and cooldown of the reactor. Group 2 systems can perform all required safety functions in the event of an accident, even one which disables Group 1. Within the Group 2 area, safety systems that perform similar functions, such as Shutdown System 1 (SDS1) and SDS2, are also separated from each other.

To guard against cross-lir 'ed and common-mode events and to facilitate the comprehensive seismic qualification of the Group 2 systems, the Group 1 and Group 2 systems are, to the greatest extent possible, located in separate areas of the station. The allocation of key systems to the two groups is shown in Fig. A.11.

All systems, equipment, and structures performing the functions of maintaining reactor coolant pressure boundary integrity, reactor shutdown, decay heat removal, and containment are seismically and environmentally qualified. This includes all Group 2 systems, structures, and components; the reactor building and Class I systems; and safety-related systems within the reactor building. Qualification ensures that the system, component, or structure can withstand the effects of the postulated earthquake or environmental condition. Qualification is achieved by testing and/or analysis.

The CANDU 3 plant is designed for a 0.3-g seismic loading requirement, irrespective of lesser site-imposed requirements.

\section{A.2.6 Electrical Power System}

\section{A.2.6.1 Classes of Power}

The station service power supplies are classified in order of their levels of availability requirements. Four classes that range from uninterruptible power to that which can be interrupted with limited and acceptable consequences are provided as follows: 


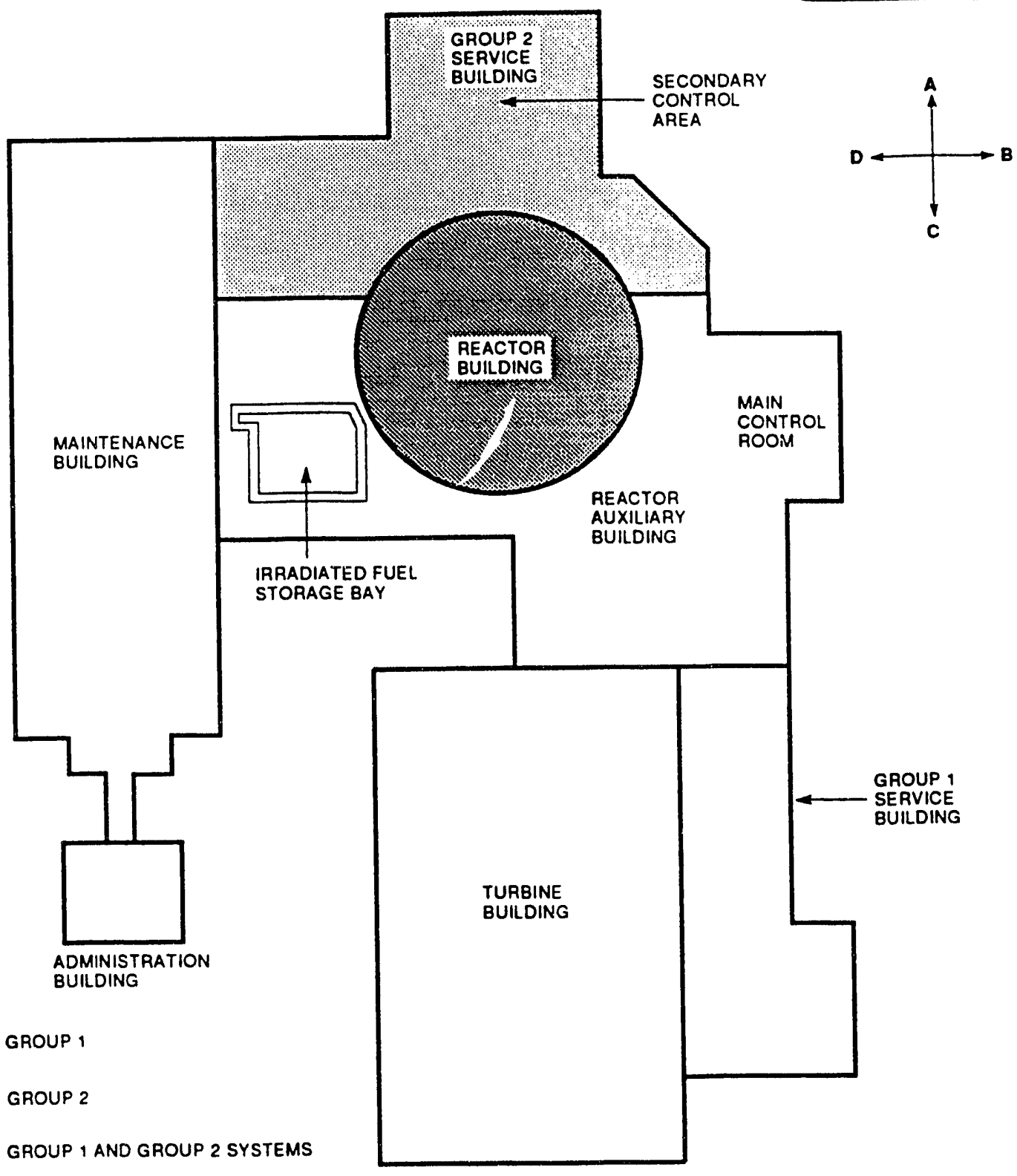

GROUP 1

SHUTDOWN

- reactor regulating SyStem heat REMOVAL

- STEAM genERATOR fEedwater SYSTEM

- local air coolers

mONITORING AND CONTROL

- MAIN CONTROL ROOM

SUPPORT SYSTEMS

- electrical power system

- instrument air system

\section{GROUP 2}

SHUTOOWN

- SHUTDOWN SYSTEM NO.2

- SHUTDOWN SYSTEM NO 1

heAT REMOVAL

- gROUP 2 FEEDWATER SYSTEM

- SHUTDOWN COOLING SYSTEM

- emERgENCY CORE COOLING SYSTEM

MONITORING AND CONTROL

- SECONDARY CONTROL AREa

\section{CONTAINMENT}

- CONTAINMENT SYSTEM

SUPPORT SYSTEMS

- group 2 electrical power system

- group 2 raw service water SySTEM

Figure A.10 Two-group separation philosophy 


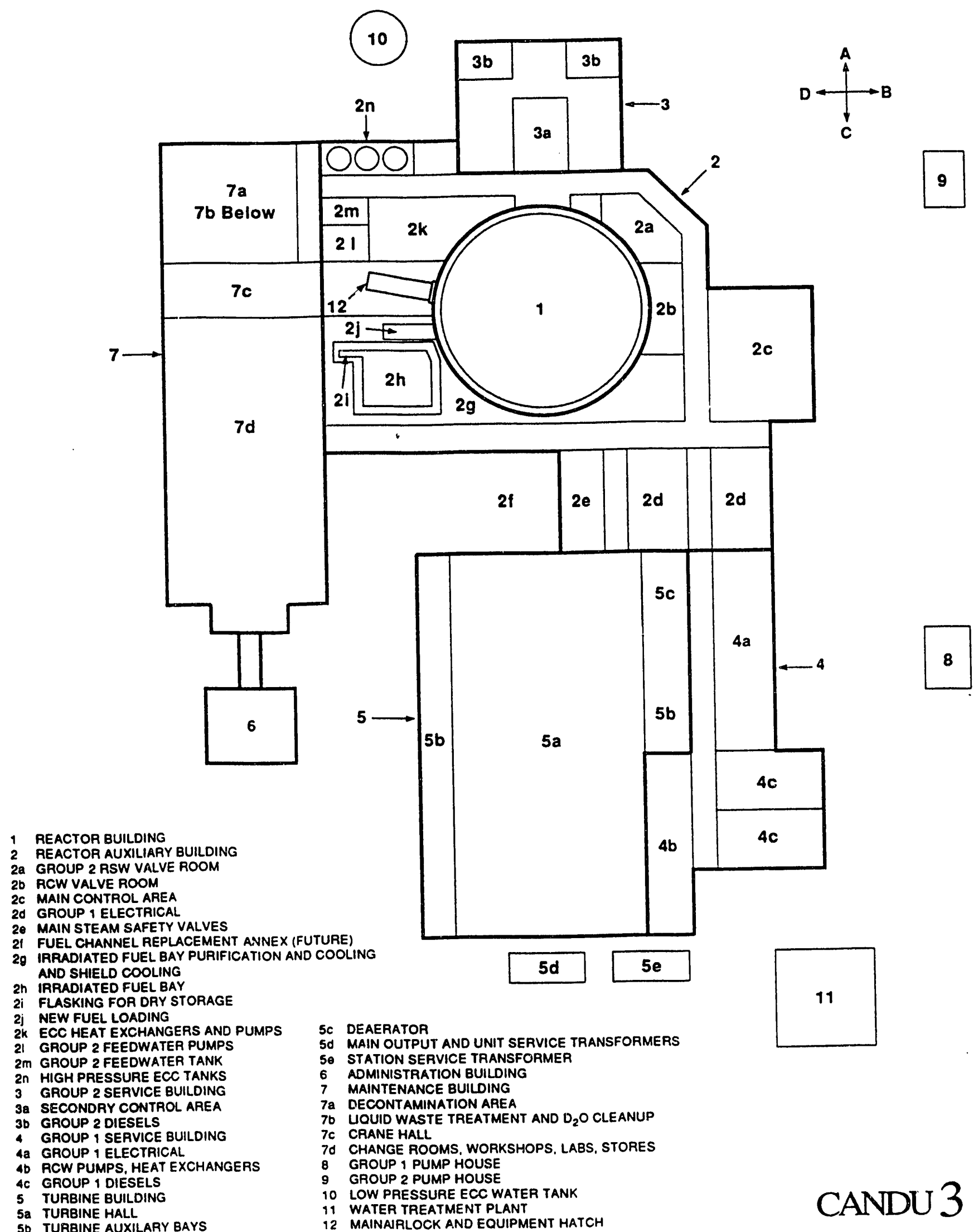

Figure A.11 Station layout-plan 
Class IV Power Supply: Alternating current (ac) power to auxiliaries and equipment that can tolerate long-duration interruptions without endangering personnel or station equipment. Class IV power is normally available to all systems and loads in the station.

Class III Power Supply: Supplies ac to auxiliaries that are necessary for the safe shutdown of the reactor and turbine and can tolerate short interruptions (up to about $3 \mathrm{~min}$ ) in their power supplies. Class III power is available to both Group 1 and Group 2 systems. Separate on-site standby generators located in the Group 2 service building provide an alternative power supply to make up the Class III Group 2 system. Connections between the Group 1 and Group 2 Class III supplies are via fully qu !ified isolation devices. Class III power is also relied upon 0 operate pumps for heat removal. The Group 2 Class Ill system, including the standby generators, is seismically qualified to be operational after a design basis earthquake.

Class II Power Supply: Uninterruptible, ac supplies for essential auxiliaries, channelized to match the redundancy requirements of station instrumentation and control systems. Class II power is available to Group 1 and Group 2 systems. The Group 2 Class II distribution system is seismically qualified to be operational after a design basis earthquake.

Class I Power Supply: Uninterruptible, direct current (dc) supplies for essential auxiliaries, channelized to match the redundancy requirements of control logic and reactor safety circuits. Class I power is available to Group 1 and Group 2 systems. The Group 2 Class I system is seismically qualified to be operational after a design basis earthquake.

\section{A.2.6.2 Odd and Even Concepts}

The station electrical distribution system is split into two independent divisions from the highest distribution voltage down through control voltages. These divisions are referred to as the "odd/even" systems and are separated in all aspects of equipment, distribution, and cable routing. This ensures redundancy of supply to systems requiring high reliability. There are duplicated systems within each of the two groups, and full separation is maintained between systems and groups.

All the power loads are allocated to one or the other division on the following basis:
- where two loads have a main and a standby function, one is on "odd" and the other on "even" divisions; and

- where two loads with a different primary function have a backup interdependence, then one is on each division.

The RRS and the safety systems have triplicated instrumentation and control channels. These channels are kept completely separate from each other with regard to equipment cabinets, cable trays, conduits, junction boxes, etc. The safety systems are also separated into two subgroups to ensure reliability and independence, particularly for the shutdown systems.

\section{A.2.6.3 Automatic Transfer System}

To provide electrical power with high reliability to the Class IV and Class III loads, an automatic transfer system is incorporated that ensures continuity of supply when either the unit supply or the system supply fails. The transfers are manually initiated for normal transfers after startup or before shutdown and are automatically initiated for reactor trips, turbine-generator trips, or loss of the transmission system.

\section{A.2.6.4 Uninterruptible Class II Power Supplies}

The instrumentation and computers are fed from three $120 \mathrm{~V}$ inverters to ensure complete independence of supply to the triplicated reactor regulating and protection instrumentation.

The Class II essential lighting and selected safety-related valve motors are normally fed from two $600-\mathrm{V}$ inverters, providing segregation between instrumentation and motor loads. Each inverter is normally supplied through a rectifier battery charger system in parallel with a battery. The rectifiers receive their supplies from Group 1 Class III buses.

If there is a Class III power failure, the inverter will continue to be supplied from the battery without interruption. In the event of an inverter malfunction, the load is transferred to the alternative Class III source.

\section{A.2.6.5 Uninterruptible Class I dc Power Supplies}

Two Group 1 independent $1250-\mathrm{V}$ storage battery banks with battery chargers are located in separate rooms and provide the power for all motors, switchgear operations, and Class II inverters. 
Group 1 battery sets are sized to support all the loads connected for up to $60 \mathrm{~min}$ following an interruption to the normal (Class III) sources. All ac power is supplied through static inverters.

Each diesel generator is sized to supply the total safe shutdown load of the unit. The Class III shutdown loads are duplicated, one complete system being fed from each diesel generator.

Each diesel generator set is capable of starting the largest Class III motor across the line while supplying other sequenced loads.

\section{A.2.6.6 Group 2 Power Supply System}

The Group 2 power supply system provides an altemative source of electric power to essential Group 1 systems if normal electrical supplies are lost. These events are specifically dealt with by the Group 2 power supply system:

1. a design basis earthquake,

2. a loss of Class IV power (LOP), and

3. a LOCA followed $24 \mathrm{~h}$ or later by a site design earthquake.

The Group 2 power supply system also provides on-site backup power to specific Group 1 station loads connected to the Class III buses. The system is contrilled from the Group 2 service building secondary cont it area with buffered links, allowing system control remotely from the main control room.

The Group 2 power supply system is provided by two $100 \%$ capacity diesel generator units. The two diesel generator sets, located in the Group 2 service building and housed in separate rooms with fire- and blast-resistant interior walls, are seismically qualified to be operational after a design basis earthquake.

If the normal power sources fail, the diesel generators will start automatically. They also start automatically on a lossof-coolant signal, but are not connected unless a LOP occurs. The diesel generators come up to speed and accept key loads within $30 \mathrm{~s}$ and full load within $2 \mathrm{~min}$ of the start signal. The fuel system has the capacity to supply the diesel generators for $7 \mathrm{~d}$. During normal plant operation, the Group 2 electrical distribution system is supplied from the Group 1 Class III system.
The Group 2 system is seismically and environmentally qualified.

Each diesel generator set is capable of starting the largest Class III (Group 2) motor across-the-line while supplying other sequenced loads.

The engines operate on a diesel fuel oil. The fuel is storted in two tanks, each having the capacity to supply a diesel generator for $7 \mathrm{~d}$ of continuous operation at nominal load. Each diesel has an indoor day tank with capacity for $8 \mathrm{~h}$ of operation. The fuel pumps that transfer fuel between the storage tank and the day tank are Juplicated. The fuel is gravity fed from the day tank to the diesel.

The diesels are air-started. Two air reservoirs are provided for each diesel. Each starting system has two air compressors, one driven by an electric motor and the other by an internal combustion engine to provide complete "black start" capability of the diesel.

\section{A.2.7 Service Systems}

\section{A.2.7.1 Group 1 Recirculated Cooling Water System}

The Group 1 recirculated cooling water system serves the following functions:

1. provide heat removal capabilities with adequate pressure to the various users in the plant at all operating conditions;

2. provide sufficient cooling to all of the Group 1 loads classified as essential, on LOP supplies;

3. provide, together with the Group 2 service water, SDC and feedwater systems, a reliable heat sink for decay heat removal and heat transport system cooldown;

4. provide chemistry control of the service water to prevent fouling and corrosion of the piping and equipment;

5. provide means for overpressure protection in the system to protect all isolable components with a volume in excess of $42.5 \mathrm{~L}$;

6. accommodate swell in the system and ensure that the system remains full at different load conditions;

7. provide means for a normal makeup water supply from the demineralized water system and a backup supply in case of large leakages or demineralized water system failure; and 
8. prevent draining of the higher portion of the recirculated cooling water piping when all pumps are shut down.

The supply portions of the system (pumps and heat exchangers) are located in the Group 1 pumphouse. The following key components are cooled by the closed-loop recirculated cooling water system.

Inside the reactor building:

1. gas analysis system coolers,

2. heat transport pumps,

3. $\mathrm{D}_{2} \mathrm{O}$ collection tank cooler,

4. fueling machine auxiliaries and heat exchanger,

5. moderator system heat exchangers,

6. reactor building coolers,

7. shutdown cooling heat exchanger,

8. moderator cover gas compressors,

9. moderator system pumps, and

10. heat transport $\mathrm{D}_{2} \mathrm{O}$ feed pumps.

Outside the reactor building:

1. $\mathrm{D}_{2} \mathrm{O}$ sampling coolers,

2. IFSB coolers,

3. end shield cooling heat exchangers,

4. chilled water system,

5. ECCS heat exchangers.

The equipment located in the turbine building requiring cooling water is also supplied by the recirculated cooling water system.

The recirculated cooling water system supply equipment consists of three pumps and four heat exchangers. Two pumps and three heat exchangers are required for normal operation at full reactor power. Only one pump and one heat exchanger are required during reactor shutdown. The pumps are supplied with Class III power.

The pumps draw water from a common header and discharge into a common manifold. Following distribution to the users, the water returns are combined before entering the recirculated cooling water heat exchangers, where the heat is rejected to the raw service water system.

\section{A.2.7.2 Group 1 Raw Service Water System}

The raw service water system is a once-through Group 1 system used for cooling the recirculated cooling water system (see Sect. 10.2.1) and cooling those systems and equipment whose inventory cannot be adequately cooled by the recirculated cooling water system.

The raw service water system comprises four $50 \%$ duty pumps and two filters. These pumps, located in the pumphouse, draw water from the forebay and supply water to the recirculated cooling water heat exchangers (also located in the Group 1 pumphouse) and various loads in the turbine building through underground piping. The raw service water pumps and the discharge piping from the pumps to the recirculated cooling water system heat exchangers are arranged in two trains.

All pumps are connected to the Group 1 Class III power buses (two pumps on the "odd" bus and the two on the "even" bus). Each flow path with one pump and one filter available is capable of meeting the system demands during loss of Class IV operation, with Class III available.

Each pump is isolated with a check valve and butterfly valve on the discharge side, permitting maintenance work on the pump at all times. Backup pumps start automatically or are stopped manually in accordance with the signals from the differential pressure switches mounted on the pump discharge header. The check valves at the pump discharge and in the common supply lines are equipped with mechanisms to allow testing during operation.

\section{A.2.7.3 Compressed Air System}

The compressed air system supplies instrument air, service air, and breathing air, filtered and dried as required, to both Group 1 and Group 2 areas of the station. In addition, the system provides backup receivers in the Group 1 area capable of supplying instrument air requirements during changeover from Class IV to Class III power, and backup local air reservoirs capable of supplying instrument air to essential users during accident conditions or on loss of Group 1 supply. To reduce or prevent postaccident pressurization of the reactor building, the system is capable of reducing or isolating instrument, breathing, and service air to the reactor building.

\section{A.2.7.4 Reactor Building Ventilation System}

The reactor building ventilation system provides air exchange and air distribution, maintains the reactor building at a slightly lower than atmospheric pressure, 
provides filtration of activity, and allows easy access to all equipment associated with the system.

Air exchange in accessible areas of the reactor building prevents buildup of activity released by local sources or spread by movement of equipment or personnel.

Maintaining a negative pressure in the reactor building from its surrounding prevents the release of activity through airlock enclosures or past door seals.

Ventilation exhaust air discharged from the building is continuously monitored for activity and filtered, if necessary, before release to the exhaust stack. Containment isolation is by two valves in series in each of the ventilation duct penetrations in the containment wall. The isolation valves are automatically closed in the event of a LOCA or activity release.

\section{A.2.8 Fire Protection}

The design for fire protection follows CSA Standard CANN293-M87 "Fire Protection for CANDU Nuclear Power Plants."

The fire protection design considers the possibility of failures of automatic or manual fire systems to extinguish a fire and the potential for interruption of equipment functions due to fire extinguishing agents.

The distinct separation between Group 1 and Group 2 guarantees that if a fire can be confined to its area of origin, the functions of at least one group are maintained.

Buildings are laid out such that they are connected only at access points. This greatly reduces the potential for fire spread between buildings. Connections between buildings are provided with fire walls equipped with fire doors. Within larger buildings, a number of fire areas are established. Each fire area is separated from another by fire walls. These fire areas establish the practical limits of any single fire.

Each fire area contains one or more fire zones. These zones contain one or more rooms having a common fire hazard protection by a common fire protection system. Fire zones are normally established to slow the spreading of fire, beat, and smoke. In certain large open areas, such as reactor buildings, turbine hall, etc., fire zones are separated by open space only. The establishment of fire zones in these areas are for fire detection purposes only.

The spread of fire, heat, or smoke across fire zones through the ventilation system is prevented by using separate ventilation systems or by providing fire dampers in ducts crossing zone boundaries.

Areas containing combustible materials that would hinder manual fire fighting because of heat and smoke are equipped with fire venting, except for areas containing radioactive materials.

All penetrations for cables, piping, and air ducts through fire walls and floors are sealed with a fireproof material.

The control of the fire detection system is by a microprocessor. The state of the system and all circuits are constantly monitored. Display of system troubles and fire alarm messages is on CRTs and printers. In addition to alarm functions, the system will also control fire dampers and ventilation fans and supervise sprinkler valves and fire pumps.

The central fire alarm panel, a display CRT, and a printer is provided in the main control center area. An auxiliary display CRT or printer is provided in the secondary control area.

Fire detection is based on a zoned system to facilitate the location of an alarm source. Each building is divided into a number of fire zones. When a detector senses a fire, the zone from which the alarm came is indicated on the display CRT and printer, and the local alarm device for that zone is actuated automatically. Fire alarm signals are distinctly different from signals for other plant emergencies. Response instructions can also be given over the plant nublic address system.

\section{A.3 Special Safety Systems}

Special safety systems are systems that are specifically incorporated in the plant to mitigate the consequences of a serious process failure requiring reactor shutdown, decay heat removal, and retention of released radioactivity. Special safety systems perform no function in the normal operation of the plant. They consist of the following:

1. SDS1,

2. SDS2, 


\section{ECCS, and}

4. containment system (containment structures and containment isolation system).

The CANDU designs are significantly different than from U.S. LWRs. Major considerations are the unique conditions attending the use of natural uranium fuel with $\mathrm{D}_{2} \mathrm{O}$ coolant and moderator. This results in a large reactor with potential for spatial instabilities, which tends to drive the need for computer control systems. Also, the reactor exhibits a positive void coefficient of reactivity. In the event of a large-break LOCA, the void and attendant reactivity increase is such that the normal reactivity control units are inadequate to shut down the reactor. Therefore, two fast-acting, independent shutdown systems are used; one is mechanical, and the other uses injection of liquid poison into the moderator.

The reactor may not be operated without all the special safety systems being functional. Process systems that provide reliable services such as electrical power, cooling water, and air supplies to the special safety systems are referred to as safety-related or safety support systems and are described in Sect. 7.2 of the CSR.

The design methods used to ensure that the safety requirements for each type of system or structure are satisfied include redundancy, diversity, separation, qualification, quality assurance, and the use of appropriate design codes and standards.

\section{A.3.1 Shutdown Systems}

The CANDU 3 utilizes two shutdown systems, SDS1 and SDS2.

The primary method of quickly terminating reactor operation when certain parameters enter an unacceptable range is the release of $\mathbf{2 4}$ spring-assisted gravity-drop absorber elements or "shutoff rods." SDS1 employs a logic system having three independent channels that detect the requirement for reactor trip and de-energize dc clutches to release the shutoff rods into the moderator. The reactor unit may not be operated without SDS1 being functional. (SDS2 uses a liquid injection system, which is described later.)

\section{A.3.1.1 Functional Requirements}

The two shutdown systems are designed in compliance with Atomic Energy Control Board (AECB) Regulatory Document R8 "Requirements for Shutdown Systems for
CANDU Nuclear Plants"* and must meet the following key requirements:

1. For events requiring prompt shutdown action, each shutdown system, acting alone, can ensure that

- the reactor is rendered subcritical and maintained subcritical,

- the reference dose limits are not exceeded, and

- the integrity of the HTS is maintained (excluding break points).

Emergency core cooling and containment functions may be credited as appropriate.

2. For relevant events listed in Table $1,{ }^{*}$ each shutdown system shall ensure that fuel in the reactor with no defects before the event does not fail as a consequence of the event (excluding fuel in the failed channel).

3. Each shutdown system must be environmentally qualified to the most severe conditions under which it is required to function.

4. Each shutdown system must meet an unavailability target of $<10^{-3}$ year/year ( $<9 \mathrm{~h} /$ year).

5. The two shutdown systems must incorporate the principles of redundancy, diversity, and separation throughout their design.

6. The two shutdown systems must be completely independent of the process systems.

For purposes of assessing the performance of SDS1, the following conservative requirements are used:

1. For all relevant process failures (see Table A.2), SDS1, with the two most effective shutoff rods assumed out of action, shall have sufficient speed and negative reactivity depth to reduce the reactor power to levels consistent with available cooling. (The detector types are identified in Table A.3.)

2. For an in-core loss-of-coolant event, the depth (with one row of two shutoff rods plus the most effective rod assumed out of service) shall be adequate to shut down the reactor and maintain a shutdown state until operator action can be credited.

\section{A.3.1.2 System Description}

\section{Reactor and process measurements}

The design philosophy is based on triplicated measurements of each variable, with protective action initiated when any two of the three trip channels are tripped by any

\footnotetext{
*Atomic Energy Control Board, Regulatory Document R8, "Requirements for Shutdown Systems in CANDU Nuclear Plants," 1987.
} 
Table A.2 Coverage of process failures by SDS1 and independently by SDS2

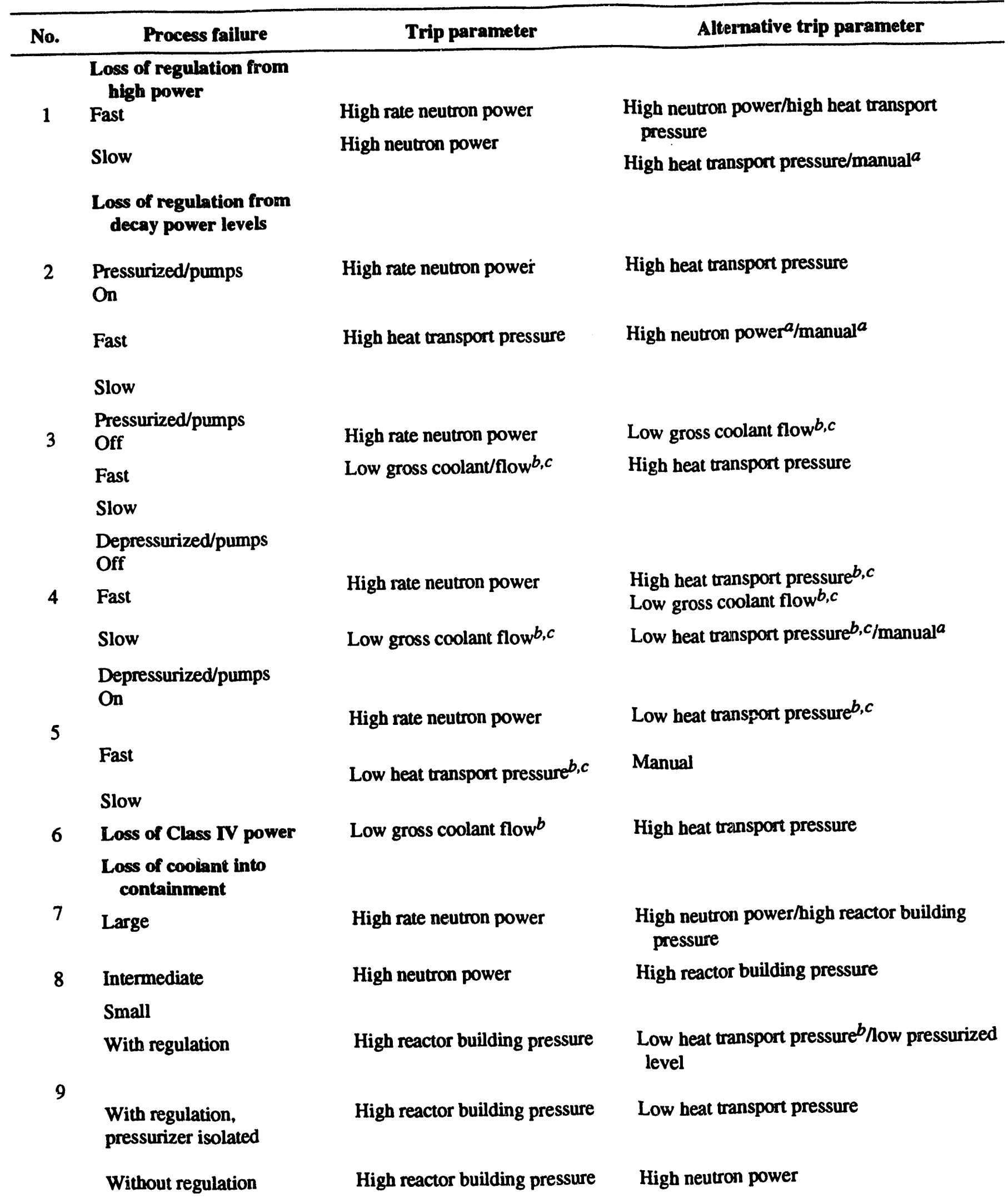


Table A.2 (continued)

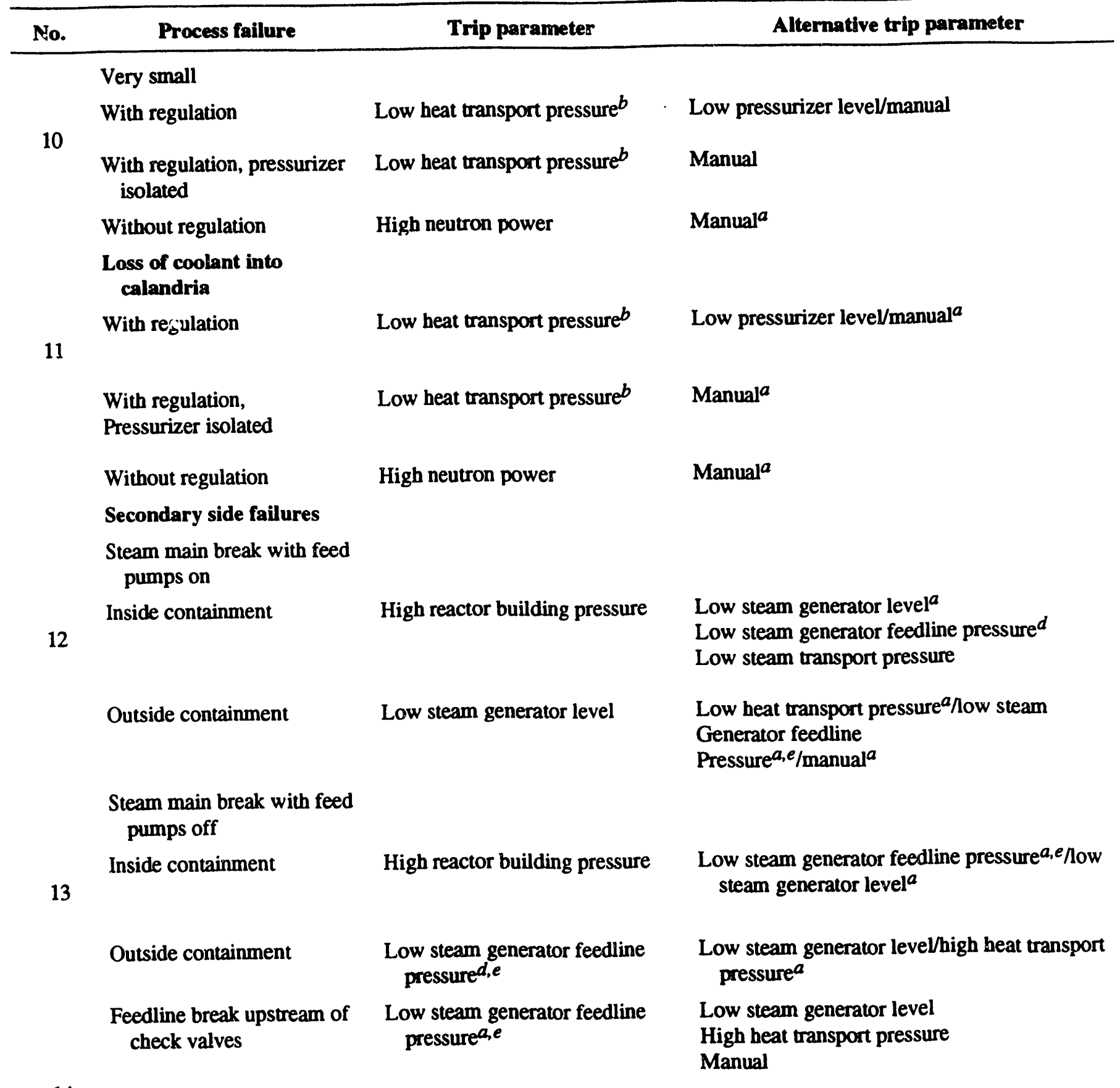

14

Downstream of check valves High reactor building pressure

Low steam generator levellow steam generator Feedline pressure ${ }^{a, e} /$ high heat transport pressure, af/manualaf 
Table A.2 (continued)

\begin{tabular}{|c|c|c|c|}
\hline No. & Process failure & Trip parameter & Alternative trip parameter \\
\hline 15 & $\begin{array}{l}\text { Loss of feedwater control } \\
\text { (e.g., closure of feedwater } \\
\text { valves to a steam } \\
\text { generator) }\end{array}$ & Low steam generator level & High heat transport pressure ${ }^{a} /$ manualf \\
\hline 16 & Feedwater pumps trip & Low steam generator level & $\begin{array}{l}\text { High heat transport pressureaf } \\
\text { Low steam generator feedline pressure }{ }^{a, e}\end{array}$ \\
\hline
\end{tabular}

A Alternative trip paramete rs that provide trip coverage over a limited range of event scale (e.g., break size).

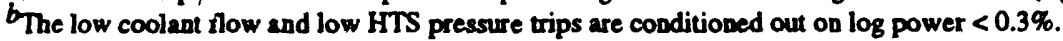

${ }^{c}$ Trip acts as high power trip in effect because it is increasing power; this instigates a trip by removing the conditioned-out state.

${ }^{d}$ Feedline pressure may precede steam generator low level.

The low steam generator feedline pressure trip is conditioned out when log power $<10 \%$.

$f_{\text {If }} \mathbf{4 \%}$ feedwater flow is available after trip.

Source: Adapied from Ref. 1.

Table A.3 SDS1 trip parameters

\begin{tabular}{|c|c|c|}
\hline No. & Trip parameter & Detector type \\
\hline $\begin{array}{l}1 \\
2\end{array}$ & $\begin{array}{l}\text { Neutron p'wer } \\
\text { Rate log neutron } \\
\text { power }\end{array}$ & $\begin{array}{l}\text { Vertical in-core detectors } \\
\text { Ion chambers }\end{array}$ \\
\hline 3 & HTS flow & $\begin{array}{l}\text { Differential pressure } \\
\text { transmitters }\end{array}$ \\
\hline 4 & HTS pressure & Pressure transmitters \\
\hline 5 & $\begin{array}{l}\text { Reactor building } \\
\text { pressure }\end{array}$ & Pressure transmitters \\
\hline 6 & Pressurizer level & $\begin{array}{l}\text { Differential pressure } \\
\text { transmitters }\end{array}$ \\
\hline 7 & $\begin{array}{l}\text { Steam generator } \\
\text { level }\end{array}$ & $\begin{array}{l}\text { Differential pressure } \\
\text { transmitters nn both } \\
\text { steam gec.erators }\end{array}$ \\
\hline 8 & $\begin{array}{l}\text { Steam generator } \\
\text { feedline pressure }\end{array}$ & $\begin{array}{l}\text { Pressure transmitters on } \\
\text { individual feedlines }\end{array}$ \\
\hline 9 & Moderator level & $\begin{array}{l}\text { Differential pressure } \\
\text { transmitters }\end{array}$ \\
\hline
\end{tabular}

variable or combination of variables. This is referred to as "general" coincident logic, as opposed to "local" coincidence logic employed in the SDS2 design. (With "local," two of three signals for a givel. variable must trip to give a channel trip.) A single-loop component or power supply failure will not incapacitate or spuriously invoke the operation of the safety system.

As indicated in Table A.2, there are nine measured variables that can initiate a reactor trip through SDS1. The selection of variables is such that, to the maximum extent practicabie, there are reưundanti señsing parameters for all categories of process fi:ilures identified (Table A.2). The reactor trip can also be manually initiated by the operator. The nine measured variables are listed below.

1. Neutron power: Inconel in-core flux detectors are provided in each of three channels for overpower or loss-of-regulation protection. The detectors are located in the vertical in-core flux detector assemblies and are in guide tubes separate from any regulating system detectors. The detectors are of the straight individually replaceable type and are three lattice pitches long. A linear amplifier converts each detector current to a corresponding voltage signal. The voltage signals are processed in the trip computers to compensate for the overpromptness of the Inconel detector signal. After compensation, the output signal continues to lead the heat flux from fuel to coolant. Low pass filter compensation for SDS2, on the other hand, is greater such that the signal closely matches fuel to coolant heat flux. The purpose of this is to favor trips of SDS1 and avoid unnecessary trips of SDS2.

2. Rate of logarithmic neutron power. Six uncompensated ion chambers, located in separate housings on each side of the calandria (three on each side), are provided for SDS1. Each housing also contains a regulating system ion chamber, or startup instrumentation, and an SDS2 ion chamber in separate cavities within the housing, plus a test shutter.

3. HTS pressure: HTS pressure is measured at three widely separated locations on each side of the two reactor outlet headers. The pressure transmitters are mounted on channelized instrument racks. Regular loop testing is conducted from the main control room. Both ingh pressure and low pressure are used as trip signals. 
These pressure transmitters also provide the signal for the heat transport liquid relief valves (LRVs). Two LRVs connect the HTS to the bleed condenser. Pushbuttons are located in the main control room to open these valves for testing. Individual indicators monitor valve status.

4. HTS flow: HTS flow is measured in a total of $\mathbf{1 4}$ feeders. Flow readings from seven feeders are used for SDS1, while the other seven readings are used for SDS2. The logic is arranged such that each trip channel has at least two measurements, one from each coolant pass. The trip is conditioned out automatically at very low power or shutdown conditions when coolant flow is much below normal.

5. Reactor building pressure: A triplicated measurement of the reactor building pressure is provided for SDS1. The equipment associated with each channel is mounted on instrument racks. Each set of racks is used for one channel only.

Reactor building pressure is normally beld slightly negative with respect to atmospheric by the reactor building ventilation system. If the pressure rises above the set point, the reactor will be tripped by SDS1.

6. Steam generator level: The steam generator low level trip provides protection against secondary-side failures.

7. Pressurizer level: Low pressurizer level is a trip parameter effective for small LOCAs. The trip is conditioned out automatically at very low power levels to allow for draining the pressurizer during maintenance.

8. Steam generator feedline pressure: Each channel monitors the pressure in the two steam generator feedlines between the feedwater control valve and the steam generator. This trip parameter protects against secondary-side failures that could result in the loss of the steam generators as a heat sink.

9. Moderator level: Moderator level is a trip parameter effective for loss of moderator cooling and moderator pipe break accidents. A trip is given on both high and low moderator levels. The moderator level trip is the only one that is peculiar to SDS1.

Logic processing and testing. There are three independent channels, having completely independent and physically separated power supplies, trip parameter sensors, instrumentation. trip computers, and annunciation. When any two of the three channels trip, the shutoff rods are dropped.
The trip logic, trip testing, and display functions for both shutdown systems make use of trip computers, display/test computers, and CRT displays on the main control room and secondary control area panels and consoles. This technology has been used in Darlington, Nuclear Generating Station.

One trip computer per channel is used in each shutdown system. The trip computers replace all the analog compensators of the neutron overpower trip, all analog trip comparators, all programmable digital comparators, and relay logic used in previous designs. The final two-out-ofthree voting will continue to be done using relays. The final two relay voting logic modules control two separate banks of clutch coils (12 rods each) as shown in Fig. A.12.

The trip network is monitored to provide a positive indication of the state of the trip logic, by verifying the correct operation of all contacts in the two-out-of-three networks when a channel is tested.

Equipment layout. The shutoff unit housings are located on the reactivity mechanism deck. This permits controlled access to the clutches, motors, potentiometers, gearboxes, and winches for removal or for maintenance one at a time.

Instrumentation. The detector types used in shutdown systems are as follows:

1. Displays: All the information required on the tripping parameters and the status and operation of the system can be displayed on CRTs in the main control room and in the secondary control area at the operator's command.

2. Power supplies: Separately channeled Group 2(a), Class I and Class II power supplies are provided for each channel of SDS1. The logic is arranged so that any loss of power to a channel results in a channel trip.

The dc clutches, operated from rectified, redundant Class II power, release on loss of power.

Channel power supplies are individually monitored, and any loss is annunciated. The power supplies to the neutron instrumentation and the process transmitters are arranged so that a trip occurs on a general loss of Class II power. Fuse failures or events causing loss of power to individual transmitters are annunciated. These individual power losses also result in an irrational signal to the trip computer and a subsequent channel trip. 


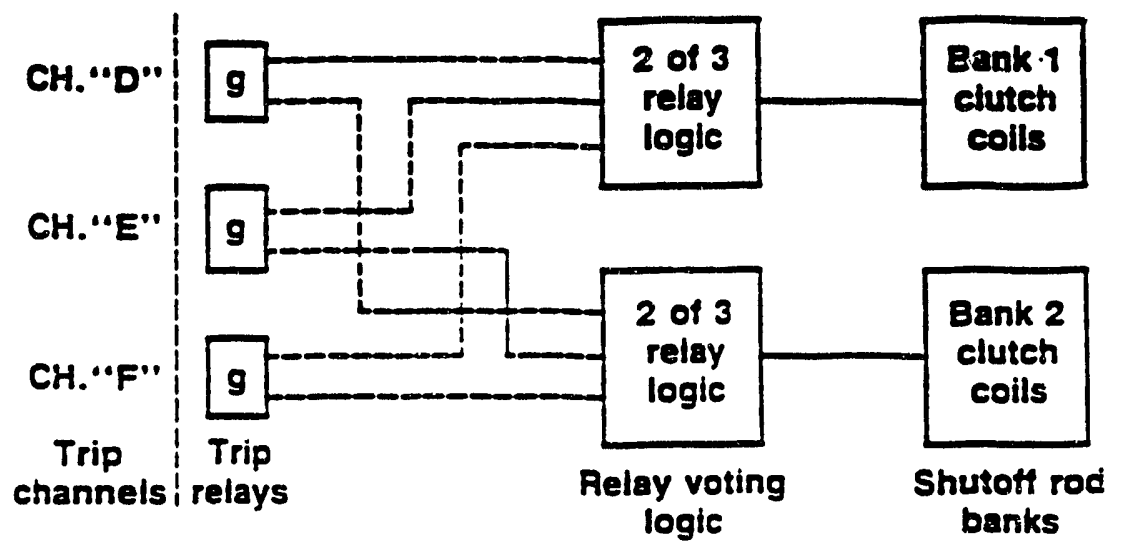

(a) Typieal logic for actuating shutaft rods

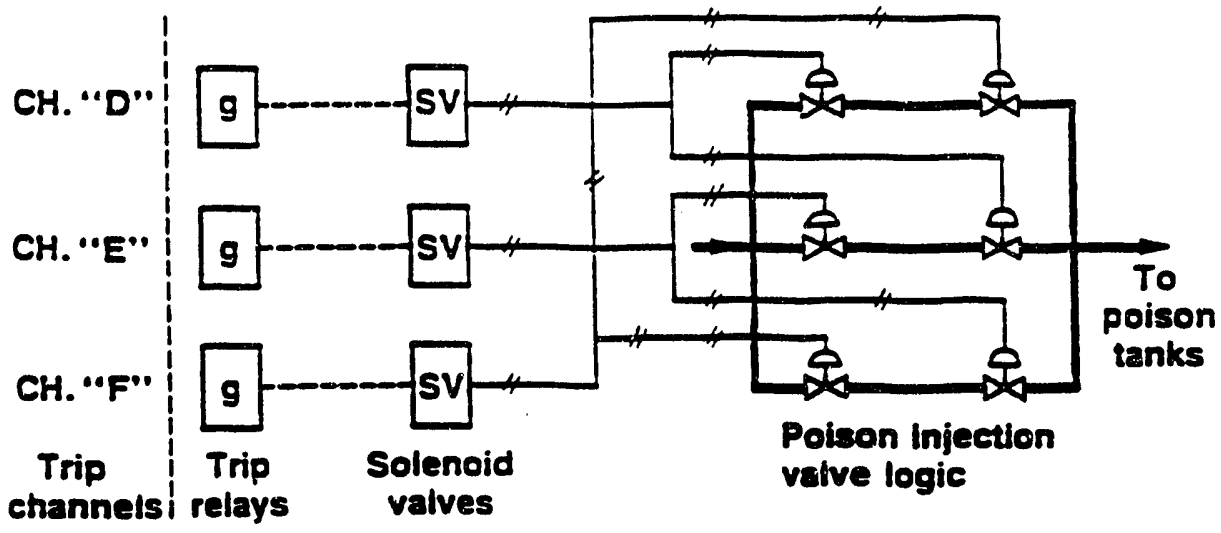

(b) Typical logic for actuating poison injection system

Figure A.12 Schematics of logic for actuating mechanical elements of shutdown systems 
3. Annunciation: The status of all trip parameters is sent to the plant display system through a fiber-optic link for annunciation and event sequencing. During upset conditions, the time and sequence of various parameters exceeding their limits may be printed out on demand.

\section{A.3.2 Shutdown System 2}

SDS2 is the second system for quickly terminating fission power when certain parameters enter an unacceptable range. This occurs via the rapid injection of concentrated gadolinium nitrate solution into the moderator through horizontal nozzle assemblies. SDS2 employs a logic system with three independent channels that sense the requirement for shutdown and open fast-acting valves that release high-pressure helium to inject the gadolinium poison into the moderator.

This system incorporates design features to prevent unnecessary injections when the SDS1 has acted normally; however, there is no physical coupling between SDS1 and SDS2.

\section{A.3.2.1 Functional Requirement}

SDS2 is designed in compliance with AECB Regulatory Document R-8 "Requirements for Shutdown Systems for CANDU Nuclear Power Plants."* For purposes of assessing the performance of SDS2, the most effective nozzle is assumed out of action. The remaining injectors shall be of sufficient speed and negative reactivity to reduce the reactor power to levels consistent with available cooling for all process failures identified in Table A.2.

\section{A.3.2.2 SDS2 System Description}

Figure A.13 shows a simplified schematic diagram of SDS2.

A vessel containing high-pressure helium supplies the source of energy for rapid poison injection. The tank is connected, through six quick-opening valves arranged in three successive pairs, to a helium header that services the poison tanks. The quick-opening valves are air-to-close, spring-to-open so that they fail safe on loss of air supply or electrical power. The six cylindrical poison tanks are mounted on the outside wall of the reactor vault. Each of these poison tanks contains gadolinium nitrate solution. The nominal solution concentration is $8000 \mathrm{mg}$ of

\footnotetext{
*Atomic Energy Control Board, Regulatory Document R8, "Requirements for Shutdown Systems in CANDU Nuclear Plants," 1987.
}

gadolinium per kilogram of $\mathrm{D}_{2} \mathrm{O}$ and is verified by an online recirculating sampling system.

Each poison tank is connected by a stainless steel pipe to a horizontal in-core injection tube nozzle that spans the calandria and is immersed in the moderator. Six Zircaloy-2 nozzles penetrate the calandria horizontally and at right angles to the fuel channel tubes. Holes are drilled into the nozzle along its length to form four rows of jets, which permit complete dispersion of the poison into the moderator.

There is a liquid-to-liquid interface between the poison solution and the moderator, as shown in Fig. A.13. Movement of the interface is caused by the poison very slowly migrating by diffusion from an area of high concentration to an area of low concentration. Also, physical motion of the liquid back and forth in the line causes a small amount of mixing of the poison solution with the moderator. This motion is caused by variations in the moderator level.

Two conductivity probes are installed in the poison injection line downstream of each poison tank. One is located close to the bottom of the poison tank to monitor the poison concentration and alarm on low poison concentration. The second probe is located close to the bellows assembly of the shield tank to detect when poison solution reaches the downstream top of the U-section. Upon alarm from any of the latter probes, the associated poison injection line must be backflushed to pull the poison interface back to the ball valve.

Each poison tank contains a floating polyethylene ball that seats at the top of the poison tank before injection to restrict the movement of poison upward due to variations in moderator level. When an injection is initiated, the helium gas pressure transfers the poison to the calandria, and the ball falls to the tank bottom. In the bottom position, the ball seats at the poison tank outlet and prevents the release of high-pressure helium to the calandria.

Each poison tank can be isolated by manual isolating valves located in the gas and poison legs to permit maintenance and testing on a poison tank without disabling the shutdown system. The operator is warned by alarm if valve closure occurs on more than one poison tank.

Measurements are made of helium makeup supply pressure, helium supply tank pressure (by two different mcthods), injection tank level, and injection tank ball 
Appendix A

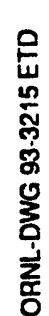

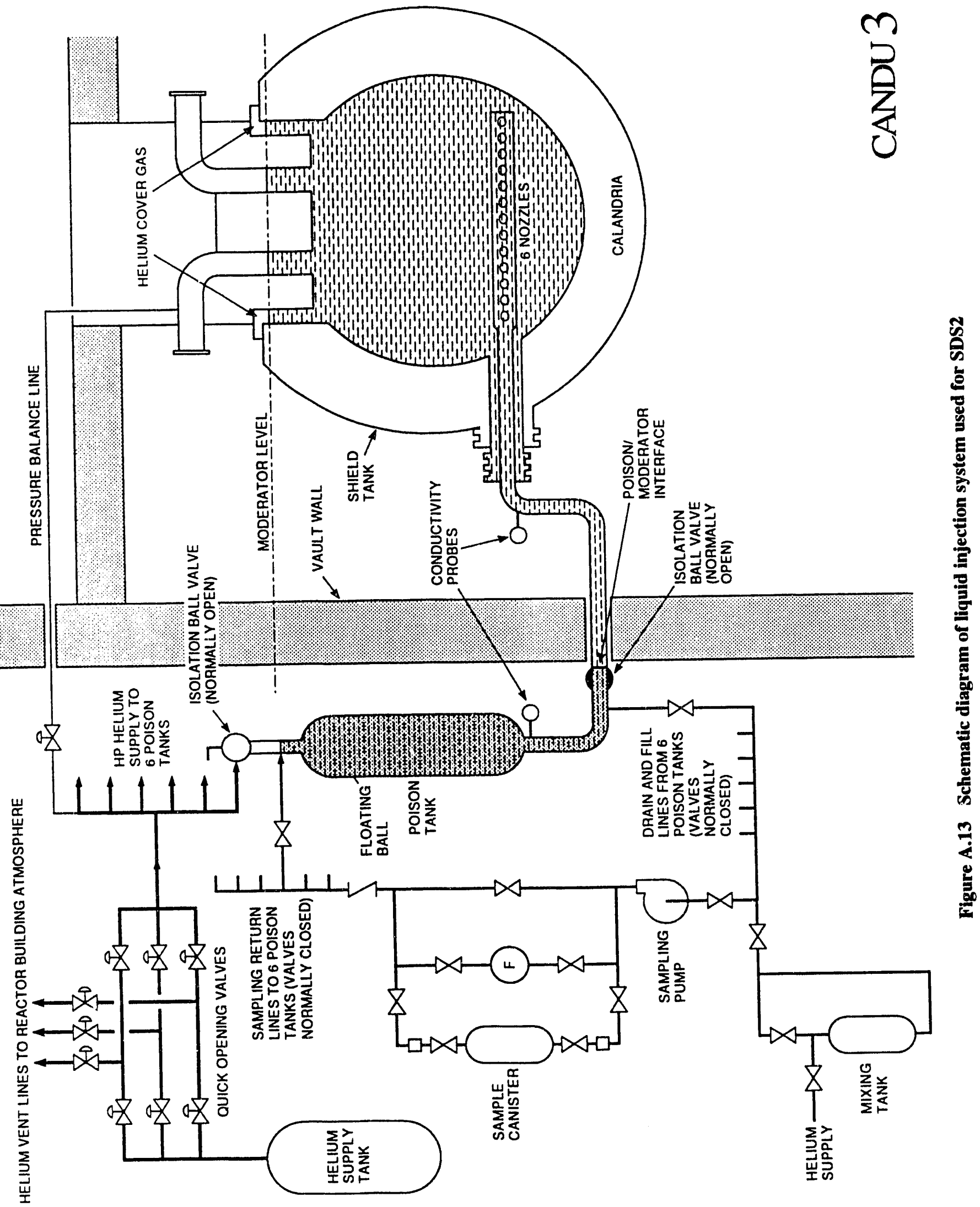


location. Deviation from specified limits by any measurement initiates an alarm in the main control room. Limit switches are provided on each of the six quickopening valves, three vent valves, and helium makeup valve at the closed and opened positions.

\section{A.3.2.3 Equipment Layout}

The quick-opening valves and poison tanks are located outside the reactor vault, where they are accessible during reactor operation. The poison tanks are situated at the vault wall to minimize injection time.

The ball valves in the poison injection line are inside the reactor vault to minimize the time for the poison to reach the calandria. The drain valves are adjacent to these ball valves to ensure the poison interface is at the ball valve after backflushing. Hence, these ball valves and drain valves have extended spindles to allow operation from the outside of the vault wall.

The ion chambers and in-core detectors for SDS2 are horizontally mounted, and their cables are routed separately from those of SDS1.

The cubicles containing the trip computers and relay logic for each channel are located in a Group 2 control equipment area (adjacent to the secondary control area). (This control equipment area is separated from the control equipment area for SDS1.) Because local coincidence is used, there are cross-connections among the three channel trip computers.

A section of the safety systems panels and console in the main control room is allocated solely to SDS2. The SDS2 alarm windows are on a vertical panel, while the trip test and channel select switches, display CRTs, and the manual trip buttons for SDS2 are mounted on the console. These are connected to the SDS2 trip and display computers in the secondary control area by channelized fiber-optic data links.

\section{A.3.2.4 Reactor and Process Measurements}

The design philosophy is based on triplicating the measurement of each variable and initiating protective action when any two of the three trip channels are tripped by the same variable (i.e., local coincidence logic). A single-loop component or power supply failure will not incapacitate or spuriously invoke the operation of the safety system.
Eight measured parameters can initiate a reactor SDS2, as shown in Table A.4. These are the same parameters that initiate SDS1, except for moderator level. The selection of parameters is such that, where practicable, there are redundant sensing parameters for all categories of process failures identified. The system can also be manually tripped by the operator from the main control room or the secondary control area.

- Displays: All the information required on the tripping parameters and the status and operation of the system can be displayed on CRTs in the main control room and the secondary control area, at the operator's command.

- Power supplies: Separately channeled Group 2(b) Class I and Class II power supplies are connected to each of the SDS2 channels. The logic and instrumentation have been designed so that a channel trips on loss of power.

Table A.4 SDS2 trip parameters and detectors used

\begin{tabular}{|c|c|}
\hline Trip parameter & Detector type \\
\hline Neutron power & $\begin{array}{l}\text { Horizontal in-core } \\
\text { detectors }\end{array}$ \\
\hline Rate log neutron power & Ion chambers \\
\hline HTS flow & $\begin{array}{l}\text { Differential pressure } \\
\text { transmitter }\end{array}$ \\
\hline HTS pressure & Pressure transmitter \\
\hline $\begin{array}{l}\text { Reacto: building } \\
\text { pressure }\end{array}$ & Pressure transmitter \\
\hline Pressurizer level & $\begin{array}{l}\text { Differential pressure } \\
\text { transmitter }\end{array}$ \\
\hline Steam generator level & $\begin{array}{l}\text { Differential pressure } \\
\text { transmitter on both } \\
\text { steam generators }\end{array}$ \\
\hline $\begin{array}{l}\text { Steam generator feedline } \\
\text { pressure }\end{array}$ & $\begin{array}{l}\text { Pressure transmitter on } \\
\text { individual feedlines }\end{array}$ \\
\hline
\end{tabular}

\section{A.3.2.5 Logic Processing}

There are three independent channels, separate from the three used for SDS1. Local coincidence is used, that is, two out of three channels indicating a trip for the same parameter will initiate poison injection. The combination of a channel trip for one parameter combined with a different channel tripped for another variable will not initiate a poison injection. A six-helium valve configuration ensures a very simple and reliable design. (See Fig. A.12.) 
There are three alternate helium paths, each with injection valves and an interspace vent valve. Special logic prevents the testing of two different valve pairs within $10 \mathrm{~min}$ of each other. This ensures that the interspace between the helium injection valves is depressurized, and it prevents spurious partial injections.

SDS2 has computerization of the trip logic, system testing, and monitoring and display functions. Implementation is the same as for SDS1. The reactor may not be operated at power if SDS2 is unavailable. Interlocks are provided as follows for interface with other systems.

\section{A.3.3 Emergency Core Cooling System}

\section{A.3.3.1 System Functional Requirements}

The ECCS is designed in accordance with the requirements outlined in AECB Regulatory Document R-9.*

1. Cooling requirements: The system must be designed to maintain or re-establish sufficient cooling of the fuel and fuel channels for all LOCA specified in Tables 1 and 2 of Document R-9 to prevent fuel failure or limit the release of fission products from the fuel and to maintain fuel channel integrity.

2. Environmental Requirements: Emergency core cooling equipment, required to operate or continue operating following exposure to severe environmental conditions following a loss of coolant, must be environmentally qualified to withstand the worst of these conditions.

3. Unavailability requirements: The system must be designed to meet the unavailability target of $10^{-3}$ year/year ( $<9 \mathrm{~h} /$ year). Each component of the system and subsystems will be monitored and/or tested onpower to demonstrate that this target is met. Calculations will be used to verify that the system unavailability target is met. Valves located inside containment will be accessible to permit testing and maintenance during normal reactor operation.

The design of the system must take into account the long-term reliability of those components that must continue to function during the long-term recirculation mode.

Redundancy must be provided such that failure of any single component in the system will not impair the system to the extent that it will not meet its minimum allowable performance requirements.

\footnotetext{
*Atomic Energy Control Board, Regulatory Document R9, "Requirements for Emergency Core Cooling System in CANDU Nuclear P̈lants," 1987.
}

4. Seismic requirements: Equipment/components in the system and subsystems needed to maintain cooling of the fuel must be designed to withstand an earthquake of site design earthquake intensity.

5. Tornado requirements: A loss of coolant is not postulated during or following a tormado, and as a result the ECCS is not required to withstand a tornado.

6. Separation and independence requirements: The ECCS must be physically and operationally independent from other systems, except for those that are required to assist in the system operation.

The layout of the system is such that failure of piping in another system or in the ECCS will not impair the rest of the system.

7. Penetration requirements: The system piping penetrating containment must comply with the requirements of AECB Regulatory Document R-7.†

8. Leakage control requirements: Components/equipment in the system outside containment must be enclosed such that any leakage that may occur during the longterm recovery mode can be controlled.

9. Shielding requirements: Shielding must be provided for equipment located outside the reactor building to allow operator access to adjacent areas during the ECCS operation in the recovery mode.

\section{A.3.3.2 Summary Description}

The ECCS supplies emergency coolant to the reactor headers in the event of a LOCA.

The system operation is divided into two parts: short-term injection and long-term recirculation. Short-term injection consists of two stages: high- and low-pressure injection. During the high-pressure injection (HPI) stage, water from the accumulator tanks is injected into the HTS by pressurized gas. As this water is depleted, low-pressure injection (LPI) automatically takes over, injecting water from a grade level tank via the emergency core cooling pumps. The water level in the grade level tank is continuously monitored via triplicated level measurements. A connection is provided to this tank for demineralized water makeup and for initial filling.

When this water supply is depleted, the long-term operation automatically begins by recirculating a mixture

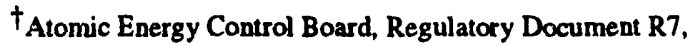

"Requirements for Containment Systems for CANDU Nuclear Power Plants," 1987.
} 
of $\mathrm{H}_{2} \mathrm{O}$ and $\mathrm{D}_{2} \mathrm{O}$ from the reactor building sump back into the HTS via the heat exchangers and pumps.

The ECCS is triggered when the HTS pressure drops to a predetermined value and any one of the emergency core cooling conditioning signals is activated. Figure A.14 is a schematic diagram of the ECCS.

\section{System components}

1. Accumulator water tanks: The water tanks are normally isolated from the upstream gas tank by gas isolation valves and on the downstream side by the HPI valves. Because the water in the accumulator tanks is normally stagnant, facilities for chemical control are provided.

2. Accumulator gas tank: The tank is cylindrical with hemispherical heads. Pressurized gas stored in this tank is used to inject water from the water tanks into the HTS following a loss of coolant. An air compressor, backed up by a compressed nitrogen supply, maintains the gas tank pressure.

3. Grade level tank: This tank is maintained at atmospheric pressure and is insulated. The stored water is maintained at about $21^{\circ} \mathrm{C}$ by recirculating water through an external electric heater, if required in winter. Chemical addition is provided to minimize corrosion.

4. Emergency core cooling pumps: Two $100 \%$ duty pumps, energized from Group 2 Class III buses, ensure long-term reliability and postdesign-basis-earthquake operation. Instrumentation is supplied to detect failure of the operating pump and to automatically start the standby pump.

5. Heat exchangers: Two $100 \%$ plate-type heat exchangers in the recovery pump discharge line maintain the coolant flow at or below $60^{\circ} \mathrm{C}$ at the entry to the HTS. The temperature at the pumps is $\sim 70^{\circ} \mathrm{C}$ when first pumping the mixture of $\mathrm{D}_{2} \mathrm{O}$ and $\mathrm{H}_{2} \mathrm{O}$ from the reactor building.

The heat exchangers remove residual and decay heat from the coolant. To ensure long-term reliability and operation of the ECCS after a site design earthquake, the cooling water to the heat exchanger, normally supplied by the recirculated cooling water system, is backed up by the seismically qualified Group 2 raw service water system.

6. Valves: Redundant valves, in parallel, are provided wherever power-operated valves are required to open for system operation. Most valves are provided with electric actuators which fail "as is."
Instrumentation and control. The ECCS is controlled by dedicated computers that perform the initiation, monitoring, display, and testing functions.

Each signal essential for system operation is triplicated so that a single-signal loop component or power supply failure does not incapacitate or spuriously invoke the operation of the system. Triplication includes isolation between loops of the three channels and the use of unique transmitter mounting racks, electrical cubicles, initiation computers, and power supplies for each channel.

The logic used with the three channels is such that a trip of any two channels in the heat transport pressure monitoring loops in conjunction with any two-out-of-three conditioning signal trips will generate the LOCA signal (LOCS). Both the break-size-dependent and break-locationdependent LOCA mitigation features in the early design described in the $\mathrm{CSR}^{1}$ have been eliminated. ${ }^{*}$ Emergency core coolant is applied uniformly to both the reactor inlet and outlet headers for any LOCA signal. ${ }^{*}$

Electrical supply to valves. The controls and power supplies for each valve of a pair of valves are separate and independent. They are referred to as the "odd" and "even" circuits.

All electrical valves required to operate to allow HPI from the accumulator tanks are supplied from Group 2, Class II power. Those required to operate for LPI from grade level tank and the long-term recirculation phase are supplied from Group 2, Class III power.

\section{A.3.3.3 System Operation}

General. The ECCS does not operate during normal reactor operation but remains fully poised to be activated on a LOCA.

Following a LOCA, the HTS pressure drops, the pressurizer level is depleted, the pressure inside the reactor building rises, and the shutdown systems initiate a reactor trip.

Blowdown. Following a loss of coolant, the heat transport pressure drops at a rate dependent on the size of the break. The time from the loss of coolant until the heat transport

\footnotetext{
*Alomic Energy of Canada, Limited, Technologies, Rockville, Maryland, personal communication to Oak Ridge National Laboratory Staff, March $10,1992$.
} 
Appendix A

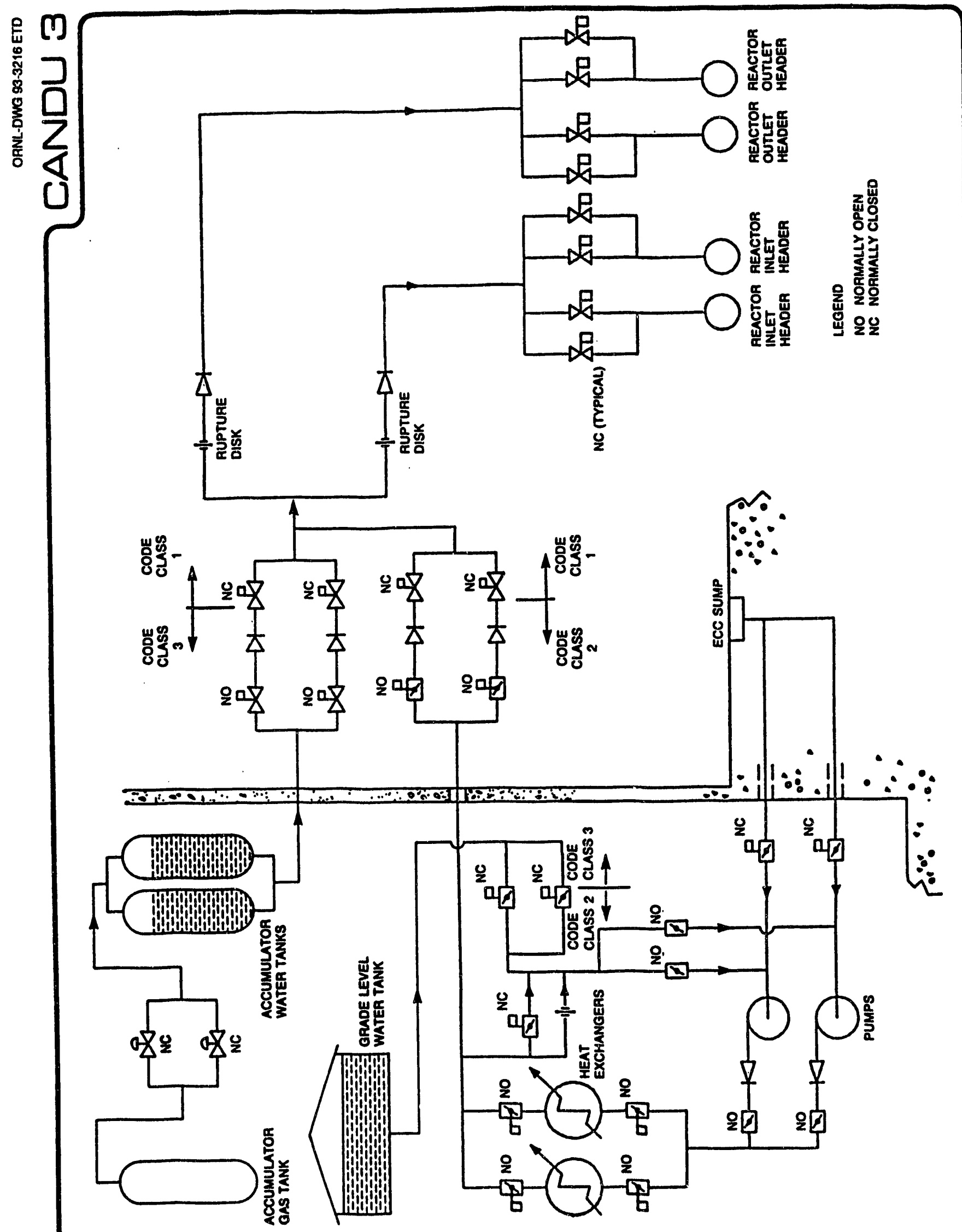


pressure reaches the injection pressure is known as the blowdown period.

For large-size breaks, fuel cooling may or may not be maintained depending on the break size and location. For small breaks, the initial ECCS injection pressure is such that fuel cooling is maintained during blowdown. Therefore, the purpose of injection is to restore cooling for large breaks and maintain cooling for small breaks.

Emergency core cooling initiation. The ECCS is initiated on an LOCS. To generate this signal, the HTS pressure has to fall to a predetermined value, and one of the conditioning variables (high reactor building pressure or low pressurizer level) has to be activated. A low pressurizer level signal is used as a conditioning variable for detection of a small loss of coolant. The conditioning signals are provided to prevent spurious operation of the system.

The LOCS alone will initiate ECI. However, the scram signal comes first; the LOCS is a separate signal that comes later.

The system logic performs the following functions:

- opens the gas isolation valves, the HPI valves, and $\mathrm{D}_{2} \mathrm{O}$ isolation valves;

- starts one of the emergency core cooling pumps;

- $\quad$ opens the grade level tank isolation valves;

- $\quad$ starts the Group 2 Class III diesels;

- opens the MSSVs; and

- trips the beat transport pumps.

In addition to these, a separate signal for steam generator crash cooldown, independent of the ECCS, is provided.

The rupture disks in the ECCS burst when the gas isolation and HPI valves open. Flow into the primary circuit begins when the HTS pressure falls below the high-pressure emergency core coolant injection pressure.

For large breaks, rapid ("crash") steam generator cooldown is effected to reduce the transfer of heat from the steam generator secondary side to the primary coolant. In the steady-state emergency core cooling period, the steam generators provide a long-term heat sink for "small" breaks. This is achieved by opening the MSSVs. Water to the steam generators is supplied by the feedwater system, backed up by the Group 2 feedwater system (FW2).

During the full sequence of emergency core cooling operation, decay heat removal is by transfer of heat to the steam generators or by discharge of fluid through the break. The latter mode predominates for the large breaks. The former mode predominates for small breaks.

Short-term emergency core cooling. The water injected from the accumulator tanks under pressure is directed via the reactor beaders to the fuel channels to refill the core. On low water level in the accumulator tanks, the HPI valves are closed to prevent air from being entrained into the HTS.

While HPI from the accumulator tanks is under way, one of the two emergency core cooling pumps is recirculating water via the bypass loop. If one pump fails to start (indicated by a low pump differential pressure), the standby pump starts automatically. The flow of emergency core coolant from the grade level tank via the emergency core cooling pumps begins when the pressure downstream of the check valves falls below the pressure generated by the pumps.

Long-term emergency core cooling operations. The lowpressure operation starts following the short-term injection reactor building sump stage. A triplicated, high-level signal in the reactor building sump or a triplicated low-level signal in the ECCS grade level tank initiates opening of the cooling water valves to the emergency core cooling heat exchanger and the recovery line isolation valves to the reactor building sump. The low-level signal in the grade level tank closes the valves in the pump suction line from the tank. The mixture of the heat transport coolant and water from the emergency core cooling tanks collected on the floor and sump of the reactor building is then returned to the HTS by the emergency core cooling pumps. For large breaks, decay heat is removed from the core via the coolant discharged from the break, and this heat is transferred to the recirculated cooling water (or the Group 2 raw service water as a backup) via the heat exchanger.

For small breaks, decay heat is transferred to the steam generators and rejected via the MSSVs. These valves have a total capacity of over $100 \%$ steam flow at normal steam generator pressure.

The steam generator feedwater supply during operation after a loss of coolant is provided by the main feedwater 
pumps on Class IV power or by the auxiliary feed pump, which draws water from the deaerator and the demineralized water storage tank. An alternative source of feedwater to the steam generators is provided by the FW2. The feedwater to the steam generators is required during the long-term emergency core cooling operation following a small break.

\section{A.3.4 Containment System}

\section{A.3.4.1 System Functional Requirements}

The basic function of the containment system is to form a continuous, pressure-confining envelope about the reactor core and HTS to limit the release of radioactive material resulting from an accident to the external environment. This accident could be either a failure of fuel cooling or an accident that releases radioactive material into the containment without a rise in containment internal pressure.

To achieve this overall function, the containment system must include the following related safety functions:

1. Isolation: to ensure closure of all openings in containment when an accident occurs.

2. Pressure/activity reduction: to control and assist in reducing the internal pressure and free radioactive material released into containment by an accident.

3. Hydrogen control: to limit concentrations of hydrogen/deuterium within containment after an accident to prevent detonation or deflagration.

4. Monitoring: to monitor conditions within containment and the status of containment equipment before, during, and after an accident.

In addition to its safety role, the containment structure also serves the following functions:

1. To limit the release of radioactive materials from the reactor to the environment during normal operations.

2. To provide external shielding against radiation sources within containment during normal operations and after an accident.

3. To protect reactor systems against external events such as tornados, floods, etc.

\section{A.3.4.2 Design Basis}

The containment system complies with AECB Regulatory Document R-7, "Requirements for Containment Systems for CANDU Nuclear Power Plants."* The design pressure for the containment is the maximum building pressure resulting from any failure of the HTS coupled with unavailability of the most effective active pressure reduction system.

The containment design pressure may be exceeded during a secondary-side failure (e.g., a main steam-main break), provided that no structural damage to containment (cracking) results.

The maximum leakage rate (used in safety analyses) is $5 \%$ of containment free volume per day at the design pressure. The containment is designed for a test-acceptance leakage rate of $2 \% / d$ at the design pressure.

The containment is designed for an unavailability of not more than $10^{-3}$ year/year ( $<9 \mathrm{~h} /$ year).

Test facilities and procedures are provided to confirm that the containment system (including required safety support systems) operates when required and to demonstrate the reliability of the system.

The containment envelope, including the containment isolation devices, for example, in the reactor building ventilation system, is seismically qualified for a design basis earthquake.

Control measures are included to limit hydrogen/deuterium content within any significant enclosed subvolume of containment following an accident to below the deflagration limit.

\section{A.3.4.3 System Description}

The containment system includes a reinforced concrete containment structure (the reactor building) with a reinforced concrete dome and an internal steel liner, access airlocks, equipment hatch, building air coolers for pressure reduction, hydrogen deflagration system, ${ }^{\dagger}$ and a containment isolation system consisting of valves or dampers in the ventilation ducts and certain process lines penetrating the containment envelope. The containment envelope

\footnotetext{
"Atomic Energy Control Board, Regulatory Document R7, "Requirements for Containinent Systems for CANDU Nuclear Power Plants," 1987.

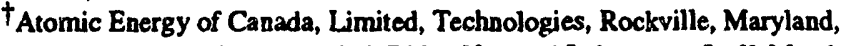
personal communication to Oak Ridge National Laboratory Staff, March 10, 1992.
} 
consists of the building structure, piping and ducts, and airlocks and a batch (see Fig. A.15).

Containment components and subsystems. The containment system comprises the following structures, components, and subsystems:

1. A reinforced concrete containment structure, $1.2 \mathrm{~m}$ thick, with a reinforced concrete dome and base slab, with a 6-mm steel liner covering the inside of the concrete walls, dome, and base slab.

2. Steel pipe and ducting, forming part of the containment boundary where they penetrate containment.

3. Piping and cable penetrations, which provide an engineered seal at the point where piping, ducting, and electric cables penetrate containment.

4. Containment isolation: Dual valves or dampers on process penetrations that are automatically closed on high containment pressure or activity within containment.

5. Airlock, emergency airlock, and equipment hatch.

6. Reactor building air coolers: The air coolers operate during normal plant operation to cool the building and maintain a suitable environment for personnel working within the reactor building. The air coolers are also used to cool the reactor building atmosphere, condense released steam, and thereby reduce containment internal pressure following a failure of the HTS or steam system within containment.

By promoting steam condensation, the air coolers also act to remove soluble radioactive material (except noble gases) from the containment atmosphere and to sweep hydrogen/deuterium buildups from the reactor vault following an accident.

The air coolers operate on Group 1 power and cooling, and because they are not needed more than $24 \mathrm{~h}$ after an accident, are not required to be seismically qualified.

The design basis for the building air coolers is established by normal operational heat loads and postaccident heat removal requirements.

In addition to handling air flow under normal operational conditions, the fan motors for building air coolers operating on Class III power are also rated to handle continuously the steam/water/air mixture and the temperature existing at the design value of overpressure under accident conditions.
7. Hydrogen igniters: Located at the bottom of the steam generators box and in the upper part of the reactor building, to ensure that hydrogen/deuterium releases are ignited at low concentrations (about 6\%), thus ensuring that concentrations sufficient for a detonation or deflagration do not occur.

Instrumentation and monitoring. Containment has the following instrumentation and monitoring capabilities:

1. Containment isolation:

- Pressure and activity measurements (triplicated) required to initiate isolation.

- Status and testing indications on all isolation devices, and airlock seals and doors.

2. Gross leakage monitoring: Measurements of building temperatures, pressure, humidities, and inflows/outflows (plus related computation).

3. Containment systems: Status of and controls over containment subsystems and equipment such as air coolers, hydrogen igniters, etc.

4. Postaccident monitoring: Qualified instrumentation for monitoring containment pressures, temperatures, radioactivity, and hydrogen content before, during, and after an accident.

Associated systems. The reactor building vapor recovery system and ventilation system control the reactor building humidity and airborne activity at low levels during normal operations. They also would be used for long-term postaccident cleanup and plant rehabilitation.

However, these systems are not required to mitigate or limit the consequences of any accident and are not part of the containment system.

\section{A.3.4.4 Operating Modes}

Normal operating conditions. Containment ventilation dampers are all normally open. The pressure within containment is slightly less than atmospheric pressure, with small pressure variations because of operation of the vapor recovery system and pressure balancing within the reactor building.

Off-normal conditions. For extremely small HTS leaks, the vapor recovery system removes moisture, but the relative humidity (dewpoint) may rise slightly.

For very small HTS leaks, the building coolers condense the steam. Building air temperatures may rise slightly. 


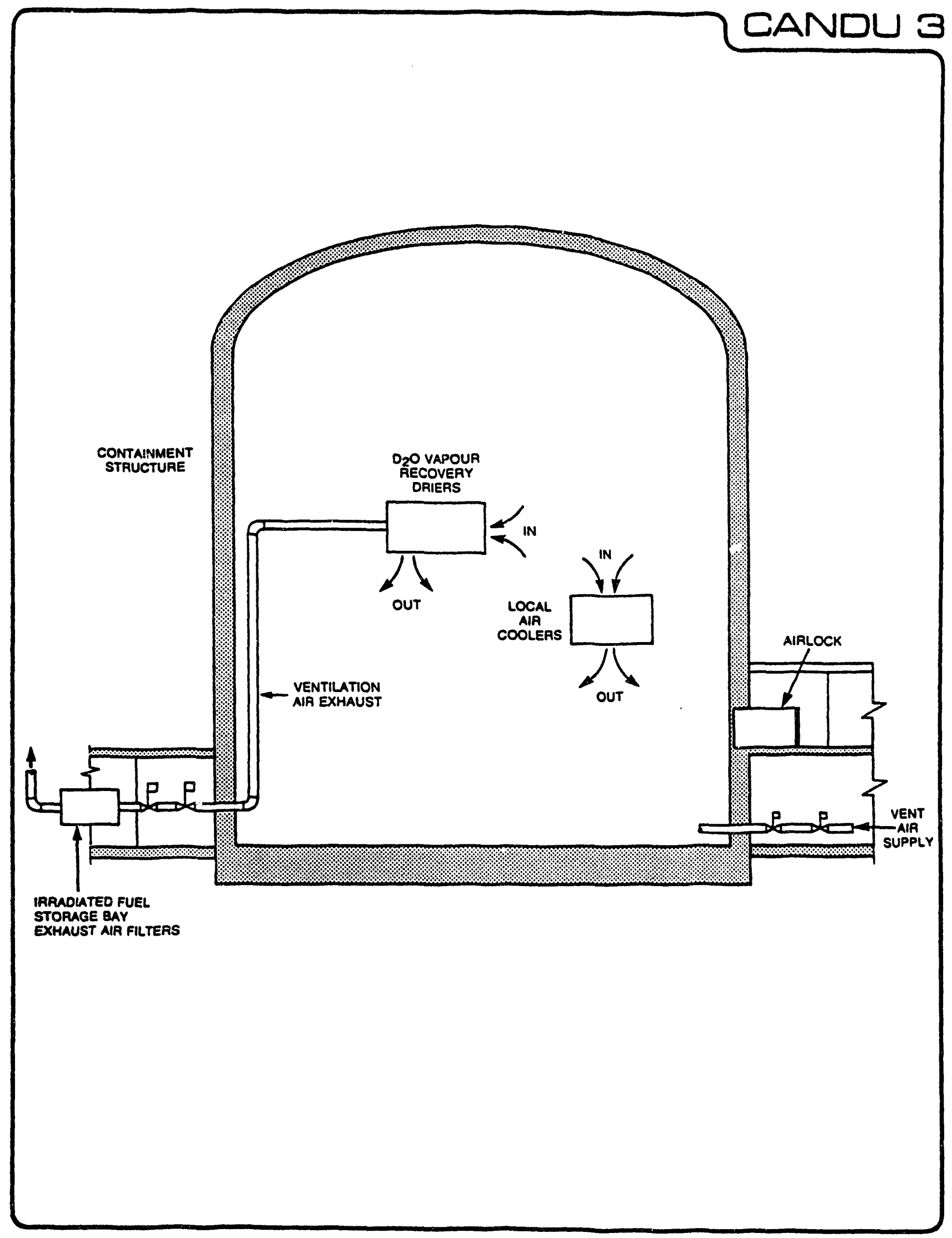

Figure A.15 Reactor containment system 
For larger breaks, building coolers are insufficient to reduce the building pressure following steam ingress. The pressure rises and, at a set overpressure, containment pressure sensors initiate containment closure. Other sensors associated with the reactor cause a reactor trip. The containment is also automatically isolated in the event of a high radioactivity signal, which may or may not occur following a LOCA.

Following a reactor trip, energy is to be removed from the HTS and from within the reactor building by the steam generators, or the shutdown cooling heat exchangers, or the emergency core cooling heat exchangers, depending on the size of the break and the time after shutdown. The reactor building pressure rises to a peak, which depends on the location and size of break. Subsequent pressure reduction is due to condensation on the walls, plus cooling provided by the air coolers.

Initial containment atmosphere cleanup can be performed by the $\mathrm{D}_{2} \mathrm{O}$ vapor recovery dryers. In the long term, the containment envelope may be vented to the atmosphere through the dryers and the reactor building ventilation system filter train.

The $\mathrm{D}_{2} \mathrm{O}$ vapor recovery system can be operated at building overpressures up to the containment design pressure. Discharge through the ventilation system filter train is restricted to near-atmospheric pressure conditions and is a postaccident rehabilitative function.

\section{A.4 Summary of CANDU 3 Design Overview}

The material in this chapter was obtained directly from the CSR $^{1}$ and the Technical Outline. ${ }^{2}$ The depth involved in this condensation was deemed to be sufficient to orient the reader with regard to CANDU 3 design, particularly as it differs from standard U.S. LWR practice, and should be adequate to allow understanding of the rest of this report. However, the reader interested in more details is referred to the original sources.

\section{References}

1. Atomic Energy of Canada, Limited, "CANDU 3 Conceptual Safety Report," Vols. 1 and 2, 1989."

2. Atomic Energy of Canada, Limited, "The CANDU 3 Technical Outline," Rev. 11, June 1992."

\footnotetext{
*Available in NRC PDR for inspection and copying for a fee.
} 


\section{Appendix B \\ System Cut Set Results}

\section{B.1 Presentation of System Cut Set Results}

This section presents the cut sets developed for each system in the analysis. The fault tres were analyzed and the results produced using the Integrated Reliability and Risk Analysis System (IRRAS) Version 4.0 (Ref. 1). Some of the system models are complex and result in a large number of cut sets. In these cases, the repol $\omega$ have been shortened to show oniy those cut sets with three or less failures. The system results are presented in ths same order as in Chap. 5. Table B.1 presunts a legend for identifying the equipment represented by the basic event designators.

Table B.2 presents the system cut set results.

\section{B.2 Discussion of System Cut Seí Results}

The fault tree analysis identifies potential failure mechanisms in the sys. ${ }^{*} . \mathrm{s}$ used to mitigate accident scenarios. The fault trees wure constructed using the available information, and they reflect the analyst's understanding of how the systems are intended to function. This section presents a discussion of important results from the fault tree analysis.

\section{B.2.1 Reactor Reguidting System}

The reactor reg slating system (RRS) controls reacior power fluctua' ions during normal reaclor power operations. Three potential single failures were ia entified for the RRS. These included potential failure of the operator to initiate RRS, possible mechanical bindin's of the RRS control absorbers, and possible failure of the absorber coils to release.

\section{B.2.2 Shutdown System 1}

Shutdown System 1 (SDS1) is a special safety system that requires a reliability of $1 \times 10^{-3}$ with no single failures. The fault tree model resulted in two potential single failures identified. These potential single failures involve mechanical binding of shut-off rods or failure of rod coils to release. There would have to be a failure of at least three rods or coils since the system is designed for success even if the two most effective rods are unavailable. Failures of this sort would most likely be common-mode failures.

\section{B.2.3 Shutdown System 2}

Shutdown System 2 (SDS2) is also a special safety system. For SDS2, no potential single point failures were identified.

\section{B.2.4 Moderator Liquid Poison}

The moderator liquid poison system (NLP) is used in failure to shutdown (FTSD) sequences. The MIP for the most part is a passive gravity-fed system. All icientified potential MLP failures were single failures, including failure of the operator to actuate the system.

\section{B.2.5 Group 1 Feedwater System}

No single failure mechanisms were identified for the Group 1 feedwater system (FW1). FW1 does depend on plant air; if plant air is lost and not restored within $1.5 \mathrm{~h}$, the FW 1 boiler level control valves will fail closed.

\section{B.2.6 Group 2 Feedwater}

No potential single failure mechanisms were identified for the Group 2 feedwater system (FW2). Except for failure of the plant control system (PCS) to supply an initiation signal to FW2, all FW2 iailures required at least two component failures. A potential operaior failure to supply makeup water to the supply tank, coupled with a tank level indicator failure, could disable FW2. The supply tank has a 10-h supply and therefore must be refilled when the tank is emptied.

\section{B.2.7 Auxiliary Feedwater}

T.. \& auxiliary feedwater system (AFW) is a very simple system consisting of a diesel-driven pump and a discharge valve. Three potential single failures were identified for the AFW. These include pump failure due to loss of diesel power, mechanical pump failure, and failure of the AFW discharge valve to open.

\section{B.2.8 Heat Transport System}

The heat transport system (HTS) fault tree is only used in this report for large-break loss-of-coolant analyses. The present HTS design includes four HTS pumps, each of which feeds one-fourth of the CANDU 3 fuel channels. Mechanical failure of any of these pumps would constitute a single failure, since insufficient cooling of one-fourth of 


\section{Appendix B}

the fuel channels would occur. HTS pump failure could also occur due to loss of Class IV power (LOP).

\section{B.2.9 Condenser Steam Discharge Valves}

The primary observation for the condenser steam discharge valves (CSDs) is that they require plant air to operate. The CSDs could also fail if the plant control system, which would scnd the signals to actuate the valves, fails. No sinsle point failures were identified for the CSDs.

\section{B.2.10 Atmospheric Steam Discharge Valves}

The atmospheric steam discharge valves (ASDs) are used to remove heat from the main steam system when the condenser is not available. The comments made above for the CSDs hold for the ASDs. Failure of plant air, then, represents a potential common-mode failure mechanism for the ASDs and CSDs.

\section{B.2.11 Shutdown Cooling System}

The shutdown cooling system (SDC) is a manually initiated system. Human error to initiate the system was the main contributor to potential SDC failure. It should be recognized, however, that SDC initiation is expected to be a well-rehearsed event.

\section{B.2.12 Moderator Cooling System}

The moderator cooling system (MCS) is used as the last line of defense for heat removal from the CANDU 3 fuel channels. The MCS fault tree analysis identified three potential single failures and three potential system-related failures. The single failures are failure of the MCS isolation valve to close and failure of either of the MCS pumps. The system failures are failure of even or odd Group 1 Class III power or failure of the recirculating cooling water (RCW).

\section{B.2.13 Emergency Core Cooling System}

The overall emergency core cooling system (ECCS) [highpressure injection (HPD), low-pressure injection (LPI), and ECC recirculation (REC)] is a special safety system and therefore requires a reliability of $1 \times 10^{-3}$ with no single failures. The fault tree analysis identified no potential single point failures for HPI, LPI, and REC. All other ECCS cut sets involve either ECCS signal failure or potential failures of at least two pieces of equipment.

\section{B.2.14 Bleed Condenser System}

The fault tree analysis for bleed condenser system (BCS) suggests that the support systems are an important contributor to failure to bottle the bleed condenser. The $\mathrm{D}_{2} \mathrm{O}$ tank level control valve and one of the two bleed condenser level control valves are assumed to be supplied from Group 1 Class II power. Therefore, electric power support could result in a failure to isolate the bleed condenser. Loss of signal from the PCS could also directly result in BCS failure.

\section{B.2.15 Steam Generator Isolation}

The fault tree analysis for steam generator isolation (ISO) suggests three potential single failures and two potential system failure mechanisms. The potential single failures include failure of the operator to isolate the flow, isolation valve signal failure, and failure of the isolation valve to close. The isolation valve is air-operated and fails open on loss of air or Group 2 Class I power.

\section{B.2.16 Liquid Relief Valve Closure}

The fault tree analysis identified two potential single failures and three system failures that influence liquid relief valve closure (LRC). Both liquid relief valves must close to avoid losing inventory from the primary system. Mechanical failure of either of the valves would result in LRC failure. These valves also require air and Group 2 Class I power for closure. This means that failure of the air system or loss of Group 2 Class I power would result in failure of the LRC. Finally, LRC failure could result from loss of signal from the PCS.

\section{B.2.17 Crash Cooling}

No potential single failure mechanisms were identified for the crash cooling (CC) system. Support system failures that could lead to CC failure are failure of plant air, failure of Group 2 Class II power, and failure of main steam safety valves (MSSVs) to receive an initiation signal from the ECCS.

\section{B.2.18 Main Steam Safety Valves}

The fault tree analysis did not identify any potential single failure mechanisms for the main steam safety valves (MSSVs). All cut sets involved failure of pairs of MSSVs. 


\section{B.2.19 Emergency Generators}

The diesel generators were not modeled in detail since little information was available regarding the diesel generator design.

\section{Reference}

1. K. D. Russell et al., Idaho National Engineering Laboratory, Integrated Reliability and Risk Analysis System, USNRC Report NUREG/CR-5813, ID 83415, January $1992 .{ }^{*}$

\footnotetext{
*Available from National Technical Information Service, Springfield, VA 22161.
} 
Appendix B

Table B.1 Basic event designator descriptions

Code

\section{Systems}

F-

F-AFW

F-BCS

F-CON

F-D2O

F-FW1

F-FW2

F-GEN

F-HPI

F-HTS

F-LPI

F-LRC

F-LRO

F-MCS

F-MLP

F-MSV

F-REC

F-RRS

F-SD1

F-SD2

F-SDC

$S$ -

S-ECC

S-EL

S-FIW

S-AIR

S-PCS

S-RCW

S-RSW

S-SW2

\section{Components}

\section{Code description}

front-line systems

auxiliary feedwater system

bleed condenser isolation

steam dump

$\mathrm{D}_{2} \mathrm{O}$ makeup system

group 1 feedwater system

group 2 feedwater system

backup diesel generator power

high-pressure injection mode of ECCS

heat transport system

low-pressure injection mode of ECCS

liquid relief valves close

liquid relief valves open

moderator cooling system

moderator liquid poison system

main steam safety valves

recirculation mode of ECCS

reactor regulating system

shutdown system 1

shutdown system 2

shutdown cooling system

support systems

ECCS control system

electric power systems

fire water system

plant air system

plant control system

recirculated cooling water system

group 1 raw service water system

group 2 raw service water system

$\begin{array}{ll}\text { ASA } & \text { alternate sensor A } \\ \text { ASB } & \text { alternate sensor B } \\ \text { ATA } & \text { alternate transmitter A } \\ \text { ATB } & \text { alternate transmitter B } \\ \text { CI } & \text { conductivity indicator } \\ \text { CR } & \text { control rod (shutdown rod) } \\ \text { DIESEL } & \text { diesel motor } \\ \text { FV } & \text { flow valve }\end{array}$




\section{Components}

$\begin{array}{ll}\text { ASD\# } & \text { atmospheric steam discharge valve (with designator) } \\ \text { BV } & \text { bypass valve } \\ \text { CNV } & \text { control or regulating valve } \\ \text { CV } & \text { check valve } \\ \text { D2LV } & \text { D O level control valve } \\ \text { DISV } & \text { discharge valve } \\ \text { DV } & \text { drain valve } \\ \text { HE } & \text { human error (operator error) } \\ \text { HX\# } & \text { heat exchanger (with designator) } \\ \text { IISV } & \text { inlet isolation valve } \\ \text { INV } & \text { injection valve } \\ \text { ISV\# } & \text { isolation valve (with designator) } \\ \text { IV } & \text { inlet valve } \\ \text { LA } & \text { level alarm } \\ \text { LI } & \text { level indicator } \\ \text { MSSV\# } & \text { main steam safety valve (with designator) } \\ \text { OISV } & \text { outlet isolation valve } \\ \text { OV } & \text { outlet valve } \\ \text { PI } & \text { pressure indicator } \\ \text { PIPE } & \text { pipe or header } \\ \text { PMP\# } & \text { pump (with designator) } \\ \text { PS } & \text { primary sensor } \\ \text { PT } & \text { primary transmitter } \\ \text { PT\# } & \text { poison tank (with designator) } \\ \text { REL\# } & \text { relay (with designator) } \\ \text { RESPOWR } & \text { onsite power restored } \\ \text { RSS } & \text { recirculating sampling system } \\ \text { SDV\# } & \text { steam discharge valve (with designator) } \\ \text { SIG } & \text { signal fault } \\ \text { SIG-LP-HTS } & \text { low pressure in heat transport system signal } \\ \text { SIG-HP-RBL } & \text { high pressure in reactor building signal } \\ \text { SIG-LI-PSZ } & \text { low level in pressurizer signal } \\ \text { SIG-SD2 } & \text { SDS2 initiation signal } \\ \text { SIG-SGP } & \text { high steam generator pressure signal } \\ \text { SG\# } & \text { steam generator (with designator) } \\ \text { SV } & \text { suction valve } \\ \text { TC } & \text { trip computer } \\ \text { TL } & \text { trip logic } \\ \text { TK } & \\ \text { V\# or VLV\# } & \text { valve (with designator) } \\ \text { WV\# } & \\ & \end{array}$


Appendix B

Table B.1 (cont.)

\section{Failure modes}

BD

$\mathrm{BR}$ or $\mathrm{BK}$

mechanical binding

CG

CM

COIL

CONC

FC

FO

LEVEL

break or rupture

clog (flow restriction)

common mode

coil fails to release

improper concentration

fails closed (fails to open)

fails open (fails to close)

improper level

\section{Function}

Cl

coolant injection (high-pressure ECCS)

Gl

gas injection (high-pressure ECCS)

\section{Electric power designator}

$\begin{array}{ll}\text { I } & \text { Class I } \\ \text { II } & \text { Class II } \\ \text { III } & \text { Class III } \\ \text { IV } & \text { Class IV } \\ 1 & \text { Group 1 } \\ 2 & \text { Group 2 } \\ \text { O } & \text { Odd bus } \\ \text { E } & \text { Even bus }\end{array}$


System: RRS

\begin{tabular}{ccl} 
Cut & & \\
No. & Size & CUT SETS \\
\hline 1 & 1 & F-RRS-HE \\
2 & 1 & F-RRS-CR-BD \\
3 & 1 & F-RRS-CR-COIL \\
4 & 2 & F-RRS-O, F-RRS-E
\end{tabular}

System: SD1

\begin{tabular}{rll}
$\begin{aligned} \text { Cut } \\
\text { No. }\end{aligned}$ & Size & CUT SETS \\
\hline 1 & 1 & F-SD1-CR-BD-CM \\
2 & 1 & F-SD1-CR-COIL-CM \\
3 & 2 & F-SD1-TC-D, F-SD1-TC-E \\
4 & 2 & F-SD1-TC-D, F-SD1-TC-F \\
5 & 2 & F-SD1-TC-E, F-SD1-TC-F \\
6 & 2 & F-SD1-TLA-REL1, F-SD1-TLA-REL2 \\
7 & 2 & F-SD1-TLA-REL1, F-SD1-TLA-REL3 \\
8 & 2 & F-SD1-TLA-REL2, F-SD1-TLA-REL3 \\
9 & 2 & F-SD1-TLB-REL1, F-SD1-TLB-REL2 \\
10 & 2 & F-SD1-TLB-REL1, F-SD1-TLB-REL3 \\
11 & 2 & F-SD1-TLB-REL2, F-SD1-TLB-REL3
\end{tabular}

System: SD2

\begin{tabular}{ccl}
$\begin{array}{c}\text { Cut } \\
\text { No. }\end{array}$ & Size & CUT SETS \\
\hline 1 & 2 & F-SD2-ISV1-PT1, F-SD2-ISV1-PT2 \\
2 & 2 & F-SD2-ISV1-PT1, F-SD2-ISV1-PT3 \\
3 & 2 & F-SD2-ISV1-PT1, F-SD2-ISV1-PT4 \\
4 & 2 & F-SD2-ISV1-PT1, F-SD2-ISV1-PT5 \\
5 & 2 & F-SD2-ISV1-PT1, F-SD2-ISV1-PT6 \\
6 & 2 & F-SD2-ISV1-PT1, F-SD2-ISV2-PT2 \\
7 & 2 & F-SD2-ISV1-PT1, F-SD2-ISV2-PT3 \\
8 & 2 & F-SD2-ISV1-PT1, F-SD2-ISV2-PT4 \\
9 & 2 & F-SD2-ISV1-PT1, F-SD2-ISV2-PT5
\end{tabular}


Table B.2 (cont.)

\begin{tabular}{lll}
\hline 10 & 2 & F-SD2-ISV1-PT1, F-SD2-ISV2-PT6 \\
11 & 2 & F-SD2-ISV1-PT2, F-SD2-ISV1-PT3 \\
12 & 2 & F-SD2-ISV1-PT2, F-SD2-ISV1-PT4 \\
13 & 2 & F-SD2-ISV1-PT2, F-SD2-ISV1-PT5 \\
14 & 2 & F-SD2-ISV1-PT2, F-SD2-ISV1-PT6 \\
15 & 2 & F-SD2-ISV1-PT2, F-SD2-ISV2-PT1 \\
16 & 2 & F-SD2-ISV1-PT2, F-SD2-ISV2-PT3 \\
17 & 2 & F-SD2-ISV1-PT2, F-SD2-ISV2-PT4 \\
18 & 2 & F-SD2-ISV1-PT2, F-SD2-ISV2-PT5 \\
19 & 2 & F-SD2-ISV1-PT2, F-SD2-ISV2-PT6 \\
20 & 2 & F-SD2-ISV1-PT3, F-SD2-ISV1-PT4 \\
21 & 2 & F-SD2-ISV1-PT3, F-SD2-ISV1-PT5 \\
22 & 2 & F-SD2-ISV1-PT3, F-SD2-ISV1-PT6 \\
23 & 2 & F-SD2-ISV1-PT3, F-SD2-ISV2-PT1 \\
24 & 2 & F-SD2-ISV1-PT3, F-SD2-ISV2-PT2 \\
25 & 2 & F-SD2-ISV1-PT3, F-SD2-ISV2-PT4 \\
26 & 2 & F-SD2-ISV1-PT3, F-SD2-ISV2-PT5 \\
27 & 2 & F-SD2-ISV1-PT3, F-SD2-ISV2-PT6 \\
28 & 2 & F-SD2-ISV1-PT4, F-SD2-ISV1-PT5 \\
29 & 2 & F-SD2-ISV1-PT4, F-SD2-ISV1-PT6 \\
30 & 2 & F-SD2-ISV1-PT4, F-SD2-ISV2-PT1 \\
31 & 2 & F-SD2-ISV1-PT4, F-SD2-ISV2-PT2 \\
32 & 2 & F-SD2-ISV1-PT4, F-SD2-ISV2-PT3 \\
33 & 2 & F-SD2-ISV1-PT4, F-SD2-ISV2-PT5 \\
34 & 2 & F-SD2-ISV1-PT4, F-SD2-ISV2-PT6 \\
35 & 2 & F-SD2-ISV1-PT5, F-SD2-ISV1-PT6 \\
36 & 2 & F-SD2-ISV1-PT5, F-SD2-ISV2-PT1 \\
37 & 2 & F-SD2-ISV1-PT5, F-SD2-ISV2-PT2 \\
38 & 2 & F-SD2-ISV1-PT5, F-SD2-ISV2-PT3 \\
39 & 2 & F-SD2-ISV1-PT5, F-SD2-ISV2-PT4 \\
40 & 2 & F-SD2-ISV1-PT5, F-SD2-ISV2-PT6 \\
41 & 2 & F-SD2-ISV1-PT6, F-SD2-ISV2-PT1 \\
42 & 2 & F-SD2-ISV1-PT6, F-SD2-ISV2-PT2 \\
43 & 2 & F-SD2-ISV1-PT6, F-SD2-ISV2-PT3 \\
44 & 2 & F-SD2-ISV1-PT6, F-SD2-ISV2-PT4 \\
45 & 2 & F-SD2-ISV1-PT6, F-SD2-ISV2-PT5 \\
46 & 2 & F-SD2-ISV2-PT1, F-SD2-ISV2-PT2 \\
47 & 2 & F-SD2-ISV2-PT1, F-SD2-ISV2-PT3 \\
48 & 2 & F-SD2-ISV2-PT1, F-SD2-ISV2-PT4 \\
49 & 2 & F-SD2-ISV2-PT1, F-SD2-ISV2-PT5 \\
50 & 2 & F-SD2-ISV2-PT1, F-SD2-ISV2-PT6 \\
51 & 2 & F-SD2-ISV2-PT2, F-SD2-ISV2-PT3 \\
53 & 2 & F-SD2-ISV2-PT2, F-SD2-ISV2-PT4 \\
\hline 35 & 2 & F-SD2-ISV2-PT2, F-SD2-ISV2-PT5 \\
& & F-SD2-ISV2-PT3, F-SD2-ISV2-PT4
\end{tabular}


Table B.2 (cont.)

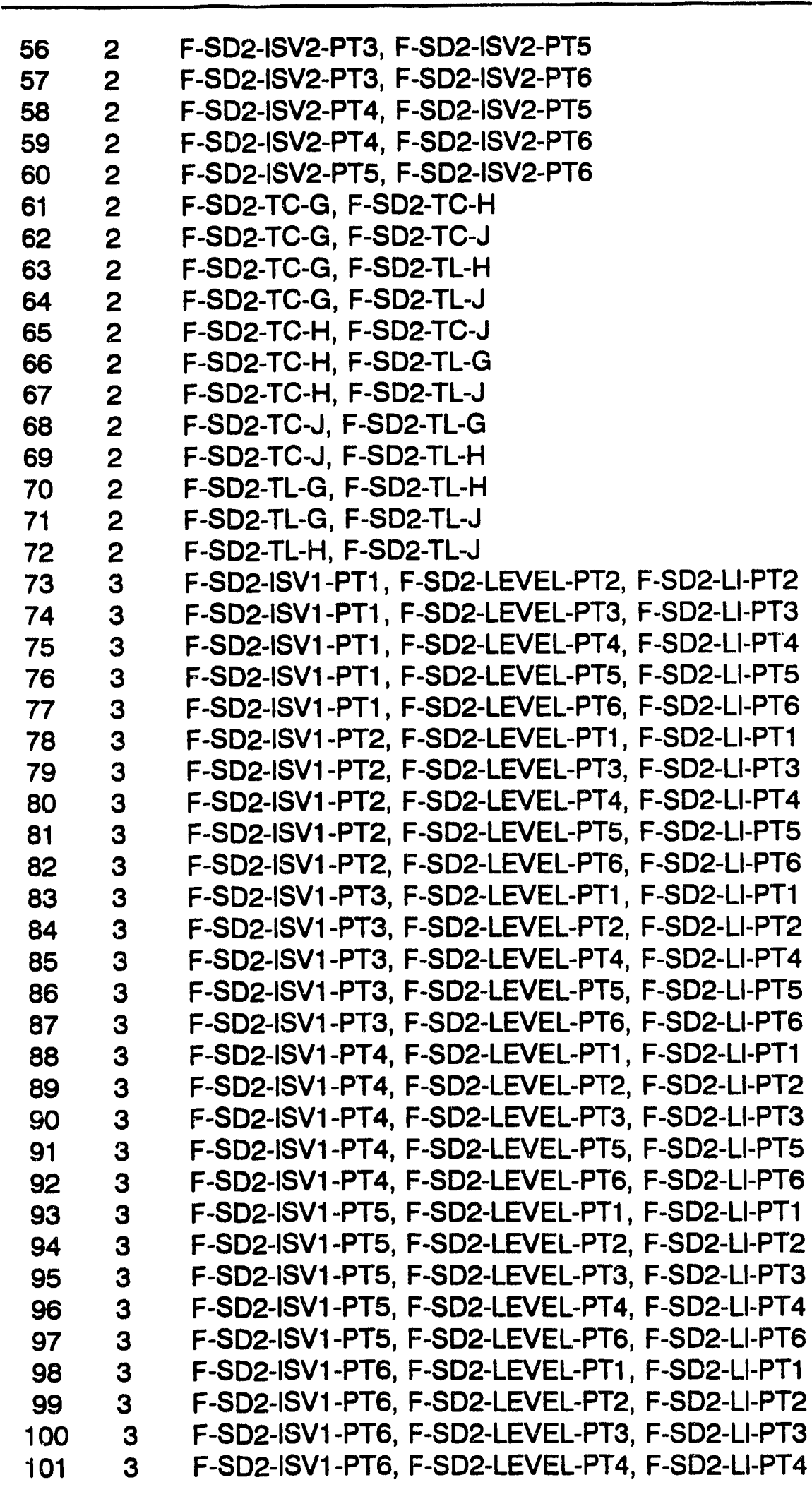


Table B.2 (cont.)

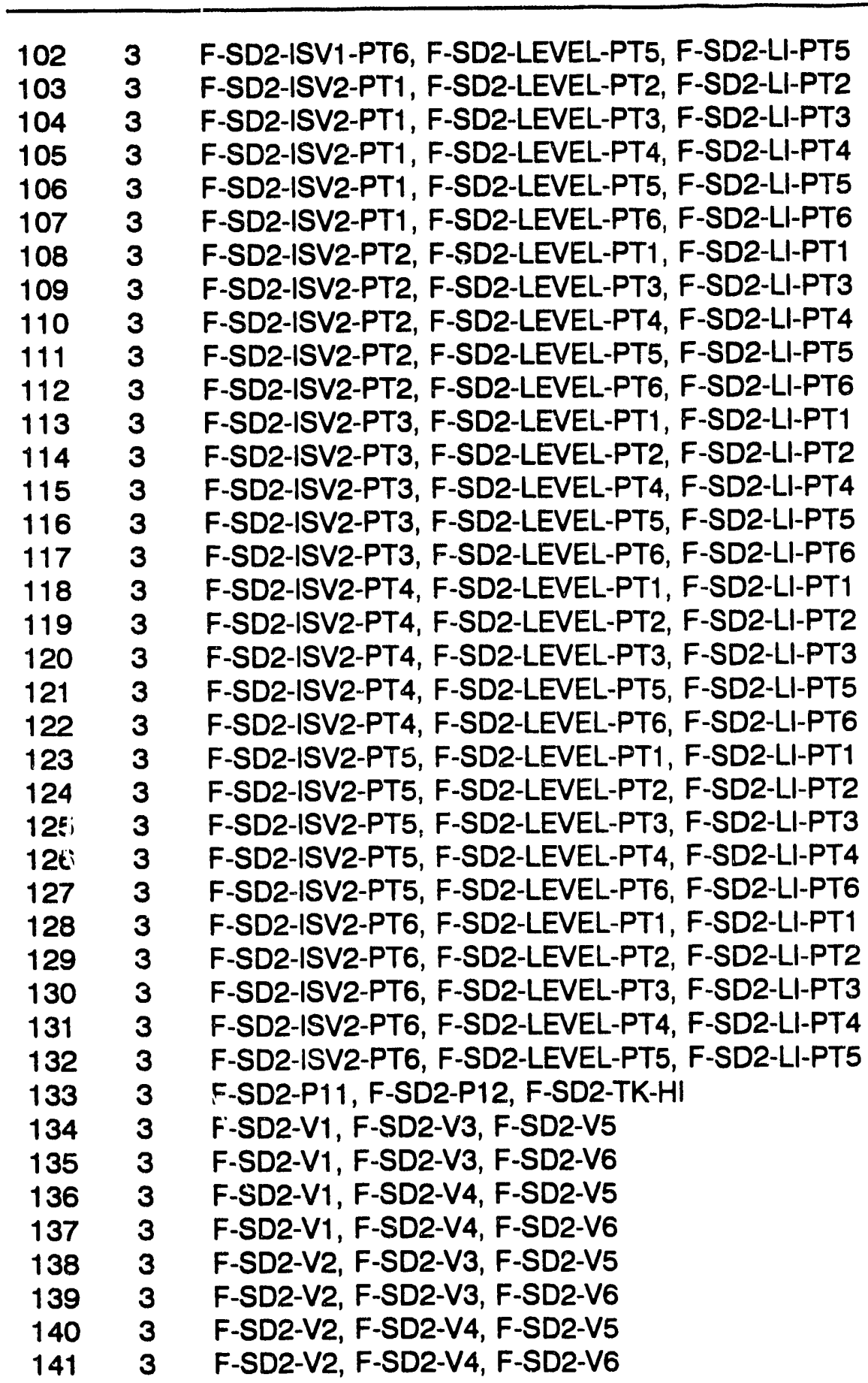


Table B.2 (cont.)

System: MLP

Cut

No. Size CUT SETS

$\begin{array}{lll}1 & 1 & \text { F-MLP-FV } \\ 2 & 1 & \text { F-MLP-HE } \\ 3 & 1 & \text { F-MLP-IV } \\ 4 & 1 & \text { F-MLP-LA }\end{array}$

System: FW1

Cut

No. Size CUT SETS

\begin{tabular}{ccl}
- & - & \\
\hline 1 & 1 & S-AIR \\
2 & 2 & F-FW1-BV, F-FW1-ISV1 \\
3 & 2 & F-FW1-BV, F-FW1-ISV2 \\
4 & 2 & F-FW1-CNV2, S-EL-II-1-O \\
5 & 2 & F-FW1-DV2, S-EL-IV-O \\
6 & 2 & F-FW1-HE, S-RCW \\
7 & 2 & F-FW1-ISV1, S-EL-II-1-O \\
8 & 2 & F-FW1-ISV1, S-PCS \\
9 & 2 & F-FW1-ISV2, S-EL-II-1-O \\
10 & 2 & F-FW1-ISV2, S-PCS \\
11 & 2 & F-FW1-PMP2, S-EL-IV-O \\
12 & 2 & S-EL-II-1-E, S-EL-II-1-O \\
13 & 2 & S-EL-IV-E, S-EL-IV-O \\
14 & 2 & S-FWW, S-RCW \\
15 & 3 & F-FW1-CNV1, F-FW1-CNV2, F-FW1-CNV3 \\
16 & 3 & F-FW1-CNV1, F-FW1-CNV2, S-PCS \\
17 & 3 & F-FW1-CNV1, F-FW1-CNV3, S-EL-II-1-E \\
18 & 3 & F-FW1-CNV1, S-EL-II-1-E, S-PCS \\
19 & 3 & F-FW1-DV1, F-FW1-DV2, F-FW1-DV3 \\
20 & 3 & F-FW1-DV1, F-FW1-DV2, F-FW1-PMP3 \\
21 & 3 & F-FW1-DV1, F-FW1-DV2, S-PCS \\
22 & 3 & F-FW1-DV1, F-FW1-DV3, F-FW1-PMP2 \\
23 & 3 & F-FW1-DV1, F-FW1-DV3, S-EL-IV-E \\
24 & 3 & F-FW1-DV1, F-FW1-PMP2, F-FW1-PMP3 \\
25 & 3 & F-FW1-DV1, F-FW1-PMP2, S-PCS \\
26 & 3 & F-FW1-DV1, F-FW1-PMP3, S-EL-IV-E \\
27 & 3 & F-FW1-DV1, S-EL-IV-E, S-PCS \\
28 & 3 & F-FW1-DV2, F-FW1-DV3, F-FW1-PMP1 \\
& &
\end{tabular}


Table B.2 (cont.)

\begin{tabular}{lll}
\hline 29 & 3 & F-FW1-DV2, F-FW1-PMP1, F-FW1-PMP3 \\
30 & 3 & F-FW1-DV2, F-FW1-PMP1, S-PCS \\
31 & 3 & F-FW1-DV3, F-FW1-PMP1, F-FW1-PMP2 \\
32 & 3 & F-FW1-DV3, F-FW1-PMP1, S-EL-IV-E \\
33 & 3 & F-FW1-PMP1, F-FW1-PMP2, F-FW1-PMP3 \\
34 & 3 & F-FW1-PMP1, F-FW1-PMP2, S-PCS \\
35 & 3 & F-FW1-PMP1, F-FW1-PMP3, S-EL-IV-E \\
36 & 3 & F-FW1-PMP1, S-EL-IV-E, S-PCS
\end{tabular}

System: FW2

\begin{tabular}{ccl} 
Cut & & \\
No. & Size & CUT SETS \\
\hline 1 & 1 & S-PCS \\
2 & 2 & F-FW2-HE, F-FW2-LI-TK \\
3 & 2 & F-FW2-IV1, F-FW2-IV2 \\
4 & 2 & F-FW2-IV1, F-FW2-OV2 \\
5 & 2 & F-FW2-IV1, F-FW2-PMP2 \\
6 & 2 & F-FW2-IV1, S-EL-III-2-E \\
7 & 2 & F-FW2-IV2, F-FW2-OV1 \\
8 & 2 & F-FW2-IV2, F-FW2-PMP1 \\
9 & 2 & F-FW2-IV2, S-EL-III-2-O \\
10 & 2 & F-FW2-OV1, F-FW2-OV2 \\
11 & 2 & F-FW2-OV1, F-FW2-PMP2 \\
12 & 2 & F-FW2-OV1, S-EL-III-2-E \\
13 & 2 & F-FW2-OV2, F-FW2-PMP1 \\
14 & 2 & F-FW2-OV2, S-EL-III-2-O \\
15 & 2 & F-FW2-PMP1, F-FW2-PMP2 \\
16 & 2 & F-FW2-PMP1, S-EL-III-2-E \\
17 & 2 & F-FW2-PMP2, S-EL-II-2-O \\
18 & 2 & S-EL-II-2-E, S-EL-II-2-O \\
19 & 2 & S-EL-III-2-E, S-EL-III-2-O \\
20 & 3 & F-FW2-ISV1-SG1, F-FW2-ISV1-SG2, S-EL-II-2-E \\
21 & 3 & F-FW2-ISV2-SG1, F-FW2-ISV2-SG2, S-EL-II-2-O
\end{tabular}


Table B.2 (cont.)

\section{System: AFW}

\begin{tabular}{ccl} 
Cut & & \\
No. & Size & CUT SETS \\
\hline 1 & 1 & F-AFW-DIESEL \\
2 & 1 & F-AFW-DV \\
3 & 1 & F-AFW-PMP \\
4 & 1 & S-PCS
\end{tabular}

System: HTS

\begin{tabular}{ccl} 
Cut & & \\
No. & Size & CUT SETS \\
\hline 1 & 1 & F-HTS-PMP1 \\
2 & 1 & F-HTS-PMP2 \\
3 & 1 & F-HTS-PMP3 \\
4 & 1 & F-HTS-PMP4 \\
5 & 1 & S-EL-IV-E \\
6 & 1 & S-EL-IV-O
\end{tabular}

System: CSD

\begin{tabular}{ccl}
$\begin{array}{c}\text { Cut } \\
\text { No. }\end{array}$ & Si_e & CUT SETS \\
\hline 1 & 1 & S-AIR \\
2 & 1 & S-PCS \\
3 & 2 & F-CSD-SDV1, F-CSD-SDV2 \\
4 & 2 & F-CSD-SDV1, S-EL-II-2-E \\
5 & 2 & F-CSD-SDV2, S-EL-II-2-O \\
6 & 2 & F-CSD-SDV3, F-CSD-SDV4 \\
7 & 2 & F-CSD-SDV3, S-EL- II-2-E \\
8 & 2 & F-CSD-SDV4, S-EL- II-2-O \\
9 & 2 & S-EL-II-2-O, S-EL-II-2-E
\end{tabular}


Table B.2 (cont.)

System: ASD

\begin{tabular}{ccl} 
Cut & & \\
No. & Size & CUT SETS \\
\hdashline 1 & -1 & S-AIR \\
2 & 1 & S-PCS \\
3 & 2 & F-ASD-ASD1, F-ASD-ASD2 \\
4 & 2 & F-ASD-ASD1, S-EL-II-2-E \\
5 & 2 & F-ASD-ASD2, S-EL-II-2-O \\
6 & 2 & S-EL-II-2-E, S-EL-II-2-O
\end{tabular}

System: SDC

\begin{tabular}{ccl} 
Cut & & \\
No. & Size & CUT SETS \\
\hline 1 & 1 & F-SDC-HE \\
2 & 1 & S-PCS \\
3 & 2 & F-SDC-HX1, F-SDC-HX2 \\
4 & 2 & F-SDC-HX1, S-RCW \\
5 & 2 & F-SDC-IISV1, F-SDC-IISV2 \\
6 & 2 & F-SDC-IISV1, S-EL-II-2-E \\
7 & 2 & F-SDC-IISV2, S-EL-II-2-O \\
8 & 2 & F-SDC-OISV1, F-SDC-OISV2 \\
9 & 2 & F-SDC-OISV1, S-EL-II-2-E \\
10 & 2 & F-SDC-OISV2, S-EL- II-2-O \\
11 & 2 & F-SDC-PMP1, F-SDC-PMP2 \\
12 & 2 & F-SDC-PMP1, S-EL-II-2-E \\
13 & 2 & F-SDC-PMP2, S-EL-III-2-O \\
14 & 2 & S-EL-II-2-E, S-EL- II-2-O \\
15 & 2 & S-EL-II-2-E, S-EL-III-2-O \\
16 & 2 & S-RCW, S-SW2
\end{tabular}




\section{System: MCS}

\begin{tabular}{ccl}
$\begin{array}{ccl}\text { Cut } \\
\text { No. }\end{array}$ & Size & CUT SETS \\
\hline 1 & -1 & F-MCS-ISV-FC \\
2 & 1 & F-MCS-PMP1 \\
3 & 1 & EMCS-PMP2 \\
4 & 1 & S-EL-III-1-E \\
5 & 1 & S-EL-III-1-O \\
6 & 1 & S-RCW
\end{tabular}

System: HPI

Cut

No. Size CUT SETS

\begin{tabular}{ccl}
\hline 1 & 1 & \\
2 & 2 & S-ECC \\
3 & 2 & F-HPI-INV1, F-HPI-INV2 \\
4 & 2 & F-HPI-INV1, S-EL-II-2-E \\
5 & 2 & F-HPI-INV1A, S-HPI-INV1B \\
6 & 2 & F-HPI-INV1B, S-EL-II-2-O \\
7 & 2 & F-HPI-INV2, S-EL-II-2-O \\
8 & 2 & F-HPI-INV2A, F-HPI-INV2B \\
9 & 2 & F-HPI-INV2A, S-EL-II-2-E \\
10 & 2 & F-HPI-INV2B, S-EL-II-2-O \\
11 & 2 & F-HPI-ISV1-GI, F-HPI-ISV2-GI \\
12 & 2 & F-HPI-ISV1-GI, S-EL-II-2-E \\
13 & 2 & F-HPI-ISV2-GI, S-EL-II-2-O \\
14 & 2 & F-HPI-LI-CITK, F-HPI-TK-CI \\
15 & 2 & F-HPI-OV1A, F-HPI-OV1B \\
16 & 2 & F-HPI-OV1A, S-EL-II-2-E \\
17 & 2 & F-HPI-OV1B, S-EL-II-2-O \\
18 & 2 & F-HPI-OV2A, F-HPI-OV2B \\
19 & 2 & F-HPI-OV2A, S-EL-II-2-E \\
20 & 2 & F-HPI-OV2B, S-EL-II-2-O \\
21 & 2 & F-HPI-PI-GI-TK, F-HPI-TK-GI \\
22 & 2 & F-HPI-SIG1-LPHTS, F-HPI-SIG2-LPHTS \\
23 & 2 & F-HPI-SIG1-LPHTS, F-HPI-SIG3-LPHTS \\
24 & 2 & F-HPI-SIG2-LPHTS, F-HPI-SIG3-LPHTS \\
25 & 2 & S-EL-II-2-E, S-EL-II-2-O
\end{tabular}


Appendix B

Table B.2 (cont.)

System: LPI

\begin{tabular}{rrl} 
Cut & & \\
No. & Size & CUT SETS \\
\hline 1 & 1 & S-ECC \\
2 & 2 & F-HPI-ISV1-GI, F-HPI-ISV2-GI \\
3 & 2 & F-HPI-ISV1-GI, S-EL-III-2-E \\
4 & 2 & F-HPI-ISV2-GI, S-EL-III-2-O \\
5 & 2 & F-LPI-INV1, F-LPI-INV2 \\
6 & 2 & F-LPI-INV1, S-EL-III-2-E \\
7 & 2 & F-LPI-INV2, S-EL-III-2-O \\
8 & 2 & F-LPI-ISV1, F-LPI-ISV2 \\
9 & 2 & F-LPI-ISV1, S-EL-III-2-E \\
10 & 2 & F-LPI-ISV2, S-EL-III-2-O \\
11 & 2 & F-LPI-LI-TK, F-LPI-TK \\
12 & 2 & F-LPI-PMP1, F-LPI-PMP2 \\
13 & 2 & F-LPI-PMP1, S-EL-III-2-E \\
14 & 2 & F-LPI-PMP2, S-EL-III-2-O \\
15 & 2 & S-EL-III-2-E, S-EL-III-2-O
\end{tabular}

System: REC

\begin{tabular}{ccl}
$\begin{array}{c}\text { Cut } \\
\text { No. }\end{array}$ & Size & CUT SETS \\
\hline 1 & 1 & S-ECC \\
2 & 2 & F-LPI-ISV1, F-LPI-ISV2 \\
3 & 2 & F-LPI-ISV1, S-EL-III-2-E \\
4 & 2 & F-LPI-ISV2, S-EL-III-2-O \\
5 & 2 & F-REC-HX1, F-REC-HX2 \\
6 & 2 & F-REC-ISV1, F-REC-ISV2 \\
7 & 2 & F-REC-ISV1, S-EL-III-2-E \\
8 & 2 & F-REC-ISV2, S-EL-III-2-O \\
9 & 2 & S-EL-III-2-E, S-EL-III-2-O \\
10 & 2 & S-RCW, S-SW2
\end{tabular}




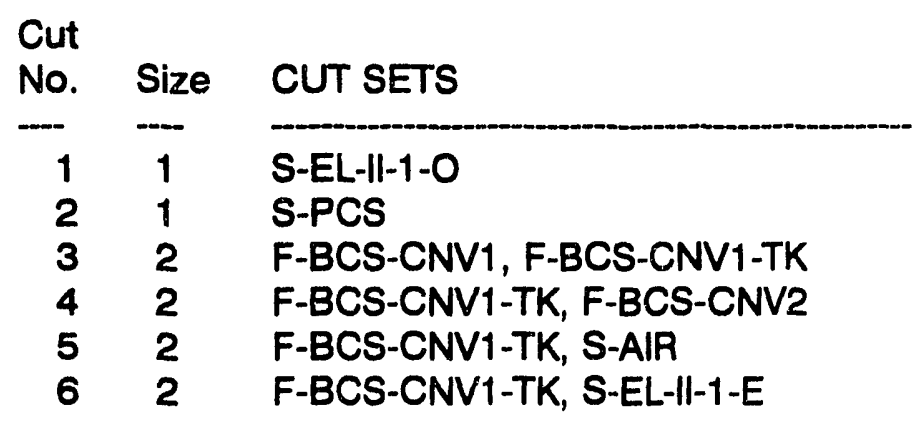

System: ISO

\begin{tabular}{ccl} 
Cut & & \\
No. & Size & CUT SETS \\
\hline 1 & 1 & F-ISO-HE \\
2 & 1 & F-ISO-SIG \\
3 & 1 & F-ISO-VLV-FO \\
4 & 1 & S-AIR \\
5 & 1 & S-EL-II-1-O
\end{tabular}

System: LRC

\begin{tabular}{ccl}
$\begin{array}{c}\text { Cut } \\
\text { No. }\end{array}$ & Size & CUT SETS \\
\hline 1 & 1 & F-LRC-VLV1 \\
2 & 1 & F-LRC-VLV2 \\
3 & 1 & S-AIR \\
4 & 1 & S-EL-II-1-E \\
5 & 1 & S-EL-II-1-O \\
6 & 1 & S-PCS
\end{tabular}


Table B.2 (cont.)

System: CC

Cut

No. Size CUT SETS

$\begin{array}{ccl}- & -1 & \text { S-AIR } \\ 2 & 1 & \text { S-ECC } \\ 3 & 1 & \text { S-EL-II-2-E } \\ 4 & 1 & \text { S-EL-II-2-O } \\ 5 & 2 & \text { F-MSV-MSSV1-SG1, F-MSV-MSSV2-SG1 } \\ 6 & 2 & \text { F-MSV-MSSV1-SG1, F-MSV-MSSV3-SG1 } \\ 7 & 2 & \text { F-MSV-MSSV1-SG1, F-MSV-MSSV4-SG1 } \\ 8 & 2 & \text { F-MSV-MSSV1-SG2, F-MSV-MSSV2-SG2 } \\ 9 & 2 & \text { F-MSV-MSSV1-SG2, F-MSV-MSSV3-SG2 } \\ 10 & 2 & \text { F-MSV-MSSV1-SG2, F-MSV-MSSV4-SG2 } \\ 11 & 2 & \text { F-MSV-MSSV2-SG1, F-MSV-MSSV3-SG1 } \\ 12 & 2 & \text { F-MSV-MSSV2-SG1, F-MSV-MSSV4-SG1 } \\ 13 & 2 & \text { F-MSV-MSSV2-SG2, F-MSV-MSSV3-SG2 } \\ 14 & 2 & \text { F-MSV-MSSV2-SG2, F-MSV-MSSV4-SG2 } \\ 15 & 2 & \text { F-MSV-MSSV3-SG1, F-MSV-MSSV4-SG1 } \\ 16 & 2 & \text { F-MSV-MSSV3-SG2, F-MSV-MSSV4-SG2 }\end{array}$

System: MSV

Cut

No. Size CUT SETS

$\begin{array}{rrl}1 & 2 & \text { F-MSV-MSSV1-SG1, F-MSV-MSSV2-SG1 } \\ 2 & 2 & \text { F-MSV-MSSV1-SG1, F-MSV-MSSV3-SG1 } \\ 3 & 2 & \text { F-MSV-MSSV1-SG1, F-MSV-MSSV4-SG1 } \\ 4 & 2 & \text { F-MSV-MSSV1-SG2, F-MSV-MSSV2-SG2 } \\ 5 & 2 & \text { F-MSV-MSSV1-SG2, F-MSV-MSSV3-SG2 } \\ 6 & 2 & \text { F-MSV-MSSV1-SG2, F-MSV-MSSV4-SG2 } \\ 7 & 2 & \text { F-MSV-MSSV2-SG1, F-MSV-MSSV3-SG1 } \\ 8 & 2 & \text { F-MSV-MSSV2-SG1, F-MSV-MSSV4-SG1 } \\ 9 & 2 & \text { F-MSV-MSSV2-SG2, F-MSV-MSSV3-SG2 } \\ 10 & 2 & \text { F-MSV-MSSV2-SG2, F-MSV-MSSV4-SG2 } \\ 11 & 2 & \text { F-MSV-MSSV3-SG1, F-MSV-MSSV4-SG1 } \\ 12 & 2 & \text { F-MSV-MSSV3-SG2, F-MSV-MSSV4-SG2 }\end{array}$


Appendix B

Table B.2 (cont.)

System: GEN

Cut

No. Size CUT SETS

1 1 RESPWR 


\section{Appendix C \\ Event Tree Analysis Results}

\section{C.1 Introduction}

Analysis of the event trees discussed in Chap. 6 results in the sequence cut sets, which are used to categorize the sequences as EC-I, EC-I, etc. This appendix is provided to present the sequence cut sets along with the information used as the basis for categorizing the analyzed events as well as the other initiators represented by those events. The intention in providing this information is to show the intermediate steps used to arrive at the categorization results presented in Chap. 7.

A set of two tables is presented for each analyzed event. The first table is the cut set listing for the event sequences. Four additional columns are included to give information regarding the types of failures that make up each cut set and whether or not the cut set is a determinant failure. The first three columns simply show how many of each type of failure (component failure, human error, or support system failure) make up the cut set. The last column indicates whether the cut set is a determinant failure. A determinant failure is a cut set that results in the sequence being classified in the most limiting category, with EC-I being the most limiting and EC-IV the least limiting. There can be more than one determinant failure as there may be multiple cut sets that would result in the sequence being classified in its most limiting category. If all cut sets for a sequence had $\geq 3$ failures, no determinant cut sets are shown.

The cut set listing was limited to only those cut sets involving three failures or less. Since a sequence cut set having $\geq 3$ failures results in an EC-IV categorization and only those with $<3$ failures can be determinant cut sets, showing cut sets with more than three failures provides little value. $\alpha, m^{2}$ that if a sequence resulted in all cuts having $>3$ failures, no cut set listing is provided for that sequence.

The second table in each set provides the categorization information for the sequ'snces for all initiators represented by the event. This table lists each sequence for the analyzed event with a brief description of the determinant failure(s). Subsequent columns contain the initiating events (IEs), their frequency, and the resulting bin and category for each sequence based on the $\mathbb{E}$ frequency and the determinant failure(s). The bin information is from the flow chart in Chap. 3 that delineates the categorization process.

\section{C.2 Large-Break Loss-of-Coolant Event Analysis Results}

This section provides the analysis results for the largebreak loss-of-coolant. Table C. 1 shows the cut set information, and Table C. 2 shows the sequence categorization results.

\section{C.3 Small-Break Loss-of-Coolant Event Analyses Results}

Two small-break loss-of-coolant events were analyzed: liquid relief valve failure and feeder tube break. Table C.3 is the cut set information for liquid relief valve failure, and Table C. 4 presents the sequence categorization results for events represented by the liquid relief valve failure event. Tables C.5 and C. 6 provide this information for the feeder tube break.

\section{C.4 Loss of Class IV Power Event Analysis Results}

This section provides the analysis results for the loss of Class IV power event. Table C.7 lists the cut set information, and Table C.8 gives the sequence categorization results.

\section{C.5 Undercooling Event Analyses Results}

Two undercooling events were analyzed: feedwater piping break in the reactor building and feedwater piping break in the turbine building. Table C. 9 lists the cut set information for feedwater piping breaks in the reactor building, and Table C.10 presents the sequence categorization results for events represented by this event. Tables C.11 and C.12 provide this information for the feedwater piping break in the turbine building.

\section{C.6 SCRAM Event Analysis Results}

This section provides the analysis results for the SCRAM event. Table C.13 lists the cut set information, and Table C.14 provides the sequence categorization results. 
Table C.1 Feeder tube header break sequence cut sets

\begin{tabular}{||c|c|c|c|c|}
\hline Initiating Event - Feeder Tube Header Break & \multicolumn{3}{|l|}{ Sequence: LB-A } \\
\hline \hline Sequence Level Cut Sets & $\begin{array}{c}\text { Component } \\
\text { Failures }\end{array}$ & $\begin{array}{c}\text { Human } \\
\text { Errors }\end{array}$ & $\begin{array}{c}\text { Support } \\
\text { System } \\
\text { Failures }\end{array}$ & $\begin{array}{c}\text { Determinant } \\
\text { Failure? }\end{array}$ \\
\hline NONE & NA & NA & NA & NA \\
\hline
\end{tabular}

\begin{tabular}{||l|c|c|c|c||}
\hline Initiating Event - Feeder Tube Header Break & \multicolumn{2}{|l||}{ Sequence: LB-B } \\
\hline \multicolumn{1}{|c|}{ Sequence Level Cut Sets } & $\begin{array}{c}\text { Componeat } \\
\text { Failures }\end{array}$ & $\begin{array}{c}\text { Human } \\
\text { Errors }\end{array}$ & $\begin{array}{c}\text { Support } \\
\text { Syatem } \\
\text { Failures }\end{array}$ & $\begin{array}{c}\text { Determinant } \\
\text { Failure ? }\end{array}$ \\
\hline F-REC-ISV1, F-REC-ISV2 & 2 & & & Y \\
\hline F-REC-ISV1, S-EL-III-2-E & 1 & & 1 & \\
\hline F-REC-ISV2, S-EL-III-2-O & 1 & & 1 & \\
\hline F-REC-HX1, F-REC-HX2 & 2 & & & Y \\
\hline
\end{tabular}

\begin{tabular}{|c|c|c|c|c|}
\hline \multirow{2}{*}{$\frac{\text { Initiating Event - Feeder Tube Header Break }}{\text { Sequence Level Cut Sets }}$} & \multicolumn{4}{|c|}{ Sequence: $L B-C$} \\
\hline & $\begin{array}{l}\text { Component } \\
\text { Failures }\end{array}$ & $\begin{array}{l}\text { Human } \\
\text { Errors }\end{array}$ & $\begin{array}{l}\text { Support } \\
\text { System } \\
\text { Failures }\end{array}$ & $\begin{array}{l}\text { Determinant } \\
\text { Failure? }\end{array}$ \\
\hline S-RCW, S-SW2 & & & 2 & \\
\hline F-MCS-PMP1, F-REC-ISV1, F-REC-ISV2 & 3 & & & \\
\hline F-MCS-PMP2, F-REC-ISV1, F-REC-ISV2 & 3 & & & \\
\hline F-REC-ISV1, F-REC-ISV2, S-EL-III-1-O & 2 & & 1 & \\
\hline F-REC-ISV1, F-REC-ISV2, S-RCW & 2 & & 1 & \\
\hline F-MCS-ISV-FC, F-REC-ISV1, F-REC-ISV2 & 3 & & & \\
\hline F-REC-ISV1, F-REC-ISV2, S-EL-III-1-E & 2 & & 1 & \\
\hline F-REC-ISV1, S-EL-III-1-E, S-EL-III-2-E & 1 & & 2 & \\
\hline F-MCS-PMP1, F-REC-ISV2, S-EL-III-2-O & 2 & & 1 & \\
\hline F-MCS-PMP2, F-REC-ISV2, S-EL-III-2-O & 2 & & 1 & \\
\hline
\end{tabular}


Table C.1 (cont.)

\begin{tabular}{||l|c|c|c|c||}
\hline F-REC-ISV1, S-EL-III-2-E, S-RCW & 1 & & 2 & \\
\hline F-REC-ISV2, S-EL-III-1-E, S-EL-III-2-O & 1 & & 2 & \\
\hline F-REC-ISV2, S-EL-III-2-O, S-RCW & 1 & & 2 & \\
\hline F-REC-ISV2, S-EL-III-1-O, S-EL-III-2-O & 1 & & 2 & \\
\hline F-REC-ISV1, S-EL-III-1-O, S-EL-III-2-E & 1 & & 2 & \\
\hline F-MCS-ISV-FC, F-REC-ISV2, S-EL-III-2-O & 2 & & 1 & \\
\hline F-MCS-PMP2, F-REC-ISV1, S-EL-III-2-E & 2 & & 1 & \\
\hline F-MCS-PMP1, F-REC-ISV1, S-EL-III-2-E & 2 & & 1 & \\
\hline F-MCS-ISV-FC, F-REC-ISV1, S-EL-III-2-E & 2 & & 1 & \\
\hline F-REC-HX1, F-REC-HX2, S-RCW & 2 & & 1 & \\
\hline F-MCS-ISV-FC, F-REC-HX1, F-REC-HX2 & 3 & & & \\
\hline F-REC-HX1, F-REC-HX2, S-EL-III-1-E & 2 & & 3 & \\
\hline F-MCS-PMP2, F-REC-HX1, F-REC-HX2 & & & & \\
\hline F-MCS-PMP1, F-REC-HX1, F-REC-HX2 & 3 & & & \\
\hline F-REC-HX1, F-REC-HX2, S-EL-III-1-O & 2 & & 1 & \\
\hline
\end{tabular}

\begin{tabular}{|c|c|c|c|c|}
\hline \multirow{2}{*}{$\frac{\text { Initiating Event - Feeder Tube Header Break }}{\text { Sequence Level Cut Sets }}$} & \multicolumn{4}{|c|}{ Sequence: $L B-D$} \\
\hline & $\begin{array}{l}\text { Component } \\
\text { Failures }\end{array}$ & $\begin{array}{l}\text { Human } \\
\text { Errors }\end{array}$ & $\begin{array}{l}\text { Support } \\
\text { System } \\
\text { Failures } \\
\end{array}$ & $\begin{array}{l}\text { Determinant } \\
\text { Failure? }\end{array}$ \\
\hline F-LPI-ISV1, F-LPI-ISV2 & 2 & & & $\mathbf{Y}$ \\
\hline F-LPI-PMP1，F-LPI-PMP2 & 2 & & & $Y$ \\
\hline F-LPI-INV1, F-LPI-INV2 & 2 & & & $\mathrm{Y}$ \\
\hline F-LPI-PMP1, S-EL-III-2-E & 1 & & 1 & \\
\hline F-LPI-PMP2, S-EL-III-2-O & 1 & & 1 & \\
\hline F-LPI-ISV2, S-EL-III-2-O & 1 & & 1 & \\
\hline F-HPI-ISV1-GI, S-EL-III-2-E & 1 & & 1 & \\
\hline F-LPI-LI-TK, F-LPI-TK & 2 & & & $\mathbf{Y}$ \\
\hline F-HPI-ISV2-GI, S-EL-III-2-O & 1 & & 1 & \\
\hline F-LPI-INV2, S-EL-III-2-O & 1 & & 1 & \\
\hline F-LPI-ISV1, S-EL-III-2-E & 1 & & 1 & \\
\hline F-LPI-INV1, S-EL-III-2-E & 1 & & 1 & \\
\hline S-EL-III-2-E, S-EL-IIII-2-O & & & 2 & \\
\hline
\end{tabular}


Table C.1 (cont.)

\begin{tabular}{|c|c|c|c|c|}
\hline Initiating Event - Feeder Tube Header Break & Sequence & $B-E$ & & \\
\hline Sequence Level Cut Sets & $\begin{array}{c}\text { Component } \\
\text { Failures }\end{array}$ & $\begin{array}{l}\text { Human } \\
\text { Errors }\end{array}$ & $\begin{array}{l}\text { Support } \\
\text { System } \\
\text { Failures }\end{array}$ & $\begin{array}{l}\text { Determinant } \\
\text { Failure? }\end{array}$ \\
\hline F-LPI-INV1, F-LPI-INV2, S-RCW & 2 & & 1 & \\
\hline F-LPI-ISV1, F-LPI-ISV2, S-EL-III-1-O & 2 & & 1 & \\
\hline F-LPI-INV1, F-LPI-INV2, F-MCS-ISV-FC & 3 & & & \\
\hline F-LPI-ISV1, F-LPI-ISV2, F-MCS-PMP1 & 3 & & & \\
\hline F-LPI-ISV1, F-LPI-ISV2, S-EL-III-1-E & 2 & & 1 & \\
\hline F-LPI-ISV1, F-LPI-ISV2, F-MCS-ISV-FC & 3 & & & \\
\hline F-LPI-ISV1, F-LPI-ISV2, F-MCS-PMP2 & 3 & & & \\
\hline F-LPI-INV1, F-LPI-INV2, S-EL-III-1-E & 2 & & 1 & \\
\hline F-LPI-INV1, F-LPI-INV2, F-MCS-PMP1 & 3 & & & \\
\hline F-LPI-PMP1, F-LPI-PMP2, F-MCS-PMP1 & 3 & & & \\
\hline F-LPI-PMP1, F-LPI-PMP2, S-EL-III-1-E & 2 & & 1 & \\
\hline F-LPI-PMP1, F-LPI-PMP2, S-EL-III-1-O & 2 & & 1 & \\
\hline F-LPI-PMP1，F-LPI-PMP2, F-MCS-PMP2 & 3 & & & \\
\hline F-LPI-PMP1, F-LPI-PMP2, F-MCS-ISV-FC & 3 & & & \\
\hline F-LPI-INV1, F-LPI-INV2, S-EL-III-1-O & 2 & & 1 & \\
\hline F-LPI-PMP1, F-LPI-PMP2, S-RCW & 2 & & 1 & \\
\hline F-LPI-ISV1, F-LPI-ISV2, S-RCW & 2 & & 1 & \\
\hline F-LPI-INV1, F-LPI-INV2, F-MCS-PMP2 & 3 & & & \\
\hline F-LPI-PMP2, F-MCS-ISV-FC, S-EL-III-2-O & 2 & & 1 & \\
\hline F-LPI-PMP2, S-EL-III-2-O, S-RCW & 1 & & 2 & \\
\hline F-LPI-PMP2, F-MCS-PMP2, S-EL-III-2-O & 2 & & 1 & \\
\hline F-LPI-PMP2, S-EL-III-1-E, S-EL-III-2-O & 1 & & 2 & \\
\hline F-HPI-ISV1-GI, S-EL-III-1-O, S-EL-III-2-E & 1 & & 2 & \\
\hline F-LPI-PMP2, F-MCS-PMP1, S-EL-III-2-O & 2 & & 1 & \\
\hline F-HPI-ISV1-GI, F-MCS-PMP1, S-EL-III-2-E & 2 & & 1 & \\
\hline F-HPI-ISV1-GI, S-EL-III-2-E, S-RCW & 1 & & 2 & \\
\hline F-LPI-ISV1, S-EL-III-1-O, S-EL-III-2-E & 1 & & 2 & \\
\hline F-HPI-ISV1-GI, F-MCS-ISV-FC, S-EL-III-2-E & 2 & & 1 & \\
\hline F-HPI-ISV1-GI, F-MCS-PMP2, S-EL-III-2-E & 2 & & 1 & \\
\hline
\end{tabular}


Table C.1 (cont)

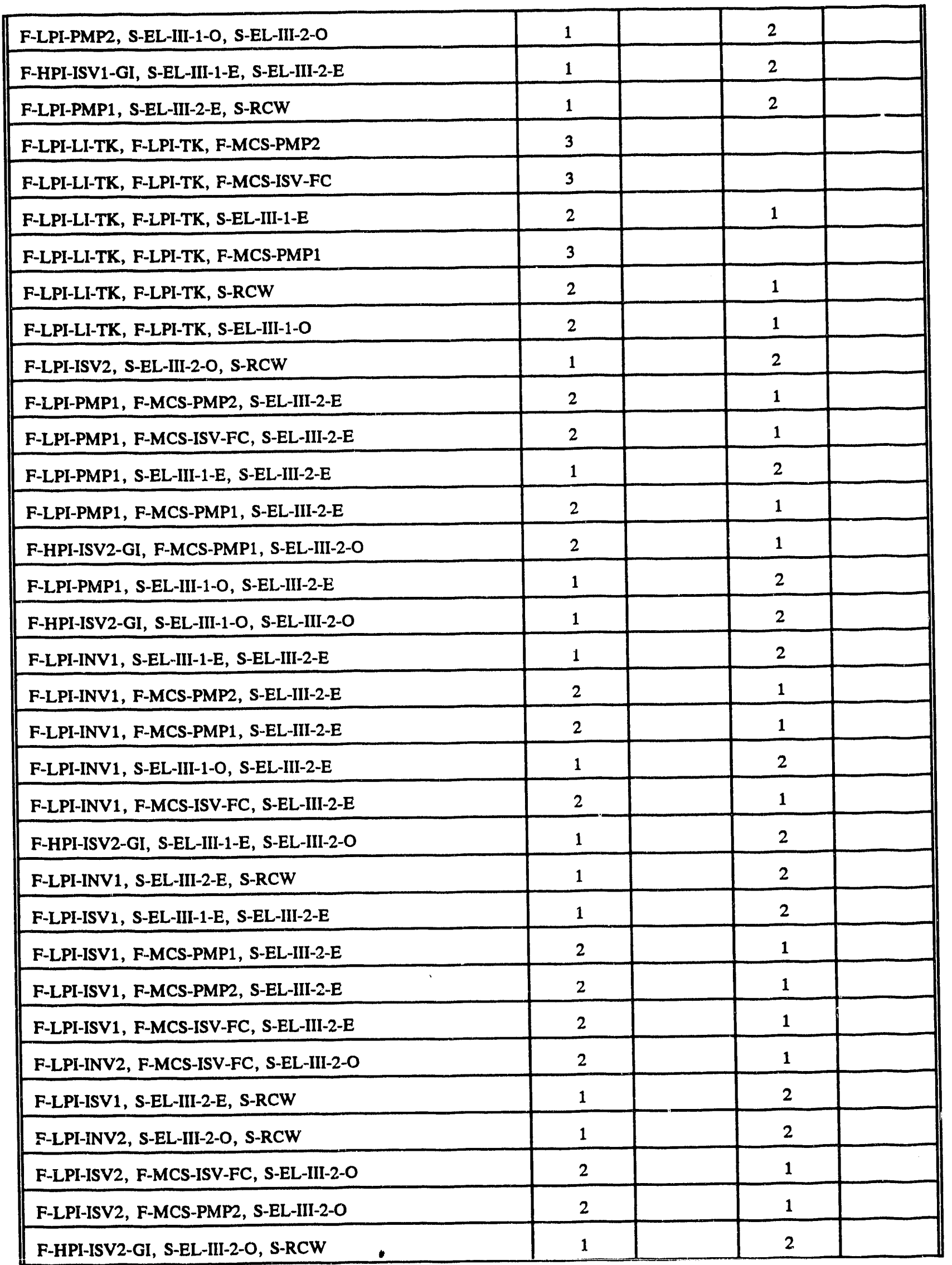


Table C.1 (cont.)

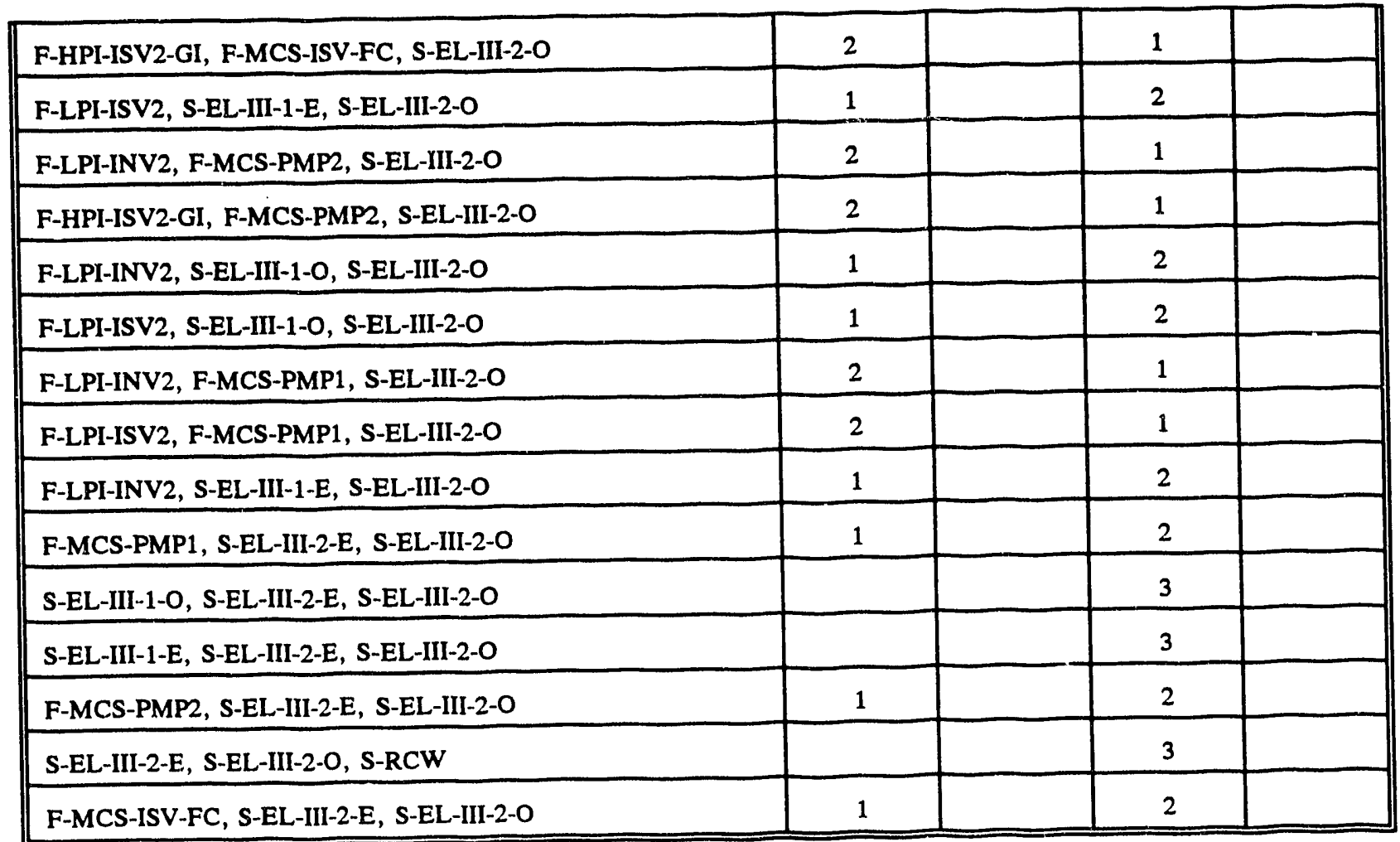

\begin{tabular}{|c|c|c|c|c|}
\hline \multirow{2}{*}{$\frac{\text { Initiating Event - Feeder Tube Header Break }}{\text { Sequence Level Cut Sets }}$} & \multicolumn{4}{|c|}{ Sequence: $\boldsymbol{L B}-\boldsymbol{F}$} \\
\hline & $\begin{array}{l}\text { Component } \\
\text { Faitures }\end{array}$ & $\begin{array}{l}\text { Human } \\
\text { Errors }\end{array}$ & $\begin{array}{l}\text { Support } \\
\text { System } \\
\text { Failures }\end{array}$ & $\begin{array}{l}\text { Determinant } \\
\text { Failure? }\end{array}$ \\
\hline S-ECC & & & 1 & $\mathrm{Y}$ \\
\hline F-HPI-SIG1-LPHTS, F-HPI-SIG3-LPHTS & 2 & & & $\mathrm{Y}$ \\
\hline F-HPI-OV2A, F-HPI-OV2B & 2 & & & $\mathbf{Y}$ \\
\hline F-HPI-SIG2-LPHTS, F-HPI-SIG3-LPHTS & 2 & & & $\mathbf{Y}$ \\
\hline F-HPI-SIG1-LPHTS, F-HPI-SIG2-LPHTS & 2 & & & $Y$ \\
\hline F-HPI-INV2A, F-HPI-INV2B & 2 & & & $Y$ \\
\hline F-HPI-ISV1-GI, F-HPI-ISV2-GI & 2 & & & $\mathrm{Y}$ \\
\hline F-HPI-OV1A, F-HPI-OV1B & 2 & & & $\mathrm{Y}$ \\
\hline F-HPI-INV1, F-HPI-INV2 & 2 & & & $\mathbf{Y}$ \\
\hline F-HPI-INV1A, F-HPI-INV1B & 2 & & & $\mathbf{Y}$ \\
\hline F-HPI-PI-GI-TK, F-HPI-TK-GI & 2 & & & $Y$ \\
\hline F-HPI-INV1B, S-EL-II-2-O & 1 & & 1 & \\
\hline F-HPI-ISV2-GI, S-EL-II-2-O & 1 & & 1 & \\
\hline F-HPI-ISV1-GI, S-EL-II-2-E & 1 & & 1 & \\
\hline
\end{tabular}


Table C.1 (cont)

\begin{tabular}{||l|c|c|c|c||}
\hline F-HPI-LI-CITK, F-HPI-TK-CI & 2 & & & $Y$ \\
\hline F-HPI-INV1, S-EL-II-2-E & 1 & & 1 & \\
\hline F-HPI-INV1A, S-EL-II-2-E & 1 & & 1 & \\
\hline F-HPI-OV1A, S-EL-II-2-E & 1 & & 1 & \\
\hline F-HPI-INV2B, S-EL-II-2-O & 1 & & 1 & \\
\hline F-HPI-OV1B, S-EL-II-2-O & 1 & & 1 & \\
\hline F-HPI-INV2, S-EL-II-2-O & 1 & & 1 & \\
\hline F-HPI-OV2A, S-EL-II-2-E & 1 & & 1 & \\
\hline F-HPI-OV2B, S-EL-II-2-O & 1 & & 1 & \\
\hline F-HPI-INV2A, S-EL-II-2-E & 1 & & 1 & \\
\hline S-EL-II-2-E, S-EL-II-2-O & & & 2 & \\
\hline
\end{tabular}

\begin{tabular}{|c|c|c|c|c|}
\hline \multirow{2}{*}{$\begin{array}{c}\text { Initiating Event - Feeder Tube Header Break } \\
\text { Sequence Level Cut Sets }\end{array}$} & \multicolumn{4}{|c|}{ Sequence: $L B-G$} \\
\hline & $\begin{array}{l}\text { Component } \\
\text { Failures }\end{array}$ & $\begin{array}{c}\text { Human } \\
\text { Errors }\end{array}$ & $\begin{array}{l}\text { Support } \\
\text { System } \\
\text { Failuses }\end{array}$ & $\begin{array}{l}\text { Determinant } \\
\text { Failure? }\end{array}$ \\
\hline F-MCS-PMP2, S-ECC & 1 & & 1 & \\
\hline F-MCS-ISV-FC, S-ECC & 1 & & 1 & \\
\hline S-ECC, S-EL-III-1-E & & & 2 & \\
\hline S-ECC, S-RCW & & & 2 & \\
\hline F-MCS-PMP1, S-ECC & 1 & & 1 & \\
\hline S-ECC, S-EL-HII-1-O & & & 2 & \\
\hline F-HPI-OV2A, F-HPI-OV2B, F-MCS-PMP2 & 3 & & & \\
\hline F-HPI-OV2A, F-HPI-OV2B, S-EL-III-1-E & 2 & & 1 & \\
\hline F-HPI-OV2A, F-HPI-OV2B, F-MCS-ISV-FC & 3 & & & \\
\hline F-HPI-OV2A, F-HPI-OV2B, F-MCS-PA^D1 & 3 & & & \\
\hline F-HPI-OV2A, F-HPI-OV2B, S-RCW & 2 & & 1 & \\
\hline F-HPI-OV2A, F-HPI-OV2B, S-EL-III-1-O & 2 & & 1 & \\
\hline F-HPI-SIG1-LPHTS, F-HPI-SIG3-LPHTS, F-MCS-ISV-FC & 3 & & & \\
\hline F-HPI-SIG1-LPHTS, F-HPI-SIG3-LPHTS, F-MCS-PMP2 & 3 & & & \\
\hline F-HPI-SIG1-LPHTS, F-HPI-SIG3-LPHTS, S-RCW & 2 & & 1 & \\
\hline F-HPI-OV1A, F-HPI-OV1B, F-MCS-PMP1 & 3 & & & \\
\hline F-HPI-OV1A, F-HPI-OV1B, S-EL-III-1-E & 2 & & 1 & \\
\hline F-HPI-INV2A, F-HPI-INV2B, F-MCS-PMP2 & 3 & & & \\
\hline
\end{tabular}


Table C.1 (cont)

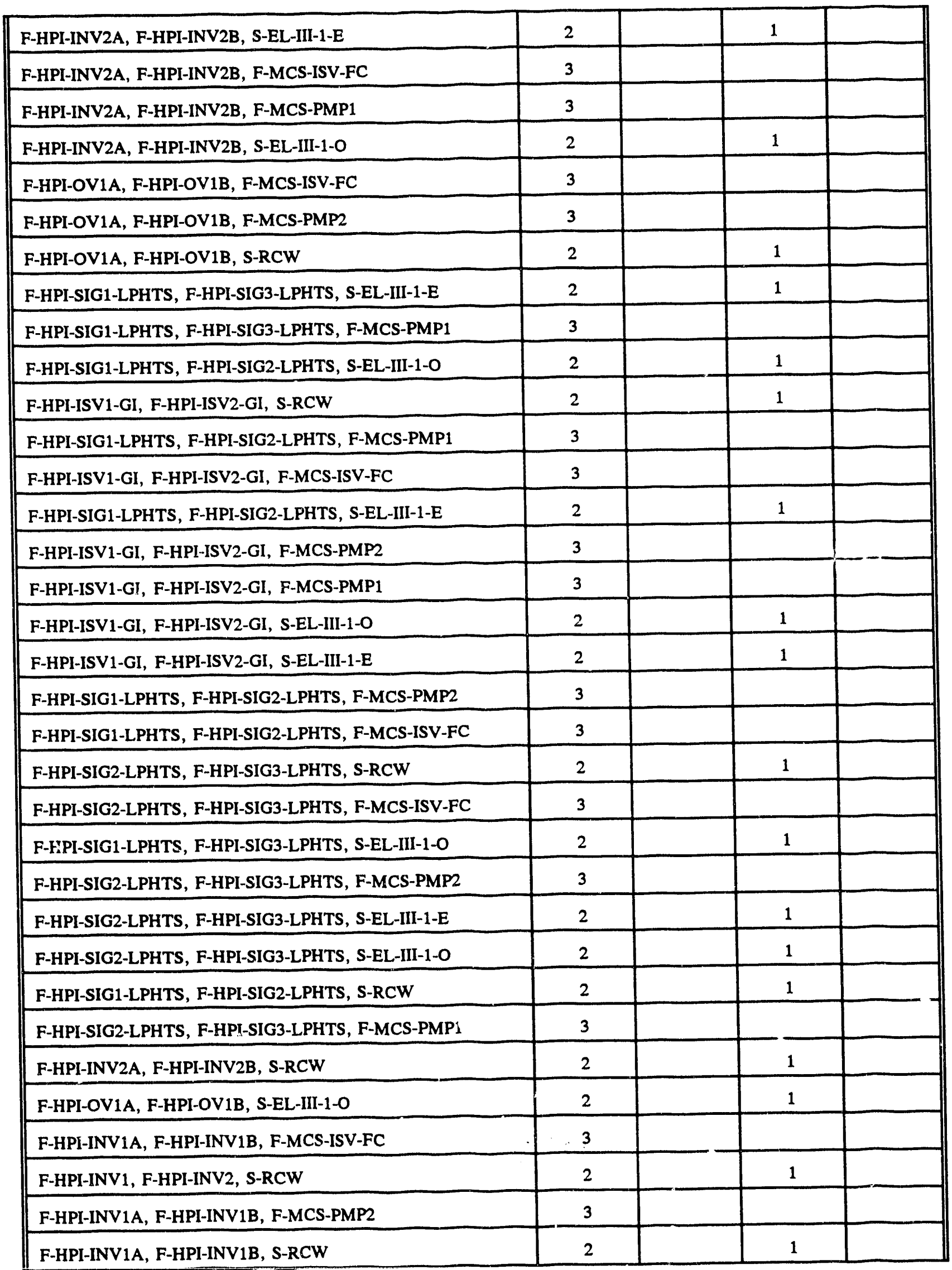


Table C.1 (cont.)

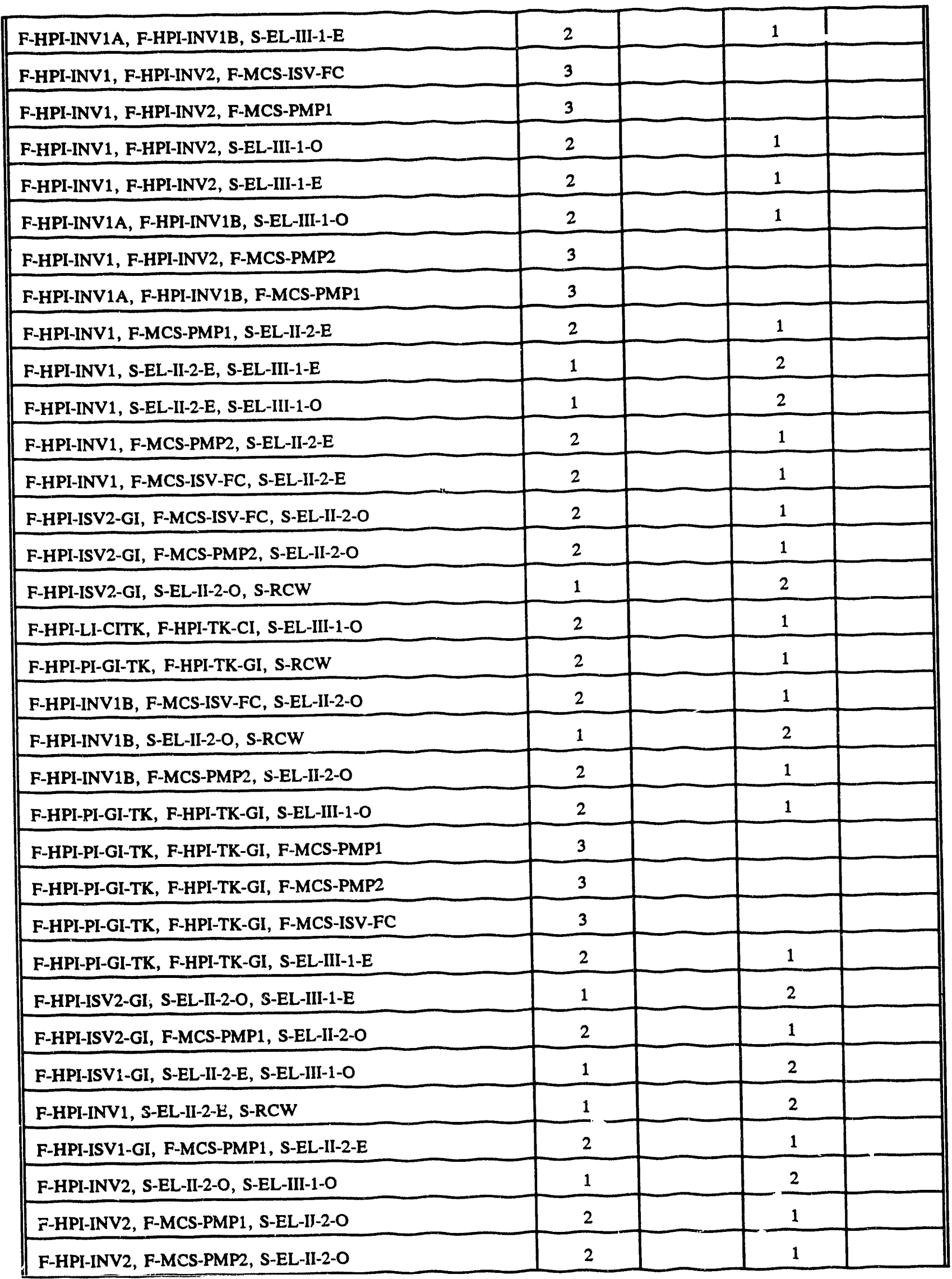




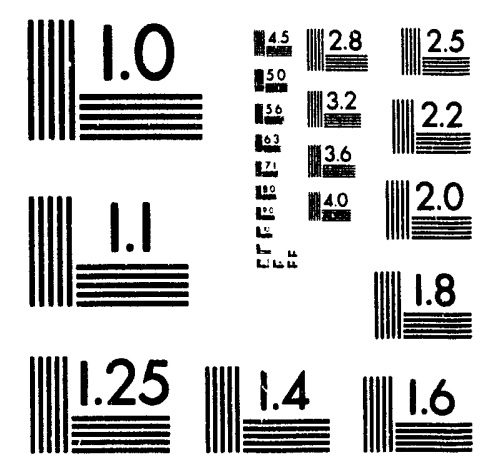



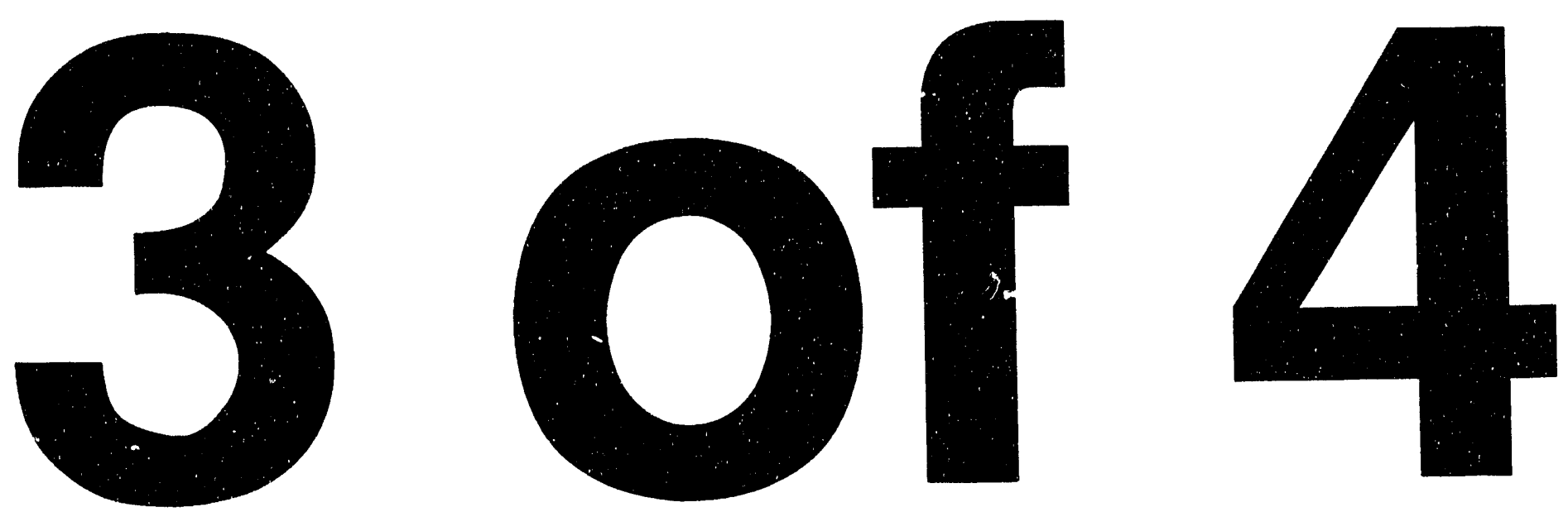
Table C.1 (cont)

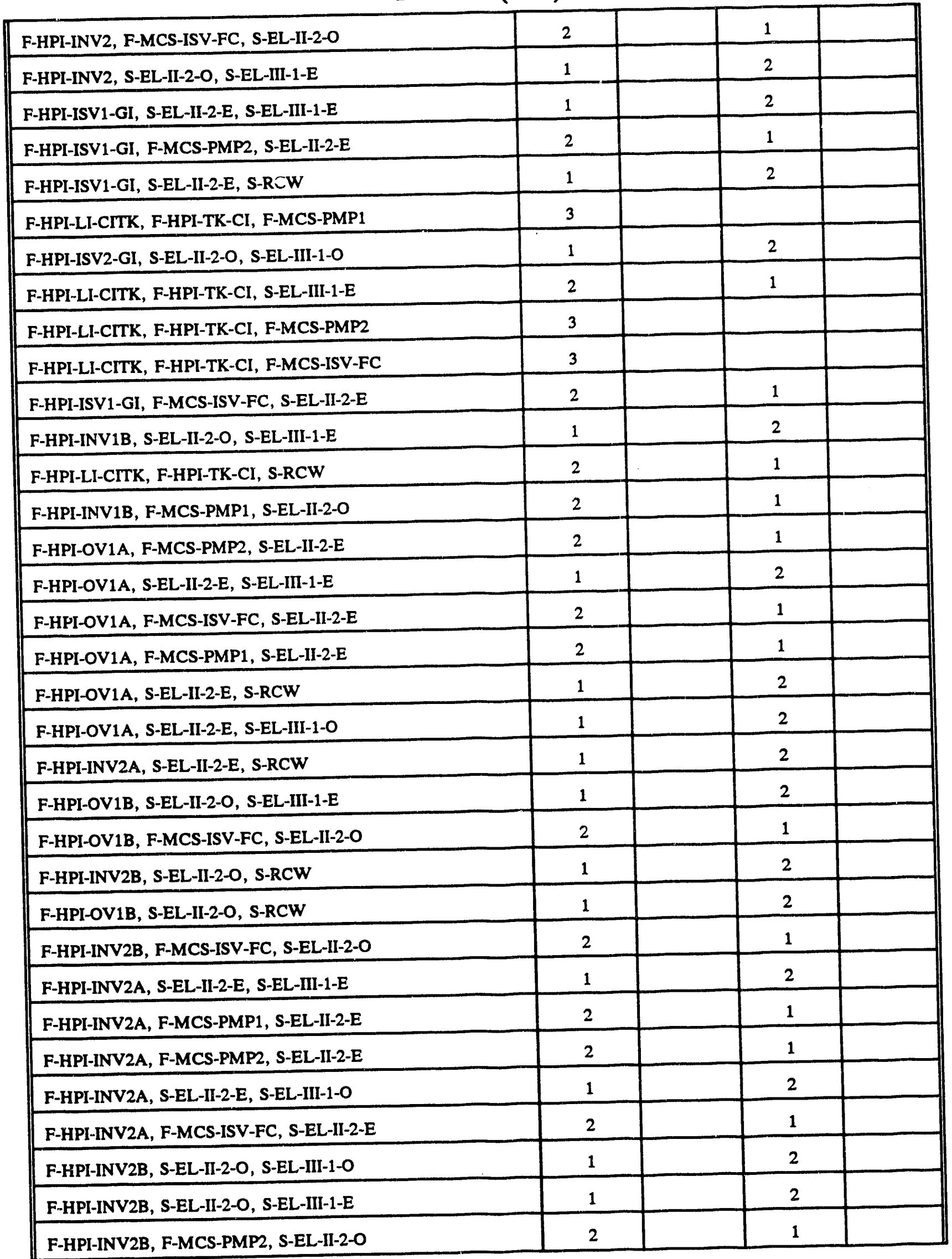


Table C.1 (cont)

\begin{tabular}{|c|c|c|c|}
\hline F-HPI-INV2B, F-MCS-PMP1, S-EL-II-2-O & 2 & 1 & \\
\hline F-HPI-OV1B, F-MCS-PMP1, S-EL-II-2-O & 2 & 1 & \\
\hline F-HPI-OV1B, F-MCS-PMP2, S-EL-II-2-O & 2 & 1 & \\
\hline F-HPI-INV1A, S-EL-II-2-E, S-EL-III-1-O & 1 & 2 & \\
\hline F-HPI-INV1A, F-MCS-PMP1, S-EL-II-2-E & 2 & 1 & \\
\hline F-HPI-OV1B, S-EL-II-2-O, S-EL-III-1-O & 1 & 2 & \\
\hline F-HPI-INV1A, S-EL-II-2-E, S-EL-III-1-E & 1 & 2 & \\
\hline F-HPI-OV2A, F-MCS-PMP1, S-EL-II-2-E & 2 & 1 & \\
\hline F-HPI-INV1A, F-MCS-PMP2, S-EL-II-2-E & 2 & 1 & \\
\hline F-HPI-INV1A, S-EL-II-2-E, S-RCW & 1 & 2 & \\
\hline F-HPI-INV1B, S-EL-II-2-O, S-EL-III-1-O & 1 & 2 & \\
\hline F-HPI-INV1A, F-MCS-ISV-FC, S-EL-II-2-E & 2 & 1 & \\
\hline F-HPI-OV2A, S-EL-II-2-E, S-EL-III-1-E & 1 & 2 & \\
\hline F-HPI-OV2A, S-EL-II-2-E, S-EL-III-1-O & 1 & 2 & \\
\hline F-HPI-OV2A, F-MCS-PMP2, S-EL-II-2-E & 2 & 1 & \\
\hline F-HPI-OV2B, F-MCS-PMP2, S-EL-II-2-O & 2 & 1 & \\
\hline F-HPI-OV2B, S-EL-II-2-O, S-RCW & 1 & 2 & \\
\hline F-HPI-OV2B, S-EL-II-2-O, S-EL-III-1-E & 1 & 2 & \\
\hline F-HPI-INV2, S-EL-II-2-O, S-RCW & 1 & 2 & \\
\hline F-HPI-OV2B, F-MCS-ISV-FC, S-EL-II-2-O & 2 & 1 & \\
\hline F-HPI-OV2A, S-EL-II-2-E, S-RCW & 1 & 2 & \\
\hline F-HPI-OV2B, F-MCS-PMP1, S-EL-II-2-O & 2 & 1 & \\
\hline F-HPI-OV2A, F-MCS-ISV-FC, S-EL-II-2-E & 2 & 1 & \\
\hline F-HPI-OV2B, S-EL-II-2-O, S-EL-III-1-O & 1 & 2 & \\
\hline F-MCS-ISV-FC, S-EL-II-2-E, S-EL-II-2-O & 1 & 2 & \\
\hline S-EL-II-2-E, S-EL-II-2-O, S-RCW & & 3 & \\
\hline F-MCS-PMP2, S-EL-II-2-E, S-EL-II-2-O & 1 & 2 & \\
\hline S-EL-II-2-E, S-EL-II-2-O, S-EL-III-1-O & & 3 & \\
\hline S-EL-II-2-E, S-EL-II-2-O, S-EL-III-1-E & & 3 & \\
\hline F-MCS-PMP1, S-EL-II-2-E, S-EL-II-2-O & 1 & 2 & \\
\hline
\end{tabular}


Appendix C

Table C.1 (cont.)

\begin{tabular}{|c|c|c|c|c|}
\hline \multirow{2}{*}{$\begin{array}{c}\text { Initiating Event - Forter Tube Header Break } \\
\text { Sequence Level Cut Sets }\end{array}$} & \multicolumn{4}{|c|}{ Sequence: $L B-H$} \\
\hline & $\begin{array}{c}\text { Composent } \\
\text { Failures }\end{array}$ & $\begin{array}{l}\text { Human } \\
\text { Erron }\end{array}$ & $\begin{array}{l}\text { Support } \\
\text { Syptem } \\
\text { Failures }\end{array}$ & $\begin{array}{l}\text { Determinant } \\
\text { Failure? }\end{array}$ \\
\hline F-HTS-PMP3 & 1 & & & $\mathbf{Y}$ \\
\hline F-HTS-PMP4 & 1 & & & $\mathbf{Y}$ \\
\hline F-HTS-PMP2 & 1 & & & $\mathbf{Y}$ \\
\hline F-HTS-PMP1 & 1 & & & $\mathbf{Y}$ \\
\hline S-EL-IV-E & & & 1 & \\
\hline S-EL-IV-O & & & 1 & \\
\hline
\end{tabular}

\begin{tabular}{|c|c|c|c|c|}
\hline \multirow{2}{*}{$\begin{array}{c}\text { Initiating Event - Feeder Tube Header Break } \\
\text { Sequence Level Cut Sets }\end{array}$} & \multicolumn{4}{|c|}{ Sequence: $L B-I$} \\
\hline & $\begin{array}{l}\text { Component } \\
\text { Failures }\end{array}$ & $\begin{array}{c}\text { Human } \\
\text { Errors }\end{array}$ & $\begin{array}{l}\text { Support } \\
\text { System } \\
\text { Faihures }\end{array}$ & $\begin{array}{l}\text { Determinant } \\
\text { Failure? }\end{array}$ \\
\hline F-REC-ISV1, F-REC-ISV2, S-EL-IV-O & 2 & & 1 & \\
\hline F-REC-ISV1, F-REC-ISV2, S-EL-IV-E & 2 & & 1 & \\
\hline F-HTS-PMP2, F-REC-ISV1, F-REC-ISV2 & 3 & & & \\
\hline F-HTS-PMP1, F-REC-ISV1, F-REC-ISV2 & 3 & & & \\
\hline F-HTS-PMP3, F-REC-ISV1, F-REC-ISV2 & 3 & & & \\
\hline F-HTS-PMP4, F-REC-ISV1, F-REC-ISV2 & 3 & & & \\
\hline F-HTS-PMP3, F-REC-ISV1, S-EL-III-2-E & 2 & & 1 & \\
\hline F-REC-ISV2, S-EL-III-2-O, S-EL-IV-E & 1 & & 2 & \\
\hline F-HTS-PMP2, F-REC-ISV1, S-EL-III-2-E & 2 & & 1 & \\
\hline F-HTS-PMP4, F-REC-ISV1, S-EL-III-2-E & 2 & & 1 & \\
\hline F-HTS-PMP1, F-REC-ISV1, S-EL-III-2-E & 2 & & 1 & \\
\hline F-HTS-PMP2, F-REC-ISV2, S-EL-III-2-O & 2 & & 1 & \\
\hline F-REC-ISV2, S-EL-III-2-O, S-EL-IV-O & 1 & & 2 & \\
\hline F-HTS-PMP3, F-REC-ISV2, S-EL-III-2-O & 2 & & 1 & \\
\hline F-HTS-PMP1, F-REC-ISV2, S-EL-III-2-O & 2 & & 1 & \\
\hline F-HTS-PMP4, F-REC-ISV2, S-EL-III-2-O & 2 & & 1 & \\
\hline F-REC-ISV1, S-EL-III-2-E, S-EL-IV-O & 1 & & 2 & \\
\hline F-REC-ISV1, S-EL-III-2-E, S-EL-IV-E & 1 & & 2 & \\
\hline F-HTS-PMP3, F-REC-HX1, F-REC-HX2 & 3 & & & \\
\hline F-HTS-PMP4, F-REC-HX1, F-REC-HX2 & 3 & & & \\
\hline
\end{tabular}


Table C.1 (cont)

\begin{tabular}{||l|l|l|l|l||}
\hline F-HTS-PMP2, F-REC-HX1, F-REC-HX2 & 3 & & & \\
\hline F-REC-HX1, F-REC-HX2, S-EL-IV-O & 2 & & 1 & \\
\hline F-HTS-PMP1, F-REC-HX1, F-REC-HX2 & 3 & & & \\
\hline F-REC-HX1, F-REC-HX2, S-EL-IV-E & 2 & & 1 & \\
\hline
\end{tabular}

\begin{tabular}{||l|c|c|c|c||}
\hline \multicolumn{1}{|l|}{ Initiating Event - Feeder Tube Header Break } & \multicolumn{2}{l||}{ Sequence: LB-J } \\
\hline Sequence Level Cut Sets & $\begin{array}{c}\text { Component } \\
\text { Failures }\end{array}$ & $\begin{array}{c}\text { Human } \\
\text { Errors }\end{array}$ & $\begin{array}{c}\text { Support } \\
\text { System } \\
\text { Failures }\end{array}$ & $\begin{array}{c}\text { Determinant } \\
\text { Failure ? }\end{array}$ \\
\hline F-HTS-PMP3, S-RCW, S-SW2 & 1 & & 2 & \\
\hline F-HTS-PMP4, S-RCW, S-SW2 & 1 & & 2 & \\
\hline F-HTS-PMP2, S-RCW, S-SW2 & 1 & & 2 & \\
\hline F-HTS-PMP1, S-RCW, S-SW2 & 1 & & 2 & \\
\hline S-EL-IV-E, S-RCW, S-SW2 & & & 3 & \\
\hline S-EL-IV-O, S-RCW, S-SW2 & & & 3 & \\
\hline
\end{tabular}

\begin{tabular}{|c|c|c|c|c|}
\hline \multirow{2}{*}{$\begin{array}{c}\text { Initiating Event - Feeder Tube Header Break } \\
\text { Sequence Level Cut Sets }\end{array}$} & \multicolumn{4}{|c|}{ Sequence: $\boldsymbol{L B}-\boldsymbol{K}$} \\
\hline & $\begin{array}{l}\text { Component } \\
\text { Failures }\end{array}$ & $\begin{array}{l}\text { Human } \\
\text { Errors }\end{array}$ & $\begin{array}{l}\text { Support } \\
\text { System } \\
\text { Failures }\end{array}$ & $\begin{array}{l}\text { Determinent } \\
\text { Failure? }\end{array}$ \\
\hline F-LPI-INV1, F-LPI-INV2, S-EL-IV-E & 2 & & 1 & \\
\hline F-HTS-PMP4, F-LPI-ISV1, F-LPI-ISV2 & 3 & & & \\
\hline F-LPI-INV1, F-LPI-INV2, S-EL-IV-O & 2 & & 1 & \\
\hline F-HTS-PMP3, F-LPI-ISV1, F-LPI-ISV2 & 3 & & & \\
\hline F-HTS-PMP2, F-LPI-ISV1, F-LPI-ISV2 & 3 & & & \\
\hline F-LPI-ISV1, F-LPI-ISV2, S-EL-IV-O & 2 & & 1 & \\
\hline F-HTS-PMP1, F-LPI-ISV1, F-LPI-ISV2 & 3 & & & \\
\hline F-HTS-PMP2, F-LPI-INV1, F-LPI-INV2 & 3 & & & \\
\hline F-HTS-PMP3, F-LPI-INV1, F-LPI-INV2 & 3 & & & \\
\hline F-HTS-PMP3, F-LPI-PMP1, F-LPI-PMP2 & 3 & & & \\
\hline F-HTS-PMP2, F-LPI-PMP1, F-LPI-PMPi & 3 & & & \\
\hline F-HTS-PMP4, F-LPI-PMP1, F-LPI-PMP2 & 3 & & & \\
\hline F-HTS-PMP1, F-LPI-PMP1, F-LPI-PMP2 & 3 & & & \\
\hline F-LPI-PMP1, F-LPI-PMP2, S-EL-IV-O & 2 & & 1 & \\
\hline F-HTS-PMP4, F-LPI-INV1, F-LPI-INV2 & 3 & & & \\
\hline
\end{tabular}


Table C.1 (cont.)

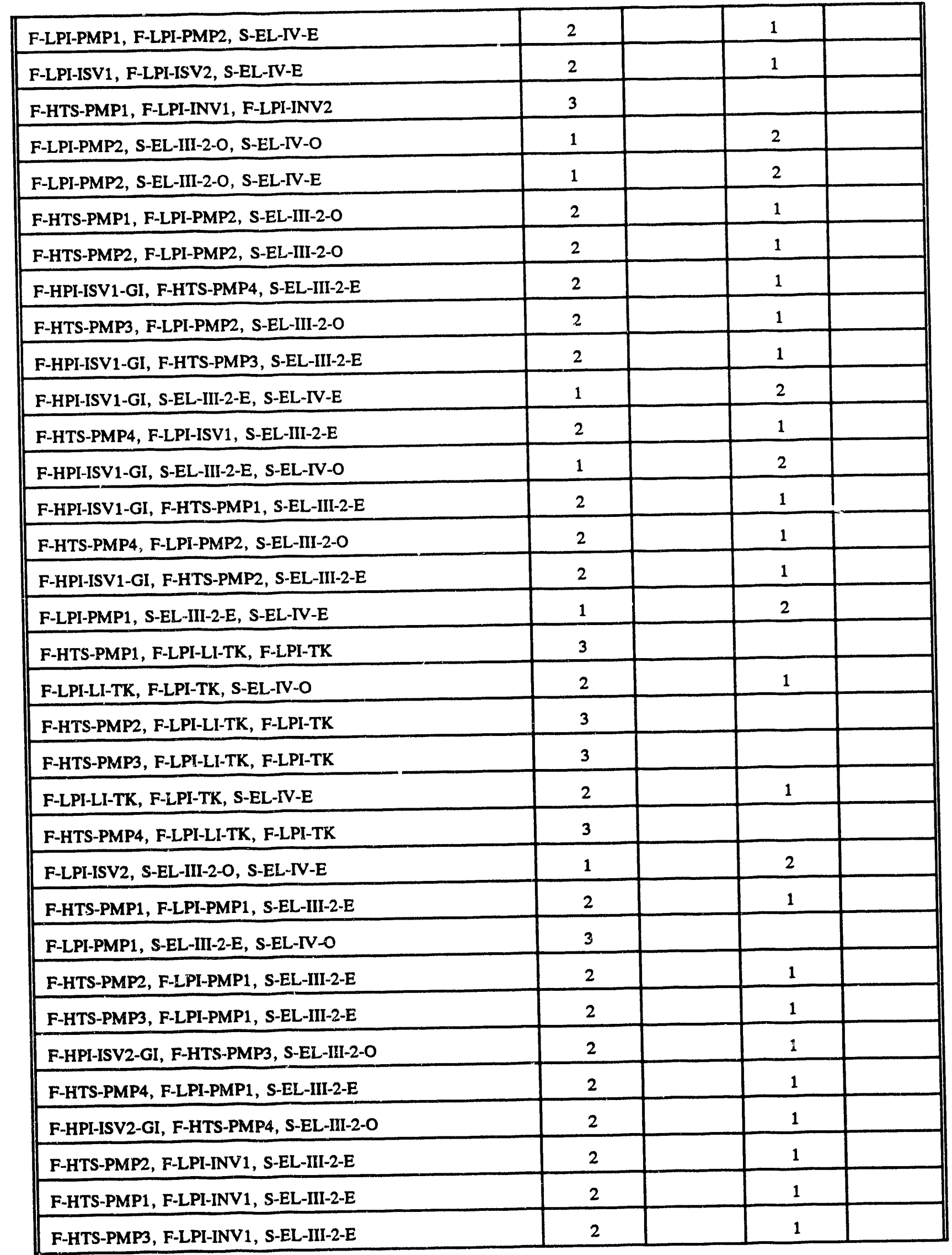


Table C.1 (cont)

\begin{tabular}{|c|c|c|c|}
\hline F-HTS-PMP4, F-LPI-INV1, S-EL-III-2-E & 2 & 1 & \\
\hline F-LPI-INV1, S-EL-III-2-E, S-EL-IV-O & 1 & 2 & \\
\hline F-HPI-ISV2-GI, F-HTS-PMP2, S-EL-III-2-O & 2 & 1 & \\
\hline F-LPI-INV1, S-EL-III-2-E, S-EL-IV-E & 1 & 2 & \\
\hline F-HTS-PMP2, F-LPI-ISV1, S-EL-III-2-E & 2 & 1 & \\
\hline F-HTS-PMP3, F-LPI-ISV1, S-EL-III-2-E & 2 & 1 & \\
\hline F-HTS-PMP1，F-LPI-ISV1, S-EL-III-2-E & 2 & 1 & \\
\hline F-LPI-ISV1, S-EL-III-2-E, S-EL-IV-O & 1 & 2 & \\
\hline F-LPI-INV2, S-EL-III-2-O, S-EL-IV-O & 1 & 2 & \\
\hline F-LPI-ISV1, S-EL-HII-2-E, S-EL-IV-E & 1 & 2 & \\
\hline F-LPI-INV2, S-EL-III-2-O, S-EL-IV-E & 1 & 2 & \\
\hline F-LPI-ISV2, S-EL-III-2-O, S-EL-IV-O & 1 & 2 & \\
\hline F-HTS-PMP1, F-LPI-ISV2, S-EL-III-2-O & 2 & 1 & \\
\hline F-HPI-ISV2-GI, S-EL-III-2-O, S-EL-IV-E & 1 & 2 & \\
\hline F-HPI-ISV2-GI, S-EL-III-2-O, S-EL-IV-O & 1 & 2 & \\
\hline F-HTS-PMP2, F-LPI-ISV2, S-EL-III-2-O & 2 & 1 & \\
\hline F-HTS-PMP1, F-LPI-INV2, S-EL-III-2-O & 2 & 1 & \\
\hline F-HPI-ISV2-GI, F-HTS-PMP1, S-EL-III-2-O & 2 & 1 & \\
\hline F-HTS-PMP4, F-LPI-INV2, S-EL-III-2-O & 2 & 1 & \\
\hline F-HTS-PMP4, F-LPI-ISV2, S-EL-III-2-O & 2 & 1 & \\
\hline F-HTS-PMP3, F-LPI-INV2, S-EL-III-2-O & 2 & 1 & \\
\hline F-HTS-PMP3, F-LPI-ISV2, S-EL-III-2-O & 2 & 1 & \\
\hline F-HTS-PMP2, F-LPI-INV2, S-EL-III-2-O & 2 & 1 & \\
\hline F-HTS-PMP3, S-EL-III-2-E, S-EL-III-2-O & 1 & 2 & \\
\hline F-HTS-PMP4, S-EL-III-2-E, S-EL-III-2-O & 1 & 2 & \\
\hline F-HTS-PMP2, S-EL-III-2-E, S-EL-III-2-O & 1 & 2 & \\
\hline F-HTS-PMP1, S-EL-III-2-E, S-EL-III-2-O & 1 & 2 & \\
\hline S-EL-III-2-E, S-EL-III-2-O, S-EL-IV-E & & 3 & \\
\hline S-EL-III-2-E, S-EL-III-2-O, S-EL-IV-O & & 3 & \\
\hline
\end{tabular}


Table C.1 (cont)

\begin{tabular}{|c|c|c|c|c|}
\hline Initiating Event - Feeder Tube Header Break & Sequenc & $L B-M$ & & \\
\hline Sequence Level Cut Sets & $\begin{array}{l}\text { Component } \\
\text { Failures }\end{array}$ & $\begin{array}{l}\text { Yuuman } \\
\text { Errors }\end{array}$ & $\begin{array}{l}\text { Suppon } \\
\text { System } \\
\text { Failures }\end{array}$ & $\begin{array}{l}\text { Determinant } \\
\text { Faihure? }\end{array}$ \\
\hline F-HTS-PMP1, S-ECC & 1 & & 1 & \\
\hline S-ECC, S-EL-IV-O & & & 2 & \\
\hline F-HTS-PMP2, S-ECC & 1 & & 1 & \\
\hline S-ECC, S-EL-IV-E & & & 2 & \\
\hline F-HTS-PMP3, S-ECC & 1 & & 1 & \\
\hline F-HTS-PMP4, S-ECC & 1 & & 1 & \\
\hline F-HPI-OV2A, F-HPI-OV2B, F-HTS-PMP1 & 3 & & & \\
\hline F-HPI-OV2A, F-HPI-OV2B, F-HTS-PMP2 & 3 & & & \\
\hline F-HPI-OV2A, F-HPI-OV2B, S-EL-IV-O & 2 & & 1 & \\
\hline F-HPI-OV2A, F-HPI-OV2B, F-HTS-PMP3 & 3 & & & \\
\hline F-HPI-OV2A, F-HPI-OV2B, S-EL-IV-E & 2 & & 1 & \\
\hline F-HPI-OV2A, F-HPI-OV2B, F-HTS-PMP4 & 3 & & & \\
\hline F-HPI-SIG1-LPHTS, F-HPI-SIG3-LPHTS, S-EL-IV-O & 2 & & 1 & \\
\hline F-HPI-SIG1-LPHTS, F-HPI-SIG3-LPHTS, F-HTS-PMP1 & 3 & & & \\
\hline F-HPI-SIG1-LPHTS, F-HPI-SIG3-LPHTS, S-EL-IV-E & 2 & & 1 & \\
\hline F-HPI-OV1A, F-HPI-OV1B, F-HTS-PMP3 & 3 & & & \\
\hline F-HPI-OV1A, F-HPI-OV1B, F-HTS-PMP2 & 3 & & & \\
\hline F-HPI-INV2A, F-HPI-INV2B, F-HTS-PMP1 & 3 & & & \\
\hline F-HPI-INV2A, F-HPI-INV2B, F-HTS-PMP2 & 3 & & & \\
\hline F-HPI-INV2A, F-HPI-INV2B, S-EL-IV-O & 2 & & 1 & \\
\hline F-HPI-INV2A, F-HPI-INV2B, F-HTS-PMP3 & 3 & & & \\
\hline F-HPI-INV2A, F-HPI-INV2B, F-HTS-PMP4 & 3 & & & \\
\hline F-HPI-OV1A, F-HPI-OV1B, S-EL-IV-O & 2 & & 1 & \\
\hline F-HPI-OV1A, F-HPI-OV1B, F-HTS-PMP1 & 3 & & & \\
\hline F-HPI-OV1A, F-HPI-OV1B, S-EL-IV-F, & 2 & & 1 & \\
\hline F-HPI-SIG1-LPHTS, F-HPI-SIG3-LPHTS, F-HTS-PMP2 & 3 & & & \\
\hline F-HPI-SIG1-LPHTS, F-HPI-SIG3-LPHTS, F-HTS-PMP3 & 3 & & & \\
\hline F-HPI-SIG1-LPHTS, F-HPI-SIG2-LPHTS, F-HTS-PMP4 & 3 & & & \\
\hline F-HPI-ISV1-GI, F-HPI-ISV2-GI, S-EL-IV-E & 2 & & 1 & \\
\hline F-HPI-SIG1-LPHTS, F-HPI-SIG2-LPHTS, F-HTS-PMP3 & 3 & & & \\
\hline F-HPI-ISV1-GI, F-HPI-ISV2-GI, S-EL-IV-O & 2 & & 1 & \\
\hline
\end{tabular}


Table C.1 (cont.)

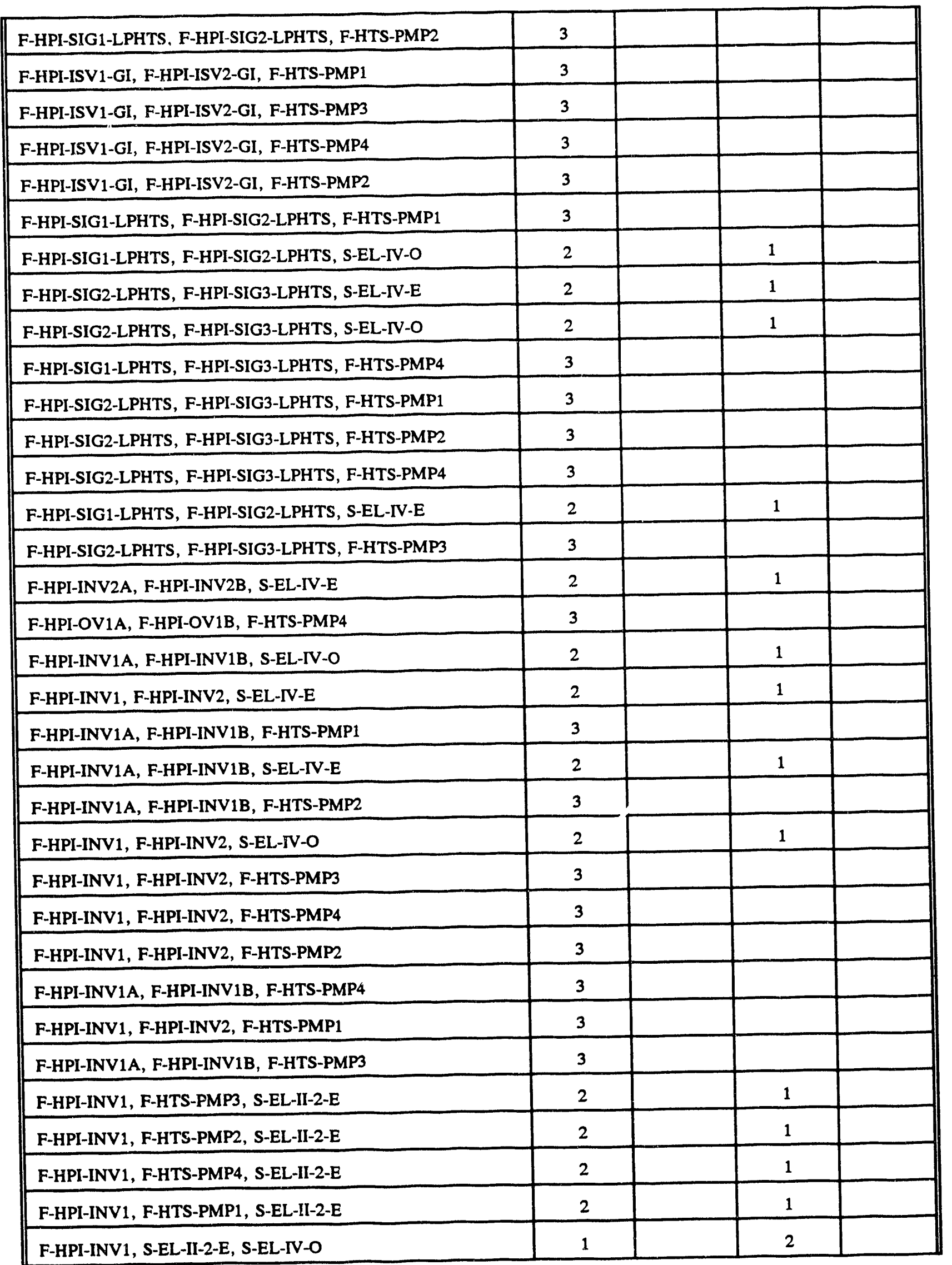


Table C.1 (cont.)

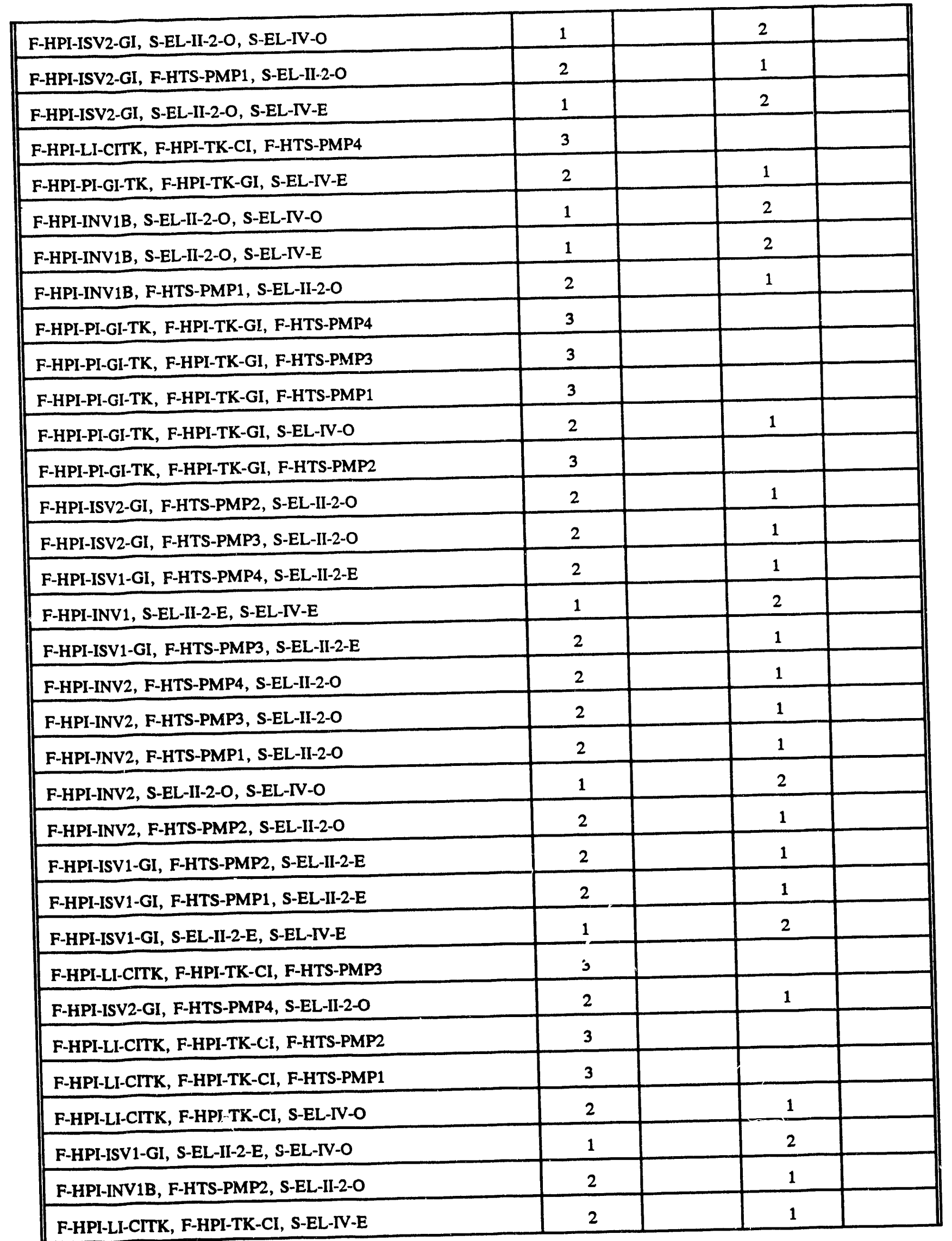


Table C.1 (cont)

\begin{tabular}{|c|c|c|c|}
\hline F-HPI-INV1B, F-HTS-PMP3, S-EL-II-2-O & 2 & 1 & \\
\hline F-HPI-OV1A, F-HTS-PMP1, S-EL-II-2-E & 2 & 1 & \\
\hline F-HPI-OV1A, F-HTS-PMP2, S-EL-II-2-E & 2 & 1 & \\
\hline F-HPI-OV1A, S-EL-II-2-E, S-EL-IV-O & 1 & 2 & \\
\hline F-HPI-OV1A, F-HTS-PMP3, S-EL-II-2-E & 2 & 1 & \\
\hline F-HPI-OV1A, S-EL-II-2-E, S-EL-IV-E & 1 & 2 & \\
\hline F-HPI-OV1A, F-HTS-PMP4, S-EL-II-2-E & 2 & 1 & \\
\hline F-HPI-INV2A, S-EL-II-2-E, S-EL-IV-E & 1 & 2 & \\
\hline F-HPI-OV1B, F-HTS-PMP2, S-EL-II-2-O & 2 & 1 & \\
\hline F-HPI-OV1B, S-EL-II-2-O, S-EL-IV-O & 1 & 2 & \\
\hline F-HPI-INV2B, S-EL-II-2-O, S-EL-IV-E & 1 & 2 & \\
\hline F-HPI-OV1B, S-EL-II-2-O, S-EL-IV-E & 1 & 2 & \\
\hline F-HPI-INV2B, S-EL-II-2-O, S-EL-IV-O & 1 & 2 & \\
\hline F-HPI-INV2A, F-HTS-PMP2, S-EL-II-2-E & 2 & 1 & \\
\hline F-HPI-INV2A, F-HTS-PMP3, S-EL-II-2-E & 2 & 1 & \\
\hline F-HPI-INV2A, F-HTS-PMP1, S-EL-II-2-E & 2 & 1 & \\
\hline F-HPI-INV2A, F-HTS-PMP4, S-EL-II-2-E & 2 & 1 & \\
\hline F-HPI-INV2A, S-EL-II-2-E, S-EL-IV-O & 1 & 2 & \\
\hline F-HPI-INV2B, F-HTS-PMP4, S-EL-II-2-O & 2 & 1 & \\
\hline F-HPI-INV2B, F-HTS-PMP2, S-EL-II-2-O & 2 & 1 & \\
\hline F-HPI-INV2B, F-HTS-PMP1, S-EL-II-2-O & 2 & 1 & \\
\hline F-HPI-INV2B, F-HTS-PMP3, S-EL-II-2-O & 2 & 1 & \\
\hline F-HPI-OV1B, F-HTS-PMP3, S-EL-II-2-O & 2 & 1 & \\
\hline F-HPI-OV1B, F-HTS-PMP1, S-EL-II-2-O & 2 & 1 & \\
\hline F-HPI-INV1A, F-HTS-PMP4, S-EL-II-2-E & 2 & 1 & \\
\hline F-HPI-INV1A, F-HTS-PMP3, S-EL-II-2-E & 2 & 1 & \\
\hline F-HPI-OV1B, F-HTS-PMP4, S-EL-II-2-O & 2 & 1 & \\
\hline F-HPI-INV1A, F-HTS-PMP2, S-EL-II-2-E & 2 & 1 & \\
\hline F-HPI-OV2A, F-HTS-PMP3, S-EL-II-2-E & 2 & 1 & \\
\hline F-HPI-INV1A, F-HTS-PMP1, S-EL-II-2-E & 2 & 1 & \\
\hline F-HPI-INV1A, S-EL-II-2-E, S-EL-IV-E & 1 & 2 & \\
\hline F-HPI-INV1B, F-HTS-PMP4, S-EL-II-2-O & 2 & 1 & \\
\hline F-HPI-INV1A, S-EL-II-2-E, S-EL-IV-O & 1 & 2 & \\
\hline F-HPI-OV2A, F-HTS-PMP2, S-EL-II-2-E & 2 & 1 & \\
\hline
\end{tabular}


Appendix C

Table C.1 (cont)

\begin{tabular}{|c|c|c|c|}
\hline F-HPI-OV2A, F-HTS-PMP4, S-EL-II-2-E & 2 & 1 & \\
\hline F-HPI-OV2A, F-HTS-PMP1, S-EL-II-2-E & 2 & 1 & \\
\hline F-HPI-OV2B, F-HTS-PMP1, S-EL-II-2-O & 2 & 1 & \\
\hline F-HPI-OV2B, S-EL-II-2-O, S-EL-IV-E & 1 & 2 & \\
\hline F-HPI-OV2B, F-HTS-PMP2, S-EL-II-2-O & 2 & 1 & \\
\hline F-HPI-INV2, S-EL-II-2-O, S-EL-IV-E & 1 & 2 & \\
\hline F-HPI-OV2B, S-EL-II-2-O, S-EL-IV-O & 1 & 2 & \\
\hline F-HPI-OV2A, S-EL-II-2-E, S-EL-IV-E & 1 & 2 & \\
\hline F-HPI-OV2B, F-HTS-PMP3, S-EL-II-2-O & 2 & 1 & \\
\hline F-HPI-OV2A, S-EL-II-2-E, S-EL-IV-O & 1 & 2 & \\
\hline F-HPI-OV2B, F-HTS-PMP4, S-EL-II-2-O & 2 & 1 & \\
\hline S-EL-II-2-E, S-EL-II-2-O, S-EL-IV-O & & 3 & \\
\hline S-EL-II-2-E, S-EL-II-2-O, S-EL-IV-E & & 3 & \\
\hline F-HTS-PMP1, S-EL-II-2-E, S-EL-II-2-O & 1 & 2 & \\
\hline F-HTS-PMP4, S-EL-II-2-E, S-EL-II-2-O & 1 & 2 & \\
\hline F-HTS-PMP2, S-EL-II-2-E, S-EL-II-2-O & 1 & 2 & \\
\hline F-HTS-PMP3, S-EL-II-2-E, S-EL-II-2-O & 1 & 2 & \\
\hline
\end{tabular}

\begin{tabular}{|c|c|c|c|c|}
\hline \multirow{2}{*}{$\begin{array}{c}\text { Initiating Event - Feeder Tube Header Break } \\
\text { Sequence Level Cut Sets }\end{array}$} & \multicolumn{4}{|c|}{ Sequence: $L B-N$} \\
\hline & $\begin{array}{l}\text { Component } \\
\text { Failures }\end{array}$ & $\begin{array}{c}\text { Human } \\
\text { Errors }\end{array}$ & $\begin{array}{l}\text { Support } \\
\text { System } \\
\text { Faitures } \\
\end{array}$ & $\begin{array}{l}\text { Determinant } \\
\text { Failure? }\end{array}$ \\
\hline F-HTS-PMP3, F-MCS-ISV-FC, S-ECC & 2 & & 1 & \\
\hline F-HTS-PMP3, S-ECC, S-RCW & 1 & & 2 & \\
\hline F-HTS-PMP3, F-MCS-PMP2, S-ECC & 2 & & 1 & \\
\hline F-HTS-PMP2, S-ECC, S-EL-III-1-O & 1 & & 2 & \\
\hline F-HTS-PMP2, F-MCS-PMP1, S-ECC & 2 & & 1 & \\
\hline F-HTS-PMP2, F-MCS-PMP2, S-ECC & 2 & & 1 & \\
\hline F-HTS-PMP2, F-MCS-ISV-FC, S-ECC & 2 & & 1 & \\
\hline F-HTS-PMP2, S-ECC, S-EL-III-1-E & 1 & & 2 & \\
\hline F-HTS-PMP3, S-ECC, S-EL-III-1-E & 1 & & 2 & \\
\hline F-HTS-PMP3, F-MCS-PMP1, S-ECC & 2 & & 1 & \\
\hline F-HTS-PMP4, F-MCS-PMP1, S-ECC & 2 & & 1 & \\
\hline F-HTS-PMP4, S-ECC, S-EL-III-1-E & 1 & & 2 & \\
\hline
\end{tabular}


Table C.1 (cont)

\begin{tabular}{|c|c|c|c|}
\hline F-HTS-PMP4, S-ECC, S-EL-III-1-O & 1 & 2 & \\
\hline F-HTS-PMP4, F-MCS-PMP2, S-ECC & 2 & 1 & \\
\hline F-HTS-PMP4, F-MCS-ISV-FC, S-ECC & 2 & 1 & \\
\hline F-HTS-PMP3, S-ECC, S-EL-III-1-O & 1 & 2 & \\
\hline F-HTS-PMP4, S-ECC, S-RCW & 1 & 2 & \\
\hline F-HTS-PMP2, S-ECC, S-RCW & 1 & 2 & \\
\hline F-HTS-PMP1, S-ECC, S-EL-III-1-O & 1 & 2 & \\
\hline S-ECC, S-EL-IV-O, S-RCW & & 3 & \\
\hline S-ECC, S-EL-III-1-O, S- EL-IV-E & & 3 & \\
\hline F-MCS-ISV-FC, S-ECC, S-EL-IV-O & 1 & 2 & \\
\hline F-MCS-PMP1, S-ECC, S-EL-IV-E & 1 & 2 & \\
\hline S-ECC, S-EL-III-1-E, S-EL-IV-E & & 3 & \\
\hline F-MCS-ISV-FC, S-ECC, S-EL-IV-E & 1 & 2 & \\
\hline F-MCS-PMP2, S-ECC, "'-EL-IV-E & 1 & 2 & \\
\hline F-MCS-PMP2, S-ECC, S-EL-IV-O & 1 & 2 & \\
\hline S-ECC, S-EL-III-1-E, S-EL-IV-O & & 3 & \\
\hline F-HTS-PMP1, S-ECC, S-EL-III-1-E & 1 & 2 & \\
\hline F-HTS-PMP1, F-MCS-PMP2, S-ECC & 2 & 1 & \\
\hline F-HTS-PMP1, F-MCS-PMP1, S-ECC & 2 & 1 & \\
\hline F-HTS-PMP1，F-MCS-ISV-FC, S-ECC & 2 & 1 & \\
\hline F-HTS-PMP1, S-ECC, S-RCW & 1 & 2 & \\
\hline F-MCS-PMP1, S-ECC, S-EL-IV-O & 1 & 2 & \\
\hline S-ECC, S-EL-III-1-O, S-EL-IV-O & & 3 & \\
\hline S-ECC, S-EL-IV-E, S-RCW & & 3 & \\
\hline
\end{tabular}


Table C.1 (cont)

\begin{tabular}{|c|c|c|c|c|}
\hline \multirow{2}{*}{$\frac{\text { Initiating Event - Feeder Tube Header Break }}{\text { Sequence Level Cut Sets }}$} & \multicolumn{4}{|c|}{ Sequence: $L B-O$} \\
\hline & $\begin{array}{l}\text { Composent } \\
\text { Failures }\end{array}$ & $\begin{array}{l}\text { Humanan } \\
\text { Errons }\end{array}$ & $\begin{array}{l}\text { Support } \\
\text { Syotem } \\
\text { Failures }\end{array}$ & $\begin{array}{l}\text { Determinant } \\
\text { Friture? }\end{array}$ \\
\hline F-SD1-CR-BD-CM & & & 1 & $\mathbf{Y}$ \\
\hline F-SD1-CR-COIL-CM & & & 1 & $\mathbf{Y}$ \\
\hline F-SD1-TLB-REL2, F-SD1-TLB-REL3 & 2 & & & $\mathbf{Y}$ \\
\hline F-SD1-TLB-REL1, F-SD1-TLB-REL2 & 2 & & & $\mathbf{Y}$ \\
\hline F-SD1-TLA-REL1, F-SD1-TLA-REL2 & 2 & & & $\mathbf{Y}$ \\
\hline F-SD1-TLB-REL1, F-SD1-TLB-REL3 & 2 & & & $\mathbf{Y}$ \\
\hline F-SD1-TLA-REL2, F-SD1-TLA-REL3 & 2 & & & $\mathbf{Y}$ \\
\hline F-SD1-TLA-REL1, F-SD1-TLA-REL3 & 2 & & & $\mathbf{Y}$ \\
\hline F-SD1-TC-D, F-SD1-TC-E & 2 & & & $\mathbf{Y}$ \\
\hline F-SD1-TC-D, F-SD1-TC-F & 2 & & & $\mathbf{Y}$ \\
\hline F-SD1-TC-E, F-SD1-TC-F & 2 & & & $\mathbf{Y}$ \\
\hline
\end{tabular}

\begin{tabular}{|c|c|c|c|c|}
\hline \multirow{2}{*}{$\begin{array}{c}\text { Initiating Event - Feeder Tube Header Break } \\
\text { Sequence Level Cut Sets }\end{array}$} & \multicolumn{4}{|c|}{ Sequence: $\boldsymbol{L B}-\boldsymbol{P}$} \\
\hline & $\begin{array}{l}\text { Componeant } \\
\text { Failures }\end{array}$ & $\begin{array}{l}\text { Human } \\
\text { Enrors }\end{array}$ & $\begin{array}{l}\text { Support } \\
\text { Symen } \\
\text { Failurea }\end{array}$ & $\begin{array}{c}\text { Determimant } \\
\text { Failure? }\end{array}$ \\
\hline F-REC-ISV1, F-REC-ISV2, F-SD1-CR-BD-CM & 2 & & 1 & \\
\hline F-REC-ISV1, F-REC-ISV2, F-SD1-CR-COIL-CM & 2 & & 1 & \\
\hline F-REC-ISV2, F-SD1-CR-BD-CM, S-EL-III-2-O & 1 & & 2 & \\
\hline F-REC-ISV1, F-SD1-CR-COIL-CM, S-EL-III-2-E & 1 & & 2 & \\
\hline F-REC-ISV1, F-SD1-CR-BD-CM, S-EL-III-2-E & 1 & & 2 & \\
\hline F-REC-ISV2, F-SD1-CR-COIL-CM, S-EL-III-2-O & 1 & & 2 & \\
\hline F-REC-HX1, F-REC-HX2, F-SD1-CR-BD-CM & 2 & & 1 & \\
\hline F-REC-HX1, F-REC-HX2, F-SD1-CR-COIL-CM & 2 & & 1 & \\
\hline
\end{tabular}

\begin{tabular}{|c|c|c|c|c|}
\hline Initiating Event - Feeder Tube Header Break & \multicolumn{2}{|l|}{ Sequence: LB-Q } \\
\hline Sequence Level Cut Sets & $\begin{array}{c}\text { Composent } \\
\text { Failures }\end{array}$ & $\begin{array}{c}\text { Humen } \\
\text { Erron }\end{array}$ & $\begin{array}{c}\text { Support } \\
\text { System } \\
\text { Frihurea }\end{array}$ & $\begin{array}{c}\text { Determinant } \\
\text { Faikure ? }\end{array}$ \\
\hline F-SD1-CR-BD-CM, S-RCW, S-SW2 & & & 3 & \\
\hline F-SD1-CR-COIL-CM, S-RCW, S-SW2 & & & 3 & \\
\hline
\end{tabular}


Table C.1 (cont)

\begin{tabular}{|c|c|c|c|c|}
\hline \multirow[t]{2}{*}{ Initiating Event - Feeder Tube Header Break } & \multicolumn{4}{|c|}{ Sequence: $\boldsymbol{L B}-\boldsymbol{R}$} \\
\hline & $\begin{array}{l}\text { Component } \\
\text { Failures }\end{array}$ & $\begin{array}{l}\text { Human } \\
\text { Emrons }\end{array}$ & $\begin{array}{l}\text { Suppon } \\
\text { System } \\
\text { Failures }\end{array}$ & $\begin{array}{l}\text { Determimant } \\
\text { Faihure? }\end{array}$ \\
\hline F-LPI-INV1, F-LPI-INV2, F-SD1-CR-COIL-CM & 2 & & 1 & \\
\hline F-LPI-ISV1, F-LPI-ISV2, F-SD1-CR-COIL-CM & 2 & & 1 & \\
\hline F-LPI-PMP1, F-LPI-PMP2, F-SD1-CR-BD-CM & 2 & & 1 & \\
\hline F-LPI-ISV1, F-LPI-ISV2, F-SD1-CR-BD-CM & 2 & & 1 & \\
\hline F-LPI-PMP1, F-LPI-PMP2, F-SD1-CR-COIL-CM & 2 & & 1 & \\
\hline F-LPI-INV1, F-LPI-INV2, F-SD1-CR-BD-CM & 2 & & 1 & \\
\hline F-LPI-PMP2, F-SD1-CR-BD-CM, S-EL-III-2-O & 1 & & 2 & \\
\hline F-LPI-PMP2, F-SD1-CR-COIL-CM, S-EL-III-2-O & 1 & & 2 & \\
\hline F-HPI-ISV1-GI, F-SD1-CR-COIL-CM, S-EL-III-2-E & 1 & & 2 & \\
\hline F-LPI-PMP1, F-SD1-CR-BD-CM, S-EL-III-2-E & 1 & & 2 & \\
\hline F-LPI-PMP1, F-SD1-CR-COIL-CM, S-EL-III-2-E & 1 & & 2 & \\
\hline F-LPI-LI-TK, F-LPI-TK, F-SD1-CR-BD-CM & 2 & & 1 & \\
\hline F-LPI-LI-TK, F-LPI-TK, F-SD1-CR-COIL-CM & 2 & & 1 & \\
\hline F-LPI-ISV2, F-SD1-CR-BD-CM, S-EL-III-2-O & 1 & & 2 & \\
\hline F-HPI-ISV1-GI, F-SD1-CR-BD-CM, S-EL-III-2-E & 1 & & 2 & \\
\hline F-HPI-ISV2-GI, F-SD1-CR-COIL-CM, S-EL-III-2-O & 1 & & 2 & \\
\hline F-LPI-INV1, F-SD1-CR-BD-CM, S-EL-III-2-E & 1 & & 2 & \\
\hline F-LPI-INV1, F-SD1-CR-COIL-CM, S-EL-III-2-E & 1 & & 2 & \\
\hline F-LPI-ISV1, F-SD1-CR-BD-CM, S-EL-III-2-E & 1 & & 2 & \\
\hline F-LPI-INV2, F-SD1-CR-BD-CM, S-EL-III-2-O & 1 & & 2 & \\
\hline F-LPI-INV2, F-SD1-CR-COIL-CM, S-EL-III-2-O & 1 & & 2 & \\
\hline F-LPI-ISV2, F-SD1-CR-COIL-CM, S-EL-III-2-O & 1 & & 2 & \\
\hline F-LPI-ISV1, F-SD1-CR-COIL-CM, S-EL-III-2-E & 1 & & 2 & \\
\hline F-HPI-ISV2-GI, F-SD1-CR-BD-CM, S-EL-III-2-O & 1 & & 2 & \\
\hline F-SD1-CR-COIL-CM, S-EL-III-2-E, S-EL-III-2-O & & & 3 & \\
\hline F-SD1-CR-BD-CM, S-EL-III-2-E, S-EL-III-2-O & & & 3 & \\
\hline
\end{tabular}




\begin{tabular}{|c|c|c|c|c|}
\hline \multirow{2}{*}{$\begin{array}{c}\text { Initiating Event - Feeder Tube Header Break } \\
\text { Sequence Level Cut Sets }\end{array}$} & \multicolumn{4}{|c|}{ Sequence: $L B-T$} \\
\hline & $\begin{array}{c}\text { Component } \\
\text { Failures }\end{array}$ & $\begin{array}{c}\text { Human } \\
\text { Emrors }\end{array}$ & $\begin{array}{l}\text { Support } \\
\text { System } \\
\text { Faihures }\end{array}$ & $\begin{array}{l}\text { Determinent } \\
\text { Fuihure : }\end{array}$ \\
\hline F-SD1-CR-BD-CM, S-ECC & & & 2 & \\
\hline F-SD1-CR-COIL-CM, S-ECC & & & 2 & \\
\hline F-HPI-SIG2-LPHTS, F-HPI-SIG3-LPHTS, F-SD1-CR-COIL-CM & 2 & & 1 & \\
\hline F-HPI-SIG2-LPHTS, F-HPI-SIG3-LPHTS, F-SD1-CR-BD-CM & 2 & & 1 & \\
\hline F-HPI-SIG1-LPHTS, F-HPI-SIG2-LPHTS, F-SD1-CR-BD-CM & 2 & & 1 & \\
\hline F-HPI-SIG1-LPHTS, F-HPI-SIG3-LPHTS, F-SD1-CR-COIL-CM & 2 & & 1 & \\
\hline F-HPI-SIG1-LPHTS, F-HPI-SIG3-LPHTS, F-SD1-CR-BD-CM & 2 & & 1 & \\
\hline F-HPI-OV1A, F-HPI-OV1B, F-SD1-CR-COIL-CM & 2 & & 1 & \\
\hline F-HPI-OV2A, F-HPI-OV2B, F-SD1-CR-COIL-CM & 2 & & 1 & \\
\hline F-HPI-SIG1-LPHTS, F-HPI-SIG2-LPHTS, F-SD1-CR-COIL-CM & 2 & & 1 & \\
\hline F-HPI-ISV1-GI, F-HPI-ISV2-GI, F-SD1-CR-BD-CM & 2 & & 1 & \\
\hline F-SD1-TLB-REL2, F-SD1-TLB-REL3, S-ECC & 2 & & 1 & \\
\hline F-SD1-TLB-REL1, F-SD1-TLB-REL3, S-ECC & 2 & & 1 & \\
\hline F-SD1-TLB-REL1, F-SD1-TLB-REL2, S-ECC & 2 & & 1 & \\
\hline F-SD1-TLA-REL1, F-SD1-TLA-REL2, S-ECC & 2 & & 1 & \\
\hline F-SD1-TLA-REL2, F-SD1-TLA-REL3, S-ECC & 2 & & 1 & \\
\hline F-HPI-ISV1-GI, F-HPI-ISV2-GI, F-SD1-CR-COIL-CM & 2 & & 1 & \\
\hline F-SD1-TLA-REL1, F-SD1-TLA-REL3, S-ECC & 2 & & 1 & \\
\hline F-HPI-OV1A, F-HPI-OV1B, F-SD1-CR-BD-CM & 2 & & 1 & \\
\hline F-HPI-OV2A, F-HPI-OV2B, F-SD1-CR-BD-CM & 2 & & 1 & \\
\hline F-HPI-INV1, F-HPI-INV2, F-SD1-CR-COIL-CM & 2 & & 1 & \\
\hline F-HPI-INV1, F-HPI-INV2, F-SD1-CR-BD-CM & 2 & & 1 & \\
\hline F-HPI-INV1A, F-HPI-INV1B, F-SD1-CR-COIL-CM & 2 & & 1 & \\
\hline F-HPI-INV2A, F-HPI-INV2B, F-SD1-CR-COIL-CM & 2 & & 1 & \\
\hline F-HPI-INV2A, F-HPI-INV2B, F-SD1-CR-BD-CM & 2 & & 1 & \\
\hline F-HPI-INV1A, F-HPI-INV1B, F-SD1-CR-BD-CM & 2 & & 1 & \\
\hline F-HPI-INV1A, F-SD1-CR-BD-CM, S-EL-II-2-E & 1 & & 2 & \\
\hline F-HPI-INV1B, F-SD1-CR-COIL-CM, S-EL-II-2-O & 1 & & 2 & \\
\hline F-HPI-ISV1-GI, F-SD1-CR-COIL-CM, S-EL-II-2-E & 1 & & 2 & \\
\hline F-HPI-ISV1-GI, F-SD1-CR-BD-CM, S-EL-II-2-E & 1 & & 2 & \\
\hline F-HPI-LI-CITI, F-HPI-TK-CI, F-SD1-CR-BD-CM & 2 & & 1 & \\
\hline
\end{tabular}


Table C.1 (cont)

\begin{tabular}{|c|c|c|c|}
\hline F-HPI-PI-GI-TK, F-HPI-TK-GI, F-SD1-CR-COIL-CM & 2 & 1 & \\
\hline F-HPI-INV1, F-SD1-CR-BD-CM, S-EL-II-2-E & 1 & 2 & \\
\hline F-HPI-INV2, F-SD1-CR-COIL-CM, S-EL-II-2-O & 1 & 2 & \\
\hline F-HPI-INV1, F-SD1-CR-COIL-CM, S-EL-II-2-E & 1 & 2 & \\
\hline F-HPI-INV1B, F-SD1-CR-BD-CM, S-EL-II-2-O & 1 & 2 & \\
\hline F-HPI-PI-GI-TK, F-HPI-TK-GI, F-SD1-CR-BD-CM & 2 & 1 & \\
\hline F-HPI-OV1A, F-SD1-CR-BD-CM, S-EL-II-2-E & 1 & 2 & \\
\hline F-HPI-LI-CITK, F-HPI-TK-CI, F-SD1-CR-COIL-CM & 2 & 1 & \\
\hline F-HPI-ISV2-GI, F-SD1-CR-COIL-CM, S-EL-II-2-O & 1 & 2 & \\
\hline F-HPI-OV2A, F-SD1-CR-BD-CM, S-EL-II-2-E & 1 & 2 & \\
\hline F-HPI-ISV2-GI, F-SD1-CR-BD-CM, S-EL-II-2-O & 1 & 2 & \\
\hline F-HPI-OV2B, F-SD1-CR-COIL-CM, S-EL-II-2-O & 1 & 2 & \\
\hline F-HPI-OV2B, F-SD1-CR-BD-CM, S-EL-II-2-O & 1 & 2 & \\
\hline F-HPI-OV1B, F-SD1-CR-BD-CM, S-EL-II-2-O & 1 & 2 & \\
\hline F-HPI-OV1B, F-SD1-CR-COIL-CM, S-EL-II-2-O & 1 & 2 & \\
\hline F-HPI-OV1A, F-SD1-CR-COIL-CM, S-EL-II-2-E & 1 & 2 & \\
\hline F-HPI-OV2A, F-SD1-CR-COIL-CM, S-EL-II-2-E & 1 & 2 & \\
\hline F-HPI-INV2B, F-SD1-CR-BD-CM, S-EL-II-2-O & 1 & 2 & \\
\hline F-HPI-INV2B, F-SD1-CR-COIL-CM, S-EL-II-2-O & 1 & 2 & \\
\hline F-HPI-INV1A, F-SD1-CR-COIL-CM, S-EL-II-2-E & 1 & 2 & \\
\hline F-HPI-INV2A, F-SD1-CR-BD-CM, S-EL-II-2-E & 1 & 2 & \\
\hline F-HPI-INV2A, F-SD1-CR-COIL-CM, S-EL-II-2-E & 1 & 2 & \\
\hline F-HPI-INV2, F-SD1-CR-BD-CM, S-EL-II-2-O & 1 & 2 & \\
\hline F-SD1-CR-COIL-CM, S-EL-II-2-E, S-EL-II-2-O & & 3 & \\
\hline F-SD1-CR-BD-CM, S-EL-II-2-E, S-EL-II-2-O & & 3 & \\
\hline F-SD1-TC-D, F-SD1-TC-F, S-ECC & 2 & 1 & \\
\hline F-SD1-TC-E, F-SD1-TC-F, S-ECC & 2 & 1 & \\
\hline F-SD1-TC-D, F-SD1-TC-E, S-ECC & 2 & 1 & \\
\hline
\end{tabular}


Appendix C

Table C.1 (cont)

\begin{tabular}{|c|c|c|c|c|}
\hline Initiating Event - Feeder Tube Header Break & Sequen & $\boldsymbol{L B}-\boldsymbol{U}$ & & \\
\hline Sequence Level Cut Sets & $\begin{array}{l}\text { Component } \\
\text { Failures }\end{array}$ & $\begin{array}{c}\text { Human } \\
\text { Errora }\end{array}$ & $\begin{array}{l}\text { Support } \\
\text { System } \\
\text { Failures }\end{array}$ & $\begin{array}{l}\text { Determinant } \\
\text { Failure? }\end{array}$ \\
\hline F-MCS-PMP1, F-SD1-CR-BD-CM, S-ECC & 1 & & 2 & \\
\hline F-SD1-CR-COIL-CM, S-ECC, S-EL-III-1-E & & & 3 & \\
\hline F-MCS-PMP1, F-SD1-CR-COIL-CM, S-ECC & 1 & & 2 & \\
\hline F-SD1-CR-BD-CM, S-ECC, S-EL-III-1-O & & & 3 & \\
\hline F-SD1-CR-BD-CM, S-ECC, S-EL-III-1-E & & & 3 & \\
\hline F-SD1-CR-COIL-CM, S-ECC, S-EL-1II-1-0 & & & 3 & \\
\hline F-MCS-PMP2, F-SD1-CR-COIL-CM, S-ECC & 1 & & 2 & \\
\hline F-MCS-ISV-FC, F-SD1-CR-BD-CM, S-ECC & 1 & & 2 & \\
\hline F-SD1-CR-COIL-CM, S-ECC, S-RCW & & & 3 & \\
\hline F-MCS-ISV-FC, F-SD1-CR-COIL-CM, S-ECC & 1 & & 2 & \\
\hline F-SD1-CR-BD-CM, S-ECC, S-RCW & & & 3 & \\
\hline F-MCS-PMP2, F-SD1-CR-BD-CM, S-ECC & 1 & & 2 & \\
\hline
\end{tabular}

\begin{tabular}{|c|c|c|c|c|}
\hline \multirow{2}{*}{$\begin{array}{c}\text { Initiating Event - Feeder Tube Header Break } \\
\text { Sequence Level Cut Sets }\end{array}$} & \multicolumn{4}{|c|}{ Sequence: $\boldsymbol{L B}-\boldsymbol{V}$} \\
\hline & $\begin{array}{c}\text { Component } \\
\text { Faikures }\end{array}$ & $\begin{array}{l}\text { Humanon } \\
\text { Errors }\end{array}$ & $\begin{array}{l}\text { Support } \\
\text { System } \\
\text { Failures }\end{array}$ & $\begin{array}{l}\text { Determinent } \\
\text { Failure? }\end{array}$ \\
\hline F-SD1-CR-COIL-CM, S-EL-IV-O & 1 & & 1 & \\
\hline F-HTS-PMP1, F-SD1-CR-BD-CM & 1 & & 1 & \\
\hline F-SD1-CR-BD-CM, S-EL-IV-O & & & 2 & \\
\hline F-HTS-PMP1, F-SD1-CR-COIL-CM & 1 & & 1 & \\
\hline F-SD1-CR-COIL-CM, S-EL-IV-E & & & 2 & \\
\hline F-HTS-PMP2, F-SD1-CR-BD-CM & 1 & & 1 & \\
\hline F-HTS-PMP3, F-SD1-CR-COIL-CM & 1 & & 1 & \\
\hline F-HTS-PMP4, F-SD1-CR-BD-CM & 1 & & 1 & \\
\hline F-HTS-PMP3, F-SD1-CR-BD-CM & 1 & & 1 & \\
\hline F-SD1-CR-BD-CM, S-EL-IV-E & & & 2. & \\
\hline F-HTS-PMP2, F-SD1-CR-COIL-CM & 1 & & 1 & \\
\hline F-HTS-PMP4, F-SD1-CR-COIL-CM & 1 & & 1 & \\
\hline F-HTS-PMP4, F-SD1-TLB-REL1, F-SD1-TLB-REL3 & 3 & & & \\
\hline F-HTS-PMP3, F-SD1-TLB-REL1, F-SD1-TLB-REL3 & 3 & & & \\
\hline
\end{tabular}


Table C.1 (cont)

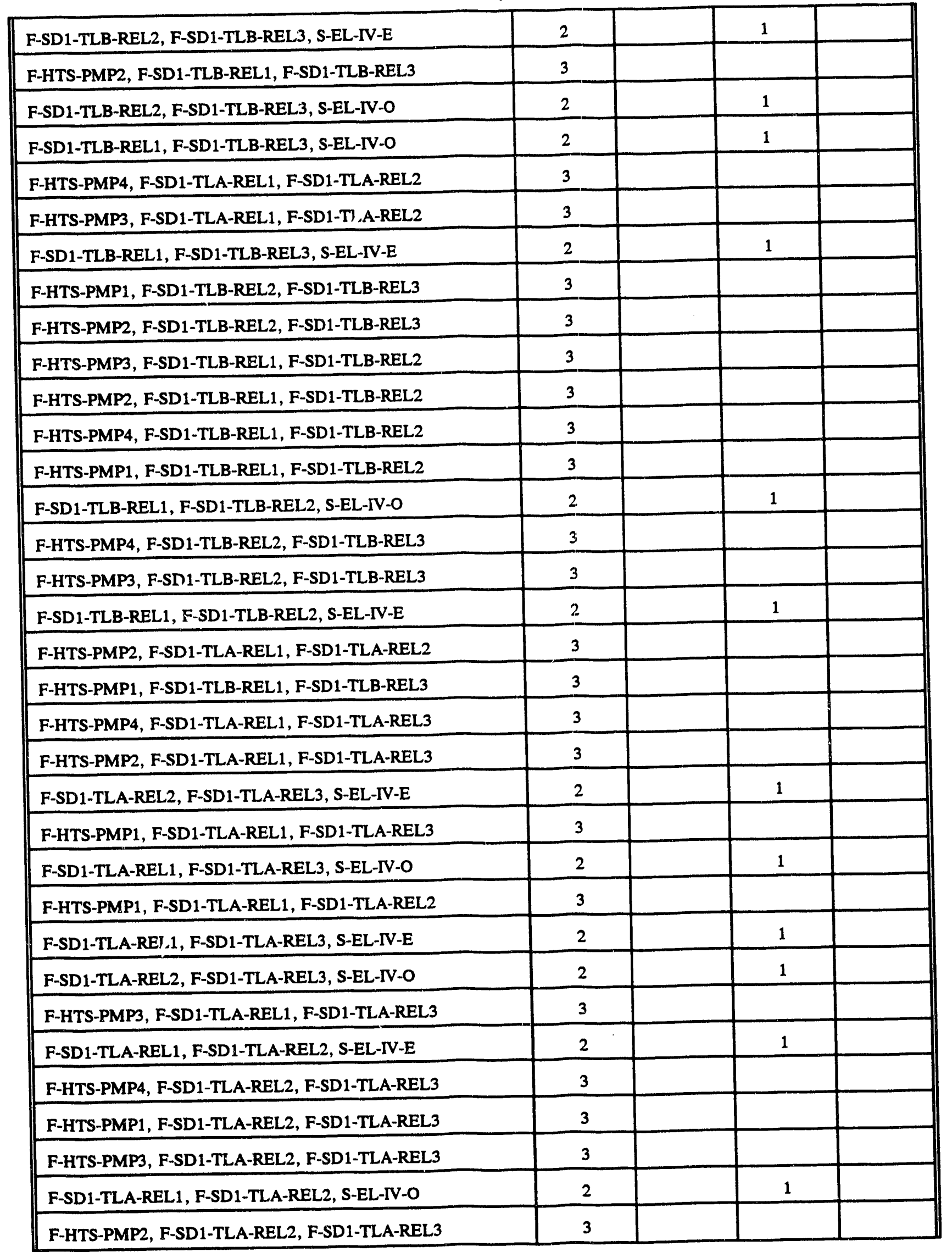




\begin{tabular}{|c|c|c|c|}
\hline F-SD1-TC-D, F-SD1-TC-F, S-EL-IV-E & 2 & 1 & \\
\hline F-HTS-PMP4, F-SD1-TC-D, F-SD1-TC-E & 3 & & \\
\hline F-HTS-PMP3, F-SD1-TC-D, F-SD1-TC-E & 3 & & \\
\hline F-SD1-TC-D, F-SD1-TC-F, S-EL-IV-O & 2 & 1 & \\
\hline F-HTS-PMP1, F-SD1-TC-D, F-SD1-TC-E & 3 & & \\
\hline F-SD1-TC-D, F-SD1-TC-E, S-EL-IV-O & 2 & 1 & \\
\hline F-HTS-PMP1, F-SD1-TC-D, F-SD1-TC-F & 3 & & \\
\hline F-SD1-TC-D, F-SD1-TC-E, S-EL-IV-E & 2 & 1 & \\
\hline F-HTS-PMP2, F-SD1-TC-D, F-SD1-TC-E & 3 & & \\
\hline F-HTS-PMP4, F-SD1-TC-E, F-SD1-TC-F & 3 & & \\
\hline F-HTS-PMP3, F-SD1-TC-E, F-SD1-TC-F & 3 & & \\
\hline F-HTS-PMP2, F-SD1-TC-E, F-SD1-TC-F & 3 & & \\
\hline F-SD1-TC-E, F-SD1-TC-F, S-EL-IV-E & 2 & 1 & \\
\hline F-HTS-PMP1, F-SD1-TC-E, F-SD1-TC-F & 3 & & \\
\hline F-SD1-TC-E, F-SD1-TC-F, S-EL-IV-O & 2 & 1 & \\
\hline F-HTS-PMI3, F-SD1-TC-D, F-SD1-TC-F & 3 & & \\
\hline F-HTS-PM P4, F-SD1-TC-D, F-SD1-TC-F & 3 & & \\
\hline F-HTS-FMP2, F-SD1-TC-D, F-SD1-TC-F & 3 & & \\
\hline
\end{tabular}

\begin{tabular}{|c|c|c|c|c|}
\hline \multirow{2}{*}{$\begin{array}{c}\text { Initiating Event - Feeder Tube Header Break } \\
\text { Sequence Level Cut Sets }\end{array}$} & \multicolumn{4}{|c|}{ Sequence: $L B-A A$} \\
\hline & $\begin{array}{c}\text { Component } \\
\text { Failures }\end{array}$ & $\begin{array}{l}\text { Human } \\
\text { Errors }\end{array}$ & $\begin{array}{l}\text { Support } \\
\text { System } \\
\text { Failures }\end{array}$ & $\begin{array}{l}\text { Determinant } \\
\text { Failure? }\end{array}$ \\
\hline F-HTS-PMP3, F-SD1-CR-BD-CM, S-ECC & 1 & & 2 & \\
\hline F-HTS-PMP2, F-SD1-CR-COIL-CM, S-ECC & 1 & & 2 & \\
\hline F-HTS-PMP3, F-SD1-CR-COIL-CM, S-ECC & 1 & & 2 & \\
\hline F-HTS-PMP4, F-SD1-CR-BD-CM, S-ECC & 1 & & 2 & \\
\hline F-HTS-PMP2, F-SD1-CR-BD-CM, S-ECC & 1 & & 2 & \\
\hline F-HTS-PMP4, F-SD1-CR-COIL-CM, S-ECC & 1 & & 2 & \\
\hline F-HTS-PMP1, F-SD1-CR-COIL-CM, S-ECC & 1 & & 2 & \\
\hline F-SD1-CR-BD-CM, S-ECC, S-EL-IV-O & & & 3 & \\
\hline F-SD1-CR-COIL-CM, S-ECC, S-EL-IV-E & & & 3 & \\
\hline F-SD1-CR-COIL-CM, S-ECC, S-EL-IV-O & & & 3 & \\
\hline F-SD1-CR-BD-CM, S-ECC, S-EL-IV-E & & & 3 & \\
\hline F-HTS-PMP1, F-SD1-CR-BD-CM, S-ECC & 1 & & 2 & \\
\hline
\end{tabular}


Table C.1 (cont.)

\begin{tabular}{|c|c|c|c|c|}
\hline Initiating Event - Feeder Tube Header Break & Sequenc & $L B-A C$ & & \\
\hline Sequence Level Cut Sets & $\begin{array}{l}\text { Component } \\
\text { Failures }\end{array}$ & $\begin{array}{l}\text { Human } \\
\text { Errors }\end{array}$ & $\begin{array}{l}\text { Suppon } \\
\text { System } \\
\text { Failures }\end{array}$ & $\begin{array}{l}\text { Deverminant } \\
\text { Failure? }\end{array}$ \\
\hline F-SD1-CR-COIL-CM, F-SD2-ISV1-PT5, F-SD2-ISV2-PT2 & 2 & & 1 & \\
\hline F-SD1-CR-COIL-CM, F-SD2-ISV2-PT2, F-SD2-ISV2-PT5 & 2 & & 1 & \\
\hline F-SD1-CR-COIL-CM, F-SD2-ISV1-PT2, F-SD2-ISV2-PT5 & 2 & & 1 & \\
\hline F-SD1-CR-COIL-CM, F-SD2-ISV1-PT2, F-SD2-ISV1-PT5 & 2 & & 1 & \\
\hline F-SD1-CR-BD-CM, F-SD2-ISV1-PT5, F-SD2-ISV2-PT2 & 2 & & 1 & \\
\hline F-SD1-CR-BD-CM, F-SD2-ISV2-PT2, F-SD2-ISV2-PT5 & 2 & & 1 & \\
\hline F-SD1-CR-BD-CM, F-SD2-ISV1-PT3, F-SD2-ISV1-PT5 & 2 & & 1 & \\
\hline F-SD1-CR-BD-CM, F-SD2-ISV1-PT3, F-SD2-ISV2-PT5 & 2 & & 1 & \\
\hline F-SD1-CR-COIL-CM, F-SD2-ISV1-PT5, F-SD2-ISV2-PT3 & 2 & & 1 & \\
\hline F-SD1-CR-COIL-CM, F-SD2-ISV2-PT3, F-SD2-ISV2-PT5 & 2 & & 1 & \\
\hline F-SD1-CR-COIL-CM, F-SD2-ISV1-PT3, F-SD2-ISV2-PT5 & 2 & & 1 & \\
\hline F-SD1-CR-COIL-CM, F-SD2-ISV1-PT3, F-SD2-ISV1-PT5 & 2 & & 1 & \\
\hline F-SD1-CR-BD-CM, F-SD2-ISV1-PT5, F-SD2-ISV2-PT3 & 2 & & 1 & \\
\hline F-SD1-CR-BD-CM, F-SD2-ISV2-PT3, F-SD2-ISV2-PT5 & 2 & & 1 & \\
\hline F-SD1-CR-BD-CM, F-SD2-ISV1-PT2, F-SD2-ISV2-PT5 & 2 & & 1 & \\
\hline F-SD1-CR-BD-CM, F-SD2-ISV1-PT2, F-SD2-ISV1-PT5 & 2 & & 1 & \\
\hline F-SD1-CR-BD-CM, F-SD2-TL-G, F-SD2-TL-J & 2 & & 1 & \\
\hline F-SD1-CR-COIL-CM, F-SD2-TL-G, F-SD2-TL-J & 2 & & 1 & \\
\hline F-SD1-CR-COIL-CM, F-SD2-TL-H, F-SD2-TL-J & 2 & & 1 & \\
\hline F-SD1-CR-BD-CM, F-SD2-TL-H, F-SD2-TL-J & 2 & & 1 & \\
\hline F-SD1-CR-BD-CM, F-SD2-TL-G, F-SD2-TL-H & 2 & & 1 & \\
\hline F-SD1-CR-COIL-CM, F-SD2-TL-G, F-SD2-TL-H & 2 & & 1 & \\
\hline F-SD1-CR-BD-CM, F-SD2-ISV1-PT3, F-SD2-ISV1-PT4 & 2 & & 1 & \\
\hline F-SD1-CR-BD-CM, F-SD2-ISV1-PT3, F-SD2-ISV2-PT4 & 2 & & 1 & \\
\hline F-SD1-CR-COIL-CM, F-SD2-ISV1-PT4, F-SD2-ISV2-PT3 & 2 & & 1 & \\
\hline F-SD1-CR-COIL-CM, F-SD2-ISV2-PT3, F-SD2-ISV2-PT4 & 2 & & 1 & \\
\hline F-SD1-CR-COIL-CM, F-SD2-ISV1-PT3, F-SD2-ISV2-PT4 & 2 & & 1 & \\
\hline F-SD1-CR-COIL-CM, F-SD2-ISV1-PT3, F-SD2-ISV1-PT4 & 2 & & 1 & \\
\hline F-SD1-CR-BD-CM, F-SD2-ISV1-PT4, F-SD2-ISV2-PT3 & 2 & & 1 & \\
\hline F-SD1-CR-BD-CM, F-SD2-ISV2-PT3, F-SD2-ISV2-PT4 & 2 & & 1 & \\
\hline F-SD1-CR-BD-CM, F-SD2-ISV1-PT4, F-SD2-ISV1-PT5 & 2 & & 1 & \\
\hline
\end{tabular}


Appendix C

Table C.1 (cont.)

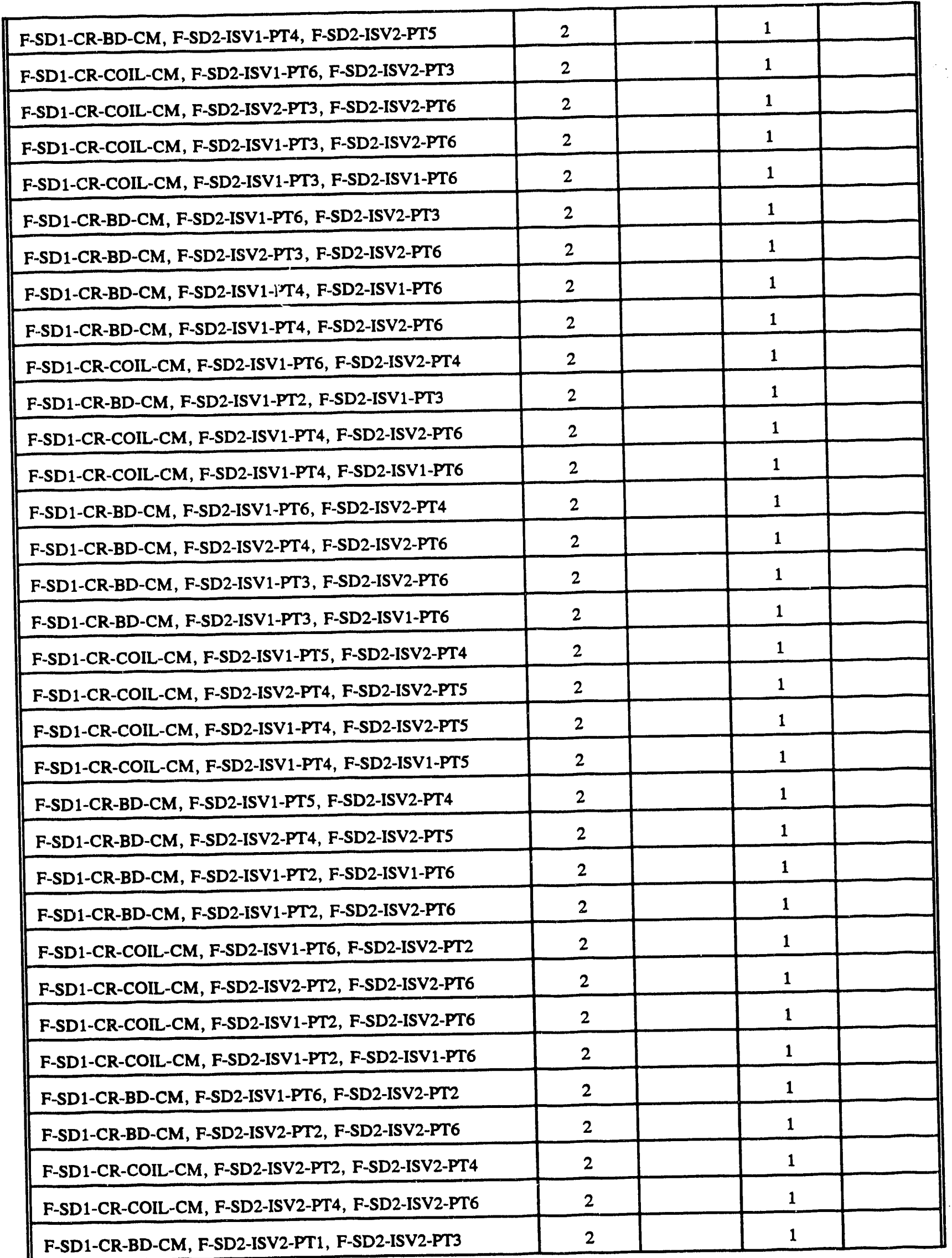


Table C.1 (cont.)

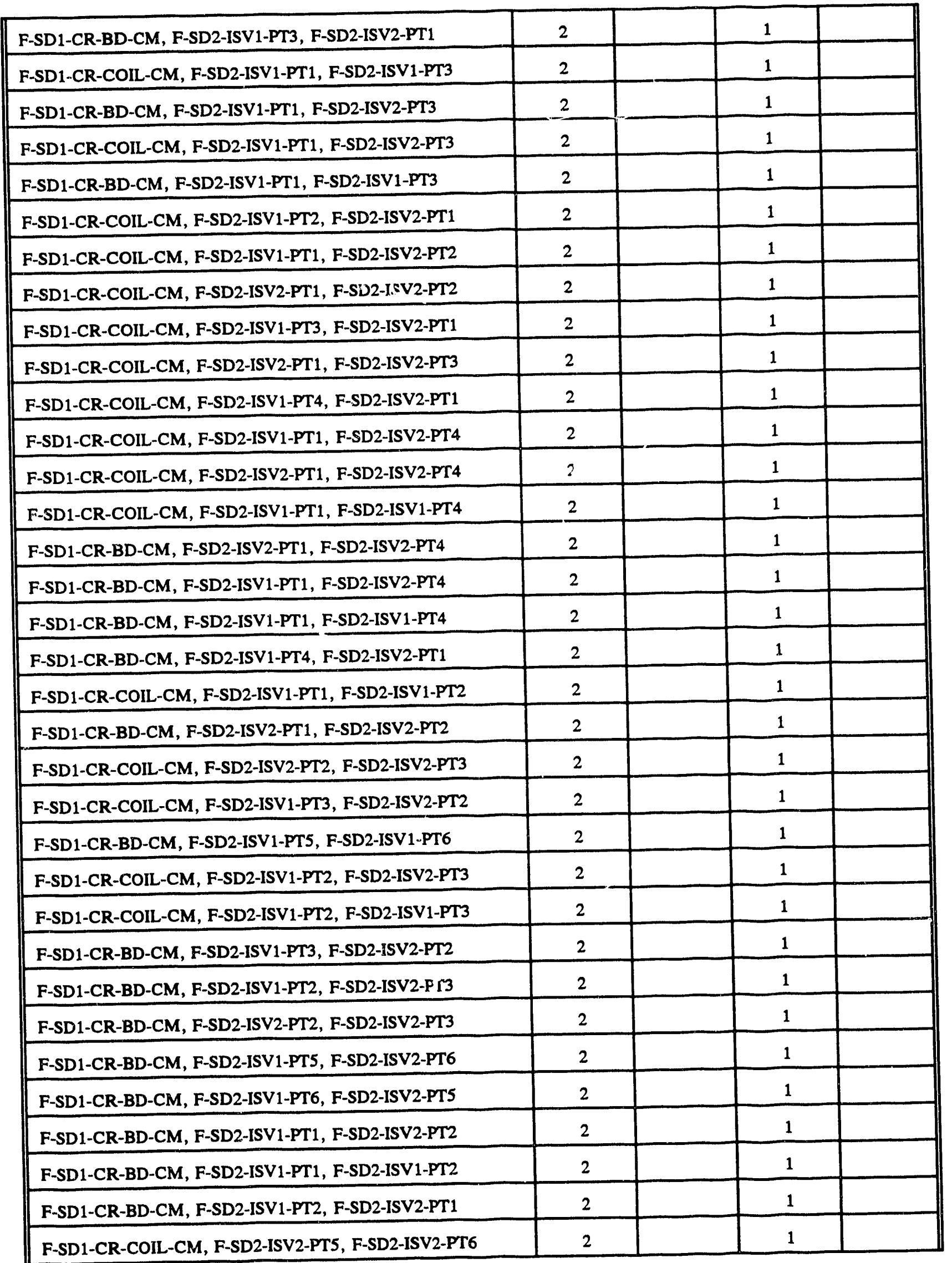


Table C.1 (cont.)

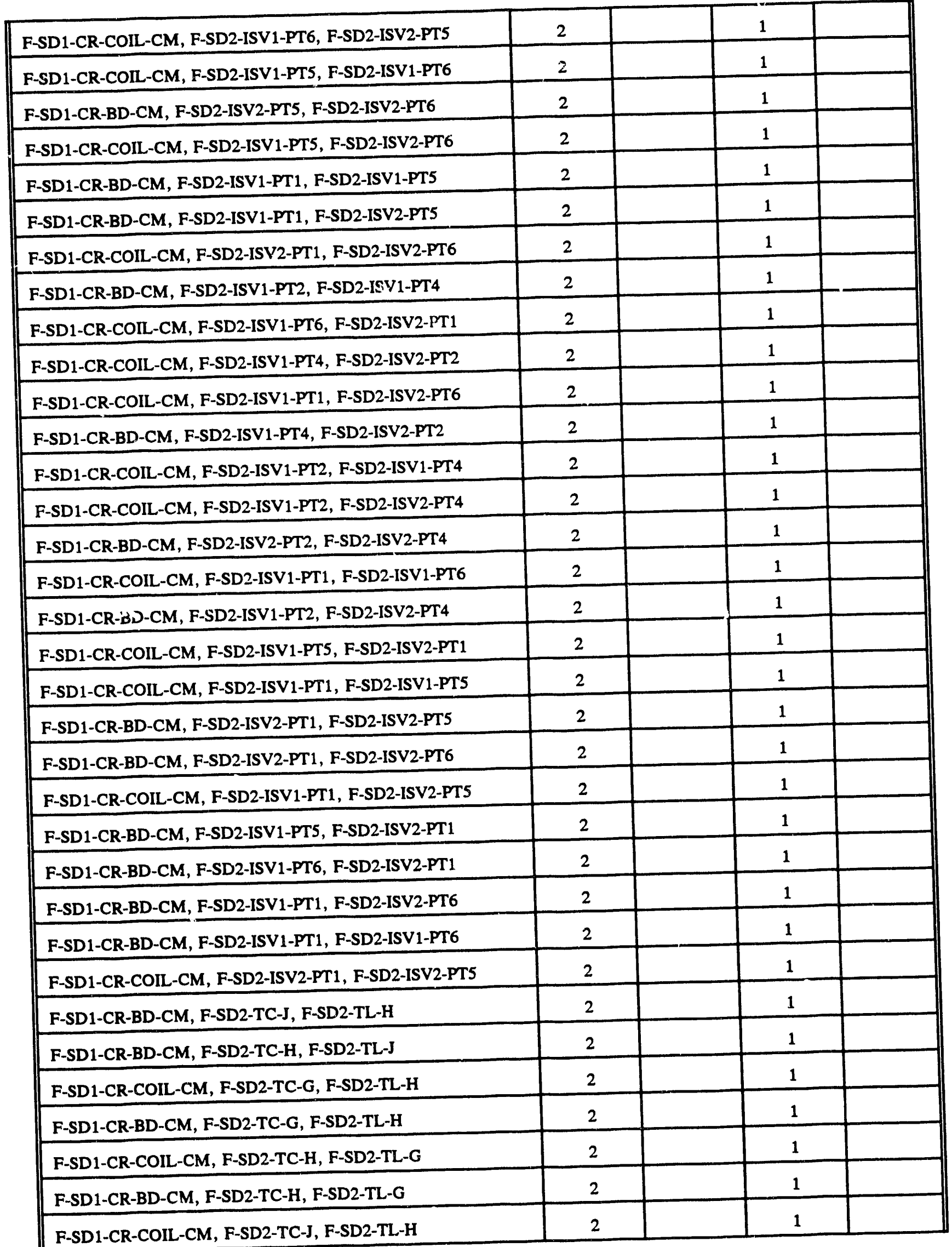


Appendix C

Table C.1 (cont.)

\begin{tabular}{||l|c|c|c|c||}
\hline F-SD1-CR-BD-CM, F-SD2-TC-G, F-SD2-TL-J & 2 & & 1 & \\
\hline F-SD1-CR-BD-CM, F-SD2-TC-J, F-SD2-TL-G & 2 & & 1 & \\
\hline F-SD1-CR-COIL-CM, F-SD2-TC-G, F-SD2-TL-J & 2 & & 1 & \\
\hline F-SD1-CR-COIL-CM, F-SD2-TC-J, F-SD2-TL-G & 2 & & 1 & \\
\hline F-SD1-CR-COIL-CM, F-SD2-TC-H, F-SD2-TL-J & 2 & & 1 & \\
\hline F-SD1-CR-COIL-CM, F-SD2-TC-G, F-SD2-TC-J & 2 & & 1 & \\
\hline F-SD1-CR-BD-CM, F-SD2-TC-G, F-SD2-TC-H & 2 & & 1 & \\
\hline F-SD1-CR-COIL-CM, F-SD2-TC-G, F-SD2-TC-H & 2 & & 1 & \\
\hline F-SD1-CR-BD-CM, F-SD2-TC-H, F-SD2-TC-J & 2 & & 1 & \\
\hline F-SD1-CR-COIL-CM, F-SD2-TC-H, F-SD2-TC-J & 2 & & 1 & \\
\hline F-SD1-CR-BD-CM, F-SD2-TC-G, F-SD2-TC-J & 2 & & 1 & \\
\hline
\end{tabular}


Table C.2 LBLOCA events sequence categorization: representative initiating event - feeder tube header break

\begin{tabular}{|c|c|c|c|c|c|}
\hline \multicolumn{2}{|c|}{ Specific Initiator } & \multicolumn{2}{|c|}{$\begin{array}{c}\text { Feeder tube header } \\
\text { break }\end{array}$} & \multicolumn{2}{|c|}{$\begin{array}{l}\text { Backflow into } \\
\text { ECCS }\end{array}$} \\
\hline & E Frequency & & $\times 10^{-4}$ & & $<10^{-6}$ \\
\hline Sequence & Determinant Failures & $\operatorname{Bin}$ & Category & $\operatorname{Bin}$ & Category \\
\hline$\overline{\mathrm{LB}-\mathrm{A}}$ & $\mathrm{N} / \mathrm{A}$ & $\bar{E}$ & EC-II & I & EC-III \\
\hline LB-B & $\begin{array}{c}2 \text { valves, } \\
2 \text { heat exchangers }\end{array}$ & G & EC-III & $\mathrm{K}$ & EC-IV \\
\hline$\overline{\mathrm{LB}-\mathrm{C}}$ & $\geq 3$ failures & $\overline{\mathrm{H}}$ & EC-IV & $\overline{\mathrm{L}}$ & EC-IV \\
\hline LB-D & $\begin{array}{l}2 \text { valves, } 2 \text { pumps, } \\
\text { undetected low coolant } \\
\text { tank level }\end{array}$ & G & EC-III & $\mathbf{K}$ & EC-IV \\
\hline LB-E & $\geq 3$ failures & $\mathbf{H}$ & EC-IV & $\mathrm{L}$ & EC-IV \\
\hline LB-F & $\begin{array}{l}\text { support system, } 2 \text { signals, } \\
2 \text { valves, undetected low } \\
\text { gas tank pressure, } \\
\text { undetected low coolant } \\
\text { tank volume }\end{array}$ & G & EC-III & $\mathbf{K}$ & EC-IV \\
\hline$\overline{\mathrm{LB}-\mathrm{G}}$ & $\geq 3$ failures & $\overline{\mathbf{H}}$ & EC-IV & $\bar{L}$ & EC-IV \\
\hline$\overline{\mathrm{LB}-\mathrm{H}}$ & pump failure & $\overline{\mathrm{F}}$ & EC-II & $\mathbf{J}$ & EC-III \\
\hline LB-I & $\geq 3$ failures & $\overline{\mathbf{H}}$ & $\overline{\text { EC-IV }}$ & $\overline{\mathrm{L}}$ & EC-IV \\
\hline LB-J & $\geq 3$ failures & $\overline{\mathbf{H}}$ & $\overline{\text { EC-IV }}$ & $\overline{\mathrm{L}}$ & EC-IV \\
\hline$\overline{\mathrm{LB}-\mathrm{K}}$ & $\geq 3$ failures & $\overline{\mathbf{H}}$ & EC-IV & $\overline{\mathrm{L}}$ & EC-IV \\
\hline$\overline{\mathrm{LB}-\mathrm{L}}$ & $\geq 3$ failures & $\overline{\mathrm{H}}$ & EC-IV & $\overline{\mathrm{L}}$ & EC-IV \\
\hline$\overline{\text { LB-M }}$ & $\geq 3$ failures & $\overline{\mathbf{H}}$ & EC-IV & $\overline{\mathrm{L}}$ & EC-IV \\
\hline$\overline{\text { LB-N }}$ & $\geq 3$ failures & $\overline{\mathbf{H}}$ & EC-IV & $\overline{\mathrm{L}}$ & EC-IV \\
\hline LB-O & $\begin{array}{l}\text { common mode failure, } \\
2 \text { relays, } \\
2 \text { trip computers }\end{array}$ & G & EC-III & $\mathbf{K}$ & EC-IV \\
\hline$\overline{\text { LB-P }}$ & $\geq 3$ failures & $\overline{\mathrm{H}}$ & EC-IV & $\overline{\mathbf{L}}$ & EC-IV \\
\hline LB-Q & $\geq 3$ failures & $\overline{\mathrm{H}}$ & EC-IV & $\overline{\mathrm{L}}$ & EC-IV \\
\hline$\overline{\mathrm{LB}-\mathrm{R}}$ & $\geq 3$ failures & $\overline{\mathrm{H}}$ & EC-IV & $\overline{\mathrm{L}}$ & EC-IV \\
\hline LB-S & $\geq 3$ failures & $\overline{\mathrm{H}}$ & EC-IV & $\overline{\mathrm{L}}$ & EC-IV \\
\hline$\overline{\text { LB-T }}$ & $\geq 3$ failures & $\overline{\mathrm{H}}$ & EC-IV & $\bar{L}$ & EC-IV \\
\hline LB-U & $\geq 3$ failures & $\bar{H}$ & EC-IV & $\overline{\mathrm{L}}$ & EC-IV \\
\hline$\overline{\mathrm{LB}-\mathrm{V}}$ & $\geq 3$ failures & $\overline{\mathrm{H}}$ & EC-IV & $\overline{\mathrm{L}}$ & EC-IV \\
\hline LB-W & $\geq 3$ failures & $\overline{\mathrm{H}}$ & $\overline{\text { EC-IV }}$ & $\overline{\mathrm{L}}$ & EC-IV \\
\hline$\overline{\text { LB-X }}$ & $\geq 3$ failures & $\overline{\mathrm{H}}$ & EC-IV & $\overline{\mathrm{L}}$ & EC-IV \\
\hline LB-Y & $\geq 3$ failures & $\overline{\mathrm{H}}$ & $\overline{\text { EC-IV }}$ & $\overline{\mathrm{L}}$ & EC-IV \\
\hline$\overline{L B}-\mathrm{Z}$ & $\geq 3$ failures & $\overline{\mathrm{H}}$ & $\overline{\text { EC-IV }}$ & $\overline{\mathrm{L}}$ & EC-IV \\
\hline$\overline{\text { LB-AA }}$ & $\geq 3$ failures & $\overline{\mathrm{H}}$ & EC-IV & $\overline{\mathrm{L}}$ & EC-IV \\
\hline$\overline{\mathrm{LB}-\mathrm{AB}}$ & $\geq 3$ failures & $\overline{\mathrm{H}}$ & EC-IV & $\bar{L}$ & EC-IV \\
\hline$\overline{\mathrm{LB}-\mathrm{AC}}$ & $\geq 3$ failures & $\overline{\mathrm{H}}$ & EC-IV & $\overline{\mathrm{L}}$ & $\overline{\text { EC-IV }}$ \\
\hline
\end{tabular}


Table C.3 Liquid relief valve failure sequence cut sets

\begin{tabular}{|c|c|c|c|c|}
\hline Initiating Event - Liquid Relief Valve Failure & \multicolumn{4}{|c|}{ Sequence: $L R V F-A$} \\
\hline Sequence Ievel Cut Sets & $\begin{array}{l}\text { Composent } \\
\text { Fuilures }\end{array}$ & $\begin{array}{l}\text { Human } \\
\text { Emore }\end{array}$ & $\begin{array}{l}\text { Support } \\
\text { Syntem } \\
\text { Failures }\end{array}$ & $\begin{array}{l}\text { Determinant } \\
\text { Faikure? }\end{array}$ \\
\hline NONE & NA & NA & NA & NA \\
\hline
\end{tabular}

\begin{tabular}{|c|c|c|c|c|}
\hline Initiating Fvent - Liquid Relief Valve Failure & Sequenc & LRVF & & \\
\hline Szquence Level Cut Set's & $\begin{array}{c}\text { Componenent } \\
\text { Fajulure }\end{array}$ & $\begin{array}{l}\text { Humpon } \\
\text { Errons }\end{array}$ & $\begin{array}{l}\text { Support } \\
\text { System } \\
\text { Failure }\end{array}$ & $\begin{array}{l}\text { Determinemt } \\
\text { Failure? }\end{array}$ \\
\hline S-AIR & & & 1 & $r$ \\
\hline S-EL-II-2-E, S-EL-1I-2-O & & & 2 & \\
\hline F-ASD-ASD1, F-CSD-SDV1, S-EL-II-2-E & 2 & & 1 & \\
\hline F-ASD-ASD2, F-CSD-SDV4, S-EL-II-2-O & 2 & & 1 & \\
\hline F-ASD-ASD1, F-CSD-SDV3, S-EL-II-2-E & 2 & & 1 & \\
\hline F-ASD-ASD2, F-CSD-SDV2, S-EL-II-2-O & 2 & & 1 & \\
\hline
\end{tabular}

\begin{tabular}{|c|c|c|c|c|}
\hline Initiating Event - Liquid Relief Valve Failure & Sequenc & LRVF & & \\
\hline Sequence Level Cut Sets & $\begin{array}{l}\text { Composent } \\
\text { Fritures }\end{array}$ & $\begin{array}{l}\text { Humen } \\
\text { Errors }\end{array}$ & $\begin{array}{l}\text { Susport } \\
\text { Syyntem } \\
\text { Faihurea }\end{array}$ & $\begin{array}{l}\text { Decermiment } \\
\text { Friuhre? }\end{array}$ \\
\hline F-MSV-MSS:3-SG1, F-MSV-MSSV4-SG1, S-AIR & 2 & & 1 & \\
\hline F-MSV-MSSV1-SG1, F-MSV-MSSV3-SG1, S-AIR & 2 & & 1 & \\
\hline F-MSV-MSSV1-SG12, F-MSV-MSSV2-SG2, S-AIR & 2 & & 1 & \\
\hline F-MSV-MSSV1-SCi2, F-MSV-MSSV3-SG2, S-AIR & 2 & & 1 & \\
\hline F-MSV-MSSV2-SG1, F-MSV-MSSV3-SG1, S-AIR & 2 & & 1 & \\
\hline F-MSV-MSSV2-SG2, F-MSV-MSSV3-SG2, S-AIR & 2 & & 1 & \\
\hline
\end{tabular}


Appendix C

Table C.3 (cont.)

\begin{tabular}{||l|c|c|c||}
\hline F-MSV-MSSV1-SG1, F-MSV-MSSV4-SG1, S-AIR & 2 & & 1 \\
\hline F-MSV-MSSV2-SG2, F-MSV-MSSV4-SG2, S-AIR & 2 & & 1 \\
\hline F-MSV-MSSV1-SG2, F-MSV-MSSV4-SG2, S-AIR & 2 & & 1 \\
\hline F-MSV-MSSV3-SG2, F-MSV-MSSV4-SG2, S-AIR & 2 & & 1 \\
\hline F-MSV-MSSV1-SG1, F-MSV-MSSV2-SG1, S-AIR & 2 & & 1 \\
\hline F-MSV-MSSV2-SG1, F-MSV-MSSV4-SG1, S-AIR & 2 & & 1 \\
\hline
\end{tabular}

\begin{tabular}{|c|c|c|c|c|}
\hline \multirow{2}{*}{$\begin{array}{c}\text { Initiating Event - Liquid Relief Valve Failure } \\
\text { Sequence Level Cut Sets }\end{array}$} & \multicolumn{4}{|c|}{ Sequence: $L R V F-I$} \\
\hline & $\begin{array}{c}\text { Component } \\
\text { Fuitures }\end{array}$ & $\begin{array}{c}\text { Human } \\
\text { Erron } \\
\end{array}$ & $\begin{array}{l}\text { Suppor } \\
\text { System } \\
\text { Falurese }\end{array}$ & $\begin{array}{c}\text { Determinant } \\
\text { Failure? } \\
\end{array}$ \\
\hline S-EL-II-1-O & & & 1 & $\mathbf{Y}$ \\
\hline S-PCS & & & 1 & $\mathbf{Y}$ \\
\hline F-BCS-CNV1-TK, S-EL-II-1-E & 1 & & 1 & \\
\hline F-BCS-CNV1, F-BCS-CNV1-TK & 2 & & & $\mathbf{Y}$ \\
\hline F-BCS-CNV1-TK, F-BCS-CNV2 & 2 & & & $\mathbf{Y}$ \\
\hline
\end{tabular}

\begin{tabular}{|c|c|c|c|c|}
\hline Initiating Event - Liquid Relief Valve Failure & Sequenc & $L R V F-$ & & \\
\hline Sequence Level Cut Sets & $\begin{array}{c}\text { Component } \\
\text { Failures }\end{array}$ & $\begin{array}{c}\text { Humen } \\
\text { Errors }\end{array}$ & $\begin{array}{l}\text { Support } \\
\text { System } \\
\text { Fuilures }\end{array}$ & $\begin{array}{l}\text { Detererminant } \\
\text { Failure? }\end{array}$ \\
\hline F-LPI-INV1, F-LPI-INV2, S-EL-II-1-O & 2 & & 1 & \\
\hline F-LPI-ISV1, F-LPI-ISV2, S-EL-II-1-O & 2 & & 1 & \\
\hline F-LPI-PMP1, F-LPI-PMP2, S-EL-II-1-O & 2 & & 1 & \\
\hline F-LPI-INV2, S-EL-II-1-O, S-EL-III-2-O & 1 & & 2 & \\
\hline F-LPI-ISV1, S-EL-II-1-O, S-EL-III-2-E & 1 & & 2 & \\
\hline F-LPI-INV1, S-EL-II-1-O, S-EL-III-2-E & 1 & & 2 & \\
\hline F-HPI-ISV2-GI, S-EL-II-1-O, S-EL-III-2-O & 1 & & 2 & \\
\hline F-LPI-PMP2, S-EL-II-1-O, S-EL-III-2-O & 1 & & 2 & \\
\hline F-LPI-PMP1, S-EL-II-1-O, S-EL-III-2-E & 1 & & 2 & \\
\hline F-HPI-ISV1-GI, S-EL-II-1-O, S-EL-III-2-E & 1 & & 2 & \\
\hline F-LPI-ISV2, S-EL-II-1-O, S-EL-III-2-O & 1 & & 2 & \\
\hline F-LPI-LI-TK, F-LPI-TK, S-EL-II-1-O & 2 & & 1 & \\
\hline F-LPI-INV1, F-LPI-INV2, S-PCS & 2 & & 1 & \\
\hline F-LPI-ISV1, F-LPI-ISV2, S-PCS & 2 & & 1 & \\
\hline
\end{tabular}


Table C.3 (cont.)

\begin{tabular}{||l|c|c|c|c||}
\hline F-LPI-PMP1, F-LPI-PMP2, S-PCS & 2 & & 1 & \\
\hline F-LPI-INV1, S-EL-III-2-E, S-PCS & 1 & & 2 & \\
\hline F-LPI-INV2, S-EL-III-2-O, S-PCS & 1 & & 2 & \\
\hline F-LPI-ISV1, S-EL-III-2-E, S-PCS & 1 & & 2 & \\
\hline F-LPI-ISV2, S-EL-III-2-O, S-PCS & 1 & & 2 & \\
\hline F-HPI-ISV2-GI, S-EL-III-2-O, S-PCS & 1 & & 2 & \\
\hline F-LPI-PMP1, S-EL-III-2-E, S-PCS & 1 & & 2 & \\
\hline S-EL-II-1-O, S-EL-III-2-E, S-EL-III-2-O & & & 3 & \\
\hline F-LPI-PMP2, S-EL-III-2-O, S-PCS & 1 & & 2 & \\
\hline F-LPI-LI-TK, F-LPI-TK, S-PCS & 2 & & 1 & \\
\hline F-HPI-ISV1-GI, S-EL-III-2-E, S-PCS & 1 & & 2 & \\
\hline S-EL-III-2-E, S-EL-III-2-O, S-PCS & & & 3 & \\
\hline
\end{tabular}

\begin{tabular}{|c|c|c|c|c|}
\hline \multirow{2}{*}{$\begin{array}{c}\text { Initiating Event - Liquid Relief Valve Failure } \\
\text { Sequence Level Cut Sets }\end{array}$} & \multicolumn{4}{|c|}{ Sequence: $L R V F-L$} \\
\hline & $\begin{array}{l}\text { Component } \\
\text { Failures }\end{array}$ & $\begin{array}{l}\text { Human } \\
\text { Errors } \\
\end{array}$ & $\begin{array}{l}\text { Suppont } \\
\text { Syptem } \\
\text { Failures }\end{array}$ & $\begin{array}{l}\text { Determinant } \\
\text { Failure? }\end{array}$ \\
\hline F-HPI-OV1A, F-HPI-OV1B, S-EL-II-1-O & 2 & & 1 & \\
\hline F-HPI-OV2A, F-HPI-OV2B, S-EL-II-1-O & 2 & & 1 & \\
\hline F-HPI-INV2A, F-HPI-INV2B, S-EL-II-1-O & 2 & & 1 & \\
\hline F-HPI-SIG1-LPHTS, F-HPI-SIG3-LPHTS, S-EL-II-1-O & 2 & & 1 & \\
\hline F-HPI-INV1A, F-HPI-INV1B, S-EL-II-1-O & 2 & & 1 & \\
\hline F-HPI-SIG2-LPHTS, F-HPI-SIG3-LPHTS, S-EL-II-1-O & 2 & & 1 & \\
\hline F-HPI-INV1, F-HPI-INV2, S-EL-II-1-O & 2 & & 1 & \\
\hline F-HPI-ISV1-GI, F-HPI-ISV2-GI, S-EL-II-1-O & 2 & & 1 & \\
\hline F-HPI-SIG1-LPHTS, F-HPI-SIG2-LPHTS, S-EL-II-1-O & 2 & & 1 & \\
\hline F-HPI-INV1, F-HPI-INV2, S-PCS & 2 & & 1 & \\
\hline F-HPI-LI-CITK, F-HPI-TK-CI, S-EL-II-1-O & 2 & & 1 & \\
\hline F-HPI-PI-GI-TK, F-HPI-TK-GI, S-EL-II-1-O & 2 & & 1 & \\
\hline F-HPI-OV1A, F-HPI-OV1B, S-PCS & 2 & & 1 & \\
\hline F-HPI-OV2A, F-HPI-OV2B, S-PCS & 2 & & 1 & \\
\hline F-HPI-INV2A, F-HPI-INV2B, S-PCS & 2 & & 1 & \\
\hline F-HPI-SIG1-LPHTS, F-HPI-SIG3-LPHTS, S-PCS & 2 & & 1 & \\
\hline F-HPI-INV1A, F-HPI-INV1B, S-PCS & 2 & & 1 & \\
\hline
\end{tabular}


Table C.3 (cont.)

\begin{tabular}{||l|c|c|c|c||}
\hline F-HPI-SIG2-LPHTS, F-HPI-SIG3-LPHTS, S-PCS & 2 & & 1 & \\
\hline F-HPI-ISV1-GI, F-HPI-ISV2-GI, S-PCS & 2 & & 1 & \\
\hline F-HPI-SIGI-LPHTS, F-HPI-SIG2-LPHTS, S-PCS & 2 & & 1 & \\
\hline F-HPI-PI-GI-TK, F-HPI-TK-GI, S-PCS & 2 & & 1 & \\
\hline F-HPI-LI-CITK, F-HPI-TK-CI, S-PCS & 2 & & 1 & \\
\hline
\end{tabular}

\begin{tabular}{|c|c|c|c|c|}
\hline \multirow{2}{*}{$\frac{\text { Initiating Event - Liquid Relief Valve Failure }}{\text { Sequence Level Cut Sets }}$} & \multicolumn{4}{|c|}{ Sequence: $L R V F-N$} \\
\hline & $\begin{array}{l}\text { Composent } \\
\text { Failures }\end{array}$ & $\begin{array}{c}\text { Human } \\
\text { Errors }\end{array}$ & $\begin{array}{l}\text { Support } \\
\text { Syptem } \\
\text { Faitures }\end{array}$ & $\begin{array}{l}\text { Determinant } \\
\text { Faiture? }\end{array}$ \\
\hline F-FW1-ISV1, S-PCS & 1 & & 1 & \\
\hline F-FW1-ISV2, S-PCS & 1 & & 1 & \\
\hline S-EL-IV-E, S-EL-IV-U, S-PCS & & & 3 & \\
\hline F-FW1-DV2, S-EL-IV-O, S-PCS & 1 & & 2 & \\
\hline S-EL-II-1-E, S-EL-II-1-O, S-PCS & & & 3 & \\
\hline F-FW1-CNV2, S-EL-II-1-O, S-PCS & 1 & & 2 & \\
\hline F-FW1-CNV1, F-FW1-CNV2, S-PCS & 2 & & 1 & \\
\hline F-FW1-CNV1, S-EL-II-1-E, S-PCS & 1 & & 2 & \\
\hline F-FW1-DV1, S-EL-IV-E, S-PCS & 1 & & 2 & \\
\hline F-FW1-DV1, F-FW1-PMP2, S-PCS & 2 & & 1 & \\
\hline F-FW1-PMP1, F-FW1-PMP2, S-PCS & 2 & & 1 & \\
\hline F-FW1-DV2, F-FW1-PMP1, S-PCS & 2 & & 1 & \\
\hline F-FW1-DV1, F-FW1-DV2, S-PCS & 2 & & 1 & \\
\hline F-FW1-PMP2, S-EL-IV-O, S-PCS & 1 & & 2 & \\
\hline F-FW1-PMP1, S-EL-IV-E, S-PCS & 1 & & 2 & \\
\hline
\end{tabular}

\begin{tabular}{|c|c|c|c|c|}
\hline \multirow{2}{*}{$\begin{array}{c}\text { Initiating Event - Liquid Relief Valve Failure } \\
\text { Sequence Level Cut Sets }\end{array}$} & \multicolumn{4}{|c|}{ Sequence: $L R V F-O$} \\
\hline & $\begin{array}{l}\text { Component } \\
\text { Failures }\end{array}$ & $\begin{array}{l}\text { Human } \\
\text { Enrors }\end{array}$ & $\begin{array}{l}\text { Support } \\
\text { Syprem } \\
\text { Failures }\end{array}$ & $\begin{array}{l}\text { Delerminant } \\
\text { Failure? }\end{array}$ \\
\hline F-FW1-HE, S-PCS, S-RCW & & 1 & 2 & \\
\hline F-FW1-ISV1, S-EL-III-1-0, S-PCS & 1 & & 2 & \\
\hline F-FW1-ISV2, S-EL-III-1-O, S-PCS & 1 & & 2 & \\
\hline F-FW1-ISV2, S-PCS, S-RCW & 1 & & 2 & \\
\hline F-FW1-ISV1, S-PCS, S-RCW & 1 & & 2 & \\
\hline
\end{tabular}


Table C.3 (cont.)

\begin{tabular}{||l|c|c|c|c||}
\hline F-FW1-ISV1, F-MCS-PMP1, S-PCS & 2 & & 1 & \\
\hline S-FIW, S-PCS, S-RCW & & & 3 & \\
\hline F-FW1-ISV2, F-MCS-PMP1, S-PCS & 2 & & 1 & \\
\hline F-FW1-ISV2, F-MCS-PMP2, S-PCS & 2 & & 1 & \\
\hline F-FW1-ISV1, F-MCS-ISV-FC, S-PCS & 2 & & 1 & \\
\hline F-FW1-ISV1, F-MCS-PMP2, S-PCS & 2 & & 1 & \\
\hline F-FW1-ISV2, S-EL-III-1-E, S-PCS & 1 & & 2 & \\
\hline F-FW1-ISV2, F-MCS-ISV-FC, S-PCS & 2 & & 1 & \\
\hline F-FW1-ISV1, S-EL-III-1-E, S-PCS & 1 & & 2 & \\
\hline
\end{tabular}

\begin{tabular}{|c|c|c|c|c|}
\hline \multirow{2}{*}{$\begin{array}{c}\text { Initiating Event - Liquid Relief Valve Failure } \\
\text { Sequence Level Cut Sets }\end{array}$} & \multicolumn{4}{|c|}{ Sequence: $L R V F-P$} \\
\hline & $\begin{array}{l}\text { Composent } \\
\text { Faikures }\end{array}$ & $\begin{array}{l}\text { Humen } \\
\text { Erron }\end{array}$ & $\begin{array}{l}\text { Support } \\
\text { System } \\
\text { Failures }\end{array}$ & $\begin{array}{l}\text { Determinant } \\
\text { Failure? }\end{array}$ \\
\hline S-EL-II-1-O, S-EL-1I-2-O & & & 2 & \\
\hline S-ECC, S-EL-II-1-O & & & 2 & \\
\hline S-AIR, S-EL-II-1-O & & & 2 & \\
\hline S-EL-II-1-O, S-EL-II-2-E & & & 2 & \\
\hline F-BCS-CNV1-TK, S-AIR & 1 & & 1 & \\
\hline S-EL-II-2-E, S-PCS & & & 2 & \\
\hline S-ECC, S-PCS & & & 2 & \\
\hline S-AIR, S-PCS & & & 2 & \\
\hline S-EL-II-2-O, S-PCS & & & 2 & \\
\hline F-MSV-MSSV3-SG1, F-MSV-MSSV4-SG1, S-EL-II-1-O & 2 & & 1 & \\
\hline F-MSV-MSSV3-SG2, F-MSV-MSSV4-SG2, S-EL-II-1-O & 2 & & 1 & \\
\hline F-MSV-MSSV2-SG1, F-MSV-MSSV4-SG1, S-EL-II-1-O & 2 & & 1 & \\
\hline F-MSV-MSSV1-SG1, F-MSV-MSSV4-SG1, S-EL-II-1-O & 2 & & 1 & \\
\hline F-MSV-MSSV2-SG1, F-MSV-MSSV3-SG1, S-EL-II-1-O & 2 & & 1 & \\
\hline F-MSV-MSSV1-SG1, F-MSV-MSSV3-SG1, S-EL-II-1-O & 2 & & 1 & \\
\hline F-MSV-MSSV1-SG2, F-MSV-MSSV3-SG2, S-EL-II-1-O & 2 & & 1 & \\
\hline F-MSV-MSSV1-SG2, F-MSV-MSSV2-SG2, S-EL-II-1-O & 2 & & 1 & \\
\hline F-MS /-MSSV2-SG2, F-MSV-MSSV4-SG2, S-EL-II-1-O & 2 & & 1 & \\
\hline F-MSV-MSSV1-SG1, F-MSV-MSSV2-SG1, S-EL-II-1-O & 2 & & 1 & \\
\hline F-MSV-MSSV2-SG2, F-MSV-MSSV3-SG2, S-EL-II-1-O & 2 & & 1 & \\
\hline
\end{tabular}


Table C.3 (cont.)

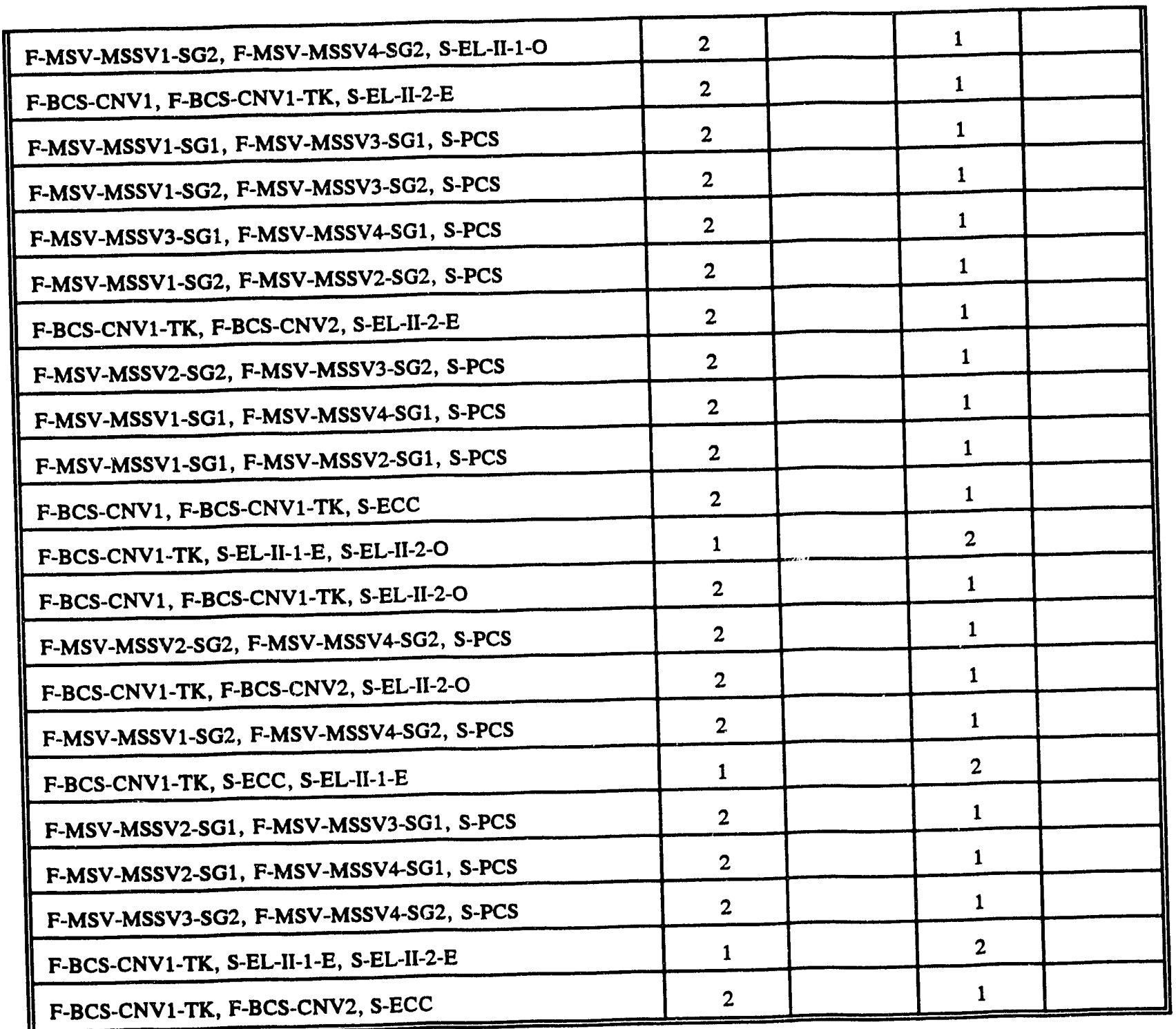

\begin{tabular}{|c|c|c|c|c|}
\hline \multirow{2}{*}{$\begin{array}{c}\text { Initiating Event - Liquid Relief Valve Failure } \\
\text { Sequence Level Cut Sets }\end{array}$} & \multicolumn{4}{|c|}{ Sequence: $L R V F-Q$} \\
\hline & $\begin{array}{l}\text { Component } \\
\text { Failures }\end{array}$ & $\begin{array}{c}\text { Humen } \\
\text { Errors }\end{array}$ & $\begin{array}{l}\text { Support } \\
\text { System } \\
\text { Faitures }\end{array}$ & $\begin{array}{l}\text { Determinant } \\
\text { Frailure? }\end{array}$ \\
\hline S-EL-II-1-O, S-EL-II-2-O, S-EL-III-1-O & & & 3 & \\
\hline F-MCS-PMP1, S-EL-II-1-O, S-EL-II-2-O & 1 & & 2 & \\
\hline S-AIR, S-EL-II-1-O, S-RCW & & & 3 & \\
\hline S-EL-II-1-O, S-EL-II-2-O, S-EL-III-1-E & & & 3 & \\
\hline F-MCS-PMP2, S-EL-II-1-O, S-EL-II-2-O & 1 & & 2 & \\
\hline S-EL-II-1-O, S-EL-II-2-O, S-RCW & & & 3 & \\
\hline S-ECC, S-EL-II-1-O, S-EL-III-1-O & & & 3 & \\
\hline
\end{tabular}


Table C.3 (cont.)

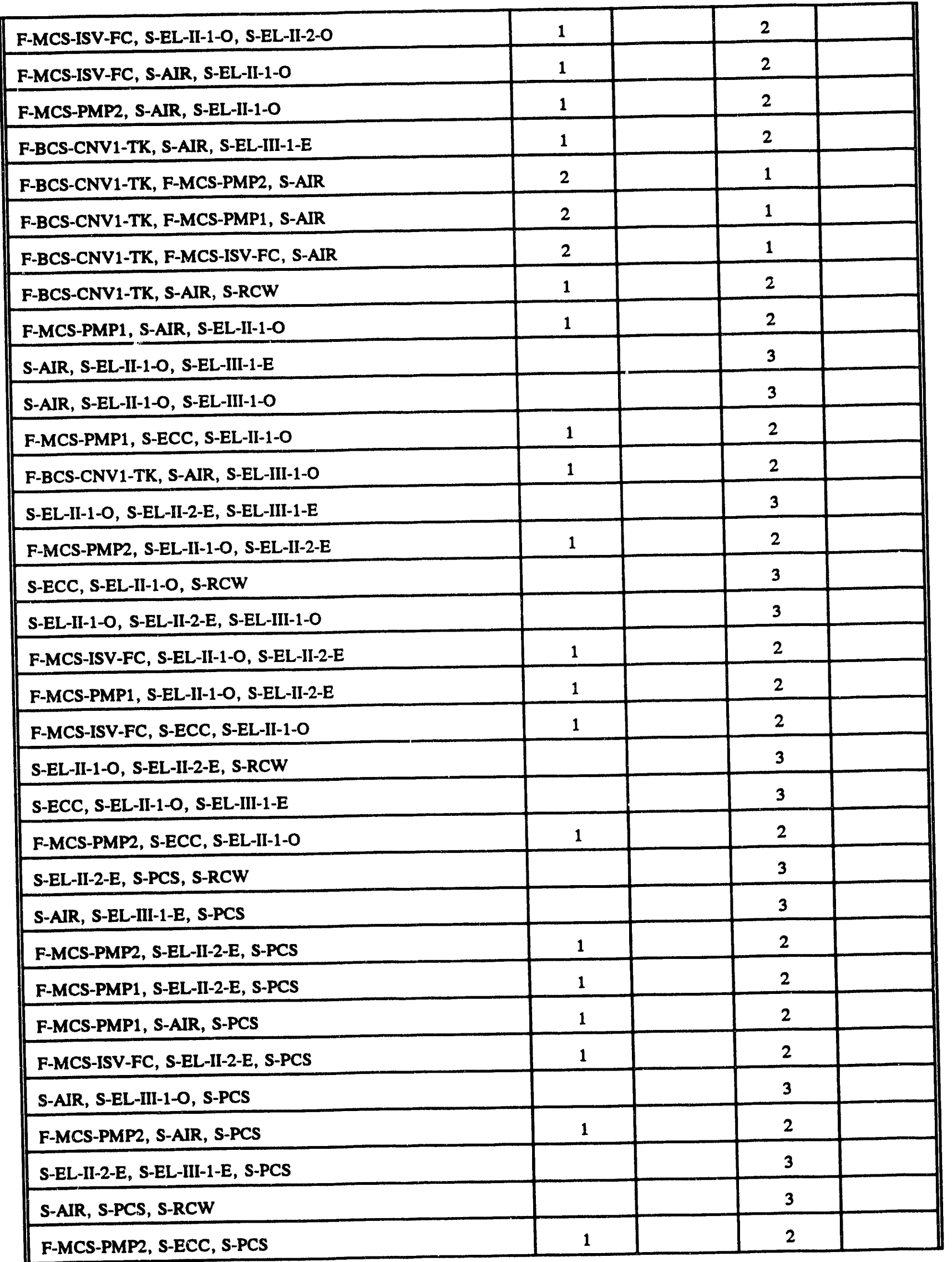


Table C.3 (cont.)

\begin{tabular}{||l|c|c|c|c||}
\hline F-MCS-PMP2, S-EL-II-2-O, S-PCS & 1 & & 2 & \\
\hline F-MCS-ISV-FC, S-EL-II-2-O, S-PCS & 1 & & 2 & \\
\hline S-EL-II-2-O, S-PCS, S-RCW & & & 3 & \\
\hline S-ECC, S-EL-III-1-O, S-PCS & & & 3 & \\
\hline S-ECC, S-EL-III-1-E, S-PCS & & & 3 & \\
\hline S-EL-II-2-O, S-EL-III-1-E, S-PCS & & & 3 & \\
\hline F-MCS-ISV-FC, S-ECC, S-PCS & 1 & & 2 & \\
\hline F-MCS-PMP1, S-ECC, S-PCS & 1 & & 2 & \\
\hline F-MCS-ISV-FC, S-AIR, S-PCS & 1 & & 2 & \\
\hline S-ECC, S-PCS, S-RCW & & & 3 & \\
\hline S-EL-II-2-O, S-EL-III-1-O, S-PCS & & & 3 & \\
\hline S-EL-II-2-E, S-EL-III-1-O, S-PCS & & & 3 & \\
\hline F-MCS-PMP1, S-EL-II-2-O, S-PCS & 1 & & 2 & \\
\hline
\end{tabular}

\begin{tabular}{||l|c|c|c|c||}
\hline \multicolumn{1}{|c|}{ Sequence Level Cut Sets } & Sequence: LRVF-R \\
\hline \hline F-SD1-CR-BD-CM & $\begin{array}{c}\text { Componeat } \\
\text { Failure }\end{array}$ & $\begin{array}{c}\text { Humen } \\
\text { Errons }\end{array}$ & $\begin{array}{c}\text { Support } \\
\text { System } \\
\text { Failures }\end{array}$ & $\begin{array}{c}\text { Delerminant } \\
\text { Failure }\end{array}$ \\
\hline F-SD1-CR-COIL-CM & & & 1 & $Y$ \\
\hline F-SD1-TLB-REL2, F-SD1-TLB-REL3 & & & 1 & $Y$ \\
\hline F-SD1-TLB-REL1, F-SD1-TLB-REL2 & 2 & & & $Y$ \\
\hline F-SD1-TLA-REL1, F-SD1-TLA-REL2 & 2 & & & $Y$ \\
\hline F-SD1-TLB-REL1, F-SD1-TLB-REL3 & 2 & & & $Y$ \\
\hline F-SD1-TLA-REL2, F-SD1-TLA-REL3 & 2 & & & $Y$ \\
\hline F-SD1-TLA-REL1, F-SD1-TLA-REL3 & 2 & & & $Y$ \\
\hline F-SD1-TC-D, F-SD1-TC-E & 2 & & & $Y$ \\
\hline F-SD1-TC-D, F-SD1-TC-F & 2 & & & $Y$ \\
\hline F-SD1-TC-E, F-SD1-TC-F & 2 & & & $Y$ \\
\hline
\end{tabular}


Table C.3 (cont.)

\begin{tabular}{|c|c|c|c|c|}
\hline \multirow{2}{*}{$\begin{array}{c}\text { Initiating Event - Liquid Relief Valve Failure } \\
\text { Sequence Level Cut Sets }\end{array}$} & \multicolumn{4}{|c|}{ Sequence: $L R V F-S$} \\
\hline & $\begin{array}{l}\text { Component } \\
\text { Faihures }\end{array}$ & $\begin{array}{c}\text { Humben } \\
\text { Errors }\end{array}$ & $\begin{array}{l}\text { Support } \\
\text { Syntem } \\
\text { Filures }\end{array}$ & $\begin{array}{l}\text { Determinent } \\
\text { Failure? }\end{array}$ \\
\hline F-SD1-CR-BD-CM, S-AIR & & & 2 & \\
\hline F-SD1-CR-COIL-CM, S-AIR & & & 2 & \\
\hline F-SD1-TLB-REL2, F-SD1-TLB-REL3, S-AIR & 2 & & 1 & \\
\hline F-SD1-TLB-REL1, F-SD1-TLB-REL3, S-AIR & 2 & & 1 & \\
\hline F-SD1-TLB-REL1, F-SD1-TLB-REL2, S-AIR & 2 & & 1 & \\
\hline F-SD1-TLA-REL2, F-SD1-TLA-REL3, S-AIR & 2 & & 1 & \\
\hline F-SD1-TLA-REL1, F-SD1-TLA-REL2, S-AIR & 2 & & 1 & \\
\hline F-SD1-TLA-REL1, F-SD1-TLA-REL3, S-AIR & 2 & & 1 & \\
\hline F-SD1-CR-COIL-CM, S-EL-II-2-E, S-EL-II-2-O & & & 3 & \\
\hline F-SD1-CR-BD-CM, S-EL-II-2-E, S-EL-II-2-O & & & 3 & \\
\hline F-SD1-TC-E, F-SD1-TC-F, S-AIR & 2 & & 1 & \\
\hline F-SD1-TC-D, F-SD1-TC-F, S-AIR & 2 & & 1 & \\
\hline F-SD1-TC-D, F-SD1-TC-E, S-AIR & 2 & & 1 & \\
\hline
\end{tabular}

\begin{tabular}{|c|c|c|c|c|}
\hline \multirow{2}{*}{$\begin{array}{c}\text { Initiating Event - Liquid Relief Valve Failure } \\
\text { Sequence Level Cut Sets }\end{array}$} & \multicolumn{4}{|c|}{ Sequence: $L R V F-Z$} \\
\hline & $\begin{array}{l}\text { Component } \\
\text { Fuiturea }\end{array}$ & $\begin{array}{l}\text { Hurnen } \\
\text { Errors }\end{array}$ & $\begin{array}{l}\text { Support } \\
\text { System } \\
\text { Failures }\end{array}$ & $\begin{array}{l}\text { Determinant } \\
\text { Failure? }\end{array}$ \\
\hline F-SD1-CR-BD-CM, S-EL-II-1-O & & & 2 & \\
\hline F-SD1-CR-COIL-CM, S-EL-II-1-O & & & 2 & \\
\hline F-SD1-CR-COIL-CM, S-PCS & & & 2 & \\
\hline F-SD1-CR-BD-CM, S-PCS & & & 2 & \\
\hline F-SD1-TLA-REL1, F-SD1-TLA-REL2, S-EL-II-1-O & 2 & & 1 & \\
\hline F-SD1-TLB-REL1, F-SD1-TLB-REL3, S-EL-1I-1-O & 2 & & 1 & \\
\hline F-SD1-TLA-REL2, F-SD1-TLA-REL3, S-EL-II-1-O & 2 & & 1 & \\
\hline F-SD1-TLB-REL2, F-SD1-TLB-REL3, S- IL-II-1-O & 2 & & 1 & \\
\hline F-SD1-TLA-REL1, F-SD1-TLA-REL3, S-EL-II-1-O & 2 & & 1 & \\
\hline F-SD1-TLB-REL1, F-SD1-TLB-REL2, S-EL-II-1-O & 2 & & 1 & \\
\hline F-BCS-CNV1-TK, F-BCS-CNV2, F-SD1-CR-COIL-CM & 2 & & 1 & \\
\hline F-BCS-CNV1-TK, F-SD1-CR-BD-CM, S-EL-II-1-E & 2 & & 1 & \\
\hline F-BCS-CNV1, F-BCS-CNV1-TK, F-SD1-CR-BD-CM & 2 & & 1 & \\
\hline
\end{tabular}


Table C.3 (cont.)

\begin{tabular}{||l|c|c|c|c||}
\hline F-BCS-CNV1, F-BCS-CNV1-TK, F-SD1-CR-COIL-CM & 2 & & 1 & \\
\hline F-BCS-CNV1-TK, F-SD1-CR-COIL-CM, S-EL-II-1-E & 1 & & 2 & \\
\hline F-SD1-TLA-REL2, F-SD1-TLA-REL3, S-PCS & 2 & & 1 & \\
\hline F-SD1-TLA-REL1, F-SD1-TLA-REL2, S-PCS & 2 & & 1 & \\
\hline F-SD1-TLA-REL1, F-SD1-TLA-REL3, S-PCS & 2 & & 1 & \\
\hline F-SD1-TLB-REL2, F-SD1-TLB-REL3, S-PCS & 2 & & 1 & \\
\hline F-SD1-TLB-REL1, F-SD1-TLB-REL3, S-PCS & 2 & & 1 & \\
\hline F-SD1-TLB-REL1, F-SD1-TLB-REL2, S-PCS & 2 & & 1 & \\
\hline F-BCS-CNV1-TK, F-BCS-CNV2, F-SD1-CR-BD-CM & 2 & & 1 & \\
\hline F-SD1-TC-D, F-SD1-TC-F, S-EL-II-1-O & 2 & & 1 & \\
\hline F-SD1-TC-E, F-SD1-TC-F, S-EL-II-1-O & 2 & & 1 & \\
\hline F-SD1-TC-D, F-SD1-TC-E, S-EL-II-1-O & 2 & & 1 & \\
\hline F-SD1-TC-D, F-SD1-TC-E, S-PCS & 2 & & 2 & 1 \\
\hline F-SD1-TC-E, F-SD1-TC-F, S-PCS & 2 & & 1 & \\
\hline F-SD1-TC-D, F-SD1-TC-F, S-PCS & & & & 1 \\
\hline
\end{tabular}

\begin{tabular}{||l|c|c|c|c||}
\hline Initiating Event - Liquid Relief Valve Failure & \multicolumn{2}{|l||}{ Sequence: LRVF-AE } \\
\hline \multicolumn{1}{|c|}{ Sequence Level Cut Sets } & $\begin{array}{c}\text { Component } \\
\text { Failures }\end{array}$ & $\begin{array}{c}\text { Human } \\
\text { Errors }\end{array}$ & $\begin{array}{c}\text { Support } \\
\text { System } \\
\text { Failures }\end{array}$ & $\begin{array}{c}\text { Determinent } \\
\text { Failure? }\end{array}$ \\
\hline F-FW1-ISV2, F-SD1-CR-COIL-CM, S-PCS & 1 & & 2 & \\
\hline F-FW1-ISV1, F-SD1-CR-COIL-CM, S-PCS & 1 & & 2 & \\
\hline F-FW1-ISV1, F-SD1-CR-BD-CM, S-PCS & 1 & & 2 & \\
\hline F-FW1-ISV2, F-SD1-CR-BD-CM, S-PCS & 1 & & 2 & \\
\hline
\end{tabular}

\begin{tabular}{||l|c|c|c|c||}
\hline \multicolumn{1}{|l|}{ Initiating Event - Liquid Relief Valve Failure } & \multicolumn{2}{l||}{ Sequence: LRVF-AG } \\
\hline \hline & $\begin{array}{c}\text { Component } \\
\text { Failures }\end{array}$ & $\begin{array}{c}\text { Human } \\
\text { Errors }\end{array}$ & $\begin{array}{c}\text { Support } \\
\text { Syonem } \\
\text { Failures }\end{array}$ & $\begin{array}{c}\text { Determinent } \\
\text { Failure? }\end{array}$ \\
\hline F-SD1-CR-COIL-CM, S-EL-II-1-O, S-EL-II-2-O & & & 3 & \\
\hline F-SD1-CR-BD-CM, S-EL-II-1-O, S-EL-II-2-O & & & 3 & \\
\hline F-SD1-CR-BD-CM, S-AIR, S-EL-II-1-O & & & 3 & \\
\hline F-SD1-CR-COIL-CM, S-AIR, S-EL-II-1-O & & & 3 & \\
\hline F-SD1-CR-COIL-CM, S-ECC, S-EL-II-1-O & & & 3 & \\
\hline F-BCS-CNV1-TK, F-SD1-CR-BD-CM, S-AIR & 1 & & 2 & \\
\hline
\end{tabular}


Table C.3 (cont.)

\begin{tabular}{||l|c|c|c|c||}
\hline F-BCS-CNV1-TK, F-SD1-CR-COIL-CM, S-AIR & 1 & & 2 & \\
\hline F-SD1-CR-BD-CM, S-EL-II-1-O, S-EL-II-2-E & & & 3 & \\
\hline F-SD1-CR-COIL-CM, S-EL-II-1-O, S-EL-II-2-E & & & 3 & \\
\hline F-SD1-CR-BD-CM, S-ECC, S-EL-II-1-O & & & 3 & \\
\hline F-SD1-CR-COIL-CM, S-AIR, S-PCS & & & 3 & \\
\hline F-SD1-CR-BD-CM, S-EL-II-2-E, S-PCS & & & 3 & \\
\hline F-SD1-CR-COIL-CM, S-EL-II-2-E, S-PCS & & & 3 & \\
\hline F-SD1-CR-BD-CM, S-AIR, S-PCS & & & 3 & \\
\hline F-SD1-CR-COIL-CM, S-EL-II-2-O, S-PCS & & & 3 & \\
\hline F-SD1-CR-BD-CM, S-EL-II-2-O, S-PCS & & & 3 & \\
\hline F-SD1-CR-COIL-CM, S-ECC, S-PCS & & & 3 & \\
\hline F-SD1-CR-BD-CM, S-ECC, S-PCS & & & 3 & \\
\hline
\end{tabular}

\begin{tabular}{|c|c|c|c|c|}
\hline \multirow{2}{*}{$\begin{array}{c}\text { Initiating Event - Liquid Relief Valve Failure } \\
\text { Sequence Level Cut Sets }\end{array}$} & \multicolumn{4}{|c|}{ Sequence: $L R V F-F T S D-A$} \\
\hline & $\begin{array}{l}\text { Component } \\
\text { Frailures }\end{array}$ & $\begin{array}{c}\text { Human } \\
\text { Errons }\end{array}$ & $\begin{array}{l}\text { Support } \\
\text { System } \\
\text { Failurea }\end{array}$ & $\begin{array}{l}\text { Determinent } \\
\text { Failure? }\end{array}$ \\
\hline F-SD1-CR-COIL-CM, F-SD2-ISV1-PT5, F-SD2-ISV2-PT2 & 2 & & 1 & \\
\hline F-SD1-CR-COIL-CM, F-SD2-ISV2-PT2, F-SD2-ISV2-PT5 & 2 & & 1 & \\
\hline F-SD1-CR-COIL-CM, F-SD2-ISV1-PT2, F-SD2-ISV2-PT5 & 2 & & 1 & \\
\hline F-SD1-CR-COIL-CM, F-SD2-ISV1-PT2, F-SD2-ISV1-PT5 & 2 & & 1 & \\
\hline F-SD1-CR-BD-CM, F-SD2-ISV1-PT5, F-SD2-ISV2-PT2 & 2 & & 1 & \\
\hline F-SD1-CR-BD-CM, F-SD2-ISV2-PT2, F-SD2-ISV2-PT5 & 2 & & 1 & \\
\hline F-SD1-CR-BD-CM, F-SD2-ISV1-PT3, F-SD2-ISV1-PT5 & 2 & & 1 & \\
\hline F-SD1-CR-BD-CM, F-SD2-ISV1-PT3, F-SD2-ISV2-PT5 & 2 & & 1 & \\
\hline F-SD1-CR-COIL-CM, F-SD2-ISV1-PT5, F-SD2-ISV2-PT3 & 2 & & 1 & \\
\hline F-SD1-CR-COIL-CM, F-SD2-ISV2-PT3, F-SD2-ISV2-PT5 & 2 & & 1 & \\
\hline F-SD1-CR-COIL-CM, F-SD2-ISV1-PT3, F-SD2-ISV2-PT5 & 2 & & 1 & \\
\hline F-SD1-CR-COIL-CM, F-SD2-ISV1-PT3, F-SD2-ISV1-PT5 & 2 & & 1 & \\
\hline F-SD1-CR-BD-CM, F-SD2-ISV1-PT5, F-SD2-ISV2-PT3 & 2 & & 1 & \\
\hline F-SD1-CR-BD-CM, F-SD2-ISV2-PT3, F-SD2-ISV2-PT5 & 2 & & 1 & \\
\hline F-SD1-CR-BD-CM, F-SD2-ISV1-PT2, F-SD2-ISV2-PT5 & 2 & & 1 & \\
\hline F-SD1-CR-BD-CM, F-SD2-ISV1-PT2, F-SD2-ISV1-PT5 & 2 & & 1 & \\
\hline F-SD1-CR-BD-CM, F-SD2-TL-G, F-SD2-TL-J & 2 & & 1 & \\
\hline
\end{tabular}


Appendix C

Table C.3 (cont.)

\begin{tabular}{|c|c|c|c|c|}
\hline F-SD1-CR-COIL-CM, F-SD2-TL-G, F-SD2-TL-J & 2 & & 1 & \\
\hline F-SD1-CR-COIL-CM, F-SD2-TL-H, F-SD2-TL-J & 2 & & 1 & \\
\hline F-SD1-CR-BD-CM, F-SD2-TL-H, F-SD2-TL-J & 2 & & 1 & \\
\hline F-SD1-CR-BD-CM, F-SD2-TL-G, F-SD2-TL-H & 2 & & 1 & \\
\hline F-SD1-CR-COIL-CM, F-SD2-TL-G, F-SD2-TL-H & 2 & & 1 & \\
\hline F-SD1-CR-BD-CM, F-SD2-ISV1-PT3, F-SD2-ISV1-PT4 & 2 & & 1 & \\
\hline F-SD1-CR-BD-CM, F-SD2-ISV1-PT3, F-SD2-ISV2-PT4 & 2 & & 1 & \\
\hline F-SD1-CR-COIL-CM, F-SD2-ISV1-PT4, F-SD2-ISV2-PTi3 & 2 & & 1 & \\
\hline F-SD1-CR-COIL-CM, F-SD2-ISV2-PT3, F-SD2-ISV2-PT4 & 2 & & 1 & \\
\hline F-SD1-CR-COIL-CM, F-SD2-ISV1-PT3, F-SD2-ISV2-PT 4 & 2 & & 1 & \\
\hline F-SD1-CR-COIL-CM, F-SD2-ISV1-PT3, F-SD2-ISV1-PT4 & 2 & & 1 & \\
\hline F-SD1-CR-BD-CM, F-SD2-ISV1-PT4, F-SD2-ISV2-PT3 & 2 & & 1 & \\
\hline F-SD1-CR-BD-CM, F-SD2-ISV2-PT3, F-SD2-ISV2-PT4 & 2 & & 1 & \\
\hline F-SD1-CR-BD-CM, F-SD2-ISV1-PT4, F-SD2-ISV1-PT5 & 2 & & 1 & \\
\hline F-SD1-CR-BD-CM, F-SD2-ISV1-PT4, F-SD2-ISV2-PT5 & 2 & & 1 & \\
\hline F-SD1-CR-COIL-CM, F-SD2-ISV1-PT6, F-SD2-ISV2-PT3 & 2 & & 1 & \\
\hline F-SD1-CR-COIL-CM, F-SD2-ISV2-PT3, F-SD2-ISV2-PT6 & 2 & & 1 & \\
\hline F-SD1-CR-COIL-CM, F-SD2-ISV1-PT3, F-SD2-ISV2-PT6 & 2 & & 1 & \\
\hline F-SD1-CR-COIL-CM, F-SD2-ISV1-PT3, F-SD2-ISV1-PT6 & 2 & & 1 & \\
\hline F-SD1-CR-BD-CM, F-SD2-ISV1-PT6, F-SD2-ISV2-PT3 & 2 & & 1 & \\
\hline F-SD1-CR-BD-CM, F-SD2-ISV2-PT3, F-SD2-ISV2-PT6 & 2 & & 1 & \\
\hline F-SD1-CR-BD-CM, F-SD2-ISV1-PT4, F-SD2-ISV1-PT6 & 2 & & 1 & \\
\hline F-SD1-CR-BD-CM, F-SD2-ISV1-PT4, F-SD2-ISV2-PT6 & 2 & & 1 & \\
\hline F-SD1-CR-COIL-CM, F-SD2-ISV1-PT6, F-SD2-ISV2-PT4 & 2 & & 1 & \\
\hline F-SD1-CR-BD-CM, F-SD2-ISV1-PT2, F-SD2-ISV1-PT3 & 2 & & 1 & \\
\hline F-SD1-CR-COIL-CM, F-SD2-ISV1-PT4, F-SD2-ISV2-PT6 & 2 & & 1 & \\
\hline F-SD1-CR-COIL-CM, F-SD2-ISV1-PT4, F-SD2-ISV1-PT6 & 2 & & 1 & \\
\hline F-SD1-CR-BD-CM, F-SD2-ISV1-PT6, F-SD2-ISV2-PT4 & 2 & & 1 & \\
\hline F-SD1-CR-BD-CM, F-SD2-ISV2-PT4, F-SD2-ISV2-PT6 & 2 & & 1 & \\
\hline F-SD1-CR-BD-CM, F-SD2-ISV1-PT3, F-SD2-ISV2-PT6 & 2 & & 1 & \\
\hline F-SD1-CR-BD-CM, F-SD2-ISV1-PT3, F-SD2-ISV1-PT6 & 2 & & 1 & \\
\hline F-SD1-CR-COIL-CM, F-SD2-ISV1-PT5, F-SD2-ISV2-PT4 & 2 & & 1 & \\
\hline F-SD1-CR-COIL-CM, F-SD2-ISV2-PT4, F-SD2-ISV2-PT5 & 2 & & 1 & \\
\hline F-SD1-CR-COIL-CM, F-SD2-ISV1-PT4, F-SD2-ISV2-PT5 & 2 & & 1 & \\
\hline
\end{tabular}


Table C.3 (cont.)

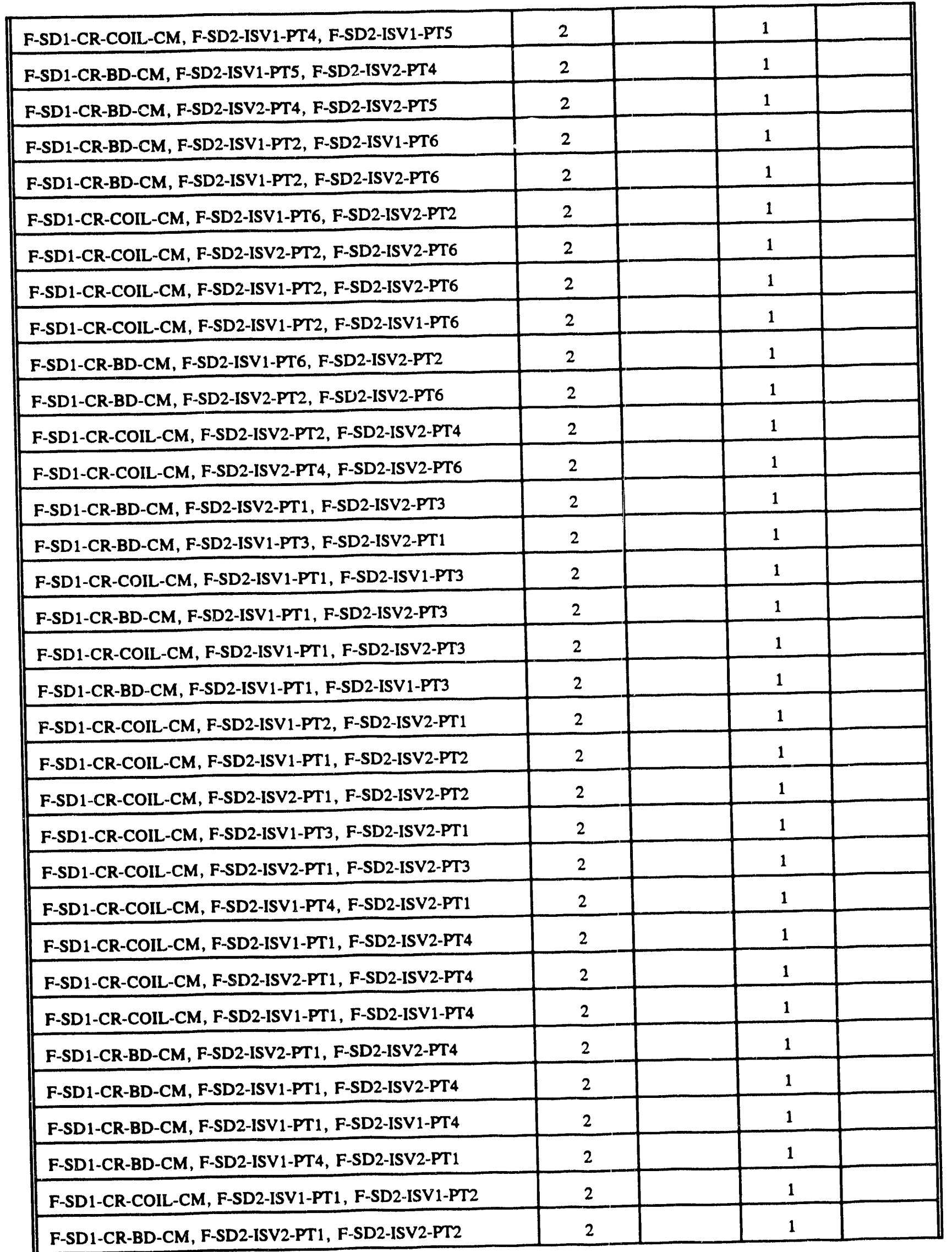


Table C.3 (cont.)

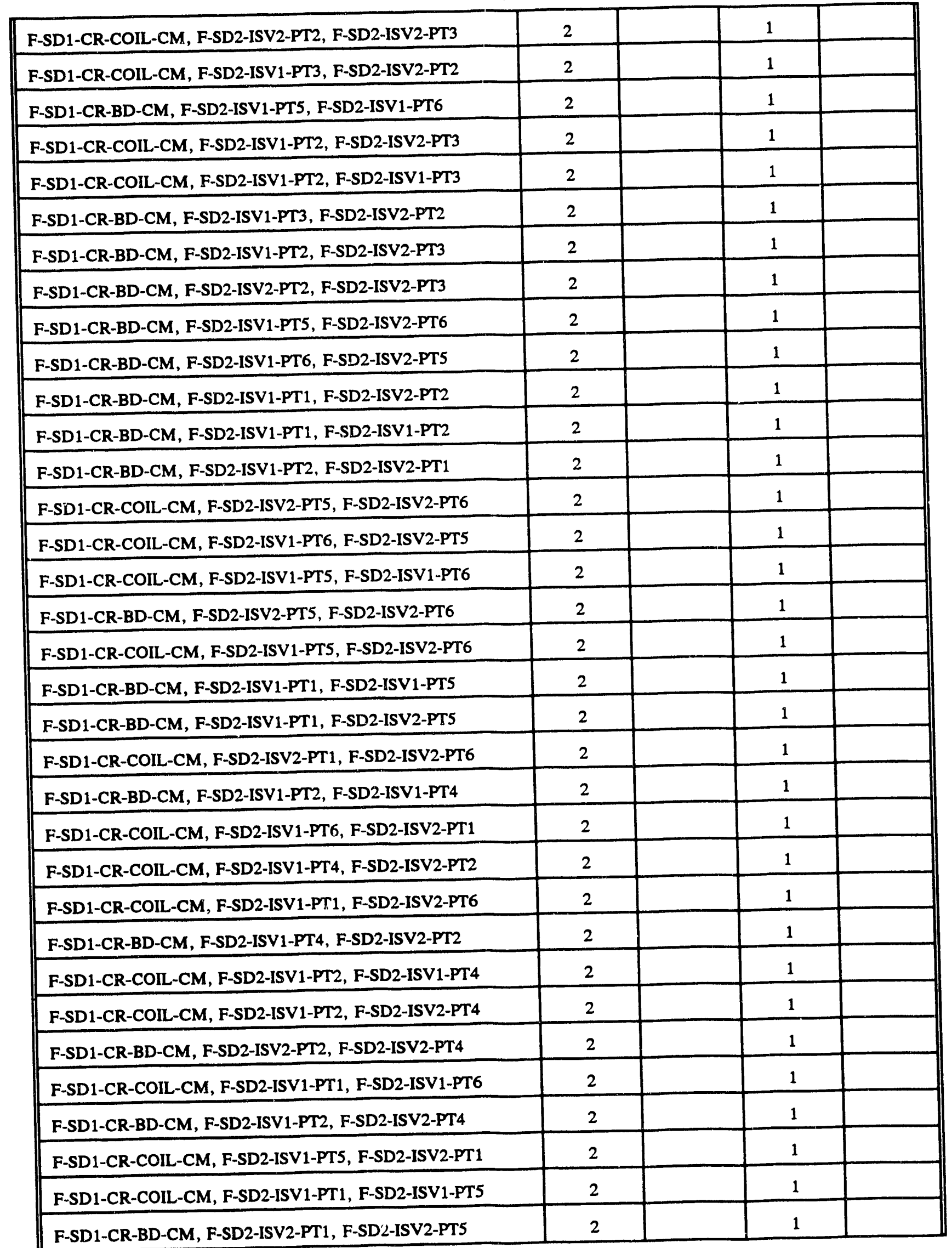


Appendix C

Table C.3 (cont.)

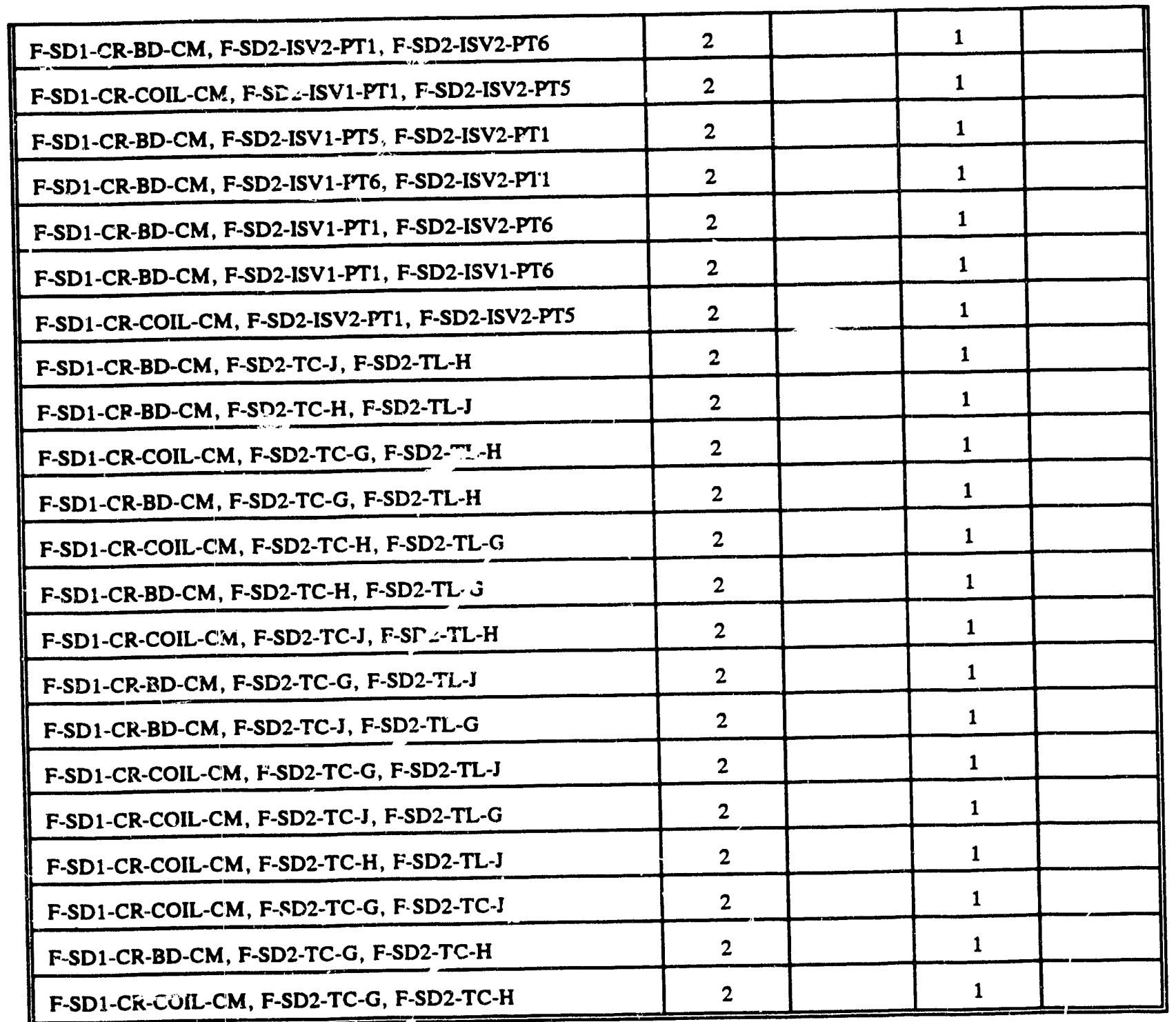


Table C.4 Small-breal loss-of-coolant events sequence categorization: representative initiating event - liquid relief valve failure

\begin{tabular}{|c|c|c|c|c|c|}
\hline \multicolumn{2}{|c|}{ Specific Initiator } & \multicolumn{2}{|c|}{$\begin{array}{l}\text { Liquid relief valve } \\
\text { failure }\end{array}$} & \multicolumn{2}{|c|}{$\begin{array}{l}\text { Failure of pressure } \\
\text { and inventory } \\
\text { control system }\end{array}$} \\
\hline \multicolumn{2}{|c|}{ IE Frequency } & \multicolumn{2}{|c|}{$1 \times 10^{-1}$} & \multicolumn{2}{|c|}{$1 \times 10^{-2}$} \\
\hline Sequence & Determinant Failures & Bin & Category & Bin & Category \\
\hline LRVF-A & NA & $\mathbf{A}$ & EC-I & $\mathbf{A}$ & EC-I \\
\hline LRVF-B & support system & $\mathrm{C}$ & EC-III & $\mathrm{C}$ & EC-III \\
\hline LRVF-C & $\geq 3$ failures & $\mathrm{D}$ & EC-IV & $\bar{D}$ & EC-IV \\
\hline LRVF-D & $\geq 3$ failures & $\mathrm{D}$ & EC-IV & $\mathrm{D}$ & EC-IV \\
\hline LRVF-E & $\geq 3$ failures & $\mathrm{D}$ & EC-IV & $\bar{D}$ & EC-IV \\
\hline LRVF-F & $\geq 3$ failures & $\bar{D}$ & EC-IV & $\bar{D}$ & EC-IV \\
\hline LRVF-G & $\geq 3$ failures & $\mathrm{D}$ & EC-IV & $\bar{D}$ & EC-IV \\
\hline LRVF-H & $\geq 3$ failures & $\bar{D}$ & EC-IV & $\mathrm{D}$ & EC-IV \\
\hline LRVF-I & $\begin{array}{c}\text { support systems, } \\
2 \text { valves } \\
\end{array}$ & C & EC-III & C & EC-III \\
\hline LRVF-J & $\geq 3$ failures & $\bar{D}$ & EC-IV & $\bar{D}$ & EC-IV \\
\hline LRVF-K & $\geq 3$ failures & $\mathrm{D}$ & EC-IV & $\bar{D}$ & EC-IV \\
\hline LRVF-L & $\geq 3$ failures & $\mathrm{D}$ & EC-IV & $\mathrm{D}$ & EC-IV \\
\hline LRVF-M & $\geq 3$ failures & D & EC-IV & $\bar{D}$ & EC-IV \\
\hline LRVF-N & $\geq 3$ failures & $\bar{D}$ & EC-IV & $\bar{D}$ & EC-IV \\
\hline LRVF-O & $\geq 3$ failures & $\mathrm{D}$ & EC-IV & $\bar{D}$ & EC-IV \\
\hline LRVF-P & $\geq 3$ failures & $\bar{D}$ & EC-IV & $\bar{D}$ & EC-IV \\
\hline LRVF-Q & $\geq 3$ failures & $\mathrm{D}$ & EC-IV & $\bar{D}$ & EC-IV \\
\hline LRVF-R & $\begin{array}{l}\text { common mode failure, } \\
2 \text { relays, } \\
2 \text { trip computers } \\
\end{array}$ & $\mathrm{C}$ & EC-III & C & EC-III \\
\hline LRVF-S & $\geq 3$ failures & $\mathrm{D}$ & EC-IV & $\bar{D}$ & EC-IV \\
\hline LRVF-T & $\geq 3$ failures & $\mathrm{D}$ & EC-IV & $\bar{D}$ & EC-IV \\
\hline LRVF.U & $\geq 3$ failures & $\bar{D}$ & EC-IV & $\mathrm{D}$ & EC-IV \\
\hline LRVF-V & $\geq 3$ failures & $\bar{D}$ & EC-IV & $\bar{D}$ & EC-IV \\
\hline LRVF-W & $\geq 3$ failures & $\mathrm{D}$ & EC-IV & D & EC-IV \\
\hline LRVF-X & $\geq 3$ failures & $\bar{D}$ & EC-IV & $\bar{D}$ & EC-IV \\
\hline LRVF-Y & $\geq 3$ failures & $\bar{D}$ & EC-IV & $\bar{D}$ & EC-IV \\
\hline LRVF-Z & $\geq 3$ failures & D & EC-IV & $\mathrm{D}$ & EC-IV \\
\hline LRVF-AA & $\geq 3$ failures & $\mathbf{D}$ & EC-IV & $\mathrm{D}$ & EC-IV \\
\hline LRVF-AB & 23 failures & $\bar{D}$ & EC-IV & D & EC-IV \\
\hline LRVF-AC & $\geq 3$ failures & D & EC-IV & $\mathrm{D}$ & EC-IV \\
\hline LRVF-AD & $\geq 3$ failures & $\mathrm{D}$ & EC-IV & $\mathrm{D}$ & EC-IV \\
\hline LRVF-AE & $\geq 3$ failures & $D$ & EC-IV & D & EC-IV \\
\hline LRVF-AF & $\geq 3$ failures & $\bar{D}$ & EC-IV & $\bar{D}$ & EC-IV \\
\hline LRVF-AG & $\geq 3$ failures & $\mathbf{D}$ & EC-IV & $\bar{D}$ & EC-IV \\
\hline LRVF-AH & $\geq 3$ failures & $\mathrm{D}$ & EC-IV & $\bar{D}$ & EC-IV \\
\hline
\end{tabular}


Table C.4 (cont.)

\begin{tabular}{|c|c|c|c|c|c|}
\hline \multicolumn{2}{|c|}{ Specific Initiator } & \multicolumn{2}{|c|}{$\begin{array}{l}\text { Liguid relief valve } \\
\text { failure }\end{array}$} & \multicolumn{2}{|c|}{$\begin{array}{l}\text { Failure of pressure } \\
\text { and inventory } \\
\text { control system }\end{array}$} \\
\hline \multicolumn{2}{|c|}{ IE Prequency } & \multicolumn{2}{|c|}{$1 \times 10^{-1}$} & \multicolumn{2}{|c|}{$1 \times 10^{-2}$} \\
\hline Sequence & Determinant Failures & Bin & Category & Bin & Category \\
\hline LRVF-FTSD-A & $\geq 3$ failures & $\bar{D}$ & EC-IV & D & EC-IV \\
\hline LRVF-FTSD-B & $\geq 3$ failures & $\bar{D}$ & EC-IV & $\bar{D}$ & EC-IV \\
\hline LRVF-FTSD-C & $\geq 3$ failures & $\bar{D}$ & EC-IV & $\mathrm{D}$ & EC-IV \\
\hline LRVF-FTSD-D & $\geq 3$ failures & $\bar{D}$ & EC-IV & $\bar{D}$ & EC-IV \\
\hline LRVF-FTSD-E & $\geq 3$ failures & $\bar{D}$ & EC-IV & $\bar{D}$ & EC-IV \\
\hline LRVF-FTSD-F & $\geq 3$ failures & $\overline{\mathrm{D}}$ & EC-IV & $\bar{D}$ & EC-IV \\
\hline LRVF-FTSD-G & $\geq 3$ failures & $\bar{D}$ & EC-IV & $\bar{D}$ & EC-IV \\
\hline LRVF-FTSD-H & $\geq 3$ failures & D & EC-IV & $\bar{D}$ & EC-IV \\
\hline LRVF-FTSD-I & 23 failures & $\bar{D}$ & EC-IV & $\mathrm{D}$ & EC-IV \\
\hline LRVF-FTSD-J & $\geq 3$ failures & $\bar{D}$ & EC-IV & $\bar{D}$ & EC-IV \\
\hline LRVF-FTSD-K & $\geq 3$ failures & $\mathrm{D}$ & EC-IV & $\mathrm{D}$ & EC-IV \\
\hline LRVF-FTSD-L & $\geq 3$ failures & $\bar{D}$ & EC-IV & $\mathrm{D}$ & EC-IV \\
\hline LRVF-FTSD-M & $\geq 3$ failures & $\bar{D}$ & EC-IV & $\mathrm{D}$ & EC-IV \\
\hline LRVF-FTSD-N & $\geq 3$ failures & $\bar{D}$ & EC-IV & $\bar{D}$ & EC-IV \\
\hline
\end{tabular}


Table C.5 Feeder tube break sequence cut sets

\begin{tabular}{|c|c|c|c|c|}
\hline \multirow{2}{*}{ Initiating Event - Feeder Tube Break } & \multicolumn{4}{|c|}{ Sequence: SBLFB-A } \\
\hline & $\begin{array}{c}\text { Component } \\
\text { Frailures }\end{array}$ & $\begin{array}{c}\text { Humen } \\
\text { Emrors }\end{array}$ & $\begin{array}{l}\text { Suppont } \\
\text { Sywtem } \\
\text { Failures }\end{array}$ & $\begin{array}{l}\text { Determimant } \\
\text { Failure? }\end{array}$ \\
\hline NONE & NA & NA & NA & NA \\
\hline
\end{tabular}

\begin{tabular}{|c|c|c|c|c|}
\hline Initiating Event - Feeder Tube Break & Sequenc & SBLFI & & \\
\hline Sequence Level Cut Sets & $\begin{array}{l}\text { Component } \\
\text { Fuihures }\end{array}$ & $\begin{array}{l}\text { Yuman } \\
\text { Erron }\end{array}$ & $\begin{array}{l}\text { Support } \\
\text { Syptem } \\
\text { Failuree }\end{array}$ & $\begin{array}{l}\text { Determinant } \\
\text { Failure? }\end{array}$ \\
\hline F-LPI-ISV1, F-LPI-ISV2 & 2 & & & $\mathbf{Y}$ \\
\hline F-LPI-PMP1, F-LPI-PMP2 & 2 & & & $\mathbf{Y}$ \\
\hline F-LPI-INV1, F-LPI-INV2 & 2 & & & $\mathbf{Y}$ \\
\hline F-LPI-PMP1, S-EL-III-2-E & 1 & & 1 & \\
\hline F-LPI-PMP2, S-EL-III-2-O & 1 & & 1 & \\
\hline F-LPI-ISV2, S-EL-III-2-O & 1 & & 1 & \\
\hline F-HPI-ISV1-GI, S-EL-III-2-E & 1 & & 1 & \\
\hline F-LPI-LI-TK, F-LPI-TK & 2 & & & $\mathbf{Y}$ \\
\hline F-HPI-ISV2-GI, S-EL-III-2-O & 1 & & 1 & \\
\hline F-LPI-INV2, S-EL-III-2-O & 1 & & 1 & \\
\hline F-LPI-ISV1, S-EL-III-2-E & 1 & & 1 & \\
\hline F-LPI-INV1, S-EL-III-2-E & 1 & & 1 & \\
\hline S-EL-III-2-E, S-EL-III-2-O & & & 2 & \\
\hline
\end{tabular}

\begin{tabular}{|c|c|c|c|c|}
\hline \multirow{2}{*}{$\frac{\text { Initiating Event - Feeder Tube Break }}{\text { Sequence Level Cut Sets }}$} & \multicolumn{4}{|c|}{ Sequence: $S B L F B-C$} \\
\hline & $\begin{array}{c}\text { Composent } \\
\text { Fraibure }\end{array}$ & $\begin{array}{l}\text { Human } \\
\text { Exrors }\end{array}$ & $\begin{array}{l}\text { Suppont } \\
\text { Syptem } \\
\text { Failuree }\end{array}$ & $\begin{array}{l}\text { Determinant } \\
\text { Faibure? }\end{array}$ \\
\hline F-LPI-INV1, F-LPI-INV2, F-MCS-ISV-FC & 3 & & & \\
\hline F-LPI-ISV1, F-LPI-ISV2, S-RCW & 2 & & 1 & \\
\hline F-LPI-INV1, F-LPI-INV2, F-MCS-PMP2 & 3 & & & \\
\hline F-LPI-ISV1, F-LPI-ISV2, S-EL-III-1-O & 2 & & 1 & \\
\hline F-LPI-ISV1, F-LPI-ISV2, F-MCS-PMP1 & 3 & & & \\
\hline F-LPI-ISV1, F-LPI-ISV2, F-MCS-PMP2 & 3 & & & \\
\hline
\end{tabular}


Table C.5 (cont.)

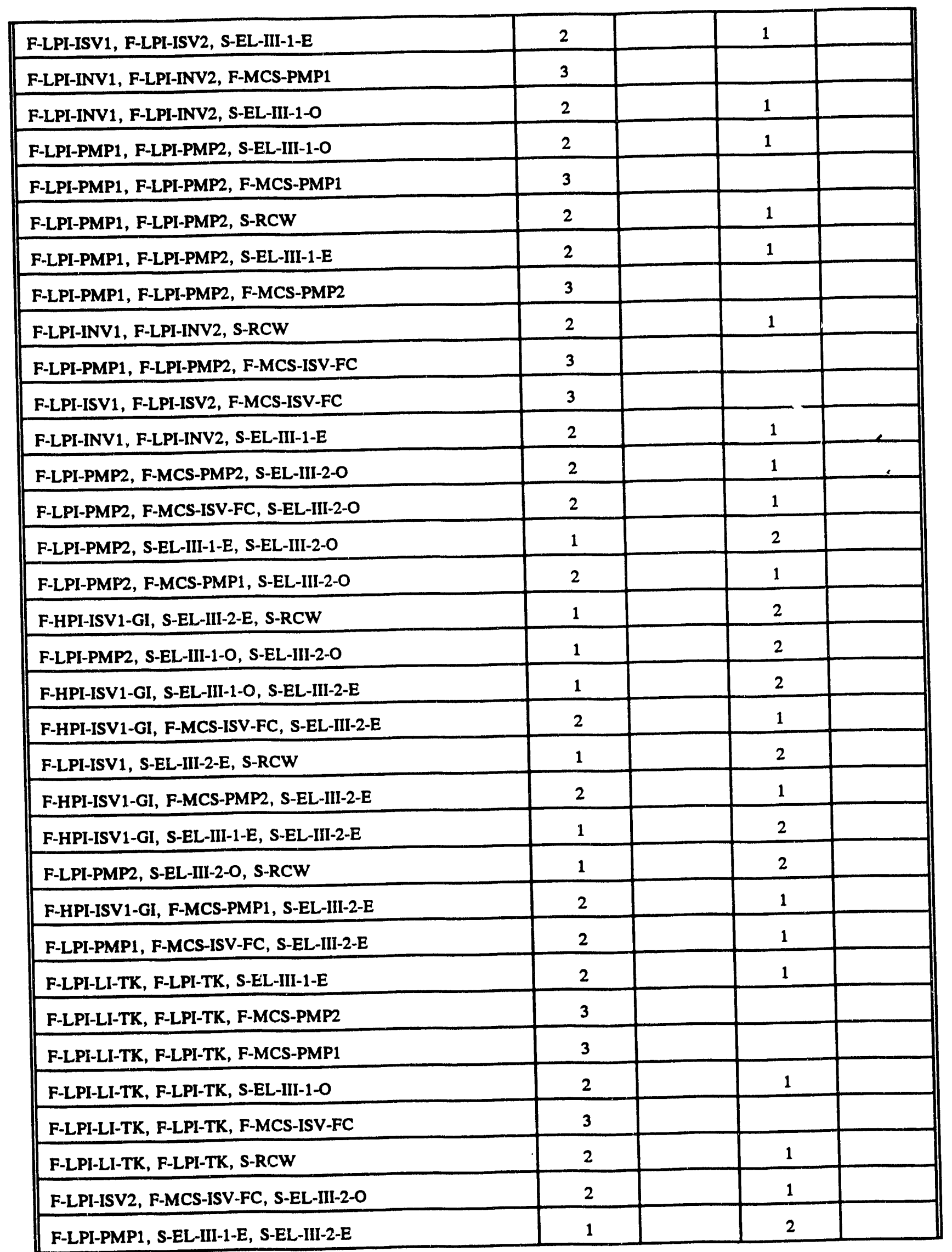


Table C.5 (cont.)

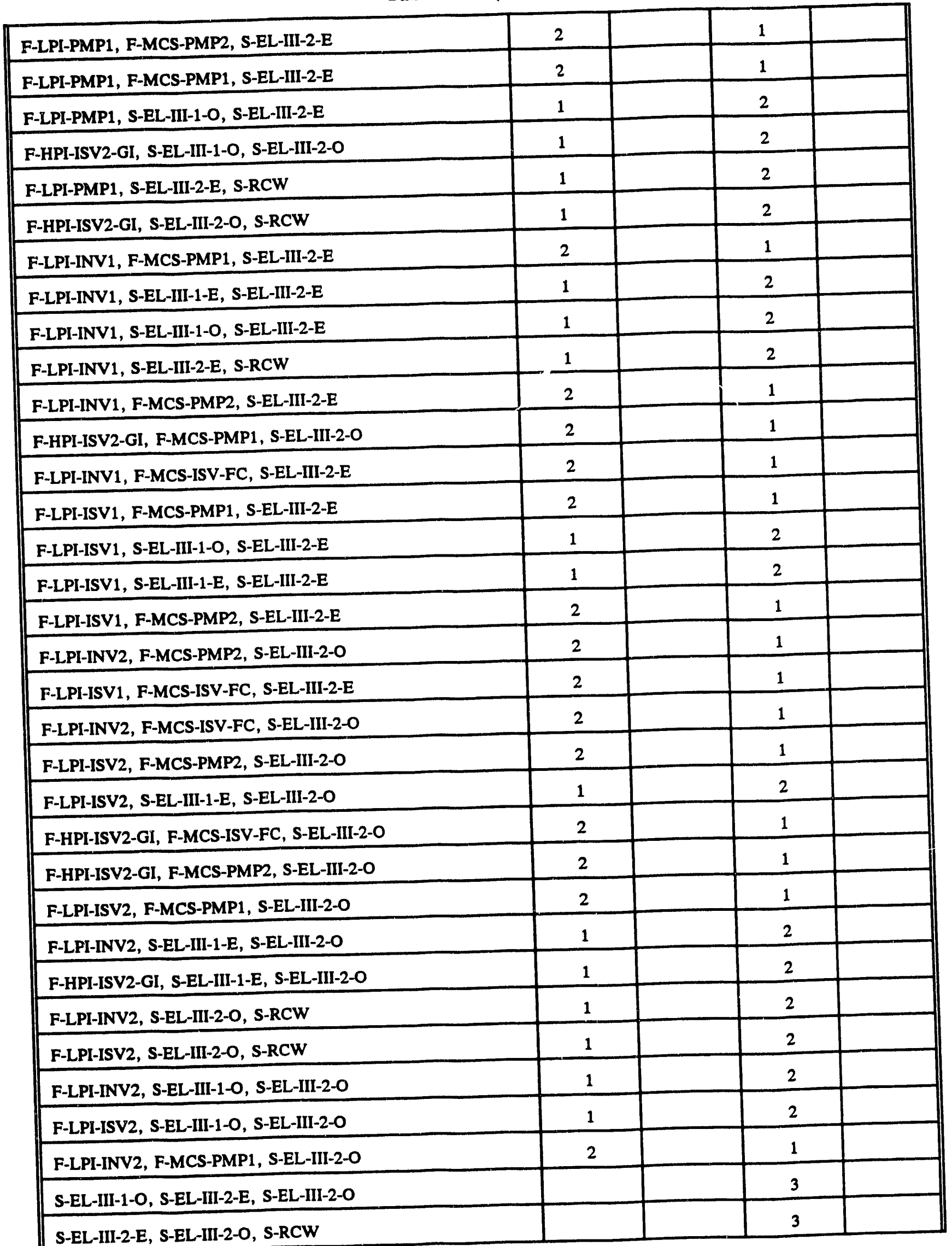


Table C.5 (cont.)

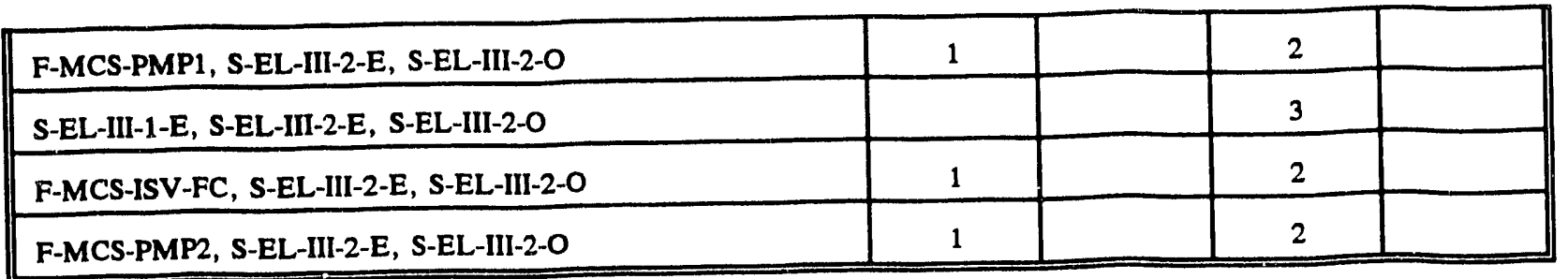

\begin{tabular}{|c|c|c|c|c|}
\hline Initiating Event - Feeder Tube Break & Sequenc & $S B L F$ & & \\
\hline Sequence Level Cut Sets & $\begin{array}{l}\text { Component } \\
\text { Fuilures }\end{array}$ & $\begin{array}{c}\text { Human } \\
\text { Errore }\end{array}$ & $\begin{array}{l}\text { Support } \\
\text { System } \\
\text { Failures }\end{array}$ & $\begin{array}{l}\text { Determinant } \\
\text { Failure? }\end{array}$ \\
\hline F-HPI-SIG1-LPHTS, F-HPI-SIG2-LPHTS & 2 & & & $\mathbf{Y}$ \\
\hline F-HPI-SIG2-LPHTS, F-HPI-SIG3-LPHTS & 2 & & & $\mathbf{Y}$ \\
\hline F-HPI-ISV1-GI, F-HPI-ISV2-GI & 2 & & & $\mathbf{Y}$ \\
\hline F-HPI-INV1, F-HPI-INV2 & 2 & & & $\mathrm{Y}$ \\
\hline F-HPI-SIG1-LPHTS, F-HPI-SIG3-LPHTS & 2 & & & $\mathbf{Y}$ \\
\hline F-HPI-OV2A, F-HPI-OV2B & 2 & & & $Y$ \\
\hline F-HPI-INV1A, F-HPI-INV1B & 2 & & & $\mathrm{Y}$ \\
\hline F-HPI-INV2A, F-HPI-INV2B & 2 & & & $\mathbf{Y}$ \\
\hline F-HPI-OV1A, F-HPI-OV1B & 2 & & & $\mathbf{Y}$ \\
\hline F-HPI-PI-GI-TK, F-HPI-TK-GI & 2 & & & $\mathbf{Y}$ \\
\hline F-HPI-LI-CITK, F-HPI-TK-CI & 2 & & & $\mathbf{Y}$ \\
\hline
\end{tabular}

\begin{tabular}{|c|c|c|c|c|}
\hline Initiating Event - Feeder Tube Break & \multicolumn{4}{|c|}{ Sequence: $S B L F B-E$} \\
\hline Sequence Level Cut Sets & $\begin{array}{l}\text { Component } \\
\text { Failures }\end{array}$ & $\begin{array}{c}\text { Humnn } \\
\text { Erron }\end{array}$ & $\begin{array}{l}\text { Support } \\
\text { Syotem } \\
\text { Failures }\end{array}$ & $\begin{array}{l}\text { Determinant } \\
\text { Failure? }\end{array}$ \\
\hline F-HPI-SIG2-LPHTS, F-HPI-SIG3-LPHTS, F-MCS-ISV-FC & 3 & & & \\
\hline F-HPI-SIG1-LPHTS, F-HPI-SIG3-LPHTS, S-RCW & 2 & & 1 & \\
\hline F-HPI-SIG2-LPHTS, F-HPI-SIG3-LPHTS, F-MCS-PMP2. & 3 & & & \\
\hline F-HPI-SIG2-LPHTS, F-HPI-SIG3-LPHTS, S-EL-III-1-E & 2 & & 1 & \\
\hline F-HPI-SIG1-LPHTS, F-HPI-SIG3-LPHTS, S-EL-III-1-O & 2 & & 1 & \\
\hline F-HPI-SIG2-LPHTS, F-HPI-SIG3-LPHTS, F-MCS-PMP1 & 3 & & & \\
\hline F-HPI-SIG1-LPHTS, F-HPI-SIG3-LPHTS, F-MCS-PMP1 & 3 & & & \\
\hline F-HPI-OV2A, F-HPI-OV2B, S-RCW & 2 & & 1 & \\
\hline F-HPI-OV2A, F-HPI-OV2B, S-EL-III-1-O & 2 & & 1 & \\
\hline F-HPI-SIG1-LPHTS, F-HPI-SIG3-LPHTS, F-MCS-ISV-FC & 3 & & & \\
\hline
\end{tabular}


Table C.5 (cont.)

\begin{tabular}{|c|c|c|c|}
\hline F-HPI-SIG1-LPHTS, F-HPI-SIG3-LPHTS, F-MCS-PMP2 & 3 & & \\
\hline F-HPI-SIG2-LPHTS, F-HPI-SIG3-LPHTS, S-EL-III-1-O & 2 & 1 & \\
\hline F-HPI-INV1, F-HPI-INV2, F-MCS-ISV-FC & 3 & & \\
\hline F-HPI-SIG2-LPHTS, F-HPI-SIG3-LPHTS, S-RCW & 2 & 1 & \\
\hline F-HPI-ISV1-GI, F-HPI-ISV2-GI, S-EL-III-1-E & 2 & 1 & \\
\hline F-HPI-ISV1-GI, F-HPI-ISV2-GI, F-MCS-PMP2 & 3 & & \\
\hline F-HPI-ISV1-GI, F-HPI-ISV2-GI, F-MCS-PMP1 & 3 & & \\
\hline F-HPI-ISV1-GI, F-HPI-ISV2-GI, S-EL-III-1-O & 2 & 1 & \\
\hline F-HPI-ISV1-GI, F-HPI-ISV2- II, F-MCS-ISV-FC & 3 & & \\
\hline F-HPI-ISV1-GI, F-HPI-ISV2-CI, S-RCW & 2 & 1 & \\
\hline F-HPI-SIG1-LPHTS, F-HPI-SIG2-LPHTS, S-RCW & 2 & 1 & \\
\hline F-HPI-SIG1-LPHTS, F-HPI-SIG2-LPHTS, F-MCS-PMP2 & 3 & & \\
\hline F-HPI-SIG1-LPHTS, F-HPI-SIG2-LFHTS, F-MCS-ISV-FC & 3 & & \\
\hline F-HPI-SIG1-LPHTS, F-HPI-SIG2-LPHTS, S-EL-III-1-E & 2 & 1 & \\
\hline F-HPI-SIG1-LPHTS, F-HPI-SIG2-LPHTS, F-MCS-PMP1 & 3 & & \\
\hline F-HPI-OV2A, F-HPI-OV2B, F-MCS-PMP1 & 3 & & \\
\hline F-HPI-SIG1-LPHTS, F-HPI-SIG2-LPHTS, S-EL-III-1-O & 2 & 1 & \\
\hline F-HPI-SIG1-LPHTS, F-HPI-SIG3-LPHTS, S-EL-III-1-E & 2 & 1 & \\
\hline F-HPI-INV1A, F-HPI-INV1B, F-MCS-PMP1 & 3 & & \\
\hline F-HPI-OV2A, F-HPI-OV2B, S-EL-III-1-E & 2 & 1 & \\
\hline F-HPI-INV1A, F-HPI-INV1B, S-EL-III-1-O & 2 & 1 & \\
\hline F-HPI-INV1A, F-HPI-INV1B, S-RCW & 2 & 1 & \\
\hline F-HPI-INV1A, F-HPI-INV1B, F-MCS-PMP2 & 3 & & \\
\hline F-HPI-INV2A, F-HPI-INV2B, F-MCS-ISV-FC & 3 & & \\
\hline F-HPI-INV1A, F-HPI-INV1B, F-MCS-ISV-FC & 3 & & \\
\hline F-HPI-INV1, F-HPI-INV2, S-EL-III-1-E & 2 & 1 & \\
\hline F-HPI-INV1, F-HPI-INV2, F-MCS-PMP2 & 3 & & \\
\hline F-HPI-INV1, F-HPI-INV2, F-MCS-PMP1 & 3 & & \\
\hline F-HPI-INV1, F-HPI-INV2, S-EL-III-1-O & 2 & 1 & \\
\hline F-HPI-INV2A, F-HPI-INV2B, F-MCS-PMP2 & 3 & & \\
\hline F-HPI-INV1, F-HPI-INV2, S-RCW & 2 & 1 & \\
\hline F-HPI-INV1A, F-HPI-INV1B, S-EL-III-1-E & 2 & 1 & \\
\hline F-HPI-OV1A, F-HPI-OV1B, S-EL-III-1-O & 2 & 1 & \\
\hline F-HPI-OV1A, F-HPI-OV1B, F-MCS-PMP1 & 3 & & \\
\hline
\end{tabular}


Table C.5 (cont.)

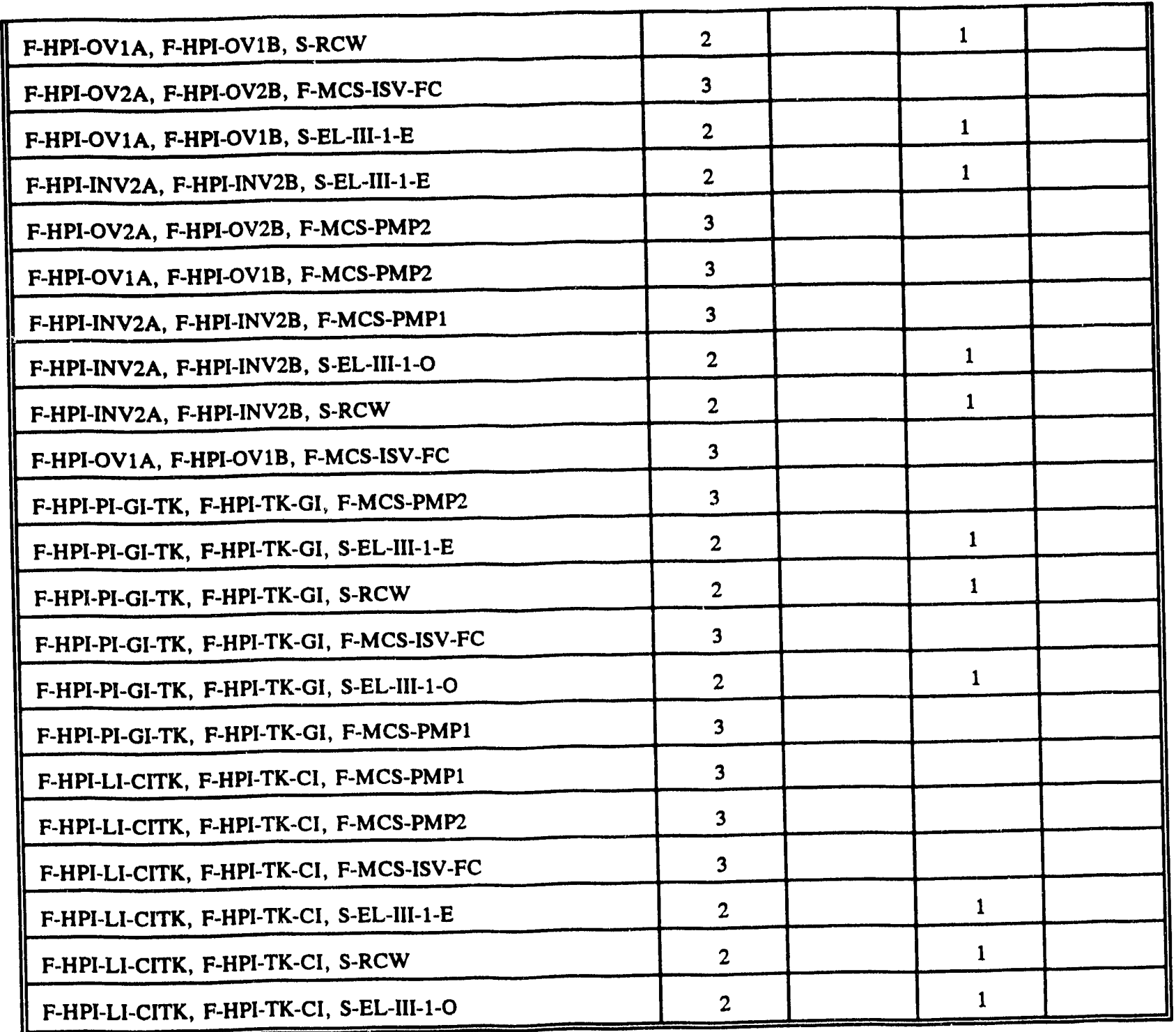

\begin{tabular}{|c|c|c|c|c|}
\hline \multirow{2}{*}{$\begin{array}{c}\text { Initiating Event - Feeder Tube Break } \\
\text { Sequence Level Cut Sets }\end{array}$} & \multicolumn{4}{|c|}{ Sequence: $S B L F B-F$} \\
\hline & $\begin{array}{l}\text { Component } \\
\text { Failures }\end{array}$ & $\begin{array}{l}\text { Human } \\
\text { Errors }\end{array}$ & $\begin{array}{l}\text { Suppont } \\
\text { System } \\
\text { Failures }\end{array}$ & $\begin{array}{l}\text { Determinant } \\
\text { Failure? }\end{array}$ \\
\hline F-FW1-ISV1, S-PCS & 1 & & 1 & \\
\hline F-FW1-ISV2, S-PCS & 1 & & 1 & \\
\hline S-EL-IV-E, S-EL-IV-O, S-PCS & & & 3 & \\
\hline F-FW1-DV2, S-EL-IV-O, S-PCS & 1 & & 2 & \\
\hline S-EL-II-1-E, S-EL-II-1-O, S-PCS & & & 3 & \\
\hline F-FW1-CNV2, S-EL-II-1-O, S-PCS & 1 & & 2 & \\
\hline F-FW1-CNV1, F-FW1-CNV2, S-PCS & 2 & & 1 & \\
\hline
\end{tabular}


Table C.5 (cont.)

\begin{tabular}{||l|c|c|c||}
\hline F-FW1-CNV1, S-EL-II-1-E, S-PCS & 1 & & 2 \\
\hline F-FW1-DV1, S-EL-IV-E, S-PCS & 1 & 2 & 1 \\
\hline F-FW1-DV1, F-FW1-PMP2, S-PCS & 2 & & 1 \\
\hline F-FW1-PMP1, F-FW1-PMP2, S-PCS & 2 & & 1 \\
\hline F-FW1-DV2, F-FW1-PMP1, S-PCS & 2 & & 1 \\
\hline F-FW1-DV1, F-FW1-DV2, S-PCS & & & 2 \\
\hline F-FW1-PMP2, S-EL-IV-O, S-PCS & 1 & & 2 \\
\hline F-FW1-PMP1, S-EL-IV-E, S-PCS & & & 2 \\
\hline
\end{tabular}

\begin{tabular}{|c|c|c|c|c|}
\hline Initiating Event - Feeder Tube Break & Sequenc & SBLF & & \\
\hline Sequence Level Cut Sets & $\begin{array}{l}\text { Component } \\
\text { Fuilures }\end{array}$ & $\begin{array}{l}\text { Human } \\
\text { Errors }\end{array}$ & $\begin{array}{l}\text { Support } \\
\text { System } \\
\text { Failures } \\
\end{array}$ & $\begin{array}{l}\text { Determinant } \\
\text { Failure? }\end{array}$ \\
\hline F-FW1-HE, S-PCS, S-RCW & & 1 & 2 & \\
\hline F-FW1-ISV1, S-EL-III-1-O, S-PCS & 1 & & 2 & \\
\hline F-FW1-ISV2, S-EL-III-1-O, S-PCS & 1 & & 2 & \\
\hline F-FW1-ISV2, S-PCS, S-RCW & 1 & & 2 & \\
\hline F-FW1-ISV1, S-PCS, S-RCW & 1 & & 2 & \\
\hline F-FW1-1SV1, F-MCS-PMP1, S-PCS & 2 & & 1 & \\
\hline S-FIW, S-PCS, S-RCW & & & 3 & \\
\hline F-FW1-ISV2, F-MCS-PMP1, S-PCS & 2 & & 1 & \\
\hline F-FW1-ISV2, F-MCS-PMP2, S-PCS & 2 & & 1 & \\
\hline F-FW1-ISV1, F-MCS-ISV-FC, S-PCS & 2 & & 1 & \\
\hline F-FW1-ISV1, F-MCS-PMP2, S-PCS & 2 & & 1 & \\
\hline F-FW1-ISV2, S-EL-III-1-E, S-PCS & 1 & & 2 & \\
\hline F-FW1-ISV2, F-MCS-ISV-FC, S-PCS & 2 & & 1 & \\
\hline F-FW1-ISV1, S-EL-III-1-E, S-PCS & 1 & & 2 & \\
\hline
\end{tabular}


Table C.5 (cont.)

\begin{tabular}{|c|c|c|c|c|}
\hline \multirow{2}{*}{$\frac{\text { Initiating Event - Feeder Tube Break }}{\text { Sequence Level Cut Sets }}$} & \multicolumn{4}{|c|}{ Sequence: $S B L F B-H$} \\
\hline & $\begin{array}{c}\text { Component } \\
\text { Fuilures }\end{array}$ & $\begin{array}{l}\text { Humen } \\
\text { Errons }\end{array}$ & $\begin{array}{l}\text { Support } \\
\text { Syotem } \\
\text { Failures }\end{array}$ & $\begin{array}{l}\text { Determinant } \\
\text { Frailure? }\end{array}$ \\
\hline S-ECC & & & 1 & $\mathrm{Y}$ \\
\hline S-EL-II-2-O & & & 1 & $\mathbf{Y}$ \\
\hline S-AIR & & & 1 & $\mathbf{Y}$ \\
\hline S-EL-II-2-E & & & 1 & $\mathbf{Y}$ \\
\hline F-MSV-MSSV1-SG2, F-MSV-MSSV2-SG2 & 2 & & & $Y$ \\
\hline F-MSV-MSSV3-SG1, F-MSV-MSSV4-SG1 & 2 & & & $\mathbf{Y}$ \\
\hline F-MSV-MSSV2-SG2, F-MSV-MSSV3-SG2 & 2 & & & $\mathbf{Y}$ \\
\hline F-MSV-MSSV1-SG2, F-MSV-MSSV3-SG2 & 2 & & & $\mathbf{Y}$ \\
\hline F-MSV-MSSV1-SG1, F-MSV-MSSV3-SG1 & 2 & & & $\mathbf{Y}$ \\
\hline F-MSV-MSSV1-SG1, F-MSV-MSSV2-SG1 & 2 & & & $\mathbf{Y}$ \\
\hline F-MSV-MSSV1-SG2, F-MSV-MSSV4-SG2 & 2 & & & $\mathbf{Y}$ \\
\hline F-MSV-MSSV2-SG1, F-MSV-MSSV4-SG1 & 2 & & & $\mathbf{Y}$ \\
\hline F-MSV-MSSV3-SG2, F-MSV-MSSV4-SG2 & 2 & & & $\mathbf{Y}$ \\
\hline F-MSV-MSSV1-SG1, F-MSV-MSSV4-SG1 & 2 & & & $\mathbf{Y}$ \\
\hline F-MSV-MSSV2-SG2, F-MSV-MSSV4-SG2 & 2 & & & $\mathbf{Y}$ \\
\hline F-MSV-MSSV2-SG1, F-MSV-MSSV3-SG1 & 2 & & & $Y$ \\
\hline
\end{tabular}

\begin{tabular}{||l|c|c|c|c||}
\hline \multicolumn{1}{|c|}{ Initiating Event - Feeder Tube Break } & \multicolumn{2}{l||}{ Sequence: SBLFB-I } \\
\hline \multicolumn{1}{|c|}{ Sequence Level Cut Sets } & $\begin{array}{c}\text { Component } \\
\text { Failures }\end{array}$ & $\begin{array}{c}\text { Human } \\
\text { Erors }\end{array}$ & $\begin{array}{c}\text { Support } \\
\text { System } \\
\text { Failures }\end{array}$ & $\begin{array}{c}\text { Determinant } \\
\text { Failure ? }\end{array}$ \\
\hline S-EL-II-2-O, S-RCW & & & 2 & \\
\hline S-ECC, S-EL-III-1-O & & & 2 & \\
\hline F-MCS-ISV-FC, S-EL-II-2-O & 1 & & 1 & \\
\hline F-MCS-PMP1, S-ECC & 1 & & 1 & \\
\hline S-ECC, S-EL-III-1-E & & & 2 & \\
\hline F-MCS-ISV-FC, S-ECC & 1 & & 1 & \\
\hline F-MCS-PMP2, S-ECC & & & 1 & \\
\hline F-MCS-PMP2, S-EL-II-2-O & 1 & & 1 & \\
\hline S-EL-II-2-O, S-EL-III-1-E & & & 2 & \\
\hline S-AIR, S-EL-III-1-E & & & 2 & \\
\hline
\end{tabular}


Table C.5 (cont.)

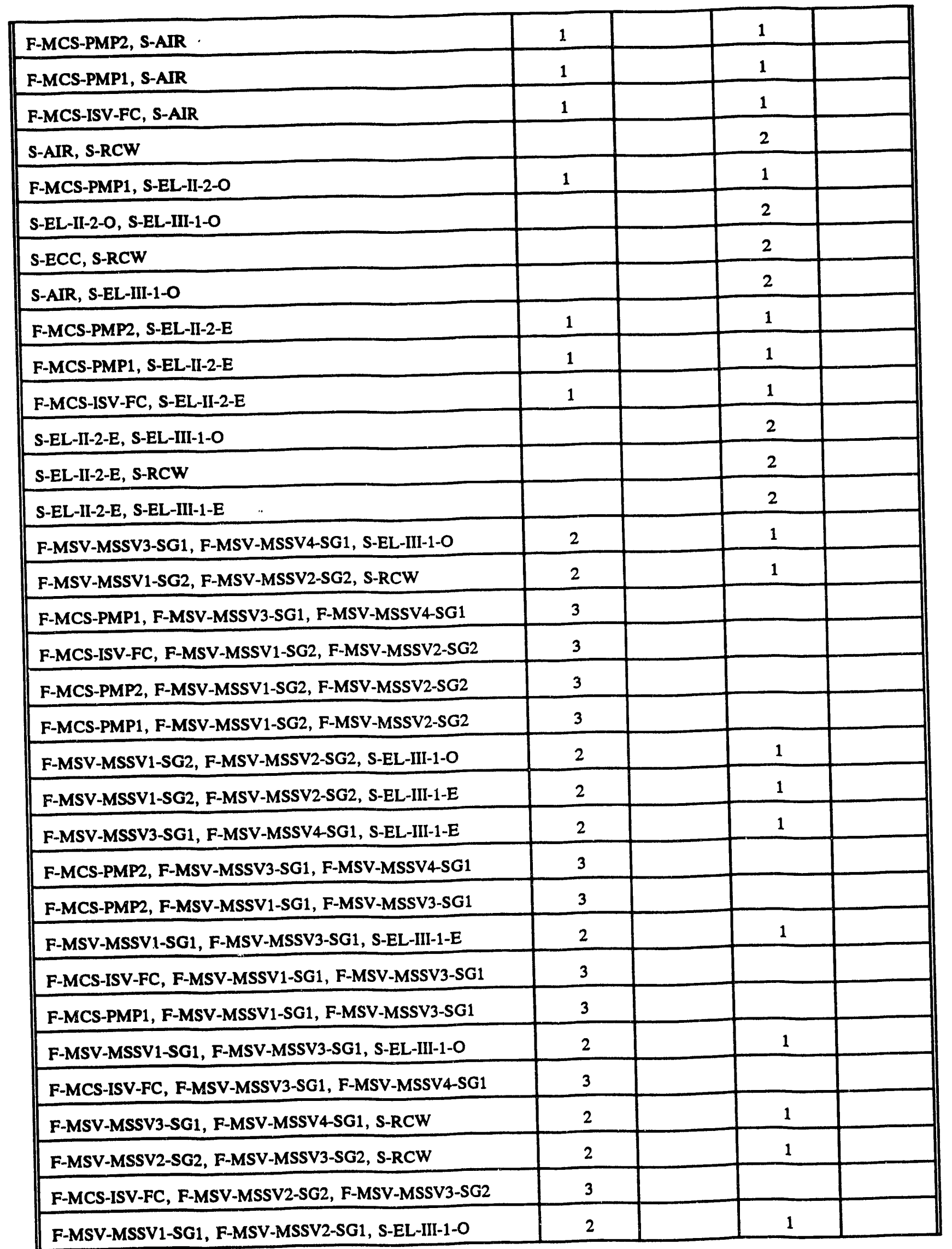


Table C.5 (cont.)

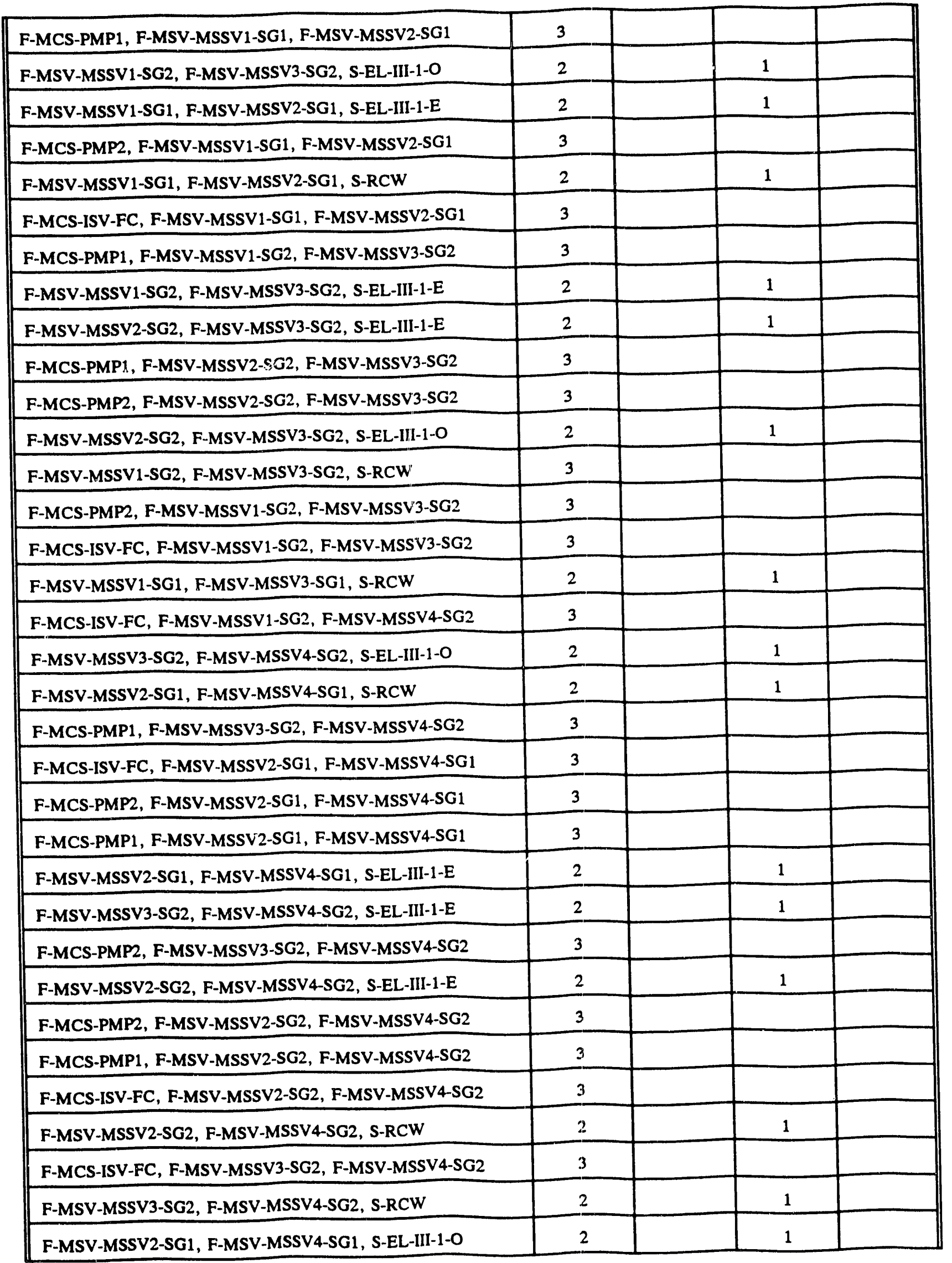


Appendix C

Table C.5 (cont.)

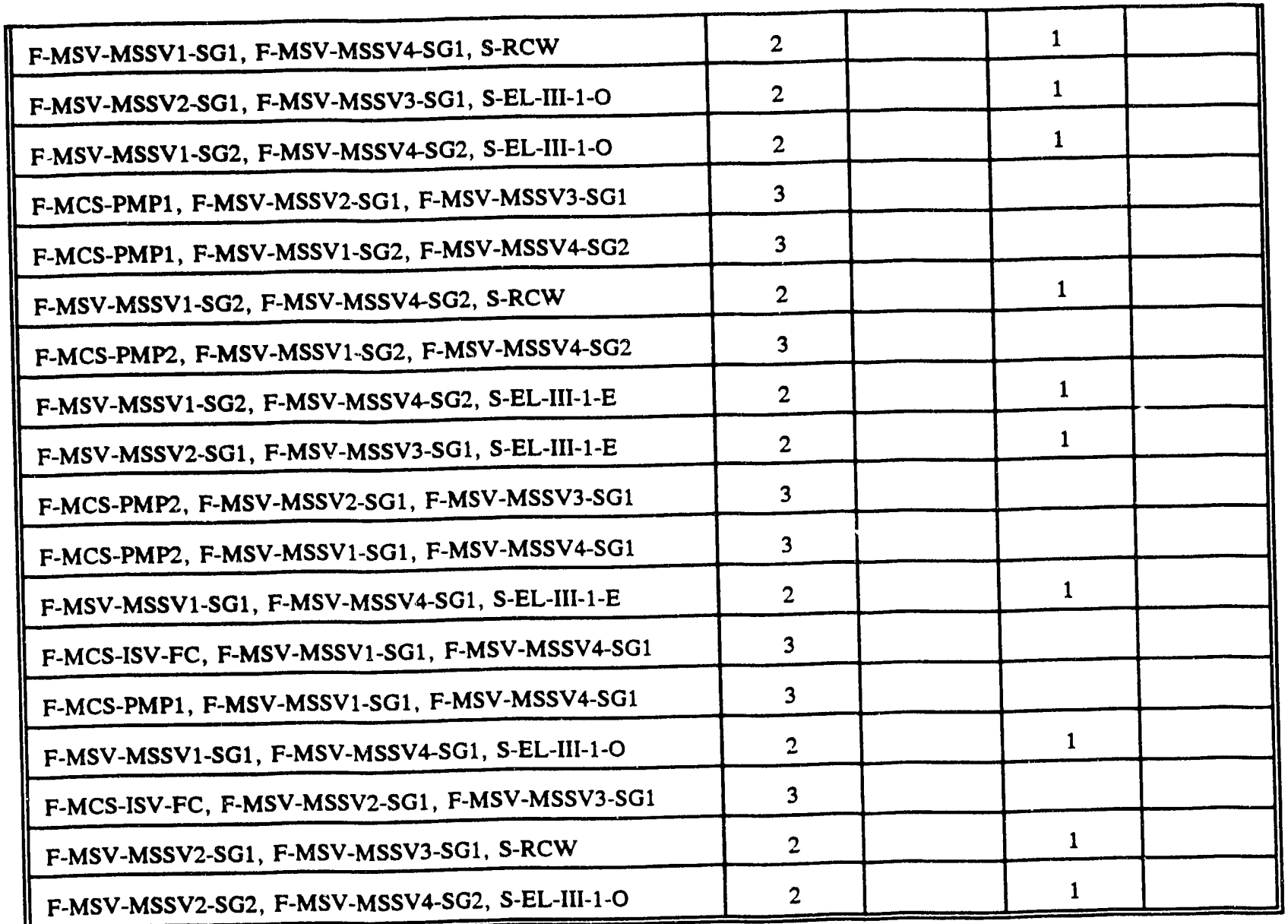

\begin{tabular}{||l|c|c|c|c||}
\hline \multicolumn{1}{|c|}{ Sequence Level Cut Sets } & \multicolumn{2}{l||}{ Sequence: SBLFB-J } \\
\hline \hline F-SD1-CR-BD-CM & $\begin{array}{c}\text { Component } \\
\text { Failures }\end{array}$ & $\begin{array}{c}\text { Humen } \\
\text { Errors }\end{array}$ & $\begin{array}{c}\text { Support } \\
\text { System } \\
\text { Failures }\end{array}$ & $\begin{array}{c}\text { Deterninant } \\
\text { Failure ? }\end{array}$ \\
\hline F-SD1-CR-COIL-CM & & & 1 & $Y$ \\
\hline F-SD1-TLB-REL2, F-SD1-TLB-REL3 & & & 1 & $Y$ \\
\hline F-SD1-TLB-REL1, F-SD1-TLB-REL2 & 2 & & & $Y$ \\
\hline F-SD1-TLA-REL1, F-SD1-TLA-REL2 & 2 & & & $Y$ \\
\hline F-SD1-TLB-REL1, F-SD1-TLB-REL3 & 2 & & & $Y$ \\
\hline F-SD1-TLA-REL2, F-SD1-TL A-REL3 & 2 & & & $Y$ \\
\hline F-SD1-TLA-REL1, F-SD1-TLA-REL3 & 2 & & & $Y$ \\
\hline F-SD1-TC-D, F-SD1-TC-E & 2 & & & $Y$ \\
\hline F-SD1-TC-D, F-SD1-TC-F & 2 & & & $Y$ \\
\hline F-SD1-TC-E, F-SD1-TC-F & 2 & & & $Y$ \\
\hline
\end{tabular}


Table C.5 (cont.)

\begin{tabular}{|c|c|c|c|c|}
\hline Initiating Event - Feeder Tube Break & Sequenc & SBLFI & & \\
\hline Sequence Level Cut Sets & $\begin{array}{l}\text { Component } \\
\text { Failures }\end{array}$ & $\begin{array}{l}\text { Humen } \\
\text { Errors }\end{array}$ & $\begin{array}{l}\text { Support } \\
\text { System } \\
\text { Failures }\end{array}$ & $\begin{array}{l}\text { Determinant } \\
\text { Failure? }\end{array}$ \\
\hline F-LPI-INV1, F-LPI-INV2, F-SD1-CR-CUIL-CM & 2 & & 1 & \\
\hline F-LPI-ISV1, F-LPI-ISV2, F-SD1-CR-COIL-CM & 2 & & 1 & \\
\hline F-LPI-PMP1, F-LPI-PMP2, F-SD1-CR-BD-CM & 2 & & 1 & \\
\hline F-LPI-ISV1, F-LPI-'sV2, r-SD1-CR-BD-CM & 2 & & 1 & \\
\hline F-LPI-PMP1, F-LPI-PMP2, F-SD1-CR-COIL-CM & 2 & & 1 & \\
\hline F-LPI-INV1, F-LPI-INV2, F-SD1-CR-BD-Cl & 2 & & 1 & \\
\hline F-LPI-PMP2, F-SD1-CR-BD-CM, S-EL-III-2-O & 1 & & 2 & \\
\hline F-LPI-PMP2, F-SD1-CR-COIL-CM, S-EL-III-2-O & 1 & & 2 & \\
\hline F-HPI-ISV1-GI, F-SD1-CR-COIL-CM, S-EL-III-2-E & 1 & & 2 & \\
\hline F-LPI-PMP1, F-SD1-CR-BD-CM, S-EL-III-2-E & 1 & & 2 & \\
\hline F-LPI-PMP1, F-SD1-CR-COIL-CM, S-EL-III-2-E & 1 & & 2 & \\
\hline F-LPI-LI-TK, F-LPI-TK, F-SD1-CR-BD-CM & 2 & & 1 & \\
\hline F-LPI-LI-TK, F-LF1-TK, F-SD1-CR-COIL-CM & 2 & & 1 & \\
\hline F-LPI-ISV2, F-SD1-CR JD-CM, S-EL-III-2-O & 1 & & 2 & \\
\hline F-HPI-ISV1-GI, F-SD1-CR-BD-CM, S-EL-III-2-E & 1 & & 2 & \\
\hline F-HPI-ISV2-GI, F-SD1-CR-COIL-CM, S-EL-III-2-O & 1 & & 2 & \\
\hline F-LPI-INV1, F-SD1-CR-BD-CM, S-EL-III-2-E & 1 & & 2 & \\
\hline F-LPI-INV1, F-SD1-CR-COIL-CM, S-EL-III-2-E & 1 & & 2 & \\
\hline F-LPI-ISV1, F-SD1-CR-BD-CM, S-EL-III-2-E & 1 & & 2 & \\
\hline F-LPI-INV2, F-SD1-CR-BD-CM, S-EL-III-2-O & 1 & & 2 & \\
\hline F-LPI-INV2, F-SD1-CR-COIL-CM, S-EL-III-2-O & 1 & & 2 & \\
\hline F-LPI-ISV2, F-SD1-CR-COIL-CM, S-EL-III-2-O & 1 & & 2 & \\
\hline F-LPI-ISV1, F-SD1-CR-COIL-CM, S-EL-III-2-E & 1 & & 2 & \\
\hline F-HPI-ISV2-GI, F-SD1-CR-BD-CM, S-EL-III-2-O & 1 & & 2 & \\
\hline F-SD1-CR-COIL-CM, S-EL-III-2-E, S-EL-III-2-O & & & 3 & \\
\hline F-SD1-CR-BD-CM, S-EL-III-2-E, S-EL-III-2-O & & & 3 & \\
\hline
\end{tabular}




\begin{tabular}{|c|c|c|c|c|}
\hline Initiating Event - Feeder Tube Break & Sequen & SBLI & & \\
\hline Sequence Level Cut Sets & $\begin{array}{l}\text { Component } \\
\text { Failures }\end{array}$ & $\begin{array}{l}\text { Human } \\
\text { Errors }\end{array}$ & $\begin{array}{l}\text { Support } \\
\text { System } \\
\text { Fnilures }\end{array}$ & $\begin{array}{c}\text { Determina } \\
\text { at Fuilure } \\
?\end{array}$ \\
\hline F-HPI-SIG1-LPHTS, F-HPI-SIG3-LPHTS, F-SD1-CR-COIL-CM & 2 & & 1 & \\
\hline F-HPI-SIG2-LPHTS, F-HPI-SIG3-LPHTS, F-SD1-CR-BD-CM & 2 & & 1 & \\
\hline F-HPI-INV1, F-HPI-INV2, F-SD1-CR-BD-CM & 2 & & 1 & \\
\hline F-HPI-SIG2-LPHTS, F-HPI-SIG3-LPHTS, F-SD1-CR-COIL-CM & 2 & & 1 & \\
\hline F-HPI-SIG1-LPHTS, F-HPI-SIG2-LPHTS, F-SD1-CR-BD-CM & 2 & & 1 & \\
\hline F-HPI-ISV1-GI, F-HPI-ISV2-GI, F-SD1-CR-BD-CM & 2 & & 1 & \\
\hline F-HPI-ISV1-GI, F-HPI-ISV2-GI, F-SD1-CR-COIL-CM & 2 & & 1 & \\
\hline F-HPI-SIG1-LPHTS, F-HIPI-SIG2-LPHTS, F-SD1-CR-COIL-CM & 2 & & 1 & \\
\hline F-HPI-OV2A, F-HPI-OV2B, F-SD1-CR-COIL-CM & 2 & & 1 & \\
\hline F-HPI-SIG1-LPHTS, F-HPI-SIG3-LPHTS, F-SD1-CR-BD-CM & 2 & & 1 & \\
\hline F-HPI-INV1A, F-HPI-INV1B, F-SD1-CR-BD-CM & 2 & & 1 & \\
\hline F-HPI-OV2A, F-HPI-OV2B, F-SD1-CR-BD-CM & 2 & & 1 & \\
\hline F-HPI-INV1, F-HPI-INV2, F-SD1-CR-COIL-CM & 2 & & 1 & \\
\hline F-HPI-INV2A, F-HPI-INV2B, F-SD1-CR-BD-CM & 2 & & 1 & \\
\hline F-HPI-INV1A, F-HPI-IIVV1B, F-SD1-CR-COIL-CM & 2 & & 1 & \\
\hline F-HPI-INV2A, F-HPI-INV2B, F-SD1-CR-COIL-CM & 2 & & 1 & \\
\hline F-HPI-OV1A, F-HPI-OV1B, F-SD1-CR-COIL-CM & 2 & & 1 & \\
\hline F-HPI-OV1A, F-HPI-OV1B, F-SD1-CR-BD-CM & 2 & & 1 & \\
\hline F-HPI-PI-GI-TK, F-HPI-TK-GI, F-SD1-CR-BD-CM & 2 & & 1 & \\
\hline F-HPI-PI-GI-TK, F-HPI-TK-GI, F-SD1-CR-COIL-CM & 2 & & 1 & \\
\hline F-HPI-LI-CITK, F-HPI-TK-CI, F-SD1-CR-BD-CM & 2 & & 1 & \\
\hline F-HPI-LI-CITK, F-HPI-TK-Cl, F-SD1-CR-COIL-CM & 2 & & 1 & \\
\hline
\end{tabular}

\begin{tabular}{|c|c|c|c|c|}
\hline Initiating Event - Feeder Tube Break & \multicolumn{4}{|c|}{ Sequence: $S B L F B-O$} \\
\hline Sequence Level Cut Sets & $\begin{array}{l}\text { Component } \\
\text { Fuilures }\end{array}$ & $\begin{array}{c}\text { Human } \\
\text { Erron }\end{array}$ & $\begin{array}{l}\text { Support } \\
\text { System } \\
\text { Failures } \\
\end{array}$ & $\begin{array}{l}\text { Determinant } \\
\text { Faiture? }\end{array}$ \\
\hline F-FW1-ISV2, F-SD1-CR-COIL-CM, S-PCS & 1 & & 2 & \\
\hline F-FW1-ISV1, F-SD1-CR-COIL-CM, S-PCS & 1 & & 2 & \\
\hline F-FW1-ISV1, F-SD1-CR-BD-CM, S-PCS & 1 & & 2 & \\
\hline F-FW1-ISV2, F-SD1-CR-BD-CM, S-PCS & 1 & & 2 & \\
\hline
\end{tabular}


Table C.5 (cont.)

\begin{tabular}{|c|c|c|c|c|}
\hline Initiating Event - Feeder Tube Break & Sequen & $S B L I$ & & \\
\hline Sequence Level Cut Sets & $\begin{array}{l}\text { Component } \\
\text { Fuilurea }\end{array}$ & $\begin{array}{l}\text { Human } \\
\text { Errori }\end{array}$ & $\begin{array}{l}\text { Support } \\
\text { Syctem } \\
\text { Failures }\end{array}$ & $\begin{array}{c}\text { Determion } \\
\text { nt Failure } \\
?\end{array}$ \\
\hline F-SD1-CR-BD-CM, S-ECC & & & 2 & \\
\hline F-SD1-CR-COIL-CM, S-EL-II-2-E & & & 2 & \\
\hline F-SD1-CR-COIL-CM, S-ECC & & & 2 & \\
\hline F-SD1-CR-BD-CM, S-EL-II-2-O & & & 2 & \\
\hline F-SD1-CR-BD-CM, S-AIR & & & 2 & \\
\hline F-SD1-CR-COIL-CM, S-EL-II-2-O & & & 2 & \\
\hline F-SD1-CR-BD-CM, S-EL-II-2-E & & & 2 & \\
\hline F-SD1-CR-COIL-CM, S-AIR & & & 2 & \\
\hline F-MSV-MSSV1-SG1, F-MSV-MSSV3-SG1, F-SD1-CR-COIL-CM & 2 & & 1 & \\
\hline F-MSV-MSSV1-SG1, F-MSV-MSSV3-SG1, F-SD1-CR-BD-CM & 2 & & 1 & \\
\hline F-MSV-MSSV3-SG1, F-MSV-MSSV4-SG1, F-SD1-CR-BD-CM & 2 & & 1 & \\
\hline F-MSV-MSSV3-SG1, F-MSV-MSSV4-SG1, F-SD1-CR-COIL-CM & 2 & & 1 & \\
\hline F-SD1-TLB-REL1, F-SD1-TLB-REL2, S-EL-II-2-O & 2 & & 1 & \\
\hline F-MSV-MSSV1-SG2, F-MSV-MSSV2-SG2, F-SD1-CR-BD-CM & 2 & & 1 & \\
\hline F-SD1-TLB-REL2, F-SD1-TLB-REL3, S-EL-II-2-O & 2 & & 1 & \\
\hline F-SD1-TLA-REL1, F-SD1-TLA-REL3, S-EL-II-2-O & 2 & & 1 & \\
\hline F-MSV-MSSV2-SG1, F-MSV-MSSV3-SG1, F-SD1-CR-COIL-CM & 2 & & 1 & \\
\hline F-SD1-TLA-REL2, F-SD1-TLA-REL3, S-EL-II-2-O & 2 & & 1 & \\
\hline F-SD1-TLA-REL1, F-SD1-TLA-REL2, S-EL-II-2-O & 2 & & 1 & \\
\hline F-MSV-MSSV1-SG2, F-MSV-MSSV2-SG2, F-SD1-CR-COIL-CM & 2 & & 1 & \\
\hline F-SD1-TLB-REL1, F-SD1-TLB-REL3, S-EL-II-2-0 & 2 & & 1 & \\
\hline F-MSV-MSSV2-SG2, F-MSV-MSSV3-SG2, F-SD1-CR-BD-CM & 2 & & 1 & \\
\hline F-SD1-TLB-REL2, F-SD1-TLB-REL3, S-AIR & 2 & & 1 & \\
\hline F-SD1-TLB-REL1, F-SD1-TLB-REL3, S-AIR & 2 & & 1 & \\
\hline F-SD1-TLB-REL1, F-SD1-TLB-REL2, S-AIR & 2 & & 1 & \\
\hline F-MSV-MSSV1-SG1, F-MSV-MSSV2-SG1, F-SD1-CR-COIL-CM & 2 & & 1 & \\
\hline F-SD1-TLA-REL1, F-SD1-TLA-REL2, S-AIR & 2 & & 1 & \\
\hline F-SD1-TLB-REL1, F-SD1-TLB-REL3, S-EL-II-2-E & 2 & & 1 & \\
\hline F-SD1-TLA-REL2, F-SD1-TLA-REL3, S-AIR & 2 & & 1 & \\
\hline F-MSV-MSSV1-SG2, F-MSV-MSSV3-SG2, F-SD1-CR-BD-CM & 2 & & 1 & \\
\hline F-MSV-MSSV2-SG2, F-MSV-MSSV3-SG2, F-SD1-CR-COIL-CM & 2 & & 1 & \\
\hline
\end{tabular}


Table C.5 (cont.)

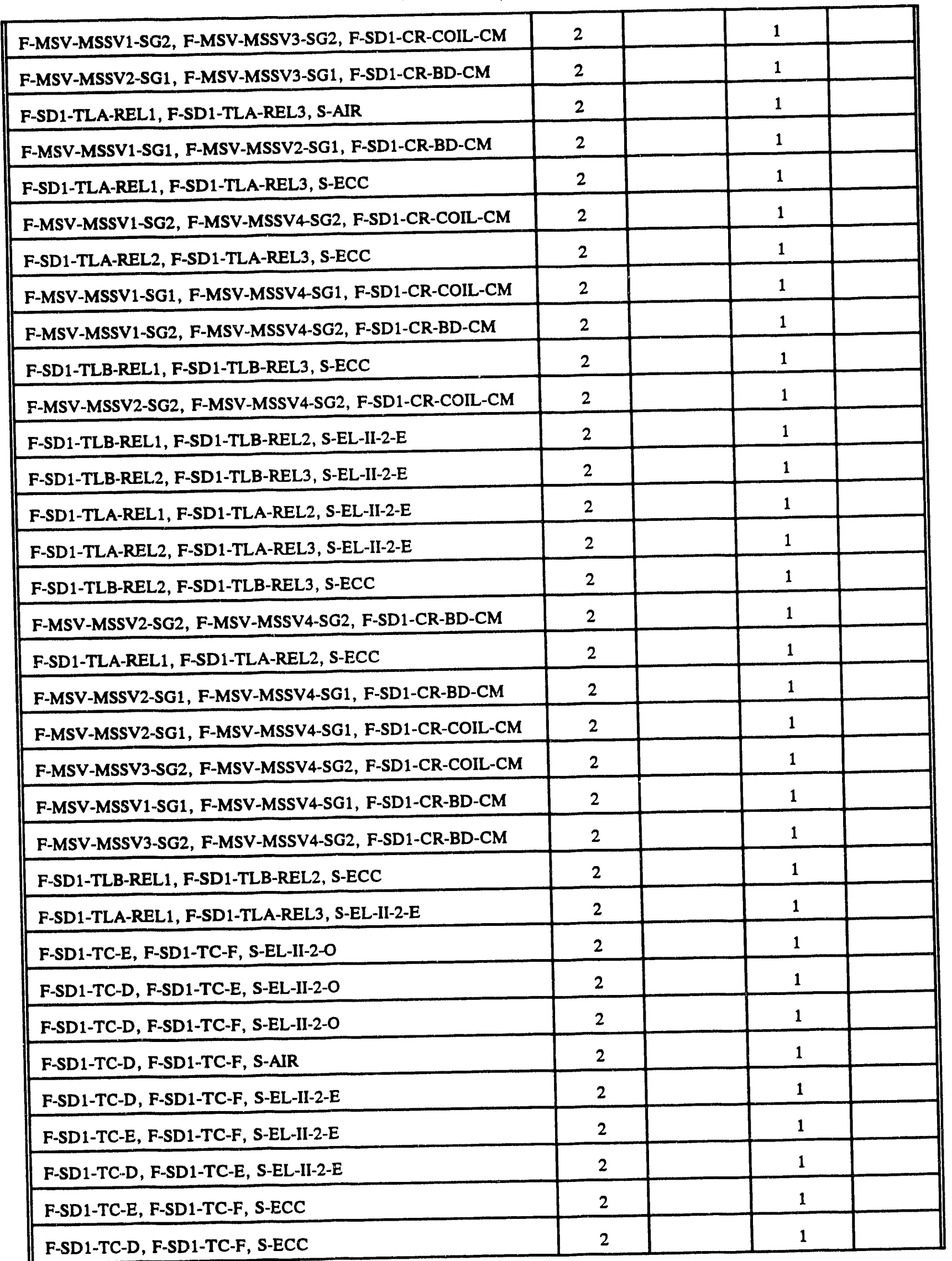


Table C.5 (cont.)

F-SD1-TC-D, F-SD1-TC-E, S-AIR

F-SD1-TC-D, F-SD1-TC-E, S-ECC

F-SD1-TC-E, F-SD1-TC-F, S-AIR

\begin{tabular}{|l|l|l|l||}
\hline 2 & & 1 & \\
\hline 2 & & 1 & \\
\hline 2 & & 1 & \\
\hline
\end{tabular}

\begin{tabular}{|c|c|c|c|c|}
\hline \multirow{2}{*}{$\begin{array}{c}\text { Initiating Event - Feeder Tube Break } \\
\text { Sequence Level Cut Sets }\end{array}$} & \multicolumn{4}{|c|}{ Sequence: $S B L F B-R$} \\
\hline & $\begin{array}{c}\text { Component } \\
\text { Failures }\end{array}$ & $\begin{array}{c}\text { Human } \\
\text { Erron }\end{array}$ & $\begin{array}{l}\text { Suppon } \\
\text { Syatem } \\
\text { Failures }\end{array}$ & $\begin{array}{c}\text { Determinent } \\
\text { Failure? }\end{array}$ \\
\hline F-MCS-PMP1, F-SD1-CR-BD-CM, S-EL-II-2-O & 1 & & 2 & \\
\hline F-SD1-CR-COIL-CM, S-EL-II-2-O, S-EL-III-1-E & & & 3 & \\
\hline F-MCS-PMP1, F-SD1-CR-COIL-CM, S-EL-II-2-O & 1 & & 2 & \\
\hline F-SD1-CR-BD-CM, S-EL-II-2-O, S-EL-III-1-O & & & 3 & \\
\hline F-SD1-CR-BD-CM, S-EL-II-2-O, S-EL-III-1-E & & & 3 & \\
\hline F-SD1-CR-COIL-CM, S-EL-II-2-O, S-EL-III-1-O & & & 3 & \\
\hline F-MCS-PMP2, F-SD1-CR-COIL-CM, S-EL-II-2-O & 1 & & 2 & \\
\hline F-MCS-ISV-FC, F-SD1-CR-BD-CM, S-EL-II-2-O & 1 & & 2 & \\
\hline F-SD1-CR-COIL-CM, S-EL-II-2-O, S-RCW & & & 3 & \\
\hline F-MCS-ISV-FC, F-SD1-CR-COIL-CM, S-EL-II-2-O & 1 & & 2 & \\
\hline F-SD1-CR-BD-CM, S-AIR, S-RCW & & & 3 & \\
\hline F-MCS-PMP2, F-SD1-CR-BD-CM, S-EL-II-2-O & 1 & & 2 & \\
\hline F-SD1-CR-COIL-CM, S-AIR, S-RCW & & & 3 & \\
\hline F-MCS-PMP1, F-SD1-CR-COIL-CM, S-AIR & 1 & & 2 & \\
\hline F-MCS-PMP1, F-SD1-CR-BD-CM, S-AIR & 1 & & 2 & \\
\hline F-SD1-CR-BD-CM, S-AIR, S-EL-III-1-O & & & 3 & \\
\hline F-SD1-CR-COIL-CM, S-AIR, S-EL-III-1-E & & & 3 & \\
\hline F-SD1-CR-COIL-CM, S-AIR, S-EL-III-1-O & & & 3 & \\
\hline F-SD1-CR-BD-CM, S-AIR, S-EL-III-1-E & & & 3 & \\
\hline F-MCS-ISV-FC, F-SD1-CR-COIL-CM, S-AIR & 1 & & 2 & \\
\hline F-MCS-ISV-FC, F-SD1-CR-BD-CM, S-AIR & 1 & & 2 & \\
\hline F-MCS-PMP2, F-SD1-CR-BD-CM, S-AIR & 1 & & 2 & \\
\hline F-SD1-CR-BD-CM, S-EL-II-2-O, S-RCW & & & 3 & \\
\hline F-MCS-PMP2, F-SD1-CR-COIL-CM, S-AIR & 1 & & 2 & \\
\hline F-SD1-CR-COIL-CM, S-ECC, S-EL-III-1-O & & & 3 & \\
\hline F-MCS-PMP1, F-SD1-CR-BD-CM, S-EL-II-2-E & 1 & & 2 & \\
\hline
\end{tabular}


Appendix C

Table C.5 (cont.)

\begin{tabular}{|c|c|c|c|}
\hline F-SD1-CR-COIL-CM, S-EL-II-2-E, S-EL-III-1-E & & 3 & \\
\hline F-MCS-PMP1, F-SD1-CR-COIL-CM, S-EL-II-2-E & 1 & 2 & \\
\hline F-SD1-CR-BD-CM, S-EL-II-2-E, S-EL-III-1-E & & 3 & \\
\hline F-SD1-CR-BD-CM, S-EL-II-2-E, S-EL-III-1-O & & 3 & \\
\hline F-MCS-PMP2, F-SD1-CR-COIL-CM, S-EL-II-2-E & 1 & 2 & \\
\hline F-MCS-ISV-FC, F-SD1-CR-BD-CM, S-EL-II-2-E & 1 & 2 & \\
\hline F-SD1-CR-COIL-CM, S-EL-II-2-E, S-RCW & & 3 & \\
\hline F-MCS-ISV-FC, F-SD1-CR-COIL-CM, S-EL-II-2-E & 1 & 2 & \\
\hline F-SD1-CR-COIL-CM, S-EL-II-2-E, S-EL-III-1-O & & 3 & \\
\hline F-MCS-PMP2, F-SD1-CR-BD-CM, S-EL-II-2-E & 1 & 2 & \\
\hline F-SD1-CR-BD-CM, S-ECC, S-RCW & & 3 & \\
\hline F-MCS-PMP1, F-SD1-CR-BD-CM, S-ECC & 1 & 2 & \\
\hline F-SD1-CR-COIL-CM, S-ECC, S-EL-III-1-E & & 3 & \\
\hline F-MCS-PMP1, F-SD1-CR-COIL-CM, S-ECC & 1 & 2 & \\
\hline F-SD1-CR-BD-CM, S-ECC, S-EL-III-1-E & & 3 & \\
\hline F-SD1-CR-BD-CM, S-ECC, S-EL-III-1-O & & 3 & \\
\hline F-MCS-PMP2, F-SD1-CR-COIL-CM, S-ECC & 1 & 2 & \\
\hline F-MCS-ISV-FC, F-SD1-CR-BD-CM, S-ECC & 1 & 2 & \\
\hline F-SD1-CR-COIL-CM, S-ECC, S-RCW & & 3 & \\
\hline F-MCS-ISV-FC, F-SD1-CR-COIL-CM, S-ECC & 1 & 2 & \\
\hline F-SD1-CR-BD-CM, S-EL-II-2-E, S-RCW & & 3 & \\
\hline F-MCS-PMP2, F-SD1-CR-BD-CM, S-ECC & 1 & 2 & \\
\hline
\end{tabular}


Table C.5 (cont.)

\begin{tabular}{|c|c|c|c|c|}
\hline \multirow{2}{*}{$\frac{\text { Initiating Event - Feeder Tube Break }}{\text { Sequence Level Cut Sets }}$} & \multicolumn{4}{|c|}{ Sequence: $S B L F B-F T S D-A$} \\
\hline & $\begin{array}{l}\text { Component } \\
\text { Failures }\end{array}$ & $\begin{array}{l}\text { Human } \\
\text { Errors }\end{array}$ & $\begin{array}{l}\text { Support } \\
\text { System } \\
\text { Failures }\end{array}$ & $\begin{array}{l}\text { Determinant } \\
\text { Failure? }\end{array}$ \\
\hline F-SD1-CR-COIL-CM, F-SD2-ISV1-PT5, F-SD2-ISV2-PT2 & 2 & & 1 & \\
\hline F-SD1-CR-COIL-CM, F-SD2-ISV2-PT2, F-SD2-ISV2-PT5 & 2 & & 1 & \\
\hline F-SD1-CR-COIL-CM, F-SD2-ISV1-PT2, F-SD2-ISV2-PT5 & 2 & & 1 & \\
\hline F-SD1-CR-COIL-CM, F-SD2-ISV1-PT2, F-SD2-ISV1-PT5 & 2 & & 1 & \\
\hline F-SD1-CR-BD-CM, F-SD2-ISV1-PT5, F-SD2-ISV2-PT2 & 2 & & 1 & \\
\hline F-SD1-CR-BD-CM, F-SD2-ISV2-PT2, F-SD2-ISV2-PT5 & 2 & & 1 & \\
\hline F-SD1-CR-BD-CM, F-SD2-ISV1-PT3, F-SD2-ISV1-PT5 & 2 & & 1 & \\
\hline F-SD1-CR-BD-CM, F-SD2-ISV1-PT3, F-SD2-ISV2-PT5 & 2 & & 1 & \\
\hline F-SD1-CR-COIL-CM, F-SD2-ISV1-PT5, F-SD2-ISV2-PT3 & 2 & & 1 & \\
\hline F-SD1-CR-COIL-CM, F-SD2-ISV2-PT3, F-SD2-ISV2-PT5 & 2 & & 1 & \\
\hline F-SD1-CR-COIL-CM, F-SD2-ISV1-PT3, F-SD2-ISV2-PT5 & 2 & & 1 & \\
\hline F-SD1-CR-COIL-CM, F-SD2-ISV1-PT3, F-SD2-ISV1-PTS & 2 & & 1 & \\
\hline F-SD1-CR-BD-CM, F-SD2-ISV1-PT5, F-SD2-ISV2-PT3 & 2 & & 1 & \\
\hline F-SD1-CR-BD-CM, F-SD2-ISV2-PT3, F-SD2-ISV2-PT5 & 2 & & 1 & \\
\hline F-SD1-CR-BD-CM, F-SD2-ISV1-PT2, F-SD2-ISV2-PT5 & 2 & & 1 & \\
\hline F-SD1-CR-BD-CM, F-SD2-ISV1-PT2, F-SD2-ISV1-PT5 & 2 & & 1 & \\
\hline F-SD1-CR-BD-CM, F-SD2-TL-G, F-SD2-TL-J & 2 & & 1 & \\
\hline F-SD1-CR-COIL-CM, F-SD2-TL-G, F-SD2-TL-J & 2 & & 1 & \\
\hline F-SD1-CR-COIL-CM, F-SD2-TL-H, F-SD2-TL-J & 2 & & 1 & \\
\hline F-SD1-CR-BD-CM, F-SD2-TL-H, F-SD2-TL-J & 2 & & 1 & \\
\hline F-SD1-CR-BD-CM, F-SD2-TL-G, F-SD2-TL-H & 2 & & 1 & \\
\hline F-SD1-CR-COIL-CM, F-SD2-TL-G, F-SD2-TL-H & 2 & & 1 & $\cdot$ \\
\hline F-SD1-CR-BD-CM, F-SD2-ISV1-PT3, F-SD2-ISV1-PT4 & 2 & & 1 & \\
\hline F-SD1-CR-BD-CM, F-SD2-ISV1-PT3, F-SD2-ISV2-PT4 & 2 & & 1 & \\
\hline F-SD1-CR-COIL-CM, F-SD2-ISV1-PT4, F-SD2-ISV2-PT3 & 2 & & 1 & \\
\hline F-SD1-CR-COIL-CM, F-SD2-ISV2-PT3, F-SD2-ISV2-PT4 & 2 & & 1 & \\
\hline F-SD1-CR-COIL-CM, F-SD2-ISV1-PT3, F-SD2-ISV2-PT4 & 2 & & 1 & \\
\hline F-SD1-CR-COIL-CM, F-SD2-ISV1-PT3, F-SD2-ISV1-PT4 & 2 & & 1 & \\
\hline F-SD1-CR-BD-CM, F-SD2-ISV1-PT4, F-SD2-ISV2-PT3 & 2 & & 1 & \\
\hline F-SD1-CR-BD-CM, F-SD2-ISV2-PT3, F-SD2-ISV2-PT4 & 2 & & 1 & \\
\hline F-SD1-CR-BD-CM, F-SD2-ISV1-PT4, F-SD2-ISV1-PT5 & 2 & & 1 & \\
\hline
\end{tabular}


Table C.5 (cont.)

\begin{tabular}{|c|c|c|c|c|}
\hline F-SD1-CR-BD-CM, F-SD2-ISV1-PT4, F-SD2-ISV2-PT5 & 2 & & 1 & \\
\hline F-SD1-CR-COIL-CM, F-SD2-ISV1-PT6, F-SD2-ISV2-PT3 & 2 & & 1 & \\
\hline F-SD1-CR-COIL-CM, F-SD2-ISV2-PT3, F-SD2-ISV2-PT6 & 2 & & 1 & \\
\hline F-SD1-CR-COIL-CM, F-SD2-ISV1-PT3, F-SD2-ISV2-PT6 & 2 & & 1 & \\
\hline F-SD1-CR-COIL-CM, F-SD2-ISV1-PT3, F-SD2-ISV1-PT6 & 2 & & 1 & \\
\hline F-SD1-CR-BD-CM, F-SD2-ISV1-PT6, F-SD2-ISV2-PT3 & 2 & & 1 & \\
\hline F-SD1-CR-BD-CM, F-SD2-ISV2-PT3, F-SD2-ISV2-PT6 & 2 & & 1 & \\
\hline F-SD1-CR-BD-CM, F-SD2-ISV1-PT4, F-SD2-ISV1-PT6 & 2 & & 1 & \\
\hline F-SD1-CR-BD-CM, F-SD2-ISV1-PT4, F-SD2-ISV2-PT6 & 2 & & 1 & \\
\hline F-SD1-CR-COIL-CM, F-SD2-ISV1-PT6, F-SD2-ISV2-PT4 & 2 & & 1 & \\
\hline F-SD1-CR-BD-CM, F-SD2-ISV1-PT2, F-SD2-ISV1-PT3 & 2 & & 1 & \\
\hline F-SD1-CR-COIL-CM, F-SD2-ISV1-PT4, F-SD2-ISV2-PT6 & 2 & & 1 & \\
\hline F-SD1-CR-COIL-CM, F-SD2-ISV1-PT4, F-SD2-ISV1-PT6 & 2 & & 1 & \\
\hline F-SD1-CR-BD-CM, F-SD2-ISV1-PT6, F-SD2-ISV2-PT4 & 2 & & 1 & \\
\hline F-SD1-CR-BD-CM, F-SD2-ISV2-PT4, F-SD2-ISV2-PT6 & 2 & 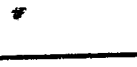 & 1 & \\
\hline F-SD1-CR-BD-CM, F-SD2-ISV1-PT3, F-SD2-ISV2-PT6 & 2 & & 1 & \\
\hline F-SD1-CR-BD-CM, F-SD2-ISV1-PT3, F-SD2-ISV1-PT6 & 2 & & 1 & \\
\hline F-SD1-CR-COIL-CM, F-SD2-ISV1-PT5, F-SD2-ISV2-PT4 & 2 & & 1 & \\
\hline F-SD1-CR-COIL-CM, F-SD2-ISV2-PT4, F-SD2-ISV2-PT5 & 2 & & 1 & \\
\hline F-SD1-CR-COIL-CM, F-SD2-ISV1-PT4, F-SD2-ISV2-PT5 & 2 & & 1 & \\
\hline F-SD1-CR-COIL-CM, F-SD2-ISV1-PT4, F-SD2-ISV1-PT5 & 2 & & 1 & \\
\hline F-SD1-CR-BD-CM, F-SD2-ISV1-PT5, F-SD2-ISV2-PT4 & 2 & & 1 & \\
\hline F-SD1-CR-BD-CM, F-SD2-ISV2-PT4, F-SD2-ISV2-PT5 & 2 & & 1 & \\
\hline F-SD1-CR-BD-CM, F-SD2-ISV1-PT2, F-SD2-ISV1-PT6 & 2 & & 1 & \\
\hline F-SD1-CR-BD-CM, F-SD2-ISV1-PT2, F-SD2-ISV2-PT6 & 2 & & 1 & \\
\hline F-SD1-CR-COIL-CM, F-SD2-ISV1-PT6, F-SD2-ISV2-PT2 & 2 & & 1 & \\
\hline F-SD1-CR-COIL-CM, F-SD2-ISV2-PT2, F-SD2-ISV2-PT6 & 2 & & 1 & \\
\hline F-SD1-CR-COIL-CM, F-SD2-ISV1-PT2, F-SD2-ISV2-PT6 & 2 & & 1 & \\
\hline F-SD1-CR-COIL-CM, F-SD2-ISV1-PT2, F-SD2-ISV1-PT6 & 2 & & 1 & \\
\hline F-SD1-CR-BD-CM, F-SD2-ISV1-PT6, F-SD2-ISV2-PT2 & 2 & & 1 & \\
\hline F-SD1-CR-BD-CM, F-SD2-ISV2-PT2, F-SD2-ISV2-PT6 & 2 & & 1 & \\
\hline F-SD1-CR-COIL-CM, F-SD2-ISV2-PT2, F-SD2-ISV2-PT4 & 2 & & 1 & \\
\hline F-SD1-CR-COIL-CM, F-SD2-ISV2-PT4, F-SD2-ISV2-PT6 & 2 & & 1 & \\
\hline F-SD1-CR-BD-CM, F-SD2-ISV2-PT1, F-SD2-ISV2-PT3 & 2 & & 1 & \\
\hline
\end{tabular}


Table C.5 (cont.)

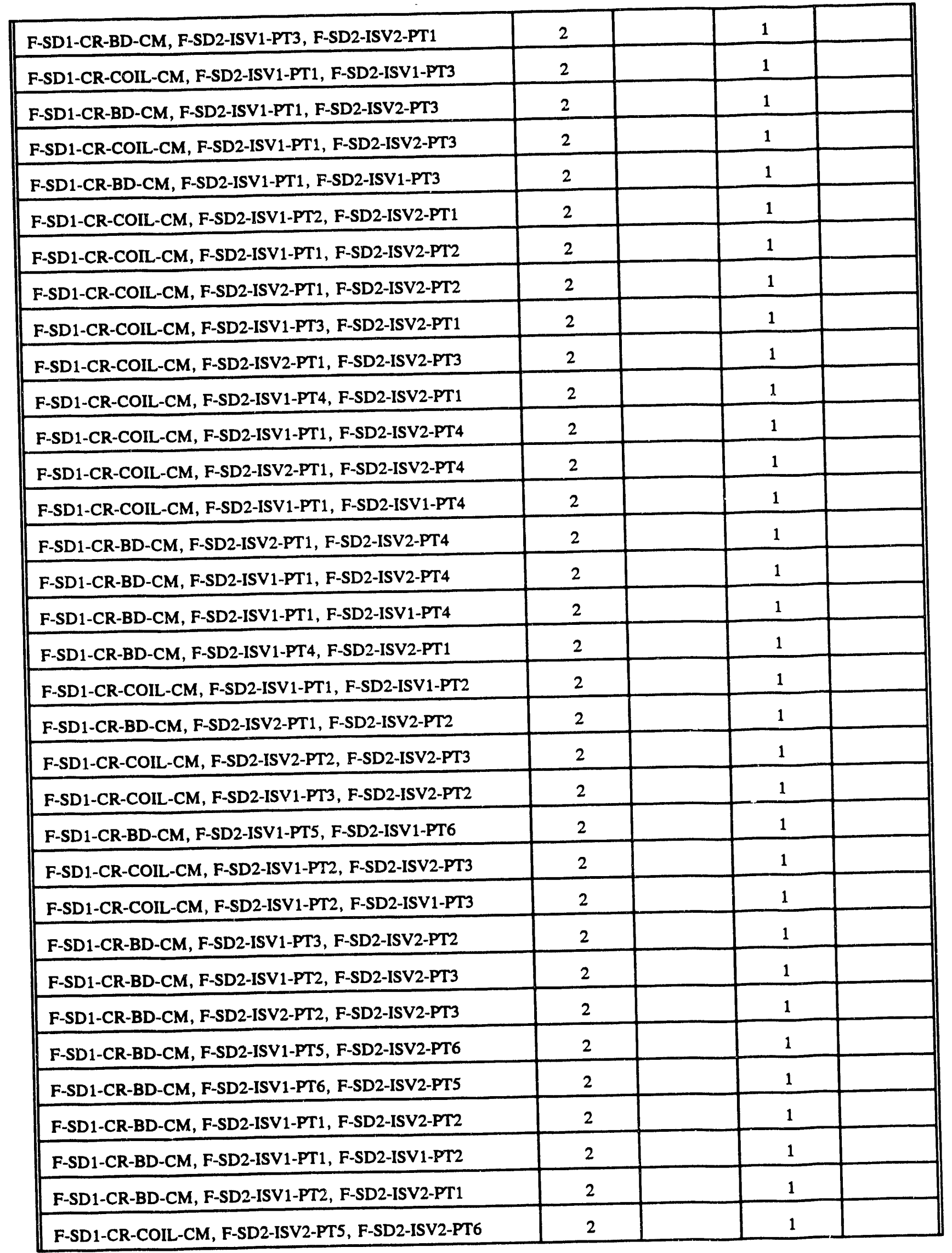


Table C.5 (cont.)

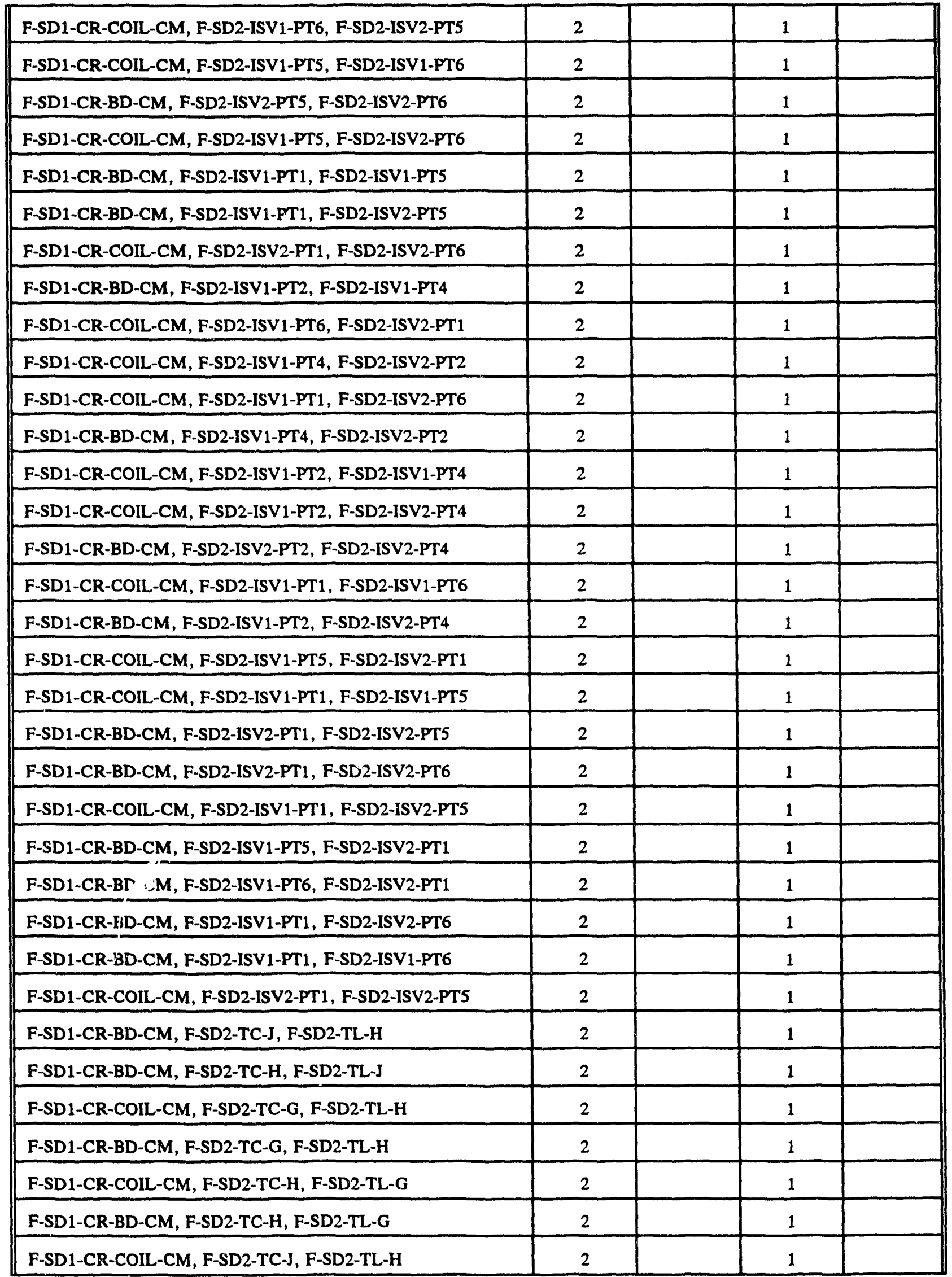


Table C.5 (cont.)

\begin{tabular}{||l|c|c|c|c||}
\hline F-SD1-CR-BD-CM, F-SD2-TC-G, F-SD2-TL-J & 2 & & 1 & \\
\hline F-SD1-CR-BD-CM, F-SD2-TC-J, F-SD2-TL-G & 2 & & 1 & \\
\hline F-SD1-CR-COIL-CM, F-SD2-TC-G, F-SD2-TL-J & 2 & & 1 & \\
\hline F-SD1-CR-COIL-CM, F-SD2-TC-J, F-SD2-TL-G & 2 & & 1 & \\
\hline F-SD1-CR-COIL-CM, F-SD2-TC-H, F-SD2-TL-J & 2 & & 1 & \\
\hline F-SD1-CR-COIL-CM, F-SD2-TC-G, F-SD2-TC-J & 2 & & 1 & \\
\hline F-SD1-CR-BD-CM, F-SD2-TC-G, F-SD2-TC-H & 2 & & 1 & \\
\hline F-SD1-CR-COIL-CM, F-SD2-TC-G, F-SD2-TC-H & 2 & & 1 & \\
\hline F-SD1-CR-BD-CM, F-SD2-TC-H, F-SD2-TC-J & 2 & & 1 & \\
\hline F-SD1-CR-COIL-CM, F-SD2-TC-H, F-SD2-TC-J & 2 & & 2 & \\
\hline F-SD1-CR-BD-CM, F-SD2-TC-G, F-SD2-TC-J & & & 1 \\
\hline
\end{tabular}


Table C.6 Small-break loss-of-coolant events sequence categorization: representative initiating event - feeder tube break

\begin{tabular}{|c|c|c|c|c|c|c|c|}
\hline \multirow{2}{*}{\multicolumn{2}{|c|}{ Specific Initiator }} & \multicolumn{2}{|c|}{$\begin{array}{c}\text { Feeder tube } \\
\text { break }\end{array}$} & \multicolumn{2}{|c|}{$\begin{array}{l}\text { Pressure tube } \\
\text { leak/rupture }\end{array}$} & \multicolumn{2}{|c|}{$\begin{array}{l}\text { Fuel handling } \\
\text { machine breaks } \\
\text { end fitting }\end{array}$} \\
\hline & & \multicolumn{2}{|c|}{$1 \times 10^{-2}$} & \multicolumn{2}{|c|}{$1 \times 10^{-2}$} & \multicolumn{2}{|c|}{$1 \times 10^{-2}$} \\
\hline Sequence & $\begin{array}{c}\text { Determinant } \\
\text { Failures }\end{array}$ & Bin & Category & Bin & Category & Bin & Category \\
\hline SBLFB-A & NA & $\bar{A}$ & EC-I & $\mathbf{A}$ & EC-I & $\bar{A}$ & EC-I \\
\hline SBLFB-B & $\begin{array}{c}2 \text { valves, } 2 \text { pumps, } \\
\text { undetected low grade } \\
\text { level tank level }\end{array}$ & C & EC-III & C & EC-III & C & EC-III \\
\hline SBLFB-C & 23 failures & $\bar{D}$ & EC-IV & D & EC-IV & $\bar{D}$ & EC-IV \\
\hline SBLFB-D & $\begin{array}{l}2 \text { signals, } 2 \text { valves, } \\
\text { undetected low gas } \\
\text { tank pressure, } \\
\text { undetected low } \\
\text { coolant tank volume }\end{array}$ & c & EC-III & C & EC-III & C & EC-III \\
\hline SBLFB-E & 23 failures & $\mathrm{D}$ & EC-IV & $\bar{D}$ & EC-IV & $\bar{D}$ & EC-IV \\
\hline SBLFB-F & $\geq 3$ failures & D & EC-IV & $\bar{D}$ & EC-IV & $\mathrm{D}$ & EC-IV \\
\hline SBLFB-G & $\geq 3$ failures & D & EC-IV & $\mathrm{D}$ & EC-IV & $\mathrm{D}$ & EC-IV \\
\hline SBLFB-H & $\begin{array}{c}\text { support systems, } 2 \\
\text { main steam safety } \\
\text { valves } \\
\end{array}$ & C & EC-III & C & EC-III & C & EC-III \\
\hline SBLFB-I & 23 failures & $\mathrm{D}$ & EC-IV & $\bar{D}$ & EC-IV & $\mathrm{D}$ & EC-IV \\
\hline SBLFB-J & $\begin{array}{l}\text { common mode } \\
\text { failure, } \\
2 \text { relays, } 2 \text { trip } \\
\text { computers }\end{array}$ & C & EC-III & C & EC-III & C & EC-III \\
\hline SBLFB-K & $\geq 3$ failures & D & EC-IV & $\bar{D}$ & EC-IV & $\mathrm{D}$ & EC-IV \\
\hline SBLFB-L & 23 failures & $\bar{D}$ & EC-IV & $\mathrm{D}$ & EC-IV & $\mathrm{D}$ & EC-IV \\
\hline SBLFB-M & $\geq 3$ failures & $\mathrm{D}$ & EC-IV & $\mathrm{D}$ & EC-IV & $\mathrm{D}$ & EC-IV \\
\hline SBLFB-N & $\geq 3$ failures & $\mathrm{D}$ & EC-IV & D & EC-IV & D & EC-IV \\
\hline SBLFB-O & $\geq 3$ failures & D & EC-IV & $\bar{D}$ & EC-IV & $\mathrm{D}$ & EC-IV \\
\hline SBLFB-P & $\geq 3$ failures & $\bar{D}$ & EC-IV & D & EC-IV & $\mathrm{D}$ & EC-IV \\
\hline SBLFB-Q & $\geq 3$ failures & $\mathrm{D}$ & EC-IV & D & EC-IV & $\bar{D}$ & EC-IV \\
\hline SBLFB-R & 23 failures & $\mathrm{D}$ & EC-IV & D & EC-IV & D & EC-IV \\
\hline SBLFB-FTSD-A & 23 failures & $\mathrm{D}$ & EC-IV & $\mathrm{D}$ & EC-IV & D & EC-IV \\
\hline SBLFB-FTSD-B & $\geq 3$ failures & $\bar{D}$ & EC-IV & $\mathrm{D}$ & EC-IV & $\mathrm{D}$ & EC-IV \\
\hline SBLFB-FTSD-C & $\geq 3$ failures & $\mathrm{D}$ & EC-IV & D & EC-IV & D & EC-IV \\
\hline SBLFB-FTSD-D & $\geq 3$ failures & $\bar{D}$ & EC-IV & $\bar{D}$ & EC-IV & $\bar{D}$ & EC-IV \\
\hline SBLFB-FTSD-E & $\geq 3$ failures & $\mathrm{D}$ & EC-IV & D & EC-IV & $\bar{D}$ & EC-IV \\
\hline SBLFB-FTSD-F & $\geq 3$ failures & $\mathrm{D}$ & EC-IV & D & EC-IV & D & EC-IV \\
\hline SBLFB-FTSD-G & $\geq 3$ failures & $\mathrm{D}$ & EC-IV & $\bar{D}$ & EC-IV & D & EC-IV \\
\hline SBLFB-FTSD-H & $\geq 3$ failures & $\mathrm{D}$ & EC-IV & $\mathbf{D}$ & EC-IV & D & EC-N! \\
\hline SBLFB-FTSD-I & 23 failures & D & EC-IV & D & EC-IV & $\mathrm{D}$ & EC-IV \\
\hline SBLFB-FTSD-J & 23 failures & D & EC-IV & $\bar{D}$ & EC-IV & D & EC-IV \\
\hline SBLFB-FTSD-K & 23 failures & $\mathrm{D}$ & EC-IV & $\mathrm{D}$ & EC-IV & $\mathrm{D}$ & EC-IV \\
\hline SBLFB-FTSD-L & $\geq 3$ failures & $\mathrm{D}$ & EC-IV & D & EC-IV & $\mathrm{D}$ & EC-IV \\
\hline SBLFB-FTSD-M & $\geq 3$ failures & D & EC-IV & D & EC-IV & D & EC-IV \\
\hline SBLFB-FTSD-N & $\geq 3$ failures & D & EC-IV & $\mathrm{D}$ & EC-IV & $\bar{D}$ & EC-IV \\
\hline
\end{tabular}


Table C.6 (cont.)

Appendix C

\begin{tabular}{|c|c|c|c|c|c|c|c|}
\hline \multirow{2}{*}{\multicolumn{2}{|c|}{ Specific Initiator }} & \multicolumn{2}{|c|}{$\begin{array}{l}\text { Leakage from } \\
\text { fuel handling } \\
\text { machine/cooling } \\
\text { system }\end{array}$} & \multicolumn{2}{|c|}{$\begin{array}{l}\text { Vent line and } \\
\text { sample line } \\
\text { leaks/breaks or } \\
\text { leakage from } \\
\text { primary system }\end{array}$} & \multicolumn{2}{|c|}{$\begin{array}{l}\text { Heat transport } \\
\text { pump seals fail }\end{array}$} \\
\hline & & & $\times 10^{-2}$ & & $\times 10^{-1}$ & & $\times 10^{-2}$ \\
\hline Sequence & Determinant Failures & Bin & Category & Bin & Category & Bin & Category \\
\hline SBLFB-A & NA & $\mathbf{A}$ & EC-I & $\mathrm{A}$ & EC-I & $\bar{A}$ & EC-I \\
\hline SBLFB-B & $\begin{array}{l}2 \text { valves, } 2 \text { pumps, undetected } \\
\text { low grade level tank level }\end{array}$ & C & EC-III & C & EC-III & C & EC-III \\
\hline SBLFB-C & $\geq 3$ failures & $\mathrm{D}$ & EC-IV & $\mathrm{D}$ & EC-IV & $\mathrm{D}$ & EC-IV \\
\hline SBLFB-D & $\begin{array}{c}2 \text { signals, } 2 \text { valves, undetected } \\
\text { low gas tank pressure, } \\
\text { undetected low coolant tank } \\
\text { volume } \\
\end{array}$ & C & EC-III & C & EC-III & c & EC-III \\
\hline SBLFB-E & $\geq 3$ failures & $\mathrm{D}$ & EC-IV & $D$ & EC-IV & $\mathrm{D}$ & EC-IV \\
\hline SBLFB-F & $\geq 3$ failures & $\mathrm{D}$ & EC-IV & $\mathrm{D}$ & EC-IV & D & EC-IV \\
\hline SBLFB-G & $\geq 3$ failures & $\mathrm{D}$ & EC-IV & $\mathrm{D}$ & EC-IV & $\mathrm{D}$ & EC-IV \\
\hline SBLFB-H & $\begin{array}{l}\text { support systems, } 2 \text { main steam } \\
\text { safety valves } \\
\end{array}$ & C & EC-III & C & EC-III & C & EC-III \\
\hline SBLFB-I & $\geq 3$ failures & $\mathrm{D}$ & EC-IV & $\mathrm{D}$ & EC-IV & D & EC-IV \\
\hline SBLFB-J & $\begin{array}{l}\text { common mode failure, } \\
2 \text { relays, } 2 \text { trip computers }\end{array}$ & C & EC-III & $\mathrm{C}$ & EC-III & C & EC-III \\
\hline SBLFB-K & 23 failures & $\mathrm{D}$ & EC-IV & D & EC-IV & $\mathrm{D}$ & EC-IV \\
\hline SBLFB-L & $\geq 3$ failures & $D$ & EC-IV & $\mathrm{D}$ & EC-IV & $\mathrm{D}$ & EC-IV \\
\hline SBLFB-M & $\geq 3$ failures & $D$ & EC-IV & $\mathrm{D}$ & EC-IV & $\mathrm{D}$ & EC-IV \\
\hline SBLFB-N & $\geq 3$ failures & $\mathrm{D}$ & EC-IV & D & EC-IV & $\bar{D}$ & EC-IV \\
\hline SBLFB-O & $\geq 3$ failures & $D$ & EC-IV & $\mathrm{D}$ & EC-IV & $\mathrm{D}$ & EC-IV \\
\hline SBLFB-P & $\geq 3$ failures & $\mathrm{D}$ & EC-IV & $\mathrm{D}$ & EC-IV & $\mathrm{D}$ & EC-IV \\
\hline SBLFB-Q & 23 failures & $D$ & EC-IV & $\mathrm{D}$ & EC-IV & D & EC-IV \\
\hline SBLFB-R & $\geq 3$ failures & $D$ & EC-IV & $\mathrm{D}$ & EC-IV & $\mathrm{D}$ & EC-IV \\
\hline SBLFB-FTSD-A & $\geq 3$ failures & $\mathrm{D}$ & EC-IV & D & EC-IV & $\mathrm{D}$ & EC-IV \\
\hline SBLFB-FTSD-B & $\geq 3$ failures & $D$ & EC-IV & $D$ & EC-IV & $\mathrm{D}$ & EC-IV \\
\hline SBLFB-FTSD-C & 23 failures & $D$ & EC-IV & $\mathrm{D}$ & EC-IV & $\mathrm{D}$ & EC-IV \\
\hline SBLFB-FTSD-D & 23 failures & $\mathrm{D}$ & EC-IV & $D$ & EC-IV & $\mathrm{D}$ & EC-IV \\
\hline SBLFB-FTSD-E & $\geq 3$ failures & $\mathrm{D}$ & EC-IV & $\mathrm{D}$ & EC-IV & $\mathrm{D}$ & EC-IV \\
\hline SBLFB-FTSD-F & $\geq 3$ failures & $D$ & EC-IV & $\mathrm{D}$ & EC-IV & $\mathrm{D}$ & EC-IV \\
\hline SBLFB-FTSD-G & $\geq 3$ failures & $D$ & EC-IV & $\mathrm{D}$ & EC-IV & $\mathrm{D}$ & EC-IV \\
\hline SBLFB-FTSD-H & $\geq 3$ failures & $D$ & EC-IV & $\mathrm{D}$ & EC-IV & $\mathrm{D}$ & EC-IV \\
\hline SBLFB-FTSD-I & $\geq 3$ failures & $D$ & EC-IV & $\mathrm{D}$ & EC-IV & $\mathrm{D}$ & EC-IV \\
\hline SBLFB-FTSD-J & $\geq 3$ failures & $\mathrm{D}$ & EC-IV & $\mathrm{D}$ & EC-IV & D & EC-IV \\
\hline SBLFB-FTSD-K & $\geq 3$ failures & D & EC-IV & $\mathrm{D}$ & EC-IV & $\mathrm{D}$ & EC-IV \\
\hline SBLFB-FTSD-L & $\geq 3$ failures & D & EC-IV & $\mathrm{D}$ & EC-IV & D & EC-IV \\
\hline SBLFB-FTSD-M & $\geq 3$ failures & D & EC-IV & D & EC-IV & D & EC-IV \\
\hline SBLFB-FTSD-N & 23 failures & D & EC-IV & $\mathrm{D}$ & EC-IV & $\mathrm{D}$ & EC-IV \\
\hline
\end{tabular}


Table C.7 Loss of Class IV power sequence cut sets

\begin{tabular}{||c|c|c|c|c||}
\hline Initiating Event - Loss of Class IV Power & \multicolumn{2}{|l||}{ Sequence: LOP-A } \\
\hline \hline Sequence Level Cut Sets & $\begin{array}{c}\text { Component } \\
\text { Failures }\end{array}$ & $\begin{array}{c}\text { Human } \\
\text { Errors }\end{array}$ & $\begin{array}{c}\text { Support } \\
\text { System } \\
\text { Failures }\end{array}$ & $\begin{array}{c}\text { Determinant } \\
\text { Faikure? }\end{array}$ \\
\hline NONE & NA & NA & NA & NA \\
\hline
\end{tabular}

\begin{tabular}{||c|c|c|c|c||}
\hline Initiating Event - LOSs of Class IV Power & \multicolumn{2}{|l||}{ Sequence: LOP-B } \\
\hline \hline Sequence Level Cut Sets & $\begin{array}{c}\text { Component } \\
\text { Faitures }\end{array}$ & $\begin{array}{c}\text { Human } \\
\text { Erors }\end{array}$ & $\begin{array}{c}\text { Support } \\
\text { System } \\
\text { Failures }\end{array}$ & $\begin{array}{c}\text { Determinent } \\
\text { Failure ? }\end{array}$ \\
\hline F-ASD-ASD1, F-ASD-ASD2 & 2 & & & $Y$ \\
\hline F-ASD-ASD2, S-EL-II-2-O & 1 & & 1 & \\
\hline F-ASD-ASD1, S-EL-II-2-E & 1 & & 1 & \\
\hline
\end{tabular}

\begin{tabular}{|c|c|c|c|c|}
\hline Initiating Event - Loss of Class IV Power & Sequenc & $L O P-F$ & & \\
\hline Sequence Level Cut Sets & $\begin{array}{l}\text { Component } \\
\text { Faitures }\end{array}$ & $\begin{array}{l}\text { Humen } \\
\text { Emrors }\end{array}$ & $\begin{array}{l}\text { Support } \\
\text { System } \\
\text { Failures }\end{array}$ & $\begin{array}{l}\text { Determinant } \\
\text { Failure? }\end{array}$ \\
\hline F-FW2-HE, F-FW2-LI-TK & 1 & 1 & & $\mathrm{Y}$ \\
\hline F-FW2-IV1, F-FW2-IV2 & 2 & & & $\mathbf{Y}$ \\
\hline F-FW2-PMP1, F-FW2-PMP2 & 2 & & & $\mathbf{Y}$ \\
\hline F-FW2-IV1, F-FW2-PMP2 & 2 & & & $\mathrm{Y}$ \\
\hline F-FW2-OV2, F-FW2-PMP1 & 2 & & & $\mathbf{Y}$ \\
\hline F-FW2-IV2, F-FW2-OV1 & 2 & & & $Y$ \\
\hline F-FW2-IV2, F-FW2-PMP1 & 2 & & & $\mathbf{Y}$ \\
\hline F-FW2-OV1, F-FW2-PMP2 & 2 & & & $\mathbf{Y}$ \\
\hline F-FW2-OV1, F-FW2-OV2 & 2 & & & $\mathbf{Y}$ \\
\hline F-FW2-IV1, F-FW2-OV2 & 2 & & & $\mathbf{Y}$ \\
\hline F-FW2-PMP1, S-EL-III-2-E & 1 & & 1 & \\
\hline
\end{tabular}


Table C.7 (cont.)

\begin{tabular}{||l|c|c|c|c||}
\hline F-FW2-IV2, S-EL-III-2-O & 1 & & 1 & \\
\hline F-FW2-OV2, S-EL-III-2-O & 1 & & 1 & \\
\hline F-FW2-IV1, S-EL-III-2-E & 1 & & 1 & \\
\hline F-FW2-OV1, S-EL-III-2-E & 1 & & 1 & \\
\hline F-FW2-PMP2, S-EL-III-2-() & 1 & & 1 & \\
\hline S-EL-III-2-E, S-EL-III-2-O & & & 2 & \\
\hline F-FW2-ISV1-SG1, F-FW2-ISV1-SG2, S IEL-II-2-E & 2 & & 1 & \\
\hline F-FW2-ISV2-SG1, F-FW2-ISV2-SG2, S-EL-II-2-O & 2 & & 1 & \\
\hline
\end{tabular}

\begin{tabular}{||c|c|c|c|c|}
\hline Initiating Event - Loss of Class IV Powy'r & \multicolumn{2}{|l|}{ Sequence: LOP-G } \\
\hline \hline Sequence Level Cut Sets & $\begin{array}{c}\text { Component } \\
\text { Failures }\end{array}$ & $\begin{array}{c}\text { Human } \\
\text { Errors }\end{array}$ & $\begin{array}{c}\text { Support } \\
\text { Syatem } \\
\text { Failures }\end{array}$ & $\begin{array}{c}\text { Determimant } \\
\text { Failure? }\end{array}$ \\
\hline S-EL-II-2-E, S-F' I-2-O & & & 2 & \\
\hline
\end{tabular}

\begin{tabular}{|c|c|c|c|c|}
\hline \multirow{2}{*}{$\frac{\text { Initiating Event - Loss of Class IV Power }}{\text { Seçuence Level Cut Sets }}$} & \multicolumn{4}{|c|}{ Sequence: $L O P-K$} \\
\hline & $\begin{array}{l}\text { Conpponent } \\
\text { Failures }\end{array}$ & $\begin{array}{c}\text { Human } \\
\text { Errons }\end{array}$ & $\begin{array}{l}\text { Suppon } \\
\text { Syatem } \\
\text { Failures }\end{array}$ & $\begin{array}{l}\text { Determinant } \\
\text { Frilure? }\end{array}$ \\
\hline F-AFW-PMP, F FW2-HE, F-FW2-LI-TK & 2 & 1 & & \\
\hline F-AFW-DIESI L, F-FW2-HE, F-FW2-LI-TK & 2 & 1 & & \\
\hline F-AFW-DV, F-FW2-HE, F-FW2-LI-TK & 2 & 1 & & \\
\hline F-AFW-DV, F-FW2-IV1, F-FW2-PiviP2 & 3 & & & \\
\hline F-AFW-DV, F-FW2-IV1, F-FW2-OV2 & 3 & & & \\
\hline F-AFW-DV, F-FW2-IV2, F-FW2-OV1 & 3 & & & \\
\hline F-AFW-DV, F-FW2-OV1, F-FW2-OV2 & 3 & & & \\
\hline F-AFW-DV, F-FW2-IV1, F-FW2-IV2 & 3 & & & \\
\hline F-AFW-DV, F-FW2-OV1, F-FW2-PMP2 & 3 & & & \\
\hline F-AFW-DV, F-FW2-PMP1, F-FW2-PMP2 & 3 & & & \\
\hline F-AFW-PMP, F-FW2-OV1, F-FW2-OV2 & 3 & & & \\
\hline F-AFW-PMP, F-FW2-OV1, F-FW2-PMP2 & 3 & & & \\
\hline F-AFW-PMP, F-FW2-IV2, F-FW2-OV1 & 3 & & & \\
\hline F-AFW-DV, F-FW2-IV2, F-1 W2-PMP1 & 3 & & & \\
\hline F-A,FW-DIESEL, F-FW2-IV2, F-FW2-PMP1 & 3 & & & \\
\hline F-AFW-PMP, F-FW2-IV1, F-FW2-PMP2 & 3 & & & \\
\hline
\end{tabular}




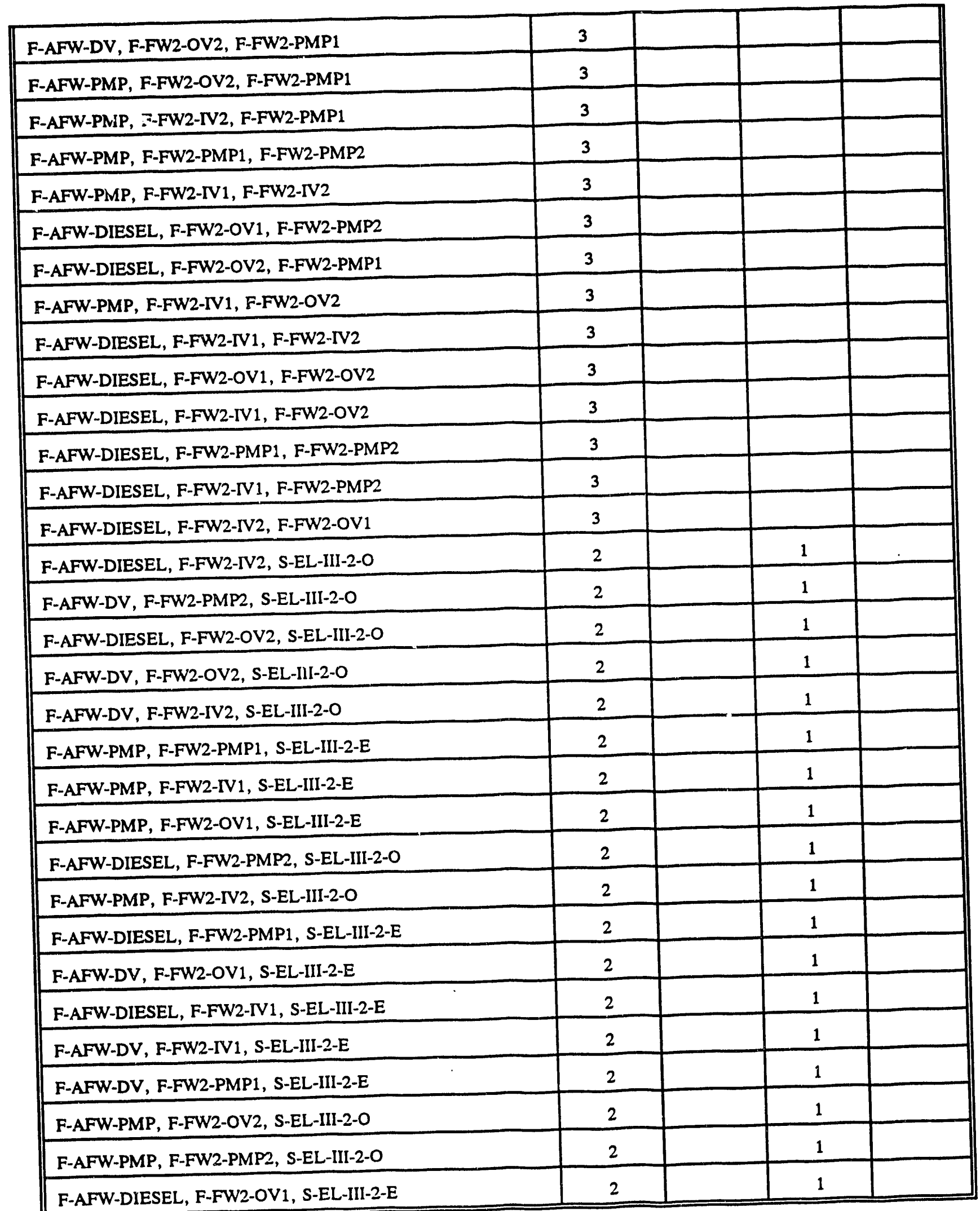


Table C.7 (cont.)

\begin{tabular}{||l|c|c|c|c||}
\hline \multicolumn{1}{|l|l||}{} & \multicolumn{2}{|l|}{ Sequence: LOP-L } \\
\hline Sequence Level Cut Sets & $\begin{array}{c}\text { Component } \\
\text { Frilures }\end{array}$ & $\begin{array}{c}\text { Human } \\
\text { Error }\end{array}$ & $\begin{array}{c}\text { Support } \\
\text { System } \\
\text { Failures }\end{array}$ & $\begin{array}{c}\text { Determinant } \\
\text { Frilure ? }\end{array}$ \\
\hline F-AFW-DIESEL, S-EL-III-2-E, S-EL-III-2-O & 1 & & 2 & \\
\hline F-AFW-DV, S-EL-III-2-E, S-EL-III-2-O & 1 & & 2 & \\
\hline F-AFW-PMP, S-EL-III-2-E, S-EL-III-2-O & 1 & & 2 & \\
\hline F-AFW-DV, S-EL-II-2-E, S-EL-II-2-O & 1 & & 2 & \\
\hline F-AFW-PMP, S-EL-II-2-E, S-EL-II-2-O & 1 & & 2 & \\
\hline F-AFW-DIESEL, S-EL-II-2-E, S-EL-II-2-O & 1 & & 2 & \\
\hline
\end{tabular}

\begin{tabular}{||l|c|c|c|c||}
\hline Initiating Event - Loss of Class IV Power & \multicolumn{2}{|l||}{ Sequence: LOP-N } \\
\hline \hline \multicolumn{1}{|c|}{ Sequence Level Cut Sets } & $\begin{array}{c}\text { Component } \\
\text { Fuilures }\end{array}$ & $\begin{array}{c}\text { Humen } \\
\text { Erron }\end{array}$ & $\begin{array}{c}\text { Support } \\
\text { System } \\
\text { Failures }\end{array}$ & $\begin{array}{c}\text { Determinant } \\
\text { Fuilure ? }\end{array}$ \\
\hline S-EL-II-1-E & & & 1 & \\
\hline F-LRC-VLV2 & 1 & & & $Y$ \\
\hline F-LRC-VLV1 & 1 & & & $Y$ \\
\hline
\end{tabular}

\begin{tabular}{|c|c|c|c|c|}
\hline \multirow{2}{*}{$\frac{\text { Initiating Event - Loss of Class IV Power }}{\text { Sequence Level Cut Sets }}$} & \multicolumn{4}{|c|}{ Sequence: $L O P-O$} \\
\hline & $\begin{array}{l}\text { Component } \\
\text { Failures }\end{array}$ & $\begin{array}{l}\text { Human } \\
\text { Errorn }\end{array}$ & $\begin{array}{l}\text { Suppon } \\
\text { System } \\
\text { Failurea }\end{array}$ & $\begin{array}{l}\text { Determinent } \\
\text { Failure? }\end{array}$ \\
\hline S-AIR & & & 1 & \\
\hline F-ASD-ASD1, F-ASD-ASD2, F-LRC-VLV2 & 3 & & & \\
\hline F-ASD-ASD1, F-ASD-ASD2, F-LRC-VLV1 & 3 & & & \\
\hline F-ASD-ASD1, F-ASD-ASD2, S-EL-II-1-E & 2 & & 1 & \\
\hline F-ASD-ASD2, S-EL-II-1-E, S-EL-II-2-O & 1 & & 2 & \\
\hline F-ASD-ASD1, F-LRC-VLV1, S-EL-II-2-E & 2 & & 1 & \\
\hline F-ASD-ASD2, F-LRC-VLV2, S-EL-II-2-O & 2 & & 1 & \\
\hline F-ASD-ASD2, F-LRC-VLV1, S-EL-II-2-O & 2 & & 1 & \\
\hline F-ASD-ASD1, F-LRC-VLV2, S-EL-II-2-E & 2 & & 1 & \\
\hline F-ASD-ASD1, S-EL-II-1-E, S-EL-II-2-E & 1 & & 2 & \\
\hline
\end{tabular}


Table C.7 (cont.)

\begin{tabular}{|c|c|c|c|c|}
\hline Initiating Event - Loss of Class IV Power & Sequenc & LOP-P & & \\
\hline Sequence Level Cut Sets & $\begin{array}{l}\text { Component } \\
\text { Failures }\end{array}$ & $\begin{array}{l}\text { Human } \\
\text { Errons }\end{array}$ & $\begin{array}{l}\text { Support } \\
\text { Syutem } \\
\text { Fuilures }\end{array}$ & $\begin{array}{l}\text { Determinant } \\
\text { Failure? }\end{array}$ \\
\hline F-MSV-MSSV3-SG1, F-MSV-MSSV4-SG1, S-AIR & 2 & & 1 & \\
\hline F-MSV-MSSV1-SG1, F-MSV-MSSV3-SG1, S-AIR & 2 & & 1 & \\
\hline F-MSV-MSSV1-SG2, F-MSV-MSSV2-SG2, S-AIR & 2 & & 1 & \\
\hline F-MSV-MSSV1-SG2, F-MSV-MSSV3-SG2, S-AIR & 2 & & 1 & \\
\hline F-MSV-MSSV2-SG1, F-MSV-MSSV3-SG1, S-AIR & 2 & & 1 & \\
\hline F-MSV-MSSV2-SG2, F-MSV-MSSV3-SG2, S-AIR & 2 & & 1 & \\
\hline F-MSV-MSSV1-SG1, F-MSV-MSSV4-SG1, S-AIR & 2 & & 1 & \\
\hline F-MSV-MSSV2-SG2, F-MSV-MSSV4-SG2, S-AIR & 2 & & 1 & \\
\hline F-MSV-MSSV1-SG2, F-MSV-MSSV4-SG2, S-AIR & 2 & & 1 & \\
\hline F-MSV-MSSV3-SG2, F-MSV-MSSV4-SG2, S-AIR & 2 & & 1 & \\
\hline F-MSV-MSSV1-SG1, F-MSV-MSSV2-SG1, S-AIR & 2 & & 1 & \\
\hline F-MSV-MSSV2-SG1, F-MSV-MSSV4-SG1, S-AIR & 2 & & 1 & \\
\hline
\end{tabular}

\begin{tabular}{|c|c|c|c|c|}
\hline Initiating Event - Loss of Class IV Power & Sequenc & LOP-S & & \\
\hline Sequence Level Cut Sets & $\begin{array}{l}\text { Component } \\
\text { Failures }\end{array}$ & $\begin{array}{l}\text { Human } \\
\text { Errors }\end{array}$ & $\begin{array}{l}\text { Support } \\
\text { System } \\
\text { Failures }\end{array}$ & $\begin{array}{l}\text { Determinant } \\
\text { Failure? }\end{array}$ \\
\hline F-FW2-HE, F-FW2-LI-TK, F-LRC-VLV1 & 2 & 1 & & \\
\hline F-FW2-HE, F-FW2-LI-TK, F-LRC-VLV2 & 2 & 1 & & \\
\hline F-FW2-HE, F-FW2-LI-TK, S-EL-II-1-E & 1 & 1 & 1 & \\
\hline F-FW2-OV1, F-FW2-PMP2, S-EL-II-1-E & 2 & & 1 & \\
\hline F-FW2-IV2, F-FW2-PMP1, F-LRC-VLV2 & 3 & & & \\
\hline F-FW2-OV1, F-FW2-OV2, S-EL-II-1-E & 2 & & 1 & \\
\hline F-FW2-OV2, F-FW2-PMP1, F-LRC-VLV2 & 3 & & & \\
\hline F-FW2-PMP1, F-FW2-PMP2, F-LRC-VLV2 & 3 & & & \\
\hline F-FW2-IV2, F-FW2-OV1, F-LRC-VLV1 & 3 & & & \\
\hline F-FW2-IV1, F-FW2-IV2, F-LRC-VLV2 & 3 & & & \\
\hline F-FW2-IV2, F-FW2-OV1, S-EL-II-1-E & 2 & & 1 & \\
\hline F-FW2-IV1, F-FW2-PMP2, S-EL-II-1-E & 2 & & 1 & \\
\hline F-FW2-OV1, F-FW2-OV2, F-LRC-VLV1 & 3 & & & \\
\hline F-FW2-IV2, F-FW2-PMP1, S-EL-II-1-E & 2 & & 1 & \\
\hline
\end{tabular}


Table C.7 (cont.)

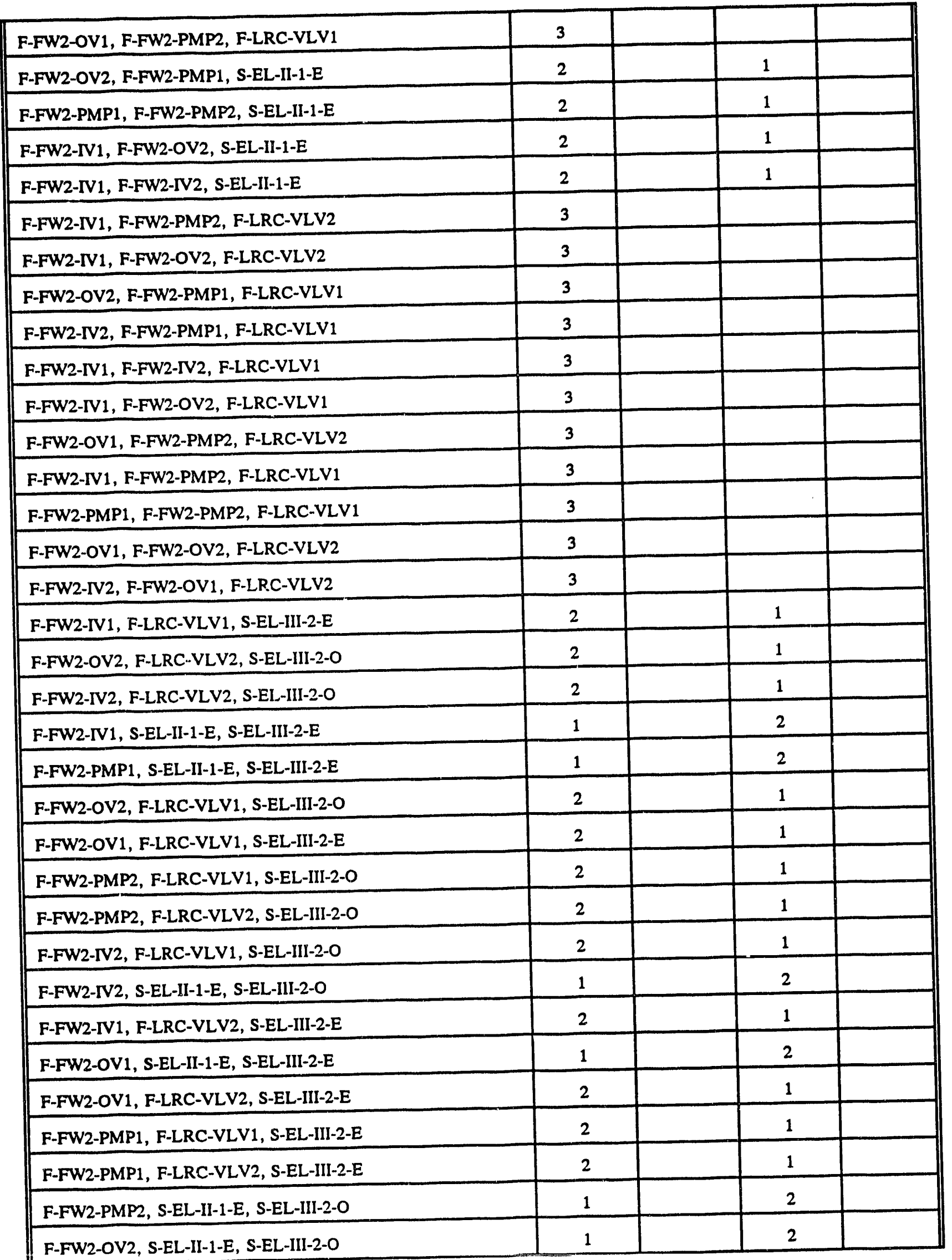


Table C.7 (cont.)

F-LRC-VLV2, S-EL-III-2-E, S-EL-III-2-O

S-EL-II-1-E, S-EL-III-2-E, S-EL-III-2-O

F-LRC-VLV1, S-EL-III-2-E, S-EL-III-2-O

\begin{tabular}{|l|l|l|l|}
\hline 1 & & 2 & \\
\hline & & 3 & \\
\hline 1 & & 2 & \\
\hline
\end{tabular}

\begin{tabular}{|c|c|c|c|c|}
\hline Initiating Event - Loss of Class IV Power & Sequenc & LOP-1 & & \\
\hline Sequence Level Cut Sets & $\begin{array}{l}\text { Component } \\
\text { Faitures }\end{array}$ & $\begin{array}{l}\text { Human } \\
\text { Errons }\end{array}$ & $\begin{array}{l}\text { Support } \\
\text { Syctem } \\
\text { Failures }\end{array}$ & $\begin{array}{l}\text { Determinant } \\
\text { Failure ? }\end{array}$ \\
\hline F-FW2-HE, F-FW2-LI-TK, S-AIR & 1 & 1 & 1 & \\
\hline F-FW2-IV1, F-FW2-IV2, S-AIR & 2 & & 1 & \\
\hline F-FW2-PMP1, F-FW2-PMP2, S-AIR & 2 & & 1 & \\
\hline F-FW2-IV1, F-FW2-OV2, S-AIR & 2 & & 1 & \\
\hline F-FW2-IV2, F-FW2-OV1, S-AIR & 2 & & 1 & \\
\hline F-FW2-IV1, F-FW2-PMP2, S-AIR & 2. & & 1 & \\
\hline F-FW2-OV1, F-FW2-OV2, S-AIR & 2 & & 1 & \\
\hline F-FW2-OV1, F-FW2-PMP2, S-AIR & 2 & & 1 & \\
\hline F-FW2-IV2, F-FW2-PMP1, S-AIR & 2 & & 1 & \\
\hline F-FW2-OV2, F-FW2-PMP1, S-AIR & 2 & & 1 & \\
\hline F-LRC-VLV1, S-EL-II-2-E, S-EL-II-2-O & 1 & & 2 & \\
\hline F-FW2-PMP1, S-AIR, S-EL-III-2-E & 1 & & 2 & \\
\hline F-FW2-IV1, S-AIR, S-EL-III-2-E & 1 & & 2 & \\
\hline F-FW2-OV2, S-AIR, S-EL-III-2-O & 1 & & 2 & \\
\hline F-FW2-OV1, S-AIR, S-EL-III-2-E & 1 & & 2 & \\
\hline S-EL-II-1-E, S-EL-II-2-E, S-EL-II-2-O & & & 3 & \\
\hline F-FW2-IV2, S-AIR, S-EL-III-2-O & 1 & & 2 & \\
\hline F-FW2-PMP2, S-AIR, S-EL-III-2-O & 1 & & 2 & \\
\hline F-LRC-VLV2, S-EL-II-2-E, S-EL-II-2-O & 1 & & 2 & \\
\hline S-AIR, S-EL-III-2-E, S-EL-III-2-O & & & 3 & \\
\hline S-AIR, S-EL-II-2-E, S-EL-II-2-O & & & 3 & \\
\hline
\end{tabular}


Table C.7 (cont.)

\begin{tabular}{||l|c|c|c|c||}
\hline \multicolumn{1}{|c|}{ Initiating Event - Loss of Class IV Power } & \multicolumn{2}{l||}{ Sequence: LOP-AA } \\
\hline Sequence Level Cut Sets & $\begin{array}{c}\text { Component } \\
\text { Fuilures }\end{array}$ & $\begin{array}{c}\text { Human } \\
\text { Erron }\end{array}$ & $\begin{array}{c}\text { Support } \\
\text { Syrtem } \\
\text { Failures }\end{array}$ & $\begin{array}{c}\text { Determinant } \\
\text { Faiture ? }\end{array}$ \\
\hline S-EL-II-1-O & & & 1 & Y \\
\hline F-BCS-CNV1-TK, S-EL-II-1-E & 1 & & 1 & \\
\hline F-BCS-CNV1-TK, F-BCS-CNV2, F-LRC-VLV2 & 3 & & & \\
\hline F-BCS-CNV1-TK, F-BCS-CNV2, F-LRC-VLV1 & 3 & & & \\
\hline F-BCS-CNV1, F-BCS-CNV1-TK, F-LRC-VLV2 & 3 & & & \\
\hline F-BCS-CNV1, F-BCS-CNV1-TK, F-LRC-VLV1 & 3 & & & \\
\hline
\end{tabular}

\begin{tabular}{|c|c|c|c|c|}
\hline \multirow{2}{*}{$\begin{array}{c}\text { Initiating Event - Loss of Class IV Power } \\
\text { Sequence Level Cut Sets }\end{array}$} & \multicolumn{4}{|c|}{ Sequence: $L O P-A B$} \\
\hline & $\begin{array}{l}\text { Component } \\
\text { Frilures }\end{array}$ & $\begin{array}{l}\text { Human } \\
\text { Errors }\end{array}$ & $\begin{array}{l}\text { Suppo-" } \\
\text { Syntem } \\
\text { Failures }\end{array}$ & $\begin{array}{l}\text { Determinant } \\
\text { Failure? }\end{array}$ \\
\hline F-LPI-ISV1, F-LPI-ISV2, S-EL-II-1-O & 2 & & 1 & \\
\hline F-LPI-PMP1, F-LPI-PMP2, S-EL-II-1-O & 2 & & 1 & \\
\hline F-LPI-INV1, F-LPI-INV2, S-EL-II-1-O & 2 & & 1 & \\
\hline F-LPI-ISV1, S-EL-II-1-O, S-EL-III-2-E & 1 & & 2 & \\
\hline F-LPI-PMP1, S-EL-II-1-O, S-EL-III-2-E & 1 & & 2 & \\
\hline F-LPI-LI-TK, F-LPI-TK, S-EL-II-1-O & 2 & & 1 & \\
\hline F-LPI-PMP2, S-EIL-II-1-O, S-EL-III-2-O & 1 & & 2 & \\
\hline F-HPI-ISV1-GI, S-EL-II-1-O, S-EL-III-2-E & 1 & & 2 & \\
\hline F-LPI-ISV2, S-EL-II-1-O, S-EL-III-2-O & 1 & & 2 & \\
\hline F-LPI-INV2, S-EL-II-1-O, S-EL-III-2-O & 1 & & 2 & \\
\hline F-HPI-ISV2-GI, S-EL-II-1-O, S-EL-III-2-O & 1 & & 2 & \\
\hline F-LPI-INV1, S-EL-II-1-O, S-EL-III-2-E & 1 & & 2 & \\
\hline
\end{tabular}

\begin{tabular}{||l|c|c|c|c||}
\hline Initiating Event - Loss of Class IV Power & \multicolumn{2}{|l||}{ Sequence: LOP-AD } \\
\hline Sequence Level Cut Sets & $\begin{array}{c}\text { Componean } \\
\text { Failures }\end{array}$ & $\begin{array}{c}\text { Humen } \\
\text { Erron }\end{array}$ & $\begin{array}{c}\text { Support } \\
\text { System } \\
\text { Failures }\end{array}$ & $\begin{array}{c}\text { Determinent } \\
\text { Failure ? }\end{array}$ \\
\hline F-HPI-SIG1-LPHTS, F-HPI-SIG2-LPHTS, S-EL-II-1-O & 2 & & 1 & \\
\hline F-HPI-SIG2-LPHTS, F-HPI-SIG3-LPHTS, S-EL-II-1-O & 2 & & 1 & \\
\hline F-HPI-ISV1-GI, F-HPI-ISV2-GI, S-EL-II-1-O & 2 & & 1 & \\
\hline F-HPI-INV1, F-HPI-INV2, S-EL-II-1-O & 2 & & 1 & \\
\hline
\end{tabular}


Table C.7 (cont.)

\begin{tabular}{|c|c|c|}
\hline F-HPI-SIG1-LPHTS, F-HPI-SIG3-LPHTS, S-EL-II-1-O & 2 & 1 \\
\hline F-HPI-OV2A, F-HPI-OV2B, S-EL-II-1-O & 2 & 1 \\
\hline F-HPI-INV1A, F-HPI-INV1B, S-EL-II-1-O & 2 & 1 \\
\hline F-HPI-INV2A, F-HPI-INV2B, S-EL-II-1-O & 2 & 1 \\
\hline F-HPI-OV1A, F-HPI-OV1B, S-EL-II-1-O & 2 & 1 \\
\hline F-HPI-PI-GI-TK, F-HPI-TK-GI, S-EL-II-1-O & 2 & 1 \\
\hline F-HPI-LI-CITK, F-HPI-TK-CI, S-EL-II-1-O & 2 & 1 \\
\hline
\end{tabular}

\begin{tabular}{|c|c|c|c|c|}
\hline Initiating Event - Loss of Class IV Power & \multicolumn{4}{|c|}{ Sequence: $L O P-A F$} \\
\hline Sequence Level Cut Sets & $\begin{array}{l}\text { Component } \\
\text { Failures }\end{array}$ & $\begin{array}{l}\text { Human } \\
\text { Errors }\end{array}$ & $\begin{array}{l}\text { Support } \\
\text { Syctem } \\
\text { Failures }\end{array}$ & $\begin{array}{l}\text { Determinant } \\
\text { Failure? }\end{array}$ \\
\hline F-FW2-HE, F-FW2-LI-TK, S-EL-II-1-O & 1 & 1 & 1 & \\
\hline F-FW2-OV1, F-FW2-OV2, S-EL-II-1-O & 2 & & 1 & \\
\hline F-FW2-OV2, F-FW2-PMP1, S-EL-II-1-O & 2 & & 1 & \\
\hline F-FW2-OV1, F-FW2-PMP2, S-EL-II-1-O & 2 & & 1 & \\
\hline F-FW2-PMP1, F-FW2-PMP2, S-EL-II-1-O & 2 & & 1 & \\
\hline F-FW2-IV2, F-FW2-PMP1, S-EL-II-1-O & 2 & & 1 & \\
\hline F-FW2-IV1, F-FW2-PMP2, S-EL-II-1-O & 2 & & 1 & \\
\hline F-FW2-IV1, F-FW2-IV2, S-EL-II-1-O & 2 & & 1 & \\
\hline F-FW2-IV2, F-FW2-OV1, S-EL-II-1-O & 2 & & 1 & \\
\hline F-FW2-IV1, F-FW2-OV2, S-EL-II-1-O & 2 & & 1 & \\
\hline F-FW2-IV2, S-EL-II-1-O, S-EL-III-2-O & 1 & & 2 & \\
\hline F-FW2-OV1, S-EL-II-1-O, S-EL-III-2-E & 1 & & 2 & \\
\hline F-FW2-OV2, S-EL-II-1-O, S-EL-III-2-O & 1 & & 2 & \\
\hline F-FW2-PMP2, S-EL-II-1-O, S-EL-III-2-O & 1 & & 2 & \\
\hline F-FW2-IV1, S-EL-II-1-O, S-EL-III-2-E & 1 & & 2 & \\
\hline F-FW2-PMP1, S-EL-II-1-O, S-EL-III-2-E & 1 & & 2 & \\
\hline Initiating Event - Loss of Class IV Power & Sequenc & $O P-A$ & & \\
\hline Sequence Level Cut Sets & $\begin{array}{l}\text { Component } \\
\text { Failures }\end{array}$ & $\begin{array}{l}\text { Human } \\
\text { Errors }\end{array}$ & $\begin{array}{l}\text { Support } \\
\text { Systerm } \\
\text { Failures } \\
\end{array}$ & $\begin{array}{l}\text { Determinent } \\
\text { Failure? }\end{array}$ \\
\hline S-EL-II-1-O, S-EL-III-2-E, S-EL-III-2-O & & & 3 & \\
\hline
\end{tabular}


Table C.7 (cont.)

\begin{tabular}{|c|c|c|c|c||}
\hline Initiating Event - Loss of Class IV Power & \multicolumn{3}{|l||}{ Sequence: LOP-AK } \\
\hline \hline Sequence Level Cut Sets & $\begin{array}{c}\text { Component } \\
\text { Failures }\end{array}$ & $\begin{array}{c}\text { Human } \\
\text { Erros }\end{array}$ & $\begin{array}{c}\text { Support } \\
\text { System } \\
\text { Failures }\end{array}$ & $\begin{array}{c}\text { Determinant } \\
\text { Failure ? }\end{array}$ \\
\hline S-PCS & & & 1 & $\mathrm{Y}$ \\
\hline
\end{tabular}

\begin{tabular}{||l|c|c|c|c||}
\hline \multicolumn{1}{|l|}{ Initiating Event - Loss of Class IV Power } & \multicolumn{2}{l||}{ Sequence: LOP-AL } \\
\hline \hline \multicolumn{1}{|c|}{ Sequence Level Cut Sets } & $\begin{array}{c}\text { Component } \\
\text { Failures }\end{array}$ & $\begin{array}{c}\text { Human } \\
\text { Erron }\end{array}$ & $\begin{array}{c}\text { Support } \\
\text { Syatem } \\
\text { Failures }\end{array}$ & $\begin{array}{c}\text { Determinant } \\
\text { Failure ? }\end{array}$ \\
\hline F-MCS-PMiP1, S-PCS & 1 & & 1 & \\
\hline S-EL-III-1-O, S-PCS & & & 2 & \\
\hline S-EL-III-1-E, S-PCS & & & 2 & \\
\hline F-MCS-PMP2, S-PCS & 1 & & 1 & \\
\hline S-PCS, S-RCW & & & 2 & \\
\hline F-MCS-ISV-FC, S-PCS & 1 & & 1 & \\
\hline
\end{tabular}

\begin{tabular}{|c|c|c|c|c|}
\hline \multirow{2}{*}{$\begin{array}{c}\text { Initiating Event - Loss of Class IV Power } \\
\text { Sequence Level Cut Sets }\end{array}$} & \multicolumn{4}{|c|}{ Sequence: $L O P-A M$} \\
\hline & $\begin{array}{l}\text { Component } \\
\text { Failures }\end{array}$ & $\begin{array}{l}\text { Human } \\
\text { Errors }\end{array}$ & $\begin{array}{l}\text { Support } \\
\text { System } \\
\text { Failures } \\
\end{array}$ & $\begin{array}{l}\text { Determinant } \\
\text { Failure? }\end{array}$ \\
\hline S-AIR, S-EL-II-1-O & & & 2 & \\
\hline S-ECC, S-EL-II-1-O & & & 2 & \\
\hline S-EL-II-1-O, S-EL-II-2-E & & & 2 & \\
\hline S-EL-II-1-O, S-EL-II-2-O & & & 2 & \\
\hline F-BCS-CNV1-TK, S-AlR & 1 & & 1 & \\
\hline S-ECC, S-PCS & & & 2 & \\
\hline S-EL-II-2-O, S-PCS & & & 2 & \\
\hline S-AIR, S-PCS & & & 2 & \\
\hline S-EL-II-2-E, S-PCS & & & 2 & \\
\hline F-MSV-MSSV1-SG1, F-MSV-MSSV4-SG1, S-EL-II-1-O & 2 & & 1 & \\
\hline F-MSV-MSSV1-SG1, F-MSV-MSSV3-SG1, S-EL-II-1-O & $?$ & & 1 & \\
\hline F-MSV-MSSV1-SG2, F-MSV-MSSV2-SG2, S-EL-II-1-O & 2 & & 1 & \\
\hline F-MSV-MSSV1-SG2, F-MSV-MSSV3-SG2, S-EL-II-1-O & 2 & & 1 & \\
\hline F-MSV-MSSV2-SG2, F-MSV-MSSV3-SG2, S-EL-II-1-O & 2 & & 1 & \\
\hline F-MSV-MSSV3-SG1, F-MSV-MSSV4-SG1, S-EL-II-1-O & 2 & & 1 & \\
\hline
\end{tabular}


Table C.7 (cont.)

\begin{tabular}{|c|c|c|c|}
\hline F-MSV-MSSV2-SG1, F-MSV-MSSV3-SG1, S-EL-II-1-O & 2 & 1 & \\
\hline F-MSV-MSSV3-SG2, F-MSV-MSSV4-SG2, S-EL-II-1-O & 2 & 1 & \\
\hline F-MSV-MSSV2-SG2, F-MSV-MSSV4-SG2, S-EL-II-1-O & 2 & 1 & \\
\hline F-MSV-MSSV1-SG2, F-MSV-MSSV4-SG2, S-EL-II-1-O & 2 & 1 & \\
\hline F-MSV-MSSV1-SG1, F-MSV-MSSV2-SG1, S-EL-II-1-O & 2 & 1 & \\
\hline F-MSV-MSSV2-SG1, F-MSV-MSSV4-SG1, S-EL-II-1-O & 2 & 1 & \\
\hline F-MSV-MSSV1-SG2, F-MSV-MSSV4-SG2, S-PCS & 2 & 1 & \\
\hline F-MSV-MSSV1-SG2, F-MSV-MSSV3-SG2, S-PCS & 2 & 1 & \\
\hline F-BCS-CNV1-TK, S-EL-II-1-E, S-EL-II-2-O & 1 & 2 & \\
\hline F-BCS-CNV1-TK, S-ECC, S-EL-II-1-E & 1 & 2 & \\
\hline F-BCS-CNV1-TK, S-EL-II-1-E, S-EL-II-2-E & 1 & 2 & \\
\hline F-MSV-MSSV2-SG2, F-MSV-MSSV4-SG2, S-PCS & 2 & 1. & \\
\hline F-MSV-MSSV3-SG2, F-MSV-MSSV4-SG2, S-PCS & 2 & 1 & \\
\hline F-MSV-MSSV1-SG1, F-MSV-MSSV4-SG1, S-PCS & 2 & 1 & \\
\hline F-MSV-MSSV1-SG1, F-MSV-MSSV3-SG1, S-PCS & 2 & 1 & \\
\hline F-MSV-MSSV1-SG1, F-MSV-MSSV2-SG1, S-PCS & 2 & 1 & \\
\hline F-MSV-MSSV2-SG1, F-MSV-MSSV4-SG1, S-PCS & 2 & 1 & \\
\hline F-MSV-MSSV3-SG1, F-MSV-MSSV4-SG1, S-PCS & 2 & 1 & \\
\hline F-MSV-MSSV2-SG1, F-MSV-MSSV3-SG1, S-PCS & 2 & 1 & \\
\hline F-MSV-MSSV1-SG2, F-MSV-MSSV2-SG2, S-PCS & 2 & 1 & \\
\hline F-MSV-MSSV2-SG2, F-MSV-MSSV3-SG2, S-PCS & 2 & 1 & \\
\hline
\end{tabular}

\begin{tabular}{||l|c|c|c|c||}
\hline \multicolumn{1}{|c|}{ Initiating Event - Loss of Class IV Power } & \multicolumn{2}{|l||}{ Sequence: LOP-AN } \\
\hline \hline Sequence Level Cut Sets & $\begin{array}{c}\text { Component } \\
\text { Failures }\end{array}$ & $\begin{array}{c}\text { Human } \\
\text { Errors }\end{array}$ & $\begin{array}{c}\text { Support } \\
\text { system } \\
\text { Failures }\end{array}$ & $\begin{array}{c}\text { Determinant } \\
\text { Failure ? }\end{array}$ \\
\hline S-EL-II-1-O, S-EL-II-2-O, S-EL-III-1-O & & & 3 & \\
\hline F-MCS-PMP1, S-EL-II-1-O, S-EL-II-2-O & 1 & & 2 & \\
\hline S-AIR, S-EL-II-1-O, S-RCW & & & 3 & \\
\hline S-EL-II-1-O, S-EL-II-2-O, S-EL-III-1-E & & & 3 & \\
\hline F-MCS-PMP2, S-EL-II-1-O, S-EL-II-2-O & 1 & & 2 & \\
\hline S-EL-II-1-O, S-EL-II-2-O, S-RCW & & & 3 & \\
\hline S-ECC, S-EL-II-1-O, S-EL-III-1-O & & & 3 & \\
\hline F-MCS-ISV-FC, S-EL-II-1-O, S-EL-II-2-O & 1 & & 2 & \\
\hline
\end{tabular}


Table C.7 (cont.)

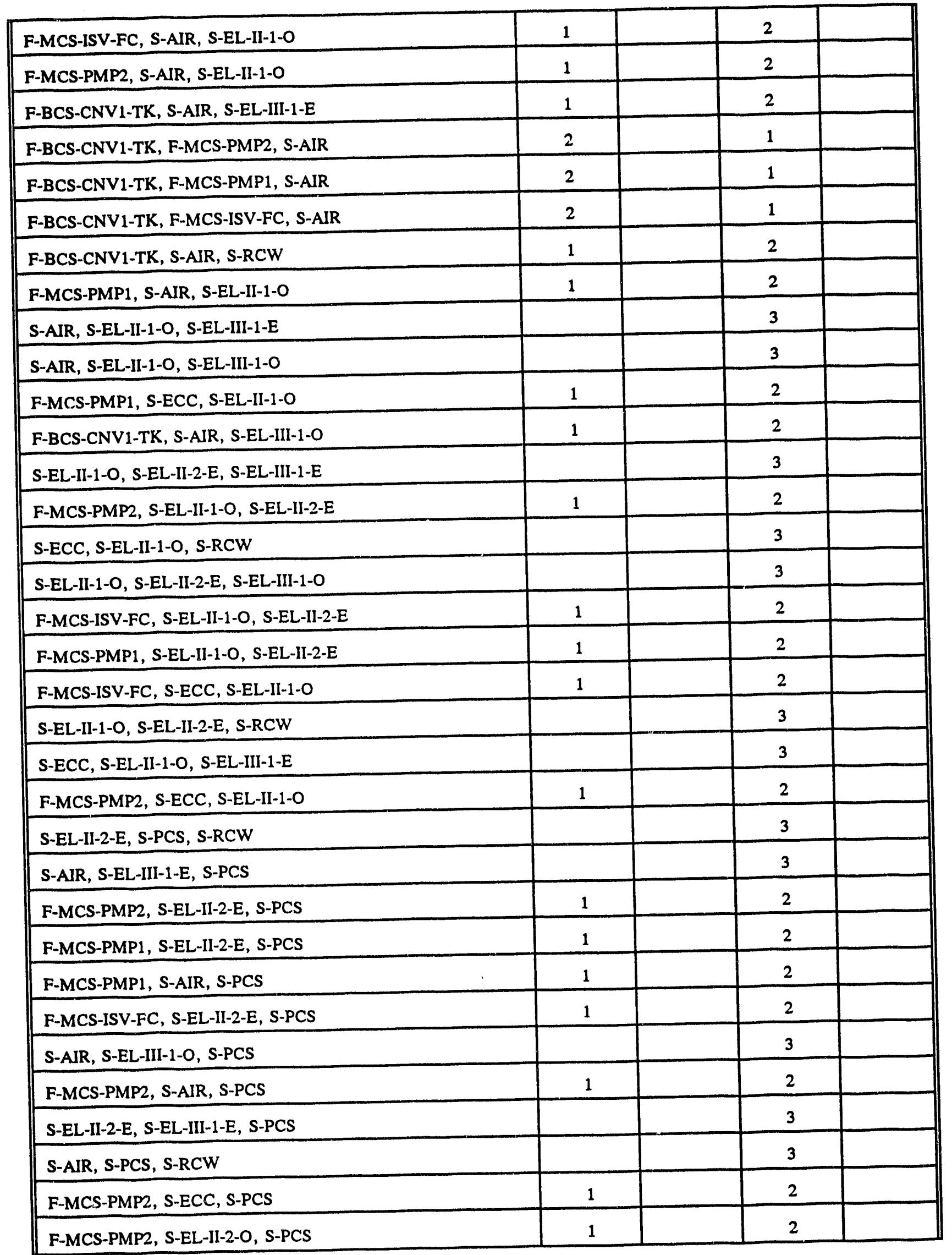


Table C.7 (cont.)

\begin{tabular}{||l|c|c|c|c||}
\hline F-MCS-ISV-FC, S-EL-II-2-O, S-PCS & 1 & & 2 & \\
\hline S-EL-II-2-O, S-PCS, S-RCW & & & 3 & \\
\hline S-ECC, S-EL-III-1-O, S-PCS & & & 3 & \\
\hline S-ECC, S-EL-III-1-E, S-PCS & & & 3 & \\
\hline S-EL-II-2-O, S-EL-III-1-E, S-PCS & & & 3 & \\
\hline F-MCS-ISV-FC, S-ECC, S-PCS & 1 & & 2 & \\
\hline F-MCS-PMP1, S-ECC, S-PCS & 1 & & 2 & \\
\hline F-MCS-ISV-FC, S-AIR, S-PCS & 1 & & 2 & \\
\hline S-ECC, S-PCS, S-RCW & & & 3 & \\
\hline S-EL-II-2-O, S-EL-III-1-O, S-PCS & & & 3 & \\
\hline S-EL-II-2-E, S-EL-III-1-O, S-PCS & & & 3 & \\
\hline F-MCS-PMP1, S-EL-II-2-O, S-PCS & & & 2 & \\
\hline
\end{tabular}

\begin{tabular}{||c|c|c|c|c||}
\hline Initiating Event - Loss of Class IV Power & \multicolumn{2}{|l||}{ Sequence: LOP-AO } \\
\hline Sequence Level Cut Sets & $\begin{array}{c}\text { Component } \\
\text { Failures }\end{array}$ & $\begin{array}{c}\text { Human } \\
\text { Errors }\end{array}$ & $\begin{array}{c}\text { Support } \\
\text { System } \\
\text { Failures }\end{array}$ & $\begin{array}{c}\text { Determinant } \\
\text { Failure ? }\end{array}$ \\
\hline RESPWR & & & 1 & $Y$ \\
\hline
\end{tabular}

\begin{tabular}{|c|c|c|c|c|}
\hline \multirow{2}{*}{$\begin{array}{c}\text { Initiating Event - Loss of Class IV Power } \\
\text { Sequence Level Cut Sets }\end{array}$} & \multicolumn{4}{|c|}{ Sequence: $L O P-A P$} \\
\hline & $\begin{array}{l}\text { Component } \\
\text { Failures }\end{array}$ & $\begin{array}{l}\text { Human } \\
\text { Errors }\end{array}$ & $\begin{array}{l}\text { Support } \\
\text { System } \\
\text { Failures }\end{array}$ & $\begin{array}{l}\text { Determinant } \\
\text { Failure? }\end{array}$ \\
\hline F-MSV-MSSV3-SG1, F-MSV-MSSV4-SG1, RESPWR & 2 & & 1 & \\
\hline F-MSV-MSSV1-SG1, F-MSV-MSSV3-SG1, RESPWR & 2 & & 1 & \\
\hline F-MSV-MSSV1-SG2, F-MSV-MSSV2-SG2, RESPWR & 2 & & 1 & \\
\hline F-MSV-MSSV1-SG2, F-MSV-MSSV3-SG2, RESPWR & 2 & & 1 & \\
\hline F-MSV-MSSV2-SG1, F-MSV-MSSV3-SG1, RESPWR & 2 & & 1 & \\
\hline F-MSV-MSSV2-SG2, F-MSV-MSSV3-SG2, RESPWR & 2 & & 1 & \\
\hline F-MSV-MSSV1-SG1, F-MSV-MSSV4-SG1, RESPWR & 2 & & 1 & \\
\hline F-MSV-MSSV2-SG2, F-MSV-MSSV4-SG2, RESPWR & 2 & & 1 & \\
\hline F-MSV-MSSV1-SG2, F-MSV-MSSV4-SG2, RESPWR & 2 & & 1 & \\
\hline F-MSV-MSSV3-SG2, F-MSV-MSSV4-SG2, RESPWR & 2 & & 1 & \\
\hline F-MSV-MSSV1-SG1, F-MSV-MSSV2-SG1, RESPWR & 2 & & 1 & \\
\hline F-MSV-MSSV2-SG1, F-MSV-MSSV4-SG1, RESPWR & 2 & & 1 & \\
\hline
\end{tabular}


Table C.7 (cont.)

\begin{tabular}{||l|c|c|c|c||}
\hline Initiating Event - Loss of Class IV Power & \multicolumn{2}{|l||}{ Sequence: LOP-AQ } \\
\hline Sequence Level Cut Sets & $\begin{array}{c}\text { Conponent } \\
\text { Failures }\end{array}$ & $\begin{array}{c}\text { Human } \\
\text { Erron }\end{array}$ & $\begin{array}{c}\text { Support } \\
\text { Syatem } \\
\text { Failure }\end{array}$ & $\begin{array}{c}\text { Determinant } \\
\text { Faiure ? }\end{array}$ \\
\hline F-AFW-DV, RESPWR & 1 & & 1 & \\
\hline F-AFW-DIESEL, RESPWR & 1 & & 1 & \\
\hline F-AFW-PMP, RESPWR & 1 & & 1 & \\
\hline
\end{tabular}

\begin{tabular}{||l|c|c|c|c||}
\hline \multicolumn{1}{|l|}{ Initiating Event - Loss of Class IV Power } & \multicolumn{2}{l||}{ Sequence: LOP-AR } \\
\hline \multicolumn{1}{|l|}{ Sequence Level Cut Sets } & $\begin{array}{c}\text { Component } \\
\text { Fuilures }\end{array}$ & $\begin{array}{c}\text { Humen } \\
\text { Errors }\end{array}$ & $\begin{array}{c}\text { Support } \\
\text { System } \\
\text { Failures }\end{array}$ & $\begin{array}{c}\text { Delerminant } \\
\text { Faiture ? }\end{array}$ \\
\hline RESPWR, S-EL-II-1-O & & & 2 & \\
\hline RESPWR, S-PCS & & & 2 & \\
\hline F-BCS-CNV1-TK, F-BCS-CNV2, RESPWR & 2 & & 1 & \\
\hline F-BCS-CNV1-TK, RESPWR, S-EL-II-1-E & 1 & & 2 & \\
\hline F-BCS-CNV1, F-BCS-CNV1-TK, RESPWR & 2 & & 1 & \\
\hline F-BCS-CNV1-TK, RESPWR, S-AIR & 1 & & 2 & \\
\hline
\end{tabular}


Table C.8 Loss of essential power supply events sequence categorization: representative initiating event - lass of Class IV power

\begin{tabular}{|c|c|c|c|c|c|c|c|}
\hline \multicolumn{2}{|c|}{ Specific Initiator } & \multicolumn{2}{|c|}{$\begin{array}{c}\text { Loss of Class } I V \\
\text { power }\end{array}$} & \multicolumn{2}{|c|}{$\begin{array}{l}\text { Loss of station } \\
\text { electric load }\end{array}$} & \multicolumn{2}{|c|}{$\begin{array}{c}\text { Offsite power } \\
\text { lost }\end{array}$} \\
\hline \multicolumn{2}{|c|}{ IE Frequency } & \multicolumn{2}{|c|}{$1 \times 10^{-2}$} & \multicolumn{2}{|c|}{$1 \times 10^{-1}$} & \multicolumn{2}{|c|}{$1 \times 10^{-6}$} \\
\hline Sequence & Determinant Failures & $\overline{B i n}$ & Category & Bin & Category & Bin & Category \\
\hline LOP-A & NA & $\mathrm{A}$ & EC-I & $A$ & EC-I & $\mathbf{A}$ & EC-I \\
\hline LOP-B & 2 valves & $\mathrm{C}$ & EC-III & $\mathrm{C}$ & EC-III & $\bar{C}$ & EC-III \\
\hline LOP-C & $\geq 3$ failures & $\mathrm{D}$ & EC-IV & $\mathrm{D}$ & EC-IV & $\mathrm{D}$ & EC-IV \\
\hline LOP-D & $\geq 3$ failures & $\mathrm{D}$ & EC-IV & $\bar{D}$ & EC-IV & $\bar{D}$ & EC-IV \\
\hline LOP-E & $\geq 3$ failures & $\mathrm{D}$ & EC-IV & $\bar{D}$ & EC-IV & $\bar{D}$ & EC-IV \\
\hline LOP-F & $\begin{array}{l}2 \text { valves and/or pumps, } \\
\text { human error and level } \\
\text { indication }\end{array}$ & $\mathrm{C}$ & EC-III & C & EC-III & C & EC-III \\
\hline LOP-G & $\geq 3$ failures & $\mathrm{D}$ & EC-IV & $\mathrm{D}$ & EC-IV & $\bar{D}$ & EC-IV \\
\hline LOP-H & $\geq 3$ failures & $\mathrm{D}$ & EC-IV & $\bar{D}$ & EC-IV & $\mathrm{D}$ & EC-IV \\
\hline LOP-I & $\geq 3$ failures & $\mathrm{D}$ & EC-IV & $\mathrm{D}$ & EC-IV & $\mathrm{D}$ & EC-IV \\
\hline LOP-J & $\geq 3$ failures & $\mathrm{D}$ & EC-IV & $\bar{D}$ & EC-IV & $\bar{D}$ & EC-IV \\
\hline LOP-K & $\geq 3$ failures & $\mathrm{D}$ & EC-IV & $\mathrm{D}$ & EC-IV & $D$ & EC-IV \\
\hline LOP-L & $\geq 3$ failures & $D$ & EC-IV & $\mathrm{D}$ & EC-IV & $\mathrm{D}$ & EC-IV \\
\hline LOP-M & $\geq 3$ failures & $\mathrm{D}$ & EC-IV & $\bar{D}$ & EC-IV & D & EC-IV \\
\hline LOP-N & valve & $\mathrm{B}$ & EC-I & $\mathrm{B}$ & EC-I & $\mathrm{B}$ & EC-I \\
\hline LOP-O & 23 failures & D & EC-IV & $\mathrm{D}$ & EC-IV & $\mathrm{D}$ & EC-IV \\
\hline LOP-P & 23 failures & $\mathrm{D}$ & EC-IV & $\bar{D}$ & EC-IV & $\mathrm{D}$ & EC-IV \\
\hline LOP-Q & $\geq 3$ failures & $D$ & EC-IV & $\bar{D}$ & EC-IV & $\mathrm{D}$ & EC-IV \\
\hline LOP-R & $\geq 3$ failures & $\bar{D}$ & EC-IV & D & EC-IV & $\mathrm{D}$ & EC-IV \\
\hline LOP-S & $\geq 3$ failures & $\mathrm{D}$ & EC-IV & $\mathrm{D}$ & EC-IV & $\mathrm{D}$ & EC-IV \\
\hline LOP-T & $\geq 3$ failures & D & EC-IV & $\bar{D}$ & EC-IV & D & EC-IV \\
\hline LOP-U & $\geq 3$ failures & $D$ & EC-IV & $\mathrm{D}$ & EC-IV & $\mathrm{D}$ & EC-IV \\
\hline LOP-V & $\geq 3$ failures & D & EC-IV & $D$ & EC-IV & $\mathrm{D}$ & EC-IV \\
\hline LOP-W & $\geq 3$ failures & $\mathrm{D}$ & EC-IV & D & EC-IV & $\mathrm{D}$ & EC-IV \\
\hline LOP-X & $\geq 3$ failures & $\mathrm{D}$ & EC-IV & $\mathrm{D}$ & EC-IV & $\mathrm{D}$ & EC-IV \\
\hline LOP-Y & $\geq 3$ failures & $\mathrm{D}$ & EC-IV & $\mathrm{D}$ & EC-IV & $D$ & EC-IV \\
\hline LOP-Z & $\geq 3$ failures & $\mathrm{D}$ & EC-IV & $D$ & EC-IV & $D$ & EC-IV \\
\hline LOP-AA & support system & $\mathrm{C}$ & EC-III & $\mathrm{C}$ & EC-III & C & EC-III \\
\hline LOP-AB & 23 failures & $\mathrm{D}$ & EC-IV & $\mathrm{D}$ & EC-IV & $\mathrm{D}$ & EC-IV \\
\hline LOP-AC & $\geq 3$ failures & $\mathrm{D}$ & EC-IV & $\mathrm{D}$ & EC-IV & D & EC-IV \\
\hline LOP-AD & $\geq 3$ failures & $D$ & EC-IV & D & EC-IV & $\mathrm{D}$ & EC-IV \\
\hline LOP-AE & $\geq 3$ failures & $\mathrm{D}$ & EC-IV & $\bar{D}$ & EC-IV & $\mathrm{D}$ & EC-IV \\
\hline LOP-AF & $\geq 3$ failures & $\mathrm{D}$ & EC-IV & $\mathrm{D}$ & EC-IV & D & EC-IV \\
\hline LOP-AG & $\geq 3$ failures & $\mathrm{D}$ & EC-IV & $\mathrm{D}$ & EC-IV & $\mathrm{D}$ & EC-IV \\
\hline LOP-AH & $\geq 3$ failures & $\mathrm{D}$ & EC-IV & $\mathrm{D}$ & EC-IV & $\bar{D}$ & EC-IV \\
\hline LOP-AI & $\geq 3$ failures & $\mathrm{D}$ & EC-IV & $\mathrm{D}$ & EC-IV & $\mathrm{D}$ & EC-IV \\
\hline LOP-AJ & $\geq 3$ failures & $D$ & EC-IV & $\mathrm{D}$ & EC-IV & $D$ & EC-IV \\
\hline LOP-AK & support system & $\mathrm{C}$ & EC-III & $\mathrm{C}$ & EC-III & $\mathrm{C}$ & EC-III \\
\hline LOP-AL & $\geq 3$ failures & $\mathrm{D}$ & EC-IV & $\mathrm{D}$ & EC-IV & $\mathrm{D}$ & EC-IV \\
\hline
\end{tabular}


Tabie C.8 (cont.)

\begin{tabular}{|c|c|c|c|c|c|c|c|}
\hline \multicolumn{2}{|c|}{ Specific Initiator } & \multicolumn{2}{|c|}{$\begin{array}{c}\text { Loss of Class IV } \\
\text { power }\end{array}$} & \multicolumn{2}{|c|}{$\begin{array}{l}\text { Loss of station } \\
\text { electric load }\end{array}$} & \multicolumn{2}{|c|}{$\begin{array}{c}\text { Offsite power } \\
\text { lost }\end{array}$} \\
\hline \multicolumn{2}{|c|}{ IE Frequency } & \multicolumn{2}{|c|}{$1 \times 10^{-2}$} & \multicolumn{2}{|c|}{$1 \times 10^{-1}$} & \multicolumn{2}{|c|}{$1 \times 10^{-0}$} \\
\hline Sequence & Determinant Failures & Bin & Category & Bin & Category & Bin & Category \\
\hline LOP-AM & $\geq 3$ failures & $\mathrm{D}$ & EC-IV & $\mathrm{D}$ & EC-IV & $\mathrm{D}$ & EC-IV \\
\hline LOP-AN & $\geq 3$ failures & $\mathrm{D}$ & EC-IV & $\mathrm{D}$ & EC-IV & $\mathrm{D}$ & EC-IV \\
\hline LOP-AO & support system & $\mathrm{C}$ & EC-III & $\mathrm{C}$ & EC-III & $\mathrm{C}$ & EC-III \\
\hline LOP-AP & $\geq 3$ failures & $\mathrm{D}$ & EC-IV & $\bar{D}$ & EC-IV & $\mathrm{D}$ & EC-IV \\
\hline LOP-AQ & $\geq 3$ failures & $\mathrm{D}$ & EC-IV & $\bar{D}$ & EC-IV & $\mathrm{D}$ & EC-IV \\
\hline LOP-AR & $\geq 3$ failures & $\mathrm{D}$ & EC-IV & $\mathrm{D}$ & EC-IV & $\mathrm{D}$ & EC-IV \\
\hline LOP-FTSD-A & $\geq 3$ failures & $\mathrm{D}$ & EC-IV & $\mathrm{D}$ & EC-IV & $\mathrm{D}$ & EC-IV \\
\hline LOP-FTSD-B & $\geq 3$ failures & $\mathrm{D}$ & EC-IV & $\mathrm{D}$ & EC-IV & $\mathrm{D}$ & EC-IV \\
\hline LOP.FTSD-C & $\geq 3$ failures & $\mathrm{D}$ & EC-IV & $\mathrm{D}$ & EC-IV & $\mathrm{D}$ & EC-IV \\
\hline LOP-FTSD-D & 23 failures & $\mathrm{D}$ & EC-IV & $\mathrm{D}$ & EC-IV & $\mathrm{D}$ & EC-IV \\
\hline LOP-FTSD-E & $\geq 3$ failures & D & EC-IV & $\mathrm{D}$ & EC-IV & $\mathrm{D}$ & EC-IV \\
\hline LOP-FTSD-F & 23 failures & $\mathrm{D}$ & EC-IV & $\mathrm{D}$ & EC-IV & $\mathrm{D}$ & EC-IV \\
\hline LOP-FTSD-G & $\geq 3$ failures & $\mathrm{D}$ & EC-IV & $\mathrm{D}$ & EC-IV & $\mathrm{D}$ & EC-IV \\
\hline LOP-FTSD-H & 23 failurios & $\mathrm{D}$ & EC-1V & $\bar{D}$ & EC-IV & $\mathrm{D}$ & EC-IV \\
\hline LOP-FTSD-I & 23 fail. .: & $\mathrm{D}$ & EC-IV & $\overline{\mathrm{D}}$ & EC-IV & $\mathrm{D}$ & EC-IV \\
\hline LOP-FTSD-J & $\geq 3$ failures & $\mathrm{D}$ & EC-IV & $D$ & EC-IV & $\mathrm{D}$ & EC-IV \\
\hline LOP-FTSD-K & $\geq 3$ failures & $\mathrm{D}$ & EC-IV & $\bar{D}$ & EC-IV & $\mathrm{D}$ & EC-IV \\
\hline LOP-FTSD-L & $\geq 3$ failures & $\mathrm{D}$ & EC-IV & $\mathrm{D}$ & EC-IV & $\mathrm{D}$ & EC-IV \\
\hline LOP-FTSD-M & 23 failures & $\mathrm{D}$ & EC-IV & $\mathrm{D}$ & EC-IV & $\mathrm{D}$ & EC-IV \\
\hline LOP-FTSD-N & $\geq 3$ failures & $\mathrm{D}$ & EC-IV & $\mathrm{D}$ & EC-IV & $\mathrm{D}$ & EC-IV \\
\hline LOP-AEs & $\geq 3$ failures & $\mathrm{D}$ & EC-IV & $\bar{D}$ & EC-IV & $\mathrm{D}$ & EC-IV \\
\hline
\end{tabular}

.


Table C.8 (cont))

\begin{tabular}{|c|c|c|c|c|c|c|c|c|c|}
\hline \multirow{2}{*}{\multicolumn{2}{|c|}{ Specific Initiator }} & \multicolumn{2}{|c|}{$\begin{array}{l}\text { Loss of flow } \\
\text { in one or all } \\
\text { heat transfer } \\
\text { loops }\end{array}$} & \multicolumn{2}{|c|}{$\begin{array}{c}\text { Decreased } \\
\text { heat } \\
\text { transport } \\
\text { system flow }\end{array}$} & \multicolumn{2}{|c|}{$\begin{array}{l}\text { Pressurizer } \\
\text { anomalies } \\
\text { (high } \\
\text { pressure, low } \\
\text { pressure, } \\
\text { spray failure) }\end{array}$} & \multicolumn{2}{|c|}{$\begin{array}{l}\text { Deformation of } \\
\text { fuel channel } \\
\text { structure that } \\
\text { restricts coolant } \\
\text { flow }\end{array}$} \\
\hline & & & $10^{-1}$ & & $10^{-2}$ & \multicolumn{2}{|c|}{$1 \times 10^{2}$} & \multicolumn{2}{|c|}{$1 \times 10^{-3}$} \\
\hline Sequence & Determinant Failures & Bin & Category & Bin & Category & Bin & Category & Bin & Category \\
\hline LOP-A & $\mathrm{NA}$ & $\mathrm{A}$ & EC-I & $\mathbf{A}$ & EC-I & A & EC-I & $E$ & EC-II \\
\hline LOP-B & 2 values & $\mathbf{C}$ & EC-III & $\mathrm{C}$ & EC-III & $\mathrm{C}$ & EC-III & G & EC-III \\
\hline LOP-C & $\geq 3$ failures & $\bar{D}$ & EC-IV & $\mathrm{D}$ & EC-IV & $\mathrm{D}$ & EC-IV & $\mathbf{H}$ & EC-IV \\
\hline LOP-D & $\geq 3$ failures & D & EC-IV & $\mathrm{D}$ & EC-IV & $D$ & EC-IV & $\mathbf{H}$ & EC-IV \\
\hline LOP-E & $\geq 3$ failures & $\mathrm{D}$ & EC-IV & $\mathrm{D}$ & EC-IV & $\mathrm{D}$ & EC-IV & $\mathrm{H}$ & EC-IV \\
\hline LOP-F & $\begin{array}{l}2 \text { valves and/or } \\
\text { pumps, human error } \\
\text { and level indication }\end{array}$ & C & EC-III & C & EC-III & C & EC-III & $\mathrm{G}$ & EC-III \\
\hline LOP-G & $\geq 3$ failures & $\mathrm{D}$ & EC-IV & $\mathrm{D}$ & EC-IV & $\mathrm{D}$ & EC-IV & $\mathbf{H}$ & EC-IV \\
\hline LOP-H & $\geq 3$ failures & $\mathrm{D}$ & EC-IV & $\mathrm{D}$ & EC-IV & $\mathrm{D}$ & EC-IV & $\mathrm{H}$ & EC-IV \\
\hline LOP-I & $\geq 3$ failures & $\mathrm{D}$ & EC-IV & $\mathrm{D}$ & EC-IV & $\mathrm{D}$ & EC-IV & $\mathbf{H}$ & EC-IV \\
\hline LOP-J & $\geq 3$ failures & $\mathrm{D}$ & EC-IV & D & EC-IV & $\mathrm{D}$ & EC-IV & $\mathbf{H}$ & EC-IV \\
\hline LOP-K & $\geq 3$ failures & $\mathrm{D}$ & EC-IV & D & EC-IV & $\mathrm{D}$ & EC-IV & $\mathbf{H}$ & EC-IV \\
\hline LOP-I & $\geq 3$ failures & $\mathrm{D}$ & EC-IV & $\mathrm{D}$ & EC-IV & $\mathrm{D}$ & EC-IV & $\mathrm{H}$ & EC-IV \\
\hline LOP-M & 23 failures & $\mathrm{D}$ & EC-IV & $\mathrm{D}$ & EC-IV & $\mathrm{D}$ & EC-IV & $\mathrm{H}$ & EC-IV \\
\hline LOP-N & valve & $\mathrm{B}$ & EC-I & $\mathrm{B}$ & EC-I & B & EC-I & $F$ & EC-II \\
\hline LOP-O & $\geq 3$ failures & $\mathrm{D}$ & EC-IV & $\mathrm{D}$ & EC-IV & $D$ & EC-IV & $\mathbf{H}$ & EC-IV \\
\hline LOP-P & $\geq 3$ failures & $D$ & EC-IV & $\mathrm{D}$ & EC-IV & $\mathrm{D}$ & EC-IV & $\mathrm{H}$ & EC-IV \\
\hline LOP-Q & 23 failures & D & EC-IV & $\mathrm{D}$ & EC-IV & $\mathrm{D}$ & EC-IV & $\mathbf{H}$ & EC-IV \\
\hline LOP-R & $\geq 3$ failures & $\mathrm{D}$ & EC-IV & $D$ & EC-IV & $D$ & EC-IV & $\mathrm{H}$ & EC-IV \\
\hline LOP-S & $\geq 3$ failures & $\mathbf{D}$ & EC-IV & $\mathrm{D}$ & EC-IV & $\mathrm{D}$ & EC-IV & $\mathbf{H}$ & EC-IV \\
\hline LOP-T & $\geq 3$ failures & $\mathrm{D}$ & EC-IV & D & EC-IV & $\mathrm{D}$ & EC-IV & $\mathrm{H}$ & EC-IV \\
\hline LOP-U & 23 failures & $\mathrm{D}$ & EC-IV & D & EC-IV & D & EC-IV & $\mathbf{H}$ & EC-IV \\
\hline LOP-V & 23 failures & $\mathrm{D}$ & EC-IV & $\mathrm{D}$ & EC-IV & $\mathrm{D}$ & EC-IV & $\mathrm{H}$ & EC-IV \\
\hline LOP-W & 23 failures & $\mathrm{D}$ & EC-IV & $\mathrm{D}$ & EC-IV & D & EC-IV & $\mathbf{H}$ & EC-IV \\
\hline LOP-X & $\geq 3$ failures & $\mathrm{D}$ & EC-IV & $\mathrm{D}$ & EC-IV & $\mathrm{D}$ & EC-IV & $\mathrm{H}$ & EC-IV \\
\hline LOP-Y & $\geq 3$ failures & D & EC-IV & $\mathrm{D}$ & EC-IV & D & EC-IV & $\mathbf{H}$ & EC-IV \\
\hline LOP-Z & $\geq 3$ failures & $\mathrm{D}$ & EC-IV & D & EC-IV & D & EC-IV & $\mathbf{H}$ & EC-IV \\
\hline LOP-AA & support system & $\mathrm{C}$ & EC-III & $\mathrm{C}$ & EC-III & $\mathrm{C}$ & EC-III & $\mathbf{G}$ & EC-III \\
\hline LOP-AB & $\geq 3$ failures & $\mathrm{D}$ & EC-IV & $\mathrm{D}$ & EC-IV & $\mathrm{D}$ & EC-IV & $\mathbf{H}$ & EC-IV \\
\hline LOP-AC & $\geq 3$ failures & $\mathrm{D}$ & EC-IV & $\mathrm{D}$ & EC-IV & $\mathrm{D}$ & EC-IV & $\mathbf{H}$ & EC-IV \\
\hline LOP-AD & $\geq 3$ failures & $\mathrm{D}$ & EC-IV & $\mathrm{D}$ & EC-IV & $\mathrm{D}$ & EC-IV & $\mathbf{H}$ & EC-IV \\
\hline LOP-AE & $\geq 3$ failures & $\mathrm{D}$ & EC-IV & D & EC-IV & $\mathrm{D}$ & EC-IV & $\mathbf{H}$ & EC-IV \\
\hline LOP-AF & $\geq 3$ failures & $\mathrm{D}$ & EC-IV & $\mathrm{D}$ & EC-IV & $\mathrm{D}$ & EC-IV & $\mathbf{H}$ & EC-IV \\
\hline LOP-AG & $\geq 3$ failures & $D$ & EC-IV & $I$ & EC-IV & $\mathrm{D}$ & EC-IV & $\mathbf{H}$ & EC-IV \\
\hline LOP-AH & $\geq 3$ failures & D & EC-IV & $\mathrm{D}$ & EC-IV & $\overline{\mathbf{D}}$ & EC-TV & $\mathbf{n}$ & EC-IV \\
\hline
\end{tabular}


Table C.8 (cont.)

\begin{tabular}{|c|c|c|c|c|c|c|c|c|c|}
\hline \multirow{2}{*}{\multicolumn{2}{|c|}{ Specific Initiator }} & \multicolumn{2}{|c|}{$\begin{array}{l}\text { Loss of flow } \\
\text { in one or all } \\
\text { heat transfer } \\
\text { loops }\end{array}$} & \multicolumn{2}{|c|}{$\begin{array}{l}\text { Decreased } \\
\text { heat } \\
\text { transport } \\
\text { system flow }\end{array}$} & \multicolumn{2}{|c|}{$\begin{array}{l}\text { Pressurizer } \\
\text { anomalies } \\
\text { (high } \\
\text { pressure, low } \\
\text { pressure, } \\
\text { spray failure) }\end{array}$} & \multicolumn{2}{|c|}{$\begin{array}{l}\text { Deformation of } \\
\text { fuel channel } \\
\text { structure that } \\
\text { restricts coolant } \\
\text { flow }\end{array}$} \\
\hline & & & $10^{-1}$ & & $10^{-2}$ & & $10^{-2}$ & & $10^{-3}$ \\
\hline Sequence & Determinant Failures & Bin & Category & Bin & Category & Bin & Category & Bin & Category \\
\hline LOP-AI & $\geq 3$ failures & $\mathrm{D}$ & EC-IV & $\mathrm{D}$ & EC-IV & $\mathrm{D}$ & EC-IV & $\mathrm{H}$ & EC-IV \\
\hline LOP-AJ & $\geq 3$ failures & $\mathrm{D}$ & EC-IV & $\mathrm{D}$ & EC-IV & $\mathrm{D}$ & EC-IV & $\mathrm{H}$ & EC-IV \\
\hline LOP-AK & support system & $\mathrm{C}$ & EC-III & $\mathrm{C}$ & EC-III & $\mathrm{C}$ & EC-III & $G$ & EC-III \\
\hline LOP-AL & $\geq 3$ failures & $\mathrm{D}$ & EC-IV & $\mathrm{D}$ & EC-IV & $\mathrm{D}$ & EC-IV & $\mathrm{H}$ & EC-IV \\
\hline LOP-AM & $\geq 3$ failures & $\mathrm{D}$ & EC-IV & $\mathrm{D}$ & EC-IV & $\mathrm{D}$ & EC-IV & $\mathrm{H}$ & EC-IV \\
\hline LOP-AN & $\geq 3$ failures & $\mathrm{D}$ & EC-IV & $\mathrm{D}$ & EC-IV & $\mathrm{D}$ & EC-IV & $\mathrm{H}$ & EC-IV \\
\hline LOP-AO & support system & $\mathrm{C}$ & EC-III & $\mathrm{C}$ & EC-III & $\mathrm{C}$ & EC-III & $G$ & EC-III \\
\hline LOP-AP & $\geq 3$ failures & $\mathrm{D}$ & EC-IV & $\mathrm{D}$ & EC-IV & $\mathrm{D}$ & EC-IV & $\mathrm{H}$ & EC-IV \\
\hline LOP-AQ & $\geq 3$ failures & $\mathrm{D}$ & EC-IV & $\mathrm{D}$ & EC-IV & $\bar{D}$ & EC-IV & $\mathrm{H}$ & EC-IV \\
\hline LOP-AR & $\geq 3$ failures & $\bar{D}$ & EC-IV & $\mathrm{D}$ & EC-IV & $\mathrm{D}$ & EC-IV & $\mathrm{H}$ & EC-IV \\
\hline LOP-FTSD-A & $\geq 3$ failures & $\mathrm{D}$ & EC-IV & $\bar{D}$ & EC-IV & $\bar{D}$ & EC-IV & $\mathrm{H}$ & EC-IV \\
\hline LOP-FTSD-B & $\geq 3$ failures & $\mathrm{D}$ & EC-IV & $\mathrm{D}$ & EC-IV & $\mathrm{D}$ & EC-IV & $\mathrm{H}$ & EC-IV \\
\hline LOP-FTSD-C & $\geq 3$ failures & $\mathrm{D}$ & EC-IV & $\mathrm{D}$ & EC-IV & $D$ & EC-IV & $\mathrm{H}$ & EC-IV \\
\hline LOP-FTSD-D & $\geq 3$ failures & $\mathrm{D}$ & EC-IV & $\mathrm{D}$ & EC-IV & $\mathrm{D}$ & EC-IV & $\mathrm{H}$ & EC-IV \\
\hline LOP-FTSD-E & $\geq 3$ failures & $\mathrm{D}$ & EC-IV & $\mathrm{D}$ & EC-IV & $\mathrm{D}$ & EC-IV & $\mathrm{H}$ & EC-IV \\
\hline LOP-FTSD-F & $\geq 3$ failures & $\mathrm{D}$ & EC-IV & $\mathrm{D}$ & EC-IV & $\mathrm{D}$ & EC-IV & $\mathrm{H}$ & EC-IV \\
\hline LOP-FTSD-G & $\geq 3$ failures & $\mathrm{D}$ & EC-IV & $\mathrm{D}$ & EC-IV & $\mathrm{D}$ & EC-IV & $\mathrm{H}$ & EC-IV \\
\hline LOP-FTSD-H & $\geq 3$ failures & $\mathrm{D}$ & EC-IV & $\mathrm{D}$ & EC-IV & $\bar{D}$ & EC-IV & $\mathrm{H}$ & EC-IV \\
\hline LOP-FTSD-I & $\geq 3$ failures & $\mathrm{D}$ & EC-IV & $\mathrm{D}$ & EC-IV & $\mathrm{D}$ & EC-IV & $\mathrm{H}$ & EC-IV \\
\hline LOP-FTSD-J & $\geq 3$ failures & $\mathrm{D}$ & EC-IV & $\mathrm{D}$ & EC-IV & $\mathrm{D}$ & EC-IV & $\mathrm{H}$ & EC-IV \\
\hline LOP-FTSD-K & $\geq 3$ failures & $\mathrm{D}$ & EC-IV & $\mathrm{D}$ & EC-IV & $\mathrm{D}$ & EC-IV & $\mathrm{H}$ & EC-IV \\
\hline LOP-FTSD-L & $\geq 3$ failures & $\mathrm{D}$ & EC-IV & $\mathrm{D}$ & EC-IV & $I$ & EC-IV & $\mathrm{H}$ & EC-IV \\
\hline LOP-FTSD-M & $\geq 3$ failures & $\mathrm{D}$ & EC-IV & $\mathrm{D}$ & EC-IV & $\mathrm{D}$ & EC-IV & $\mathrm{H}$ & EC-IV \\
\hline LOP-FTSD-N & $\geq 3$ failures & $\mathrm{D}$ & EC-IV & $\mathrm{D}$ & EC-IV & $\bar{D}$ & EC-IV & $\mathrm{H}$ & EC-IV \\
\hline LOP-AS & $\geq 3$ failures & $\mathrm{D}$ & EC-IV & D & EC-IV & $\mathrm{D}$ & EC-IV & $\mathrm{H}$ & EC-IV \\
\hline
\end{tabular}


Table C.9 Feedwater piping break in the reactor building sequence cut sets

\begin{tabular}{|c|c|c|c|c|c|}
\hline \multirow{2}{*}{\multicolumn{2}{|c|}{\begin{tabular}{|c|} 
Initiating Event $-\begin{array}{l}\text { Feedwater Piping Break in } \\
\text { the Reactor Building }\end{array}$ \\
Sequence Level Cut Sets \\
\end{tabular}}} & \multicolumn{4}{|c|}{ Sequence: $L O F W R B-A$} \\
\hline & & $\begin{array}{c}\text { Component } \\
\text { Failures }\end{array}$ & $\begin{array}{l}\text { Human } \\
\text { Errors }\end{array}$ & $\begin{array}{l}\text { Support } \\
\text { System } \\
\text { Failures }\end{array}$ & $\begin{array}{l}\text { Determinant } \\
\text { Failure? }\end{array}$ \\
\hline NONE & & NA & $\mathrm{NA}$ & $\mathrm{NA}$ & $\mathrm{NA}$ \\
\hline
\end{tabular}

\begin{tabular}{|c|c|c|c|c|}
\hline Initiating Event - Feedwater Piping Break in & \multicolumn{4}{|c|}{ Sequence: $L O F W R B-B$} \\
\hline Sequence Level Cut Sets & $\begin{array}{c}\text { Component } \\
\text { Failures }\end{array}$ & $\begin{array}{l}\text { Human } \\
\text { Errors }\end{array}$ & $\begin{array}{l}\text { Support } \\
\text { System } \\
\text { Failures }\end{array}$ & $\begin{array}{l}\text { Determinant } \\
\text { Failure? }\end{array}$ \\
\hline F-ASD-ASD1, F-ASD-ASD2 & 2 & & & $\mathrm{Y}$ \\
\hline F-ASD-ASD2, S-EL-II-2-O & 1 & & 1 & \\
\hline F-ASD-ASD1, S-EL-II-2-E & 1 & & 1 & \\
\hline
\end{tabular}

\begin{tabular}{||l|c|c|c|c||}
\hline \hline $\begin{array}{l}\text { Initiating Event - Feedwater Piping Break in } \\
\text { the Reactor Building }\end{array}$ & \multicolumn{4}{|l||}{ Sequence: LOFWRB-F } \\
\hline \hline \multicolumn{1}{|l|}{ Sequence Level Cut Sets } & $\begin{array}{c}\text { Component } \\
\text { Failures }\end{array}$ & $\begin{array}{c}\text { Human } \\
\text { Errors }\end{array}$ & $\begin{array}{c}\text { Support } \\
\text { system } \\
\text { Failures }\end{array}$ & $\begin{array}{c}\text { Determinant } \\
\text { Failure ? }\end{array}$ \\
\hline F-FW2-HE, F-FW2-LI-TK & 1 & 1 & & $\mathrm{Y}$ \\
\hline F-FW2-PMP1, F-FW2-PMP2 & 2 & & & $\mathrm{Y}$ \\
\hline F-FW2-IV1, F-FW2-IV2 & 2 & & & $\mathrm{Y}$ \\
\hline F-FW2-IV2, F-FW2-FMP1 & 2 & & & $\mathrm{Y}$ \\
\hline F-FW2-IV1, F-FW2-OV2 & 2 & & & $\mathrm{Y}$ \\
\hline F-FW2-OV2, F-FW2-PMP1 & 2 & & & $\mathrm{Y}$ \\
\hline
\end{tabular}


Table C.9 (cont.)

\begin{tabular}{|c|c|c|c|}
\hline F-FW2-IV1, F-FW2-PMP2 & 2 & & $\mathbf{Y}$ \\
\hline F-FW2-OV1, F-FW2-PMP2 & 2 & & $\mathbf{Y}$ \\
\hline F-FW2-OV1, F-FW2-OV2 & 2 & & $\mathbf{Y}$ \\
\hline F-FW2-IV2, F-FW2-OV1 & 2 & & $\mathbf{Y}$ \\
\hline F-FW2-OV2, S-EL-III-2-O & 1 & 1 & \\
\hline F-FW2-IV2, S-EL-III-2-O & 1 & 1 & \\
\hline F-FW2-PMP2, S-EL-III-2-O & 1 & 1 & \\
\hline F-FW2-OV1, S-EL-III-2-E & 1 & 1 & \\
\hline F-FW2-PMP1, S-EL-III-2-E & 1 & 1 & \\
\hline F-FW2-IV1, S-EL-III-2-E & 1 & 1 & \\
\hline F-FW2-ISV1-SG1, F-FW2-ISV1-SG2, S-EL-II-2-E & 2 & 1 & \\
\hline F-FW2-ISV2-SG1, F-FW2-ISV2-SG2, S-EL-II-2-O & 2 & 1 & \\
\hline
\end{tabular}

\begin{tabular}{|c|c|c|c|c|}
\hline \multirow{2}{*}{$\frac{\text { Initiating Event } \begin{array}{l}\text { - Feedwater Piping Break in } \\
\text { the Reactor Building }\end{array}}{\text { Sequence Level Cut Sets }}$} & \multicolumn{4}{|c|}{ Sequence: $L O F W R B-G$} \\
\hline & $\begin{array}{l}\text { Component } \\
\text { Failures }\end{array}$ & $\begin{array}{l}\text { Human } \\
\text { Erron }\end{array}$ & $\begin{array}{l}\text { Support } \\
\text { System } \\
\text { Failurea }\end{array}$ & $\begin{array}{l}\text { Delerminent } \\
\text { Fuilure ? }\end{array}$ \\
\hline S-PCS & & & 1 & $\mathbf{Y}$ \\
\hline F-FW2-HE, F-FW2-LI-TK, F-SDC-HE & 1 & 2 & & \\
\hline S-EL-III-2-E, S-EL-III-2-O & & & 2 & \\
\hline S-EL-II-2-E, S-EL-II-2-O & & & 2 & \\
\hline F-FW2-OV1, F-FW2-OV2, F-SDC-HE & 2 & 1 & & \\
\hline F-FW2-IV2, F-FW2-PMP1, F-SDC-HE & 2 & 1 & & \\
\hline F-FW2-IV2, F-FW2-OV1, F-SDC-HE & 2 & 1 & & \\
\hline F-FW2-OV2, F-FW2-PMP1, F-SDC-HE & 2 & 1 & & \\
\hline F-FW2-OV1, F-FW2-PMP2, F-SDC-HE & 2 & 1 & & \\
\hline F-FW2-IV1, F-FW2-OV2, F-SDC-HE & 2 & 1 & & \\
\hline F-FW2-PMP1, F-FW2-PMP2, F-SDC-HE & 2 & 1 & & \\
\hline F-FW2-IV1, F-FW2-PMP2, F-SDC-HE & 2 & 1 & & \\
\hline F-FW2-IV1, F-FW2-IV2, F-SDC-HE & 2 & 1 & & \\
\hline F-FW2-OV2, F-SDC-HE, S-EL-III-2-O & 1 & 1 & 1 & \\
\hline F-FW2-PMP2, F-SDC-HE, S-EL-III-2-O & 1 & 1 & 1 & \\
\hline F-FW2-IV2, F-SDC-HE, S-EL-III-2-O & 1 & 1 & 1 & \\
\hline F-FW2-OV1, F-SDC-PMP1, S-EL-III-2-E & 2 & & 1 & \\
\hline
\end{tabular}


Table C.9 (cont.)

\begin{tabular}{||l|c|c|c||}
\hline F-FW2-IV2, F-SDC-PMP2, S-EL-III-2-O & 2 & & 1 \\
\hline F-FW2-IV1, F-SDC-PMP1, S-EL-III-2-E & 2 & & 1 \\
\hline F-FW2-OV2, F-SDC-PMP2, S-EL-III-2-O & 2 & 1 & 1 \\
\hline F-FW2-IV1, F-SDC-HE, S-EL-III-2-E & 1 & 1 & 1 \\
\hline F-FW2-OV1, F-SDC-HE, S-EL-III-2-E & 1 & 1 & 1 \\
\hline F-FW2-PMP1, F-SDC-HE, S-EL-III-2-E & 1 & 1 & 1 \\
\hline F-FW2-PMP1, F-SDC-PMP1, S-EL-III-2-E & 2 & & 1 \\
\hline F-FW2-PMP2, F-SDC-PMP2, S-EL-III-2-O & 2 & & 1 \\
\hline
\end{tabular}

\begin{tabular}{|c|c|c|c|c|}
\hline \multirow{2}{*}{$\begin{array}{c}\text { Initiating Event - Feedwater Piping Break in } \\
\text { the Reactor Building }\end{array}$} & \multicolumn{4}{|c|}{ Sequence: $L O F W R B-H$} \\
\hline & $\begin{array}{l}\text { Component } \\
\text { Failures }\end{array}$ & $\begin{array}{c}\text { Human } \\
\text { Errors }\end{array}$ & $\begin{array}{l}\text { Support } \\
\text { System } \\
\text { Failures }\end{array}$ & $\begin{array}{l}\text { Determinent } \\
\text { Frilure? }\end{array}$ \\
\hline S-EL-III-1-O, S-PCS & & & 2 & \\
\hline F-MCS-ISV-FC, S-PCS & 1 & & 1 & \\
\hline F-MCS-PMP1, S-PCS & 1 & & 1 & \\
\hline S-PCS, S-RCW & & & 2 & \\
\hline S-EL-III-1-E, S-PCS & & & 2 & \\
\hline F-MCS-PMP2, S-PCS & 1 & & 1 & \\
\hline F-MCS-PMP1, S-EL-III-2-E, S-EL-III-2-O & 1 & & 2 & \\
\hline F-MCS-PMP2, S-EL-III-2-E, S-EL-III-2-O & 1 & & 2 & \\
\hline S-EL-III-1-E, S-EL-III-2-E, S-EL-III-2-O & & & 3 & \\
\hline ن-EL-II-1-O, S-EL-III-2-E, S-EL-III-2-O & & & 3 & \\
\hline S-EL-III-2-E, S-EL-III-2-O, S-RCW & & & 3 & \\
\hline F-MCS-ISV-FC, S-EL-III-2-E, S-EL-III-2-O & 1 & & 2 & \\
\hline S-EL-II-2-E, S-EL-II-2-O, S-EL-III-1-E & & & 3 & \\
\hline F-MCS-PMP2, S-EL-II-2-E, S-EL-II-2-O & 1 & & 2 & \\
\hline F-MCS-ISV-FC, S-ELL-II-2-E, S-EL-II-2-O & 1 & & 2 & \\
\hline F-MCS-PMP1, S-EL-II-2-E, S-EL-II-2-O & 1 & & 2 & \\
\hline S-EL-II-2-E, S-EL-II-2-O, S-RCW & & & 3 & \\
\hline S-EL-II-2-E, S-EL-II-2-O, S-EL-III-1-O & & & 3 & \\
\hline
\end{tabular}


Table C.9 (cont.)

\begin{tabular}{|c|c|c|c|c|}
\hline \multirow{2}{*}{$\begin{array}{c}\text { Initiating Event }-\begin{array}{l}\text { Feedwater Piping Break in } \\
\text { the Reactor Building }\end{array} \\
\text { Sequence Level Cut Sets }\end{array}$} & \multicolumn{4}{|c|}{ Sequence: LOFWRB-I } \\
\hline & $\begin{array}{c}\text { Component } \\
\text { Failures }\end{array}$ & $\begin{array}{c}\text { Human } \\
\text { Errons }\end{array}$ & $\begin{array}{l}\text { Support } \\
\text { System } \\
\text { Failures }\end{array}$ & $\begin{array}{l}\text { Determinant } \\
\text { Failure? }\end{array}$ \\
\hline F-ISO-HE & & 1 & & $\mathbf{Y}$ \\
\hline F-ISO-VLV-FO & 1 & & & $\mathbf{Y}$ \\
\hline F-ISO-SIG & 1 & & & $\mathbf{Y}$ \\
\hline S-EL-II-1-O & & & 1 & \\
\hline S-AIR & & & 1 & \\
\hline
\end{tabular}

\begin{tabular}{|c|c|c|c|c|}
\hline \multirow{2}{*}{$\begin{array}{c}\text { Initiating Event }-\begin{array}{l}\text { Feedwater Piping Break in } \\
\text { the Reactor Building }\end{array} \\
\text { Sequence Level Cut Sets }\end{array}$} & \multicolumn{4}{|c|}{ Sequence: $L O F W R B-J$} \\
\hline & $\begin{array}{l}\text { Component } \\
\text { Failures }\end{array}$ & $\begin{array}{l}\text { Humana } \\
\text { Error }\end{array}$ & $\begin{array}{l}\text { Support } \\
\text { System } \\
\text { Failures }\end{array}$ & $\begin{array}{l}\text { Determinent } \\
\text { Failure? }\end{array}$ \\
\hline F-ISO-HE, F-SDC-HE & & 2 & & $\mathbf{Y}$ \\
\hline F-ISO-HE, S-PCS & & 1 & 1 & \\
\hline F-ISO-VLV-FO, F-SDC-HE & 1 & 1 & & $\mathbf{Y}$ \\
\hline F-SDC-HE, S-EL-II-1-O & & 1 & 1 & \\
\hline F-ISO-SIG, F-SDC-HE & 1 & 1 & & $\mathbf{Y}$ \\
\hline F-SDC-HE, S-AIR & & 1 & 1 & \\
\hline S-EL-II-1-0, S-PCS & & & 2 & \\
\hline F-ISO-VLV-FO, S-PCS & 1 & & 1 & \\
\hline F-ISO-SIG, S-PCS & 1 & & 1 & \\
\hline F-ISO-HE, F-SDC-IISV1, F-SDC-IISV2 & 2 & 1 & & \\
\hline F-ISO-HE, F-SDC-PMP1, F-SDC-PMP2 & 2 & 1 & & \\
\hline F-ISO-HE, F-SDC-OISV1, F-SDC-OISV2 & 2 & 1 & & \\
\hline S-AIR, S-PCS & & & 2 & \\
\hline F-ISO-HE, F-SDC-OISV2, S-EL-II-2-O & 1 & 1 & 1 & \\
\hline F-1SO-HE, F-SDC-PMP2, S-EL-III-2-O & 1 & 1 & 1 & \\
\hline F-ISO-HE, F-SDC-PMP1, S-EL-III-2-E & 1 & 1 & 1 & \\
\hline F-ISO-HE, F-SDC-IISV1, S-EL-II-2-E & 1 & 1 & 1 & \\
\hline F-ISO-HE, F-SDC-IISV2, S-EL-II-2-O & 1 & 1 & 1 & \\
\hline F-ISO-HE, F-SDC-OISV1, S-EL-II-2-E & 1 & 1 & 1 & \\
\hline F-SDC-PMP1, F-SDC-PMP2, S-EL-11-1-O & 2 & & 1 & \\
\hline
\end{tabular}


Table C.9 (cont.)

\begin{tabular}{|c|c|c|c|c|}
\hline F-ISO-SIG, F-SDC-OISV1, F-SDC-OISV2 & 3 & & & \\
\hline F-SDC-OISV1, F-SDC-OISV2, S-EL-II-1-O & 2 & & 1 & \\
\hline F-ISO-VLV-FO, F-SDC-OISV1, F-SDC-OISV2 & 3 & & & \\
\hline F-ISO-SIG, F-SDC-IISV1, F-SDC-IISV2 & 3 & & & \\
\hline F-ISO-SIG, F-SDC-PMP1, F-SDC-PMP2 & 3 & & & \\
\hline F-SDC-IISV1, F-SDC-IISV2, S-EL-II-1-O & 2 & & 1 & \\
\hline F-ISO-VLV-FO, F-SDC-PMP1, F-SDC-PMP2 & 3 & & & \\
\hline F-ISO-VLV-FO, F-SDC-IISV1, F-SDC-IISV2 & 3 & & & \\
\hline F-ISO-HE, S-EL-III-2-E, S-EL-III-2-O & & 1 & 2 & \\
\hline F-ISO-HE, S-EL-II-2-E, S-EL-II-2-O & & 1 & 2 & \\
\hline F-ISO-HE, F-SDC-HX1, F-SDC-HX2 & 2 & 1 & & \\
\hline F-ISO-VLV-FO, F-SDC-PMP1, S-EL-III-2-E & 2 & & 1 & \\
\hline F-SDC-PMP2, S-EL-II-1-O, S-EL-III-2-O & 1 & & 2 & \\
\hline F-ISO-SIG, F-SDC-PMP1, S-EL-III-2-E & 2 & & 1 & \\
\hline F-SDC-IISV2, S-EL-II-1-O, S-EL-II-2-O & 1 & & 2 & \\
\hline F-SDC-PMP1, F-SDC-PMP2, S-AIR & 2 & & 1 & \\
\hline F-ISO-VLV-FO, F-SDC-PMP2, S-EL-III-2-O & 2 & & 1 & \\
\hline F-SDC-PMP1, S-EL-II-1-O, S-EL-III-2-E & 1 & & 2 & \\
\hline F-ISO-SIG, F-SDC-OISV1, S-EL-II-2-E & 2 & & 1 & \\
\hline F-SDC-IISV1, F-SDC-IISV2, S-AIR & 2 & & 1 & \\
\hline F-ISO-SIG, F-SDC-IISV1, S-EL-II-2-E & 2 & & 1 & \\
\hline F-SDC-OISV2, S-EL-II-1-O, S-EL-II-2-O & 1 & & 2 & \\
\hline F-ISO-VLV-FO, F-SDC-IISV1, S-EL-II-2-E & 2 & & 1 & \\
\hline F-SDC-IISV1, S-EL-II-1-O, S-EL-II-2-E & 1 & & 2 & \\
\hline F-ISO-VLV-FO, F-SDC-IISV2, S-EL-II-2-O & 2 & & 1 & \\
\hline F-ISO-SIG, F-SDC-IISV2, S-EL-II-2-O & 2 & & 1 & \\
\hline F-ISO-VLV-FO, F-SDC-OISV2, S-EL-II-2-O & 2 & & 1 & \\
\hline F-ISO-SIG, F-SDC-OISV2, S-EL-II-2-O & 2 & & 1 & \\
\hline F-ISO-VLV-FO, F-SDC-OISV1, S-EL-II-2-E & 2 & & 1 & \\
\hline F-ISO-SIG, F-SDC-PMP2, S-EL-III-2-O & 2 & & 1 & \\
\hline F-SDC-OISV1, S-EL-II-1-O, S-EL-II-2-E & 1 & & 2 & \\
\hline F-SDC-OISV1, F-SDC-OISV2, S-AIR & 2 & & 1 & \\
\hline F-ISO-SIG, S-EL-II-2-E, S-EL-II-2-O & 1 & & 2 & \\
\hline F-ISO-VLV-FO, S-EL-II-2-E, S-EL-II-2-O & 1 & & 2 & \\
\hline
\end{tabular}


Table C.9 (cont.)

\begin{tabular}{|c|c|c|c|}
\hline F-ISO-SIG, F-SDC-HX1, F-SDC-HX2 & 3 & & \\
\hline F-ISO-VLV-FO, F-SDC-HX1, F-SDC-HX2 & 3 & & \\
\hline F-SDC-HX1, F-SDC-HX2, S-EL-II-1-O & 2 & 1 & \\
\hline S-EL-II-1-O, S-EL-III-2-E, S-EL-III-2-O & & 3 & \\
\hline F-SDC-OISV2, S-AIR, S-EL-II-2-O & 1 & 2 & \\
\hline F-SDC-OISV1, S-AIR, S-EL-II-2-E & 1 & 2 & \\
\hline F-SDC-IISV2, S-AIR, S-EL-II-2-O & 1 & 2 & \\
\hline F-ISO-SIG, S-EL-III-2-E, S-EL-III-2-O & 1 & 2 & \\
\hline F-SDC-IISV1, S-AIR, S-EL-II-2-E & 1 & 2 & \\
\hline S-EL-II-1-O, S-EL-II-2-E, S-EL-II-2-O & & 3 & \\
\hline F-ISO-VLV-FO, S-EL-III-2-E, S-EL-III-2-O & 1 & 2 & \\
\hline F-SDC-PMP1, S-AIR, S-EL-III-2-E & 1 & 2 & \\
\hline F-SDC-PMP2, S-AIR, S-EL-III-2-O & 1 & 2 & \\
\hline S-AIR, S-EL-III-2-E, S-EL-III-2-O & & 3 & \\
\hline S-AIR, S-EL-II-2-E, S-EL-II-2-O & & 3 & \\
\hline F-SDC-HX1, F-SDC-HX2, S-AIR & 2 & 1 & \\
\hline
\end{tabular}

\begin{tabular}{|c|c|c|c|c|}
\hline \multirow{2}{*}{$\begin{array}{c}\text { Initiating Event } \begin{array}{l}\text { Feedwater Piping Break in } \\
\text { the Reactor Building }\end{array} \\
\text { Sequence Level Cut Sets }\end{array}$} & \multicolumn{4}{|c|}{ Sequence: $L O F W R B-K$} \\
\hline & $\begin{array}{c}\text { Component } \\
\text { Failures }\end{array}$ & $\begin{array}{l}\text { Human } \\
\text { Errors }\end{array}$ & $\begin{array}{l}\text { Support } \\
\text { System } \\
\text { Failures } \\
\end{array}$ & $\begin{array}{l}\text { Determinant } \\
\text { Failure? }\end{array}$ \\
\hline F-ISO-HE, F-MCS-ISV-FC, F-SDC-HE & 1 & 2 & & \\
\hline F-ISO-HE, F-MCS-PMP1, F-SDC-HE & 1 & 2 & & \\
\hline F-ISO-HE, F-MCS-PMP2, F-SDC-HE & 1 & 2 & & \\
\hline F-ISO-HE, F-SDC-HE, S-EL-III-1-O & & 2 & 1 & \\
\hline F-ISO-HE, F-SDC-HE, S-EL-III-1-E & & 2 & 1 & \\
\hline F-ISO-HE, F-SDC-HE, S-RCW & & 2 & 1 & \\
\hline F-ISO-HE, F-MCS-ISV-FC, S-PCS & 1 & 1 & 1 & \\
\hline F-ISO-HE, S-PCS, S-RCW & & 1 & 2 & \\
\hline F-ISO-HE, F-MCS-PMP2, S-PCS & 1 & 1 & 1 & \\
\hline F-ISO-HE, F-SDC-HX1, S-RCW & 1 & 1 & 1 & \\
\hline F-ISO-HE, S-EL-III-1-E, S-PCS & & 1 & 2 & \\
\hline F-ISO-HE, S-EL-III-1-O, S-PCS & & 1 & 2 & \\
\hline F-ISO-HE, F-MCS-PMP1, S-PCS & 1 & 1 & 1 & \\
\hline
\end{tabular}


Table C.9 (cont.)

\begin{tabular}{|c|c|c|c|c|}
\hline F-ISO-HE, S-RCW, S-SW2 & & 1 & 2 & \\
\hline F-ISO-SIG, F-MCS-PMP1, F-SDC-HE & 2 & 1 & & \\
\hline F-ISO-SIG, F-SDC-HE, S-EL-III-1-E & 1 & 1 & 1 & \\
\hline F-ISO-VLV-FO, F-SDC-HE, S-RCW & 1 & 1 & 1 & \\
\hline F-ISO-SIG, F-SDC-HE, S-EL-III-1-O & 1 & 1 & 1 & \\
\hline F-ISO-SIG, F-MCS-PMP2, F-SDC-HE & 2 & 1 & & \\
\hline F-ISO-VLV-FO, F-MCS-PMP1, F-SDC-HE & 2 & 1 & & \\
\hline F-ISO-SIG, F-MCS-ISV-FC, F-SDC-HE & 2 & 1 & & \\
\hline F-ISO-VLV-FO, F-MCS-ISV-FC, F-SDC-HE & 2 & 1 & & \\
\hline F-ISO-VLV-FO, F-MCS-PMP2, F-SDC-HE & 2 & 1 & & \\
\hline F-SDC-HE, S-EL-II-1-O, S-RCW & & 1 & 2 & \\
\hline F-ISO-VLV-FO, F-SDC-HE, S-EL-III-1-E & 1 & 1 & 1 & \\
\hline F-ISO-VLV-FO, F-SDC-HE, S-EL-III-1-O & 1 & 1 & 1 & \\
\hline F-ISO-SIG, F-SDC-HE, S-RCW & 1 & 1 & 1 & \\
\hline F-SDC-HE, S-EL-II-1-O, S-EL-III-1-E & & 1 & 2 & \\
\hline F-SDC-HE, S-EL-II-1-O, S-EL-III-1-O & & 1 & 2 & \\
\hline F-MCS-PMP2, F-SDC-HE, S-EL-II-1-O & 1 & 1 & 1 & \\
\hline F-MCS-PMP1, F-SDC-HE, S-EL-II-1-O & 1 & 1 & 1 & \\
\hline F-MCS-ISV-FC, F-SDC-HE, S-EL-II-1-O & 1 & 1 & 1 & \\
\hline F-ISO-VLV-FO, S-RCW, S-SW2 & 1 & & 2 & \\
\hline F-ISO-SIG, S-RCW, S-SW2 & 1 & & 2 & \\
\hline F-MCS-PMP1, S-EL-II-1-O, S-PCS & 1 & & 2 & \\
\hline F-MCS-ISV-FC, S-EL-II-1-O, S-PCS & 1 & & 2 & \\
\hline F-SDC-HE, S-AIR, S-EL-III-1-O & & 1 & 2 & \\
\hline F-SDC-HX1, S-EL-II-1-O, S-RCW & 1 & & 2 & \\
\hline S-EL-II-1-O, S-RCW, S-SW2 & & & 3 & \\
\hline F-ISO-VLV-FO, F-SDC-HX1, S-RCW & 2 & & 1 & \\
\hline F-SDC-HE, S-AIR, S-RCW & & 1 & 2 & \\
\hline F-MCS-PMP2, S-EL-II-1-O, S-PCS & 1 & & 2 & \\
\hline S-EL-II-1-O, S-EL-III-1-E, S-PCS & & & 3 & \\
\hline S-EL-II-1-O, S-PCS, S-RCW & & & 3 & \\
\hline F-ISO-VLV-FO, S-PCS, S-RCW & 1 & & 2 & \\
\hline F-ISO-SIG, F-SDC-HX1, S-RCW & 2 & & 1 & \\
\hline F-ISO-SIG, S-PCS, S-RCW & 1 & & 2 & \\
\hline
\end{tabular}


Table C.9 (cont.)

\begin{tabular}{|c|c|c|c|c|}
\hline F-ISO-SIG, S-EL-III-1-O, S-PCS & 1 & & 2 & \\
\hline F-ISO-VLV-FO, F-MCS-PMP1, S-PCS & 2 & & 1 & \\
\hline F-ISO-VLV-FO, S-EL-III-1-E, S-PCS & 1 & & 2 & \\
\hline F-MCS-PMP2, F-SDC-HE, S-AIR & 1 & 1 & 1 & \\
\hline F-SDC-HE, S-AIR, S-EL-III-1-E & & 1 & 2 & \\
\hline F-ISO-VLV-FO, F-MCS-PMP2, S-PCS & 2 & & 1 & \\
\hline F-MCS-PMP1, F-SDC-HE, S-AIR & 1 & 1 & 1 & \\
\hline F-ISO-VLV-FO, F-MCS-ISV-FC, S-PCS & 2 & & 1 & \\
\hline S-EL-II-1-O, S-EL-III-1-O, S-PCS & & & 3 & \\
\hline F-ISO-VLV-FO, S-EL-III-1-O, S-PCS & 1 & & 2 & \\
\hline F-ISO-SIG, S-ELL-III-1-E, S-PCS & 1 & & 2 &. \\
\hline F-ISO-SIG, F-MCS-PMP1, S-PCS & 2 & & 1 & \\
\hline F-MCS-ISV-FC, F-SDC-HE, S-AIR & 1 & 1 & 1 & \\
\hline F-ISO-SIG, F-MCS-PMP2, S-PCS & 2 & & 1 & \\
\hline F-ISO-SIG, F-MCS-ISV-FC, S-PCS & 2 & & 1 & \\
\hline F-MCS-PMP1, S-AIR, S-PCS & 1 & & 2 & \\
\hline F-SDC-HX1, S-AIR, S-RCW & 1 & & 2 & \\
\hline S-AIR, S-EL-III-1-O, S-PCS & & & 3 & \\
\hline S-AIR, S-RCW, S-SW2 & & & 3 & \\
\hline F-MCS-PMP2, S-AIR, S-PCS & 1 & & 2 & \\
\hline S-AIR, S-PCS, S-RCW & & & 3 & \\
\hline F-MCS-ISV-FC, S-AIR, S-PCS & 1 & & 2 & \\
\hline S-AIR, S-EL-III-1-E, S-PCS & & & 3 & \\
\hline
\end{tabular}

\begin{tabular}{|c|c|c|c|c|}
\hline \multirow{2}{*}{$\begin{array}{c}\text { Initiating Event }-\begin{array}{l}\text { Feedwater Piping Break in } \\
\text { the Reactor Building }\end{array} \\
\text { Sequence Level Cut Sets }\end{array}$} & \multicolumn{4}{|c|}{ Sequence: $L O F W R B-L$} \\
\hline & $\begin{array}{l}\text { Component } \\
\text { Failures }\end{array}$ & $\begin{array}{l}\text { Humen } \\
\text { Errors }\end{array}$ & $\begin{array}{l}\text { Support } \\
\text { System } \\
\text { Failurea }\end{array}$ & $\begin{array}{l}\text { Determinent } \\
\text { Failure? }\end{array}$ \\
\hline F-SD1-CR-BD-CM & & & 1 & $\mathbf{Y}$ \\
\hline F-SD1-CR-COIL-CM & & & 1 & $\mathrm{Y}$ \\
\hline F-SD1-TLB-REL2, F-SD1-TLB-REL3 & 2 & & & $\mathbf{Y}$ \\
\hline F-SD1-TLB-REL1, F-SD1-TLB-REL2 & 2 & & & $\mathbf{Y}$ \\
\hline F-SD1-TLA-REL1, F-SD1-TLA-REL2 & 2 & & & $\mathbf{Y}$ \\
\hline F-SD1-TLB-REL1, F-SD1-TLB-REL3 & 2 & & & $\mathbf{Y}$ \\
\hline
\end{tabular}


Appendix C

Table C.9 (cont.)

\begin{tabular}{||l|l|l|l|l||}
\hline F-SD1-TLA-REL2, F-SD1-TLA-REL3 & 2 & & & $Y$ \\
\hline F-SD1-TLA-REL1, F-SD1-TLA-REL3 & 2 & & & $Y$ \\
\hline F-SD1-TC-D, F-SD1-TC-E & 2 & & & $Y$ \\
\hline F-SD1-TC-D, F-SD1-TC-F & 2 & & & $Y$ \\
\hline F-SD1-TC-E, F-SD1-TC-F & 2 & & & $Y$ \\
\hline
\end{tabular}

\begin{tabular}{|c|c|c|c|c|}
\hline \multirow{2}{*}{$\begin{array}{c}\text { Initiating Event - Feedwater Piping Break in } \\
\text { the Reactor Building }\end{array}$} & \multicolumn{4}{|c|}{ Sequence: $L O F W R B-M$} \\
\hline & $\begin{array}{c}\text { Component } \\
\text { Failures }\end{array}$ & $\begin{array}{c}\text { Human } \\
\text { Errors } \\
\end{array}$ & $\begin{array}{l}\text { Support } \\
\text { System } \\
\text { Failures }\end{array}$ & $\begin{array}{c}\text { Decerminent } \\
\text { Failure ? }\end{array}$ \\
\hline F-ASD-ASD1, F-ASD-ASD2, F-SD1-CR-BD-CM & 2 & & 1 & \\
\hline F-ASD-ASD1, F-ASD-ASD2, F-SD1-CR-COIL-CM & 2 & & 1 & \\
\hline F-ASD-ASD2, F-SD1-CR-BD-CM, S-EL-II-2-O & 1 & & 2 & \\
\hline F-ASD-ASD2, F-SD1-CR-COIL-CM, S-EL-III-2-O & 1 & & 2 & \\
\hline F-ASD-ASD1, F-SD1-CR-BD-CM, S-EL-II-2-E & 1 & & 2 & \\
\hline F-ASD-ASD1, F-SD1-CR-COIL-CM, S-EL-II-2-E & 1 & & 2 & \\
\hline
\end{tabular}

\begin{tabular}{|c|c|c|c|c|}
\hline \multirow{2}{*}{$\begin{array}{c}\text { Initiating Event }-\begin{array}{l}\text { Feedwater Piping Break in } \\
\text { the Reactor Building }\end{array} \\
\text { Sequence Level Cut Sets }\end{array}$} & \multicolumn{4}{|c|}{ Sequence: $L O F W R B-Q$} \\
\hline & $\begin{array}{c}\text { Component } \\
\text { Failures } \\
\end{array}$ & $\begin{array}{l}\text { Human } \\
\text { Errors } \\
\end{array}$ & 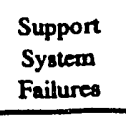 & $\begin{array}{c}\text { Determinant } \\
\text { Failure? }\end{array}$ \\
\hline F-FW2-HE, F-FW2-LI-TK, F-SD1-CR-BD-CM & 1 & 1 & 1 & \\
\hline F-FW2-HE, F-FW2-LI-TK, F-SD1-CR-COIL-CM & 1 & 1 & 1 & \\
\hline F-FW2-IV1, F-FW2-OV2, F-SD1-CR-COIL-CM & 2 & & 1 & \\
\hline F-FW2-IV1, F-FW2-IV2, F-SD1-CR-COIL-CM & 2 & & 1 & \\
\hline F-FW2-IV1, F-FW2-PMP2, F-SD1-CR-COIL-CM & 2 & & 1 & \\
\hline F-FW2-PMP1, F-FW2-PMP2, F-SD1-CR-COIL-CM & 2 & & 1 & \\
\hline F-FW2-IV2, F-FW2-OV1, F-SD1-CR-BD-CM & 2 & & 1 & \\
\hline F-FW2-OV1, F-FW2-OV2, F-SD1-CR-BD-CM & 2 & & 1 & \\
\hline F-FW2-OV1, F-FW2-PMP2, F-SD1-CR-BD-CM & 2 & & 1 & \\
\hline F-FW2-IV2, F-FW2-PMP1, F-SD1-CR-COIL-CM & 2 & & 1 & \\
\hline F-FW2-IV2, F-FW2-OV1, F-SD1-CR-COIL-CM & 2 & & 1 & \\
\hline F-FW2-OV2, F-FW2-PMP1, F-SD1-CR-COIL-CM & 2 & & 1 & \\
\hline
\end{tabular}


Table C.9 (cont.)

\begin{tabular}{|c|c|c|c|}
\hline F-FW2-IV1, F-FW2-OV2, F-SD1-CR-BD-CM & 2 & 1 & \\
\hline F-FW2-IV1, F-FW2-IV2, F-SD1-CR-BD-CM & 2 & 1 & \\
\hline F-FW2-OV1, F-FW2-OV2, F-SD1-CR-COIL-CM & 2 & 1 & \\
\hline F-FW2-PMP1, F-FW2-PMP2, F-SD1-CR-BD-CM & 2 & 1 & \\
\hline F-FW2-IV1, F-FW2-PMP2, F-SD1-CR-BD-CM & 2 & 1 & \\
\hline F-FW2-IV2, F-FW2-PMP1, F-SD1-CR-BD-CM & 2 & 1 & \\
\hline F-FW2-OV2, F-FW2-PMP1, F-SD1-CR-BD-CM & 2 & 1 & \\
\hline F-FW2-OV1, F-FW2-PMP2, F-SD1-CR-COIL-CM & 2 & 1 & \\
\hline F-FW2-OV2, F-SD1-CR-COIL-CM, S-EL-III-2-O & 1 & 2 & \\
\hline F-FW2-PMP2, F-SD1-CR-COIL-CM, S-EL-III-2-O & 1 & 2 & \\
\hline F-FW2-IV2, F-SD1-CR-COIL-CM, S-EL-III-2-O & 1 & 2 & \\
\hline F-FW2-IV1, F-SD1-CR-BD-CM, S-EL-III-2-E & 1 & 2 & \\
\hline F-FW2-IV2, F-SD1-CR-BD-CM, S-EL-III-2-O & 1 & 2 & \\
\hline F-FW2-OV1, F-SD1-CR-BD-CM, S-EL-III-2-E & 1 & 2 & \\
\hline F-FW2-OV2, F-SD1-CR-BD-CM, S-EL-III-2-O & 1 & 2 & \\
\hline F-FW2-IV1, F-SD1-CR-COIL-CM, S-EL-III-2-E & 1 & 2 & \\
\hline F-FW2-OV1, F-SD1-CR-COIL-CM, S-EL-III-2-E & 1 & 2 & \\
\hline F-FW2-PMP1, F-SD1-CR-COIL-CM, S-EL-III-2-E & 1 & 2 & \\
\hline F-FW2-PMP1, F-SD1-CR-BD-CM, S-EL-III-2-E & 1 & 2 & \\
\hline F-FW2-PMP2, F-SD1-CR-BD-CM, S-EL-III-2-O & 1 & 2 & \\
\hline
\end{tabular}

\begin{tabular}{|c|c|c|c|c|}
\hline \multirow{2}{*}{$\begin{array}{c}\text { Initiating Event - Feedwater Piping Break in } \\
\text { the Reactor Building }\end{array}$} & \multicolumn{4}{|c|}{ Sequence: $L O F W R B-R$} \\
\hline & $\begin{array}{l}\text { Component } \\
\text { Failures }\end{array}$ & $\begin{array}{l}\text { Human } \\
\text { Errors }\end{array}$ & $\begin{array}{l}\text { Support } \\
\text { System } \\
\text { Failures }\end{array}$ & $\begin{array}{l}\text { Determinant } \\
\text { Failure? }\end{array}$ \\
\hline F-SD1-CR-COIL-CM, S-PCS & & & 2 & \\
\hline F-SD1-CR-BD-CM, S-PCS & & & 2 & \\
\hline F-SD1-TLB-REL1, F-SD1-TLB-REL3, S-PCS & 2 & & 1 & \\
\hline F-SD1-TLB-REL1, F-SD1-TLB-REL2, S-PCS & 2 & & 1 & \\
\hline F-SD1-TLA-REL1, F-SD1-TLA-REL2, S-PCS & 2 & & 1 & \\
\hline F-SD1-TLB-REL2, F-SD1-TLB-REL3, S-PCS & 2 & & 1 & \\
\hline F-SD1-TLA-REL2, F-SD1-TLA-REL3, S-PCS & 2 & & 1 & \\
\hline F-SD1-TLA-REL1, F-SD1-TLA-REL3, S-PCS & 2 & & 1 & \\
\hline F-SD1-CR-COIL-CM, S-EL-III-2-E, S-EL-III-2-O & & & 3 & \\
\hline
\end{tabular}


Table C.9 (cont.)

\begin{tabular}{||l|c|c|c||}
\hline F-SD1-CR-BD-CM, S-EL-III-2-E, S-EL-III-2-O & & 3 & \\
\hline F-SD1-CR-COIL-CM, S-EL-II-2-E, S-EL-II-2-O & & 3 & \\
\hline F-SD1-TC-D, F-SD1-TC-F, S-PCS & 2 & & 1 \\
\hline F-SD1-TC-D, F-SD1-TC-E, S-PCS & 2 & & 1 \\
\hline F-SD1-TC-E, F-SD1-TC-F, S-PCS & 2 & & 1 \\
\hline F-SD1-CR-BD-CM, S-EL-II-2-E, S-EL-II-2-O & & & 3 \\
\hline
\end{tabular}

\begin{tabular}{|c|c|c|c|c|}
\hline \multirow{2}{*}{$\begin{array}{c}\text { Initiating Event }-\begin{array}{l}\text { Feedwater Piping Break in } \\
\text { the Reactor Building }\end{array} \\
\text { Sequence Level Cut Sets }\end{array}$} & \multicolumn{4}{|c|}{ Sequence: $L O F W R B-S$} \\
\hline & $\begin{array}{l}\text { Component } \\
\text { Failures }\end{array}$ & $\begin{array}{l}\text { Human } \\
\text { Errors }\end{array}$ & $\begin{array}{l}\text { Support } \\
\text { Syatem } \\
\text { Failurea }\end{array}$ & $\begin{array}{l}\text { Determinant } \\
\text { Failure? }\end{array}$ \\
\hline F-SD1-CR-BD-CM, S-EL-III-1-O, S-PCS & & & 3 & \\
\hline F-MCS-PMP1, F-SD1-CR-COIL-CM, S-PCS & a. 1 & & 2 & \\
\hline F-SD1-CR-CCHL-CM, S-EL-III-1-O, S-PCS & & & 3 & \\
\hline F-SD1-CR-BD-CM, S-PCS, S-RCW & & & 3 & \\
\hline F-MCS-PMP1, F-SD1-CR-BD-CM, S-PCS & 1 & & 2 & \\
\hline F-SD1-CR-COIL-CM, S-PCS, S-RCW & & & 3 & \\
\hline F-SD1-CR-COIL-CM, S-EL-III-1-E, S-PCS & & & 3 & \\
\hline F-MCS-PMP2, F-SD1-CR-BD-CM, S-PCS & 1 & & 2 & \\
\hline F-MCS-ISV-FC, F-SD1-CR-COIL-CM, S-PCS & 1 & & 2 & \\
\hline F-MCS-PMP2, F-SD1-CR-COIL-CM, S-PCS & 1 & & 2 & \\
\hline F-MCS-ISV-FC, F-SD1-CR-BD-CM, S-PCS & 1 & & 2 & \\
\hline F-SD1-CR-BD-CM, S-EL-III-1-E, S-PCS & & & 3 & \\
\hline
\end{tabular}

\begin{tabular}{|c|c|c|c|c|}
\hline Initiating Event - Feedwater Piping Break in & \multicolumn{4}{|c|}{ Sequence: $L O F W R B-T$} \\
\hline Sequence Level Cut Sets & $\begin{array}{l}\text { Component } \\
\text { Fuilures }\end{array}$ & $\begin{array}{l}\text { Human } \\
\text { Errors }\end{array}$ & $\begin{array}{l}\text { Support } \\
\text { System } \\
\text { Failures }\end{array}$ & $\begin{array}{l}\text { Determinant } \\
\text { Faiture? }\end{array}$ \\
\hline F-ISO-HE, F-SD1-CR-COIL-CM & & 1 & 1 & \\
\hline F-ISO-HE, F-SD1-CR-BD-CM & & 1 & 1 & \\
\hline F-SD1-CR-COIL-CM, S-EL-II-1-O & & & 2 & \\
\hline F-ISO-VLV-FO, F-SD1-CR-BD-CM & 1 & & 1 & \\
\hline E-ISO-SIG, F-SD1-CR-BD-CM & 1 & & 1 & \\
\hline
\end{tabular}




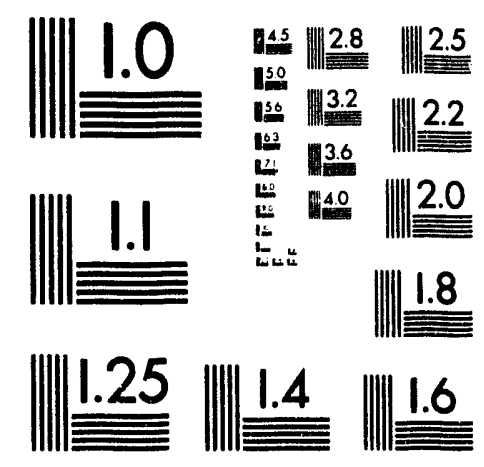



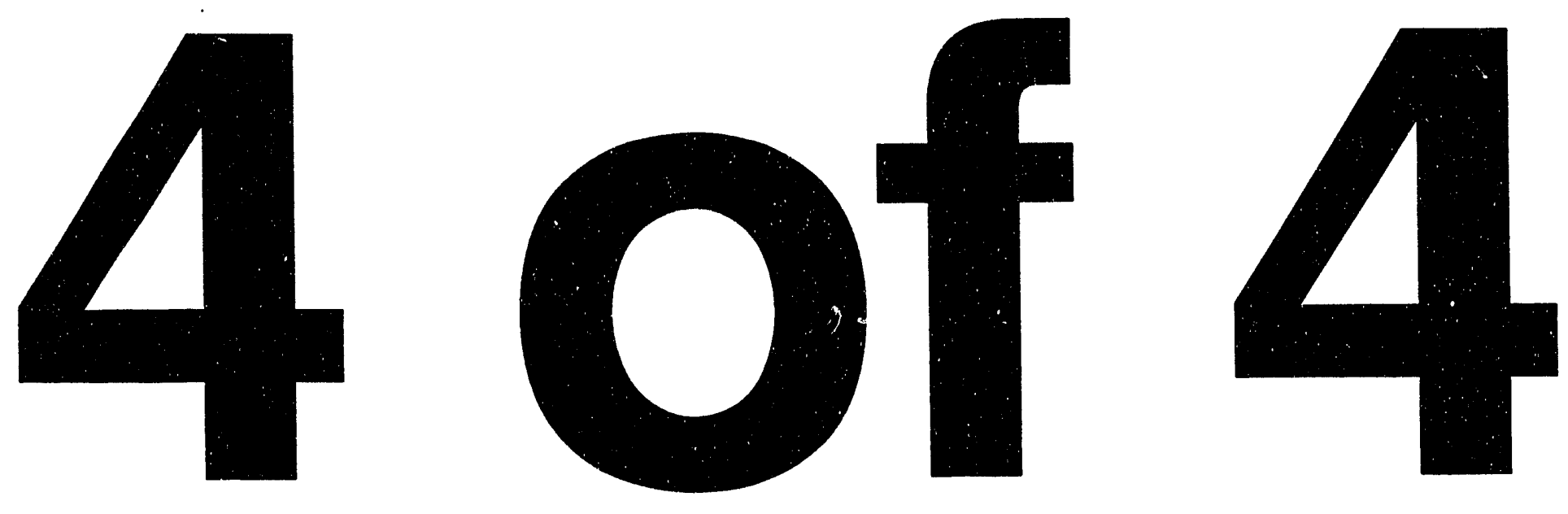
Table C.9 (cont.)

\begin{tabular}{|c|c|c|c|c|}
\hline F-ISO-VLV-FO, F-SD1-CR-COIL-CM & 1 & & 1 & \\
\hline F-SD1-CR-BD-CM, S-EL-II-1-O & & & 2 & \\
\hline F-ISO-SIG, F-SD1-CR-COIL-CM & 1 & & 1 & \\
\hline F-ISO-HE, F-SD1-TLA-REL1, F-SD1-TLA-REL2 & 2 & 1 & & \\
\hline F-ISO-HE, F-SD1-TLB-REL1, F-SD1-TLB-REL2 & 2 & 1 & & \\
\hline F-ISO-HE, F-SD1-TLB-REL1, F-SD1-TLB-REL3 & 2 & 1 & & \\
\hline F-ISO-HE, F-SD1-TLA-REL1, F-SD1-TLA-REL3 & 2 & 1 & & \\
\hline F-ISO-HE, F-SD1-TLB-REL2, F-SD1-TLB-REL3 & 2 & 1 & & \\
\hline F-ISO-HE, F-SD1-TLA-REL2, F-SD1-TLA-REL3 & 2 & 1 & & \\
\hline F-SD1-CR-BD-CM, S-AIR & & & 2 & \\
\hline F-SD1-CR-COIL-CM, S-AIR & & & 2 & \\
\hline F-ISO-VLV-FO, F-SD1-TLA-REL1, F-SD1-TLA-REL2 & 3 & & & \\
\hline F-ISO-SIG, F-SD1-TLA-REL1, F-SD1-TLA-REL2 & 3 & & & \\
\hline F-ISO-SIG, F-SD1-TLB-REL2, F-SD1-TLB-REL3 & 3 & & & \\
\hline F-SD1-TLB-REL1, F-SD1-TLB-REL3, S-EL-II-1-O & 2 & & 1 & \\
\hline F-SD1-TLB-REL1, F-SD1-TLB-REL2, S-EL-II-1-O & 2 & & 1 & \\
\hline F-ISO-VLV-FO, F-SD1-TLB-REL1, F-SD1-TLB-REL3 & 3 & & & \\
\hline F-ISO-SIG, F-SD1-TLB-REL1, F-SD1-TLB-REL3 & 3 & & & \\
\hline F-ISO-SIG, F-SD1-TLB-REL1, F-SD1-TLB-REL2 & 3 & & & \\
\hline F-SD1-TLB-REL2, F-SD1-TLB-REL3, S-EL-II-1-O & 2 & & 1 & \\
\hline F-SD1-TLA-REL1, F-SD1-TLA-REL2, S-EL-II-1-O & 2 & & 1 & \\
\hline F-ISO-VLV-FO, F-SD1-TLB-REL1, F-SD1-TLB-REL2 & 3 & & & \\
\hline F-ISO-VLV-FO, F-SD1-TLA-REL1, F-SD1-TLA-REL3 & 3 & & & \\
\hline F-SD1-TLA-REL1, F-SD1-TLA-REL3, S-EL-II-1-O & 2 & & 1 & \\
\hline F-ISO-SIG, F-SD1-TLA-REL1, F-SD1-TLA-REL3 & 3 & & & \\
\hline F-SD1-TLA-REL2, F-SD1-TLA-REL3, S-EL-II-1-O & 2 & & 1 & \\
\hline F-ISO-VLV-FO, F-SD1-TLB-REL2, F-SD1-TLB-REL3 & 3 & & & \\
\hline F-ISO-VLV-FO, F-SD1-TLA-REL2, F-SD1-TLA-REL3 & 3 & & & \\
\hline F-ISO-SIG, F-SD1-TLA-REL2, F-SD1-TLA-REL3 & 3 & & & \\
\hline F-ISO-HE, F-SD1-TC-D, F-SD1-TC-E & 2 & 1 & & \\
\hline F-ISO-HE, F-SD1-TC-D, F-SD1-TC-F & 2 & 1 & & \\
\hline F-ISO-HE, F-SD1-TC-E, F-SD1-TC-F & 2 & 1 & & \\
\hline F-SD1-TLB-REL1, F-SD1-TLB-REL2, S-AIR & 2 & & 1 & \\
\hline F-SD1-TLB-REL1, F-SD1-TLB-REL3, S-AIR & 2 & & 1 & \\
\hline
\end{tabular}


Table C.9 (cont.)

\begin{tabular}{|c|c|c|c|}
\hline F-SD1-TLA-REL1, F-SD1-TLA-REL2, S-AIR & 2 & 1 & \\
\hline F-SD1-TLA-REL2, F-SD1-TLA-REL3, S-AIR & 2 & 1 & \\
\hline F-SD1-TLA-REL1, F-SD1-TLA-REL3, S-AIR & 2 & 1 & \\
\hline F-SD1-TLB-REL2, F-SD1-TLB-REL3, S-AIR & 2. & 1 & \\
\hline F-SD1-TC-D, F-SD1-TC-F, S-EL-II-1-O & 2 & 1 & \\
\hline F-ISO-SIG, F-SD1-TC-D, F-SD1-TC-E & 3 & & \\
\hline F-ISO-SIG, F-SD1-TC-D, F-SD1-TC-F & 3 & & \\
\hline F-ISO-VLV-FO, F-SD1-TC-D, F-SD1-TC-E & 3 & & \\
\hline F-SD1-TC-E, F-SD1-TC-F, S-EL-II-1-O & 2 & 1 & \\
\hline F-SD1-TC-D, F-SD1-TC-E, S-EL-II-1-O & 2 & 1 & \\
\hline F-ISO-SIG, F-SD1-TC-E, F-SD1-TC-F & 3 & & \\
\hline F-ISO-VLV-FO, F-SD1-TC-D, F-SD1-TC-F & 3 & & \\
\hline F-ISO-VLV-FO, F-SD1-TC-E, F-SD1-TC-F & 3 & & \\
\hline F-SD1-TC-D, F-SD1-TC-F, S-AIR & 2 & 1 & \\
\hline F-SD1-TC-D, F-SD1-TC-E, S-AIR & 2 & 1 & \\
\hline F-SD1-TC-E, F-SD1-TC-F, S-AIR & 2 & 1 & \\
\hline
\end{tabular}

\begin{tabular}{|c|c|c|c|c|}
\hline \multirow{2}{*}{$\begin{array}{c}\text { Initiating Event }-\begin{array}{l}\text { Feedwater Piping Break in } \\
\text { the Reactor Building }\end{array} \\
\text { Sequence Level Cut Sets }\end{array}$} & \multicolumn{4}{|c|}{ Sequence: $L O F W R B-U$} \\
\hline & $\begin{array}{l}\text { Component } \\
\text { Failures }\end{array}$ & $\begin{array}{c}\text { Human } \\
\text { Erron }\end{array}$ & $\begin{array}{l}\text { Support } \\
\text { System } \\
\text { Failurea }\end{array}$ & $\begin{array}{l}\text { Determinant } \\
\text { Faikure? }\end{array}$ \\
\hline F-ISO-HE, F-SD1-CR-COIL-CM, F-SDC-HE & & 2 & 1 & \\
\hline F-ISO-HE, F-SD1-CR-BD-CM, F-SDC-HE & & 2 & 1 & \\
\hline F-ISO-HE, F-SD1-CR-BD-CM, S-PCS & & 1 & 2 & \\
\hline F-ISO-HE, F-SD1-CR-COIL-CM, S-PCS & & 1 & 2 & \\
\hline F-ISO-SIG, F-SD1-CR-BD-CM, F-SDC-HE & 1 & 1 & 1 & \\
\hline F-ISO-VLV-FO, F-SD1-CR-COIL-CM, F-SDC-HE & 1 & 1 & 1 & \\
\hline F-ISO-SIG, F-SD1-CR-COIL-CM, F-SDC-HE & 1 & 1 & 1 & \\
\hline F-ISO-VLV-FO, F-SD1-CR-BD-CM, F-SDC-HE & 1 & 1 & 1 & \\
\hline F-SD1-CR-BD-CM, F-SDC-HE, S-EL-II-1-O & 1 & 1 & 1 & \\
\hline F-SD1-CR-COIL-CM, F-SDC-HE, S-EL-II-1-O & & 1 & 2 & \\
\hline F-ISO-SIG, F-SD1-CR-BD-CM, S-PCS & 1 & & 2 & \\
\hline F-SD1-CR-COIL-CM, F-SDC-HE, S-AIR & & 1 & 2 & \\
\hline F-ISO-SIG, F-SD1-CR-COIL-CM, S-PCS & 1 & & 2 & \\
\hline
\end{tabular}


Table C.9 (cont.)

\begin{tabular}{||l|c|c|c|c||}
\hline F-SD1-CR-BD-CM, F-SDC-HE, S-AIR & & 1 & 2 & \\
\hline F-ISO-VLV-FO, F-SD1-CR-COIL-CM, S-PCS & 1 & & 2 & \\
\hline F-SD1-CR-BD-CM, S-EL-II-1-O, S-PCS & & & 3 & \\
\hline F-SD1-CR-COIL-CM, S-EL-II-1-O, S-PCS & & & 3 & \\
\hline F-ISO-VLV-FO, F-SD1-CR-BD-CM, S-PCS & 1 & & 2 & \\
\hline F-SD1-CR-BD-CM, S-AIR, S-PCS & & & 3 & \\
\hline F-SD1-CR-COIL-CM, S-AIR, S-PCS & & & 3 & \\
\hline
\end{tabular}

\begin{tabular}{|c|c|c|c|c|}
\hline \multirow{2}{*}{$\begin{array}{c}\text { Initiating Event } \begin{array}{l}\text { - Feedwater Piping Break in } \\
\text { the Reactor Building }\end{array} \\
\text { Sequence Level Cut Sets }\end{array}$} & \multicolumn{4}{|c|}{ Sequence: $L O F W R B-F T S D-A$} \\
\hline & $\begin{array}{l}\text { Componeat } \\
\text { Failures }\end{array}$ & $\begin{array}{c}\text { Human } \\
\text { Emors }\end{array}$ & $\begin{array}{l}\text { Support } \\
\text { System } \\
\text { Failures }\end{array}$ & $\begin{array}{c}\text { Determinant } \\
\text { Failure? }\end{array}$ \\
\hline F-SD1-CR-COIL-CM, F-SD2-ISV1-PT5, F-SD2-ISV2-PT2 & 2 & & 1 & \\
\hline F-SD1-CR-COIL-CM, F-SD2-ISV2-PT2, F-SD2-ISV2-PT5 & 2 & & 1 & \\
\hline F-SD1-CR-COIL-CM, F-SD2-ISV1-PT2, F-SD2-ISV2-PT5 & 2 & & 1 & \\
\hline F-SD1-CR-COIL-CM, F-SD2-ISV1-PT2, F-SD2-ISV1-PT5 & 2 & & 1 & \\
\hline F-SD1-CR-BD-CM, F-SD2-ISV1-PTS, F-SD2-ISV2-PT2 & 2 & & 1 & \\
\hline F-SD1-CR-BD-CM, F-SD2-ISV2-PT2, F-SD2-ISV2-PT5 & 2 & & 1 & \\
\hline F-SD1-CR-BD-CM, F-SD2-ISV1-PT3, F-SD2-ISV1-PT5 & 2 & & 1 & \\
\hline F-SD1-CR-BD-CM, F-SD2-ISV1-PT3, F-SD2-ISV2-PTS & 2 & & 1 & \\
\hline F-SD1-CR-COIL-CM, F-SD2-ISV1-PT5, F-SD2-ISV2-PT3 & 2 & & 1 & \\
\hline F-SD1-CR-COIL-CM, F-SD2-ISV2-PT3, F-SD2-ISV2-PT5 & 2 & & 1 & \\
\hline F-SD1-CR-COIL-CM, F-SD2-ISV1-PT3, F-SD2-ISV2-PT5 & 2 & & 1 & \\
\hline F-SD1-CR-COIL-CM, F-SD2-ISV1-PT3, F-SD2-ISV1-PT5 & 2 & & 1 & \\
\hline F-SD1-CR-BD-CM, F-SD2-ISV1-PT5, F-SD2-ISV2-PT3 & 2 & & 1 & \\
\hline F-SD1-CR-BD-CM, F-SD2-ISV2-PT3, F-SD2-ISV2-PT5 & 2 & & 1 & \\
\hline F-SD1-CR-BD-CM, F-SD2-ISV1-PT2, F-SD2-ISV2-PT5 & 2 & & 1 & \\
\hline F-SD1-CR-BD-CM, F-SD2-ISV1-PT2, F-SD2-ISV1-PT5 & 2 & & 1 & \\
\hline F-SD1-CR-BD-CM, F-SD2-TL-G, F-SD2-TL-J & 2 & & 1 & \\
\hline F-SD1-CR-COIL-CM, F-SD2-TL-G, F-SD2-TL-J & 2 & & 1 & \\
\hline F-SD1-CR-COIL-CM, F-SD2-TL-H, F-SD2-TL-J & 2 & & 1 & \\
\hline F-SD1-CR-BD-CM, F-SD2-TL-H, F-SD2-TL-J & 2 & & 1 & \\
\hline F-SD1-CR-BD-CM, F-SD2-TL-G, F-SD2-TL-H & 2 & & 1 & \\
\hline F-SD1-CR-COIL-CM, F-SD2-TL-G, F-SD2-TL-H & 2 & & 1 & \\
\hline
\end{tabular}


Table C.9 (cont.)

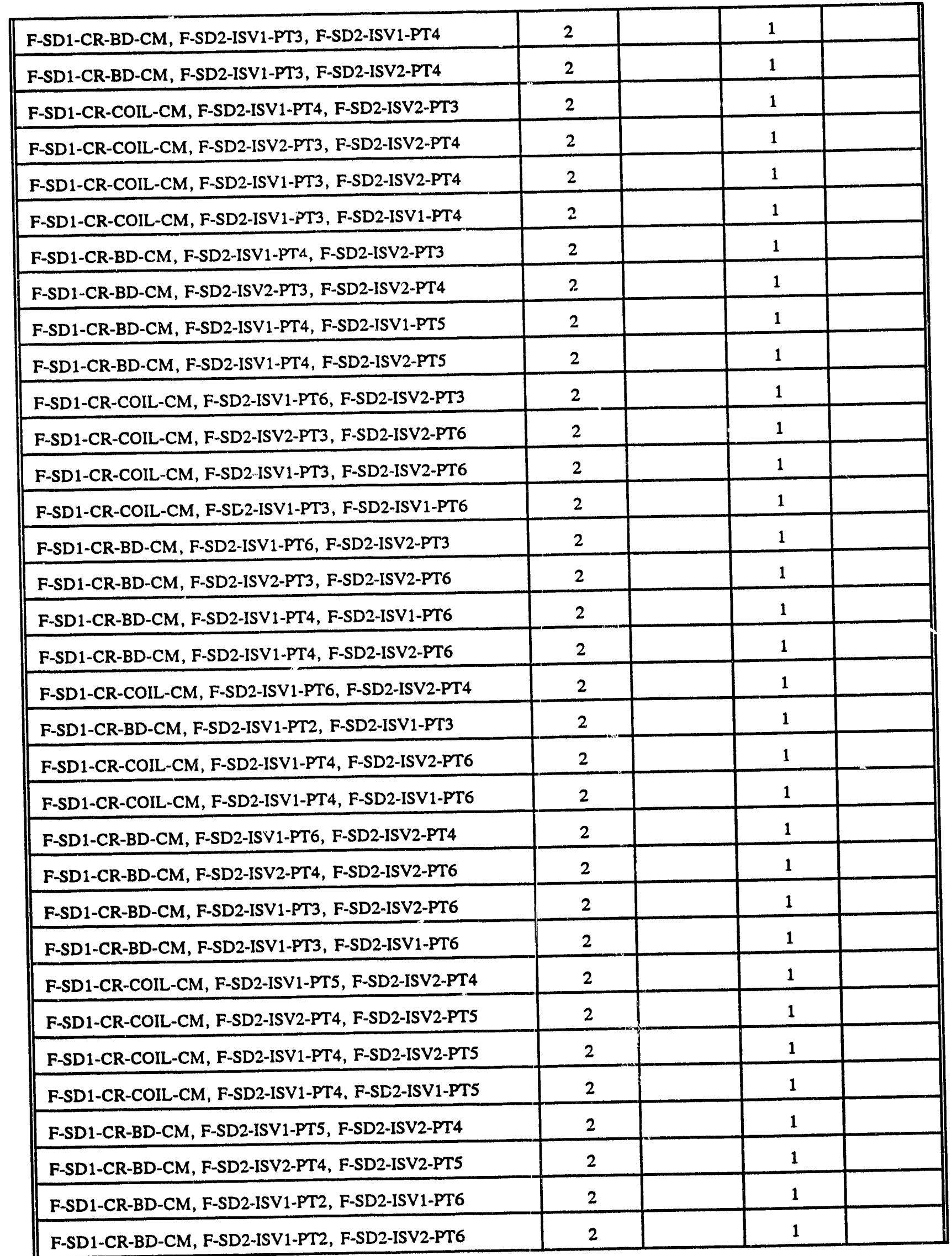


Table C.9 (cont.)

\begin{tabular}{|c|c|c|c|}
\hline F-SD1-CR-COIL-CM, F-SD2-ISV1-PT6, F-SD2-ISV2-PT2 & 2 & 1 & \\
\hline F-SD1-CR-COIL-CM, F-SD2-ISV2-PT2, F-SD2-ISV2-PT6 & 2 & 1 & \\
\hline F-SD1-CR-COIL-CM, F-SD2-ISV1-PT2, F-SD2-ISV2-PT6 & 2 & 1 & \\
\hline F-SD1-CR-COIL-CM, F-SD2-ISV1-PT2, F-SD2-ISV1-PT6 & 2 & 1 & \\
\hline F-SD1-CR-BD-CM, F-SD2-ISV1-PT6, F-SD2-ISV2-PT2 & 2 & 1 & \\
\hline F-SD1-CR-BD-CM, F-SD2-ISV2-PT2, F-SD2-ISV2-PT6 & 2 & 1 & \\
\hline F-SD1-CR-COIL-CM, F-SD2-ISV2-PT2, F-SD2-ISV2-PT4 & 2 & 1 & \\
\hline F-SD1-CR-COIL-CM, F-SD2-ISV2-PT4, F-SD2-ISV2-PT6 & 2 & 1 & \\
\hline F-SD1-CR-BD-CM, F-SD2-ISV2-PT1, F-SD2-ISV2-PT3 & 2 & 1 & \\
\hline F-SD1-CR-BD-CM, F-SD2-ISV1-PT3, F-SD2-ISV2-PT1 & 2 & 1 & \\
\hline F-SD1-CR-COIL-CM, F-SD2-ISV1-PT1, F-SD2-ISV1-PT3 & 2 & 1 & \\
\hline F-SD1-CR-BD-CM, F-SD2-ISV1-PT1, F-SD2-ISV2-PT3 & 2 & 1 & \\
\hline F-SD1-CR-COIL-CM, F-SD2-ISV1-PT1, F-SD2-ISV2-PT3 & 2 & 1 & \\
\hline F-SD1-CR-BD-CM, F-SD2-ISV1-PT1, F-SD2-ISV1-PT3 & 2 & 1 & \\
\hline F-SD1-CR-COIL-CM, F-SD2-ISV1-PT2, F-SD2-ISV2-PT1 & 2 & 1 & \\
\hline F-SD1-CR-COIL-CM, F-SD2-ISV1-PT1, F-SD2-ISV2-PT2 & 2 & 1 & \\
\hline F-SD1-CR-COIL-CM, F-SD2-ISV2-PT1, F-SD2-ISV2-PT2 & 2 & 1 & \\
\hline F-SD1-CR-COIL-CM, F-SD2-ISV1-PT3, F-SD2-ISV2-PT1 & 2 & 1 & \\
\hline F-SD1-CR-COIL-CM, F-SD2-ISV2-PT1, F-SD2-ISV2-PT3 & 2 & 1 & \\
\hline F-SD1-CR-COIL-CM, F-SD2-ISV1-PT4, F-SD2-ISV2-PT1 & 2 & 1 & \\
\hline F-SD1-CR-COIL-CM, F-SD2-ISV1-PT1, F-SD2-ISV2-PT4 & 2 & 1 & \\
\hline F-SD1-CR-COIL-CM, F-SD2-ISV2-PT1, F-SD2-ISV2-PT4 & 2 & 1 & \\
\hline F-SD1-CR-COIL-CM, F-SD2-ISV1-PT1, F-SD2-ISV1-PT4 & 2 & 1 & \\
\hline F-SD1-CR-BD-CM, F-SD2-ISV2-PT1, F-SD2-ISV2-PT4 & 2 & 1 & \\
\hline F-SD1-CR-BD-CM, F-SD2-ISV1-PT1, F-SD2-ISV2-PT4 & 2 & 1 & \\
\hline F-SD1-CR-ED-CM, F-SD2-ISV1-PT1, F-SD2-ISV1-PT4 & 2 & 1 & \\
\hline F-SD1-CR-BD-CM, F-SD2-ISV1-PT4, F-SD2-ISV2-PT1 & 2 & 1 & \\
\hline F-SD1-CR-COIL-CM, F-SD2-ISV1-PT1, F-SD2-ISV1-PT2 & 2 & 1 & \\
\hline F-SD1-CR-BD-CM, F-SD2-ISV2-PT1, F-SD2-ISV2-PT2 & 2 & 1 & \\
\hline F-SD1-CR-COIL-CM, F-SD2-ISV2-PT2, F-SD2-ISV2-PT3 & 2 & 1 & \\
\hline F-SD1-CR-COIL-CM, F-SD2-ISV1-PT3, F-SD2-ISV2-PT2 & 2 & 1 & \\
\hline F-SD1-CR-BD-CM, F-SD2-ISV1-PT5, F-SD2-ISV1-PT6 & 2 & 1 & \\
\hline F-SD1-CR-COIL-CM, F-SD2-ISV1-PT2, F-SD2-ISV2-PT3 & 2 & 1 & \\
\hline F-SD1-CR-COIL-CM, F-SD2-ISV1-PT2, F-SD2-ISV1-PT3 & 2 & 1 & \\
\hline
\end{tabular}


Table C.9 (cont.)

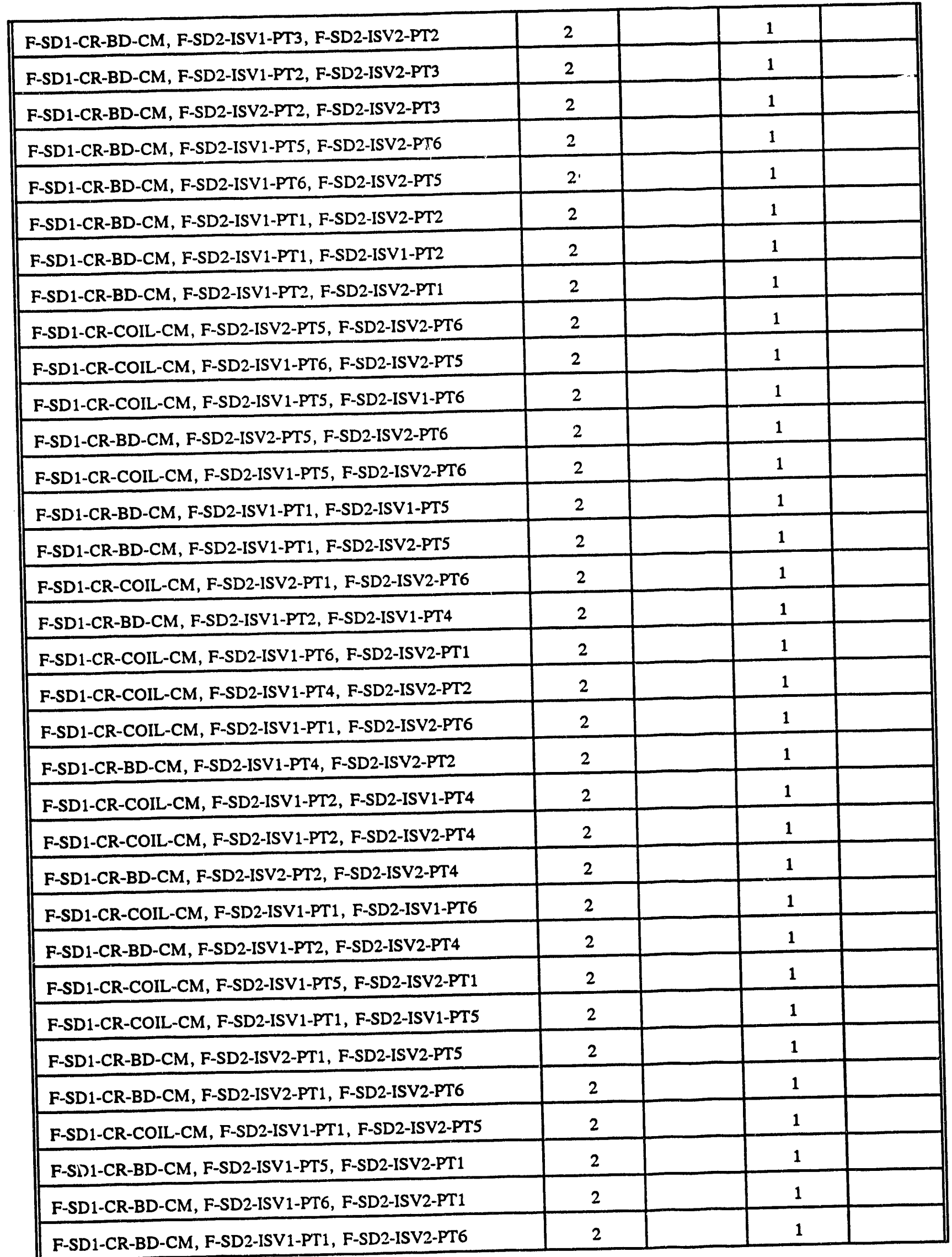


Table C.9 (cont.)

\begin{tabular}{|c|c|c|c|}
\hline F-SD1-CR-BD-CM, F-SD2-ISV1-PT1, F-SD2-ISV1-PT6 & 2 & 1 & \\
\hline F-SD1-CR-COIL-CM, F-SD2-ISV2-PT1, F-SD2-ISV2-PT5 & 2 & 1 & \\
\hline F-SD1-CR-BD-CM, F-SD2-TC-J, F-SD2-TL-H & 2 & 1 & \\
\hline F-SD1-CR-BD-CM, F-SD2-TC-H, F-SD2-TL-J & 2 & 1 & \\
\hline F-SD1-CR-COIL-CM, F-SD2-TC-G, F-SD2-TL-H & 2 & 1 & \\
\hline F-SD1-CR-BD-CM, F-SD2-TC-G, F-SD2-TL-H & 2 & 1 & \\
\hline F-SD1-CR-COIL-CM, F-SD2-TC-H, F-SD2-TL-G & 2 & 1 & \\
\hline F-SD1-CR-BD-CM, F-SD2-TC-H, F-SD2-TL-G & 2 & 1 & \\
\hline F-SD1-CR-COIL-CM; F-SD2-TC-J, F-SD2-TL-H & 2 & 1 & \\
\hline F-SD1-CR-BD-CM, F-SD2-TC-G, F-SD2-TL-J & 2 & 1 & \\
\hline F-SD1-CR-BD-CM, F-SD2-TC-J, F-SD2-TL-G & 2 & 1 & \\
\hline F-SD1-CR-COIL-CM, F-SD2-TC-G, F-SD2-TL-J & 2 & 1 & \\
\hline F-SD1-CR-COIL-CM, F-SD2-TC-J, F-SD2-TL-G & 2 & 1 & \\
\hline F-SD1-CR-COIL-CM, F-SD2-TC-H, F-SD2-TL-J & 2 & 1 & \\
\hline F-SD1-CR-COIL-CM, F-SD2-TC-G, F-SD2-TC-J & 2 & 1 & \\
\hline F-SD1-CR-BD-CM, F-SD2-TC-G, F-SD2-TC-H & 2 & 1 & \\
\hline F-SD1-CR-COIL-CM, F-SD2-TC-G, F-SD2-TC-H & 2 & 1 & \\
\hline F-SD1-CR-BD-CM, F-SD2-TC-H, F-SD2-TC-J & 2 & 1 & \\
\hline F-SD1-CR-COIL-CM, F-SD2-TC-H, F-SD2-TC-J & 2 & 1 & \\
\hline F-SD1-CR-BD-CM, F-SD2-TC-G, F-SD2-TC-J & 2 & 1 & \\
\hline
\end{tabular}


Table C.10 Undercooling events sequence categorization: representative initiating event - feedwater piping break in the reactor building

\begin{tabular}{|c|c|c|c|c|c|}
\hline \multicolumn{2}{|c|}{ Specific Initiator } & \multicolumn{2}{|c|}{$\begin{array}{l}\text { Feedwater piping break } \\
\text { in the reactor building }\end{array}$} & \multicolumn{2}{|c|}{$\begin{array}{l}\text { Steam generator } \\
\text { tube failure }\end{array}$} \\
\hline \multicolumn{2}{|c|}{ IE Frequency } & \multicolumn{2}{|c|}{$1 \times 10^{-5}$} & \multicolumn{2}{|c|}{$1 \times 10^{-3}$} \\
\hline Sequence & Determinant Failures & Bin & Category & Bin & Category \\
\hline LOFWRB-A & N/A & $I$ & EC-III & $E$ & EC-II \\
\hline LOFWRB-B & 2 valves & $\mathrm{K}$ & EC-IV & $\mathbf{G}$ & EC-III \\
\hline LOFWRB-C & $\geq 3$ failures & $L$ & EC-IV & $\mathrm{H}$ & EC-IV \\
\hline LOFWRB-D & $\geq 3$ failures & L & EC-IV & $\mathrm{H}$ & EC-IV \\
\hline LOFWRB-E & $\geq 3$ failures & $L$ & EC-IV & $\mathbf{H}$ & EC-IV \\
\hline LOFWRB-F & $\begin{array}{l}\text { tank level indicator and } \\
\text { human error, } 2 \text { pumps } \\
\text { and/or valves }\end{array}$ & $\mathbf{K}$ & EC-IV & $\mathbf{G}$ & EC-III \\
\hline LOFWRB-G & support system & $\mathbf{K}$ & EC-IV & $\mathbf{G}$ & EC-III \\
\hline LOFWRB-H & $\geq 3$ failures & $L$ & EC-IV & $\mathrm{H}$ & EC-IV \\
\hline LOFWRB-I & $\begin{array}{l}\text { signal failure, valve } \\
\text { failure, human error }\end{array}$ & $\mathbf{J}$ & EC-III & $\mathbf{F}$ & EC-II \\
\hline LOFWRB-J & $\begin{array}{l}\text { signal or valve and human } \\
\text { error, } 2 \text { human errors }\end{array}$ & $\mathbf{K}$ & EC-IV & $\mathbf{G}$ & EC-III \\
\hline LOFWRB-K & $\geq 3$ failures & $\mathrm{L}$ & EC-IV & $\mathrm{H}$ & EC-IV \\
\hline LOFWRB-L & $\begin{array}{l}\text { common mode, } \\
2 \text { trip logic relays, } \\
2 \text { trip computers }\end{array}$ & $\mathbf{K}$ & EC-IV & $\mathbf{G}$ & EC-III \\
\hline LOFWRB-M & $\geq 3$ failures & $L$ & EC-IV & $\mathbf{H}$ & EC-IV \\
\hline LOFWRB-N & $\geq 3$ failures & $\mathrm{L}$ & EC-IV & $\mathrm{H}$ & EC-IV \\
\hline LOFWRB-O & $\geq 3$ failures & $\mathrm{L}$ & EC-IV & $\mathbf{H}$ & EC-IV \\
\hline LOFWRB-P & $\geq 3$ failures & $\mathrm{L}$ & EC-IV & $\mathrm{H}$ & EC-IV \\
\hline LOFWRB-Q & $\geq 3$ failures & $\mathrm{L}$ & EC-IV & $\mathrm{H}$ & EC-IV \\
\hline LOFWRB-R & $\geq 3$ failures & $L$ & EC-IV & $\mathrm{H}$ & EC-IV \\
\hline LOFWRB-S & $\geq 3$ failures & $\mathrm{L}$ & EC-IV & $\mathrm{H}$ & EC-IV \\
\hline LOFWRB-T & $\geq 3$ failures & $\mathrm{L}$ & EC-IV & $\mathrm{H}$ & EC-IV \\
\hline LOFWRB-U & $\geq 3$ failures & $\mathrm{L}$ & EC-IV & $\mathbf{H}$ & EC-IV \\
\hline LOFWRB-FTSD-A & $\geq 3$ failures & $L$ & EC-IV & $\mathrm{H}$ & EC-IV \\
\hline LOFWRB-FTSD-B & $\geq 3$ failures & $\mathrm{L}$ & EC-IV & $\mathrm{H}$ & EC-IV \\
\hline LOFWRB-FTSD-C & $\geq 3$ failures & $L$ & EC-IV & $\mathbf{H}$ & EC-IV \\
\hline LOFWRB-FTSD-D & $\geq 3$ failures & L & EC-IV & $\mathbf{H}$ & EC-IV \\
\hline LOFWRB-FTSD-E & $\geq 3$ failures & $\underline{L}$ & EC-IV & $\mathrm{H}$ & EC-IV \\
\hline LOFWRB-FTSD-F & $\geq 3$ failures & $L$ & EC-IV & $\mathrm{H}$ & EC-IV \\
\hline LOFWRB-FTSD-G & $\geq 3$ failures & $L$ & EC-IV & $\mathrm{H}$ & EC-IV \\
\hline LOFWRB-FTSD-H & $\geq 3$ failures & $\mathbf{L}$ & EC-IV & $\mathrm{H}$ & EC-IV \\
\hline LOFWRB-FTSD-I & $\geq 3$ failures & $\mathbf{L}$ & EC-IV & $\mathbf{H}$ & EC-IV \\
\hline LOFWRB-FTSD-J & $\geq 3$ failures & $\mathrm{L}$ & EC-IV & $\mathrm{H}$ & EC-IV \\
\hline LOFWRB-FTSD-K & $\geq 3$ failures & $L$ & EC-IV & $\mathbf{H}$ & EC-IV \\
\hline LOFWRB-FTSD-L & $\geq 3$ failures & $\mathrm{L}$ & EC-IV & $\mathrm{H}$ & EC-IV \\
\hline LOFWRB-FTSD-M & $\geq 3$ failures & $\mathrm{L}$ & EC-IV & $\mathrm{H}$ & EC-IV \\
\hline LOFWRB-FTSD-N & $\geq 3$ failures & $\mathbf{L}$ & EC-IV & $\mathrm{H}$ & EC-IV \\
\hline
\end{tabular}


Table C.11 Feedwater piping break in the turbine building cut sets

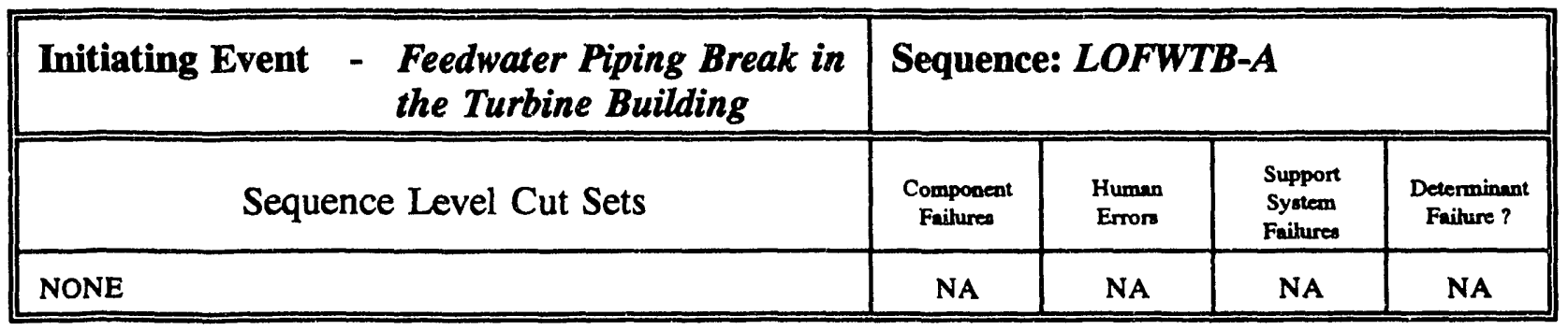

\begin{tabular}{|c|c|c|c|c|}
\hline Initiating Event - Feedwater Piping Break in & \multicolumn{4}{|c|}{ Sequence: $L O F W T B-B$} \\
\hline Sequence Level Cut Sets & $\begin{array}{l}\text { Componeat } \\
\text { Failures }\end{array}$ & $\begin{array}{c}\text { Human } \\
\text { Errors }\end{array}$ & $\begin{array}{l}\text { Support } \\
\text { System } \\
\text { Failures }\end{array}$ & $\begin{array}{l}\text { Determinant } \\
\text { Failure? }\end{array}$ \\
\hline S-AIR & & & 1 & $\mathbf{Y}$ \\
\hline F-ASD-ASD1, F-ASD-ASD2 & 2 & & & $\mathbf{Y}$ \\
\hline F-ASD-ASD2, S-EL-II-2-O & 1 & & 1 & \\
\hline F-ASD-ASD1, S-EL-II-2-E & 1 & & 1 & \\
\hline
\end{tabular}

\begin{tabular}{|c|c|c|c|c|}
\hline \multirow{2}{*}{$\begin{array}{c}\text { Initiating Event }-\begin{array}{l}\text { Feedwater Piping Break in } \\
\text { the Turbine Building }\end{array} \\
\text { Sequence Level Cut Sets }\end{array}$} & \multicolumn{4}{|c|}{ Sequence: $L O F W T B-C$} \\
\hline & $\begin{array}{c}\text { Component } \\
\text { Failures }\end{array}$ & $\begin{array}{c}\text { Human } \\
\text { Emon }\end{array}$ & $\begin{array}{l}\text { Support } \\
\text { System } \\
\text { Faihures }\end{array}$ & $\begin{array}{l}\text { Delerminant } \\
\text { Faihure? }\end{array}$ \\
\hline F-MSV-MSSV3-SG1, F-MSV-MSSV4-SG1, S-AIR & 2 & & 1 & \\
\hline F-MSV-MSSV1-SG1, F-MSV-MSSV3-SG1, S-AIR & 2 & & 1 & \\
\hline F-MSV-MSSV1-SG2, F-MSV-MSSV2-SG2, S-AIR. & 2 & & 1 & \\
\hline F-MSV-MSSV1-SG2, F-MSV-MSSV3-SG2, S-AIR & 2 & & 1 & \\
\hline F-MSV-MSSV2-SG1, F-MSV-MSSV3-SG1, S-AIR & 2 & & 1 & \\
\hline F-MSV-MSSV2-SG2, F-MSV-MSSV3-SG2, S-AIR & 2 & & 1 & \\
\hline F-MSV-MSSV1-SG1, F-MSV-MSSV4-SG1, S-AIR & 2 & & 1 & \\
\hline F-MSV-MSSV2-SG2, F-MSV-MSSV4-SG2, S-AIR & 2 & & 1 & \\
\hline F-MSV-MSSV1-SG2, F-MSV-MSSV4-SG2, S-AIR & 2 & & 1 & \\
\hline F-MSV-MSSV3-SG2, F-MSV-MSSV4-SG2, S-AIR & 2 & & 1 & \\
\hline F-MSV-MSSV1-SG1, F-MSV-MSSV2-SG1, S-AIR & 2 & & 1 & \\
\hline F-MSV-MSSV2-SG1, F-MSV-MSSV4-SG1, S-AIR & 2 & & 1 & \\
\hline
\end{tabular}




\begin{tabular}{|c|c|c|c|c|}
\hline \multirow{2}{*}{$\begin{array}{c}\text { Initiating Event }-\begin{array}{l}\text { Feedwater Piping Break in } \\
\text { the Turbine Building }\end{array} \\
\text { Sequence Level Cut Sets }\end{array}$} & \multicolumn{4}{|c|}{ Sequence: $L O F W T B-F$} \\
\hline & $\begin{array}{l}\text { Component } \\
\text { Failures }\end{array}$ & $\begin{array}{l}\text { Human } \\
\text { Errors }\end{array}$ & $\begin{array}{l}\text { Support } \\
\text { Syotem } \\
\text { Failures }\end{array}$ & $\begin{array}{l}\text { Determinant } \\
\text { Failure? }\end{array}$ \\
\hline F-FW2-HE, F-FW2-LI-TK & 1 & 1 & & $\mathbf{Y}$ \\
\hline F-FW2-PMP1, F-FW2-PMP2 & 2 & & & $\mathbf{Y}$ \\
\hline F-FW2-IV1, F-FW2-IV2 & 2 & & & $\mathbf{Y}$ \\
\hline F-FW2-IV2, F-FW2-PMP1 & 2 & & & $\mathbf{Y}$ \\
\hline F-FW2-IV1, F-FW2-OV2 & 2 & & & $\mathbf{Y}$ \\
\hline F-FW2-OV2, F-FW2-PMP1 & 2 & & & $\mathbf{Y}$ \\
\hline F-FW2-IV1, F-FW2-PMP2 & 2 & & & $\mathbf{Y}$ \\
\hline F-FW2-OV1, F-FW2-PMP2 & 2 & & & $\mathbf{Y}$ \\
\hline F-FW2-OV1, F-FW2-OV2 & 2 & & & $\mathbf{Y}$ \\
\hline F-FW2-IV2, F-FW2-OV1 & 2 & & & $Y$ \\
\hline F-FW2-OV2, S-EL-III-2-O & 1 & & 1 & \\
\hline F-FW2-IV2, S-EL-III-2-O & 1 & & 1 & \\
\hline F-FW2-PMP2, S-EL-III-2-O & 1 & & 1 & \\
\hline F-FW2-OV1, S-EL-III-2-E & 1 & & 1 & \\
\hline F-FW2-PMP1, S-EL-III-2-E & 1 & & 1 & \\
\hline F-FW2-IV1, S-EL-III-2-E & 1 & & 1 & \\
\hline F-FW2-ISV1-SG1, F-FW2-ISV1-SG2, S-EL-II-2-E & 2 & & 1 & \\
\hline F-FW2-ISV2-SG1, F-FW2-ISV2-SG2, S-EL-II-2-O & 2 & & 1 & \\
\hline
\end{tabular}

\begin{tabular}{|c|c|c|c|c|}
\hline \multirow{2}{*}{$\begin{array}{c}\text { Initiating Event }-\begin{array}{l}\text { Feedwater Piping Break in } \\
\text { the Turbine Building }\end{array} \\
\text { Sequence Level Cut Sets }\end{array}$} & \multicolumn{4}{|c|}{ Sequence: $L O F W T B-G$} \\
\hline & $\begin{array}{l}\text { Component } \\
\text { Failures }\end{array}$ & $\begin{array}{l}\text { Human } \\
\text { Erron }\end{array}$ & $\begin{array}{l}\text { Support } \\
\text { Syatem } \\
\text { Failurea }\end{array}$ & $\begin{array}{l}\text { Determinant } \\
\text { Filure? }\end{array}$ \\
\hline S-PCS & & & 1 & $\mathbf{Y}$ \\
\hline F-FW2-HE, F-FW2-LI-TK, F-SDC-HE & 1 & 2 & & \\
\hline S-EL-III-2-E, S-EL-III-2-O & & & 2 & \\
\hline S-EL-II-2-E, S-EL-II-2-O & & & 2 & \\
\hline F-FW2-OV1, F-FW2-OV2, F-SDC-HE & 2 & 1 & & \\
\hline F-FW2-IV2, F-FW2-PMP1, F-SDC-HE & 2 & 1 & & \\
\hline F-FW2-IV2, F-FW2-OV1, F-SDC-HE & 2 & 1 & & \\
\hline
\end{tabular}


Table C.11 (cont.)

\begin{tabular}{|c|c|c|c|c|}
\hline F-FW2-OV2, F-FW2-PMP1, F-SDC-HE & 2 & 1 & & \\
\hline F-FW2-OV1, F-FW2-PMP2, F-SDC-HE & 2 & 1 & & \\
\hline F-FW2-IV1, F-FW2-OV2, F-SDC-HE & 2 & 1 & & \\
\hline F-FW2-PMP1, F-FW2-PMP2, F-SDC-HE & 2 & 1 & & \\
\hline F-FW2-IV1, F-FW2-PMP2, F-SDC-HE & 2 & 1 & & \\
\hline F-FW2-IV1, F-FW2-IV2, F-SDC-HE & 2 & 1 & & \\
\hline F-FW2-OV2, F-SDC-HE, S-EL-III-2-O & 1 & 1 & 1 & \\
\hline F-FW2-PMP2, F-SDC-HE, S-EL-III-2-O & 1 & 1 & 1 & \\
\hline F-FW2-IV2, F-SDC-HE, S-EL-III-2-O & 1 & 1 & 1 & \\
\hline F-FW2-OV1, F-SDC-PMP1, S-EL-III-2-E & 2 & & 1 & \\
\hline F-FW2-IV2, F-SDC-PMP2, S-EL-III-2-O & 2 & & 1 & \\
\hline F-FW2-IV1, F-SDC-PMP1, S-EL-III-2-E & 2 & & 1 & \\
\hline F-FW2-OV2, F-SDC-PMP2, S-EL-III-2-O & 2 & & 1 & \\
\hline F-FW2-IV1, F-SDC-HE, S-EL-III-2-E & 1 & 1 & 1 & \\
\hline F-FW2-OV1, F-SDC-HE, S-EL-III-2-E & 1 & 1 & 1 & \\
\hline F-FW2-PMP1, F-SDC HE, S-EL-III-2-E & 1 & 1 & 1 & \\
\hline F-FW2-PMP1, F-SDC-PMP1, S-EL-III-2-E & 2 & & 1 & \\
\hline F-FW2-PMP2, F-SDC-PMP2, S-EL-III-2-O & 2 & & 1 & \\
\hline
\end{tabular}

\begin{tabular}{|c|c|c|c|c|}
\hline \multirow{2}{*}{$\begin{array}{c}\text { Initiating Event }-\begin{array}{l}\text { Feedwater Piping Break in } \\
\text { the Turbine Building }\end{array} \\
\text { Sequence Level Cut Sets }\end{array}$} & \multicolumn{4}{|c|}{ Sequence: $L O F W T B-H$} \\
\hline & $\begin{array}{l}\text { Component } \\
\text { Failures }\end{array}$ & $\begin{array}{l}\text { Human } \\
\text { Errors }\end{array}$ & $\begin{array}{l}\text { Support } \\
\text { System } \\
\text { Failures }\end{array}$ & $\begin{array}{l}\text { Determinant } \\
\text { Failure? }\end{array}$ \\
\hline S-EL-III-1-O, S-PCS & & & 2 & \\
\hline F-MCS-ISV-FC, S-PCS & 1 & & 1 & \\
\hline F-MCS-PMP1, S-PCS & 1 & & 1 & \\
\hline S-PCS, S-RCW & & & 2 & \\
\hline S-EL-III-1-E, S-PCS & & & 2 & \\
\hline F-MCS-PMP2, S-PCS & 1 & & 1 & \\
\hline F-MCS-PMP1, S-EL-III-2-E, S-E'L-III-2-O & 1 & & 2 & \\
\hline F-MCS-PMP2, S-EL-III-2-E, S-EL-III-2-O & 1 & & 2 & \\
\hline S-EL-III-1-E, S-EL-III-2-E, S-EL-III-2-O & & & 3 & \\
\hline S-EL-III-1-O, S-EL-III-2-E, S-EL-III-2-O & & & 3 & \\
\hline S-EL-III-2-E, S-EL-III-2-O, S-RCW & & & 3 & \\
\hline
\end{tabular}


Appendix C

Table C.11 (cont.)

\begin{tabular}{|l|c|c|c|c|}
\hline F-MCS-ISV-FC, S-EL-III-2-E, S-EL-III-2-O & 1 & & 2 & \\
\hline S-EL-II-2-E, S-EL-II-2-O, S-EL-III-1-E & & & 3 & \\
\hline F-MCS-PMP2, S-EL-II-2-E, S-EL-II-2-O & 1 & & 2 & \\
\hline F-MCS-ISV-FC, S-EL-II-2-E, S-EL-II-2-O & 1 & & 2 & \\
\hline F-MCS-PMP1, S-EL-II-2-E, S-EL-II-2-O & 1 & & 2 & \\
\hline S-EL-III-2-E, S-EL-II-2-O, S-RCW & & & 3 & \\
\hline S-EL-II-2-E, S-EL-II-2-O, S-EL-III-1-O & & & 3 & \\
\hline
\end{tabular}


Table C.12 Undercooling events sequence categorization: representative initiating event - feedwater piping break in the turbine building

\begin{tabular}{|c|c|c|c|c|c|c|c|c|c|}
\hline \multirow{2}{*}{\multicolumn{2}{|c|}{ Specific Initiator }} & \multicolumn{2}{|c|}{$\begin{array}{l}\text { Feedwater } \\
\text { piping break in } \\
\text { the turbine } \\
\text { building }\end{array}$} & \multicolumn{2}{|c|}{ Turbine trip } & \multicolumn{2}{|c|}{$\begin{array}{l}\text { Loss of } \\
\text { condenser } \\
\text { vacuum }\end{array}$} & \multicolumn{2}{|c|}{$\begin{array}{l}\text { Loss of normal } \\
\text { feedwater flow }\end{array}$} \\
\hline & & \multicolumn{2}{|c|}{$1 \times 10^{-3}$} & \multicolumn{2}{|c|}{$1 \times 10^{\circ}$} & \multicolumn{2}{|c|}{$1 \times 10^{1}$} & \multicolumn{2}{|c|}{$1 \times 10^{-0}$} \\
\hline Sequence & Determinant Failures & Bin & Category & Bin & Category & Bin & Category & Bin & Category \\
\hline LOFWTB-A & NA & $\mathrm{E}$ & EC-II & $\mathbf{A}$ & EC-I & $A$ & EC-I & $\mathbf{A}$ & EC-I \\
\hline LOFWTB-B & $\begin{array}{l}2 \text { valves, support } \\
\text { system }\end{array}$ & G & EC-III & c & EC-III & C & EC-III & C & EC-III \\
\hline LOFWTB-C & 23 failures & $\mathrm{H}$ & EC-IV & $\mathrm{D}$ & EC-IV & D & EC-IV & $D$ & EC-IV \\
\hline LOFWTB-D & 23 failures & $\mathbf{H}$ & EC-IV & $D$ & EC-IV & D & EC-IV & $\mathrm{D}$ & EC-IV \\
\hline LOFWTB-E & $\geq 3$ failures & $\mathrm{H}$ & EC-IV & $\mathrm{D}$ & EC-IV & $\mathrm{D}$ & EC-IV & D & EC-IV \\
\hline LOFWTB-F & $\begin{array}{l}\text { tank level indicator } \\
\text { and human error, } \\
2 \text { pumps and/or valves }\end{array}$ & G & EC-III & $\mathrm{C}$ & EC-III & C & EC-III & C & EC-III \\
\hline LOFWTB-G & support system & $\mathbf{G}$ & EC-III & C & EC-III & $\mathbf{C}$ & EC-III & $\mathbf{C}$ & EC-III \\
\hline LOFWTB-H & 23 failures & $\mathrm{H}$ & EC-IV & $\mathrm{D}$ & EC-IV & D & EC-IV & D & EC-IV \\
\hline LOFWTB-FTSD-A & $\geq 3$ failures & $\mathrm{H}$ & EC-IV & $\mathrm{D}$ & EC-IV & $D$ & EC-IV & $\mathrm{D}$ & EC-IV \\
\hline LOFWTB-FTSD-B & $\geq 3$ failures & $\mathrm{H}$ & EC-IV & $\mathrm{D}$ & EC-IV & D & EC-IV & D & EC-IV \\
\hline LOFWTB-FTSD-C & 23 failures & $\mathrm{H}$ & EC-IV & $\mathrm{D}$ & EC-IV & $\mathrm{D}$ & EC-IV & $\mathrm{D}$ & EC-IV \\
\hline LOFWTB-FTSD-D & 23 failures & $\mathbf{H}$ & EC-IV & $\mathrm{D}$ & EC-IV & D & EC-IV & D & EC-IV \\
\hline LOFWTB-FTSD-E & $\geq 3$ failures & $\mathrm{H}$ & EC-IV & $\mathrm{D}$ & EC-IV & $D$ & EC-IV & $D$ & EC-IV \\
\hline LOFWTB-FTSD-F & 23 failures & $\mathbf{H}$ & EC-IV & $\mathrm{D}$ & EC-IV & $D$ & EC-IV & $\mathrm{D}$ & EC-IV \\
\hline LOFWTB-FTSD-G & $\geq 3$ failures & $\mathrm{H}$ & EC-IV & $\mathrm{D}$ & EC-IV & $\mathrm{D}$ & EC-IV & D & EC-IV \\
\hline LOFWTB-FTSD-H & 23 failui es & $\mathrm{H}$ & EC-IV & D & EC-IV & $\mathrm{D}$ & EC-IV & $\mathrm{D}$ & EC-IV \\
\hline LOFWTB-FTSD-I & 23 failures & $\mathrm{H}$ & EC-IV & $\mathrm{D}$ & EC-IV & $\mathrm{D}$ & EC-IV & D & EC-IV \\
\hline LOFWTB-FTSD-J & $\geq 3$ failures & $\mathbf{H}$ & EC-IV & $\mathrm{D}$ & EC-IV & $\mathrm{D}$ & EC-IV & $\mathrm{D}$ & EC-IV \\
\hline LOFWTB-FTSD-K & 23 failures & $\mathrm{H}$ & EC-IV & $\mathrm{D}$ & EC-IV & $\mathrm{D}$ & EC-IV & $D$ & EC-IV \\
\hline LOFWTB-FTSD-L & $\geq 3$ failures & $\mathrm{H}$ & EC-IV & $\mathrm{D}$ & EC-IV & $\mathrm{D}$ & EC-IV & D & EC-IV \\
\hline LOFWTB-FTSD-M & 23 failures & $\mathbf{H}$ & EC-IV & D & EC-IV & $D$ & EC-IV & $D$ & EC-IV \\
\hline LOFWTB-FTSD-N & $\geq 3$ failures & $\mathbf{H}$ & EC-IV & $\mathrm{D}$ & EC-IV & $\mathrm{D}$ & EC-IV & $\mathbf{D}$ & EC-IV \\
\hline
\end{tabular}


Table C.12 (cont.)

\begin{tabular}{|c|c|c|c|c|c|c|c|}
\hline \multicolumn{2}{|c|}{ Specific Initiator } & \multicolumn{2}{|c|}{$\begin{array}{l}\text { Failure of the steam } \\
\text { generator pressure } \\
\text { control resulting } \\
\text { closure of the turbine } \\
\text { throttle valves }\end{array}$} & \multicolumn{2}{|c|}{$\begin{array}{l}\text { Loss of } \\
\text { condensate } \\
\text { pumps }\end{array}$} & \multicolumn{2}{|c|}{$\begin{array}{l}\text { Failure of } \\
\text { steam } \\
\text { generator level } \\
\text { control }\end{array}$} \\
\hline \multicolumn{2}{|c|}{ IE Frequency } & \multicolumn{2}{|c|}{$1 \times 10^{-2}$} & \multicolumn{2}{|c|}{$1 \times 10^{-1}$} & \multicolumn{2}{|c|}{$1 \times 10^{-2}$} \\
\hline Sequence & Determinant Failures & $\operatorname{Bin}$ & Category & Bin & Category & Bin & Category \\
\hline LOFWTB-A & NA & A & EC-I & $\mathbf{A}$ & EC-I & $\mathbf{A}$ & EC-I \\
\hline LOFWTB-B & $\begin{array}{l}2 \text { valves, support } \\
\text { system }\end{array}$ & C & EC-III & C & EC-III & C & EC-III \\
\hline LOFWTB-C & 23 failures & D & EC-IV & D & EC-IV & $D$ & EC-IV \\
\hline LOFWTB-D & $\geq 3$ failures & D & EC-IV & D & EC-IV & D & EC-IV \\
\hline LOFWTB-E & $\geq 3$ failures & D & EC-IV & D & EC-IV & D & EC-IV \\
\hline LOFWTB-F & $\begin{array}{l}\text { tank level indicator } \\
\text { and human error, } \\
2 \text { pumps and/or } \\
\text { valves }\end{array}$ & C & EC-III & C & EC-III & C & EC-III \\
\hline LOFWTB-G & support system & c & EC-III & C & EC-III & C & EC-III \\
\hline LOFWTB-H & $\geq 3$ failures & D & EC-IV & D & EC.IV & D & EC-IV \\
\hline LOFWTB-FTSD-A & $\geq 3$ failures & D & EC-IV & D & EC-IV & D & EC-IV \\
\hline LOFWTB-FTSD-B & 23 failures & D & EC-IV & D & EC-IV & D & EC-IV \\
\hline LOFWTB-FTSD-C & $\geq 3$ failures & D & EC-IV & D & EC-IV & D & EC-IV \\
\hline LOFWTB-FTSD-D & $\geq 3$ failures & D & EC-IV & D & EC-IV & D & EC-IV \\
\hline LOFWTB-FTSD-E & $\geq 3$ failures & D & EC-IV & D & EC-IV & $D$ & EC-IV \\
\hline LOFWTB-FTSD-F & $\geq 3$ failures & D & EC-IV & $\mathrm{D}$ & EC-IV & D & EC-IV \\
\hline LOFWTB-FTSD-G & $\geq 3$ failures & D & EC-IV & D & EC-IV & D & EC-IV \\
\hline LOFWTB-FTSD-H & $\geq 3$ failures & D & EC-IV & D & EC-IV & D & EC-IV \\
\hline LOFWTB-FTSD-I & $\geq 3$ failures & D & EC-IV & D & EC-IV & D & EC-IV \\
\hline LOFWTB-FTSD-J & $\geq 3$ failures & D & EC-IV & D & EC-IV & D & EC-IV \\
\hline LOWFTB-FTSD-K & $\geq 3$ failures & D & EC-IV & D & EC-IV & D & EC-IV \\
\hline LOFWTB-FTSD-L & $\sum 3$ failures & D & EC-IV & $\mathrm{D}$ & EC-IV & D & EC-IV \\
\hline LOFWTB-FTSD-M & $\geq 3$ failures & D & EC-IV & D & EC-IV & D & EC-IV \\
\hline LOFWTB-FTSD-N & $\geq 3$ failures & D & EC-IV & D & EC-IV & D & EC-IV \\
\hline
\end{tabular}


Table C.13 SCRAM sequence cut sets

\begin{tabular}{|c|c|c|c|c|}
\hline Initiating Event - SCRAM & \multicolumn{4}{|c|}{ Sequence: SCRAM-A } \\
\hline Sequence Level Cut Sets & $\begin{array}{l}\text { Component } \\
\text { Faibures }\end{array}$ & $\begin{array}{l}\text { Human } \\
\text { Erron }\end{array}$ & $\begin{array}{l}\text { Support } \\
\text { spyterm } \\
\text { Filured }\end{array}$ & $\begin{array}{l}\text { Decermiment } \\
\text { Faikure? }\end{array}$ \\
\hline NONE & NA & NA & NA & NA \\
\hline
\end{tabular}

\begin{tabular}{|c|c|c|c|c|}
\hline \multirow{2}{*}{$\frac{\text { Initiating Event - SCRAM }}{\text { Sequence Level Cut Sets }}$} & \multicolumn{4}{|c|}{ Sequence: SCRAM-B } \\
\hline & $\begin{array}{l}\text { Composent } \\
\text { Failures }\end{array}$ & $\begin{array}{l}\text { Human } \\
\text { Errors }\end{array}$ & $\begin{array}{l}\text { Support } \\
\text { Syptem } \\
\text { Faihures }\end{array}$ & $\begin{array}{l}\text { Determinant } \\
\text { Fuilure ? }\end{array}$ \\
\hline S-PCS & & & 1 & $\mathbf{Y}$ \\
\hline S-AIR & & & 1 & $\mathbf{Y}$ \\
\hline S-EL-II-2-E, S-EL-II-2-O & & & 2 & \\
\hline F-ASD-ASD1, F-CSD-SDV3, S-EL-II-2-E & 2 & & 1 & \\
\hline F-ASD-ASD1, F-CSD-SDV1, S-EL-III-2-E & 2 & & 1 & \\
\hline F-ASD-ASD2, F-CSD-SDV2, S-EL-II-2-O & 2 & & 1 & \\
\hline F-ASD-ASD2, F-CSD-SDV4, S-EL-II-2-O & 2 & & 1 & \\
\hline
\end{tabular}

\begin{tabular}{|c|c|c|c|c|}
\hline \multirow{2}{*}{$\frac{\text { Initiating Event - SCRAM }}{\text { Sequence Level Cut Sets }}$} & \multicolumn{4}{|c|}{ Sequence: SCRAM-C } \\
\hline & $\begin{array}{l}\text { Composent } \\
\text { Fuilures }\end{array}$ & $\begin{array}{l}\text { Human } \\
\text { Errorn }\end{array}$ & $\begin{array}{l}\text { Support } \\
\text { Syytem } \\
\text { Faihurea }\end{array}$ & $\begin{array}{l}\text { Decemminant } \\
\text { Faibure? }\end{array}$ \\
\hline F-MSV-MSSV3-SG1, F-MSV-MSSV4-SG1, S-AIR & 2 & & 1 & \\
\hline F-MSV-MSSV1-SG1, F-MSV-MSSV3-SG1, S-AIR & 2 & & 1 & \\
\hline F-MSV-MSSV1-SG2, F-MSV-MSSV2-SG2, S-AIR & 2 & & 1 & \\
\hline F-MSV-MSSV1-SG2, F-MSV-MSSV3-SG2, S-AIR & 2 & & 1 & \\
\hline F-MSV-MSSV2-SG1, F-MSV-MSSV3-SG1, S-AIR & 2 & & 1 & \\
\hline F-MSV-MSSV2-SG2, F-MSV-MSSV3-SG2, S-AIR & 2 & & 1 & \\
\hline F-MSV-MSSV1-SG1, F-MSV-MSSV4-SG1, S-AIR & 2 & & 1 & $\mathfrak{i}$ \\
\hline F-MSV-MSSV2-SG2, F-MSV-MSSV4-SG2, S-AIR & 2 & & 1 & \\
\hline
\end{tabular}


Appendix C

Table C.13 (cont.)

\begin{tabular}{||l|l|l|l|l||}
\hline F-MSV-MSSV1-SG2, F-MSV-MSSV4-SG2, S-AIR & 2 & & 1 & \\
\hline F-MSV-MSSV3-SG2, F-MSV-MSSV4-SG2, S-AIR & 2 & & 1 & \\
\hline F-MSV-MSSV1-SG1, F-MSV-MSSV2-SG1, S-AIR & 2 & & 1 & \\
\hline F-MSV-MSSV2-SG1, F-MSV-MSSV4-SG1, S-AIR & 2 & & 1 & \\
\hline
\end{tabular}

\begin{tabular}{|c|c|c|c|c|}
\hline \multirow{2}{*}{$\begin{array}{c}\text { Initiating Event - SCRAM } \\
\text { Sequence Level Cut Sets }\end{array}$} & \multicolumn{4}{|c|}{ Sequence: SCRAM-D } \\
\hline & $\begin{array}{c}\text { Composens } \\
\text { Frailures }\end{array}$ & $\begin{array}{l}\text { Humoen } \\
\text { Erron }\end{array}$ & $\begin{array}{l}\text { Suppont } \\
\text { Systemen } \\
\text { Failurea }\end{array}$ & $\begin{array}{l}\text { Determiment } \\
\text { Faihure? }\end{array}$ \\
\hline F-MSV-MSSV3-SG1, F-MSV-MSSV4-SG1, S-PCS & 2 & & 1 & \\
\hline F-MSV-MSSV1-SG1, F-MSV-MSSV3-SG1, S-PCS & 2 & & 1 & \\
\hline F-MSV-MSSV1-SG2, F-MSV-MSSV2-SG2, S-PCS & 2 & & 1 & \\
\hline F-MSV-MSSV1-SG2, F-MSV-MSSV3-SG2, S-PCS & 2 & & 1 & \\
\hline F-MSV-MSSV2-SG1, F-MSV-MSSV3-SG1, S-PCS & 2 & & 1 & \\
\hline F-MSV-MSSV2-SG2, F-MSV-MSSV3-SG2, S-PCS & 2 & & 1 & \\
\hline F-MSV-MSSV1-SG1, F-MSV-MSSV4-SG1, S-PCS & 2 & & 1 & \\
\hline F-MSV-MSSV2-SG2, F-MSV-MSSV4-SG2, S-PCS & 2 & & 1 & \\
\hline F-MSV-MSSV1-SG2, F-MSV-MSSV4-SG2, S-PCS & 2 & & 1 & \\
\hline F-MSV-MSSV3-SG2, F-MSV-MSSV4-SG2, S-PCS & 2 & & 1 & \\
\hline F-MSV-MSSV1-SG1, F-MSV-MSSV2-SG1, S-PCS & 2 & & 1 & \\
\hline F-MSV-MSSV2-SG1, F-MSV-MSSV4-SG1, S-PCS & 2 & & 1 & \\
\hline
\end{tabular}

\begin{tabular}{|c|c|c|c|c|}
\hline \multirow{2}{*}{$\begin{array}{l}\text { Initiating Event - SCRAM } \\
\text { Sequence 'Level Cut Sets }\end{array}$} & \multicolumn{4}{|c|}{ Sequence: SCRAM-G } \\
\hline & $\begin{array}{c}\text { Composent } \\
\text { Faitures }\end{array}$ & $\begin{array}{c}\text { Human } \\
\text { Erron }\end{array}$ & $\begin{array}{l}\text { Suppon } \\
\text { Syvelem } \\
\text { Frilures }\end{array}$ & $\begin{array}{l}\text { Determinant } \\
\text { Failure? }\end{array}$ \\
\hline F-FW1-ISV2, S-PCS & 1 & & 1 & \\
\hline F-FW1-ISV1, S-PCS & 1 & & 1 & \\
\hline S-AIR, S-PCS & & & 2 & \\
\hline F-FW1-CNV2, S-EL-II-1-O, S-PCS & 1 & & 2 & \\
\hline S-EL-II-1-E, S-EL-II-1-O, S-PCS & & & 3 & \\
\hline F-FW1-CNV1, S-EL-II-1-E, S-PCS & 1 & & 2 & \\
\hline F-FW1-CNV1, F-FW1-CNV2, S-PCS & 2 & & 1 & \\
\hline S-EL-IV-E, S-EL-IV-O, S-PCS & & & 3 & \\
\hline F-FW1-PMP1, F-FW1-PMP2, S-PCS & 2 & & 1 & \\
\hline
\end{tabular}


Table C.13 (cont.)

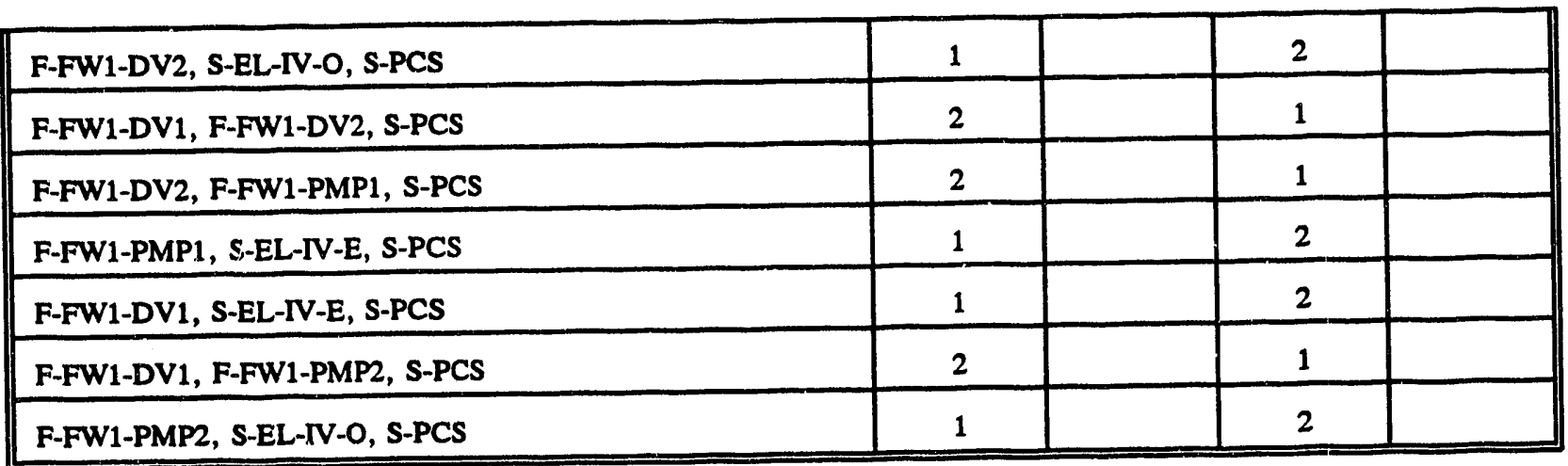

\begin{tabular}{|c|c|c|c|c|}
\hline \multirow{2}{*}{$\begin{array}{l}\text { Initiating Event - SCRAM } \\
\text { Sequence Level Cut Sets }\end{array}$} & \multicolumn{4}{|c|}{ Sequence: SCRAM-H } \\
\hline & $\begin{array}{l}\text { Component } \\
\text { Fuilurea }\end{array}$ & $\begin{array}{l}\text { Hummen } \\
\text { Erron }\end{array}$ & $\begin{array}{l}\text { Support } \\
\text { Syutem } \\
\text { Failurea } \\
\end{array}$ & $\begin{array}{l}\text { Determimant } \\
\text { Faihure? }\end{array}$ \\
\hline F-FW1-HE, S-PCS, S-RCW & & 1 & 2 & \\
\hline F-FW1-ISV2, F-MCS-ISV-FC, S-PCS & 2 & & 1 & \\
\hline F-FW1-ISV2, S-EL-III-1-0, S-PCS & 1 & & 2 & \\
\hline F-FW1-ISV2, S-PCS, S-RCW & 1 & & 2 & \\
\hline F-FW1-ISV1, S-PCS, S-RCW & 1 & & 2 & \\
\hline F-FW1-ISV1, F-MCS-PMP1, S-PCS & 2 & & 1 & \\
\hline S-FIW, S-PCS, S-RCW & & & 3 & \\
\hline F-FW1-ISV1, S-EL-III-1-O, S-PCS & 1 & & 2 & \\
\hline F-FW1-ISV2, F-MCS-PMP2, S-PCS & 2 & & 1 & \\
\hline F-FW1-ISV2, F-MCS-PMP1, S-PCS & 2 & & 1 & \\
\hline F-FW1-ISV1, F-MCS-PMP2, S-PCS & 2 & & 1 & \\
\hline F-FW1-ISV1, F-MCS-ISV-FC, S-PCS & 2 & & 1 & \\
\hline F-FW1-ISV2, S-EL-III-1-E, S-PCS & 1 & & 2 & \\
\hline F-FW1-ISV1, S-EL-III-1-E, S-PCS & 1 & & 2 & \\
\hline S-AIR, S-EL-III-1-O, S-PCS & & & 3 & \\
\hline S-AIR, S-PCS, S-RCW & & & 3 & \\
\hline F-MCS-PMP1, S-AIR, S-PCS & 1 & & 2 & \\
\hline F-MCS-PMP2, S-AIR, S-PCS & 1 & & 2 & \\
\hline S-AIR, S-EL-III-1-E, S-PCS & & & 3 & \\
\hline F-MCS-ISV-FC, S-AIR, S-PCS & 1 & & 2 & \\
\hline
\end{tabular}


Table C.14 Reactivity transient events sequence categorization: representative initiating cvent - SCRAM

\begin{tabular}{|c|c|c|c|c|c|c|c|}
\hline \multicolumn{2}{|c|}{ Specific Initiator } & \multicolumn{2}{|c|}{$S C R A M$} & \multicolumn{2}{|c|}{$\begin{array}{l}\text { Uncontrolled } \\
\text { control rod } \\
\text { assembly } \\
\text { withdrawl }\end{array}$} & \multicolumn{2}{|c|}{$\begin{array}{l}\text { Control rod } \\
\text { maloperation } \\
\text { (part length control } \\
\text { rods, rod ejection, } \\
\text { or rod drop) }\end{array}$} \\
\hline \multicolumn{2}{|c|}{ IE Frequency } & \multicolumn{2}{|c|}{$1 \times 10^{-}$} & \multicolumn{2}{|c|}{$1 \times 10^{-2}$} & \multicolumn{2}{|c|}{$1 \times 10^{\circ}$} \\
\hline Sequence & $\begin{array}{c}\text { Determinant } \\
\text { Failures }\end{array}$ & Bin & Category & Bin & Category & Bin & Category \\
\hline SCRAM-A & NA & $\mathbf{A}$ & EC-I & $\mathbf{A}$ & EC-I & $\mathbf{A}$ & EC-I \\
\hline SCRAM-B & support systems & C & EC-III & $\mathbf{C}$ & EC-III & C & EC-III \\
\hline SCRAM-C & $\geq 3$ failures & D & EC-IV & $\mathbf{D}$ & EC-IV & D & EC-IV \\
\hline SCRAM-D & $\geq 3$ failures & $D$ & EC-IV & D & EC-IV & D & EC-IV \\
\hline SCRAM-E & $\geq 3$ failures & D & EC-IV & $\mathbf{D}$ & EC-IV & $\mathrm{D}$ & EC-IV \\
\hline SCRAM-F & $\geq 3$ failures & $\mathrm{D}$ & EC-IV & $\mathbf{D}$ & EC-IV & D & E.C-IV \\
\hline SCRAM-G & $\geq 3$ failures & D & EC-IV & D & EC-IV & D & EC-IV \\
\hline SCRAM-H & 23 failures & D & EC-IV & $\mathbf{D}$ & EC-IV & D & EC-IV \\
\hline SCRAM-FTSD-A & $\geq 3$ failures & D & EC-IV & D & EC-IV & D & EC-IV \\
\hline SCRAM-FTSD-B & $\geq 3$ failures & D & EC-IV & D & EC-IV & $\mathbf{D}$ & EC-IV \\
\hline SCRAM-FTSD-C & 23 failures & D & EC-IV & $\mathbf{D}$ & EC-IV & D & EC-IV \\
\hline SCRAM-FTSD-D & $\geq 3$ failures & $D$ & EC-IV & $D$ & EC-IV & D & EC-IV \\
\hline SCRAM-FTSD-E & $\geq 3$ failures & D & EC-IV & $D$ & EC-IV & D & EC-IV \\
\hline SCRAM-FTSD-F & $\geq 3$ failures & D & EC-IV & D & EC-IV & D & EC-IV \\
\hline SCRAM-FTSD-G & $\geq 3$ failures & D & EC-IV & D & EC-IV & D & EC-IV \\
\hline SCRAM-FTSD-H & $\geq 3$ failures & $\mathrm{D}$ & EC-IV & D & EC-IV & D & EC-IV \\
\hline SCRAM-FTSD-I & $\geq 3$ failures & $\mathrm{D}$ & EC-IV & D & EC-IV & $\mathrm{D}$ & EC-IV \\
\hline SCRAM-FTSD-J & $\geq 3$ failures & D & EC-IV & $\mathbf{D}$ & EC-IV & D & EC-IV \\
\hline SCRAM-FTSD-K & $\geq 3$ failures & D & EC-IV & D & EC-IV & D & EC-IV \\
\hline SCRAM-FTSD-L & $\geq 3$ failures & D & EC-IV & D & EC-IV & D & EC-IV \\
\hline SCRAM-FTSD-M & $\geq 3$ failures & D & EC-IV & D & EC-IV & D & EC-IV \\
\hline SCRAM-FTSD-N & 23 failures & D & EC-IV & $\mathrm{D}$ & EC-IV & $\mathrm{D}$ & EC-IV \\
\hline
\end{tabular}


Table C.14 (cont.)

\begin{tabular}{|c|c|c|c|c|c|c|c|}
\hline \multicolumn{2}{|c|}{ Specific Initiator } & \multicolumn{2}{|c|}{$\begin{array}{c}\text { Rod position } \\
\text { error (pressure, } \\
\text { temperature, } \\
\text { power } \\
\text { imbalance) }\end{array}$} & \multicolumn{2}{|c|}{$\begin{array}{l}\text { Moderator } \\
\text { anomalies }\end{array}$} & \multicolumn{2}{|c|}{$\begin{array}{l}\text { Feedwater system } \\
\text { malfunctions that } \\
\text { result in an increase } \\
\text { in feedwater flow or a } \\
\text { decrease in feedwater } \\
\text { temperature }\end{array}$} \\
\hline \multicolumn{2}{|c|}{ IE Frequency } & \multicolumn{2}{|c|}{$1 \times 10^{-2}$} & \multicolumn{2}{|c|}{$1 \times 10^{-2}$} & \multicolumn{2}{|c|}{$1 \times 10^{-}$} \\
\hline Sequence & $\begin{array}{l}\text { Determinant } \\
\text { Failures }\end{array}$ & Bin & Category & Bin & Category & Bin & Category \\
\hline SCRAM-A & NA & $\mathbf{A}$ & EC-I & $\mathbf{A}$ & EC-I & $\mathbf{A}$ & EC-I \\
\hline SCRAM-B & support systems & $\mathrm{C}$ & EC-III & C & EC-III & C & EC-III \\
\hline SCRAM-C & $\geq 3$ failures & $\mathrm{D}$ & EC-IV & $\mathrm{D}$ & EC-IV & $D$ & EC-IV \\
\hline SCRAM-D & $\geq 3$ failures & $\mathrm{D}$ & EC-IV & $\mathrm{D}$ & EC-IV & $\mathrm{D}$ & EC-IV \\
\hline SCRAM-E & 23 failures & $\mathrm{D}$ & EC-IV & $\mathrm{D}$ & EC-IV & $\mathrm{D}$ & EC-IV \\
\hline SCRAM-F & $\geq 3$ failures & D & EC-IV & D & EC-IV & D & EC-IV \\
\hline SCRAM-G & $\geq 3$ failures & $\mathrm{D}$ & EC-IV & $\mathrm{D}$ & EC-IV & $\mathrm{D}$ & EC-IV \\
\hline SCRAM-H & $\geq 3$ failures & $\mathrm{D}$ & EC-IV & D & EC-IV & D & EC-IV \\
\hline SCRAM-FTSD-A & 23 failures & D & EC-IV & $\mathrm{D}$ & EC-IV & $\mathrm{D}$ & EC-IV \\
\hline SCRAM-FTSD-B & 23 failures & $\mathrm{D}$ & EC-IV & D & EC-IV & D & EC-IV \\
\hline SCRAM-FTSD-C & $\geq 3$ failures & $\mathrm{D}$ & EC-IV & $\mathrm{D}$ & EC-IV & $\mathrm{D}$ & EC-IV \\
\hline SCRAM-FTSD-D & 23 failures & $\mathrm{D}$ & EC-IV & $\mathrm{D}$ & EC-IV & $\mathrm{D}$ & EC-IV \\
\hline SCRAM-FTSD-E & $\geq 3$ failures & $\mathrm{D}$ & EC-IV & $\mathrm{D}$ & EC-IV & $\mathrm{D}$ & EC-IV \\
\hline SCRAM-FTSD-F & 23 failures & $\mathrm{D}$ & EC-IV & D & EC-IV & $\mathrm{D}$ & EC-IV \\
\hline SCRAM-FTSD-G & 23 failures & $\mathrm{D}$ & EC-IV & $\mathrm{D}$ & EC-IV & $D$ & EC-IV \\
\hline SCRAM-FTSD-H & $\geq 3$ failures & D & EC-IV & $\mathrm{D}$ & EC-IV & $\mathrm{D}$ & EC-IV \\
\hline SCRAM-FTSD-I & 23 failures & $\mathrm{D}$ & EC-IV & $\mathrm{D}$ & EC-IV & $\mathrm{D}$ & EC-IV \\
\hline SCRAM-FTSD-J & $\geq 3$ failures & $\mathrm{D}$ & EC-IV & $\mathrm{D}$ & EC-IV & $\mathrm{D}$ & EC-IV \\
\hline SCRAM-FTSD-K & $\geq 3$ failures & D & EC-IV & $\mathrm{D}$ & EC-IV & D & EC-IV \\
\hline SCRAM-FTSD-L & 23 failures & D & EC-IV & D & EC-IV & D & EC-IV \\
\hline SCRAM-FTSD-M & 23 failures & D & EC-IV & $\mathrm{D}$ & EC-IV & $\mathrm{D}$ & EC-IV \\
\hline SCRAM-FTSD-N & 23 failures & $\mathrm{D}$ & EC-IV & D & EC-IV & $\mathrm{D}$ & EC-IV \\
\hline
\end{tabular}


Table C.14 (cont)

\begin{tabular}{|c|c|c|c|c|c|c|c|}
\hline \multicolumn{2}{|c|}{ Specific Initiator } & \multicolumn{2}{|c|}{$\begin{array}{l}\text { Steam pressure } \\
\text { regulator } \\
\text { malfunction or } \\
\text { failure that results } \\
\text { in increasing steam } \\
\text { flow (turbine } \\
\text { overspeed) }\end{array}$} & \multicolumn{2}{|c|}{$\begin{array}{c}\text { Inadvertent } \\
\text { opening of a } \\
\text { steam } \\
\text { generator relief } \\
\text { or safety valve }\end{array}$} & \multicolumn{2}{|c|}{$\begin{array}{l}\text { Increased heat } \\
\text { transfer flow or } \\
\text { inventory }\end{array}$} \\
\hline \multicolumn{2}{|c|}{ IE Frequency } & \multicolumn{2}{|c|}{$1 \times 10^{2}$} & \multicolumn{2}{|c|}{$1 \times 10^{-2}$} & \multicolumn{2}{|c|}{$1 \times 10^{-2}$} \\
\hline Sequence & $\begin{array}{l}\text { Determinant } \\
\text { Failures }\end{array}$ & Bin & Category & Bin & Category & Bin & Category \\
\hline$\overline{\text { SCRAM-A }}$ & $\overline{\text { NA }}$ & $\overline{\mathrm{A}}$ & EC-I & $\overline{\mathbf{A}}$ & EC-I & $\bar{A}$ & EC-I \\
\hline SCRAM-B & support systems & C & EC-III & C & EC-III & C & EC-III \\
\hline SCRAM-C & $\geq 3$ failures & D & EC-IV & D & EC-IV & D & EC-IV \\
\hline SCRAM-D & $\geq 3$ failures & D & EC-IV & $\bar{D}$ & EC-IV & $\mathrm{D}$ & EC-IV \\
\hline SCRAM-E & $\geq 3$ failures & D & EC-IV & $\bar{D}$ & EC-IV & D & EC-IV \\
\hline SCRAM-F & 23 finilures & D & EC-IV & D & EC-IV & $\mathrm{D}$ & EC-IV \\
\hline SCRAM-G & $\geq 3$ failures & D & EC-IV & D & EC-IV & D & EC-IV \\
\hline SCRAM-H & $\geq 3$ failures & D & EC-IV & $\bar{D}$ & EC-IV & D & EC-IV \\
\hline SCRAM-FTSD-A & $\geq 3$ failures & D & EC-IV & D & EC-IV & $\mathrm{D}$ & EC-IV \\
\hline SCRAM-FTSD-B & $\geq 3$ failures & $\bar{D}$ & EC-IV & $\bar{D}$ & EC-IV & D & EC-IV \\
\hline SCRAM-FTSD-C & $\geq 3$ failures & $D$ & EC-IV & D & EC-IV & $\bar{D}$ & EC-IV \\
\hline SCRAM-FTSD-D & $\geq 3$ failures & D & EC-IV & D & EC-IV & D & EC-IV \\
\hline SCRAM-FTSD-E & $\geq 3$ failures & D & EC-IV & D & EC-IV & D & EC-IV \\
\hline SCRAM-FTSD-F & $\geq 3$ failures & D & EC-IV & D & EC-IV & $\bar{D}$ & EC-IV \\
\hline SCRAM-FTSD-G & $\geq 3$ failures & D & EC-IV & $\bar{D}$ & EC-IV & $\bar{D}$ & EC-IV \\
\hline SCRAM-FTSD-H & $\geq 3$ failures & $D$ & EC-IV & D & EC-IV & D & EC-IV \\
\hline SCRAM-FTSD-I & 23 failures & $D$ & EC-IV & D & EC-IV & D & EC-IV \\
\hline SCRAM-FTSD-I & $\geq 3$ failures & D & EC-IV & $\bar{D}$ & EC-IV & $\bar{D}$ & EC-IV \\
\hline SCRAM-FTSD-K & $\geq 3$ failures & D & EC-IV & $\bar{D}$ & EC-IV & $\bar{D}$ & EC-IV \\
\hline SCRAM-FTSD-L & $\geq 3$ failures & D & EC-IV & D & EC-IV & D & EC-IV \\
\hline SCRAM-FTSD-M & $\geq 3$ failures & D & EC-IV & $\bar{D}$ & EC-IV & D & EC-IV \\
\hline SCRAM-FTSD-N & $\geq 3$ failures & $\mathrm{D}$ & EC-IV & $\bar{D}$ & EC-IV & $\bar{D}$ & EC-IV \\
\hline
\end{tabular}


Table C.14 (cont)

\begin{tabular}{|c|c|c|c|c|c|c|c|}
\hline \multicolumn{2}{|c|}{ Specific Initiator } & \multicolumn{2}{|c|}{$\begin{array}{l}\text { Steamline piping } \\
\text { breaks inside or } \\
\text { outside } \\
\text { containment }\end{array}$} & \multicolumn{2}{|c|}{$\begin{array}{l}\text { Startup of an } \\
\text { inactive heat transfer } \\
\text { loop or recirculating } \\
\text { loop at an incorrect } \\
\text { temperature }\end{array}$} & \multicolumn{2}{|c|}{$\begin{array}{l}\text { Degradation or } \\
\text { loss of moderator } \\
\text { flow }\end{array}$} \\
\hline \multicolumn{2}{|c|}{ IE Frequency } & \multicolumn{2}{|c|}{$1 \times 10^{-5}$} & \multicolumn{2}{|c|}{$1 \times 10^{-3}$} & \multicolumn{2}{|c|}{$1 \times 10^{-2}$} \\
\hline Sequence & $\begin{array}{l}\text { Determinant } \\
\text { Fsilures }\end{array}$ & Bin & Category & Bin & Category & Bin & Category \\
\hline SCRAM-A & NA & $\mathrm{E}$ & EC-II & $\mathrm{E}$ & EC-II & $\mathbf{A}$ & EC-I \\
\hline SCRAM-B & support systems & $\mathbf{G}$ & EC-III & G & EC-III & $\mathrm{C}$ & EC-III \\
\hline SCRAM-C & 23 failures & $\mathrm{H}$ & EC-IV & $\mathbf{H}$ & EC-IV & D & EC-IV \\
\hline SCRAM-D & $\geq 3$ failures & $\mathbf{H}$ & EC-IV & $\mathrm{H}$ & EC-IV & D & EC-IV \\
\hline SCRAM-E & 23 failures & $\mathrm{H}$ & EC-IV & H & EC-IV & D & EC-IV \\
\hline SCRAM-F & 23 failures & $\mathrm{H}$ & EC-IV & $\mathrm{H}$ & EC-IV & $\mathrm{D}$ & EC-IV \\
\hline SCRAM-G & 23 failures & $\mathrm{H}$ & EC-IV & $\mathbf{H}$ & EC-IV & D & EC-IV \\
\hline SCRAM-H & $\geq 3$ failures & $\mathbf{H}$ & EC-IV & $\mathbf{H}$ & EC-IV & $\mathrm{D}$ & EC-IV \\
\hline SCRAM-FTSD-A & $\sum 3$ failures & $\mathbf{H}$ & EC-IV & $\mathrm{H}$ & EC-IV & D & EC-IV \\
\hline SCRAM-FTSD-B & $\geq 3$ failures & $\mathbf{H}$ & EC-IV & $\mathbf{H}$ & EC-IV & $\mathrm{D}$ & EC-IV \\
\hline SCRAM-FTSD-C & $\geq 3$ failures & H & EC-IV & $\mathrm{H}$ & EC-IV & D & EC-IV \\
\hline SCRAM-FTSD-D & 23 failures & $\mathrm{H}$ & EC-IV & $\mathrm{H}$ & EC-IV & D & EC-IV \\
\hline SCRAM-FTSD-E & $\geq 3$ failures & $\mathbf{H}$ & EC-IV & $\bar{H}$ & EC-IV & D & EC-IV \\
\hline SCRAM-FTSD-F & $\geq 3$ failures & $\mathbf{H}$ & EC-IV & $\mathbf{H}$ & EC-IV & D & EC-IV \\
\hline SCRAM-FTSD-G & $\geq 3$ failures & $\mathbf{H}$ & EC-IV & $\mathbf{H}$ & EC-IV & $D$ & EC-IV \\
\hline SCRAM-FTSD-H & $\geq 3$ failures & $\mathrm{H}$ & EC-IV & $\mathbf{H}$ & EC-IV & D & EC-IV \\
\hline SCRAM-FTSD-I & $\geq 3$ failures & $\mathbf{H}$ & EC-IV & $\mathrm{H}$ & EC-IV & D & EC-IV \\
\hline SCRAM-FTSD-J & $\geq 3$ failures & H & EC-IV & $\mathbf{H}$ & EC-IV & $\mathrm{D}$ & EC-IV \\
\hline SCRAM-FTSD-K & $\geq 3$ failures & H & EC-IV & $\mathrm{H}$ & EC-IV & $\bar{D}$ & EC-IV \\
\hline SCRAM-FTSD-L & 23 failures & H & EC-IV & $\mathrm{H}$ & EC-IV & D & EC-IV \\
\hline SCRAM-FTSD-M & 23 failures & H & EC-IV & $\mathrm{H}$ & EC-IV & $\mathrm{D}$ & EC-IV \\
\hline SCRAM-FTSD-N & 23 failures & $\mathrm{H}$ & EC-IV & $\mathbf{H}$ & EC-IV & $\bar{D}$ & EC-IV \\
\hline
\end{tabular}


Table C.14 (cont)

\begin{tabular}{|c|c|c|c|c|c|c|c|}
\hline \multirow{2}{*}{\multicolumn{2}{|c|}{ Specific Initiator }} & \multicolumn{2}{|c|}{$\begin{array}{c}\text { Degradation or } \\
\text { loss of moderator } \\
\text { cooling }\end{array}$} & \multicolumn{2}{|c|}{$\begin{array}{c}\text { Loss of } \\
\text { moderator } \\
\text { inventory }\end{array}$} & \multicolumn{2}{|c|}{$\begin{array}{l}\text { Failure of the } \\
\text { cover gas system }\end{array}$} \\
\hline & & \multicolumn{2}{|c|}{$1 \times 10^{-2}$} & \multicolumn{2}{|c|}{$1 \times 10^{-2}$} & \multicolumn{2}{|c|}{$1 \times 10^{-2}$} \\
\hline Sequence & $\begin{array}{l}\text { Determinant } \\
\text { Failures }\end{array}$ & Bin & Category & Bin & Category & Bin & Category \\
\hline SCRAM-A & NA & $\mathbf{A}$ & EC-I & A & EC-I & $\mathbf{A}$ & EC-I \\
\hline SCRAM-B & support systems & C & EC-III & C & EC-III & $\mathbf{C}$ & EC-III \\
\hline SCRAM-C & 23 iallures & $\mathrm{D}$ & EC-IV & $\mathrm{D}$ & EC-IV & D & EC-IV \\
\hline SCRAM-D & $\geq 3$ failures & D & EC-IV & D & EC-IV & $\mathrm{D}$ & EC-IV \\
\hline SCRAM-E & $\geq 3$ failures & D & EC-IV & D & EC-IV & $\mathrm{D}$ & EC-IV \\
\hline SCRAM-F & 23 failures & D & EC-IV & $\bar{D}$ & EC-IV & D & EC-IV \\
\hline SCRAM-G & $\geq 3$ failures & D & EC-IV & D & EC-IV & $\mathrm{D}$ & EC-IV \\
\hline SCRAM-H & 23 failures & $\mathrm{D}$ & EC-IV & D & EC-IV & $\mathrm{D}$ & EC-IV \\
\hline SCRAM-FTSD-A & $\geq 3$ failures & D & EC-IV & D & EC-IV & $\mathrm{D}$ & EC-IV \\
\hline SCRAM-FTSD-B & $\geq 3$ failures & D & $\overline{\text { EC-IV }}$ & $D$ & EC-IV & $\bar{D}$ & EC-IV \\
\hline SCR'AM-FTSD-C & $\geq 3$ failures & D & EC-IV & $D$ & EC-IV & $\mathrm{D}$ & EC-IV \\
\hline SCRAM-FTSD-D & 23 failures & D & EC-IV & $D$ & EC-IV & $\mathrm{D}$ & EC-IV \\
\hline SCRAM-FTSD-E & $\geq 3$ failures & $\mathrm{D}$ & EC-IV & D & EC-IV & $\mathrm{D}$ & EC-IV \\
\hline SCRAM-FTSD-F & $\geq 3$ failures & $\mathrm{D}$ & EC-IV & D & EC-IV & $\mathrm{D}$ & EC-IV \\
\hline SCRAM-FTSD-G & $\geq 3$ failures & $\mathrm{D}$ & EC-IV & D & EC-IV & D & EC-IV \\
\hline SCRAM-FTSD-H & $\geq 3$ failures & $\mathrm{D}$ & EC-IV & D & EC-IV & $\mathrm{D}$ & EC-IV \\
\hline SCRAM-FTSD-I & $\geq 3$ failures & D & EC-IV & $D$ & EC-IV & D & EC-IV \\
\hline SCRAM-FTSD-J & 23 failures & D & EC-IV & D & EC-IV & D & EC-IV \\
\hline SCRAM-FTSD-K & 23 failures & D & EC-IV & D & EC-IV & D & EC-IV \\
\hline SCRAM-FTSD-L & 23 failures & D & EC-IV & $\mathrm{D}$ & EC-IV & D & EC-IV \\
\hline SCRAM-FTSD-M & $\geq 3$ failures & $\mathrm{D}$ & EC-IV & D & EC-IV & D & EC-IV \\
\hline SCRAM-FTSD-N & 23 failures & D & EC-IV & $\bar{D}$ & EC-IV & $\mathrm{D}$ & EC-IV \\
\hline
\end{tabular}


Table C.14 (cont)

\begin{tabular}{|c|c|c|c|c|c|}
\hline \multicolumn{2}{|c|}{ Specific Initiator } & \multicolumn{2}{|c|}{$\begin{array}{c}\text { Moderator } \\
\text { deuteruium excursion }\end{array}$} & \multicolumn{2}{|c|}{$\begin{array}{l}\text { Loss of calandria } \\
\text { structural integrity }\end{array}$} \\
\hline \multicolumn{2}{|c|}{ TE Frequency } & \multicolumn{2}{|c|}{$1 \times 10^{-4}$} & \multicolumn{2}{|c|}{$1 \times 10^{-3}$} \\
\hline Sequence & $\begin{array}{c}\text { Determinant } \\
\text { Failures }\end{array}$ & Bin & Category & Bin & Category \\
\hline SCRAM-A & NA & $E$ & EC-II & $\mathbf{E}$ & EC-II \\
\hline SCRAM-B & support systems & $\mathrm{G}$ & EC-III & $\mathbf{G}$ & EC-III \\
\hline SCRAM-C & $\geq 3$ failures & $\mathrm{H}$ & EC-IV & $\overline{\mathbf{H}}$ & EC-IV \\
\hline SCRAM-D & $\geq 3$ failures & $\mathbf{H}$ & EC-IV & $\mathbf{H}$ & EC-IV \\
\hline SCRAM-E & $\geq 3$ failures & $\mathbf{H}$ & EC-IV & $\mathbf{H}$ & EC-IV \\
\hline SCRAM-F & $\geq 3$ failures & $\mathrm{H}$ & EC-IV & $\mathrm{H}$ & EC-IV \\
\hline SCRAM-G & $\geq 3$ failures & $\mathrm{H}$ & EC-IV & $\mathrm{H}$ & EC-IV \\
\hline SCRAM-H & $\geq 3$ failures & $\mathbf{H}$ & EC-IV & $\mathbf{H}$ & EC'IV \\
\hline SCRAM-FTSD-A & $\geq 3$ failures & $\mathrm{H}$ & EC-IV & $\mathbf{H}$ & EC-IV \\
\hline SCRAM-FTSD-B & $\geq 3$ failures & $\mathrm{H}$ & EC-IV & $\mathrm{H}$ & EC-IV \\
\hline SCRAM-FTSD-C & $\geq 3$ failures & $\mathrm{H}$ & EC-IV & $\mathbf{H}$ & EC-IV \\
\hline SCRAM-FTSD-D & $\geq 3$ failures & $\mathrm{H}$ & EC-IV & $\mathrm{H}$ & EC-IV \\
\hline SCRAM-FTSD-E & $\geq 3$ failures & $\mathrm{H}$ & EC-IV & $\mathrm{H}$ & EC-IV \\
\hline SCRAM-FTSD-F & $\geq 3$ failures & $\mathbf{H}$ & EC-IV & $\mathbf{H}$ & EC-IV \\
\hline SCRAM-FTSD-G & $\geq 3$ failures & $\mathbf{H}$ & EC-IV & $\mathbf{H}$ & EC-IV \\
\hline SCRAM-FTSD-H & $\geq 3$ failures & $\mathbf{H}$ & EC-IV & $\mathbf{H}$ & EC-IV \\
\hline SCRAM-FTSD-I & $\geq 3$ failures & $\mathbf{H}$ & EC-IV & $\mathrm{H}$ & EC-IV \\
\hline SCRAM-FTSD-J & $\geq 3$ failures & $\underline{\mathbf{H}}$ & EC-IV & $\mathbf{H}$ & EC-IV \\
\hline SCRAM-FTSD-K & $\geq 3$ failures & $\mathrm{H}$ & EC-IV & $\mathbf{H}$ & EC-IV \\
\hline SCRAM-FTSD-L & $\geq 3$ failures & $\mathbf{H}$ & EC-IV & $\mathrm{H}$ & EC-IV \\
\hline SCRAM-FTSD-M & $\geq 3$ failures & $\mathbf{H}$ & EC-IV & $\mathbf{H}$ & EC-IV \\
\hline SCRAM-FTSD-N & $\geq 3$ failures & $\mathbf{H}$ & EC-IV & $\mathbf{H}$ & EC-IV \\
\hline
\end{tabular}




\section{Appendix D \\ Check of Methodology Integrity}

Although the methodology described in Chap. 3 is qualitative, it has a basis in quantitative analysis. The event category criteria used in the methodology discriminates based on single, double, or more failures, with multiple failures being assigned to categories of higher consequences. This is done to acknowledge that larger numbers of independent failures, while usually leading to more severe consequences, are decreasingly less likely to occur. The check of the methodology described below takes advantage of this underlying quantitative basis. Performing these checks lends confidence to the methodology by demonstrating the consistency between both methods.

For this methodology check, the fault trees are quantified using very conservative values for the identified failures. These values include:

Human error (nonroutine or low training factor) Human error (routine or high training factor) $10^{-1}$ Active component failure Passive component failure $10^{-2}$ $10^{-2}$ $10^{-3}$ $10^{-3}$ Support system failure (safety related) Support system failure (nonsafety related) $10^{-2}$

The quantification is carried through the fault and event trees. Solution of the event trees yields a frequency of occurrence for each sequence. The frequency for each sequence is the product of the initiating event frequency and the probability associated with each failed system(s) (obtained from quantification of the fault trees). The quantified sequences were classified according to the following frequency of occurrence:

EC-I- $P$ (per year) $\geq 10^{-2}$ (one or more in a plant lifetime) EC-II $-10^{-2}>\mathrm{P}$ (per year) $\geq 10^{-4}$

EC-III $-10^{-4}>\mathrm{P}$ (per year) $\geq 10^{-6}$

EC-IV $-10^{-6}>\mathrm{P}$ (per year)

The EC-II limit was set at $10^{-4}$ because this corresponded to an event that occurs once in the 100-year lifetime of a population of plants (assumed to be 100 plants). Also frequencies of $10^{-4}$ to $10^{-5}$ are currently acknowledged for core damage events in probabilistic risk assessment analyses. Flagging differences of two or more categories is done to reflect uncertainty associated with the rigor of this analysis.

Tables D.1 through D.7 show the comparisons of sequence categorizations by the two methods for the representative initiating events. 
Table D.1 Feeder tube header break sequence comparisons

\begin{tabular}{|c|c|c|c|c|}
\hline Sequence & $\begin{array}{l}\text { Sequence } \\
\text { Frequency }\end{array}$ & $\begin{array}{l}\text { Categorization } \\
\text { by Frequency }\end{array}$ & $\begin{array}{l}\text { Categorization } \\
\text { by Primary } \\
\text { Method }\end{array}$ & Consistent \\
\hline LB-A & $1 \mathrm{E}-02$ & EC-I & EC-II & $\mathbf{Y}$ \\
\hline LB-B & 1E-08 & EC-IV & EC-III & $\bar{Y}$ \\
\hline LB-C & 2E-09 & EC-IV & EC-IV & $\mathbf{Y}$ \\
\hline LB-D & 4E-08 & EC-IV & EC-III & $\mathbf{Y}$ \\
\hline LB-E & $2 \mathrm{E}-09$ & EC-IV & EC-IV & $\bar{Y}$ \\
\hline LB-F & $2 \mathrm{E}-07$ & EC-IV & EC-III & $\mathbf{Y}$ \\
\hline LB-G & $1 \mathrm{E}-08$ & EC-IV & EC-IV & $\bar{Y}$ \\
\hline LB-H & $6 \mathrm{E}-06$ & EC-III & EC-II & $\bar{Y}$ \\
\hline LB-I & $7 \mathrm{E}-10$ & EC-IV & EC-IV & $\bar{Y}$ \\
\hline LB-J & $6 \mathrm{E}-11$ & EC-IV & EC-IV & $\mathbf{Y}$ \\
\hline LB-K & 2E-09 & EC-IV & EC-IV & $\bar{Y}$ \\
\hline LB-L & $e^{1}$ & EC-IV & EC-IV & $\mathrm{Y}$ \\
\hline LB-M & $1 \mathrm{E}-08$ & EC-IV & EC-IV & $Y$ \\
\hline LB-N & $3 \mathrm{E}-10$ & EC-IV & EC-IV & $\mathbf{Y}$ \\
\hline LB-O & $3 \mathrm{E}-07$ & EC-IV & EC-III & $\mathbf{Y}$ \\
\hline LB-P & $2 \mathrm{E}-11$ & EC-IV & EC-IV & $\mathbf{Y}$ \\
\hline LB-Q & $2 \mathrm{E}-12$ & EC-IV & EC-IV & $\mathbf{Y}$ \\
\hline LB-R & $8 \mathrm{E}-11$ & EC-IV & EC-IV & $\mathbf{Y}$ \\
\hline LB-S & $\varepsilon$ & EC-IV & EC-IV & $Y$ \\
\hline LB-T & $5 \mathrm{E}-10$ & EC-IV & EC-IV & $\mathbf{Y}$ \\
\hline LB-U & $1 \mathrm{E}-11$ & EC-IV & EC-IV & $Y$ \\
\hline LB-V & $2 \mathrm{E}-08$ & EC-IV & EC-IV & $\mathbf{Y}$ \\
\hline LB-W & $\varepsilon$ & EC-IV & EC-IV & $\bar{Y}$ \\
\hline LB-X & $\varepsilon$ & EC-IV & EC-IV & $\mathbf{Y}$ \\
\hline LB-Y & $\varepsilon$ & EC-IV & EC-IV & $\mathrm{Y}$ \\
\hline LB-Z & $\varepsilon$ & EC-IV & EC-IV & $\mathbf{Y}$ \\
\hline LB-AA & $1 \mathrm{E}-11$ & EC-IV & EC-IV & $\mathbf{Y}$ \\
\hline LB-AB & $\varepsilon$ & EC-IV & EC-IV & $\mathbf{Y}$ \\
\hline LB-AC & $1 \mathrm{E}-09$ & EC-IV & EC-IV & $\mathbf{Y}$ \\
\hline
\end{tabular}

${ }^{1}$ Value is below the cutoff of $1 \mathrm{E}-15$. 
Table D2 Liquid relief valve failure sequence compurisons

\begin{tabular}{|c|c|c|c|c|}
\hline Sequence & $\begin{array}{l}\text { Sequence } \\
\text { Frequency }\end{array}$ & $\begin{array}{l}\text { Categorization } \\
\text { by Frequency }\end{array}$ & $\begin{array}{l}\text { Categorization } \\
\text { by Primary } \\
\text { Method }\end{array}$ & Consistent \\
\hline LRVF-A & $1 \mathrm{E}-01$ & EC-I & EC-I & $\bar{Y}$ \\
\hline LRVF-B & $1 \mathrm{E}-04$ & EC-II & $\overline{E C}-\mathrm{II}$ & $\bar{Y}$ \\
\hline LRVF-C & 1E-07 & $\overline{\text { EC-IV }}$ & EC-IV & $\overline{\mathbf{Y}}$ \\
\hline LRVF-D & $\varepsilon$ & EC-IV & EC-IV & $\bar{Y}$ \\
\hline LRVF-E & e & EC-IV & EC-IV & $\bar{Y}$ \\
\hline LRVF-F & $e$ & EC-IV & EC-IV & $\bar{Y}$ \\
\hline LRVF-G & $e$ & EC-IV & EC-IV & $\bar{Y}$ \\
\hline LRVF-H & e & EC-IV & EC-IV & $\bar{Y}$ \\
\hline LRVF-I & $1 \mathrm{E}-0.3$ & EC-II & EC-III & $\bar{Y}$ \\
\hline LRVF-J & $4 \mathrm{E}-07$ & EC-IV & EC-IV & $\bar{Y}$ \\
\hline LRVF-K & $\bar{\varepsilon}$ & EC-IV & EC-IV & $\bar{Y}$ \\
\hline LRVF L & $1 \mathrm{E}-06$ & EC-III & EC-IV & $\bar{Y}$ \\
\hline LRVF-M & $\varepsilon$ & EC-IV & $\overline{E C-I V}$ & $\bar{Y}$ \\
\hline LiRVF-N & $2 \mathrm{E}-06$ & EC-III & EC-IV & $\bar{Y}$ \\
\hline IRVF-O & $2 \mathrm{E}-07$ & EC-IV & EC-IV & $y$ \\
\hline LRVF-P & $7 \mathrm{E}-06$ & EC-III & EC-IV & $\bar{Y}$ \\
\hline LPVF-Q & $3 \mathrm{E}-07$ & EC-IV & EC-IV & $\bar{Y}$ \\
\hline LRVF-R & $3 \mathrm{E}-04$ & EC-II & EC-III & $\bar{Y}$ \\
\hline L.RVF-S & 3E-07 & EC-IV & $\overline{E C}-\overline{I V}$ & $\bar{Y}$ \\
\hline LRVF-T & $\bar{\epsilon}$ & EC-IV & EC-IV & $\bar{Y}$ \\
\hline LRVF-U & $\epsilon$ & EC-IV & EC-IV & $\bar{Y}$ \\
\hline LRVF-V & $\bar{\epsilon}$ & EC-IV & EC-IV & $\bar{Y}$ \\
\hline LRVF.W & $\bar{\epsilon}$ & EC-IV & EC-IV & $\overline{\mathbf{Y}}$ \\
\hline$\overline{\mathrm{LEVF}}-\mathrm{X}$ & $\bar{\epsilon}$ & EC-IV & EC-IV & $\overline{\mathbf{Y}}$ \\
\hline LRVF-Y & $\epsilon$ & EC-IV & EC-I & $\bar{Y}$ \\
\hline LRVF-Z & $3 \mathrm{E}-06$ & EC-III & EC-IV & $\bar{Y}$ \\
\hline LRVF-AA & $\bar{\epsilon}$ & EC-IV & EC-IV & $\bar{Y}$ \\
\hline LRVF-AB & e & EC-IV & EC-IV & $\bar{Y}$ \\
\hline LRVF-AC & e & EC-IV & EC-IV & $\bar{Y}$ \\
\hline LRVF-AD & $\varepsilon$ & EC-IV & EC-IV & $\overline{\mathbf{Y}}$ \\
\hline LRVF-AE & 4E-09 & EC-IV & EC-IV & $\bar{Y}$ \\
\hline LRVF-AF & $e$ & EC-IV & EC-IV & $\bar{Y}$ \\
\hline LRVF-AG & $1 \mathrm{E}-08$ & EC-IV & EC-IV & $\bar{Y}$ \\
\hline LRVF-AH & e & $\overline{\text { EC-IV }}$ & $\overline{\text { EC-IV }}$ & $\overline{\mathbf{Y}}$ \\
\hline
\end{tabular}


Table D.2 (cont)

\begin{tabular}{|c|c|c|c|c|}
\hline Sequence & $\begin{array}{l}\text { Sequence } \\
\text { Frequency }\end{array}$ & $\begin{array}{l}\text { Categorization } \\
\text { by Frequency }\end{array}$ & $\begin{array}{l}\text { Categorization } \\
\text { by Primary } \\
\text { Method }\end{array}$ & Consistent \\
\hline LRVF-FTSD-A & $1 \mathrm{E}-06$ & EC-III & EC-IV & $\bar{Y}$ \\
\hline LRVF-FTSD-B & $\bar{c}$ & EC-IV & EC-IV & $\bar{Y}$ \\
\hline LRVF-FTSD-C & $\bar{E}$ & EC-IV & EC-IV & $\bar{Y}$ \\
\hline LRVF-FTSD-D & $\bar{\epsilon}$ & EC-IV & EC-IV & $\bar{Y}$ \\
\hline LRVF-FTSD-E & $\bar{e}$ & EC-IV & EC-IV & $\bar{Y}$ \\
\hline LRVF-FTSD-F & $e$ & EC-iV & EC-IV & $\bar{Y}$ \\
\hline LRVF-FTSD-G & $e$ & EC-IV & EC-IV & $\mathbf{Y}$ \\
\hline LRVF-FTSD-H & $\varepsilon$ & EC-IV & EC-IV & $\bar{Y}$ \\
\hline LRVF-FTSD-I & $\varepsilon$ & EC-IV & EC-IV & $\bar{Y}$ \\
\hline LRVF-FTSD-J & $\bar{\varepsilon}$ & EC-IV & EC-IV & $\bar{Y}$ \\
\hline LRVF-FTSD-K & $\bar{\epsilon}$ & EC-IV & EC-IV & $\bar{Y}$ \\
\hline LRVF-FTSD-L & $\varepsilon$ & EC-IV & EC-IV & $\bar{Y}$ \\
\hline LRVF-FTSD-M & $\bar{e}$ & EC-IV & EC-IV & $\bar{Y}$ \\
\hline LRVF-FTSD-N & $\bar{\varepsilon}$ & EC-IV & EC-IV & $\bar{Y}$ \\
\hline
\end{tabular}


Table D.3 Feeder tube break sequence comparisons

\begin{tabular}{|c|c|c|c|c|}
\hline Sequence & $\begin{array}{l}\text { Sequence } \\
\text { Frequency }\end{array}$ & $\begin{array}{l}\text { Categorization } \\
\text { by Frequency }\end{array}$ & $\begin{array}{c}\text { Categorization } \\
\text { by Primary } \\
\text { Method }\end{array}$ & Consistent \\
\hline SBLFB-A & $1 \mathrm{E}-02$ & EC-I & EC-I & $\bar{Y}$ \\
\hline SBLFB-B & 4E-06 & EC-III & EC-III & $\mathbf{Y}$ \\
\hline SBLFB-C & $2 \mathrm{E}-07$ & EC-IV & EC-IV & $\bar{Y}$ \\
\hline SBLFB-D & 9E-06 & EC-III & EC-III & $\bar{Y}$ \\
\hline SBLFB-E & 6E-07 & EC-IV & EC-IV & $\bar{Y}$ \\
\hline SBLFB-F & $2 \mathrm{E}-07$ & EC-IV & EC-IV & $\bar{Y}$ \\
\hline SBLFB-G & $2 \mathrm{E}-08$ & EC-IV & EC-IV & $\mathbf{Y}$ \\
\hline SBLFB-H & 5E-05 & EC-III & EC-III & $\bar{Y}$ \\
\hline SBLFB-I & $3 \mathrm{E}-06$ & EC-III & EC-IV & $\overline{\mathrm{Y}}$ \\
\hline SBLFB-J & $3 \mathrm{E}-05$ & EC-III & EC-III & $\bar{Y}$ \\
\hline SBLFB-K & $8 \mathrm{E}-09$ & EC-IV & EC-IV & $\bar{Y}$ \\
\hline SBLFB-L & $\varepsilon$ & EC-IV & EC-IV & $\mathbf{Y}$ \\
\hline SBLFB-M & $2 \mathrm{E}-08$ & EC-IV & EC-IV & $\bar{Y}$ \\
\hline SBLFB-N & $\varepsilon$ & EC-IV & EC-IV & $\bar{Y}$ \\
\hline SBLFB-O & 4E-10 & EC-IV & EC-IV & $Y$ \\
\hline SBLFB-P & $\varepsilon$ & EC-IV & EC-IV & $\overline{\mathbf{Y}}$ \\
\hline SBLFB-Q & $1 \mathrm{E}-07$ & EC-III & EC-IV & $\bar{Y}$ \\
\hline SBLFB-R & 5E-09 & EC-IV & EC-IV & $\bar{Y}$ \\
\hline SBLFB-FTSD-A & $1 \mathrm{E}-07$ & EC-IV & EC-IV & $\bar{Y}$ \\
\hline SBLFB-FTSD-B & $\varepsilon$ & EC-IV & EC-IV & $\mathbf{Y}$ \\
\hline SBLFB-FTSD-C & $\varepsilon$ & EC-IV & EC-IV & $\bar{Y}$ \\
\hline SBLFB-FTSD-D & $\varepsilon$ & EC-IV & EC-IV & $\bar{Y}$ \\
\hline SBLFB-FTSD-E & $\varepsilon$ & EC-IV & EC-IV & $\bar{Y}$ \\
\hline SBLFB-FTSD-F & $\varepsilon$ & EC-IV & EC-IV & $\bar{Y}$ \\
\hline SBLFB-FTSD-G & $\varepsilon$ & EC-IV & EC-IV & $\bar{Y}$ \\
\hline SBLFB-FTSD-H & $\bar{c}$ & EC-IV & EC-IV & $\bar{Y}$ \\
\hline SBLFB-FTSD-I & $\varepsilon$ & EC-IV & EC-IV & $\bar{Y}$ \\
\hline SBLFB-FTSD-J & $\varepsilon$ & EC-IV & EC-IV & $\bar{Y}$ \\
\hline SBLFB-FTSD-K & $\varepsilon$ & EC-IV & EC-IV & $\bar{Y}$ \\
\hline SBLFB-FTSD-L & $e$ & EC-IV & EC-IV & $\bar{Y}$ \\
\hline SBLFB-FTSD-M & $e$ & EC-IV & EC-IV & $\bar{Y}$ \\
\hline SBLFB-FTSD-N & $\bar{e}$ & EC-IV & EC-IV & $\bar{Y}$ \\
\hline
\end{tabular}


Table D.4 Loss of Class IV power sequence comparisons

\begin{tabular}{|c|c|c|c|c|}
\hline Sequence & $\begin{array}{l}\text { Sequence } \\
\text { Frequency }\end{array}$ & $\begin{array}{l}\text { Categorization } \\
\text { by Frequency }\end{array}$ & $\begin{array}{c}\text { Categorization } \\
\text { by Primary } \\
\text { Method }\end{array}$ & Consistent \\
\hline LOP-A & $1 \mathrm{E}-02$ & EC-I & EC-I & $\bar{Y}$ \\
\hline LOP-B & 1E-06 & EC-III & EC-III & $\mathbf{Y}$ \\
\hline LOP-C & $\varepsilon$ & EC-IV & EC-IV & $\bar{Y}$ \\
\hline LOP-D & $e$ & EC-IV & EC-IV & $\bar{Y}$ \\
\hline LOP-E & $e$ & EC-IV & EC-IV & $\bar{Y}$ \\
\hline LOP-F & $2 \mathrm{E}-05$ & EC-III & EC-III & $\bar{Y}$ \\
\hline LOP-G & 1E-08 & EC-IV & EC-IV & $\bar{Y}$ \\
\hline LOP-H & $e$ & EC-IV & EC-IV & $\bar{Y}$ \\
\hline LOP-I & $\varepsilon$ & EC-IV & EC-IV & $\bar{Y}$ \\
\hline LOP-J & $\bar{\varepsilon}$ & EC-IV & EC-IV & $\bar{Y}$ \\
\hline LOP-K & $6 \mathrm{E}-07$ & EC-IV & EC-IV & $\bar{Y}$ \\
\hline LOP-L & 6E-10 & EC-IV & EC-IV & $\bar{Y}$ \\
\hline LOP-M & $\varepsilon$ & EC-IV & EC-IV & $\bar{Y}$ \\
\hline LOP-N & 3E-04 & EC-II & EC-I & $\bar{Y}$ \\
\hline LOP-O & 1E-05 & EC-III & EC-IV & $\bar{Y}$ \\
\hline LOP-P & $1 \mathrm{E}-08$ & EC-IV & EC-IV & $\bar{Y}$ \\
\hline LOP-Q & $\varepsilon$ & EC-IV & EC-IV & $\bar{Y}$ \\
\hline LOP-R & $\varepsilon$ & EC-IV & EC-IV & $\bar{Y}$ \\
\hline LOP-S & 6E-07 & EC-IV & EC-IV & $\bar{Y}$ \\
\hline LOP-T & $2 \mathrm{E}-08$ & EC-IV & EC-IV & $\bar{Y}$ \\
\hline LOP-U & $\varepsilon$ & EC-IV & EC-IV & $\bar{Y}$ \\
\hline LOP-V & $\varepsilon$ & EC-IV & EC-IV & $\bar{Y}$ \\
\hline$\overline{\text { LOP-W }}$ & $\varepsilon$ & EC-IV & EC-IV & $\bar{Y}$ \\
\hline LOP-X & $\varepsilon$ & EC-IV & EC-IV & $\bar{Y}$ \\
\hline LOP-Y & $\bar{\varepsilon}$ & EC-IV & EC-IV & $\bar{Y}$ \\
\hline LOP-Z & $\varepsilon$ & EC-IV & EC-IV & $\bar{Y}$ \\
\hline LOP-AA & 1E-04 & EC-II & EC-III & $\bar{Y}$ \\
\hline LOP-AB & 4E-08 & EC-IV & EC-IV & $\bar{Y}$ \\
\hline LOP-AC & $\varepsilon$ & EC-IV & EC-IV & $\bar{Y}$ \\
\hline LOP-AD & 9E-08 & EC-IV & EC-IV & $\mathbf{Y}$ \\
\hline LOP-AE & $e$ & EC-IV & EC-IV & $\bar{Y}$ \\
\hline LOP-AF & $2 \mathrm{E}-07$ & EC-IV & EC-IV & $\bar{Y}$ \\
\hline LOP-AG & 1E-10 & EC-IV & EC-IV & $\bar{Y}$ \\
\hline
\end{tabular}


Table D.4 (cont)

\begin{tabular}{|c|c|c|c|c|}
\hline Sequence & $\begin{array}{l}\text { Sequence } \\
\text { Frequency }\end{array}$ & $\begin{array}{l}\text { Categorization } \\
\text { by Frequency }\end{array}$ & $\begin{array}{l}\text { Categorization } \\
\text { by Primary } \\
\text { Method }\end{array}$ & Consistent \\
\hline LOP-AH & $\boldsymbol{\epsilon}$ & EC-IV & EC-IV & $\bar{Y}$ \\
\hline LOP-AI & e & EC-IV & EC-IV & $\mathbf{Y}$ \\
\hline LOP-AJ & e & EC-IV & EC-IV & $\mathbf{Y}$ \\
\hline LOP-AK & $1 \mathrm{E}-05$ & EC-III & EC-III & $\bar{Y}$ \\
\hline LOP-AL & $6 \mathrm{E}-07$ & EC-IV & EC-IV & $Y$ \\
\hline LOP-AM & $7 \mathrm{E}-07$ & EC-IV & EC-IV & $\mathbf{Y}$ \\
\hline LOP-AN & $3 \mathrm{E}-08$ & EC-IV & EC-IV & $\mathbf{Y}$ \\
\hline LOP-AO & $1 \mathrm{E}-05$ & EC-III & EC-III & $\mathbf{Y}$ \\
\hline LOP-AP & $1 \mathrm{E}-08$ & EC-IV & EC-IV & $\mathbf{Y}$ \\
\hline LOP-AQ & 3E-07 & EC-IV & EC-IV & $\mathbf{Y}$ \\
\hline LOP-AR & 1E-07 & EC-IV & EC-IV & $Y$ \\
\hline LOP-FTSD-A & $\bar{E}$ & EC-IV & EC-IV & $\mathbf{Y}$ \\
\hline LOP-FTSD-B & $\bar{\varepsilon}$ & EC-IV & EC-IV & $\mathbf{Y}$ \\
\hline LOP-FTSD-C & $\varepsilon$ & EC-IV & EC-IV & $\mathbf{Y}$ \\
\hline LOP-FTSD-D & $\boldsymbol{\epsilon}$ & EC-IV & EC-IV & $\mathbf{Y}$ \\
\hline LOP-FTSD-E & $\varepsilon$ & EC-IV & EC-IV & $\mathbf{Y}$ \\
\hline LOP-FTSD-F & $\boldsymbol{\epsilon}$ & EC-IV & EC-IV & $\mathrm{Y}$ \\
\hline LOP-FTSD-G & $\varepsilon$ & EC-IV & EC-IV & $\mathbf{Y}$ \\
\hline LOP-FTSD-H & $\varepsilon$ & EC-IV & EC-IV & $\mathbf{Y}$ \\
\hline LOP-FTSD-I & $\bar{c}$ & EC-IV & EC-IV & $\mathbf{Y}$ \\
\hline LOP-FTSD-J & $\bar{\epsilon}$ & EC-IV & EC-IV & $\mathbf{Y}$ \\
\hline LOP-FTSD-K & $\varepsilon$ & EC-IV & EC-IV & $\mathbf{Y}$ \\
\hline LOP-FTSD-L & $\varepsilon$ & EC-IV & EC-IV & $\mathbf{Y}$ \\
\hline LOP-FTSD-M & $\bar{\epsilon}$ & EC-IV & EC-IV & $\mathbf{Y}$ \\
\hline LOP-FTSD-N & $\varepsilon$ & EC-IV & EC-IV & $\mathbf{Y}$ \\
\hline LOP-AS & $\varepsilon$ & EC-IV & EC-IV & $\mathbf{Y}$ \\
\hline
\end{tabular}


Table D.5 Feedwater piping break in the reactor building sequence comparisons

\begin{tabular}{|c|c|c|c|c|}
\hline Sequence & $\begin{array}{l}\text { Sequence } \\
\text { Frequency }\end{array}$ & $\begin{array}{l}\text { Categorization } \\
\text { by Frequency }\end{array}$ & $\begin{array}{c}\text { Categorization } \\
\text { by Primary } \\
\text { Method }\end{array}$ & Consistent \\
\hline LOFWRB-A & $1 \mathrm{E}-05$ & EC-III & EC-III & $\bar{Y}$ \\
\hline LOFWRB-B & 1E-09 & EC-IV & EC-IV & $\bar{Y}$ \\
\hline LOFWRB-C & $\boldsymbol{E}$ & EC-IV & EC-IV & $\bar{Y}$ \\
\hline LOFWRB-D & $\epsilon$ & EC-IV & EC-IV & $\bar{Y}$ \\
\hline LOFWRB-E & $e$ & EC-IV & EC-IV & $\bar{Y}$ \\
\hline LOFWRB-F & 2E-08 & EC-IV & EC-IV & $\mathbf{Y}$ \\
\hline LOFWRB-G & $1 \mathrm{E}-08$ & EC-IV & EC-IV & $\bar{Y}$ \\
\hline LOFWRB-H & $6 \mathrm{E}-10$ & EC-IV & EC-IV & $\overline{\mathbf{Y}}$ \\
\hline LOFWRB-I & 1E-06 & EC-III & EC-III & $\bar{Y}$ \\
\hline LOFWRB-J & $1 \mathrm{E}-08$ & EC-IV & EC-IV & $\mathbf{Y}$ \\
\hline LOFWRB-K & 9E-10 & EC-IV & EC-IV & $\bar{Y}$ \\
\hline LOFWRB-L & $3 \mathrm{E}-08$ & EC-IV & EC-IV & $\mathbf{Y}$ \\
\hline LOFWRB-M & $2 \mathrm{E}-12$ & EC-IV & EC-IV & $\mathrm{Y}$ \\
\hline LOFWRB-N & $\boldsymbol{\varepsilon}$ & EC-IV & EC-IV & $\mathbf{Y}$ \\
\hline LOFWRB-O & $\varepsilon$ & EC-IV & EC-IV & $\mathbf{Y}$ \\
\hline LOFWRB-P & $\boldsymbol{\varepsilon}$ & EC-IV & EC-IV & $\mathbf{Y}$ \\
\hline LOFWRB-Q & $4 \mathrm{E}-11$ & EC-IV & EC-IV & $\mathbf{Y}$ \\
\hline LOFWRB-R & $3 \mathrm{E}-11$ & EC-IV & EC-IV & $\mathbf{Y}$ \\
\hline LOFWRB-S & 1E-12 & EC-IV & EC-IV & $\mathbf{Y}$ \\
\hline LOFWRB-T & 3E-09 & EC-IV & EC-IV & $\mathbf{Y}$ \\
\hline LOFWRB-U & $3 \mathrm{E}-11$ & EC-IV & EC-IV & $\mathbf{Y}$ \\
\hline LOFWRB-FTSD-A & $1 \mathrm{E}-10$ & EC-IV & EC-IV & $\mathbf{Y}$ \\
\hline LOFWRB-FTSD-B & $\varepsilon$ & EC-IV & EC-IV & $\mathbf{Y}$ \\
\hline LOFWRB-FTSD-C & $e$ & EC-IV & EC-IV & $\mathbf{Y}$ \\
\hline LOFWRB-FTSD-D & $\varepsilon$ & EC-IV & EC-IV & $\bar{Y}$ \\
\hline LOFWRB-FTSD-E & e & EC-IV & EC-IV & $\bar{Y}$ \\
\hline LOFWRB-FTSD-F & $\varepsilon$ & EC-IV & EC-IV & $\mathbf{Y}$ \\
\hline LOFWRB-FTSD-G & $e$ & EC-IV & EC-IV & $\bar{Y}$ \\
\hline LOFWRB-FTSD-H & $\varepsilon$ & EC-IV & EC-IV & $\mathbf{Y}$ \\
\hline LOFWRB-FTSD-I & e & EC-IV & EC-IV & $\mathbf{Y}$ \\
\hline LOFWRB-FTSD-J & 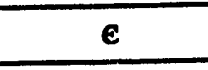 & EC-IV & EC-IV & $\bar{Y}$ \\
\hline LOFWRB-FTSD-K & $e$ & EC-IV & EC-IV & $\bar{Y}$ \\
\hline LOFWRB-FTSD-L & $\epsilon$ & EC-IV & EC-IV & $\mathbf{Y}$ \\
\hline LOFWRB-FTSD-M & $e$ & EC-IV & EC-IV & $\mathbf{Y}$ \\
\hline LOFWRB-FTSD-N & $\varepsilon$ & EC-IV & EC-IV & $\mathbf{Y}$ \\
\hline
\end{tabular}


Table D.6 Feedwater piping break in the turbine building sequence comparisons

\begin{tabular}{|c|c|c|c|c|}
\hline Sequence & $\begin{array}{l}\text { Sequence } \\
\text { Frequency }\end{array}$ & $\begin{array}{l}\text { Categorization } \\
\text { by Frequency }\end{array}$ & $\begin{array}{l}\text { Categorization } \\
\text { by Primary } \\
\text { Method }\end{array}$ & Consistent \\
\hline LOFWTB-A & $1 \mathrm{E}-03$ & EC-II & EC-II & $\mathbf{Y}$ \\
\hline LOFWTB-B & 1E-06 & EC-III & EC-III & $\mathbf{Y}$ \\
\hline LOFWTB-C & 1E-09 & EC-IV & EC-IV & $\mathbf{Y}$ \\
\hline LOFWTB-D & e & EC-IV & EC-IV & $\bar{Y}$ \\
\hline LOFWTB-E & 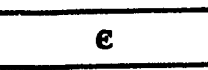 & EC-IV & EC-IV & $\bar{Y}$ \\
\hline LOFWTB-F & $2 \mathrm{E}-06$ & EC-III & EC-III & $\mathbf{Y}$ \\
\hline LOFWTB-G & $1 E-06$ & EC-III & EC-III & $\bar{Y}$ \\
\hline LOFWTB-H & $6 \mathrm{E}-08$ & EC-IV & EC-IV & $\bar{Y}$ \\
\hline LOFWTB-FTSD-A & $\varepsilon$ & EC-IV & EC-IV & $\mathbf{Y}$ \\
\hline LOFWTB-FTSD-B & $\epsilon$ & EC-IV & EC-IV & $\bar{Y}$ \\
\hline LOFWTB-FTSD-C & $\varepsilon$ & EC-IV & EC-IV & $\bar{Y}$ \\
\hline LOFWTB-FTSD-D & e & EC-IV & EC-IV & $\bar{Y}$ \\
\hline LOFWTB-FTSD-E & e & EC-IV & EC-IV & $\mathrm{Y}$ \\
\hline LOFWTB-FTSD-F & $\epsilon$ & EC-IV & EC-IV & $\bar{Y}$ \\
\hline LOFWTB-FTSD-G & 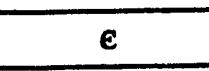 & EC-IV & $\overline{\text { EC-IV }}$ & $\bar{Y}$ \\
\hline LOFWTB-FTSD-H & e & EC-IV & EC-IV & $\bar{Y}$ \\
\hline LOFWTB-FTSD-I & $\epsilon$ & EC-IV & EC-IV & $\bar{Y}$ \\
\hline LOFWTB-FTSD-J & c & EC-IV & EC-IV & $\bar{Y}$ \\
\hline LOFWTB-FTSD-K & e & EC-IV & EC-IV & $\bar{Y}$ \\
\hline LOFWTB-FTSD-L & e & EC-IV & EC-IV & $\mathbf{Y}$ \\
\hline LOFWTB-FTSD-M & $\bar{E}$ & EC-IV & EC-IV & $\bar{Y}$ \\
\hline LOFWTB-FTSD-N & $\epsilon$ & EC-IV & EC-IV & $\bar{Y}$ \\
\hline
\end{tabular}


Table D.7 SCRAM sequence comparisons

\begin{tabular}{|c|c|c|c|c|}
\hline Sequence & $\begin{array}{l}\text { Sequence } \\
\text { Frequency }\end{array}$ & $\begin{array}{l}\text { Categorization } \\
\text { by Frequency }\end{array}$ & $\begin{array}{c}\text { Categorization } \\
\text { by Primary } \\
\text { Method }\end{array}$ & Consistent \\
\hline SCRAM-A & $1 \mathrm{E}+00$ & EC-I & EC-I & $\bar{Y}$ \\
\hline SCRAM-B & $2 \mathrm{E}-03$ & EC-II & EC-III & $\mathbf{Y}$ \\
\hline SCRAM-C & $1 \mathrm{E}-06$ & EC-III & EC-IV & $\mathbf{Y}$ \\
\hline SCRAM-D & $1 \mathrm{E}-06$ & EC-III & EC-IV & $\bar{Y}$ \\
\hline SCRAM-E & $\varepsilon$ & EC-IV & EC-IV & $\bar{Y}$ \\
\hline SCRAM-F & $\varepsilon$ & EC-IV & EC-IV & $\mathbf{Y}$ \\
\hline SCRAM-G & $2 \mathrm{E}-05$ & EC-III & EC-IV & $\overline{\mathbf{Y}}$ \\
\hline SCRAM-H & $2 \mathrm{E}-06$ & EC-III & EC-IV & $\overline{\mathbf{Y}}$ \\
\hline SCRAM-FTSD-A & $\varepsilon$ & EC-IV & EC-IV & $\mathbf{Y}$ \\
\hline SCRAM-FTSD-B & $\varepsilon$ & EC-IV & EC-IV & $\mathbf{Y}$ \\
\hline SCRAM-FTSD-C & $\varepsilon$ & EC-IV & EC-IV & $\bar{Y}$ \\
\hline SCRAM-FTSD-D & $\varepsilon$ & EC-IV & EC-IV & $\bar{Y}$ \\
\hline SCRAM-FTSD-E & $\varepsilon$ & EC-IV & EC-IV & $\bar{Y}$ \\
\hline SCRAM-FTSD-F & $\varepsilon$ & EC-IV & EC-IV & $\bar{Y}$ \\
\hline SCRAM-FTSD-G & $\bar{\varepsilon}$ & EC-IV & $\overline{\text { EC-IV }}$ & $\overline{\mathbf{Y}}$ \\
\hline SCRAM-FTSD-H & $\varepsilon$ & EC-IV & EC-IV & $\bar{Y}$ \\
\hline SCRAM-FTSD-I & $\varepsilon$ & EC-IV & EC-IV & $\bar{Y}$ \\
\hline SCRAM-FTSD-J & $\varepsilon$ & EC-IV & EC-IV & $\bar{Y}$ \\
\hline SCRAM-FTSD-K & $E$ & EC-IV & EC-IV & $\bar{Y}$ \\
\hline SCRAM-FTSD-L & $\varepsilon$ & EC-IV & EC-IV & $\bar{Y}$ \\
\hline SCRAM-FTSD-M & $\varepsilon$ & EC-IV & EC-IV & $\bar{Y}$ \\
\hline SCRAM-FTSD-N & $\boldsymbol{\varepsilon}$ & EC-IV & EC-IV & $\bar{Y}$ \\
\hline
\end{tabular}




\section{Appendix E \\ Comparison to AECL Analyzed Events}

This appendix is included to show the comparison of events contained in this analysis to the events contained in Atomic Energy of Canada, Limited (AECL) CANDU 3 Conceptual Safety Report (CSR). ${ }^{1}$ This was done for the sake of confidence that the events analyzed in this report are representative of the spectrum of events for the CANDU 3 design.

Four types of events are analyzed in the CANDU 3 CSR:1

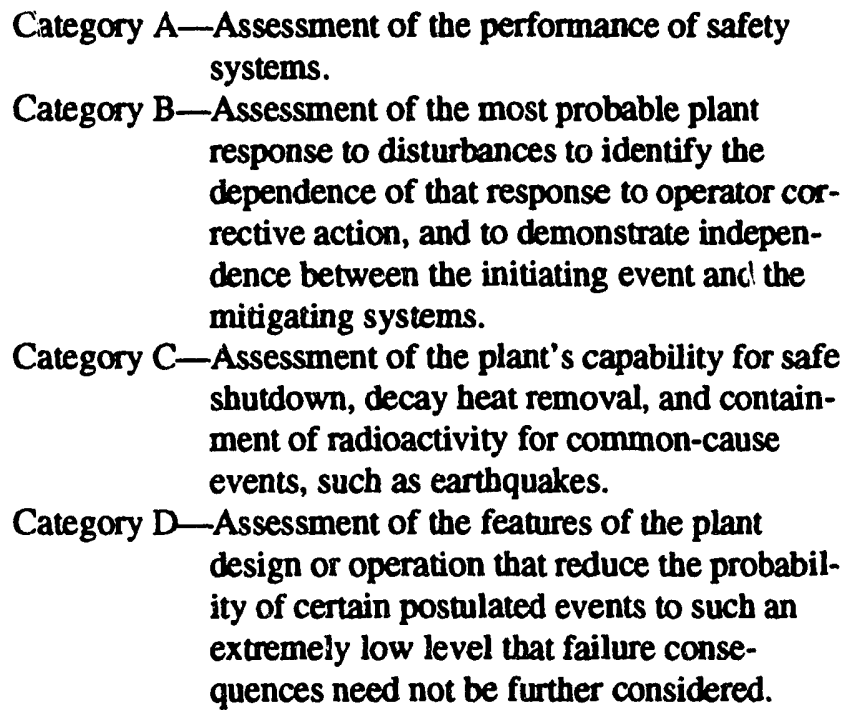

The specific events analyzed in the CSR are the following:

\section{Category A}

1. Large Loss of Coolant

2. Large Loss of Coolant with ECCS Unavailable

3. Pressure Tube Rupture with ECCS Unavailable

4. Large Loss of Coolant with Failure of Containment Local Air Coolers*

5. Steam Line Break with Failure of Containment Local Air Coolers*

6. Loss of Class IV Power

7. Single Heat Transport Pump 'Trip

8. Single Heat Transport Pump Seizure

9. Large Loss of Coolant with Loss of Class IV Power

\section{Category B}

1. Failures of Electric Power Supplies

2. Failures of Service Water Supplies*

3. Loss of Steam Inventory via a Steamline Break
4. Condensate System Failures Resulting in Interruption of Condensate Flow*

6. Condensate Line Breaks*

7. Condenser Failure Resulting in Loss of Feedwater Circulating Flow

8. Failure of Boiler Pressure Control

9. Feedwater Line Breaks

10. Total Interruption or Reduction of Feedwater to the Steam Generators

11. Pressure Tube Rupture

12. Large Loss of Coolant

13. Small Loss of Coolant

14. Pressure Tube Leak Into the Annulus Gas System*

15. Fueling Machine Failure while on Reactor Causing an End Fitting Failure

Category $\mathbf{C}^{*}$

1. Earthquake

2. Site Flooding from Extermal Sources

3. Station Fires

4. Tornadoes

Category D*

1. Steam Generator Support Failure

2. Steam Generator Shell Failure

3. Turbine Breakup

4. Massive Failure of Cooling Water Intake Tunnel

5. Massive Failure of Cooling Water Discharge Duct

6. Failure of Heat Transport Pump Casing or Drive Shaft

7. Pressurizer Failure

8. Degasser-Condenser Failure

The preceding categories or events marked with an "*" are events that were not covered by this analysis. Events involving the containment or initiated by failure of a support system were not covered in this analysis. Category C events were not covered because external event analysis was not included in the scope of this analysis. Category D events are events that require structural or other type of analyses, which are well beyond the rigor and scope of this analysis.

Table E.1 is provided to show the correspondence of the events analyzed for this report to the events listed above. Some of the events were specifically analyzed and others were represented by one of the analyzed events. Those represented by an event are indicated by bold italics. 
Appendix E

Table E.1 Correspondence of sequences to CSR ivents

\begin{tabular}{||c|c|}
\hline Analyzed Event & CORRESPONDING CSR EVENT \\
\hline $\begin{array}{c}\text { Feeder Tube Header } \\
\text { Break }\end{array}$ & A-1, A-2, A-9, B-12 \\
\hline Liquid Relief Valve Failure & B-13 \\
\hline Feeder Tube Break & A-3, B-11, B-13, B-15 \\
\hline Loss of Class IV Power & A-6, A-7, A-8, B-1 \\
\hline $\begin{array}{c}\text { Feedwater Piping Break } \\
\text { in the Reactor Building }\end{array}$ & B-9, B-10 \\
\hline $\begin{array}{c}\text { Feedwater Piping Break } \\
\text { in the Turbine Building }\end{array}$ & B-7, B-8, B-9, B-10 \\
\hline SCRAM & B-3 \\
\hline
\end{tabular}

\section{Reference}

1 Atomic Energy of Canada, Limited, "CANDU 3 Conceptual Safety Report," Vols. 1 and 2, 1989."

* Available in NRC PDR for inspection and copying for a fee. 


\section{Internal Distribution}

\author{
1. S. J. Ball \\ 2. W. P. Barthold \\ 3. J. J. Carbajo \\ 4. N. Clapp \\ 5. G. J. Dyer \\ 6-7. M. H. Fontana \\ 8. E. C. Fox \\ 9. J. E. Jones Jr. \\ 10. T. S. Kress \\ 11-12. M. A. Linn \\ 13. W. A. McAfee \\ 14. D. G. Morris \\ 15. G. A. Murphy \\ 16. S. C. Nelson
}

\author{
17-18. M. Olszewski \\ 19. R. T. Primm \\ 20. C. E. Pugh \\ 21. C. C. Southmayd \\ 22. R. P. Wichner \\ 23. V. K. Wilkinson \\ 24-25. J. R. Wolfgong \\ 26-27. A. L. Wright \\ 28. ORNL Patent Section \\ 29. Central Research Library \\ 30. Document Reference Section \\ 31-32. Laboratory Records Department \\ 33. Laboratory Records (RC)
}

\section{External Distribution}

34. B. W. Sheron, Director, Division of Systems Research, U.S. Nuclear Regulatory Commission, Washington, DC 20555

35. T. L. King, Division of Systems Research, U.S. Nuclear Regulatory Commission, Washington, DC 20555

36. L. M. Shotkin, Division of Systems Research, U.S. Nuclear Regulatory Commission, Washington, DC 20555

37-39. A. J. Szukiewicz, Division of Systems Research, U.S. Nuclear Regulatory Commission, Washington, DC 20555

40. R. O. Meyer, Division of Systems Research, U.S. Nuclear Regulatory Commission, Washington, DC 20555

41. Z. R. Rosztoczy, Division of Systems Research, U.S. Nuclear Regulatory Commission, Washington, DC 20555

42. D. D. Ebert, Division of Systems Research, U.S. Nuclear Regulatory Commission, Washington, DC 20555

43. T. H. Cox, Nuclear Reactor Regulation, U.S. Nuclear Regulatory Commission, Washington, DC 20555

44. J. N. Donohew, Nuclear Reactor Regulation, U.S. Nuclear Regulatory Commission, Washington, DC 20555

45. E. D. Throm, Nuclear Reactor Regulation, U.S. Nuclear Regulatory Commission, Washington, DC 20555

46. L. Rib, AECL Technologies, 9210 Corporate Boulevard, Suite 410, Rockville, MD 20850

47. R. Curtis, AECL Technologies, 9210 Corporate Boulevard, Suite 410, Rockville, MD 20850

48. M. Fletcher, AECL Technologies, 9210 Corporate Boulevard, Suite 410, Rockville, MD 20850

49. Office of Assistant Manager for Energy Research and Development, DOE-ORO, Oak Ridge, TN 37831

50-51. Office of Scientific and Technical Information, P. O. Box 62, Oak Ridge, TN 37831 

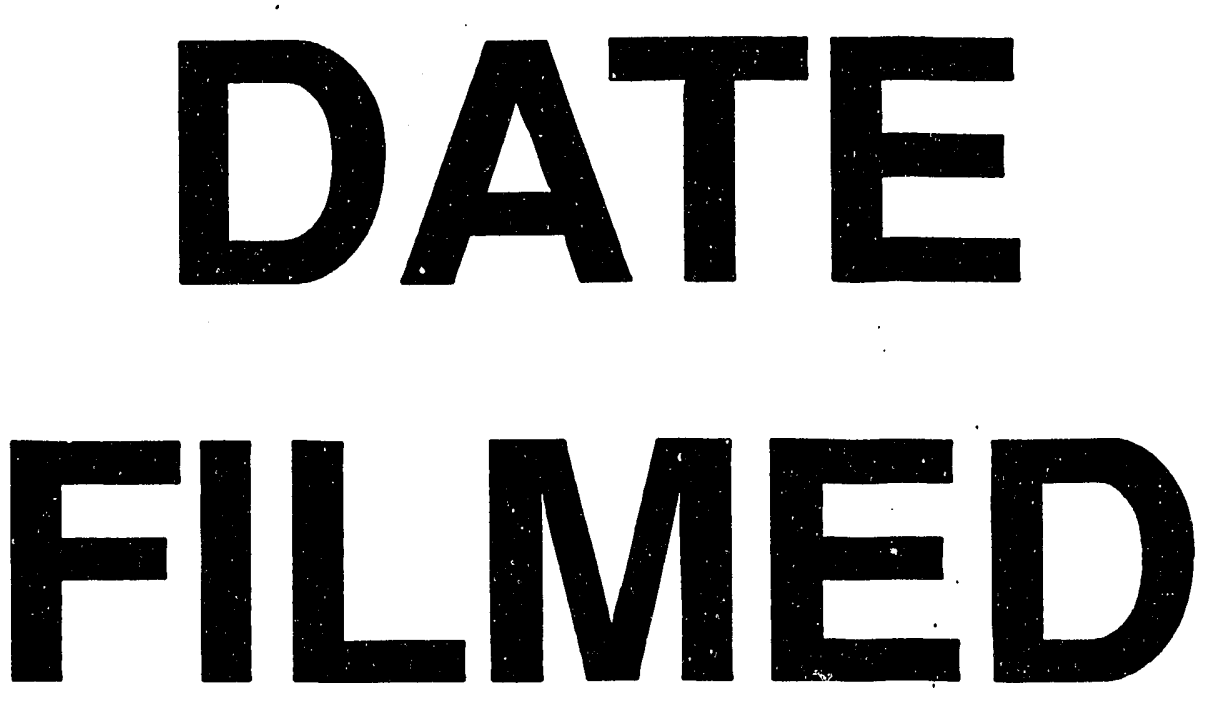

$9 / 28 / 93$
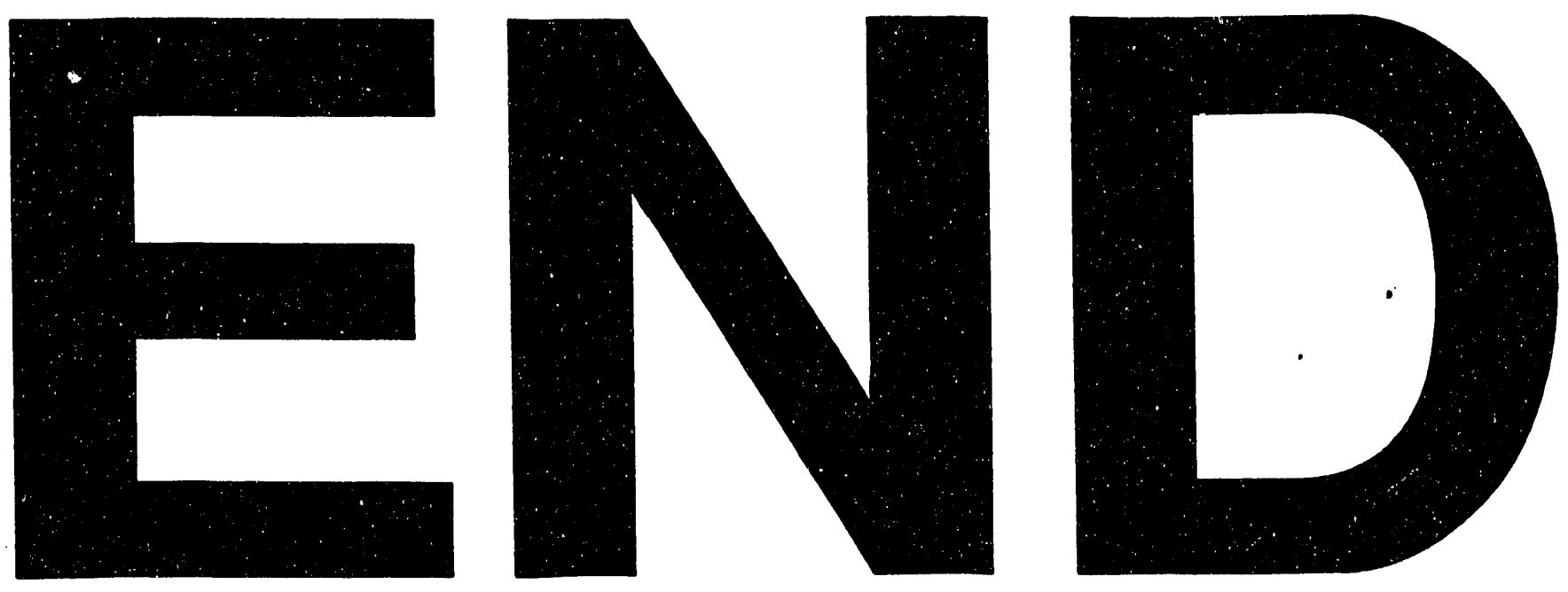
